\title{
Gabriel TARDE
}

Philosophe et sociologue français, 1843-1904

(1892)

\section{ÉTUDES PÉNALES ET SOCIALES}

Un document produit en version numérique par Réjeanne Toussaint, bénévole, Courriel: rtoussaint@aei.ca

Dans le cadre de la collection: "Les classiques des sciences sociales" Site web: http://www.uqac.ca/Classiques_des_sciences_sociales/

Une collection développée en collaboration avec la Bibliothèque Paul-Émile-Boulet de l'Université du Québec à Chicoutimi Site web: http://bibliotheque.uqac.ca/ 
Cette édition électronique a été réalisée par Réjeanne Toussaint, bénévole, à partir de l'article de :

\section{Gabriel TARDE}

Philosophe et sociologue français, 1843-1904

\section{Études pénales et sociales.}

Lyon : A. Storck, Éditeur. Paris : G. Masson, Éditeur, 1892, 460 pp. Collection : Bibliothèque de criminologie.

Polices de caractères utilisée :

Pour le texte: Times New Roman, 14 points.

Pour les citations : Times New Roman 10 points.

Pour les notes de bas de page : Times, 10 points.

Édition électronique réalisée avec le traitement de textes Microsoft Word 2004 pour Macintosh.

Mise en page sur papier format

LETTRE (US letter), 8.5' x 11',)

Édition complétée le 1 er août 2005 à Chicoutimi, Ville de Saguenay, province de Québec. 


\section{Gabriel TARDE}

Philosophe et sociologue français, 1843-1904

\section{(1892) \\ Études pénales et sociales}

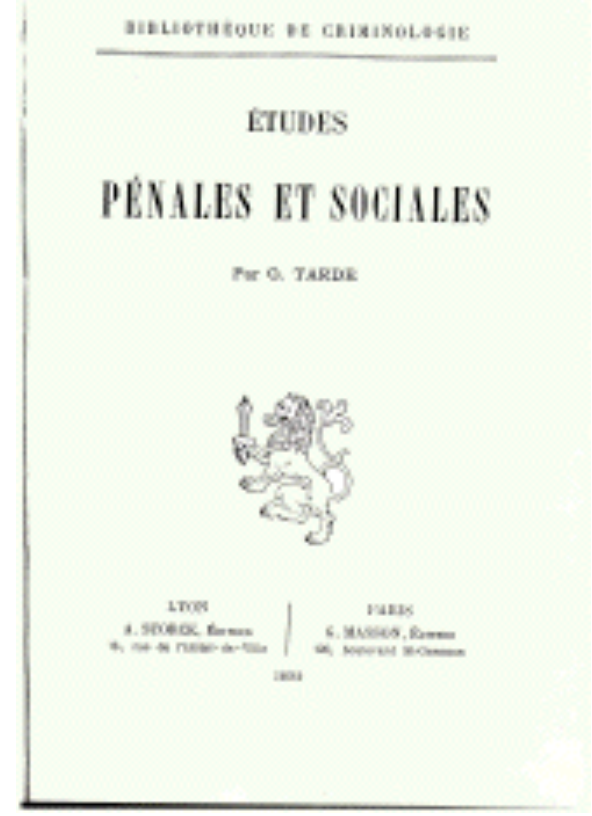

Lyon: A. Storck, Éditeur. Paris : G. Masson, Éditeur, 1892, 460 pp. Collection : Bibliothèque de criminologie. 


\section{Table des matières}

\section{Avant-propos de l'auteur.}

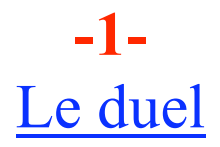

Le duel et la criminologie. "Si le suicide est la forme subjective de l'homicide, le duel en est la forme réciproque. » Pourquoi, il faut étudier le duel, malgré sa rareté et bien qu'il soit en décroissance.

\section{Chapitre I : Le duel dans le passé}

I. Absence du duel chez les Grecs et chez les Romains ; nécessité de ne pas confondre le duel véritable qui a pour cause l'honneur blessé, et celui qui a lieu pour la patrie, pour la gloire militaire ou pour tout autre motif

II. Le duel divinatoire des Germains, le duel légal du roi Gondebaut; enthousiasme soulevé par la loi Gombette. Le duel judiciaire et la trêve de Dieu. La guerre privée et le duel par mandat.

III. Succès du duel au XVIe siècle; à cette époque il est constitué; sa morphologie est à peu près achevée; du duel divinatoire il a conservé le caractère mystique; de la guerre privée il a retenu la nécessité d'une escorte. Preuves à l'appui de cette opinion. - Rapport sur duel, sur la guerre et l'assassinat au XVIe siècle ; exemples. Le côté brillant du duel considéré, dans une certaine mesure, comme une résurrection du tournoi

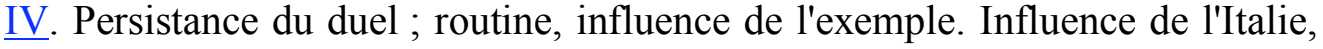
berceau du duel moderne au XVe siècle. Duel à outrance sous Henri III et Louis XIII ; manie d'imiter les grands seigneurs ; toute-puissance du préjugé. Le duel dans le Cid ; recrudescence de l'épidémie au temps des troubles et des révolutions. Edit de 1679. Efficacité de l'interdiction. Reprise des duels sous Louis XV et sous Louis XVI

\section{Chapitre deuxième : $\underline{\text { Le duel dans le présent }}$}

I. Le duel d'après la Révolution, la royauté, l'empire, la république. Statistiques. Leur utilité d'après M. Lacassagne. Statistiques Italiennes 
II. Influence de la galerie : fréquence du duel littéraire. Action dominante des grands centres

III. Le duel militaire. Rien n'est plus contraire au but de l'armée que le duel. Circulaire ministérielle de M. de Freycinet. Il y a injustice absolue à punir en tout cas le blessé

IV. Le duel dans l'armée allemande; le duel recommandé par l'empereur; imitation de l'armée italienne. - Contraste avec l'armée anglaise, c'est sur cette dernière que la nôtre doit prendre modèle ; importance du duel militaire au point de vue social

\section{Chapitre troisième : Les causes et les remèdes}

Considérations générales sur les causes sociales du duel.

Causes météorologiques, incertitude des résultats (courbes de Lacassagne ; Teissier, Ferréus, etc).

Causes sociales : en général ce sont les mêmes qui agissent sur l'homicide et dans le même sens. Objections à la théorie du développement inverse de l'homicide et du suicide, de Morselli et Ferri.

Action des grandes villes, influence de la profession.

Influence néfaste des femmes et de l'esprit féminin en général. Responsabilité des littérateurs.

Indulgence incompréhensible de la classe éclairée pour le duel. Crecdo quia absurdum. Le duel est non seulement barbare mais il est ridicule. Cependant il a et surtout il a eu sa beauté ; c'est un témoignage que la vie ne vaut pas la peine d'être vécue moyennant une honte, ou l'apparence même d'une honte; c'est aussi un témoignage que l'individu ne veut pas seulement pour lui-même, mais surtout pour la société, aux préjugés de laquelle il s'immole ou immole un être que souvent il ne hait point... 55-69

Le duel est l'écho d'un temps où le courage était tout, mais le duel ce n'est pas la bravoure seulement, c'est l'orgueil et la véracité élevée à la hauteur du suprême devoir. En quoi le duel est contraire au progrès.

La valeur n'est plus la maîtresse qualité de l'homme moderne : la générosité, l'équité, l'ardeur au travail passent avant tout. 
En quoi la question de la guerre est liée à celle du duel. Prophylaxie de la guerre et du duel ; établissement d'une Cour suprême des nations et de tribunaux d'honneur

Réforme à faire dans la législation. - Compléter les lois sur la diffamation et sur l'injure. Institution de tribunaux d'honneur en rapport avec notre état actuel et nos goûts démocratiques.

Distinction à faire entre la notoriété et l'honneur proprement dit. La valeur morale et sociale d'un homme est le produit de la notoriété par l'honneur.

La loi s'est placée à un point de vue d'égalité trop étroite ou mal comprise nécessité de faire entrer en ligne de compte l'importance du tirage de la feuille calomniatrice. Comment à ce point de vue il faut entendre l'égalité. L'honneur est un bien réel, de plus en plus précieux, mais aussi de plus en plus fragile. Idées de M. Worms à ce sujet. Réfutation.

«L'honneur consiste pour chacun de nous dans la persuasion plus ou moins forte possédée par nous et partagée par un nombre plus ou moins grand de personnes autour de nous ou loin de nous, que nous valons beaucoup, non seulement par les services que nous pouvons rendre comme instrument de travail ou de plaisir, mais par notre propre existence jugée digne d'être et de durer. »

Étude des moyens susceptibles de protéger l'honneur. Légitimité des peines d'honneur.

Nécessité de supprimer la législation capricieuse, incohérente du jury, superstition plus fatale que celle du duel, issue comme elle des mêmes faux principes

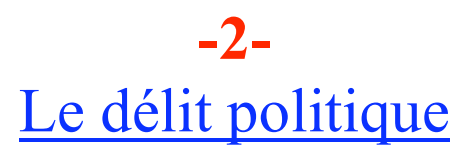

I. - Critique générale de la méthode employée par M. Lombroso pour édifier une théorie de la criminalité

II. - Recherches de Jacoby sur la richesse de chaque département en hommes remarquables, sur l'influence de la constitution du terrain. - Action de la race sur la production du génie.

Études analogues de Lombroso en France ; concordance des résultats. Facteur laissé dans l'ombre par tous deux; enchaînements rationnels des innovations réelles ou imaginaires formant des séries réversibles ou irréversibles ; exemples. 
Le génie est un accident historique où s'exprime une nécessité logique. Calendrier du génie, analogue au calendrier du crime de Lacassagne. Quelques statistiques de M. Ribot. Calendrier insurrectionnel de Lombroso

III. - Relations entre la génialité d'un département et son esprit politique d'après Jacoby. Impossibilité d'établir un rapport entre l'orographie et la génialité. - Étude critique sur le "misonéisme » de Lombroso. Le conservatisme politique ne saurait être pris à priori, et sans autre explication, pour une marque de stérilité artistique, agricole ou scientifique.

A côté du penchant à se répéter, il y a chez l'homme un penchant à innover. Lutte entre le caprice et l'habitude

IV. - Il faut distinguer les inventions conformes à l'esprit général de la société où elles éclosent, et celles qui lui sont contraires. Différence entre la rébellion et la régénération. Influence très secondaire des conditions météorologiques, orographiques, etc.

$\underline{\text { V. - Conclusions }}$

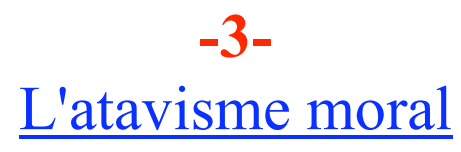

I. - Thèse de M. Colajanni : Il n'y a pas de type physique criminel ; le criminel n'est ni un fou, ni un épileptique, ni un dégénéré. C'est un revenant des temps de nos ancêtres éloignés, mais uniquement au sens moral. - Tout caractère mental n'est-il pas nécessairement lié à un caractère corporel ? - Non, dit M. Colajanni. C'est la fonction qui fait l'organe. Toute fonction cérébrale, et en particulier la moralité, n'est pas localisée dans des compartiments déterminés du cerveau. L'évolution physique n'est pas parallèle à l'évolution psychomorale

II. - Conception de Brown-Séquard, admise par Colajanni, sur les localisations cérébrales. Extension aux facultés intellectuelles et morales. - Les facultés les plus primitives sont celles qui sont le moins localisées. - Contradiction avec l'opinion de M. Colajanni, sur la modernité de la moralité et sa non-localisation. Contradiction du principe de la fonction cause de l'organe et du contraste supposé entre la variabilité morale et intellectuelle de l'humanité et la permanence physique du type humain. Conciliation de cette permanence avec la loi de l'évolution. Il ne faut pas confondre la variabilité sociale avec la variabilité morale

III. - Interprétation tératologique (Ribot) et interprétation atavistique. Origine Intra-utérine de la plupart des anomalies des malfaiteurs. - Incompatibilité du caractère criminel avec l'existence et la conservation d'une société. Hypothèse de 
Sergi sur la formation du caractère moral par couches successives stratifiées. Réfutation : il n'y a pas stratification, mais enchevêtrements multiples

IV. - Phytogénèse et ontogénèse. - Criminel et enfant : critique de la loi générale du parallélisme entre la phytogénèse et l'ontogénèse. Il n'y a aucune similitude entre l'enfant et le criminel.

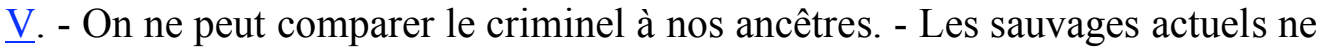
peuvent nous donner une idée de nos ancêtres. Société simiennes. - Sociétés animales

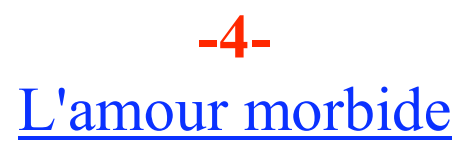

Ce que c'est que l'amour morbide. - Différence entre l'amour ordinaire et les aberrations de l'amour. Entre l'amour normal et l'amour morbide il y a une différence de nature, non de degré. - L'amour normal poursuit deux fins ; conditions nécessaires pour que ces deux fins s'accordent

L'idéal d'un amour normal ressemble à celui d'un autre amour normal ; l'amour morbide est suscité par les objets les plus divers

Dans l'amour morbide il y a fragmentation de l'individualité et l'un des fragments est l'instrument passif de l'autre ; il y a auto-suggestion

L'amour normal exalte les défauts et les qualités de l'amant : il ne pousse au crime que le criminel. - Responsabilité des auteurs de crimes passionnels ; jamais une passion pathologique n'entraîne un crime passionnel. - L'amour morbide est impuissant à féconder l'art

\section{$-5-$ \\ Quatre crimes passionnels}

\section{$\underline{\text { L'affaire Chambige }}$}

Adolescence de Chambige ; - son caractère jaloux et boudeur

Plus tard se fait jour chez lui une prédisposition aux troubles nerveux : étudiant, il s'isole volontairement

Causes probables de l'amour de Mme G... pour Chambige. La duplicité apparente de Mme G... est due au dédoublement de son être moral par l'amour; 
d'un côté la femme honnête et normale ; de l'autre l'être en proie à une obsession amoureuse

Notes écrites par Chambige pendant sa détention; ses qualités de littérateur psychologue

Influence du milieu sur les deux amants. - Poursuites exercées par le Parquet de Constantine ; leur nécessité. Appréciations du verdict

A-t-on le droit d'enlever la vie à quelqu'un sur sa demande ou sur son autorisation ?

\section{$\underline{\text { L'affaire Wladimiroff }}$}

Portrait du criminel. Mme D... son éducation. Causes du crime de Wladimiroff - sa responsabilité

\section{$\underline{\text { Les Affaires Weiss et Achet }}$}

Qu'est-ce que le délit nécessaire ? - C'est un genre très vaste dont la légitime défense n'est qu'un cas particulier.

Naufrage de la Mignonette, de la Méduse

Classification possible des délits en délits nécessaires, délits utiles, délits superflus

Affaire d'Aïn-Fezza. - Portrait de Jeanne Daniloff. Violence de son amour pour Roque. Le crime de Mme Weiss n'est pas un délit nécessaire, sa condamnation est méritée

Le crime de Chantelle

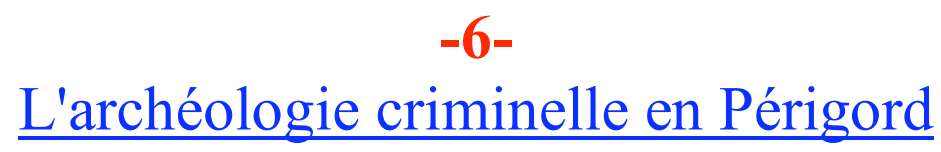

Intérêt que présenteraient pour le «criminologue » les études d'archéologie criminelle ; sur quels documents cette science pourrait être édifiée. - L'archéologie criminelle dans le Périgord. -Transformations psychologiques de la magistrature. Le juge d'autrefois et le juge d'aujourd'hui 
I. - Délits absents ou rarissimes jadis : viols, attentats à la pudeur

II. - Crimes qui ne sont plus des crimes aujourd'hui (maquerellage, blasphèmes, infractions aux commandements de l'Eglise, non catholicité, etc. ). Procès faits à des morts. -Condamnation de la mémoire des personnes. Persécution des calvinistes par le présidial d'Agen. - Crime d'émigration. - La notion d'une liberté de conscience et même d'une liberté individuelle quelconque manque dans toutes les classes de la société. - Interdiction de sortir la nuit; le concubinage est l'objet de poursuites sérieuses; droit de censure exercé par la communauté de village, par le père de famille. - Le rapt puni de mort. - Sous ces exagérations éclate le sentiment de l'honneur familial. - Crime de sorcellerie. Les petits seigneurs se livrent au brigandage et au pillage des propriétés du voisinage. - Le cambriolage n'est pas inconnu

III. - Impossibilité de donner la statistique des crimes contre les personnes ; les crimes en effet restent souvent impunis; cependant les documents prouvent que s'il y avait plus d'actes de violence qu'aujourd'hui, il y avait moins de vols, d'homicides et d'attentats à la pudeur. Peu de duels à la fin du XVIIe siècle ; les affaires d'honneur sont portées devant la justice ou devant la cour des Maréchaux. - Statistique criminelle du Registre criminel de Saint-Martin des Champs. - Faible criminalité due à l'effroi des tortures. - La criminalité moderne est caractérisée par moins de grossièreté et plus d'astuce. - Meurtres d'impétuosité. - Rareté du vol comme mobile du crime. - Sévérité extrême pour le vol; indulgence pour l'homicide qui n'a pas le vol pour but. - Rigueur avec laquelle est puni l'infanticide; abondance des meurtriers dans la noblesse ; fréquence des méfaits commis en troupe. - Leur rareté actuelle due à notre émancipation individuelle. Fréquence des vols sacrilèges dans les églises alors très riches. - Faits de violence. -La violence est la note caractéristique des mœurs du passé. -Rixes, luttes dans le clergé, dans la noblesse. - Importance attachée alors aux questions de préséance. Mésintelligence fréquente entre le presbytère et le château. - Brutalité des huissiers, sans cesse battus par les gentilshommes et les militaires

IV. - Conclusions ; contraste entre la délictuosité violente de nos ancêtres et la délictuosité astucieuse de leurs petits-neveux, -Transformations subies par la criminalité sous l'ancien régime même; prétextes fournis par toutes les révolutions ; le calvinisme, la Fronde, etc. - Impunité fréquente.

Fonctionnement des anciens tribunaux. - Nombre élevé des magistrats.

Cruauté, diversité, étrangeté fréquente des peines (exécution en effigie, amende honorable, etc.). - Échange de malfaiteurs entre les diverses cours criminelles, par application de la peine du bannissement, hors du ressort de la juridiction ; particularités diverses. 
Nécessité de ne pas juger les temps passés seulement par leur aspect criminel et de ne pas conclure que tout, dans notre état social actuel, est préférable à celui de nos pères

\section{$-7-$ \\ $\underline{\text { La crise de droit moral }}$ et la crise de droit pénal}

I. - Crise actuelle de la morale ; théorie des idées-forces de M. Fouillée d'une part. -Théories des novateurs italiens de l'autre; derniers travaux de l'école de criminologie italienne: réédition de l'Uomo di genio; ouvrage du docteur Salvatore Ottolenzi. - Delinquenza et punibilita, de Rizonne Navarra. - Discours de M. Ferri à la Chambre Italienne. - Ouvrages de Garofalo, Alongi, etc.

Travaux de l'école positiviste française.

Les Archives d'anthropologie criminelle du D• Lacassagne. Travaux de MM. Bourde, Bertillon, Benoist, de MM. Topinard, Féré ; d'après Féré la criminalité native n'est qu'une des formes de la dégénérescence ; objections et critiques; ce qu'il faut enten-dre par « folie morale ». - Abus du mot « anomalie »

Progrès extrinsèques des nouvelles idées. - Fondation d'une Revista d'anthropologia criminale à Madrid (Dr Alvarez Taladriz). - Propagation par les écoles adverses. - Travaux de M. Innamorati. - La préméditation, de M. Alimena.

Étude critique de ces travaux

Le devoir de punir, de M. Mouton. Le principe du droit, de M. Emile Beaussire.

Conclusion et réponse à $\mathrm{M}$. Beaussire ; la définition du délit

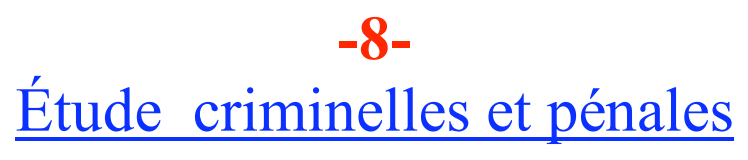

I. - L'anthropologie et la statistique ont, pour le moment, donné tout ce qu'on pouvait momentanément attendre d'elles : désormais il reste à édifier avec les matériaux qu'elles ont fournis 
II. - Crime et suicide de Corre. - Influence de l'étranger. - Travaux du docteur Xavier Francotte, de M. Prins, de M. César Silio ; appréciations et critiques

III. - Influence de la chaleur d'après M. Silio, « La chaleur réveille tous les instincts ; les mauvais comme les bons ». - Statistiques à l'appui.

Statistiques françaises de M. Yvernès. - Rapport officiel de 1880. - Résultats. Concordance des courbes espagnoles et des courbes françaises

IV. - Travaux du Dr Dortel. - Ses conclusions. - Type professionnel du criminel d'habitude. - Type pénitentiaire de M. Gauthier. - La responsabilité atténuée, par le Dr Henri Thierry

V. - La folla delinquente de M. Scipio Sighele. - Étude critique sur la criminalité de la foule

L'esprit de foule et l'esprit de secte - Distinction à faire entre les deux.

VI. - Le délit nécessaire, par M. Paul Moriaud. - Le cas de légitime défense. Analyse et critique

VII. - Les Attentats à l'honneur, par M. Emile Worms. - Le duel. - L'Utilita nel diritto penale classico, de M. Vaccaro. -Choses d'Amérique, par Max Leclerc. L'Amour meurtrier, du Dr Laurent. - Les Régicides, du Dr Régis. - Importance des travaux accomplis sous l'inspiration du Dr Lacassagne - La submersion, par Barlerin. - L'affaire Gouffé, par M. Lacassagne. - Rapports de MM. Lacassagne et Coutagne. - Autres travaux lyonnais. - Avenir de l'Archéologie criminelle

\section{-9- \\ L'idée de culpabilité}

I. - La notion de culpabilité doit-elle disparaître ?

Peut-elle être renouvelée? doit-elle être maintenue comme un dogme socialement nécessaire, quoique scientifiquement insoutenable?

Si l'on définit la culpabilité de telle manière qu'elle implique la liberté d'indifférence, le libre arbitre etc., la culpabilité s'évanouit.

Pour juger quelqu'un coupable, nous n'avons pas besoin d'imaginer qu'il a exercé une causalité libre, il nous suffit qu'il ait mis en jeu sa causalité propre. Nécessité de tenir le libre arbitre à l'écart de la question pénale 
Derniers refuges du libre arbitre. - Idées de M Delboeuf. - Pour lui le libre arbitre n'est plus qu'un veto suspensif. Or, dans les crimes actuels, au moment de l'action criminelle, il y a généralement bien peu de temps pour que le veto puisse s'exercer

II. - Il y a deux conditions de la culpabilité d'un individu $1^{\circ}$ que l'acte ait pour cause une personne; $2^{\circ}$ que cette personne soit demeurée la même dans le sens social du mot. - Qu'est-ce que le moi ? - Où s'arrête son domaine ?.

L'apogée de la responsabilité identité c'est l'âge où se réalise la perfection du système intérieur, la stabilité de son équilibre par la prépondérance définitive d'une idée ou d'une passion autour de laquelle tout gravite dans l'âme, et qui trouve hors de l'âme, dans un milieu social conforme, ou conformé à ses fins, une occasion de se déployer ; on est d'autant plus coupable qu'on est plus adapté à soimême et à son milieu.

Objections diverses. - L'hypnotisme. - Réfutation. - Délits et crimes d'opinion; en quoi ils diffèrent des autres crimes et des autres délits ; pourquoi il est irrationnel de s'indigner contre un sectaire de bonne foi.

Influence des maladies de la personnalité. - Pour qu'un acte me soit imputable il ne faut pas que je l'aie accompli sous le coup de ces maladies de la volonté et de la personnalité récemment étudiées par M. Ribot. Il faut que je me souvienne de mon acte puisque je dois être resté la même personne.

Ce que c'est que la honte et le remords

III. - Atténuation de la responsabilité, encore accordée de nos jours quand il n'y a pas identité morale entre la victime et le meurtrier.

Facilité avec laquelle on excuse les violences commises sur un peuple barbare : une éducation intellectuelle de premier ordre permet seule de faire comprendre la solidarité presque sociale de l'homme au sein de la faune terrestre

Le talion et l'origine de la justice pénale. - Erreur des historiens. - Tribunal domestique des peuples anciens. - Remarque de M. Dareste à ce sujet.

Discussion critique et conclusion. - Appuyée sur l'importance de l'identité personnelle et de la similitude sociale du criminel, l'idée de culpabilité est exacte 


\section{$-10-$ \\ $\underline{\text { Les maladies de l'imitation }}$}

I. - Le caractère d'être imitatif est le propre de tout acte vraiment social, à l'exclusion de tous autres. La société se compose d'individus se ressemblant imitativement tout en s'utilisant les uns les autres

L'impressionnabilité imitative est une de nos propriétés cérébrales les plus caractéristiques. - Du prestige. - De l'intimidation et de l'hypnotisation. L'hypnotisation est l'action d'un individu sur plusieurs autres; l'intimidation est l'action de plusieurs individus sur un seul; elle est d'autant plus forte que le nombre d'individus intimidants est plus considérable

- Physiologie de l'intimidé

- L'intimidation naît du sentiment qu'a l'intimidé d'être dissemblable au public et du désir qu'il a de lui ressembler. Elle ne cesse que quand l'intimidé s'est rendu semblable aux personnes qui l'entourent (il reste alors à l'intimidé qui ne l'est plus, une disposition à recevoir l'empreinte d'autrui). - Elle cesse encore quand l'intimidé a rendu son auditoire semblable à lui-même. - L'intimidation n'est pas contagieuse

II. - Analogie entre le cerveau et la société : les diverses cellules cérébrales et les individus composant la société ; l'imitation est à la société ce que la mémoire est à l'esprit. - Imitation-coutume et imitation-mode. - La logique sociale règle le sort des exemples reçus par mode ou coutume

III. - La marche normale de l'imitation est ab interioribus ad exteriora

L'imitation saine est celle qui conserve les inventions conformes à l'idéal de la société où l'on vit; elle est liée à l'invention. L'Angleterre est le type de l'imitativité saine

IV. - Maladies de l'imitation. - Imitation inexacte. - Ne pas confondre dans les transformation du langage, l'altération proprement dite et l'évolution vers la simplicité; dans l'évolution des religions, les dégénérescences avec leur renouvellement; dans les constitutions et les législations, l'application inexacte des lois et décrets avec les innovations réfléchies et conscientes; dans les arts, la décadence avec le progrès

V. - La stabilité relative des constitutions, des industries, des arts, de la grammaire, etc., assurent leur renouvellement sérieux et profond, leur progrès 
$L^{\prime}$ imitativité peut être : $1^{\circ}$ lente et tenace : $2^{\circ}$ rapide et fugace ; $3^{\circ}$ lente et fugace ; $4^{\circ}$ rapide et tenace ; la dernière combinaison est seule avantageuse. L'accent est un exemple de la première combinaison. - Les épidémies religieuses du XIVe siècle, et même les conversions actuelles faites par les missionnaires sont des exemples de la deuxième combinaison - Alternatives d'imitation rapide et d'imitation lente dans la philosophie, les sciences, la politique

Deux types d'imitation rapide, d'imitation mode :

$1^{\circ}$ Imitation professionnelle entre égaux et semblables ;

$2^{\circ}$ Imitation hors de la sphère sociale

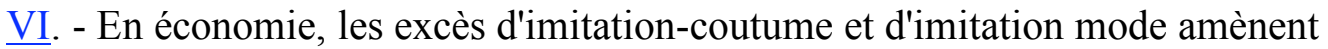
des crises économiques. - De même en religion et en législation les crises religieuses et législatives

Imitation-mode dans l'habillement et dans la toilette, pour le costume comme pour le reste ; l'imitation va du supérieur à l'inférieur et des hommes aux femmes ; de même nous y constatons la loi générale de la consécration de la mode en coutume (imitation rapide et tenace) : de même aussi la loi : l'imitation va ab interioribus ad exteriora.

Les voyages sont une forme d'imitation; imitation-coutume et surtout imitation-mode.

VII. - Maladies de l'imitation dans l'art. - imitation-mode et imitation-couturne en morale. - Leurs alternatives ; les avantages de cette alternative

But de l'imitation. - L'imitation-coutume doit prévaloir sur l'imitation-mode

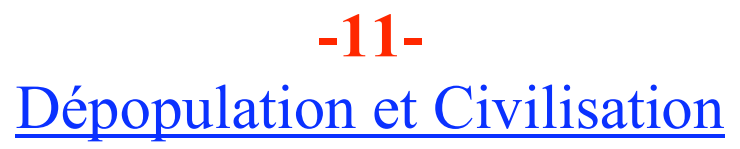

Cause véritable de la dépopulation - La natalité est en raison inverse de la civilisation

Pour M. Dumont la cause de la dépopulation se résume en l'idéalisme individuel.- Définition : le désir d'arriver au rang social le plus élevé. - L'égalité démocratique est la cause première de l'idéalisme

Distinguer l'égalité en fait et l'égalité en droit. - L'avènement de l'égalité en droit diminue l'égalité en fait et augmente le désir de la lutte chez l'individu 
Ce ne sont pas, ni notre passé monarchique ni notre passé religieux qui sont cause des vices de notre démocratie. - Au contraire, la religion rend le mariage fécond

La religion tendant à perpétuer le culte de la famille lutte contre l'idéalisme individuel

La civilisation et la démocratie n'amènent nécessairement l'infériorité vitale que si le culte du foyer disparaît vie?

Remède contre la dépopulation. - Vaut-il mieux multiplier les vies qu'élever la

\section{$-12-$ \\ Les idées sociologiques de Guyau}

Le livre de son ami M. Fouillée. - Guyau ; sa précocité

Ses idées et sa morale. - L'expansion de la vie ; son accroissement et son élargissement au dehors.

Comment s'explique et se légitime le sacrifice aux autres. - Le devoir est-il une sorte d'instinct moral?

Le Risque métaphysique de Guyau, - Importance des illusions et de l'ignorance dans l'accomplissement du devoir. - La société doit-elle entretenir ces illusions et cette ignorance, a-t-elle le droit et le devoir de mentir, dans l'intérêt de sa propre conservation ? - La société doit combattre l'erreur et n'enseigner que ce qu'elle croit être la vérité

Explication sociomorphique des dieux par Guyau.

Importance esthétique prêtés par Guyau à l'éducation devenue pour lui l'Art supérieur.

L'évolution des sociétés est une lente et difficile fusion des psychologies individuelles en une psychologie sociale.

Cela suppose trois choses: l'accord des croyances (oeuvre de la religion), l'accord des désirs (oeuvre de la morale); l'accord des sensations elles-mêmes (oeuvre des beaux-arts). - Rites, jeu et jouissance. - Rôle du culte : source religieuse de l'art. - Le culte a été la première forme de l'art industriel 
Faut-il dire religion ou irréligion de l'avenir ? - Rôle futur de la science

Guyau poète ; ses poésies sont comme la musique dont ses théories sont le libretto. - Tyrannie de la tradition et de la coutume dans la versification. Indépendance de Guyau.

\section{$-13-$ \\ $\underline{\text { Le suffrage dit universel }}$}

Le suffrage universel a un grand mérite : il fonctionne. - Sa force consiste à être réputé l'expression pure et complète, infaillible et indiscutable, de la souveraineté nationale, dogme menteur et nécessaire de l'âge moderne 439-440

Mais est-il conforme à l'opinion et à la volonté du pays ; les traduit-il avec une fidélité suffisante, tout au moins approximative?

I. - Les quatre cinquièmes de la nation ne votent pas; ils restent étrangers à la consultation numérique de la nation. - Les femmes et les enfants devraient voter. Le refus de les admettre au scrutin est la manifestation d'un instinct barbare (le droit du plus fort) que le progrès de la civilisation doit refouler

Pour les femmes et les enfants le vote aurait lieu par un mandataire légal

La part électorale du célibat masculin devrait être du seizième ; alors qu'elle est du quart avec le système actuel

Pourquoi il est injuste que la voix d'un père de famille qui incarne en lui, 3, 4, 5, 10 têtes différentes, n'ait pas plus de valeur que celle d'un célibataire de 21 ans, et puisse être neutralisée par elle.

Rôle prépondérant des célibataires dans notre démocratie; sa tendance à devenir une éphébocratie. - Différence avec les républiques antiques qui remettaient exclusivement aux vieillards, aux patres familias la puissance publique. - Lassitude et indifférence progressive des électeurs pour la scrutin; explication de cette fatigue

L'électeur de 20 à 25 ans devrait compter pour un ;

L'électeur de 25 à 30 ans devrait compter pour deux ;

L'électeur de 30 à 50 ans devrait compter pour quatre. cinq, six; par suite de l'accroissement graduel de sa famille. - Plus tard, ses enfants devenus majeurs son vote retomberait par degré. 
Il ne faut pas se préoccuper de savoir à quel parti politique, un tel mode de scrutin, serait profitable, mais seulement se bien pénétrer de l'idée qu'il traduirait l'opinion et la volonté de la nation entière, avec beaucoup plus d'exactitude que le scrutin actuellement employé. - Conclusions. 


\section{Avant-propos}

Ce livre est composé, en majeure partie, de morceaux détachés qui ont déjà paru dans différentes Revues ${ }^{1}$, à des dates plus ou moins récentes. Se rééditer, s'exhumer ainsi soi-même, en ce temps où les morts vont si vite, cela peut bien avoir l'air d'une vaine protestation contre notre commune destinée d'oubli. Mais cela n'est pas vrai toujours. Quand des articles épars ne sont que l'application d'une même doctrine à des actualités variées, rassembler ces feuilles volantes en les réimprimant, ce n'est pas tâcher de les faire revivre, c'est, à vrai dire, les faire paraître pour la première fois sous leur véritable jour, grâce à leur mutuel reflet qui les entre-éclaire. Comme leur union fait toute leur force, si force il y a, leur auteur évite de la sorte le désagrément d'être mal compris d'après un fragment incomplet de sa pensée. C'est précisément le cas des études qu'on va lire. Elles ont trait à des questions du jour, à des crimes ou à des idées qui ont passionné l'opinion; et j'y ai mêlé, non sans intention, à des problèmes agités par les criminalistes des problèmes plus généraux

Dans la Revue philosophique, la Revue des Deux Mondes, les Archives de l'anthropologie criminelle, la Revue scientifique. 
soulevés par les sociologues. Par ce mélange, j'ai tenu à affirmer une fois de plus le caractère éminemment social des recherches d'ordre pénal : c'est surtout considéré comme un aspect singulier et néfaste des sociétés que le crime est instructif. Il est l'ombre portée de ces grands corps, et, bien qu'il soit téméraire souvent de juger du corps d'après l'ombre, les variations de celle-ci ne sont pas sans enseignement. Il semble que maintenant la nôtre s'allonge, comme il arrive au déclin des jours, et c'est pourquoi il importe d'y prendre garde.

\section{G. T.}


Gabriel Tarde, Études pénales et sociales (1892)

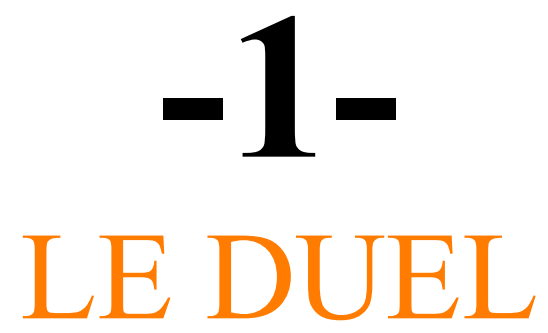

$\underline{\text { Retour à la table des matières }}$

Les nouveaux criminalistes ont cru, non seulement éclairer, mais étendre le sujet de leurs études, en étudiant, à côté de l'homicide, le suicide, et recherchant les rapports des deux. Mais je ne sais pourquoi ils ont négligé les ressources que leur eût offertes, au même point de vue, une question tout aussi importante par son intérêt théorique, sinon pratique, celle du duel. Si le suicide est la forme subjective de l'homicide, le duel en est la forme réciproque, et, si l'on a pu alléguer, sans le démontrer, que la progression de l'homicide est en raison inverse de celle du suicide, on pourrait tout aussi bien, ni mieux ni plus mal, plutôt mieux que plus mal, essayer de prouver, comme je le hasarderai bientôt, que l'homicide et le duel suivent une marche à peu près parallèle en somme. Le duel, par suite, se rattache au meurtre bien plus intimement, bien plus réellement que le suicide ; et il est, je le répète, surprenant que la criminologie, si portée à élargir son territoire par tant d'annexions récentes, n'ait pas encore annexé ce faubourg à sa porte ${ }^{1}$.

Deux écrivains distingués, M. Gil Fortoul, espagnol, clans sa Filosofla penal, M. Berenini, Italien, dans Offese e diffese (1891) rapprochent heureusement le duel et l'adultère comme étant à la fois des délits amnistiés par l'opinion après avoir été dans le passé des crimes capitaux. Un peu étrange peut-être, ce rapport entre un combat illicite et un amour illégitime 
Je sais bien que le suicide est un fruit raffiné de notre civilisation, qu'il croît et grandit avec elle, qu'il se propage dans chaque milieu et dans chaque pays suivant son degré d'élévation sociale, et dans l'armée en particulier d'après la hauteur du grade ; tandis que le duel est une survivance du passé, en train de diminuer numériquement et surtout de s'adoucir, de devenir de plus en plus inoffensif, à mesure que nous nous civilisons davantage, malgré une recrudescence peutêtre factice due au militarisme contemporain. Mais, précisément parce que le duel est un anachronisme, sa persistance singulière est un problème très curieux à scruter théoriquement. Ici éclate dans toute sa force inaperçue la souveraineté sociale de la coutume, de l'imitation du passé, toute-puissante même dans le cœur des soi-disant contempteurs du passé. Elle se révèle encore mieux, cette suggestion atavistique, dans les raisonnements étranges, aussi absurdes qu'accrédités, par lesquels cette institution féodale, le plus sanglant ou le plus ridicule lambeau des vieilles mœurs, s'efforce de se justifier, pour se dissimuler sa vraie origine.

Pratiquement, cette étude n'est pas non plus négligeable. Il y a loin, certes, des 8202 suicides de 1887 en France aux 53 duels qui ont eu lieu parmi nous cette même année (si j'en crois l'Annuaire de Ferréus); d'autant mieux que, sur ces 53 rencontres, il y a en seulement trois morts. Trois Morts d'un côté, 8202 morts de l'autre; l'écart est grand. Il peut paraître moindre, au premier coup d'œil, en Italie, où, en 1887 toujours, on comptait 1449 suicides et 278 duels ; mais ces 278 combats acharnés, par bonheur, n'ont été mortels que deux fois. Ce n'est point là un grand carnage. Le moindre accident de chemin de fer fait plus de victimes. On le voit, la question qui nous occupe n'est pas de celles qui touchent de très près au progrès ou au déclin de la population; et, quand même le changement des mœurs exorciserait pour tout de bon et à jamais ce spectre attardé de la chevalerie, la France ni sa voisine d'au-delà des Alpes ne seraient guère plus peuplées qu'elles ne le sont. Pourtant, c'est là une considération bien superficielle; et on a raison de ne pas s'arrêter à une objection analogue quand le problème de la peine de mort est

de deux personnes. Mais il est certain que l'un et l'autre ont successivement connu l'excès de la plus terrible pénalité et l'impunité la plus complète. 
remis sur le tapis. Qu'est-ce, a-t-on objecté aussi, qu'une dizaine de têtes criminelles à perdre ou à sauver par an; et à quoi bon tant s'occuper d'elles? Leur peine, capitale ou non, n'est point, en tout cas, une affaire capitale. - Grave erreur. Si insignifiante que soit devenue la mortalité, cholérique dans une grand ville, à la suite d'une épidémie de choléra, elle suffit à faire redouter un retour offensif du fléau; aussi les médecins s'acharnent-ils à extirper cette dernière racine du mal, à éteindre ce dernier foyer de l'incendie. Bonne ou mauvaise, une institution en déclin, aussi longtemps qu'elle n'est pas tout à fait morte, est toujours susceptible d'un regaillardissement imprévu, à la faveur d'un de ces caprices de la mode ou de ces vents révolutionnaires qui se déchaînent sans se faire annoncer. Il s'agit donc, avant tout, de savoir si elle est bonne ou mauvaise, afin de lutter pour sa précieuse conservation dans le premier cas, pour sa destruction complète dans le second. Il faut toujours raisonner dans l'hypothèse où ce qui semble un débris pourrait redevenir un germe plein de sève et d'avenir. En 1789, à la veille de la Révolution, la peine de mort était depuis longtemps déclinante; mais, si elle eût été abolie alors, et que son abolition eût été consacrée par l'usage, (ce que je suis loin de désirer, du reste), il est possible que la Révolution, ne trouvant pas cette arme redoutable sous sa main, eût hésité à l'exhumer d'un passé honni pour en faire usage; il y aurait eu encore, sans doute, des massacres spontanés; peut-être n'y aurait-il pas eu, ou y aurait-il eu moins, de férocités judiciaires. Qui eût prévu en 1788 la Terreur? Et, pour rentrer dans notre sujet, qui, avant les guerres de religion du XVIe siècle, dans la France paisible et prospère de Louis XII, eût prévu la fureur des combats singuliers que le démon des batailles allait susciter à cette horrible époque ? Nul ne peut affirmer avec quelque certitude que le vingtième siècle, si nous lui léguons le duel, même à l'état de décrépitude où nous le voyons, ne lui rendra pas à l'occasion sa vigueur sanguinaire d'autrefois. Voici que, depuis la guerre de 1870, toutes les armées européennes se mettent à vanter cet exercice d'escrime, ce procédé de réconciliation entre camarades ; les autorités militaires, -a llemandes, italiennes ou autres - encouragent ces dispositions. Mais l'armée, à présent, c'est la nation; acclimaté dans les casernes, préconisé et enraciné comme institution militaire, le duel ne tardera pas à refleurir comme institution nationale. C'est le danger, lointain encore j'espère, mais bon à prévoir et à prévenir. 
La division de notre sujet nous est naturellement indiquée. Il convient, d'abord, d'esquisser l'histoire et même la géographie du duel, son évolution dans le temps et même sa répartition dans l'espace. S'il est un phénomène social, en effet, dont l'intelligence soit impossible sans la connaissance de ses phases antérieures et aussi de ses variantes extérieures, c'est assurément celui-là. En second lieu, nous occupant du duel contemporain, nous aurons à discuter quelques documents statistiques relativement à ses progrès ou à ses déclins, et à préciser ses caractères. Le duel militaire, comme espèce frappante du genre, méritera une section à part. - Enfin, remontant aux causes du mal, que nous trouverons principalement dans l'insuffisance de la protection légale et judiciaire de l'honneur, nous nous efforcerons de chercher les remèdes. 
Gabriel Tarde, Études pénales et sociales (1892)

\section{-1- Le duel \\ Chapitre premier \\ Le duel dans le passé}

I

$\underline{\text { Retour à la table des matières }}$

Rien de plus naturel, en toute espèce animale, que de se battre avec un individu de son propre sexe, si ce n'est de s'accoupler avec un individu d'un sexe différent. Nous voyons les taureaux entre eux, les vaches entre elles dans les prairies, les coqs dans les basses-cours, se livrer des combats analogues aux scènes de pugilat de nos paysans à l'auberge ou de nos écoliers en récréation. Le duel, donc, pourrait-on dire, est tout à fait conforme à la nature, sinon à la raison; il faudrait chercher ses véritables sources dans les instincts du monde animal, et tout ce que le monde social y aurait ajouté de particularités, de formalités, de règles arbitraires, ne serait qu'une enluminure historique de ce texte fourni par la vie. Mais c'est là un exemple entre mille des erreurs auxquelles on s'expose par l'abus du point de vue naturaliste. L'explication qu'on donne ainsi du duel n'explique rien; car elle explique aussi bien la guerre, l'homicide, les jeux du cirque, et tous autres exercices sanglants. Il s'agit de savoir pourquoi, - l'instinct de combativité étant donné, bien entendu, ainsi que la haine et la 
vengeance, - ces forces vivantes ont reçu une direction sociale capable d'imprimer à leurs produits des formes si caractéristiques et si étranges. Ces formes, - par exemple, rendez-vous à heure fixe dans un lieu désigné, choix des armes, nécessité de témoins, cérémonial, - sont non pas la chose accessoire, mais la chose essentielle ici. Or, s'il est naturel de tomber à bras raccourcis sur quelqu'un qui vous vole votre maîtresse ou même vous insulte, il ne l'est pas de se contenir sur le moment, d'aller chercher des seconds, de consentir à se battre au pistolet ou à l'épée, quand on ignore le maniement de ces armes, avec un adversaire qui y est passé maître ; et, assurément, il n'est pas de combat de bêtes qui ressemble à la rencontre de deux gentilshommes français du XVIIIe siècle se faisant des politesses sur le terrain avant de s'entre-tuer.

Tout au plus pourrait-on découvrir dans les sociétés animales quelques traces anticipées de ce phénomène humain. Mais alors il est à remarquer que les bêtes ont infiniment plus d'esprit que nous. Le duel, ou ce qui peut à la rigueur paraître mériter ce nom, n'est raisonnable que chez les abeilles. Quand, dans une ruche, il y a par hasard deux reines, leurs sujettes, pénétrées de la maxime qu'on ne peut servir deux maîtres à la fois, les entourent, les pressent, les forcent à se percer réciproquement de leurs aiguillons, jusqu'à ce que l'une d'elles tombe morte sur le champ de miel. Ce conflit est nécessaire ; mais quelle nécessité que, de deux hommes qui se sont traités d'insolents ou d'imbéciles, l'un disparaisse ? On ne voit pas que les peuples, à l'instar des abeilles, aient jamais songé à faire battre leurs chefs pour vider des querelles où l'intérêt seul de ceux-ci, non de ceux-là, était en jeu ; ni les Français ni les Espagnols n'y ont contraint François 1er et Charles-Quint, ni les Romains Octave et Antoine, ni les Grecs Achille et Agamemnon. Imaginaire ou réel, le démêlé de ces derniers est bien propre à montrer que le duel était inconnu des anciens : ces deux rois ont beau s'injurier publiquement, dans l'Iliade, jamais l'idée ne leur vient de croiser le fer. Supposez qu'un gentilhomme de la cour des Valois ait vu sa maîtresse enlevée par un grand seigneur, qu'il ait été en plein camp, devant l'armée, appelé lâche et poltron, couvert de toutes les épithètes infamantes, et que, pour toute vengeance, il se soit enfermé sous sa tente. Avec quel mépris Brantôme, Montluc, d'Aubigné et tous les écrivains du temps parleraient de lui! Telle a été pourtant la conduite du bouillant fils de 
Pélée. Jugée avec nos préjugés, elle est d'une lâcheté inouïe. Ce sont ces préjugés dont il s'agit de rendre compte ; et il est clair, d'après ce qui précède, qu'il faut chercher leur berceau postérieurement à l'antiquité gréco-romaine.

Est-ce à dire que la nature humaine ait été pelleversée profondément depuis le monde antique ? Est-ce à dire, comme on l'a dit, que le sentiment de l'honneur fût étranger au cœur des Thémistocles et des Alcibiades, des Scipions et des Cicérons ? Si l'honneur est le désir d'être honoré, si être, honoré c'est être jugé, dans son milieu, serviable aux amis, redoutable aux ennemis, fidèle aux engagements, incapable de trahir et de mentir, nos aïeux de Rome et d'Athènes n'ont rien à apprendre de nous sous ce rapport. Essentiellement vaniteux et vindicatifs, préoccupés de l'opinion extérieure à un point extraordinaire, ils avaient tout ce qu'il fallait pour ressentir le point d'honneur avec intensité. N'importe, ils ont ignoré le duel. Je n'appelle pas duel, en effet, tout combat d'un contre un; et, d'autre part, il y a eu aux XVIe et XVIIe siècles, de nos jours même (par exemple à Compiègne, le 28 janvier 1885, une rencontre au sabre entre six cavaliers du $13 \cdot$ dragons), des combats à 4, 6, 8 combattants qui étaient de vrais duels, parce qu'une offense à l'honneur leur avait donné naissance. Le combat des six cavaliers dont je viens de parler ne peut nullement se comparer à celui des trois Horaces contre les trois Curiaces; et alors même qu'il n'y aurait eu qu'un seul Horace se battant contre un seul Curiace, cette bataille par délégation, inspirée par une générosité patriotique où l'amour-propre ulcéré et la vengeance exaspérée n'entraient pour rien, ne serait pas un duel. Je suis de l'avis de M. Cauchy, dans son savant ouvrage 1 : " Ces mots de duel, de combat singulier, sont trop vagues, car ils se rapportent seulement au nombre des combattants et non au motif qui leur a fait prendre les armes ». Le motif est l'âme des actes; il n'y a rien de commun que le nom entre l'homicide par vengeance et l'homicide par cupidité, entre le suicide hindou par piété religieuse et le suicide européen par désespoir ou par folie; il n'y a pas plus d'identité réelle entre le duel véritable, qui a pour cause l'honneur blessé, et celui qui a lieu pour la patrie ou la gloire militaire. Les batailles homériques n'étaient en ce dernier sens qu'un certain groupement de duels simultanés entre Grecs et Troyens ;

Du duel, par Eugène Cauchy, 2 vol. (Guillaumin, 1863). 
et ce serait cependant perdre son temps que d'y chercher le berceau du duel moderne. Il n'en est pas moins vrai qu'il convient de rectifier ce qu'il y a d'exagéré dans l'idée précédente ; bien souvent un même acte, en se répétant d'âge en âge, change d'âme, comme un organe demeuré identique dans sa forme essentielle change de fonction; et dans ce cas, qui est le cas du duel, il est utile, pour le bien connaître, de suivre l'enchaînement de ses métempsycoses avant celui de ses métamorphoses. Deux transformations bien distinctes d'ailleurs, et qu'il faut se garder de confondre dans le terme unique d'évolution. Depuis le XVIe siècle, le duel, réellement éclos, s'est simplement métamorphosé; mais auparavant il s'était métempsycosé pour ainsi dire.

\section{II}

$\underline{\text { Retour à la table des matières }}$

Rendons justice à qui de droit : aux ancêtres des Allemands revient l'honneur d'avoir conçu et enfanté l'embryon de cette coutume barbare. Chez les Germains, d'après Tacite, était usité le procédé divinatoire qui suit. Les généraux ne se faisaient pas assister d'augures qui égorgeaient des poulets sacrés, comme chez les Romains; non, mais avant de livrer bataille, on faisait battre ensemble un prisonnier ennemi et un guerrier, et d'après l'issue de ce combat singulier, on augurait bien ou mal de la bataille projetée. C'était une manière comme une autre d'interroger la divinité. De là à faire servir le même moyen de divination pour décider, dans les procès obscurs, civils et criminels, et avant tout jugement, de quel côté était le bon droit ou la culpabilité, il n'y avait qu'un pas facile à franchir. Il fut franchi dès avant le moyen-âge ; car si la loi Gombette, en 501, autorise et réglemente la preuve par combat, elle ne l'a certainement pas inventée. Nul législateur n'est, ni n'en peut être l'inventeur. Il résulte du texte même de cette loi que la cruelle procédure autorisée par elle s'était déjà introduite et avait eu un grand succès. Gondebaud n'a fait que suivre cet entraînement,et ce qui le prouve le mieux, c'est qu'il cherche à se prouver à lui-même le contraire, comme feront après lui tous les apologistes du duel, même à notre époque, en lui découvrant après coup les avantages les plus imaginaires et les plus étranges. Le duel a 
du bon, dit le roi bourguignon dans ses motifs, il est un remède au parjure des plaideurs. Cela peut faire pendant à la raison alléguée par un général au sénat italien : le duel d'après lui, est un moyen de raccommodement entre officiers. "Nous avons reconnu avec peine que le plus souvent on ne craint pas d'offrir le serment sur des choses que l'on ignore, ou de se parjurer au sujet de celles que l'on sait. Voulant détruire une aussi criminelle habitude, nous ordonnons ici que, si la partie à laquelle le serment aura été offert le refuse et déclare, dans sa confiance en la vérité de son dire que son adversaire peut être convaincu par les armes, les juges ne dénient point le combat. » Ainsi, pour éviter que les plaideurs se parjurent, on permet qu'ils s'entre-tuent; et voilà le meurtre légal suffisamment justifié ! Et ce raisonnement a paru si convaincant que, cinq siècles plus tard, comme le remarque Cauchy, Otton-le-Grand s'y appuie lui-même pour substituer, chez les Lombards, la preuve par combat à la preuve par serment. Au XVIe siècle, on argumentera en faveur du duel en invoquant l'exemple biblique de David et de Goliath; au XVIIIe siècle, on dira qu'il a contribué à la politesse des conversations, etc. Je le demande encore, après avoir posé ailleurs la même question à propos de bien d'autres sujets, l'hypnotisée qui cède à une suggestion absurde, en se persuadant obéir à la raison qu'elle allègue, procède-telle autrement que tous ces grands personnages, parmi lesquels j'ai le regret de compter Charlemagne lui-même ? - Il est pénible d'avoir à constater que jamais invention salutaire à l'humanité, jamais liberté précieuse, octroyée par un prince, ne fut accueillie avec autant d'enthousiasme que la faculté de se battre judiciairement. À peine la loi Gombette est-elle promulguée, aussitôt, d'après Saint-Avit, «non seulement les individus valides mais les infirmes et les vieillards courent au combat pour les plus futiles motifs, et dans ces conflits atroces surviennent beaucoup d'homicides injustes. » C'est une rage, contre laquelle les foudres mêmes des conciles et les menaces de l'enfer sont impuissantes.

On peut se demander incidemment pourquoi, de toutes les ordalies, le duel judiciaire a eu seul la chance de persister jusqu'à nos jours, tandis que d'autres, telles que l'épreuve par le fer rouge, n'ont laissé aucune trace après elles. Assurément, toute stupide qu'elle était, cette dernière était moins dangereuse, si j'en crois les détails qui nous sont donnés sur elle par Dareste dans ses Études sur l'Histoire du Droit. En 
Hongrie, où l'épreuve par le fer rouge, qui le plus souvent était un fer à peine chaud, a été pratiquée jusqu'au XIIe siècle, on a toujours constaté qu'elle était fort peu redoutée des patients. Encore une fois, qu'est-ce qui a mérité au duel de durer plus longtemps que cette ordalie anodine ? Je ne me charge pas de l'expliquer, autrement que par un caprice de l'imitation.

Entre le duel divinatoire des Germains et le duel moderne, le duel judiciaire sert de transition. Comme le premier, il est fondé sur une croyance superstitieuse et répond au besoin de connaître ou de prouver. Mais déjà le mobile de la vengeance y apparaît; le guerrier germain et le prisonnier ennemi qui se battaient n'avaient aucun grief personnel l'un contre l'autre, tandis que les plaideurs qui se frappent d'estoc et de taille sous les yeux du juge ont eu à se plaindre l'un de l'autre. Toutefois, la curiosité du juge qui cherche à savoir où est le bon droit, sinon la curiosité des combattants eux-mêmes qui attendent peut-être de l'issue du combat la solution de leurs doutes inavoués sur le mérite de leur cause, est le besoin principal que ce duel cherche à satisfaire. Le besoin de se venger d'une offense et de rendre mal pour mal n'est ici que secondaire. Aussi le duel proprement dit a-t-il, je crois, une autre source encore que le combat judiciaire; il est le confluent d'une double évolution, celle du combat judiciaire et celle des guerres privées qui ont désolé le haut moyen-âge. Si l'on ne le rattache à cette seconde source, la nécessité des assistants servant de témoins ne s'explique en aucune manière. Il n'y avait pas de témoins dans le combat judiciaire; pour témoin unique, il y avait le juge, dont le rôle était tout différent, - ainsi que celui des quatre chevaliers qui gardaient le champ-clos : ceux-ci n'avaient nulle part dans la querelle. Mais quand un baron d'alors avait à se laver d'une injure adressée par un de ses pairs, il sortait de son château avec sa petite troupe et ravageait les terres de l'offenseur, à charge de revanche, ce qui donnait lieu à des escarmouches continuelles consacrées par la coutume. Le droit de guerre privée est réputé le plus noble privilège féodal ; il était l'image d'un droit royal, et semblait faire des seigneurs autant de petits rois. L'Église, désespérant de le supprimer, n'a pu que le restreindre par la trêve de Dieu. On appelait ainsi l'obligation imposée à l'offensé de laisser s'écouler quarante jours avant d'entrer en campagne. Ce délai, qui permettait aux passions de se calmer, ou à l'offenseur de s'armer pour se défendre, à moins qu'il ne composàt, tendait à adoucir 
et à réglementer la vengeance d'une manière comparable à celle du duel moderne qui veut qu'on diffère un certain temps, qu'on ajourne à heure fixe la réparation d'une offense, et que les conditions de la lutte soient égalisées. La guerre privée, avant la trêve, était le plus souvent un échange de préjudices, une série de représailles, comme la vendetta corse qui consiste en assassinats alternatifs, ou alternativement tentés. Après la trêve, elle devint une suite de vrais combats. Par là se vérifie le passage habituel de l'unilatéral au réciproque que j'ai cru pouvoir ériger en loi ${ }^{1}$.

On comprend sans beaucoup de peine comment la guerre privée a pu susciter le duel. Si les barons tenaient beaucoup à leur privilège belliqueux, ils en souffraient énormément, et l'on a dû s'efforcer de réduire ce mal si cher aux moindres proportions. Comme suite naturelle au progrès qu'avait opérée la trêve de Dieu, on en vint, dans chacune de ces expéditions commandées par la coutume tyrannique, exécutées parfois sans entraînement, à se concerter pour ne mettre en présence qu'une poignée d'hommes des deux partis, au lieu de faire une levée générale des vassaux. Chacun des deux chefs, n'emmenait avec lui qu'une faible troupe, deux ou trois compagnons seulement dans certains cas, et était appelé à se mesurer personnellement avec son adversaire. Les seconds, dans nos duels, représentent ce reste rudimentaire des deux armées seigneuriales. C'est l'opinion de Cauchy. Peut-être cependant serait-il plus exact de dire qu'ils représentent les sicaires, les assassins délégués ou auxiliaires, dont les barons firent usage au fur et à mesure que l'extension du pouvoir monarchique 2 les empêcha de guerroyer ouvertement les uns contre les autres. À la guerre privée s'est substitué de la sorte l'homicide par mandat ${ }^{3}$, dont le duel n'est, en somme, que la mutualisation, pour

Je me permets de renvoyer sur ce point à mes Lois de 1'Imitation (Alcan, 1890 ). [Texte disponible dans Les Classiques des sciences sociales. JMT.]

2 D'abord Philippe-le-Bel édicta que la guerre du roy suspendrait les guerres des seigneurs; ce qui était une trêve du roi ajoutée à celle de Dieu. Puis, après la guerre de Cent ans, la milice royale, devenue permanente, fut assez forte pour oser supprimer les milices féodales.

3 La guerre privée obligeait souvent les barons - ou en Italie les cités républicaines - à stipendier des troupes mercenaires, faute d'une milice suffisante à lever sur leur propre territoire. Or, les condottieri qui conduisaient ces hordes, n'étaient-ce pas des chefs de sicaires à la solde non des particuliers mais des États ou des principauyés ? Il est certain que l'époque où fleurissait en Italie le condottierisme est aussi celle où le sicarisme y prospérait, et l'on doit penser que la plus vieille de ces deux institutions, la première, a suscité l'autre, née à son image et ressemblance. 
ainsi parler, en tant qu'il oblige les seconds, comme cela avait lieu au XVIIe siècle encore, à se battre eux-mêmes.

Avant de disparaître entièrement devant son remplaçant, la guerre privée s'est prolongée jusqu'au seuil de l'ère moderne, et même elle a eu sa reprise momentanée au XVIe siècle. Alors le même phénomène s'est reproduit, attesté par les historiens; et il peut servir de preuve à l'hypothèse ci-dessus. Dans son discours sur les duels 1, Brantôme dit que, avant l'époque où la grande mode des combats singuliers a sévi de son temps, deux gentilshommes qui s'étaient offensés devaient par prudence se faire accompagner en tout lieu, même dans les rues, d'une longue escorte de gens armés, recrutés d'ordinaire parmi les « enfants de la mate » (c'est-à-dire les filous), les «espadassins» et autres individus de même acabit. "Si bien que, se rencontrant dans une rue de Paris, même à la cour (mais cela peu souvent, car l'on craignait la Majesté et son prévost de l'hostel), là on se tuoient et s'estropioient les uns les autres comme mouches et bestes ». Il a vu cela fréquemment à Paris, ajoute-t-il, mais surtout à Milan « où, la dernière fois que j'y fus, j'y demeuray un mois... pour apprendre à tirer des armes du grand Tappe, très bon tireur d'armes alors ; mais je jure que, tant que j'y fus, il ne se passa jour que je ne visse une vingtaine de quadrilles (d'escadrons de cavaliers) de ceux qui avaient querelle se promener ainsi par la ville; et, se recontrant, se battoient et se tuoient, si bien qu'on en voyant sur le pavé étendus en place une infinité, encor qu'ils fussent armés de jache maniche, ganti de presa et segreta in testa (de jaques de maille, de gantelets et d'une secrète en tête) ». Or, l'entretien de troupes pareilles était fort coûteux ; les truands ont bon appétit, leur profession est d'aller s'offrir à quiconque peut avoir besoin d'eux, et ils entendent gagner à ce métier. Il y avait donc économie d'argent, et surtout de sang, à remplacer ces levées de bandits par des cartels réguliers. "Puisque de deux maux il faut choisir le moindre, j'argue qu'en tels combats (les duels) il n'y a que deux ou trois au plus qui meurent... on n'y voit point arriver tant d'abus, de désordres, supercheries et inconvénients comme en ces rencontres de bandes contre bandes. " Aussi, dans plusieurs armées, a-t-on vu alors les généraux, par exemple le prince de Melfe en Piémont, rendre des ordonnances par lesquelles le duel était imposé comme unique moyen

Discours sur les duels, de Brantôme (Paris, 1887), voir p. 143 et suiv. 
de vider les querelles. Ces ordres, il est vrai, au début « furent un peu rudes à tenir, mais, après en avoir fait pendre une douzaine, un chacun eut crainte et fut sage », c'est-à-dire se borna à tuer, pour un mot après boire, un ou deux de ses camarades ou à être tué par eux, au lieu de risquer, pour ce même motif, la vie de tous ses amis et des leurs. On conçoit, en somme, le succès du duel au XVIe siècle : cette forte saignée évitait une hémorragie mortelle. De notre temps à qui et à quoi sert la petite saignée qui en est l'image?

\section{III}

$\underline{\text { Retour à la table des matières }}$

Le duel est constitué au XVIe siècle; l'ère de sa transsubstantiation pour ainsi dire est close. Il continuera sans doute à se transformer ou à se modifier jusqu'à nos jours, par sa descente graduelle des hauteurs de la noblesse aux dernières couches du peuple, conformément à la loi de l'imitation du supérieur par l'inférieur ${ }^{1}$; il ira aussi se précisant de mieux en mieux dans ses règles et son étiquette de plus en plus uniformes, en vertu d'une autre loi de l'imitation ${ }^{2}$. Mais ses traits essentiels ne changeront guère, sa morphologie est à peu près achevée. Arrêtons-nous un instant pour remarquer en lui la trace manifeste des origines diverses que nous lui attribuons. Du duel divinatoire et du duel judiciaire, il a retenu le caractère mystique ou superstitieux, la présomption de culpabilité attachée à la défaite. De la guerre privée et de l'homicide par mandat, il a retenu la nécessité d'une escorte appelée seconds ou témoins, et, par malheur aussi, le droit à la perfidie, à la déloyauté même et à la férocité dans une mesure telle que le duelliste alors et l'assassin se confondent souvent ${ }^{3}$. - Sur ces deux points la preuve abonde.

\footnotetext{
V. nos Lois de l'imitation. p. 243 et suiv.

Voir ibidem, p, 214 et suiv.

Observons que ces deux sources du duel, la guerre privée et le duel judiciaire, s'enchaînent l'un à l'autre par un lien que les lois de l'imitation servent à expliquer. Le succès du duel judiciaire au moyen âge tient en grande partie à ce qu'il a paru être, et a été en effet, une copie, à l'usage des roturiers eux-mêmes, de la guerre privée, qui était le privilège des nobles.
} 
En premier lieu, on voit, par la lettre de Henri Il autorisant le fameux duel de la Châtaigneraye et de Jarnac en 1547, que, à cette époque, le duel était réputé encore jugement de Dieu, argument suprême à défaut d'autre raisonnement, ultima ratio virorum. Le roi permet aux deux adversaires de se battre parce qu'il n'est pas possible de prouver autrement si Jarnac a menti ou non en tenant les propos diffamatoires qui lui sont reprochés. Les grands de l'État lui ont fait entendre "que les causes du différend étaient hors de preuve; au moyen de quoi la vérité ne peut être sue ni l'innocent justifié que par les armes. " Henri Il était si bien persuadé de la validité d'une telle preuve que d'avance il condamnait le vaincu ${ }^{1}$ de ce combat à être déchu de noblesse, dégradé de tous titres, déshonoré. Du reste, Jarnac et la Châtaigneraye étaient pénétrés de la même conviction. Le second, dans son cartel adressé au premier, s'exprime ainsi : «Je vous envoie la patente du camp qu'il a plu au Roy m'octroyer, dedans lequel (camp) je veux vous prouver avec armes offensives.. que vous avez dit que vous avez couché avec votre belle-mère ${ }^{2}$ et l'avez chevauchée... » Ce n'est pas là un fait isolé. En 1559, lors de la disgrâce de Diane de Poitiers, « on voulut, dit Forneron ${ }^{3}$, la faire condamner à son tour par un duel» qui eut lieu avec le même apparat que le précédent. On pourrait citer d'autres exemples. Après tout, elle ne laisse pas d'être touchante, cette foi naïve en la force divine du droit, et il nous siérait mal d'en rire, si nous n'avons à lui opposer que notre foi nouvelle au droit divin de la force. - Du reste, tout vestige de cette superstition a-t-il disparu à la fin même du XIXe siècle? Je n'en répondrais pas. Quand, à une date récente, M. Floquet s'est battu avec le général Boulanger, l'issue du combat était attendue par les deux partis politiques de la France avec une anxiété où l'on sentait l'idée inconsciente que l'honneur de chacun d'eux était intéressé dans cette escrime de deux hommes. Il est certain que le coup d'épée reçu par le général, vaincu contre toute attente ${ }^{4}$, a été la première atteinte

A la vérité il tenait pour presque certain que son favori La Châtaigneraye, serait vainqueur. Mais on sait que l'événement trompa son attente.

2 La seconde femme de son père.

3 Les ducs de Guise,

4 L'observation montre cependant que, dans les duels entre militaires et civils, ces derniers ont d'ordinaire l'avantage ; ils l'auraient même 99 fois sur 100, en Allemagne, en Autriche, en France, en Italie, en Espagne, partout, si l'on en croyait la Revista penale (mai 1890. p. 444). - 
sérieuse au prestige du pseudo-César et a fait singulièrement pâlir son étoile. C'est ainsi qu'après la défaite, encore plus inattendue, du brave Châtaigneraye, tout le parti du roi se sentit humilié et comme déshonoré. - Dans sa brochure, intéressante d'ailleurs, sur le Duel 1, le Dr Teissier n'est pas loin de partager ce sentiment; il en prend tout juste la moitié. Suivant lui, le duel, non pas au pistolet, mais à l'épée, donne habituellement la victoire au bon droit. «Celui qui a demandé le combat, étant offensé, est le plus souvent vainqueur, car elle (l'épée) nécessite une grande confiance en soi-même et la conviction entière que l'on cherche à défendre son honneur injustement attaqué. » Cette opinion, sans doute, est exceptionnelle parmi les savants; mais elle semble régner implicitement dans le monde des romanciers et des dramaturges. Neuf fois sur dix, quand les héros d'un roman ou d'une pièce de théâtre vont sur le terrain, c'est le personnage sympathique et intéressant qui triomphe. Vo victis, est la devise des littérateurs aussi bien que des barbares.

En second lieu, il suffit de lire une histoire quelconque des moeurs de la cour et de la noblesse sous les derniers Valois, ou de parcourir l'ouvrage de Brantôme cité plus haut, pour savoir à combien de guetapens, de cruautés froides, d'assassinats déguisés, servait de pavillon le nom de duel. Dans le combat de 1559, autorisé par le roi, dont il a été question plus haut, le parent de Diane de Poitiers, Matas, "défié par le jeune Achon de Mouron, désarma son adversaire, dédaigna de le frapper pour imiter Jarnac qui n'avait pas tué La Châtaigneraye, lui tourna le dos et remonta à cheval. Pendant ce temps, Achon, ayant ramassé son épée, courut après lui et lui donna un grand coup d'épée à travers le corps. Matas tomba mort 2. " Achon ne fut pas poursuivi, bien que cet homicide se doublât d'ingratitude ; car, d'après la morale du temps, Matas aurait eu le droit, fréquemment exercé, de l'achever une fois à terre. - Sous Henri IV encore, les duels sont féroces. Un type de duelliste enragé est Lagarde-Valon ${ }^{3}$. " Il écrivait aux gens que poursuivait sa haine des billets dans ce style. Ta maison en cendres, ta femme violée, tes enfants perdus. Ton ennemi mortel,

Cedant arma togœ. Si le préjugé de la preuve par combat subsistait encore dans toute sa vigueur, ce résultat serait écrasant pour l'honneur de l'armée.

1 Le duel au point de vue médico-légal, par le Dr Teissier (Storck, 1890).

2 Hist. des ducs de Gutse, par Forneron.

3 Hist. anecdotique du duel, par Colombey (1863). 
Lagarde. " Sont-ce là des lettres d'assassin ou de spadassin? Eh bien, ce criminel-né était traité d'ami intime par les grands personnages de son temps. - Sous Louis XIII, les guerres de religion se rallument, le duel refleurit; on cite alors celui de deux provençaux qui, dans une même barrique, s'égorgèrent à coups de couteau, ou cet autre de deux seigneurs qui, se tenant par la main gauche, se poignardèrent avec la droite, ou le cas de ce chevalier d'Andrieux qui, à trente ans, avait tué en duel soixante-douze hommes. Tallemant des Réaux conte que, deux gentilshommes s'étant querellés dans une chambre, l'hiver, l'offensé plus vigoureux, empoigne l'autre, le porte sur le feu et l'y fait griller. Sommes-nous chez des sauvages?

Mais c'est surtout au XVIe siècle, et pendant le feu des guerres civiles, que les rapports du duel avec la guerre et l'assassinat apparaissent clairement. Les mots de spadassin et de sicaire ont passé alors de l'Italien dans notre langue, - de même que les termes de charlatan et de bouffon. Malheureusement l'importation des choses avait précédé celle des mots. Des sicaires de profession, en ce tempslà, ont été décorés, anoblis, publiquement récompensés ${ }^{1}$ par des princes et des rois. On comprend ce qu'un tel exemple, propagé de haut en bas, a pu engendrer d'épidémies sanguinaires. Sully, le pacifique et intègre Sully, parle comme il suit, dans ses mémoires, de la manière dont se sont conduits Duras et Rozan, dans leur duel avec le vicomte de Turenne sur une place publique d'Agen, en 1579. «On dit... qu'ils n'avaient obligation de l'avantage qu'ils avaient eu sur Turenne qu'à une finesse peu permise. » Cette finesse peu permise consistait en ceci : au moment où Turenne et son second, vainqueurs, avaient la générosité de relever leurs adversaires, des assassins embusqués par ceux-ci, neuf ou dix hommes armés, " fondirent sur le vicomte et le laissèrent sur la place percé de vingt-deux coups », dont il trouva moyen, d'ailleurs, de ne pas mourir ${ }^{2}$.

Quant à Brantôme, qui reflète exactement les sentiments moraux de ses contemporains de la haute noblesse, il faut le lire pour se faire

Hist. des ducs de Guise, par Formeron, tome II, p. 136 et 379.

2 Ceux qui ont lu ma Philosophie pénale remarqueront peut-être combien les faits cités ici et plus loin viennent à l'appui des idées que j'ai développées dans ce livre, p. 328 et S., sur l'action morale et immorale des classes supérieures. 
une idée de ce qu'a dù avoir de démoralisant pour tout un public de roturiers le spectacle d'acteurs à la fois si brillants et si vicieux, si braves et si cruels, si héroïques et si criminels, objets de l'admiration et de l'envie universelles. Leurs vices et leurs crimes étant plus faciles à copier que leurs vertus et leurs exploits, on devine la portée de leur exemple, prolongé en bas indéfiniment longtemps après la réforme et l'adoucissement des mœurs dans ces sphères supérieures. Le discours sur les duels scandalise à bon droit l'auteur de la préface, M. de Pène, par l'énormité des manœuvres déloyales et des horreurs qui s'y étalent avec candeur. Il est certain pourtant que nos duels d'aujourd'hui dérivent de ceux-là en droite ligne, mais ils leur ressemblent comme le debitum conjugale, machinal et officiel, de deux vieux époux, ressemble aux ébats de deux jeunes amants. Et c'est même là une raison de plus de souhaiter son abolition définitive : ne vient-il pas un âge où ce que deux vieux époux ont de mieux à faire est de renoncer aux jeux de la jeunesse ? - Brantôme pourtant a ses instants d'indignation ; il partage celle d'un duelliste qu'on soupçonne de porter des charmes sur lui et qui refuse de se laisser fouiller pour les chercher, tout en ne se faisant aucun scrupule d'employer des stratagèmes perfides, bien autrement efficaces qu'un "billet nécromancien $"{ }^{1}$. Non seulement chacun avait ses bottes secrètes, et le secret des inventions d'escrime était gardé comme à présent celui des inventions industrielles (ou même médicales) les plus précieuses, mais encore combattre à armes inégales était permis. Il est vrai que combattre le torse nu, comme à présent, eût paru de la dernière sauvagerie. - Au demeurant, la casuistique du duel commence à s'élaborer alors, et Brantôme parle souvent de fameux «docteurs duellistes ». Mais c'est dans les deux siècles suivants que ce singulier code et cette absurde étiquette achèvent de se perfectionner.

Il y a là toute une parade et un cérémonial chevaleresques qui ne se comprendraient pas si, aux deux sources déjà reconnues du duel, on

\footnotetext{
D'après une communication due à l'amicale obligeance du Dr Corre dont les études sur les mœurs des créoles ont été si justement appréciées, les duels créoles, qui gardent tout à fait l'allure pompeuse d'autrefois, ont retenu aussi du duel ancien le côté superstitieux. Le Dr Corre a pris copie d'un cahier de formules relatives à la préparation de charmes propres à assurer le triomphe d'un duelliste ou d'un amoureux. Il y a maintes recettes pour charmer les armes. Je ne les transcris pas. Elles prescrivent des préparations de dos de serpent dans de l'esprit de vin, ou des mélanges de laudanum avec de l'eau bénite, un oeuf couvé, de l'eau de mer, etc. (Corre. Le crime en pays créoles. Lyon, Storck, 1890).
} 
n'en ajoutait une troisième : les tournois. Cette variété importante des jeux militaires du passé, usitée dès le IXe siècle, réglementée par Geoffroy de Treuilly en 1066, a servi de modèle au duel sous certains rapports extérieurs et superficiels. Dans l'ordonnance de 1306, qui restreint le combat judiciaire en le réglementant, Philippe-le-Bel l'astreint à un appareil théâtral, à une procédure solennelle, manifestement imitée des tournois. Et, entre parenthèses, je ferai remarquer combien cette forme cérémonieuse, succédant à un extérieur beaucoup plus simple, s'accorde peu avec les idées de Spencer sur le gouvernement cérémoniel des temps primitifs, Philippe-le-Bel n'a fait, d'ailleurs, en rapprochant les deux institutions dont il s'agit, que consacrer les tendances de son époque. Les dames, qui étaient l'inspiration unique, mystiquement amoureuse, des tournois, sont devenues l'occasion de plus en plus fréquente des duels dans une société en voie de civilisation. La magnificence, le luxe d'armements et d'apprêts, qui étaient de règle dans les tournois, se sont introduits peu à peu dans certains duels, par exemple dans celui de Jarnac qui a commencé par ruiner en frais son adversaire avant de le terrasser. Les témoins des duels ont fini par se modeler sur les juges des tournois, qui étaient chargés de veiller à l'observation des usages, à l'emploi des précautions dans l'intérêt des combattants, et de mesurer les épées afin qu'elles fussent toujours égales. Quand le tournoi est mort avec Henri II, il s'est mis peu à peu à ressusciter dans les formes devenues plus polies et plus inoffensives du duel ${ }^{1}$, qui est allé s'éloignant de ses origines superstitieuses et féroces. Le duel, simple miniature à présent ou plutôt caricature de tournoi, sans éclat, sans grâce et sans femmes.

En même temps que le tournois, métempsycosé, se continuait ainsi dans le duel policé et adouci, il se transformait d'une autre manière par le carrousel. Dans sa remarquable vue générale sur l'histoire politique de l'Europe, M. Lavisse observe qu'il est assez étrange de voir, à l'origine des temps modernes, qui ont inauguré l'ère de la guerre perpétuelle après des siècles relativement paisibles, le tournoi dangereux devenir le carrousel inoffensif, et le chevalier belliqueux devenir le cavalier mondain. Cela prouve qu'il ne faut pas toujours juger des mœurs d'un peuple d'après la nature de ses plaisirs. C'est pendant la longue paix de l'Empire romain et l'adoucissement universel des âmes, que s'est répandue la mode des jeux du cirque. 


\section{IV}

$\underline{\text { Retour à la table des matières }}$

Voilà donc le duel maintenant tout formé, héritier des sottises et des atrocités de la barbarie, combinées avec les brutales élégances de la chevalerie : épave de la féodalité pieusement recueillie par notre démocratie. Admirons d'abord la longévité de cette absurdité ; elle dure depuis plus de neuf siècles si l'on remonte à ses éléments. Les démentis n'ont pas manqué, certes, dès le début, au préjugé sur lequel la preuve par le combat était fondée. En 1385, un gentilhomme nommé Legris, accusé d'avoir outragé et violé la dame de Carrouge, fut vaincu en combat judiciaire et, par conséquent, pendu. Mais, après sa mort, le véritable coupable du crime fut découvert et avoua. N'importe, le crédit de cette sanglante ineptie n'en fut guère diminué, pas plus que ne l'était, chez les Athéniens mêmes, celui du temple de Delphes, après la fausseté démontrée de l'un de ses oracles. Brantôme est encore très convaincu que la défaite en duel est une punition divine (p. 52 et s.) soit parce qu'on a une injuste cause, soit " pour d'autres fautes passées ». Il sait bien qu'à Rome, deux gentilshommes s'étant battus pour s'être reproché l'un à l'autre le vice infâme, celui qui en était taché fut vainqueur, et contraignit son ennemi, pur de cette souillure, à le déclarer homme de bien et d'honneur. Mais « ce sont là des secrets de Dieu ». Combien a-t-il vu aussi de cavaliers triompher en duel pour défendre l'honneur de leurs dames, "encore qu'elles fussent les plus grandes p... du monde, et connues pour telles d'eux » et de bien d'autres ! Mais c'était leur devoir d'agir ainsi. De nos jours, si l'on comptait les duels où le blessé a eu raison, cette statistique découragerait-elle les duellistes ? Nullement. On peut dire, il est vrai, qu'à présent, dans ces combats devenus de plus en plus singuliers, il n'y a, en général, ni victoire ni défaite ; le blessé n'y est pas vaincu, il n'est qu'un perdant à un jeu de hasard : quatre fois sur cinq, ou neuf fois sur dix, il pourrait continuer à se battre, sans l'interposition des témoins. Mais c'est bien là ce qu'il y a de plus étrange, une institution qui se survit alors qu'elle a visiblement perdu toute signification; et rien ne montre plus à nu la force de la routine. 
Je sais bien que, sous cette routine, il y a la nature humaine ${ }^{1}$; que, sous cette forme du duel, imitativement répétée d'âge en âge et de peuple à peuple, coutume féodale ravivée en mode intense au XVIe siècle et redevenue coutume routinière de nos jours, il y a un fond organique et physiologique, inné, non imité, une passion naturelle de vengeance et de talion, qui s'exprime par elle, et se satisfait par elle. Mais cette passion même, cette tendance spontanée à rendre mal pour mal, qui est propre à toute vie animale, qui est aussi naturelle que l'irritabilité des tissus vivants, pourquoi est-elle sujette à des alternatives historiques d'exacerbation ou de rémittence ? Pourquoi se développe-t-elle dans tel ou tel sens, et revêt-elle des couleurs si distinctes, à Florence, à Madrid, à Paris, au XVIe siècle, au XVIIIe, au XIXe ? L'entraînement de l'exemple, de l'exemple des pères ou de celui des contemporains jugés supérieurs, rend seul compte de ces crises et de ces développements caractéristiques. Le français, cela est certain, était plus vindicatif sous Henri III et sous Louis XIII qu'il ne l'est aujourd'hui ; en outre, il l'était autrement. La race pourtant n'a pas changé. Un simple démenti était alors une injure plus blessante que les épithètes mêmes de lâche et de traître, et le déshonneur était, non de mentir, au vu et su de tout le monde, mais de se laisser dire qu'on avait menti. Ne faut-il pas demander la raison de tout cela, en grande partie, au contact des gentilshommes français avec les noblesses italiennes ou espagnoles pendant les guerres d'Italie, et, pour une part aussi, au contact des français entre eux, plus fréquent que jamais, dans les cours et les armées, à la mutuelle émulation des amours-propres qui s'y enflaient démesurément sur le modèle des orgueils castillans et des vanités romaines? Cette enflure des cours n'est-elle pas toute

Quand je dis que tout phénomène social, en tant que social, est une imitation ou un composé d'imitations, je n'entends pas dire que l'on imite toujours pour imiter. Rarement l'imitation se sert de but à elle-même et se réduit à une simple moutonnerie; le plus souvent elle s'emploie à satisfaire un besoin différent; mais c'est une nécessité sociale que, pour atteindre un but quelconque, nous choisissions un moyen copié ou fait de copies; et, en outre, ce but, luimême, ce besoin, s'il a son germe premier dans l'organisme humain, s'est développé en nous par suggestion ambiante, par imitation inconsciente, tandis que d'autres besoins, tout aussi fondés sur la nature humaine, diminuaient, avortaient peu à peu, toujours par imitation. Si l'ont tient compte de ces considérations, on verra que je n'ai pas exagéré l'importance de mon principe sociologique. 
espagnole ? ${ }^{1}$ Cette indulgence à la perfidie et au mensonge, malgré cette indignation contre le démenti, n'est-elle pas toute italienne?

C'est, en effet, l'Italie, probablement, qui a été le berceau du duel moderne, au XVe siècle. De ce foyer brillant ont rayonné sur le monde européen, avec les arts, les lettres classiques et la politique nouvelle, la religion de la vengeance, culte traditionnel de ce pays, et, par suite ${ }^{2}$, ses rites principaux, la pratique de l'empoisonnement, l'emploi des sicaires, le duel. Cette mode n'a sévi parmi nous, avec la fureur inouïe dont j'ai à parler, qu'à partir des guerres d'Italie ; les mots qui se rapportent au duel, cartel, spadassin, escrime, le mot duel lui-même, sont d'étymologie italienne ou espagnole. L'Italie, avant l'Espagne, au commencement des temps modernes, a été la nationtype, sur laquelle toutes ses voisines se réglaient. On l'a imitée en ceci comme en tout le reste, parce qu'elle éblouissait les yeux, parce que sa supériorité sociale était manifeste; ainsi, la raison pour laquelle la contagion du duel a passé d'Italie en France, est précisément la même qui l'a fait se répandre de la noblesse dans la bourgeoisie, et même de notre sexe à l'autre.

Ce dernier phénomène surtout est significatif et peut servir à mesurer la violence de la contagion. On voit partout les petits singer les grands ; mais, quand les femmes mêmes singent les hommes, c'est signe que l'entraînement de l'exemple est exceptionnel. L'édit de Louis XIV de 1651 contre le duel est la preuve que ce fléau commençait à gagner les roturiers français; et cet effort législatif, pour arrêter ce débordement, peut être comparé aux lois somptuaires qui, par leur sévérité même contre le penchant des classes inférieures à refléter le luxe des classes supérieures, atteste la force de ce mobile. En Espagne, de même, monopolisé d'abord par la noblesse, ainsi que le montre l'édit d'Isabelle, en 1480, le duel se démocratise par degrés, et sa vulgarisation motive la loi du 3 mai 1716. Étrange engouement des

Même quand, par hasard, on faisait des excuses, il était de règle de se pavaner. « C'est ce que j'ouïs dire une fois à $\mathrm{M}$. de Guise qu'un gentilhomme, pour faire réparation à un autre qu'il aura grandement offensé, ne se fera point tort de dire : Je vous prie me pardonner. Mais, en disant ce mot, il faut qu'il mette la main sur son espée ou sur sa dague, avec une contenance assurée... » Cela devait être d'un haut comique.

2 Je dis par suite, conformément à la loi de l'imitation, intérieure à l'imitation extérieure (ab interioribus ad exteriora) dont j'ai cité des exemples dans mes Lois de l'Imitation. 
vanités bourgeoises! La première chose que fait le bourgeois gentilhomme de Molière, c'est de prendre un maître d'armes ${ }^{1}$, après avoir pris un tailleur distingué : imiter le luxe des grands seigneurs, passe encore, on comprend cette tentation; imiter leurs démêlés sanglants, quelle folie! Et quel beau spécimen de la singerie humaine ! Pourtant, cela, en somme, est le fait habituel et normal en son étrangeté même. Mais que dire des duellistes en jupons? Sous Louis XIII, les mœurs des beaux cavaliers se communiquent aux femmes. On en cite qui se sont battues soit entre elles, soit contre des hommes qui, d'ordinaire, j'ai honte de l'avouer, n'ont pas poussé la galanterie jusqu'à se laisser vaincre, mais, au contraire, les ont blessées ou même tuées. L'une d'elles ${ }^{2}$ très belle amazone bottée, l'épée au côté et des pistolets à l'arçon de sa selle, se battit par jalousie avec son amant, qui la défit; après quoi ils se réconcilièrent. Une Mme de Saint-Balmont, d'après Tallemant, a tué ou fait prisonniers de sa main, dans des duels ou des combats, plus de 400 hommes. Sous Louis XIV encore, la Maupin tua en duel trois hommes l'un après l'autre : et, même au temps de Voltaire, ne voit-on pas la marquise de Nesle et la comtesse de Polignac se battre au pistolet pour le duc de Richelieu qui, par distraction, leur avait donné rendez-vous au même lieu et à la même heure ? La marquise eut, paraît-il, un petit bout de l'oreille emporté par une balle.

Mais je ne peux pas me décider à quitter cette terrible époque de Henri III et de Louis XIII, où la maladie que j'étudie a eu son apogée. J'y reviens pour bien montrer la toute-puissance alors du préjugé sur les âmes. Il n'est pas de meilleur document que le Cid à cet égard. Quand le vieux don Diègue a reçu de Gomez un soufflet et qu'il appelle le bras vengeur de son fils, Rodrigue n'hésite pas un instant à se battre avec le père de Chimène ; et il le tue. Et, après l'avoir tué, il ose se présenter devant Chimène, lui expliquer sa conduite :

Tu sais comme un soufflet touche un homme de cœur...

J'avais part à l'affront, j'en ai cherché l'auteur,

Je l'ai vu, j'ai vengé mon honneur et mon père ;

«Ayez-vous envie de tuer les gens?» demande Mme Jourdain à son mari qui prend des leçons d'escrime. Ce mot exprime bien le bon sens plébéien de l'époque, où se battre en duel et tuer semblaient encore un privilège de noblesse.

2 Hist. anecdotique du duel, par Colombey, p. 66. 
Je le ferais encor si j'avais à le faire..

... Écouter ton amour, obéir à ta voix.

C'était m'en rendre indigne et diffamer ton choix.

Il ajoute, à la vérité, qu'il est prêt à se laisser percer le coeur par elle si elle veut exercer sa vengeance à son tour. Notez la réponse de Chimène :

Ah! Rodrigue, il est vrai, quoique ton ennemie, Je ne te puis blâmer d'avoir fui l'infâmie, Et, de quelque façon qu'éclatent mes douleurs, Je ne t'accuse point, je pleure mes malheurs... Je sais ce que l'honneur, après un tel outrage. Demandait à l'ardeur d'un généreux courage ; Tu n'as fait le devoir que d'un homme de bien..,

La scène est si admirable, l'âme de ces temps ressuscite en nous si miraculeusement à sa lecture, que nous ne nous étonnons presque pas, si ce n'est à la réflexion, d'entendre une fille, et une fille tendre, fière, délicate, pleine de piété filliale, qualifier homme de bien le meurtrier de son père.

Rares alors, à coup sûr, devaient être les duels finissant par un déjeuner précédé d'une égratignure. Quelques chiffres peuvent donner une idée du sérieux de ces rencontres, et aussi de leur nombre. De 1589 à 1608, d'après Pierre de l'Estoile, il y eut 7 ou 8000 gentilshommes français qui périrent en combat singulier ${ }^{1}$; et il est certain du reste que, dans le même intervalle de temps, 7000 lettres de grâce ont été expédiées et scellées en matière de duel... Un autre auteur contemporain, Jean de Chevalier, dans son discours sur les duels, imprimé en 1609, dit que, en Limousin, pendant 7 à 8 mois au plus, 120 gentils-hommes furent tués sur le terrain. Pendant les 8 ans de la minorité de Louis XIV, il en périt de la même manière 4000. Sur les champs de bataille, ou dans les champs clos, l'ancienne noblesse a versé le plus pur de son sang; et c'est peut-être une des principales causes par lesquelles s'explique cet épuisement fréquent des races aristocratiques, signalé par tant de savants.

Cité par Gauchy. 
On remarquera que les temps de troubles et de révolutions, en déchaînant les ambitions et hypertrophiant les orgueils, donnent lieu, comme on pouvait s'y attendre, à une recrudescence de duels. Effrayante est l'épidémie pendant la Ligue, de même que, aux XIVe et XVe siècles, la guerre de Cent ans avait été marquée par un redoublement de guerres privées, en dépit de la trève $d u$ roi. Le règne pacificateur d'Henri IV jeta des cendres sur ce feu; mais, avec le ravivement des luttes religieuses après sa mort, il se ranime. Nouvel apaisement sous Richelieu; nouvelle poussée du mal sous la Fronde. En 1643, duel pour les beaux yeux de Mme de Longueville entre un descendant des Guise et un descendant de Coligny, sur la place Royale. Règle générale : quand on se bat sur les places publiques la société est bien malade. Et je ne suivrai pas Cousin dans l'admiration émue que ce spectacle lui cause. Il y a seulement à faire observer que, à cette date encore, le duel gardait ce caractère théâtral où se marque sa dérivation du tournoi et du jugement de Dieu. Il l'a conservé de nos jours même parmi les créoles de nos anciennes colonies, suivant le Dr Corre. - Mais l'astre du Grand Roi se lève, et il semble, après l'édit de 1679, que l'hydre du duel soit écrasée ; au moins est-il hors de doute que, jusqu'à la fin du règne, la fermeté de la répression et la sagesse relative de la législation, ajoutées à l'adoucissement singulier des mœurs, avaient rendu les cartels très rares. L'édit dont je viens de parler avait su mettre le doigt sur le véritable remède au fléau : il avait établi ${ }^{1}$ un tribunal d'honneur réellement autorisé et respecté de tous, le tribunal des maréchaux de France, qui était destiné à arrêter dès leur source les querelles entre gentilshommes. Son devoir était de s'en enquérir, d'en prévoir les suites, et, dans le cas où un conflit paraîtrait à craindre, de faire surveiller les parties, de leur imposer l'escorte d'archers, anges gardiens militaires, les suivant partout comme leur ombre. Cela ne rappelle-t-il pas le luxe de précautions en usage dans les asiles contre les fous affligés d'une monomanie de suicide? Les maréchaux pouvaient non seulement graduer mais diversifier la peine suivant la nature de l'offense. En cas de coups, de soufflets, il était permis à l'offensé d'infliger le talion à son adversaire, après que celuici était sorti de prison.

A vrai dire, et cela vaut encore mieux, il ne l'avait pas créé de toutes pièces ; le tribunal des maréchaux existait déjà, mais Louis XIV l'employa très heureusement à ses fins. 
Cette législation a été réellement efficace ; le préambule de l'édit de 1704 atteste que le duel a presque disparu. Voltaire confirme cette attestation. Basnage, protestant réfugié, joint lui-même l'expression de sa reconnaissance à celle de ses contemporains envers Louis XIV, auteur d'un si beau résultat ${ }^{1}$. - Et l'on viendra ensuite nous développer des paradoxes sur l'inefficacité des lois et des peines! Cependant, s'il est une matière où cette thèse erronée ait eu une apparence de raison, c'est bien celle qui nous occupe, vu l'impuissance si fréquente des lois et des pénalités les plus sévères à endiguer la fureur des combattants. Mais c'est que Louis XIV, le premier, avait touché le noeud de la question. Nous y reviendrons. Soyons sûrs que, si le Misanthrope avait été composé sous Louis XIII, sous la Fronde même, Oronte eût envoyé à Alceste un cartel; à cette époque, les hommes de lettres mêmes sont des duellistes fougueux, par exemple Malherbe et Voiture. Mais, dans la pièce de Molière, le ridicule poète outré de l'offense qu'il croit avoir reçue d'Alceste, lui envoie simplement une assignation devant le tribunal des maréchaux; et Philinte nous raconte ${ }^{2}$ cette audience qui se termine, comme ont dû se terminer la plupart des affaires portées à la connaissance de cette cour. Alceste grommela un semblant de rétractation, quelque chose comme : «Je suis bien fâché de n'avoir pas pu trouver votre sonnet meilleur »;

Et dans une embrassade on leur a, pour conclure, Fait vite envelopper toute la procédure.

Vingt ans plus tôt, ils se seraient pourfendus au lieu de s'embrasser. Les bonnes lois et les intelligents gouvernements servent à quelque chose.

Dans les inventaires-résumés des archives des anciens présidiaux et sénéchaux, publiés officiellement par nos archivistes départementaux, on voit mentionner fort peu de duels à partir de Louis XIV. Dans celui de ces inventaires que j'ai étudié avec le plus de soin parce qu'il concerne mon pays natal, c'est-à-dire dans celui du présidial de Sariat, publié avec beaucoup d'intelligence par M. Villepelet, il n'est fait mention, dans l'intervalle de 1676 à 1790, que de sept duels. A coup sûr, Il y en a eu d'omis. Mais, en faisant même très large la part des omissions, la faiblesse d'un tel chiffre est à noter. Car, dans notre siècle seulement, l'arrondissement de Sarlat, inférieur cependant en étendue à l'ancienne juridiction présidiale, a compté beaucoup plus de combats singuliers, - sans parler même de ceux du général Fournier.

2 Acte IV, scène I. 
Mais, sous Louis XV et Louis XVI même, la répression s'affaiblit, et le duel se remet à sévir ${ }^{1}$ sous des formes extrêmement courtoises d'ailleurs et conformes à la politesse du siècle. On se complimente en s'alignant. Le motif des duels devient de plus en plus frivole, et leur issue de moins en moins tragique; "témoin Dorsant, qui, d'après Colombey, eut trois duels dans une semaine, le premier pour avoir été regardé de travers, le second pour avoir été regardé en face, le troisième pour n'avoir pas été regardé du tout. » Le duel cependant était en voie de décroissance à l'heure où la Révolution éclate. Dans les cahiers de la noblesse, il n'est pas question du duel; dans ceux du Tiers-État, cinquante-six bailliages s'élèvent contre «la barbare indulgence avec laquelle le duel était toléré », mais quatre-vingt-dixhuit réclament la suppression des lois contre le duel, espérant qu'elles allaient devenir inutiles. Et c'était bien là, en effet, de toutes les illusions de cette enthousiaste époque, la plus excusable. Ne semblaitil pas que, en cette déroute du vieux monde, cette vieillerie, déjà démodée sous l'ancien régime, dût être la première à succomber? Aurait-on pu croire que, toutes les coutumes, toutes les traditions, même les meilleures du passé, que, tous les droits, même les plus légitimes, mais entachés de la moindre trace de féodalité, venant à être arrachés de force, ce lambeau sanglant d'un âge abhorré,le plus détestable des privilèges et des usages aristocratiques, survivrait seul ? - Il a survécu pourtant; à la grande stupéfaction des naïfs qui jugeaient à jamais close l'ère des combats.

À l'Assemblée nationale, qui venait de proclamer les droits de l'homme, allait écheoir l'honneur d'ouvrir la série des duels parlementaires : duels sérieux, pour cause sérieuse, entre Barnave et Cazalès, entre Lameth et le due de Castries. Le 13 novembre 1790, déjà, une députation municipale, Bailly en tête, dépose une pétition à la barre de l'Assemblée, exprimant « ses alarmes sur la fréquence des combats singuliers dans la capitale. »Un décret de la Constituante, édictant l'amnistie en faveur de tous les accusés pour duel depuis le 14 juillet 1789, indique, par ses motifs, que les beaux jours de cette chevaleresque institution étaient revenus. "Considérant que, depuis

Assez faiblement du reste. "L'avocat Barbier qui est si fort à l'affût des menus potins de la cour et de la ville ne trouve à signaler de 1720 à 1741 que quatorze duels suivis de mort. » (Le Duel, par Teissier, p. 15). 
les premiers moments de la Révolution, l'opposition momentanée des opinions a déterminé les citoyens à des provocations qu'ils n'eussent point faites s'ils avaient eu le temps de réfléchir et de ne consulter que leurs sentiments réels ; qu'il en est résulté des instructions criminelles qui ont enlevé à la société.... etc. » - Ainsi, non seulement tous les abus, mais toutes les grâces et les grandeurs de l'ancienne vie, politesse des manières et douceur du savoir-vivre descendues de la cour des rois aux derniers rangs du peuple, solennités du culte, confréries, processions, fêtes, si chères aux ayeux, croyances et institutions, majesté royale, tout a péri ; mais, parmi ces ruines, une fleur refleurit, la féroce ordalie mérovingienne, l'antique sacrement de la vengeance ! Cela rappelle ce polynésien, converti à la civilisation européenne, qui des mœurs de ses ancêtres avait tout rejeté - sauf la pratique de l'anthropophagie.

Sous l'Empire, le duel sévèrement réprimé par le maître décroît; sa rareté, même dans les armées impériales, est attestée par le baron Pasquier en 1829 à la Commission pour l'étude d'un projet de loi sur la matière qui nous occupe. Il n'y a à citer, comme exceptions, que certains duellistes à outrance, tels que le général Fournier-Sarlovèse, mon compatriote 1 , dont certaines affaires pourraient figurer sous la rubrique de l'homicide. Mais, au début troublé de la Restauration, d'après les rapports des procureurs généraux du temps, comme plus tard après la révolution de 1830 et celle de 1848, on se remet à croiser le fer. Il est vrai que, le 24 février, sur les marches de l'Hôtel-de-Ville où ils se rencontrent, Louis Blanc et Eugène Pelletan, qui devaient se battre, s'embrassent; et que, peu de jours après, eut lieu une manifestation populaire contre le duel sur la tombe d'Armand Carrel. On y entendit Émile de Girardin lui-même - l'adversaire trop heureux du fameux publiciste, on le sait - prendre la parole pour réclamer l'abolition des combats singuliers après celle de la peine de mort. C'était logique : se battre en duel et abattre l'échafaud, c'est la plus évidente des inconséquences. - Malheureusement, ces démonstrations ont été des voeux platoniques : la série des coup d'épée retentissants reprend de plus belle, et, en novembre 1849, une proposition de loi contre le duel est repoussée par l'Assemblée. - Mais jamais, on peut le

Né à Sarlat. Voir, sur ses 22 duels consécutifs et légendaires avec son camarade Dupont, le Figaro du 4 mars 1877. 
dire, la puissance du préjugé ne s'est montrée si subjugante qu'à cette même date, quand Proudhon lui-même, après avoir refusé une première fois de se battre avec Félix Pyat, a fini cependant par accepter le cartel, parce qu'il ne se sentait pas de taille à braver sur ce point l'opinion! 
Gabriel Tarde, Études pénales et sociales (1892)

\section{-1- Le duel}

\section{Chapitre deuxième}

\section{Le duel dans le présent}

Le duel est-il en hausse ou en baisse numérique depuis le commencement de notre siècle ? Quels sont aujourd'hui ses caractères et son degré de gravité ? Il est assez difficile de répondre avec précision à ces questions, faute de documents suffisants; nous allons l'essayer toutefois. On verra bientôt, je crois, que, dans ces dernières années, il semble y avoir eu une légère augmentation, mais que, dans l'ensemble, depuis la Restauration, il y a eu diminution; qu'en outre cette déplorable coutume se localise de plus en plus dans certaines professions, celle des journalistes, des hommes politiques, des officiers de l'armée, et, par ce caractère professionnel de plus en plus marqué, semble se prêter à une extirpation moins difficile qu'autrefois. On va voir aussi qu'une des grandes causes de la persistance du duel est l'absence d'une législation spéciale à notre sujet, ce qui nous a valu les lamentables palinodies d'une jurisprudence oscillant d'un excès à l'autre, tantôt jugeant que le duel est un assassinat ou une tentative 
d'assassinat parce qu'elle veut rendre la loi applicable quand même à des faits non prévus par elle, tantôt décidant que la loi ne s'y applique pas et absolvant par suite le duel et l'homicide commis en duel.

Les édits contre les duels étant une institution d'ancien régime abolie par la Révolution, la pensée de les faire revivre en formulant une loi spéciale sur cette matière, aurait paru contre-révolutionnaire, bien qu'il ne parût pas aristocratique de se battre comme les grands seigneurs de jadis ; et c'est sans doute au fond la raison qui a motivé le silence inexplicable de nôtre Code pénal à cet égard. Le législateur, disait-on, ne voulait pas faire au duel l'honneur de le nommer. C'est très fâcheux; car, en général, ces pudeurs législatives ont des conséquences que ne prévoient pas leurs auteurs. Notre Code civil, par exemple, n'a pas voulu faire à cette espèce d'état civil qu'il appelle en passant le concubinage et que de nos jours on nomme familièrement collage, l'honneur de s'occuper de lui : et de là il est résulté que, la recherche de la paternité, même en pareil cas, étant interdite, tandis que, en cas de mariage, la présomption de paternité est invincible, le sexe masculin a tout avantage à préférer la forme non légale d'union à la forme légale et s'y précipite de plus en plus. La loi a favorisé le collage en le dédaignant. Il en a été ainsi du duel.

Sous le premier Empire, le duel, avons-nous dit, était rare. Le Parquet, s'inspirant des motifs de la loi, le poursuivait comme crime ou comme délit, suivant les circonstances, par application plus ou moins forcée de la loi ordinaire. - Au début de la Restauration, il se multiplie ${ }^{1}$, et plusieurs procureurs généraux jugent avec raison que le moment est venu de traiter législativement un point si grave. En 1819, ce problème est à l'ordre du jour; et les discussions auxquels il donne lieu à la Chambre des Pairs, à la Chambre des députés, à la Cour de Cassation, témoignent de la préoccupation dont il est l'objet. Si une proposition de $\mathrm{M}$. Clausel de Coussergue tendant à combler la lacune de nos lois pénales, est repoussée, la loi du 17 et 26 mai de cette même année sur la diffamation et l'injure, source première de toute les lois postérieures sur la Presse, cette arme à longue portée de la calomnie, s'attaque à la racine du mal et vise directement le but à poursuivre, sans l'atteindre cependant. Par malheur, pendant que les

C'est reconnu officiellement; V. Cauchy, t. I, p. 289, notes. 
assemblées politiques s'efforçaient de remédier à la situation, la Cour de Cassation, par son célèbre arrêt du 8 avril 1819, contribuait à l'empirer. Elle déclarait le duel non punissable d'après le Code de 1810. Cette jurisprudence a régné jusqu'à l'arrêt contraire du 22 juin 1837 qui, sous l'inspiration de Dupin, refoula de force le duel et ses conséquences sous l'application du droit commun. D'une indulgence exagérée on passait à une sévérité draconnienne.

Malgré tout, ce changement de jurisprudence a eu du bon. D'après un rapport du Garde des Sceaux, en 1846, il a fait tomber de 25 à 6 par année le nombre moyen des homicides commis en duel. Cette assertion s'appuie sur les statistiques suivantes :

\begin{tabular}{|c|c|c|c|c|}
\hline En & 1827 & 19 & morts & \\
\hline - & 1828 & 29 & - & \\
\hline - & 1829 & 13 & - & \\
\hline - & 1830 & 20 & - & \\
\hline - & 1831 & 25 & - & \\
\hline 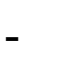 & 1832 & 28 & - & \\
\hline - & 1833 & 32 & - & période agitée \\
\hline 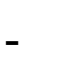 & 1834 & 23 & - & \\
\hline - & 1839 & 6 & - & \\
\hline - & 1840 & 3 & - & \\
\hline - & 1841 & 6 & - & \\
\hline 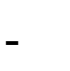 & 1842 & 7 & - & \\
\hline 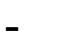 & 1843 & 6 & - & \\
\hline
\end{tabular}

Il est certain qu'un tel contraste des chiffres avant et après l'arrêt de 1837 est éloquent en faveur de l'utilité d'une répression. Mais, même abaissé à la moyenne de six par an, le nombre des homicides en duel est très supérieur à la moyenne actuelle qui, de 1880 à 1889, est inférieure à deux par an. D'où l'on doit induire que le nombre moyen des duels était au moins trois fois supérieur à celui d'aujourd'hui ou que les duels étaient trois fois plus sérieux et plus acharnés.

L'Annuaire du duel par Ferréus *, publication due à l'initiative privée mais qui paraît consciencieusement faite, présente les éléments 
bruts d'une statistique du duel civil. Les duels militaires en sont exclus, sauf de très rares exceptions, ainsi que les duels étrangers. Il est probable que l'auteur a dû laisser échapper, dans le dépouillement des journaux de Paris et de provinces qui lui ont servi de dossiers, un certain nombre d'affaires; un faible nombre sans nul doute, car il est bien rare que les affaires dites d'honneur, même les plus insignifiantes, n'aient pas un retentissement excessif. Toutes sortes d'affaires de sang, assassinat, duel, peine de mort, passionnent et attroupent le public. Voici les résultats que j'extrait de ce rapport :

\begin{tabular}{lccc||c} 
Année & $\begin{array}{c}\text { Duels } \\
\text { consommés }\end{array}$ & $\begin{array}{c}\text { Duels } \\
\text { arrangés }\end{array}$ & Total & Morts en duel \\
$\mathbf{1 8 8 0}$ & 31 & 9 & 40 & 2 \\
$\mathbf{1 8 8 1}$ & 32 & 10 & 42 & 0 \\
$\mathbf{1 8 8 2}$ & 31 & 17 & 48 & 1 \\
$\mathbf{1 8 8 3}$ & 40 & 25 & 65 & 1 \\
$\mathbf{1 8 8 4}$ & 48 & 12 & 60 & 2 \\
$\mathbf{1 8 8 5}$ & 52 & 11 & 63 & 1 \\
$\mathbf{1 8 8 6}$ & 51 & 19 & 70 & 2 \\
$\mathbf{1 8 8 7}$ & 52 & 24 & 76 & 3 \\
$\mathbf{1 9 8 8}$ & 47 & 26 & 73 & 2 \\
$\mathbf{1 8 8 9}$ & 47 & 14 & 61 & 2 \\
Total & 431 & 167 & 598 & 16
\end{tabular}

Il y a donc eu une progression assez sensible au cours de ces dix année; si l'élévation des chiffres ne se produisait qu'aux époques marquées par des crises électorales, 1885 et 1889, cette augmentation pourrait être regardée comme passagère ; mais elle est assez régulière, et, chose étrange, les deux années dont il s'agit, la seconde surtout, sont loin de se signaler par la force exceptionnelle de leur contingent. - Il est regrettable que les chiffres du duel militaire nous fassent défaut.

D'après M. Teissier, « depuis 1875, il y a eu en France647 duels ; mais les duels militaires ne figurent pas dans ce chiffre. Il y a eu en moyenne un mort sur 77 combats. " J'ignore où cet auteur a puisé ses chiffres. La mortalité en duel, d'après les miens, est deux fois plus forte. Sur 422 combats effectués (les duels militaires retranchés), il y a 
en douze morts, c'est-à-dire à très peu près un mort sur 35 combats. Ajoutons qu'il y a eu aussi une quarantaine de blessures graves, c'està-dire à peu près une blessure grave sur dix combats. - Quelques-unes de ces affaires ne seraient pas indignes de figurer dans le livre de Brantôme. Lisez entre les ligne de ce sec compte-rendu de Ferréus : «7 septembre (1882). M. D...directeur du Petit Caporal. M. de M...directeur du Combat... A la première reprise, un coup fourré a lieu; les deux adversaires sont atteints, M. D... de trois coups d'épée, sous l'aisselle, à la main, et grièvement à la tête; M. de M... en pleine poitrine. M. de M... meurt sur le coup.» Autre procès-verbal : «février (1884). M. W... professeur d'anglais. M. G... officier d'infanterie de marine. Rencontre à l'épée. A la deuxième reprise, $\mathrm{M}$. W... reçoit quatorze pouces de fer dans la poitrine et meurt sur le champ. M. W... fils, témoin de son père, prend l'épée et veut continuer le combat. M. G. s'y refuse. »

En Italie, la progression indiquée n'existe pas ; il y aurait plutôt une tendance opposée. Nous pouvons ici nous fier sans réserve à la statistique qui nous sert de guide. Bien que préparée par un simple particulier, M. Jacopo Galli, elle a eu l'honneur d'être acceptée par M. Bodio et de figurer dans sa savante publication officielle. - Entre parenthèses, nous devrions avoir quelque honte en France, au berceau de la statistique, de nous voir devancés sur ce point par nos voisins; et « au moment, dirons-nous avec notre ami M. Lacassagne, où la statistique criminelle que publie annuellement notre garde des sceaux va, paraît-il, sous prétexte d'économie mal comprise, être soumise à des restrictions qui diminueront son importance, il peut être utile de montrer l'utilité de semblables renseignements ", même de ceux ou plutôt surtout de ceux qui, comme les résultats relatifs au suicide et au duel, n'ont avec la criminalité qu'un lien indirect. 
Cette statistique italienne n'embrasse que neuf années complètes, de 1880 à 1888. Elle a trait au duel militaire et au duel civil, malheureusement confondus ensemble. Voici les chiffres :

\begin{tabular}{cccccc} 
Années & Duels & Morts & À l'épée & Au sabre & Au pistolet \\
& & & & & \\
$\mathbf{1 8 8 0}$ & 282 & 7 & 6 & 260 & 16 \\
$\mathbf{1 8 8 1}$ & 271 & 5 & 10 & 246 & 15 \\
$\mathbf{1 8 8 2}$ & 268 & 3 & 12 & 239 & 17 \\
$\mathbf{1 8 8 3}$ & 259 & 6 & 8 & 231 & 20 \\
$\mathbf{1 8 8 4}$ & 287 & 8 & 10 & 258 & 19 \\
$\mathbf{1 8 8 5}$ & 261 & 2 & 4 & 241 & 16 \\
$\mathbf{1 8 8 6}$ & 249 & 6 & 9 & 223 & 17 \\
$\mathbf{1 8 8 7}$ & 278 & 2 & 11 & 243 & 24 \\
$\mathbf{1 8 8 8}$ & 269 & 4 & 9 & 245 & 15 \\
\hline \hline
\end{tabular}

Ainsi, de 282 on descend presque régulièrement à 269 après être descendu même à 249. Mais la moyenne est encore très supérieure à celle de notre pays, même en faisant abstraction du duel militaire, dont l'importance peut être évaluée approximativement d'après d'autres données. En voyant, il est vrai, que l'arme choisie dans la presque totalité des cas a été, non pas comme chez nous l'épée ou le pistolet, mais le sabre, on pourrait induire de là que la grande majorité des duellistes est sous les drapeaux. Mais, dans le choix de cette arme, on doit plutôt voir une imitation de l'Allemagne dont l'Italie s'est engouée si étrangement. D'autre part, on nous apprend, deux pages plus loin, que, pour l'année 1888, (on ne parle pas des autres), sur 538 combattants il n'y a eu que 165 militaires ${ }^{1}$.

Sur ces 165 militaires, il n'y a que huit sous-officiers et douze élèves d'écoles militaires; tout le reste est pris parmi les officiers. même supérieurs. Il me semble en résulter que la coutume du duel est restée là-bas plus aristocratique que chez nous, où elle est descendue jusqu'aux simples soldats. Dans le peuple italien, le coup de couteau, coltellata, tient lieu avantageusement du coup d'épée comme mode de vengeance. 
En prenant la moitié de ce chiffre, nous pouvons compter 82 ou 83 duels au compte de l'armée. C'est un peu plus du tiers seulement du chiffre total ; reste, au compte des civils, le chiffre de 167 combats. Il est considérable, surtout si l'on observe qu'au-delà des Alpes l'homicide est décuple du nôtre et que souvent le duel fait avec lui, pour ainsi dire, double emploi pour la vengeance de l'honneur.

\section{II}

$\underline{\text { Retour à la table des matières }}$

Classés suivant les motifs qui les ont inspirés, les duels italiens se répartissent autrement que les duels français. En Italie, sur 2842 duels ${ }^{1}$, 974 sont attribués à des polémiques de journalistes, 780 à des altercations d'autres sortes, 348 à la politique, 219 à des insultes, 183 à des raisons d'ordre intime, etc. Je ne donne que les chiffres principaux. Si élevée que soit la part du journalisme dans cette répartition, et bien qu'elle tienne la tête de la liste, elle n'est pourtant que le tiers de la somme entière 2. Mais, en France, elle est des deux tiers environ, c'est-à-dire deux fois plus forte. C'est du moins le résultat que j'ai obtenu en faisant, le recensement attentif du répertoire de Ferréus. Souvent le motif du duel n'est pas indiqué ; il ne l'est pas 63 fois. En retranchant ce chiffre de celui de 598, total des duels (effectués ou tentés), on trouve 535 duels, dont 363 m'ont paru, d'après l'explication souvent un peu trop sommaire qui les accompagne, avoir pour cause évidente des articles de journaux, et pour acteurs, la plupart du temps, des journalistes. J'ajoute que 60 ont eu lieu entre hommes politiques ou pour des querelles politiques, et que 109 seulement sont attribuables à des motifs divers, parmi lesquels les raisons d'ordre intime ont une place insignifiante.

Ce chiffre total est supérieur à celui que nous avons fourni tout à 1'heure : c'est qu'il s'y ajoute les résultats fournis par sept mois de 1879 et six mois de 1889 .

2 Pour l'année 1888, on compte, sur 538 combattants, 155 publicistes ; c'est encore la même proportion à peu près. 
Cette prépondérance énorme et presque absorbante ( $\mathrm{du}$ duel littéraire, pour ainsi dire, est à remarquer. Elle donne au duel contemporain sa couleur propre qui s'accentue à mesure que notre civilisation poursuit sa marche. Si elle est plus marquée chez nous que chez nos voisins, c'est peut-être, - soit dit sans les offenser, - parce que notre population est plus généralement, sinon plus hautement, civilisée que la leur. La Presse est chez nous, plus encore que chez eux, une puissance en train de devenir toute-puissante. Comme directrice des esprits et des mœurs, elle a succédé au clergé du moyenâge (qui se battait aussi) et à la noblesse des deux derniers siècles. Elle a emprunté à cette dernière le goût fashionable et aristocratique du duel, mais en le façonnant à son gré. Dirons-nous qu'il est devenu le risque professionnel du métier de publiciste, ou bien l'un de ses trucs et de ses moyens de réclame plus usés encore qu'usités, ou même l'un des symptômes qui décèlent, l'intensité de cette maladie aiguë qui y est endémique, l'irritation et l'inflammation des amours-propres ? En tout cas, il est certain que la classe des hommes de lettres peut être considérée, - avec les casernes -comme le conservatoire $d u$ duel parmi nous ; et l'on est autorisé à dire, d'après les chiffres ci-dessous, que, si les journalistes ne donnaient pas ce fâcheux exemple au reste de la nation, d'ailleurs fort peu empressé à la suivre, aucun civil en France ne se battrait plus. A un autre point de vue, voisin de celui qui précède, rien ne prouve mieux que cette proportion croissante et exorbitante des duels pour cause de presse, l'amoindrissement, l'évanouissement graduel de l'utilité qu'on prête au duel comme réparation de l'honneur blessé. Jadis, aux beaux jours des cartels une injure à huis clos, devant deux ou trois amis ou sans témoin même, suffisait le plus souvent à armer les meilleurs amis l'un contre l'autre. A présent, un homme insulté en petit comité n'a jamais ou presque jamais recours aux armes : voilà un procédé reconnu inutile d'ores et déjà pour l'immense majorité des outrages à l'honneur. C'est seulement la publicité, la grande publicité de l'injure ou de la diffamation, qui nous décide à mettre flamberge au vent. On en a la preuve, non seulement par le contingent énorme de la Presse dans le duel, mais encore par celui de la Politique et de ce que nous avons appelé motifs divers. La plus grande partie des duels classés sous ces deux dernières rubriques est motivée par des altercations dans des lieux publics, bourses, cercles, théâtres, Palais-Bourbon. - Il est clair, au fond, d'après tout cela, qu'on se bat de plus en plus pour la galerie 
ou à cause de la galerie. Ce n'est pas à la gravité de l'injure, c'est à sa publicité, que l'épée ou le pistolet apportent leur remède; et ce spécifique, annoncé bruyamment, rarement mortel, le plus souvent inoffensif, ne guérissant jamais rien, prend en vérité un aspect de plus en plus charlatanesque. - Les populations s'en détourneraient depuis longtemps si elles ne voyaient l'aristocratie des temps nouveaux y recourir encore.

L'aristocratie de nos démocraties, c'est, je l'ai dit et j'ai cru le démontrer ailleurs ${ }^{1}$, les grandes villes, et d'abord les capitales. Or, à cet égard, il importe de noter que, sur les 598 duels enregistrés par Ferréus, 107 seulement m'ont paru être d'origine provinciale par leur cause ou le domicile habituel des combattants. Donc, les quatre cinquièmes des duels français sont parisiens; ils éclosent dans les plus parisiens des milieux de Paris; et, quant à ceux qui composent le dernier cinquième, ils prennent naissance eux-mêmes pour la plupart dans des grandes villes, Marseille, Nîmes, Lyon, etc. Le duel, en somme, est essentiellement urbain; il n'existe pour ainsi dire pas de duel rural. Combien nous sommes loin des temps où cette coutume était dans sa splendeur! Pendant les guerres de religion du XVIe siècle, on se battait partout, dans les campagnes comme dans les villes, autour des châteaux autant qu'à la cour. Maintenant, il est agréable de constater que le virus se localise. Seulement, le malheur est que ses lieux de refuge, sont des lieux élevés, fort en vue et points de mire universels. Ils sont de deux sortes : les capitales d'une part, dont je viens de parler, et, d'autre part, les armées.

\section{III}

$\underline{\text { Retour à la table des matières }}$

Le duel militaire mérite d'arrêter quelques instants notre attention. L'armée donne le ton en fait d'honneur, comme Paris en fait de goût, et son exemple, bon ou mauvais, doit avoir une influence énorme sur la propagation des combats singuliers, surtout depuis le formidable

Je me permets de renvoyer sur ce point la lecture à mes Lois de l'Imitation et à ma

Philosophie pénale (2e édition, Storck, 1891). 
accroissement des contingents. La caserne étroite et close d'autrefois, où les fléaux pouvaient naître et mourir sur place, s'est transformée en caserne ouverte, largement et très hospitalièrement ouverte à tous, d'où toutes les contagions peuvent déborder dans la nation toute entière. - Mais, en revanche, cette transformation a l'avantage de faciliter le remède au mal. Car il est infiniment plus aisé, par l'action de la discipline et des punitions réglementaires, d'agir sur le milieu militaire que sur le milieu civil pour l'extirpation des abus. - Pour ces deux motifs, il importe de savoir où en est la coutume du duel dans nos régiments et ce que l'autorité militaire a fait pour la déraciner.

L'armée est pour le sociologue un champ d'études unique. Elle lui montre, en une société spéciale, non pas artificielle, trop naturelle au contraire, mais exceptionnellement dense, homogène et forte, la caractéristique vraie des faits sociaux et leur rapport vrai avec les faits vitaux, par suite de l'exagération même des uns et des autres. Par le choix de sa population, purgée de tout élément parasite et encombrant, d'enfants, de femmes, de vieillards, d'infirmes, tout entière dans la pleine vigueur de l'âge, du sexe et de la santé, les fonctions physiologiques, les instincts de race, les tendances innées à la lâcheté, au courage, à la perfidie ou à la droiture, choses héréditaires et vitales, s'élèvent au plus haut point d'énergie. Et, par la densité extrême de sa population toujours rassemblée, les fonctions sociales proprement dites, les actions de présence et de contact mental qui se multiplient entre individus rapprochés, les qualités acquises et exemplairement suggérées, entrent en jeu avec une force extraordinaire. On peut révoquer en doute ailleurs la puissance de l'éducation, de la suggestion initiative ; ici elle est patente, ainsi que la subordination habituelle de l'hérédité, employée merveilleusement par sa rivale. Si divers qu'y arrivent les tempéraments et les caractères, ils s'y refondent, ils y plient ou ils y rompent sous l'uniforme moral qui y est de mise, aussi despotique que la règle. On y voit clairement que la nature du rapport social élémentaire est le commandement ou l'obéissance, l'imposition par l'un et l'acceptation par l'autre d'une idée ou d'une volonté ; que d'ailleurs la nature de l'acte social, soit de la part de celui qui commande et persuade, soit de la part de celui qui obéit et croit, est d'être une copie d'actes semblables, ou une combinaison originale de 
copies ${ }^{1}$, qu'enfin la nature du lien social, de la cohésion non physique ni sexuelle entre individus différents, consiste dans l'unanimité, la solidarité produite à la longue par le fonctionnement de cet acte et par la répétition de ce rapport, qui ont fini par faire passer de l'âme du chef dans l'âme du dernier des soldats un même but général et une même foi à l'efficacité des moyens commandés pour l'atteindre, à l'utilité du poste et de la tâche spéciale imposés à chacun.

Telle est l'armée, société intense; elle n'a de factice que son intensité même, l'excessive pureté de l'élément social en elle. Plus pur déjà dans les villes que dans les campagnes, il est incomparablement plus pur encore dans les casernes que dans les villes. Voilà pourquoi bien ou mal, tout y est contagieux et exagéré : la crainte d'un seul, en un clin d'œil, y devient panique, l'ardeur d'un seul furia francese. L'empire de l'opinion y est absolu. Autant la force des engouements et des désengouements, la tyrannie des opinions toutes faites, circulant de bouche en bouche, et des conduites toutes tracées, est plus grande dans les milieux urbains que dans les milieux ruraux, autant elle est encore supérieure dans les milieux militaires ${ }^{2}$. Tantôt la rapidité des changements opérés par mode, tantôt et plus souvent la ténacité des coutumes, même des coutumes les plus contradictoires au but de l'armée, telles que le suicide et le duel, y témoignent du penchant essentiel de l'homme en société à se modeler sur son semblable. Chose remarquable, nulle part la similitude des hommes, nulle part leur inégalité, ne sont portées si haut : mais l'inégalité hiérarchique n'y est qu'un moyen nécessaire d'assimilation rapide, de diffusion presque instantanée d'un sentiment ou d'un dessein particulier dans le coeur de tous.

Il est vrai que, dans le monde, l'imitation est d'habitude toute spontanée, inconsciente et involontaire la plupart du temps; dans les

C'est à dire d'être la direction des forces vitales dans le sens qui lui est tracé par la voie d'une action d'autrui elle-même imitée de la sorte, en remontant jusqu'à un premier acte original et, comme tel, extra-social, suscité par l'observation de la nature ou l'éruption d'un génie naturel. Tout être étant original dans une certaine mesure, remarquons-le, il est impossible que son action soit jamais imitation pure ; elle est toujours variation, c'est-à-dire invention jusqu'à un certain point.

2 Sur la propagation extrêmement rapide des délit et des suicides, une fois l'initiative donnée dans un régiment, on peut lire Setti, l'Esercito e la sua criminalita, p. 15. - Consulter aussi un mémoire de Gorre, la Criminalité dans I'armée, (Storck, 1890). 
régiments elle est forcée, calculée, voulue. Mais sa précision s'en accroît et sa nature n'en est point changée. Imiter pour imiter, comme fait l'imbécile, ou imiter pour réaliser une fin poursuivie par imitation, communiquée par contagion d'autrui, comme fait l'homme d'esprit, cela revient au même à ce point de vue. Du reste, précisément parce que tout s'opère ou tend à s'opérer à l'armée par calcul conscient, les erreurs énormes de calcul et les inconscientes inconséquences où l'on voit tomber parfois les états-majors les plus éclairés par l'effet de certaines traditions dont ils sont imbus, ou de certains entraînements qui les subjuguent, sont d'éclatantes preuves du pouvoir qui appartient à l'exemple humain.

Quoi de plus contraire en particulier, au but de l'armée, que le duel? Sérieux, il lui fait perdre des vies utiles sur le champ de bataille ; inoffensif, il serait propre à la ridiculiser. Est-il possible de s'illusionner sur ce point? Non, semble-t-il; et certainement, s'il s'agissait d'importer cette coutume barbare dans un régiment qui n'en aurait jamais entendu parler, son introduction se heurterait à des protestations unanimes. Mais il s'agit de l'expulser, et de tous côtés on proteste pour le maintenir comme on a protesté contre la suppression des tambours. Passe encore pour la routine du tambour, elle n'est que bruyante ; mais celle de l'épée ou du fleuret est dangereuse. Moins dangereuse que celle du suicide, je le veux bien : seulement le suicide, qui décime les armées européennes, et dont les officiers donnent l'exemple aux troupes, est un mal contre lequel les efforts des chefs ne peuvent rien. Il n'en est pas de même du duel, qu'ils pourraient réfréner en cessant de se le permettre à eux-mêmes, ou qu'ils devraient au moins ne pas encourager soit en le permettant soit en l'ordonnant à leurs inférieurs. Si l'armée est le lieu d'élection du duel, c'est leur faute.

Il est monstrueux que le duel puisse être autorisé, et parfois ordonné, par l'autorité militaire. Pourtant cela est certain, et notoire ; les documents officiels eux-mêmes en font foi. D'abord il est à noter que jamais les duels militaires n'ont été l'objet de poursuites en conseil de guerre. Ce fait est déjà significatif. Or, en 1862, un duel suivi de mort avant eu lieu entre deux sergents du 41 • d'infanterie, le ministre de la Justice s'émut et saisit son collègue de la guerre. " Le duel, dit le garde des sceaux, si rigoureusement poursuivi conformément aux lois 
par les organes de la justice criminelle, n'est pas seulement toléré dans l'armée mais encore encouragé, prescrit ou autorisé ouvertement par les chefs de corps. Cette différence si tranchée entre la conduite des autorités civiles et militaires n'est-elle pas de nature à affaiblir le respect des lois du pays ? N'y a-t-il pas eu un changement regrettable dans les procédés des chefs de corps qui se bornaient à fermer les yeux sur certains abus dont la tolérance est devenue un encouragement?» Cette dernière phrase semble indiquer que l'abus dont se plaint le ministre est de date récente ; peut-être s'est-il glissé dans l'armée à la suite des guerres de Crimée et d'Italie, comme nous avons vu la guerre de 1870 lui prêter une nouvelle vigueur.

En réponse à cette note, le bureau de la justice militaire, consulté, émit un avis conforme aux désirs du garde des sceaux, et, depuis cette époque, «les ministres de la guerre n'ont cessé de rappeler aux généraux, en réponse à des communications particulières, que, le duel étant défendu par les lois civiles et religieuses, l'autorité militaire ne devait jamais prescrire de rencontres par les armes, mais devait se borner à veiller à ce que, dans les rencontres demandées par les intéressés, tout se passât d'une façon loyale. On pourrait même citer plusieurs exemples de chefs de corps punis disciplinairement pour avoir contraint des hommes à se battre ${ }^{1} \gg$. - Dans une de ces lettres, le Ministre s'exprime ainsi : "Je sais qu'il existe des cas où l'honneur se trouve tellement compromis ou engagé qu'il est bien difficile, pour des militaires surtout, de n'avoir pas recours à la voie des armes; mais ces cas sont heureusement rares... »

Parmi les théologiens d'ancien régime s'est élevée la question de savoir si le duel est licite ou peut être excusé quand il a lieu avec la permission du Prince. Cajetan est porté à accueillir cette excuse ; mais le docte Suarez, qui ne transige pas avec les principes, la repousse avec indignation. Et, en cela, qui le croirait ? il est de l'avis du cardinal de Richelieu. Celui-ci refuse de même, et expressément, au Prince le droit d'autoriser l'effusion inutile du sang. Nos officiers, on le voit, sont plus absolutistes que ce théoricien et ce praticien éminent de l'absolutisme.

Je reproduis les termes d'une communication qui m'est adressée par un correspondant des plus compétents, à la suite de recherches qu'il a eu l'obligeance de faire sur ma demande. 
Depuis vingt ans, l'esprit de réforme et d'innovation s'est donné carrière, surtout en ce qui concerne l'armée. A-t-il touché au duel militaire ? Oui, mais avec une timidité qui contraste singulièrement avec sa hardiesse habituelle. Une circulaire de M. de Freycinet, qu'il faut louer du reste en partie, (8 juillet 1889), supprime le duel obligatoire en laissant subsister le duel facultatif et autorisé, et substitue l'épée de combat au fleuret comme arme réglementaire. Cette circulaire a-t-elle eu ou aura-t-elle le sort de celles qui l'ont précédée? On peut le craindre. Elle a été diversement jugée. Approuvée hautement et entièrement par M. Henry Fouquier ${ }^{1}$, elle est critiquée à plusieurs reprises par le Progrès militaire, en ce qui a trait à sa seconde disposition. M. de Freycinet motive la préférence accordée à l'épée par le danger plus grand que présenterait le fleuret. Cette raison ne persuade pas les écrivains autorisés de ce journal. "L'épée embroche tout aussi bien que le fleuret, d'autant plus que le soldat ne sait pas la manier du tout... Puisque c'est l'escrime au fleuret qui est seule enseignée dans les salles militaires, laissons nos soldats se battre au fleuret. Il faut une grande habitude pour utiliser avec une épée rigide les principes de la pointe. Autant mettre des bâtons pointus dans la main des pauvres diables 2 ». Dans un autre article, la même feuille insiste. "L'épée est un anachronisme en 1890 ; on l'a si bien reconnu que le ministre de la guerre a obligé tous ceux qui en sont armés (fonctionnaires ou employés de l'intendance et médecins), à y joindre le revolver ». Quelle est la bataille où l'on se bat maintenant à l'épée quand on s'aborde? «Dans les combats corps à corps, on se tire des coups de revolver, ou se donne des coups de sabre, l'on s'embroche à coups de baïonnette, ou l'on s'assomme à coups de crosse... L'épée, dégaînée sur un champ de bataille, ne résiste pas au bâton manié par une main robuste, et encore moins au fusil tenu à deux mains par la crosse $»$.

Eh bien, c'est cette arme, digne du Musée de Cluny, c'est cette miniature de la rapière chevaleresque, que le duel tend à éterniser, soit dans l'armée, soit au dehors. Et l'on ne voit, certes pas, l'utilité d'en imposer le maniement à de malheureux soldats, «ferrailleurs malgré

Dans le Progrès, article intitulé Le duel et l'armée, daté du 10 octobre 1889.

2 Le Progrès militaire du 24 juillet 1889. - L'autre article est du 9août 1890. 
eux » dont « l'attitude généralement incorrecte et piteuse n'est pas faite pour relever la science des armes ». - Mais l'épée a son prestige propre, sa noblesse traditionnelle, et je ne puis m'empêcher de voir là le motif inavoué et inconscient de la prédilection si générale des duellistes pour elle.

La puissance extraordinaire des traditions, même féodales, dans les armées, même les plus intelligentes et les plus éclairées, nous est révélée encore par une singularité du duel militaire dans certains régiments. Sur l'ordre du colonel, deux sous-officiers ou deux hommes de la troupe viennent de se battre, en présence d'un officier et d'un maître d'armes. L'un des deux adversaires reçoit une légère blessure - peu grave d'habitude, vu la distance qui les sépare. Qu'advient-il ensuite? L'un de ces deux combattants, qui ont combattu par obéissance, ou du moins avec une autorisation régulière, est condamné à quelques jours de salle de police! C'est déjà bien étrange ; mais voilà qui devient incroyable ; le puni, c'est le blessé. Je ne dis pas que cet usage règne partout, mais il est pratiqué passim. «Depuis $1874{ }^{1}$, dit un maître d'armes de l'armée, on a vu des chefs de corps punir le duelliste blessé ». Tantôt le blessé fait le total de la punition infligée aux deux, le non blessé étant gracié : tantôt il fait le double de la punition primitivement infligée, sans que le non-blessé soit gracié ; d'autres fois cependant sa punition n'est pas augmentée. Dans tous les cas, bien entendu, le duel a été autorisé ». - J'aurais bien voulu savoir quelles raisons on allègue pour justifier cette étrangeté. Probablement on doit dire qu'il y a là une prime d'encouragement à l'adresse et à la vigueur, une sorte de prix d'escrime. Mais il est trop clair que c'est là purement et simplement une survivance des jugements de Dieu, le dernier écho du préjugé qui dans le vaincu du combat désignait un coupable ${ }^{2}$.

M. Lacassagne, avec son obligeance ordinaire, a bien voulu recueillir pour moi l'information suivante, ainsi que beaucoup d'autres.

2 En Italie, ce n'est pas le blessé seul qui est puni, mais d'après les renseignements que je dois à l'amitié de M. Enrico Ferri, les deux combattants reçoivent une punition. Malgré cela, - car, avec le duel, on nage toujours dans l'absurde. - si un militaire défié refuse de se battre, « il est expulsé de l'armée, ou bien on prend des mesures contre lui, plus ou moins légales ». 


\section{IV}

Retour à la table des matières

En vérité, quand on voit de telles pratiques se perpétuer et passer inaperçues, sans que personne s'en indigne ni s'en étonne, on n'est plus surpris qu'au moyen-âge le duel judiciaire, quoique réprouvé par l'Eglise (comme l'est le duel militaire par les circulaires ministérielles) ait été béni souvent par le prêtre (comme le duel militaire est autorisé par le colonel ou le capitaine), et que, nonobstant cette bénédiction, la sépulture ecclésiastique ait été refusée au vaincu (comme la salle de police est infligée au blessé). On comprend dès lors, et à plus forte raison, les édits royaux autorisant les combats de Jarnac et de la Châtaigneraye, et la pompe royale de ces boucheries dans la cour du Louvre, devant la plus galante des cours, au grand ébahissement de l'ambassadeur turc. Une image de ce brillant appareil, un souvenir des vieux tournois, revit parfois dans nos armées. Je lis ce qui suit dans l'Annuaire de Ferréus : " 28 janvier (1885), Duel au sabre entre six cavaliers du 13• dragons, à Compiègne. 25 minutes de combat. A la deuxième reprise, trois cavaliers sont blessés à l'avant-bras, mais sans gravité. Quelques officiers, des médecins et des prévôts, assistaient au combat, outre les témoins. "

Je dis que de tels spectacles sont affligeants pour la raison humaine. J'oppose à cette indulgence, à cette complaisance incompréhensible des autorités civiles ou militaires d'aujourd'hui pour le duel, leur sévérité d'autrefois, et je me l'explique d'autant moins que le duel est déclinant, chaque jour plus repoussé par le bon sens, l'humanité, le progrès des moeurs. Le duel se meurt de lui-même, en effet; il se survit ; son âme, la vengeance haineuse et féroce, le dépit passionné de se tuer réciproquement a disparu; il n'en reste guère plus que la forme extérieure et l'écorce, comme celle d'un saule décrépit ${ }^{1}$. J'en conclus qu'il suffirait d'un effort léger pour l'abattre; et j'en

Il en est ainsi de toutes les survivances, linguistiques, religieuses, politiques, esthétiques, etc. La loi de l'imitation ab interioribus ad anteriora (voir nos Lois de l'Imitation) veut qu'il en soit ainsi. Précisément parce que le fond précède la forme, la forme finalement, doit survivre quelque temps au fond. 
trouve la preuve manifeste dans ce fait, que, malgré la faveur dont il jouit auprès de ceux qui auraient le devoir de le réprimer, il ne progresse pas davantage. Supposons qu'au XVIe siècle les chefs l'aient encouragé comme à présent; ç'eût été le signal d'un épouvantable carnage. De nos jours, on a beau le favoriser, il se chiffre par des nombres très faibles.

Il ne nous a pas été possible, il est vrai, d'avoir un dénombrement exact des duels militaires ; mais, par induction, on se convainc qu'ils sont rares. On a vu plus haut que, dans l'armée italienne, leur nombre annuel parait être de 82 ou 83 environ. Sont-ils plus nombreux chez nous? Je ne le crois pas. Ferréus, dans son Annuaire, ne les mentionne qu'à titre exceptionnel, mais il les mentionne toujours quand leur issue a été tragique. Or, il n'en compte que 7 , à savoir le duel des six officiers, rapporté plus haut, deux autres suivis de blessures graves, et quatre suivis de mort. Quatre morts en dix ans parmi les militaires, tandis que, parmi les civils, il y en a eu au moins douze, cela laisse supposer ou qu'on s'est bien rarement ou qu'on s'est bien peu sérieusement battu. Mais, d'autre part, si nous sommes bien renseignés, l'avis général dans les régiments est que le duel y est devenu plus sérieux. S'il en est ainsi, il faut croire qu'il y est bien peu fréquent, ce qui est aussi l'opinion répandue. - Que serait-ce, si l'on sévissait contre lui avec quelque fermeté ? Le soldat tient encore moins au duel qu'à la brimade ; on fera disparaître les deux quand on le voudra bien, et peut-être le premier plus facilement que la seconde.

Pourquoi ne le veut-on pas résolument? J'ai bien peur que, sur ce point comme sur d'autres, nous ne nous laissions donner le ton par nos vainqueurs. Il y a toujours eu une armée européenne sur laquelle les autres se sont réglées en tout; jadis c'était la nôtre ; au XVIe siècle, celle de l'Espagne; aujourd'hui, c'est celle de l'Allemagne, Avant 1870, le duel, dans l'armée allemande ne restait jamais impuni. Il l'était même très sévèrement. Il est vrai que, si la loi pénale punissait les officiers prussiens de la réclusion dans une forteresse pour avoir accepté un défi ${ }^{1}$, la cour d'honneur les condamnait parfois à la dégradation pour avoir refusé. En 1846, le refus de l'un d'eux lui valut la perte de son grade en vertu de ce singulier motif : " attendu qu'il a

Voir Colombey, Hist. anecdot du duel, ouvrage écrit en 1861. 
refusé en déclarant que le duel est un préjugé de caste ; qu'en agissant ainsi il a manqué de respect à ce qui doit être la base des armées, l'honneur militaire, etc. \" ${ }^{1}$. Mais l'histoire du duel nous a habitués à ce renversement de toute logique : un dilemme pareil s'offrait aux gentilshommes d'ancien régime. Même aux époques où la loi et le parlement étaient le plus féroces contre les duellistes, ceux-ci avaient à opter entre l'échafaud et le déshonneur. N'importe, les principes étaient sauvegardés par le législateur. En Allemagne, il y avait un moyen bien simple de lever la contradiction : c'était la réforme des cours d'honneur. On a fait précisément le contraire : depuis 1874, le duel militaire y est ouvertement autorisé ou toléré. Aussi s'y est-il remis à pulluler. L'empereur actuel le recommande publiquement.

A un banquet offert par une corporation d'étudiants, il a dit : «Les mensuren (duels), qu'une partie du public ne comprend pas, sont la même chose que les tournois du moyen-âge. Que cet esprit de chevalerie soit conservé tant qu'il existera des universités allemandes ! » Voilà au moins qui est franc et net, et je comprends qu'un autocrate parle ainsi; mais nos démocrates! Les étudiants allemands se battent beaucoup; il y a bien le cercle des catholiques pratiquants, qui ne permet pas le duel; mais, dans la plupart des autres, " on ne devient membre actif, dit M. de Wyzewa, (Revue des Deux Mondes, 15 mars 1891), qu'après avoir eu des duels ». A l'exemple de l'Allemagne, il en est de même en Suisse. Je lis dans une correspondance de Berne, du 4 février dernier : "Un duel au sabre a lieu en ce moment aux environs de la ville entre 15 étudiants bernois et 15 étudiants de Bâle et de Zurich venus pour provoquer leurs confrères. Plusieurs des combattants sont déjà blessés. Une voiture les ramène au fur et à mesure $»$. Ces mœurs déplorables me paraissent devoir se rattacher à celles de l'armée allemande.

Les tribunaux d'honneur s'efforçaient du reste d'empêcher la plupart des duels et ils y parvenaient. Quand par exception, ils autorisaient le combat - en dépit de la loi - l'affaire avait lieu en grande pompe comme à la cour des Valois. Dans la même année 1846, le tribunal de Munster, déjà nommé, autorisa un combat entre deux officiers, et le duel eut lieu solennellement, au milieu d'un grand concours de peuple, sous la présidence des membres de cette extraordinaire magistrature. On se battit au sabre; l'un des adversaires reçut une grave blessure à la cuisse. Voir Colombey, Hist. anecdot. du duel, p. 220). 
L'armée italienne, naturellement, a suivi cet élan ${ }^{1}$. Notez que le duel, réprimé jusque là, y avait presque disparu. On a entrepris non pas de le conserver, dit la Revista Penale, mais de l'y introduire, pour se mettre à la mode. Et pourtant Dieu sait l'opportunité de cette introduction dans la patrie de l'homicide. Dans la discussion qui a eu lieu au Sénat italien sur le projet du nouveau Code pénal, le général Mezzacapo, président d'une commission, a soutenu que « dans l'armée il faut maintenir le duel entre officiers. » Entre officiers, notez cela, souvenir du temps où le duel était un privilège de noblesse. Rien d'aristocratique comme l'armée, cette floraison de nos démocraties ${ }^{2}$. «Le duel dans la vie militaire, ajoute cet honorable sénateur, ne peut être regardé comme dans la vie civile... C'est un débouché, grâce auquel les petites inimitiés entre officiers, qui sans lui seraient durables, s'évanouissent : après un duel, ils redeviennent amis et bons camarades comme auparavant. Puis, le détruire, ne serait-ce pas affaiblir cet exquis sentiment d'honneur et de délicatesse que l'on cherche à développer chez les militaires ? » Et le ministre Zanardelli de répondre au général en lui donnant l'assurance «qu'il serait tenu compte de ses importantes considérations. » Elle sont curieuses à coup sûr. Si le duel est indispensable à l'honneur et à la camaraderie, s'il est nécessaire de chercher à s'entre-tuer pour se prouver qu'on s'estime et qu'on s'aime, pourquoi ne pas le permettre ou le prescrire aux soldats aussi bien qu'aux officiers ?

Reste à savoir, en outre, si, dans l'armée anglaise, où le duel est inconnu ${ }^{3}$, où la veuve d'un officier qui est mort en duel est déchue de ses droits à la pension, il n'y a ni honneur, ni bravoure, ni amicale fraternité. Admirables troupes, dont Bugeaud qui les avaient vues de près disait souvent que " heureusement il n'y en a pas beaucoup. » M. Teissier, cependant, reproche aux soldats anglais de se livrer à des

Lire sur ce sujet, un excellent article de la Revista penale, de mai 1890.

2 Même dans l'armée française, l'opinion oblige les officiers plus impérieusement que leurs inférieurs à laver leurs injures dans le sang. A fortiori, dans les armées étrangères. L'art. 223 du Code Pénal militaire du Hanovre, en 1841, autorisait le duel entre officiers « dans le cas où l'injure qui a donné lieu au duel est de celles qui, d'après l'opinion régnante parmi les militaires sur le point d'honneur, ne peuvent être réparées d'une autre manière. »

3 En 1884, sir Harding pouvait dire que « à Chatam où il y avait 25 dépôts de régiment et 70 à 80 officiers de différents corps vivant ensemble, il n'y avait pas eu un seul duel depuis 8 ans. » (Gauchy). C'est un progrès récent. Pendant le règne de Georges III, qui dura, il est vrai, 60 ans (1760-1820), il y avait eu 172 duels, dont 91 suivis de mort. Duels sérieux, on le voit. 
scènes de pugilat, ce qui tient d'après lui, à ce qu'ils ont perdu l'habitude de s'aligner sur le terrain, et c'est pour empêcher ce scandale dans nos rangs qu'il veut le maintien du duel chez nous. Mais il oublie que la boxe est, chez nos voisins d'outre-Manche, une institution nationale. Ils se boxeraient tout autant, quand même on les forcerait à ferrailler sous les yeux d'un prévôt. Quant à nos officiers, craint-on sérieusement que le, duel supprimé, ils ne se battent à coups de poing ? Nos soldats eux-mêmes ne se boxeraient pas davantage ${ }^{1}$.

Heureuse Angleterre! Elle échappe par sa position insulaire aux épidémies $\mathrm{du}$ continent. Efforçons-nous cependant de prendre exemple sur elle et non sur l'Allemagne. Il est temps d'en finir avec une superstition d'un autre âge. Encore pouvait-on fermer les yeux sur le duel militaire quand l'armée était un petit monde à part ${ }^{2}$; mais, je

1 D'après un renseignement qui m'est fourni par M. Delboeuf, l'armée belge à l'instar de l'armée anglaise, « ne connaît pas ou connaît peu le duel. » En Belgique, du reste, « le duel n'est pas en honneur sans toutefois être ridiculisé comme en Angleterre. «Signalons un arrêté royal de mai 1889 qui institue dans l'armée belge des Conseils d'honneur ayant pour but la suppression complète du duel. Bon à mettre en regard des encouragements donnés aux duellistes par l'empereur Guillaume.

2 Dans ce petit monde à part, le duel prenait parfois une physionomie à part: Il servait à exprimer, comme la vendetta corse, une animosité ou une émulation collectives plutôt qu'une vengeance individuelle. On lit dans les Mémoires du général Marbot, récemment parus, que, pendant la jeunesse d'Augereau, il existait entre son régiment et celui des gendarmes de Lunéville une haine invétérée, analogue à ces inimitiés de clan à clan qui désolent certains pays. Chaque fois que ces deux corps, où l'esprit de corps était si intense, se rencontraient, chacun d'eux élisait un champion parmi douze de ses meilleurs tireurs, et un combat singulier avait lieu. Citons, comme échantillon de ces rencontres féroces, le récit de l'une d'elles, dont Augereau fut le héros, et qui nous est raconté dans les Mémoires ci-dessus cités.

«L'adversaire d'Augereau était un homme terrible, tireur de premier ordre, et duelliste de profession, qui avait, les jours précédents, tué deux sergents des gardes françaises. Augereau sans se laisser intimider par la réputation de ce spadassin, se rend au café où il savait qu'il devait venir et s'assied à une table.

Le gendarme entre, et, dès qu'on lui a désigné le champion des carabiniers, il retrousse les basques de son habit, et va s'asseoir insolemment sur la table, la derrière à un pied de la figure d'Augereau.

Celui-ci, qui prenait en ce moment une tasse de café bien chaud, entrouvre doucement l'échancrure appelée ventouse, qui existait alors derrière les culottes de peau des cavaliers, et verse le liquide brûlant sur les fesses de l'impertinent gendarme.. » Celui-ci se retourne en fureur !... Voilà la querelle engagée et l'on se rend sur le terrain, suivi d'une foule de carabiniers et de gendarmes.

«Pendant le trajet, le féroce gendarme, voulant railler celui dont il comptait faire sa victime, demande à Augereau d'un ton goguenard : «Voulez-vous être enterré à la ville ou à la campagne ! » Augereau répondit: «Je préfère la campagne, j'ai toujours aimé le grand air. » - « Eh ! bien, reprend le gendarme en s'adressant à son témoin, tu le feras mettre à côté des deux que j'ai expédiés hier et avant-hier. » 
le répète, à présent qu'elle s'est élargie au point d'embrasser toute la partie mâle et adulte de la nation, le péril d'une telle négligence s'accroît chaque jour. Laissez le duel sévir dans l'armée, il s'étendra bientôt dans tout le pays. Au contraire, arrachez-le de l'armée, il sera bientôt déraciné du sol national tout entier, même du clan des publicistes. C'est là qu'il faut agir ; et c'est là justement qu'il est le plus facile d'agir. Non seulement les règlements et les pénalités sont plus efficaces là que partout ailleurs, grâce à la hiérarchie et à la discipline militaires, mais encore, là plus aisément qu'au dehors, il est possible d'instituer des cours d'honneur dignes de la confiance des hommes d'honneur. Quel homme de plume pourra se dire poussé par l'honneur à accepter un cartel quand on verra de braves officiers supérieurs, de vaillants généraux, donner l'exemple du refus?

S'il nous en coûte d'imiter nos voisins les Anglais, réglons-nous au moins sur nos bons amis les Russes, qui nous donnent ici un si excellent modèle à suivre. "Avant l'époque de Pierre le Grand, m'écrit un savant russe très bien renseigné ${ }^{1}$, il n'a jamais été question de duels en Russie. C'est de lui que datent les premières lois contre le duel, qui fut importé par les étrangers entrés à son service.

"L'usage du duel prit racine chez nous dans la noblesse et dans l'armée, et seulement parmi les officiers. C'est presque exclusivement dans ces classes qu'il se pratique encore aujourd'hui. Il est fort peu répandu et tombe en désuétude. Je connais beaucoup de monde dans différentes classes de la société, et, en rassemblant mes souvenirs, je ne me rappelle que deux personnes qui se soient battues en duel, il y a environ 30 ans. Le procureur de la Cour militaire de Moscou m'a affirmé que, depuis 25 années, il ne se souvient pas d'avoir vu une affaire de ce genre jugée par ce tribunal. Pour ce qui est de la statistique officielle, voici le nombre des duels dont les tribunaux ordinaires ont eu à s'occuper : en 1873,6 ; en 1874,2 ; en 1875,7 ; en

" C'était peu encourageant, et tout autre qu'Augereau aurait pu en être ému. Il ne le fut pas ; mais, résolu à défendre chèrement sa vie, il joua si serré que son adversaire, furieux de ne pouvoir le toucher, s'emporta et fit de faux mouvements, dont Augereau, toujours calme profita pour lui passer son épée au travers du corps, en lui disant: «Vous serez enterré à la campagne »

1 Je dois les renseignements que je transcris à l'amicale obligeance du Dr Bajenow, directeur d'un asile d'aliénés à Moscou. 
1876,7 ; en 1878,2 ; en 1879,5 ; en $1880-81,1$; en 1882,1 ; en 1883,0 ; en 1884,1 ; en 1885,3 ; en 1886,0 .

« Il y a eu une époque dans notre histoire où les duels étaient très fréquents: c'est la période des guerres napoléoniennes. Cette malheureuse mode, prolongée jusqu'à 1850, nous valut la mort prématurée de deux de nos plus grands poètes, Pouschine et Lermontow. Après la guerre de Crimée et le siège de Sébastopol, où nos officiers fraternisaient avec les officiers français, il y a eu un renouveau de la mode des duels, mais beaucoup plus court et plus accentué.

«Le duel à l'épée, qui est la règle en France, ne s'est jamais propagé chez nous, et on se bat généralement au pistolet; aussi les résultats des rencontres sont-ils beaucoup plus funestes que dans votre patrie ».

J'avais prié M. le Dr Bajenow de rechercher si, dans l'armée russe, on forçait les soldats à se battre en duel. "Cet usage, m'a-t-il répondu, est absolument inconnu chez nous, et jamais on n'a entendu parler de soldats vidant leurs querelles avec épées ou pistolets à la main; ils les vident tout bonnement et tout bêtement à coups de poing ». En somme, conclut-il, le duel n'est pas dans les mœurs du pays, et on s'y intéresse fort peu. - Puisqu'il nous est venu un si bel accès d'enthousiasme, et si bien motivé d'ailleurs, pour la sainte Russie, puissions-nous, en cela aussi, nous modeler sur elle ${ }^{1}$.

Comme exemple de la manière dont certaines autorités militaires remplissent leur devoir à ce sujet, je cite sans commentaire le fait suivant, que je lis dans la Vigie algérienne du 22 août 1891. Un médecin-major du 1er spahis, praticien de premier ordre, constate des irrégularités dans la nourriture des hommes de sa compagnie, et, comme elles sont de nature à nuire à la santé des troupes, il révèle des faits d'indélicatesse grave contre un capitaine. Celui-ci qui, précisément vient d'être surpris en flagrant délit de pédérastie, provoque en duel l'honnête et courageux médecin-major ; le docteur, à raison de l'indignité notoire de son agresseur, refuse tout engagement. Certes, Il y avait plus de courage, comme le dit très bien la Vigie algérienne, à dénoncer les actes révélés par lui qu'à accepter un cartel. Néanmoins, tout le monde n'a pas été de cet avis. Un conseil d'enquête se rassemble. Croyez-vous que ce soit pour éclaircir les faits frauduleux ou dégradants dont Il s'agit, pour flétrir un officier, Indigne de son corps ? Non, Il examine la conduite du médecin-major et décide que le médecin-major a manqué à l'honneur en ne se battant pas avec le capitaine ! 
Gabriel Tarde, Études pénales et sociales (1892)

\section{-1- Le duel}

\section{Chapitre troisième}

\section{Les causes et les remèdes}

Je sais bien que je devrais à mes lecteurs de leur esquisser un peu l'anthropologie du duelliste-né ; mais j'avoue que je n'en possède pas les éléments. Aucun Lombroso n'a encore osé aller sur le terrain mesurer le crâne, ou les réflexes rotuliens, dessiner l'oreille ou le nez, de ces terribles matamores - dirai-je mattoïdes, «épileptoïdes » ou déséquilibrés ? - C'est une lacune de ce travail, je le reconnais; je ne prétends pas épuiser mon sujet. Laissant donc de côté, sans nier ni contester nullement leur importance, mais à raison de mon incompétence, les prédispositions organiques ou physiologiques qui portent certains hommes et non d'autres à se disputer et à se battre avec le premier venu, je n'aborde que le côté social de la question des causes et des remèdes.

Or, la prépondérance des causes sociales ici est encore moins douteuse qu'en fait de crimes. Elle résulte d'abord de cette simple considération que la carte du duel, sa distribution géographique, ne 
coïncide ni avec celle des races ni avec la différence des climats, mais bien avec celle des nations ou des provinces, et que, la race et le climat restant les mêmes, il suffit d'un changement de mœurs, de religion, d'idées, sinon de législation, pour assoupir ou réveiller cette antique coutume. Est-ce que la race anglaise a changé depuis le temps des guerres de religion, où le duel y était aussi fréquent et sanglant qu'en France? Les Américains du nord sont presque de même sang que les Anglais ; cependant, chose incroyable, la grande démocratie des Etats-Unis a conservé pieusement le préjugé gothique dont il s'agit, pendant que ses congénères d'Europe, demeurés aristocrates, ne se battent plus depuis le dernier siècle.

En Asie, on ne connaît pas le duel ; en Océanie, il est pratiqué çà et là. Les Australiens semblent s'être inspirés de nos duels au pistolet: ils se battent à coups de massue lancés l'un après l'autre et qu'il est défendu de parer ${ }^{1}$. Chez ces mêmes sauvages, il existe un usage qui rappelle notre duel militaire, imposé aux soldats par leurs officiers. « Souvent, dit Letourneau d'après le voyageur anglais Folklore, quand deux femmes appartenant à un même homme se querellent, leur mari les arme chacune d'un bâton et leur ordonne de se battre. Refusentelles ? il les met d'accord en les châtiant l'une et l'autre sans pitié. » Chez les Australiens encore, le voleur est obligé de se battre en duel avec le volé. - Les Esquimaux pratiquent aussi le duel à la massue. On voit souvent le mari et l'amant se battre ainsi. - Le duel est en usage chez les Bédouins, etc.

En Europe, le duel était ignoré de l'antiquité gréco-romaine. Caton qui, recevant un crachat en plein visage, l'essuyait tranquillement, Thémistocle qui, menacé d'un coup de bâton, disait froidement: frappe, mais écoute ; Caton et Thémistocle, s'ils eussent été Français et surtout Français du XVIe siècle, auraient croisé l'épée avec leur insulteur; Corses, ils l'auraient poignardé ou fusillé avec guet-apens ; Japonais, ils se seraient ouvert le ventre devant sa porte ; courtisans de Louis XIV, ils auraient vu leur outrage réparé par sentence du tribunal des maréchaux qui, appliquant la peine du talion, aurait condamné peut-être leur adversaire à être bâtonné ou à recevoir un crachat à la figure. On voit que, si le besoin de se venger quand on se sent offensé

Teissier. Le duel. 
est inné et procède de l'évolution organique, les objets de ce sentiment, les satisfactions de ce besoin, diffèrent profondément suivant les temps et les lieux et procèdent de l'évolution historique. Chaque peuple, chaque époque, a ses plaisirs spéciaux et aussi bien ses délits ou ses crimes nationaux, impunis le plus souvent comme tels, et, de fait, imputables en partie à tous, non au seul agent qui a eu le tort d'exécuter les ordres collectifs. De même que le duelliste en France, le meurtrier par vengeance en Corse ou en Sicile tue beaucoup moins pour satisfaire une haine personnelle, tiède ou nulle parfois, que pour obéir aux sommations de l'opinion, écho de la voix des ancêtres. Coups de couteau, coups d'épée, sont également commandés par la société, par la société vivante et par les sociétés mortes, évidemment complices. Combien de Français, soldats ou civils, sont allés malgré eux se battre en duel! Combien d'Espagnols, d'Italiens, ont été assassins à contre-coeur! Combien de Japonais se sont ouvert le ventre sans le moindre enthousiasme! Tous ces gens-là ont été les confesseurs de la divinité du milieu social, du Moloch social, autocrate anonyme.

Mais dire, comme je l'ai déjà dit et démontré, qu'ils ont agi par imitation, ce n'est pas indiquer la causalité propre de leur action, c'est seulement la classer parmi les faits sociaux, dont le caractère général est d'être imitatifs. Pourquoi, d'ailleurs, ont-ils imité le modèle que d'autres duellistes leur ont donné, au lieu de se régler sur des conduites opposées ou différentes? Pourquoi, en termes plus compréhensifs, ce genre d'exemple triomphe-t-il plus ou moins, suivant les lieux et les temps, dans sa lutte ou son concours avec d'autres genres d'exemples ? Pourquoi notamment, se maintient-il à notre époque en France, malgré l'opposition de tant de courants d'imitations qui le repoussent, c'est-à-dire de la propagation d'idées, de mœurs, d'habitudes en contradiction avec cette réminiscence d'un lointain passé ? Voilà la question à résoudre. 

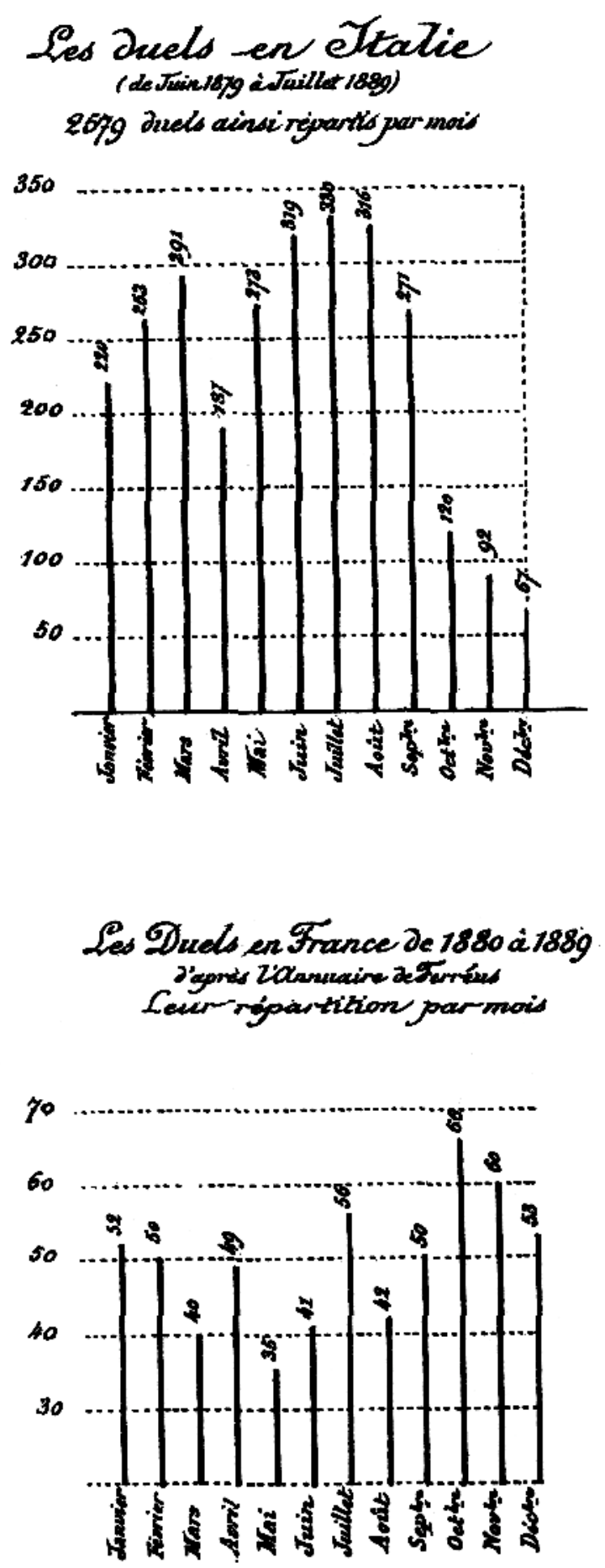
Le cours des saisons a-t-il quelque influence sur la fréquence ou la rareté des duels ? Une influence indirecte, c'est probable, à cause du ralentissement ou de l'accélération de la vie sociale par l'abréviation ou l'allongement des jours et les variations de la température. Mais je n'ai pu démêler avec netteté cette action. Elle apparaît toute différente suivant qu'on emploie à la rechercher la statistique italienne ou française. M. Lacassagne a bien voulu représenter graphiquement les résultats fournis par les indications de M. Jacob Galli dans le travail dont il a été question plus haut (Voir le tableau de la planche 1).

Il ressort de là, que le printemps et l'été seraient marqués par deux éruptions de cette maladie, séparées par une courte accalmie, et que l'automne correspondrait à sa phase la plus clémente. Cette recrudescence du mal dans la saison chaude avait déjà été affirmée pour la France elle-même, d'après Teissier, par M. Benoiston de Châteauneuf. Mais j'ai le regret de dire que l'Annuaire de Ferréus m'a conduit à des résultats dissemblables, (Voir le tableau de la planche Il, que ce recueil de documents, officieux à la vérité et sans doute incomplets, m'a permis de tracer).

Si l'on confronte ce tableau avec le précédent, on n'y trouvera qu'une coïncidence, assez remarquable à la vérité, à savoir l'élévation des courbes en juillet. Du reste, tout y est inverse ; dans l'un la courbe s'élève en mars et en mai, dans l'autre elle s'abaisse; dans l'un la plus forte dépression, dans l'autre le plus fort soulèvement, est en octobre. Passons.

Sans préjuger quelles sont les influences sociales ou autres qui agissent sur le duel, on peut croire que ce sont en partie les mêmes qui agissent sur l'homicide, et dans le même sens. En Italie, où il y a beaucoup de meurtres, il y a aussi beaucoup de duels; même coïncidence, je crois, en Espagne et en Hongrie ${ }^{1}$. En Angleterre, en Suède, en Belgique, à la fois très peu de duels et très peu de meurtres. En France, moins de meurtres qu'en Italie et plus qu'en Angleterre, et pareillement moins de duels qu'en Italie et plus qu'en Angleterre. Le parallélisme géographique, non sans exceptions toutefois, se

La statistique comparée de l'homicide a été très bien esquissée par $M$. Bosco, dans son travail sur Gli Omicidi (Rome, 1889) qui nous sert de guide. 
complète, ce semble, par le parallélisme historique. Au XVIe siècle florissaient en même temps l'assassinat et le duel. A toutes les époques de troubles, on remarque une recrudescence des deux. Actuellement, légère hausse simultanée de l'homicide et du duel français et légère baisse simultanée de l'homicide et du duel italien. En Allemagne, beaucoup de meurtres, beaucoup de duels : M. de Bismarck s'est battu un nombre incalculable de fois. -Au surplus, je n'attache pas à ces rapprochements la portée qu 'on pourrait croire. Ils signifient que le duel et l'homicide ont eu dans le passé une source commune, aux XVe et XVIe siècles, quand l'un et l'autre avaient pour principal mobile la vengeance et la haine ; mais à présent que la cupidité est de plus en plus la passion dominante du meurtrier, et le point d'honneur ou la soif de publicité l'âme du duelliste, il faut rendre cette justice à ce dernier qu'il ne ressemble plus le moins du monde à son ancien confrère ${ }^{1}$. Il y a cependant, dit-on, certains journaux où le duel, tel qu'il y est pratiqué, avec l'épée d'un spadassin chargé de se battre pour tous les rédacteurs, n'est pas sans rappeler l'assassinat par sicaires du moyenâge italien.

$\mathrm{Si}$ nous admettions le prétendu développement inverse de l'homicide et du suicide, que des savants éminents, MM. Morselli et Ferri, ont érigé en loi, nous devrions déduire de ce qui précède qu'il existe une inversion pareille entre le suicide et le duel. Quelques faits viendraient appuyer cette affirmation : depuis un siècle, le duel décroît malgré tout, et le suicide progresse toujours ; au XVIe siècle, où l'on tuait beaucoup, on se tuait extrêmement peu; actuellement, c'est le contraire. Mais, en réalité, l'antithèse ne se suit pas. En Angleterre, par exemple, il y a à la fois fort peu de suicides et encore moins de duels. Une partie des suicides, - une faible partie sans doute mais non précisée par les statistiques, - a le même mobile que la presque totalité des duels : le point d'honneur. Le banquier qui se tue pour ne pas survivre à sa réputation de solvabilité, est en cela très semblable à l'homme, ignorant l'usage des armes, qui se croit forcé par l'honneur à

A titre de curiosité, je note, dans l'ouvrage original de M. Worms sur les Attentats à l'honneur (Perrin. 1890) le problème suivant, posé par cet ingénieux et distingué écrivain, d'après Zaccharie : Doit-on regarder comme meurtrier un homme qui en a offensé un autre à tel point que celui-ci en est tombé malade et a fini par en mourir? 
se battre avec un bretteur de profession ${ }^{1}$. Se battre ainsi, n'est-ce pas se tuer à coup sûr? Les duels qui sont des demi-suicides d'une part, des demi-assassinats de l'autre, sont nombreux. Quant aux suicides par folie, par monomanie spéciale, on peut les comparer aux duels par plaisir, sans rime ni raison, tels que ceux de Fournier et de Dupont. L'amour est aussi la cause commune d'un certain nombre de suicides dont la proportion a décrû d'ailleurs, de 11 à $4 \%$ en un demi siècle, -et d'un certain nombre de duels : il me semble deviner, à lire l'Annuaire de Ferréus, que la proportion de ceux-ci décroît pareillement ou a dû singulièrement décroître depuis le dernier siècle, pendant que celle des duels causés par les polémiques augmentait. Il y a enfin quelques duels de désespoir qui seraient jusqu'à un certain point assimilables aux suicides à deux : c'est l'avis du Dr Corre, dans Crime et Suicide.

Nous avons dit plus haut que la plupart des duels français prennent naissance à Paris, et le reste dans des villes de grande ou moyenne importance. Cette action des grandes villes s'exerce à la fois sur la production des duels, des suicides et des homicides; elle est seulement plus accentuée à l'égard des duels. A population égale, on le sait, il y a deux fois plus de suicides, ainsi que de meurtriers, dans les milieux urbains que dans les milieux ruraux. - L'influence de la profession et de la position sociale se fait aussi sentir de la même manière en fait de duels et de suicides: les deux phénomènes deviennent d'autant plus fréquents qu'on s'élève davantage sur l'échelle sociale, qu'il s'agisse des classes de la société civile ou des grades de la société militaire; à cela près que, en ce qui concerne la société civile, le duel tend à s'y localiser dans le monde de la presse périodique et de la politique, tandis que le suicide s'y répand partout. En fait d'homicides, cet ordre d'influence est inverse ; les meurtriers se rencontrent d'ordinaire dans les dernières couches du peuple, dans notre siècle du moins.

Mais tout cela ne nous dit pas pourquoi le duel persiste à vivre, comment il trouve moyen de se survivre, au milieu de notre civilisation contemporaine où il fait l'effet d'un défi et d'une insulte à

Observons d'ailleurs que les maîtres d'armes se battent très rarement en duel. C'est ainsi que les avocats et les avoués ont fort peu de procès pour leur propre compte, et que les médecins s'abstiennent de se droguer. 
tous ses principes fondamentaux, chrétiens ou révolutionnaires. Pour expliquer cette survivance, il faut invoquer diverses considérations qui nous amèneront peu à peu au coeur de notre sujet.

En premier lieu, les femmes ont à s'imputer une bonne partie du mal en question. Je les ai louées ailleurs d'avoir contribué jadis au refoulement de l'homicide ; mais, à mon grand regret, j'ai à les blâmer maintenant d'avoir favorisé le maintien du duel. C'est par elles en grande partie qu'il se perpétue; je ne dis pas seulement le duel provoqué par des outrages à l'honneur féminin, par des querelles d'amoureux - celui-là est en décroissance dans la vie réelle et ne règne qu'au théâtre, - je dis le duel quelle qu'en soit l'origine. On se bat toujours pour la galerie, mais principalement pour la galerie des dames. Si elles étaient reléguées au gynécée chez nous comme chez les Grecs, si leurs jugement ne comptaient pas, si les gens outragés publiquement n'avaient à tenir compte que de l'opinion des autres hommes, beaucoup d'affaires dites d'honneur seraient assurément évitées. Elles le seraient toutes parmi les industriels, les commerçants, les hommes d'affaires, dans toutes les sphères laborieuses où un homme n'est nullement diminué aux yeux de ses camarades et de ses collègues, à son cercle, à son café, pour avoir dédaigné de répondre à une insulte par une provocation ou même pour avoir refusé un cartel. Le suffrage universel, étant masculin, ne tient pas d'ordinaire le refus de se battre pour déshonorant; je sais des hommes qui, après avoir reçu des soufflets même et les avoir tranquillement gardés, n'ont pas laissé d'être acclamés avec des majorités écrasantes, j'allais dire scandaleuses, dans divers scrutins. Inutile d'ajouter que les élus de cet ordre avaient renoncé à toute prétention sur le coeur des femmes. Mais, tant qu'un homme n'a pas fait cette difficile et très tardive abdication, il est impossible, au moment d'une affaire qu'il ne songe pas à l'espèce de déchéance sexuelle dont il serait frappé s'il avait l'air de reculer. La femme, a-t-on dit peu galamment, est une éponge de vieux préjugés; elle est le dévouement même, mais elle est aussi terriblement vindicative, comme l'étaient nos lointains aïeux; et, en Corse, en Sardaigne, en Sicile, la vendetta est surtout inspirée par elle; la Colomba de Mérimée a été peinte sur le vif. Plus que l'homme, elle vit pour autrui, et aussi pour l'opinion d'autrui; de là l'intensité de ses ressentiments, comme de ceux de l'homme primitif, toutes les fois qu'il s'agit d'une atteinte à son amour-propre, à sa 
vanité, à son honneur, à cette partie d'elle-même qui consiste dans l'idée que s'en font les autres, partie principale à ses yeux et dont sa personne réelle n'est que l'accessoire. En outre, précisément parce qu'elle est un peu poltronne, le mépris apparent ou réel de la mort affiché par le duelliste prend facilement pour elle une couleur d'héroïsme, et la moindre égratignure reçue en duel lui rend un homme intéressant. Pour motiver la génération spontanée, ex abrupto, d'un amour violent, un dramaturge ou un romancier n'imagine jamais rien de mieux.

Or, tous les hommes savent cela, et ils ne peuvent pas n'y avoir pas égard. On m'objectera que les militaires, les journalistes et les politiciens, même abstraction faite des femmes, pourraient continuer à se battre quelque temps. Mais, encore ici, les mœurs propres à ces divers mondes ont été formées de tout temps par la préoccupation des femmes : et elle n'est certes pas étrangère à cette hypertrophie, à cette hyperesthésie de l'amour-propre, qui est réputée y être fréquente ${ }^{1}$. Notons que, si la proportion des suicides d'amour reste encore importante, l'opinion des femmes ne joue cependant aucun rôle sur la marche du suicide. Le suicide est quelque chose de tout autrement sérieux que le duel, et tient à des causes beaucoup plus profondes.

Mais voyez l'inconséquence des jugements humains, surtout quand l'esprit féminin s'en mêle, avec sa logique à soi. Voilà un homme qui va se tuer. Il n'est point fou, il n'est point alcoolique, il désespère. Las de la vie, écœuré de la société, il s'en retranche; il approche de son cœur la bouche d'un revolver, la pointe d'un couteau, et il ne se trouble pas, il regarde en face la mort, ce que La Rochefoucauld juge impossible. Et cet homme qui donne cette preuve de courage, qui ne fait de mal, après tout, qu'à lui même, M. Prudhomme le juge lâche, suivant l'opinion reçue. - Et, pendant ce temps-là, Mme Prudhomme car le mari a trop souvent fait oublier la femme dans ce ménage - se pâme devant l'héroïsme d'un rédacteur de journal d'annonces qui, pour faire parler de lui, aura échangé une balle inoffensive avec un de ses

Assurément c'est pour plaire aux femmes que les jeunes gens, les écoliers même de divers pays, prenant exemple sur les journalistes et les littérateurs, se battent en duel parfois. «Par imitation, dit Corre dans Crime et suicide, les écoliers d'Écosse et d'Angleterre ont organisé des grèves; les nôtres essaient de fonder des journaux et de participer aux polémiques de leurs professeurs, fréquentent les brasseries à filles, se battent en duel... » 
amis ! - Or, gardons-nous de rire d'elle; elle a bien plus d'importance que lui. Elle est souvent jolie ; malgré toute sa sottise vaniteuse, elle excelle à dissimuler sous l'esprit d'autrui le vide du sien, sous une supériorité d'emprunt sa frivolité de nature ; elle a son cercle ; et elle a beau contredire fréquemment son époux, sa grâce seule empêche de voir qu'au fond de tout ce qu'elle dit, écrit ou fait, respire l'âme même de son époux, à savoir l'adoration béate de tout ce qui brille, l'agenouillement devant le succès, la majorité, la coutume, la mode, salués jugement de Dieu.

Pourtant, comme elle n'a jamais rien inventé, pas même ses jugements, il faut remonter plus haut qu'elle, jusqu'aux hommes qui les lui ont suggérés. Ici je n'accuserai pas les philosophes, qu'elle ne lit pas, encore moins les théologiens, qu'elle n'écoute que quand bon lui semble. Je dois même dire que ces derniers ont droit à des éloges tout particuliers, côte à côte avec Voltaire, et que l'Église seule, au milieu $\mathrm{du}$ déraisonnement universel, a tenu bon de tout temps pour les principes. Si ses prêtres ont béni les combattants des duels judiciaires, si ses temples ont souffert parfois les trophées de ces combats pendus à leurs voûtes en ex-voto, ses conciles ont toujours fulminé contre cette superstition sanguinaire ${ }^{1}$. Les philosophes ont montré moins de fermeté, et surtout les législateurs, j'ai peine à le dire. N'insistons pas. Mais ce sont surtout les littérateurs qui méritent des reproches. L'art devrait être, par l'emploi de données réelles, la réalisation d'un idéal ; traité par des virtuoses sans philosophie personnelle, il n'est que l'exploiteur des prestiges et des préjugés du passé qu'il alimente ou galvanise. Non seulement les conventions de notre art dramatique ou de notre roman ne permettent pas que le héros reçoive la moindre injure sans riposter aussitôt par l'envoi de ses témoins, mais encore, comme je l'ai dit plus haut, elles exigent le plus souvent qu'il soit vainqueur dans le combat qui s'en suit. Il n'est pas jusqu'à $M$. Daudet qui, dans l'Immortel, ne fasse battre l'odieux Paul Astier par son adversaire, contrairement à toute probabilité, mais conformément à la justice.

Troisième Concile de Valence, en 855. Concile de Trente, en 1550. Les cours ecclésiastiques et le droit canonique n'ont jamais admis le Jugement de Dieu. Leur exemple a contribué puissamment à le faire disparaître. Si, en 1260, Saint-Louis l'abolit dans son domaine royal, c'est certainement sous l'inspiration du clergé. 
Le duel est bien plus à la mode dans la littérature contemporaine qu'il ne l'était au XVIIe siècle. La Bruyère n'en parle pas dans sa galerie de portraits, où revit tout son siècle; Pascal, dans ses Provinciales, n'en parle qu'avec exécration, pour anathématiser les Jésuites qui, dans leurs écrits, ont balbutié çà et là quelques paroles d'excuse en faveur de cette abomination. - Dans toute l'œuvre de Molière, il n'en est question que deux fois, la première fois dans les Fâcheux où le principal personnage refuse de servir de second à l'un de ses amis parce qu'il trouve que le duel «nous met en mauvaise posture " ; la seconde fois, dans le Mariage forcé où, plutôt que de se battre, Sganarelle consent à se marier. Comparons-le à nos dramaturges. Émile Augier a beau représenter « l'École du bon sens », il a cru devoir fréquemment payer son tribut au minotaure du duel, tout en ne l'aimant pas. Dans Gabrielle, le jeune premier se rend irrésistible par ce procédé peu nouveau. Quant à M. Octave Feuillet, ses héros sont toujours prêts à s'aligner; c'est immanquable. Rendons cette justice à $\mathrm{M}$. Alexandre Dumas qu'il a poussé l'audace de ses paradoxes jusqu'à braver cette idole comme tant d'autres. Dans M. Alphonse, par exemple, le commandant, qui incarne en lui le devoir et l'honneur, méprise le duel. Au demeurant, il fait exception. Si l'on comptait les duels contenus dans les romans, les comédies, les drames, qui ont vu le jour en France depuis 10 ans, on trouverait certainement ce nombre vingt ou quarante fois supérieur à celui des duels qui ont réellement eu lieu dans le public français. Je ne suis pas aussi sûr que, si l'on comptait de même tous les adultères ou tous les suicides imaginés par nos romanciers ou nos dramaturges, leur chiffre s'élevât beaucoup au-dessus de celui des adultères ou des suicides vrais. Les historiens de l'avenir, si, par hasard, ils nous jugent d'après notre littérature, nous croiront beaucoup plus bretteurs que nous ne le sommes en réalité.

Mais toujours le même problème se pose à nous, et toujours plus insoluble. Car si nos femmes, nos littérateurs, nos législateurs, nos penseurs mêmes, peuvent, par leur indulgence pour le duel, expliquer en partie son maintien, c'est cette indulgence extraordinaire et presque unanime qui reste inexpliquée. En effet, tout le monde excuse ou admire le duel, mais chacun reconnaît qu'il est absurde. Credo quia absurdum. Bien mieux, ce sont précisément les gens les plus convaincus de son absurdité, c'est-à-dire les plus cultivés, les plus haut 
placés socialement, qui sont les plus prompts à s'incliner devant cette férocité traditionnelle ${ }^{1}$. Mais elle n'est pas absurde seulement, elle est devenue ridicule. Les préliminaires du combat, avec leur cérémonial réglé on ne sait par quel code obscur et compliqué auquel se soumettent ponctuellement les plus farouches démocrates; le combat lui-même d'ordinaire, grâce à la maladresse des combattants, qui veulent rester dignes; la solennité des procès-verbaux et leur publicité, tout cela, cliché, postiche, étiquette sans rime ni raison, serait d'une bouffonnerie achevée si, après tout, il n'y allait pas de deux vies humaines. Même dans les duels les plus tragiques, la note comique ne manque pas toujours. Sous la Restauration, un duel au sabre a lieu entre M. de St. et M. de P. Le premier est blessé à mort. Son adversaire et tous les témoins s'empressent autour de lui, et manifestent un vif chagrin d'un si déplorable dénouement. Un des témoins dit alors, en guise de consolation : «En tous cas, les choses se sont passées dans les règles ». - Le Diafoirus de Molière, au chevet d'un malade mort de ses purgations et de ses saignées, n'eût pas mieux dit.

Ce qu'il y a de plus amusant, c'est de voir les gens graves et bien posés, les hommes sérieux, faire sa part au duel, comme jadis ils l'ont faite à toutes les autres absurdités, à la sorcellerie, à l'astrologie, aux augures. Il faut lire Plutarque, Cicéron et autres éminents Prudhommes de l'antiquité, sur ce dernier sujet. «Certainement, cela est assez déraisonnable, il le semble du moins ; mais il y a des cas où les poulets sacrés sont indispensables, ils ont quelquefois prédit juste ». Pareillement, on convient qu'il est peu sensé de se battre pour une bagatelle, mais on ajoute qu'il y a des cas où le duel est nécessaire. Lesquels? On ne s'accorde pas là-dessus. Il se trouve que, précisément, les cas les plus graves, - diffamation de la famille, adultère, - sont ceux où le prétendu remède aggrave le mal en le divulguant.

Puis les mêmes hommes, députés ou électeurs, iront voter. Mais qui m'assure qu'en votant dans un sens plutôt que dans l'autre, ils ne se décident pas aussi contrairement à leur conviction intime? Qui me répond que leur bulletin de vote exprime autre chose qu'une Inconsciente et servile obéissance à un entraînement d'opinion ambiante et aveugle, comme leur combat singulier? 
Donc, puisqu'il en est ainsi, puisque, malgré son ridicule brochant sur sa « déraison, le duel vit toujours, nous sommes forcé d'admettre d'autres causes de sa durée, et d'abord lui reconnaître quelques mérites. Effectivement il en a eu jadis, et il en a même encore. Il a sa beauté, incontestable. Deux hommes qui vont se battre bravent la mort ou la dévisagent sans peur; ils rendent témoignage que la vie ne vaut pas la peine d'être vécue moyennant une honte ou l'apparence même d'une honte, et que, ombre vaine aussi, elle peut être immolée à l'ombre de l'homme.

Dans le passé il a été une école de savoir-vivre, peut-être de sincérité et d'égalité. Au XVIe siècle, les orgueils, - qui sont, au fond, des convictions outrées, ayant pour objets notre valeur propre, participaient à l'intensité extraordinaire des croyances d'alors, surexcitées par la contradiction et sources de si sanglantes guerres. Les orgueils féodaux, au moyen-âge, pouvaient bien être aussi robustes, aussi ridiculement excessifs ; mais ils avaient un caractère plus familial et moins individuel; et leur isolement, le défaut de communication, le stationnement de chacun sur son fief, permettaient à ces convictions contradictoires et hostiles de masquer leur contradiction et leur hostilité. Avec la Renaissance et la Réforme, l'individualisme éclôt, dans les consciences qui s'émancipent, dans les amours-propres qui se gonflent ${ }^{1}$. Du fond de chaque bourgade, de chaque châtellenie, sort un hobereau nourri et enflé de son importance locale. Tous ces importants, grands lecteurs parfois et admirateurs de l'emphase espagnole, se précipitaient, mobilisés pour la première fois, à la cour, aux nombreuses armées protestantes ou catholiques, et s'y heurtaient, y cherchant la gloire. Autant de chocs, autant de coups d'épée. C'était inévitable. Par le rapprochement confus, par la rencontre subite de ces vanités, ignorant les égards mutuels de la politesse inutiles jusque-là, le démenti qu'elles se donnent les unes aux autres se démasque brusquement. Il a peut-être fallu la mêlée des duels, l'effrayante saignée de tant de combats, pour adoucir à la longue et arrondir les angles des amours-propres aristocratiques,

De là à la fois une double frénésie du point d'honneur et du luxe, l'un et l'autre extravagants, tous deux fils naturels de la vanité, et collaborant ensemble pour ruiner l'ancienne noblesse. L'un, par le duel meurtrier, lui a pris le meilleur de son sang; l'autre ses plus beaux domaines. Au dire de Montchrestien (Économie politique), on disait communément, de son temps : « un tel porte un bois, un moulin, un pré dessus son dos ». 
comme ceux des cailloux roulés, sous l'influence aussi de l'Orgueil toujours croissant et prépondérant du monarque devant lequel tous les autres prenaient des leçons continuelles d'humilité. - De nos jours, estce qu'il ne se passe pas quelque chose d'un peu comparable à cette crise vaniteuse d'il y a trois siècles ? L'agitation démocratique, non moins puissante que les soulèvements religieux, nous a valu une mobilisation pareille des grands hommes locaux, leur émigration rurale en masse vers les grands centres, avant tout à Paris. Il y arrivent, journalistes ou hommes d'État, de tous les cafés du territoire, et, d'autant plus pleins de foi en eux-mêmes qu'ils ne croient à rien d'autre, ils ne peuvent que s'y bousculer. Le surprenant est qu'il en résulte si peu de duels.

Pour revenir au XVIe siècle, le duel y atteste le haut rang où l'on tient alors la loyauté et la franchise, et tend à l'élever encore. Considérer comme la plus mortelle injure le reproche d'avoir menti, c'est proclamer que le premier devoir de l'homme est le culte du vrai. Qui sait si, pour maintenir jusqu'à nous, paisibles hommes d'étude, ce culte intact, il n'était pas utile que des générations plus belliqueuses bondissent d'indignation au seul soupçon du mensonge, et courussent laver cette injure dans le sang ? Il est possible aussi que le duel ait alors aidé aux progrès de l'égalité. Après bien des contestations, il avait été admis qu'un gentilhomme pouvait se battre avec un autre, quelle que fût entre eux l'inégalité des rangs ${ }^{1}$. Le "capitaine Bourdeilles, » frère de Brantôme, n'hésita même pas à vouloir se battre avec un soldat qu'il avait lui-même formé au métier des armes et qui était resté six ans sous ses ordres.

Ces avantages passés du duel n'ont plus qu'une valeur historique, mais il lui reste encore celui d'être une protestation, malheureusement inconsciente et inaperçue, contre notre individualisme même d'où il naît, contre l'exagération du moi. Un homme m'a marqué du mépris ; je le lui ai rendu ; nous allons sur le terrain. Par là, que prouvonsnous ? Rien, si ce n'est que nous méprisons jusqu'à un certain point la vie ; mais, en prouvant ainsi que nous la méprisons, nous croyons suffisamment démontrer que nous ne sommes pas méprisables. Et comment cela peut-il s'entendre sans contradiction, si ce n'est à la

Voir à ce sujet Brantôme, p. 183 et 1. 
condition de penser que notre vie n'est pas tout notre être, qu'il y a en nous quelque chose d'étranger et de supérieur à ce méprisable mode d'existence; et ce quelque chose, si ce n'est pas la vie future promise aux croyants, ce ne peut être que la grande vie collective par laquelle nous nous survivrons. Par le duel, l'individu avoue qu'il n'est pas seulement pour soi, mais avant tout pour la société aux préjugés de laquelle il s'immole et immole aussi bien son ennemi, que souvent il ne hait point. Et, plus ces préjugés sont puérils, plus cette immolation est significative. "Pour l'individu qui a mis son but en soi, quoi de plus fou que la guerre et la paternité ? »dit avec raison $\mathrm{M}$. Arsène Dumont dans Civilisation et dépopulation. Il aurait pu ajouter : quoi de plus fou que le duel ? A ce point de vue, il faut convenir que la dureté, la férocité même des mœurs, dans les sociétés encore jeunes, contribue à la force du lien social. Plus, dans la cité antique, dans la Commune du moyen-âge, les individus sont prêts à sacrifier soit leur propre vie soit celle de leurs semblables à une fin qui dépasse leur intérêt particulier, à une opinion qui n'est pas leur idée particulière, autrement dit, plus il y a à la fois de dévoûment et d'inhumanité dans les mœurs, et plus le groupe social, au lieu d'être une simple personne morale, devient une personne réelle et vivante, indépendante des vies humaines qui la composent. L'adoucissement des mœurs, à l'inverse, pourrait donc bien avoir pour effet la désagrégation sociale. Oui, si cet adoucissement s'opère dans le sens d'un accroissement d'égoïsme aussi bien que de pitié ou de sensiblerie. Mais si, en diminuant l'inhumanité, la civilisation développe le dévoûment et l'amour mutuel, il n'y a pas à redouter qu'elle affaiblisse la force des peuples ; et le duel, comme la torture, comme l'esclavage, comme les atrocités pénales d'autrefois, peut alors disparaître sans danger. C'est peut-être un peu parce que notre société actuelle a une vague conscience de ses tendances égoïstes qu'elle n'ose rejeter encore le dernier débris d'une coutume barbare, où s'exprime la nécessité du sacrifice humain.

Le duel, écho d'un temps où le courage était tout, dit et a raison de dire à l'individu amolli, énervé, de notre siècle : " Il faut être brave. » Mais voilà pourquoi cette question du duel théoriquement est difficile : car elle nous oblige enfin, si nous voulons la creuser, à sonder les fondements de la morale et de l'honneur, et la valeur vraie de ces qualités morales, le courage et la fierté. Devons-nous conclure que cette valeur a été très surfaite, ou qu'elle a baissé de nos jours ? 
Soit, mais alors tout le système de nos jugements et de nos préjugés moraux est à refondre.

La bravoure, la justice et la bonté, sont les trois colonnes de la morale ; mais c'est tantôt l'une, tantôt l'autre qui a la place d'honneur. Or, suivant que la première domine les deux autres ou en est dominée, la science des mœurs est radicalement transformée. Le duel, ce n'est pas la bravoure seulement, c'est l'orgueil et la vanité élevés à la hauteur du suprême devoir, bien au-dessus de la bonté, de la justice et de la clémence, qui lui sont sacrifiées. En se battant, on cherche à se donner l'un à l'autre et à donner au public une preuve d'intrépidité, parce qu'on est persuadé que cela suffit à démontrer qu'on n'est point digne du mépris dont on cherche à se laver. On part donc de ce principe, que braver la mort est la souveraine vertu qui dispense de tout autre. Tel est le postulat caché du duel, postulat contraire au "progrès », et cependant accepté d'emblée par tant d'hommes « de progrès ». Proudhon lui-même a fait acte de foi en ce dogme, qui démentait toutes ses théories de la Justice, et Lamartine aussi, le généreux poète de la religion et de l'amour, quand il s'est battu avec le colonel Pepa, patriotiquement offensé par deux vers des Méditations. Quel spectacle que celui de ces deux nobles cœurs, ne se haïssant pas, s'aimant plutôt, s'estimant ou s'admirant l'un l'autre, et cherchant à s'entre-percer!

Il est pourtant incontestable que la voleur n'est plus la maîtresse qualité de l'homme moderne, et que la générosité, l'équité, l'ardeur au travail, passent avant. Mais demandons-nous comment il se fait que le travail et l'échange n'aient pas encore tué la guerre, non plus que le duel ? Car la question de la guerre se lie à celle du duel. La guerre aussi est contradictoire au catéchisme moral des nations européennes ; la guerre aussi est, par certains côtés, une survivance. Il fut un temps où, par le droit reconnu au pillage et à la spoliation en masse, elle avait son utilité pratique, comme le duel à l'époque où le vainqueur rançonnait le vaincu gracié. Il fut un temps où la guerre tranchait radicalement les difficultés entre les peuples, quand régnait la foi au droit divin de la victoire, quand le vaincu, considérant sa défaite comme un jugement du dieu des armées, courbait la tête sous cet arrêt. Mais à présent la guerre ruine tout le monde, et force la nation battue à s'avouer plus faible, mais non à confesser qu'elle a tort. Elle est donc 
une solution qui ne résout rien. N'importe, elle vit toujours, toujours elle est en vigueur. Pourquoi ? Parce qu'il n'existe pas de tribunal international, supra-national, pour trancher les litiges des peuples. De même, la seule raison du duel maintenant, c'est qu'il n'existe point de tribunal d'honneur, vraiment digne de ce nom.

Cependant la difficulté de constituer un tribunal d'honneur est bien moindre que celle d'établir une Cour suprême des nations. On a fait de grands pas déjà dans cette voie, et il suffit, je crois, d'un dernier effort pour toucher au terme.

Pour combattre le duel législativement, il ne faut point se borner, comme on l'a fait trop souvent, et par suite sans nulle efficacité, à édicter une loi contre lui. Sans doute, il faut cela d'abord, et il est temps que la France, devancée sur ce point par la plupart des nations européennes, suive leur exemple, remédie à cette lacune déplorable de la législation ${ }^{1}$. Mais, cela fait, rien ne sera fait, si l'on ne ' réforme

Un projet de loi contre la duel, qui n'a pas encore été discuté, a été déposé le 16 juillet 1888 par Mgr Freppel. Je crois que la majorité s'honorerait en l'accueillant, bien que son auteur ne lui agrée pas. Ce projet m'a paru très sagement conçu ; Il s'attache à prévenir le duel et non pas seulement à punir ses suites; il frappe de peines graduées, modérées, la provocation en duel, l'injure qui l'occasionne, le duel lui-même, enfin, la publication du compte-rendu d'un duel. Cette dernière disposition est excellente. - M. Lacassagne, qui s'occupe en ce moment d'un ouvrage sur Marat, me communique un projet de loi sur le duel qui figure dans le plan de législation criminelle du terrible publiciste. Je le reproduis ici à titre de curiosité :

"Quand la loi a pourvu à la réparation des offenses, on ne doit point se faire justice à soimême. Mais quand elle n'y a point pourvu, l'offensé reste son propre vengeur ; et alors le duel ne doit pas être réputé crime; car les lois de la société ne doivent point aller contre celles de la nature.

«Ceux qui sentent les inconvénients du duel demandent de quelle manière il faudrait le punir. Ils feraient mieux de chercher de quelle manière il faut le prévenir. Hé ! comment ne voyent-ils pas, que cet abus de liberté dont ils se plaignent, est l'ouvrage des législateur? On ne cesse de répéter que l'honneur doit nous être plus cher que la vie ; et les lois l'ont presque toujours compté pour rien. Qu'un homme refuse de laver un affront dans le sang de son ennemi, il est proscrit de la société : qu'il en tire vengeance, il est flétri par la justice, à moins qu'il ne soit d'un rang ou d'un état à compter sur l'impunité. Que faire dans cette cruelle alternative ? De deux maux, choisir celui qu'on redoute le moins; le devoir est donc sacrifié à l'opinion.

«Pour faire cesser l'usage barbare du duel, je ne vois que deux moyens efficaces; le premier serait que la loi ordonnât la réparation des injures.

« Pour injures qui n'attaquent point la probité, le délinquant serait condamné à faire à son adversaire, des excuses en public.

« Pour injures qui attaquent la probité, il serait condamné à une amende pécuniaire, à peu près équivalente à la perte du crédit que la diffamation pouvait occasionner à la partie adverse. 
pas, si l'on ne complète pas nos lois sur la diffamation et l'injure. C'est par ce moyen indirect, surtout, qu'on tarira la source du mal. Si, en effet, la loi et les tribunaux protégeaient nos biens aussi dérisoirement qu'ils sont censés protéger notre réputation et notre honneur, on peut être certain que la moindre usurpation de mur mitoyen, la moindre contestation à propos de borne ou de chemin de servitude, donnerait lieu à un duel entre voisins, comme à présent entre amis la moindre parole outrageante. On a cessé de se battre pour des intérêts civils à partir du moment où des tribunaux réguliers et d'une impartialité suffisante ont tranché les questions de cet ordre. On peut être sûr, de môme, que, le jour où il existera de vraies cours d'honneur, les duels disparaîtront. Toutefois, on se tromperait étrangement si l'on copiait les modèles du genre qui nous ont été légués par l'ancien régime ou qui nous sont offerts encore par l'étranger : le tribunal des maréchaux de Louis XIV, les tribunaux d'honneur de la Prusse, ne répondraient pas à nos besoins démocratiques. Je ne vois pas pourquoi il serait nécessaire d'instituer une magistrature spéciale pour la sauvegarde d'un bien qui, pour être réputé le plus précieux, ne soulève pas de procès plus délicats à juger que certains autres procès civils ou criminels. Un corps de magistrats honorés et honorables, respectueusement indépendants du pouvoir, peut embrasser les problèmes de ce genre dans la plénitude de sa juridiction.

La difficulté, c'est de faire la loi en vertu de laquelle fonctionnera cette justice. Le progrès extraordinaire des communications et le

« Pour menaces de voies de fait à la suite de quelque injure, le délinquant serait arrêté et ne serait remis en liberté que sous cautionnement de bonne conduite.

«Enfin le port d'arme serait défendu à tout tapageur, sous peine de prison perpétuelle.

« Si ce moyen se trouvait insuffisant, ce qui est plus que probable, il en est un autre qui atteindrait sûrement le but.

«Comme c'est mal prouvé qu'on ait eu raison d'insulter quelqu'un, que de le blesser ou de le tuer; quelqu'ait été le sort des armes, la loi ne déclarerait coupable que le seul agresseur; elle ordonnerait sous peine d'une très forte amende qu'il fût poursuivi par la femme, les enfants ou le plus proche parent de l'outragé, et à leur défaut par la partie publique.

«La peine décernée contre le délinquant serait de lui couper les doigts de la main dont il a manié l'arme meurtrière ; s'il venait à s'échapper, il serait condamné à un bannissement perpétuel, et le quart de ses biens confisqué au profit de l'outragé, ou de ses héritiers en cas de mort. On sent bien que cette disposition de la loi engage l'outragé à prendre des témoins de l'offense $q u$ 'il a reçue, afin de se pourvoir en justice.

«Mais pourquoi des supplices, lorsqu'on peut épargner le sang ? C'est à l'esprit philosophique, qui a détruit, presque en tous lieux, l'empire redoutable de la superstition, à détruire aussi l'empire de ce préjugé barbare. » (Marat, Plan de législation criminelle, 1790, p. $62)$. 
développement prodigieux de la presse périodique ont changé du tout au tout les conditions de l'honneur et les garanties de l'honneur dans notre siècle, et aucun jurisconsulte ne me contredira si je me risque à prétendre que, pareille aux lois de 1819, la loi de 1881 sur la diffamation et la presse est loin d'avoir répondu aux exigences d'une si grande transformation. - Qu'est-ce que l'honneur ? Sous ce même mot, on entend deux choses distinctes, susceptibles l'une et l'autre de s'accroître ou de diminuer, véritables quantités sociales comme la richesse et le crédit. Il y a l'honneur qui s'accroît en surface, par le nombre croissant de ceux qui nous connaissent en bonne part; et il y a l'honneur qui s'accroît en profondeur, par l'enracinement et la consolidation de la confiance en nous, en l'intégrité de notre caractère, chez chacun de ceux qui nous connaissent. Si l'on ne tient compte que de cette dernière acception, qui est en effet la plus essentielle, on peut dire que l'honneur d'un homme connu et estimé de quelques voisins seulement est égal à l'honneur d'un autre homme connu et estimé de plusieurs millions de ses semblables, dispersés parmi l'élite de plusieurs nations. Mais, dans le premier sens, qui a son importance majeure dans certains cas, quand il s'agit d'un homme politique, d'un commerçant ou d'un littérateur notamment, l'honneur de l'homme le plus connu est une richesse morale et sociale très supérieure à celle que représente l'honneur de l'homme obscur. Appelons notoriété, si l'on aime mieux, l'extension de la réputation en surface; réservons le nom d'honneur à son extension en profondeur; et nous pourrons dire que la valeur morale et sociale d'un homme est le produit, comme disent les mathématiciens, de la notoriété par l'honneur.

Or, il est regrettable que, par une rage aveugle d'égalité, nous nous obstinions à fermer les yeux sur cette vérité d'évidence, et à tâcher de nous persuader que l'honneur dans les deux sens mêlée du mot, est un bien égal pour tous. "Mon honneur vaut le vôtre » est une phrase qui sonne comme un axiome. Et cette axiome se vulgarise juste au moment où, par suite des inventions qui ont multiplié les contacts et les informations, l'échelle des degrés d'estime et de considération, et aussi bien de mésestime et de déconsidération, s'est considérablement agrandie. Le plus haut point d'honorabilité où un homme puisse monter, comme le dernier rang d'infamie ou il puisse descendre, est bien supérieur à celui qui était accessible à nos pères. Du Capitole, dont le faite s'est beaucoup élevé, à la Roche Tarpéienne dont l'abîme 
s'est beaucoup creusé, la chute devient chaque jour plus profonde, et, grâce à la Presse, grâce à la tribune, grâce au télégraphe, plus facile et plus prompte. L'écart entre les deux s'élargit sans cesse, l'inégalité grandit à mesure qu'on affecte de la nier et de ne pas voir les dangers qu'elle recèle.

La loi a-t-elle eu suffisamment égard à ces périls ? Non, elle a fait trop de concessions à la notion d'égalité faussement comprise. Sans doute, elle n'a pu s'empêcher d'admettre que l'honneur de certaines catégories d'hommes publics, ministres, députés, fonctionnaires de tout ordre, devait être défendu autrement que l'honneur d'un simple particulier. Mais je lui reproche de n'avoir pas poussé à bout cette distinction, de n'avoir pas divisé et subdivisé cette matière comme elle a su diviser celle des biens mobiliers ou immobiliers et des vols qui s'y rapportent. Je lui reproche d'avoir confondu et réglé pêle-mêle deux sortes de publicités bien différentes, la publicité des propos tenus dans la rue, dans un café, dans une assemblée même, et la publicité des écrits imprimés, imprimés dans des feuilles ou des revues d'un tirage très inégal et dont l'inégalité importe à considérer. C'est comme si un traité de balistique confondait les règles de l'arc ou des catapultes avec celle de nos fusils et de nos canons. Je lui reproche d'avoir trop limité les cas où la preuve de la vérité des faits diffamatoires peut être rapportée et servir de justification au diffamateur, et d'avoir étendu son égale protection sur l'honnête homme appelé voleur et sur le voleur gratifié de la même épithète, comme si l'honneur de l'un valait exactement celui de l'autre. Rolet, de nos jours, pourrait faire condamner Boileau qui l'a qualifié fripon. Je lui reproche enfin d'avoir neutralisé elle-même l'effet de ses bonnes intentions et de ses meilleures dispositions en confiant au Jury, en principe, la connaissance des actions judiciaires relatives à l'honneur. Cet hommage à une de nos superstitions les plus indéracinables a été désastreuse.

Le développement de tous ces points m'entraîneraient trop loin ; je ne puis que présenter quelques observations à l'appui de ce qui précède. - L'égalité vraie ne saurait s'entendre autrement que comme la faculté laissée à chacun de descendre ou de monter jusqu'au sommet, s'il le peut, la hiérarchie des positions sociales, que la civilisation crée et diversifie incessamment. De même qu'il y a des 
inégalités et des diversités de talent, de richesse, de métier, de fonction, il y a des inégalités et des diversités de considération ou de déconsidération, ai-je dit, sorte d'immense et invisible escalier simultanément gravi ou descendu par tous les citoyens d'une nation. La loi ne peut fermer les yeux sur ce double mouvement incessant d'ascension et de descente, qui a une importance capitale. Il importe d'empêcher que le résultat de ces changements soit un appauvrissement pour le budget national de l'honneur. Il importe de faire en sorte qu'il aille s'enrichissant. Si l'on faisait l'addition de toutes les honorabilités françaises actuelles, mesurées en profondeur et en surface, comme il vient d'être dit, et qu'on les comparât avec celles d'il y a cinquante, d'il y a cent ans, on verrait que ce capital moral, comme le chiffre de la fortune publique, a crû rapidement; mais on verrait aussi, en faisant le total de toutes les déconsidérations et mésestimes françaises d'aujourd'hui comparées à celles d'autrefois, que cette quantité négative aussi a beaucoup progressé, comme la dette publique. Est-il indifférent de savoir si la balance annuelle de ces deux sommes est à notre profit ou à notre détriment national ? La France, en somme, n'existe comme puissance morale à l'étranger que par la considération plus ou moins profonde, plus ou moins répandue, de ses représentants les plus notoires, de ses hommes d'État, de ses écrivains, de ses grands industriels, etc. Supposons que, du soir au lendemain, par suite d'un mot d'ordre de la Presse étrangère coalisée contre nous, une diffamation habile enveloppe tout notre personnel d'élite et le déconsidère profondément. Est-ce que la perte de cinq et de dix milliards ne serait pas peu de chose à côté du préjudice, même matériel, que ce bouleversement de l'opinion extérieure nous occasionnerait? Supposez aussi bien que par suite de polémiques ardentes, généralisées sur tout le territoire entre tous les journaux du pays, il n'y ait pas un homme tant soit peu marquant dans son endroit ou dans sa région qui ne soit diffamé et plus ou moins déconsidéré. Est-ce que plusieurs années de disette ou d'inondation des grands fleuves, est-ce que les ravages d'un nouveau phylloxéra équivaudraient, même pécuniairement, à cette calamité, qui porterait une atteinte si complète au crédit publie ?

On le voit donc, l'honneur est un bien réel, une propriété de plus en plus précieuse à tous égards, et dont la conservation intéresse de plus en plus la société. Mais en grandissant et se transformant, cette 
propriété est devenue d'autant plus fragile. De l'honneur solide, étroit et massif d'autrefois, limité aux frontières de la petite ville ou de la banlieue, à l'honneur superficiel, vaste et instable d'à présent, il y a aussi loin que du patrimoine tout en immeubles possédé par nos aïeux à notre richesse en titres de rente ou en actions industrielles. Jadis la loi n'avait presque pas à défendre un honneur assis, consolidé, contre les propos des gens, seule arme avec laquelle il pût être habituellement attaqué. Quand ces propos étaient tenus dans un lieu public, il y avait lieu pourtant de faire intervenir la justice, en subordonnant son intervention à la plainte de l'offensé. Mais à présent en est-il de même?

M. Worms, dans son livre sur les Attentats à l'honneur, prétend que l'honneur "soit interne, soit externe », c'est-à-dire soit dans sa réalité inhérente au caractère même de la personne honorable, soit dans l'opinion du public, n'est pas « un bien juridique », une propriété, susceptible comme telle d'être protégée légalement. Dire le contraire, c'est, à ses yeux, une erreur si grande qu'elle entraîne des conséquences énormes, telles que celles-ci, déduites par Ulrici : "On ne saurait voir une atteinte à l'honneur dans le qualificatif de voleur attribué à un individu qui s'est rendu coupable d'une soustraction frauduleuse, il importe de ne pas concéder au malfaiteur même mesure d'honneur qu'à l'honnête homme ». Voilà donc, dit M. Worms, « où conduisent de pareilles théories ! À des conclusions, à des vues indignes de figurer dans une Éthique ». J'avoue à ma honte n'être pas scandalisé par ces énormités. - La raison alléguée par M. Worms pour refuser à l'honneur le titre de bien de droit ou de bien tout court, c'est que les délits contre l'honneur, suivant lui, ne le lèsent en rien. Comment! votre honneur externe lui-même n'est pas lésé par un article de journal insinuant que vous avez commis des malversations ! Le père de Gabrielle Bompard n'a subi aucune lésion d'honneur quand l'avocat l'a diffamé en pleine Cour d'assises, et que cette diffamation a été répétée par tous les échos du monde entier! Est-ce qu'il ne suffit pas d'un petit mensonge accrédité pour faire sensiblement baisser le niveau de notre cote morale dans l'opinion extérieure, souvent même, par contre-coup, dans notre propre estime, dans notre honneur intérieur, si étrange d'ailleurs que soit ce dernier effet?. 
Dira-t-on que, précisément parce que notre réputation consiste en une croyance, et n'a pas d'autre soutien, elle est sans réalité ? Mais quelle est la propriété mobilière ou immobilière, quelle est la valeur, qui soit autre chose qu'une croyance, la foi toujours variable, susceptible de degrés et de nuances infinies, en l'utilité d'une chose ou même d'une personne? Quand la cote d'une action ou d'une obligation industrielle s'élève à la Bourse, cela signifie que, soit spontanément, soit artificiellement par une coalition de spéculateurs, menteurs habiles, le nombre de ceux qui croient au succès de l'entreprise est devenu plus grand, ou que ceux qui y croyaient y croient encore plus fort, ou que le nombre des croyants et l'intensité des croyances ont grandi à la fois. - Pareillement, ce bien éminent qui s'appelle l'honneur consiste pour chacun de nous dans la persuasion plus ou moins forte possédée par nous et partagée par un nombre plus ou moins grand de personnes autour de nous ou loin de nous, que nous valons beaucoup, non seulement par les services que nous pouvons rendre comme instrument de travail ou de plaisir, comme fonctionnaire ou comme artiste, comme industriel ou comme homme du monde, mais par notre propre existence, jugée digne d'être et de durer ${ }^{1}$. Cette persuasion s'élève ou s'abaisse, de même, incessamment, par l'effet de causes innombrables, mais trop souvent sous l'influence de médisances ou d'éloges passionnés, de camaraderies ou de coteries hostiles. Donc, si le législateur a pensé qu'il importait à l'ordre général de réprimer les spéculations coupables tendant à la ruine frauduleuse de certaines catégories d'actionnaires ou d'obligataires, je ne vois pas pourquoi il ne jugerait pas la société aussi intéressée à prévenir ou à punir la spoliation des réputations. Et, puisque le développement énorme de la richesse mobilière à notre époque l'a obligé à réglementer minutieusement, pas assez rigoureusement encore, les Sociétés anonymes ou autres qui sont les grandes fabriques ou les grands fléaux du capital, suivant les cas, il me semble que les prodigieux accroissements de la consommation des journaux l'obligent aussi à faire enfin une bonne et solide loi sur la Presse, cette machine à vapeur pour la fabrication et la destruction des renommées sur une immense échelle. Il ne faut pas plus, sous prétexte de liberté de la

Le sentiment de l'honneur, par suite, est une inconséquence chez quiconque professe des doctrines métaphysiques qui réduisent à zéro où à moins que rien la valeur de la vie et de la personnalité. Il ne saurait dès lors être pour eux qu'une erreur sacrée, un mensonge aimé de leur conscience. 
Presse, hésiter à endiguer le déchaînement quotidien des outrages, à mettre en mouvement l'action publique, d'office, contre les diffamateurs de profession, qu'on n'a hésité à entraver en apparence, et, en réalité, à fortifier la liberté d'association, en cherchant à mettre un frein, - bien insuffisant, hélas! - à l'exploitation de la petite épargne par la grande escroquerie.

On dira qu'à l'actionnaire dépouillé de sa fortune par un banquier escroc il ne reste rien, tandis qu'à l'honnête homme diffamé dans un journal il reste sa propre estime. Mais, comme je le disais plus haut, en passant, cela est loin d'être toujours vrai. En toute matière, notre adhésion à nos propres idées augmente ou diminue à notre insu suivant les variations de l'opinion environnante; jamais cependant cette action à distance des croyances d'autrui sur nos jugements n'est aussi profonde et délicate, ni aussi inconsciente à la fois, qu'en ce qui touche à notre valeur intime. Le moindre doute qui vient à peser sur notre réputation et qui fait baisser d'un degré notre cote personnelle à la Bourse de l'Opinion, se répercute au for intérieur en un resserrement douloureux de notre estime, qui résiste, il est vrai, à cette pression, mais s'épuise à cet effort. Et voilà justement pourquoi nous faisons tant de sacrifices, jugés absurdes par nous-mêmes, aux préjugés de l'opinion en ce qui concerne les « affaires d'honneur ». À tout prix, nous voulons maintenir à son niveau notre foi en nousmême, qui est notre principe vital dans la vie morale et sociale. Etre philosophe, dans le sens vulgaire et assez profond du mot, c'est présenter une résistance peu commune, exceptionnellement forte, à cette action des idées d'autrui sur les nôtres, ou de la mésestime ambiante sur notre estime intérieure. Les femmes étant, en général, aussi peu philosophes que possible, il ne faut pas s'étonner de les trouver si impressionnables à l'opinion du dehors et si favorables au duel. - Même chez les plus froids et les plus désintéressés des penseurs, combien de ruses de leur amour-propre dont ils ne s'aperçoivent pas! S'il oppose en eux des digues plus inébranlables que chez le commun des mortels à la contagion des contradictions ou des calomnies environnantes, est-ce qu'il n'ouvre pas toutes grandes, plus largement encore en eux qu'en autrui, les écluses de la conscience au flot montant des approbations et des adulations extérieures, traduites aussi en une recrudescence de foi en soi et en son propre système ? Ne voit-on pas force solitaires, qui ont opposé longtemps un 
orgueil d'airain au mépris des imbéciles, au rire des insensés, à la mésestime générale, savourer avec un appétit de vanité aiguisé par un long jeûne, comme Schopenhauer, le succès tardif de leurs ouvrages et de leurs personnes ? C'est là cependant une conduite contradictoire. Aussi, le mécanisme socio-psychologique, si je puis dire, qui règle en chacun de nous l'équilibre de nos croyances avec celles du monde d'alentour, fonctionne même chez les logiciens les plus abstrus, et, chez eux, comme chez leurs semblables, travaille en vain à affranchir l'individu de son milieu. Et nous pouvons conclure hardiment que, pour tous sans exception, « bonne renommée vaut ceinture dorée ».

Une bonne renommée est si bien une propriété que nous la voyons passer des pères aux fils comme toute autre partie du patrimoine. Tous les peuples qui ont connu la grandeur et la durée, Romains, Chinois, Égyptiens, pour ne rien dire des modernes, ont élevé haut l'importance de cet héritage moral. Rien de plus anti-social que de donner à l'honneur, comme l'auteur que je citais tout à l'heure, un sens purement individualiste. Il y a plus de vérité dans la thèse diamétralement -contraire. L'individu doit se respecter lui-même, dit Confucius, parce que "s'il manque à soi-même, il manque à ses ancêtres qui sont en lui ». Curieuse et profonde manière de justifier l'honneur, la sublimation de l'amour-propre, en y voyant un devoir envers d'autres que soi. De la sorte l'amour même et le respect de soi sont présentés comme l'amour et le respect d'autrui, et, à ce titre, dignes d'être protégés légalement. Mais M. Worms est exactement l'antipode de Confucius; son point de vue le conduit à cette conséquence forcée - et vraiment plus fâcheuse que celles dont il était scandalisé tout à l'heure, - de ne pas voir un délit dans la diffamation et l'outrage envers les morts. « D'offenser un mort, dit-il, comment en serait-il sérieusement question, puisque ce mort a disparu et que ses ossements blanchissent dans son cercueil ? " ${ }^{1}$ Mais est-ce que l'honneur de ce mort n'appartient à personne? Qu'on ne m'objecte pas ici les «droits de l'histoire ». Nul ne les respecte plus que moi. Mais seraient-ils atteints parce qu'on accorderait, (pendant un temps limité,

En vertu de son principe, M. Worms va, et devait aller, jusqu'à refuser au tuteur des irresponsables, des aliénés, le droit de poursuivre les diffamations envers eux. Pourquoi ? Parce que ces malheureux n'ont pas pu sentir l'outrage. - Mais, parce que je ne sens pas qu'on me vole ma bourse, suis-je moins volé ? 
bien entendu) ${ }^{1}$, aux descendants d'un personnage historique le droit de poursuivre des historiens ou des publicistes légers, trop prompts à formuler des jugements injurieux sans documents à l'appui ? Je voudrais que, à l'égard des vivants eux-mêmes, la preuve de la vérité des faits diffamatoires pût être rapportée plus souvent qu'elle ne l'est, et entraîner l'acquittement du diffamateur. Il suffit d'appliquer aux historiens cette règle ; ce sera pour le plus grand profit des écrivains consciencieux. Il est bon de mettre un frein au débordement des calomnies en histoire même.

- Pourquoi le législateur moderne a-t-il admis sans réserve que, à la différence des propriétés ordinaires et des vies humaines, l'honneur ne doit jamais être protégé d'office par le Parquet? Pourquoi est-il interdit au ministère public de poursuivre directement, sans plainte de l'offensé, une diffamation quelle qu'elle soit, tandis qu'il lui est ordonné de poursuivre les vols et les coups et blessures, même quand la victime ne se plaint pas, même quand elle s'est arrangée avec le délinquant moyennant un wergeld quelconque et désire arrêter l'affaire ? Je ne puis comprendre le contraste absolu de ces deux façons d'agir ${ }^{2}$. Je sais que la protection judiciaire de l'honneur exige des mains expérimentées et délicates, et que le remède ici peut être pire que le mal. Mais n'est-il pas certaines natures d'outrages contre les particuliers et contre les hommes publics, qui, par leur grossièreté, leur atrocité, leur impudence, jointes à leur publicité, sont une offense à la pudeur nationale, qu'il importe à tout le monde de voir châtier quand elle se produit, pour l'empêcher de se reproduire? Que l'on considère la Presse comme un salon ou comme un club, quelqu'un doit

1 Je dis bien entendu pour deux raisons. D'abord pour éviter à l'historien des procès innombrables avec d'innombrables héritiers. Puis, parce que, à mesure qu'il se divise entre un plus grand nombre de représentants, l'honneur du défunt se réduit à peu de chose pour chacun; sans compter qu'il en est de cet héritage comme des actions de chemin de fer destinées à ne valoir plus rien au bout d'un certain temps. En peu d'années, les personnes qui ont connu le défunt sont remplacées par d'autres qui en ont seulement ouï parler, et celles-ci à leur tour par d'autres qui ont lu quelque chose sur lui. Il y a ainsi un honneur posthume de seconde et troisième main pour ainsi dire, qui va s'idéalisant de plus en plus et perdant de sa réalité substantielle.

2 C'est d'autant moins explicable que notre loi a paru nous reconnaitre le droit d'être plus sensibles aux lésions de l'honneur qu'à celles du corps : elle Innocente en effet (loi de 1881) l'Injure provoquée par une autre Injure, tandis qu'elle se borne à considérer comme une circonstance simplement atténuante, mais non justificative, la provocation en fait de coups et blessures. Elle admet donc, en fait d'injures, le droit au talion, non en fait de blessures. 
avoir la police de ce salon ou de ce club, en chasser les mal appris. Et ce quelqu'un, c'est l'État.

Les anciens avaient sur ce point de plus saines idées que nous. Je ne veux pas revenir à la loi des Douze Tables ; pourtant Cicéron, dans sa République, la loue d'avoir prononcé la peine capitale, dont elle était avare, contre quiconque réciterait publiquement ou composerait des vers diffamatoires. Les Romains de la République, en son beau temps, ne permettaient pas qu'un homme vivant fût exposé, sur la scène, au blâme ou aux éloges. N'est-ce pas en partie à cette sévérité de Rome républicaine contre la diffamation et l'injure qu'est due l'attitude si noble et si calme de ses grands hommes devant l'insulte accidentelle, et leur ignorance du duel ou de tout autre forme violente des vengeances privées?

- C'est seulement par des considérations tirées de la tranquillité générale que peut se justifier l'interdiction légale, dans notre législation, de prouver la vérité des faits diffamatoires contre les particuliers. Il en est de cette prohibition comme de celle qui a trait à la recherche de la paternité : elle n'a que le tort d'être absolue. Le Code Pénal allemand, à l'opposé du nôtre, autorise la preuve en toute matière. Pour nous, il nous semble, que, parmi les faits diffamatoires d'ordre privé, il y aurait des distinctions à établir. Qu'on prohibe la preuve de ces faits, quand ils sont relatifs aux rapports des deux sexes, soit; mais quand ils consistent en actes contraires à la probité et à l'humanité, je ne vois nulle raison d'interdire au défendeur, dans une instance en diffamation, de prouver des délits naturels, jugés tels par la morale et par la loi, et que le législateur ordonne aux citoyens de dénoncer. Il est scandaleux que des banqueroutiers frauduleux puissent faire assigner en police correctionnelle des gens coupables de leur avoir jeté au visage le souvenir de leurs méfaits. En interdisant absolument la preuve des faits privés, on a cru protéger les particuliers ; on ne protège, en réalité, que les insulteurs par métier, qui mettent en circulation contre les plus honnêtes gens les mensonges les plus noirs avec la certitude de n'être jamais mis en demeure d'apporter une justification à l'appui. L'interdiction de la preuve, c'est l'autorisation de la calomnie. À quoi bon faire assigner et condamner le diffamateur qui ne peut se défendre ? Le public pourra croire, en dépit de cette condamnation, que vous n'avez pas été calomnié. Le 
droit de poursuivre le diffamateur n'est donc utile qu'à l'escroc, au faussaire, au coquin hardi qui n'a rien à perdre et se donne le plaisir de salir judiciairement ceux qui lui ont dit ses vérités. La loi est faite pour lui, pour lui seul.

Je crois apercevoir, sous cette interdiction de la preuve qui met au même rang l'honnête homme et le gredin diffamé, une concession de la loi au préjugé égalitaire en fait d'honneur. Je regrette aussi que, par un excès de complaisance pour cet égalitarisme mal entendu, le législateur se prive trop souvent, n'use pas assez largement des services que pourrait lui rendre, en droit pénal, l'emploi des peines d'honneur. Sur ce point, je suis heureux de me trouver d'accord avec M. Worms. Est-ce à dire que je conseille de revenir au carcan, à la marque, à la mort civile. ? Non, c'était bon peut-être quand, pour frapper le coupable dans son honneur, il fallait lui infliger une humiliation positive. Mais, à présent que les droits politiques sont universalisés, leur privation constitue une humiliation négative qui, tout en échappant au reproche de barbarie et d'inhumanité, est douloureusement sentie. Déshonorer de la sorte les diffamateurs, ce serait les punir fort justement par où ils auraient péché. On se conformerait, du reste, à la loi historique de l'évolution pénale, qui paraît pouvoir se formuler ainsi : substitution des peines négatives, privatives de la liberté par exemple, aux peines positives, afflictives, qui caractérisaient la pénalité ancienne.

- En résumé, frapper le duel directement par une loi qui punirait la simple provocation même non suivie de combat, et même la simple publication du compte-rendu d'une affaire de ce genre; et surtout frapper indirectement le duel par une bonne loi sur la Presse et la Diffamation qui distinguerait fortement entre la publicité ordinaire et la publicité par les journaux, qui proportionnerait même, jusqu'à un certain point, la responsabilité pénale du publiciste diffamateur au tirage de son journal, - qui prescrirait dans certains cas la poursuite directe des diffamations par le ministère public, même sans plainte de l'offensé, - qui autoriserait la preuve des faits diffamatoires, même d'ordre privé, relatifs à certaines catégories graves d'actes délictueux, qui enfin ne craindrait pas de léser l'honneur du diffamateur par la nature de la condamnation encourue par lui : à ces conditions, sans nul doute, nous verrions bientôt disparaître cette dernière épave féodale à 
laquelle les honnêtes gens insultés sont trop souvent encore portés à se raccrocher comme à leur dernière planche de salut, dans le péril que l'inertie de la loi fait courir à leur honneur.

Mais je me trompe, toutes ces réformes seraient à peu près inutiles si, en les édictant, on s'obstinait contre toute raison à maintenir en cette matière la juridiction du Jury, superstition plus fatale mille fois que celle du Duel, et, d'ailleurs, de même origine. Le jury, comme le duel, a commencé par être une expression présumée du jugement de la divinité. A défaut de preuves relativement à la culpabilité ou à l'innocence d'un homme, on l'obligeait à se battre, ou bien on consultait l'avis d'un petit concile de douze individus, qui étaient réputés se décider sous l'inspiration de l'Esprit-Saint. Le même optimisme, la même confiance en l'intervention divine, ont suggéré ces deux procédures, presque aussi barbares l'une que l'autre. Je ne reviendrai pas sur ce que j'ai dit ailleurs du Jury ${ }^{1}$. Mais le Jury juger le duel ! le jury juger les attentats à l'honneur qui provoquent le duel ! C'est monstrueux pour qui se donne la peine d'y réfléchir. Au jury spécialement, entre autres causes, à cette juridiction capricieuse, incohérente, avec laquelle on peut tout redouter quand on a raison, et tout espérer quand on est coupable ; au Jury, providence des insulteurs et des diffamateurs de la Presse, il faut imputer la marée montante de l'outrage imprimé, et, par suite, la persistance du duel, en notre siècle éclairé et paisible. On cite comme une singularité ce qui arriva en 1817 chez nos voisins d'outre-Manche, où, dans une affaire de Thornton, après un acquittement par le jury, le frère de la victime invoqua l'appel par le combat judiciaire et en obtint l'autorisation. On a ri de cette réminiscence du moyen-âge ; mais avons-nous bien le droit d'en rire ? Et ne voit-on pas clairement dans cette affaire, étrange en apparence, le lien, plus étroit et plus habituel qu'on ne pense, entre le Jury et le Duel, le premier rendant fréquemment le second nécessaire?

Voir à ce sujet notre Philosophie pénale, dans le chapitre intitulé le jugement. [Texte disponible dans Les Classiques des sciences sociales. JMT.] 


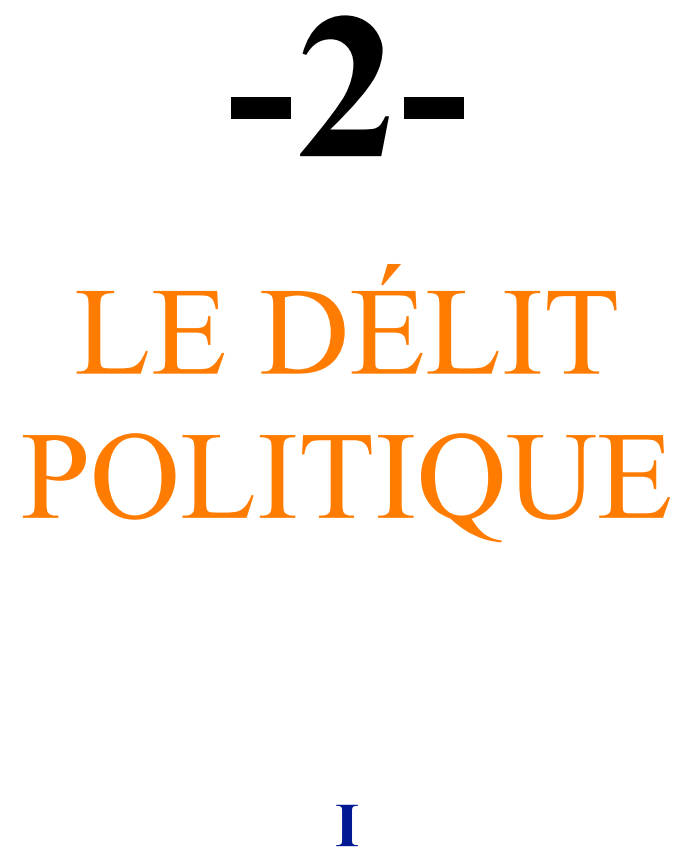

$\underline{\text { Retour à la table des matières }}$

Expliquer la criminalité par des causes générales et non simplement par des circonstances particulières, ou plutôt par des circonstances particulières qui consistent en interférences de causes générales : telle est la tâche à laquelle se sont voués les nouveaux criminalistes. Et l'on ne doit pas trouver surprenant que, après avoir essayé de faire prévaloir cette explication en ce qui concerne la criminalité de droit commun, M. Lombroso se risque à l'appliquer au délit politique lui-même. Le malheur est que sa foi obstinée au type criminel, qu'il croit découvert, en dépit des faits contraires, fausse assez gravement sa manière d'entendre les causes générales dont il s'agit. Pour lui, elles sont, avant tout, sinon exclusivement, d'ordre physique ou physiologique. Encore, tant qu'il s'est borné à étudier des 
meurtriers et des voleurs vulgaires, son point de vue a-t-il pu se soutenir. Mais, dans son dernier ouvrage ${ }^{1}$, il l'étend aux délinquants politiques, comme s'il avait voulu, en tirant lui-même les dernières conséquences de ses principes, en faciliter la réfutation. Alors même, en effet, que la prépondérance des causes d'ordre social dans la délictuosité ordinaire serait contestable ou improbable, ne semble-t-il pas qu'elle devrait rester hors de toute contestation en fait de délictuosité politique, d'excès produits par l'esprit de sédition et de révolte ? si l'on en pouvait douter, il suffirait de lire le livre dont je parle ; et c'est à ce titre principalement, malgré la multiplicité et çà et là la justesse profonde de ses aperçus, qu'il mérite d'être examiné. Je crois inutile cependant d'en faire l'examen minutieux et méthodique ; je ne m'attacherai qu'à quelques-uns des innombrables sujets sur lesquels il morcelle et pulvérise l'attention du lecteur. Notez qu'il y a là 17 chapitres hachés menu en 187 subdivisions, si j'ai bien compté, ayant chacune son étiquette; le tout dans le plus beau désordre du monde, sans lien saisissable parfois, et non sans de fréquentes contradictions.

M. Lombroso a pour méthode de ne jamais définir, ni circonscrire, les notions dont il se sert; et, comme il s'attaque toujours à des notions très complexes ou très confuses, qu'il s'agirait avant tout d'éclaircir, il se persuade trop vite, par cette complexité et cette confusion complaisantes, qu'il qualifie synthèse, échapper au reproche d'inconséquence qu'il encourt assez souvent. Qu'est-ce qu'il entend par crime? par folie? par épilepsie? C'est ce qu'on ignore tout à fait quand on a achevé de le lire. Rendons-lui toutefois cette justice, qu'il a fait de louables efforts pour distinguer en principe les actes insurrectionnels, seuls délictueux d'après lui, des actes révolutionnaires, bien que, après les avoir opposés comme contraires, il les confonde perpétuellement dans ses calculs statistiques. Mais la délimitation précise de la simple révolte et de la révolution proprement dite, si tant est qu'elle soit possible à priori, avant le résultat final, suppose un esprit en possession d'une foi politique, ou, ce qui vaut mieux encore, d'une théorie sociologique. Dire que, « en somme, les révolutions sont des phénomènes physiologiques, les

Il delito politico, (Turin, frères Bocca, 1890). Une traduction française de cet ouvrage a paru depuis que l'article ici reproduit a été publié dans la Revue philosophique il y a un an. 
révoltes des phénomènes pathologiques », c'est se payer d'une comparaison, qui n'est pas même très heureuse, car la plus bienfaisante révolution est une crise toujours dangereuse pour la santé des nations. Puis, comment le savant auteur concilie-t-il ce caractère normal, physiologique, attribué ici aux révolutions, avec ce principe répété par lui passim que l'état normal des peuples est essentiellement le misonéisme, c'est-à-dire l'attachement conservateur aux coutumes, l'hostilité déclarée contre toute innovation? Vous dites (p. 145) que le Christ et Luther ont provoqué des révolutions pures, mais que la Révolution française " et les Vêpres siciliennes », ont été en partie des révoltes. Je le veux bien ; mais, pour en décider ainsi, quelle est votre pierre de touche ? Je ne l'aperçois nulle part.

M. Lombroso n'a pas de sociologie arrêtée et propre. C'est là une fâcheuse condition pour aborder l'étude de la criminalité ordinaire, mais surtout, je le répète, celle de la criminalité politique. Je vois bien, cependant, qu'il s'évertue à combler ou à se dissimuler à lui-même cette lacune. Par tous les bouts à la fois, il saisit l'écheveau social, et, s'il ne le dévide pas, s'il l'embrouille au contraire, ce n'est pas faute de bonne volonté. Des influences innombrables, inextricables, qui concourent à produire un fait social quelconque, une révolte aussi bien qu'un trait de génie, il n'en omet pas une, pas même la plus minime ; et, successivement, avec une patience impatiente, avec une persévérance fébrile, il étudie le rôle qu'a bien pu jouer dans les événements de ce genre l'humidité ou la sécheresse du climat, la configuration du sol, la brachycéphalie, etc., etc. Chacun de ces facteurs, à son tour, nous est montré sur le devant de la scène, comme personnage important; on dirait d'un défilé d'ombres chinoises toutes au premier plan. Mais, l'auteur se noie dans ce détail d'influences accessoires ou insignifiantes; les causes dominantes n'apparaissent que pour être méconnues, reléguées dans le rang des autres; et ce qu'il y a de plus clair dans cette procession qui est loin d'être un enchaînement, c'est l'absence d'une idée directrice. Par centaines, il est vrai, M. Lombroso découvre des vérités dans le genre de celle-ci : « le minimum de génialité coïncide avec le maximum de terrains crétacés ", mais j'avoue que ce rapprochement et d'autres me laissent froid. 


\section{II}

\section{$\underline{\text { Retour à la table des matières }}$}

Je me hâte d'ajouter que son ouvrage renferme des rapprochements plus heureux, des parallélismes vraiment instructifs. Les plus importants de ceux-ci lui ont été visiblement suggérés par Jacoby qui, dans son livre sur la sélection, a le premier imaginé de tracer la carte départementale du génie français, si je puis ainsi dire, et de l'interpréter à la lumière de cartes différentes. C'était une entreprise hasardeuse et ardue, d'où Jacoby s'est tiré à son honneur. Il a dressé avec un soin minutieux la liste des hommes remarquables produits par chaque département dans un temps donné, assez long et le même pour tous, et, les rangeant par ordre de fertilité géniale décroissante, eu égard à un même chiffre de population, il a recherché s'il y avait un lien, d'abord, entre ce rang et le climat ou les caractères du sol. Il n'en a pas trouvé. "Les départements ${ }^{1}$, dit-il, qui ont le même climat, présentent les plus grandes différences sous le rapport de la fréquence des personnages remarquables, et, vice versa, les départements analogues sous ce dernier rapport se trouvent être aux extrémités opposées de la France. » Il en faut dire autant «des conditions du terrain, de la nature du sol, de. la constitution géologique. Les départements les plus opposés, sous le rapport de la fréquence des personnages remarquables se trouvent occuper les mêmes terrains; ainsi, sur le terrain tertiaire, se trouvent le département de la Seine, qui occupe le premier rang sous le rapport de la fécondité en talents et en capacités, et celui des Landes, qui , occupe le dernier rang. Les départements de la Meuse et des Hautes-Alpes, du Jura et de la Charente, présentent le même terrain (jurassique), etc. » On voit par là que Jacoby avait devancé Lombroso dans les recherches et les fouilles de cet ordre; mais, après avoir fait des sondages inutiles, il avait abandonné ses puits comme font les ingénieurs, et son successeur, en $\mathrm{y}$ descendant, a cru y découvrir des mines exploitables. Autant,

\footnotetext{
Études sur la sélection, p. 545.
} 
d'ailleurs, Lombroso est impétueux et précipité, autant Jacoby est calme et circonspect, admirable de méthode et de lucidité. S'il aperçoit un lien apparent entre deux phénomènes, il ne se hâte pas de le baptiser loi et de le généraliser. Il démêle souvent très bien, sous un semblant d'influence naturelle, une influence sociale. Par exemple, ( $\mathrm{p}$. 546), il montre à merveille que, si les départements à grandes plaines sont les plus stériles en talents, contrairement à ce que Lombroso prétend observer, cela tient tout simplement à ce que les grandes villes, foyers rayonnants de génialité autour d'elles, sont situées dans les vallées, au bord des fleuves.

Jacoby, en revanche, à la suite d'une discussion approfondie, met hors de doute l'action de la race sur la production du génie. Mais la race, telle qu'il l'entend, est elle-même un produit de l'histoire et des causes sociales quelconques qui ont refondu à leur convenance le type humain. A vrai dire, sa division de la France par races correspond si exactement à celle des anciennes provinces qu'elle est leur reproduction sous un autre nom, et parfaitement avouée du reste. C'est un plaisir de voir ce naturaliste, conduit, par la compréhension pénétrante de son esprit, à dégager l'importance prépondérante de l'élément historique et social, mieux que nul archéologue ou nul sociologue ne l'eût su faire. Il prend à part chaque groupe de départements constituant une province, et, dans chacun de ces groupes, montre clairement que la série des départements rangés suivant leur degré décroissant de génialité coïncide avec leur classement d'après la densité décroissante de leur agglomération urbaine. Voilà le résultat net et décisif de ses travaux sur ce point.

Est-ce une coïncidence simplement curieuse ou particulière à notre pays ? Non, M. Lombroso, dans son Uomo di genio, a voulu étendre à l'Italie la méthode de notre compatriote ; il a figuré aux yeux, par des teintes graduées, la productivité comparée des diverses régions italiennes en musiciens, en peintres, en sculpteurs, en architectes, célèbres ou distingués. Or, à l'esprit de ces six cartes, et quel que soit l'avis contraire de leur auteur qui n'a pas toujours l'habitude de se rendre même à l'évidence de ses propres observations, il est impossible de n'être pas frappé d'un fait qui saute aux yeux: l'influence dominante des capitales, et des capitales les plus renommées, Rome, Florence, Milan, Gênes, Parme, etc. Quant à y 
voir éclater en traits lumineux, comme on nous l'assure, l'influence de la race étrusque ou grecque et des pays de collines, j'avoue être atteint d'une cécité complète à cet égard. En somme, Jacoby est pleinement confirmé par Lombroso, que celui-ci le veuille ou non.

Celui-ci tranche avec trop de désinvolture cette obscure question des origines du génie. Quant on considère, par exemple, en ce qui concerne la musique, que les peuples de même race et de même latitude, Angleterre et Allemagne, Italie et Espagne, diffèrent profondément sous ce rapport, pendant que des peuples de races et de latitudes différentes, Italie et Allemagne, Espagne et Angleterre, présentent un degré à peu près égal d'aptitude ou d'inaptitude; quand on sait que le don de la composition musicale s'est communiqué du midi au nord, de la race italienne à la race allemande, après avoir émigré de la Grèce et de l'Orient, maintenant stériles, à Rome et à l'Occident chrétien, seuls féconds aujourd'hui ; il paraît assez difficile d'accorder au célèbre professeur de Turin que « l'influence du climat volcanique et de la race latine », est manifeste, et que la supériorité des conditions atmosphériques et climatériques sur toutes autres est indubitable. ${ }^{1}$ A chaque page, je m'étonne d'assertions telles que celleci : "Tout les pays de plaine, Belgique, Hollande, ou ceux qui, encaissés dans de hautes montagnes, sont sujets au goître et au crétinisme endémiques, comme la Suisse et la Savoie, sont dépourvus d'hommes de génie ; le petit nombre de génies que compte la Suisse sont nés... etc...». Peut-on oublier à ce point le merveilleux épanouissement de la peinture et de la marine hollandaise, du génie hollandais sous toutes ses faces en cette trop courte phase historique où les circonstances l'ont déployé ? Quant à la Suisse, je tenais pour démontré, après l'ouvrage si souvent cité de $\mathrm{M}$. de Candolle sur l'hérédité des capacités scientifiques, autre chef-d'œuvre d'analyse, que le petit peuple helvétique avait formé un contingent de grands hommes de science vraiment extraordinaire, eu égard au chiffre de sa population, M. de Candolle, non seulement a prouvé ce fait, mais l'a expliqué, et, tout naturaliste éminent qu'il est, lui aussi, il en a trouvé les raisons dans des conditions de famille, d'éducation, de mœurs, qu'il énumère judicieusement. Est-ce parce que Florence est entourée de collines et Pise en pays plat, que la première a été si féconde en

\footnotetext{
V. Uomo di genio, p. 118 et ss.
} 
génies, du moins jusqu'au XVIIe siècle, et Pise si improductive ? Avant tout, il faut se rappeler la longue hostilité de ces deux villes pendant le moyen âge, la défaite et la subordination politique de la seconde. La victoire militaire est toujours une circonstance favorable au déploiement intellectuel du vainqueur, tout autrement favorable que la collinosité de son sol, si l'on me passe ce néologisme.

Mais, cela dit, l'essentiel reste à dire encore, à notre avis. Et ni Lombroso ni Jacoby même n'en disent rien. Plus encore que le voisinage d'un grand centre ou que la chance des armes, l'avantage de se trouver porté par un ou plusieurs courants logiques d'inventions en train de se dérouler favorise l'éclosion des célébrités dans un lieu et un pays donnés. Les inventions réelles ou possibles, prises dans leur totalité par hypothèse, font partie d'un ordre rationnel que je me représente comme une sorte d'espace intellectuel dont chacune d'elles est un point fixe. Pour aller de l'une à l'autre, il y a toujours des intermédiaires à parcourir, intermédiaires qui changent si le point de départ est changé, mais qui, si le point de départ est à peu près le même, comme c'est le cas pour les sociétés humaines qui débutent toujours par la mise en rapport de cerveaux à peu près semblables en face d'une nature extérieure à peu près invariable, doivent se reproduire presque sans changements. Elles doivent donc se suivre dans un ordre linéaire, que le perfectionnement graduel des méthodes de découverte et des méthodes d'enseignement tend à rendre de plus en plus rapproché de la ligne droite, c'est-à-dire d'un certain minimum de vérités interposées au delà duquel l'abréviation ne saurait se poursuivre. On a perfectionné Euclide, on le perfectionne encore de temps en temps, on fait des traités de mécanique, d'astronomie, de physique, de chimie, d'anatomie, de physiologie, de plus en plus rigoureusement déduits et enchaînés; et que signifie ce progrès, sinon que les auteurs de ces livres se sont conformés de mieux en mieux à la série rectilinéaire, pour ainsi parler, des théorèmes ou des lois qu'ils exposent et qui tous ont été à leur date des innovations géniales, d'apparence accidentelle et fortuite ? Eh bien, ces enchaînements rationnels des innovations réelles ou imaginables forment des séries soit réversibles, soit irréversibles (comme je l'ai dit ailleurs des imitations, c'est-à-dire des inventions imitées, ayant joué un rôle social). Je n'ai pas à chercher pourquoi elles sont tantôt réversibles, tantôt irréversibles, à quoi tient leur réversibilité ou leur irréversibilité. 
Cela nous éloignerait de notre sujet. Il suffit de sentir la réalité de cette distinction, et que, par exemple, on ne peut d'aucune manière concevoir la musique de Wagner précédant celle de Mozart, ou l'orgue et le piano précédant la flûte et la harpe, ou Hernani les tragédies de Voltaire, ou les romans naturalistes les poèmes épiques, ou même l'ordre corinthien l'ordre dorique, ou le gothique fleuri, le gothique pur et sévère, bien qu'on puisse très bien imaginer le style gothique précédant le style roman, ou les instruments à cordes les instruments à vent, ou la première comédie le premier drame. Par suite, une invention a pour conditions nécessaires et sine quibus non, la production antérieure et la connaissance préalable d'autres inventions qui en sont l'antécédent logique. Combien de gens admirablement doués pour telle ou telle branche de l'art ou de la science, - car il y a fort peu de talents universels - sont morts sans avoir rien produit, parce qu'ils ont eu le malheur de naître soit avant le temps où leurs prédécesseurs logiquement nécessaires devaient apparaître, soit loin des lieux où ils auraient pu être initiés aux progrès préparatoires dûs à ceux-ci ! Combien, en des âges grossiers, d'artistes et de poètes ignorés ont péri misérablement dans un monde qui n'était pas mûr pour eux! Newton né avant Kepler, Darwin né avant Malthus et Lamark, Spencer né avant Auguste Comte, avant Hegel même, se fussent peut-être éteints dans l'obscurité. M. Lombroso, qui sait ? s'il fût né au Maroc, à Fez, qui est pourtant une ville située dans un climat très chaud, et j'ajoute une assez grande ville, de population très dense, ou bien s'il fût né à Paris mais au XVIIIe siècle, avant Darwin, Broca et Jacoby, n'aurait jamais écrit l'Uomo délinquente, l'Uomo de genio ni le Delitto politico. Sans doute il eût écrit autre chose, mais, sans doute aussi, avec un moindre succès.

Il faut donc tenir compte, en première ligne, de ces lois supérieures qui régissent souverainement l'évolution logique des idées géniales, et dont leur évolution réelle n'est jamais qu'une application fragmentaire et mutilée, si l'on veut comprendre, en n'importe quel ordre de faits, l'apparition du génie. Le génie est un accident historique où s'exprime une nécessité logique. Le génie est la rencontre de deux rencontres, le confluent de deux confluents, un confluent physiologique d'aptitudes cérébrales, d'heureux legs hérités, et un confluent social d'enseignements recueillis. Mais ces aptitudes elles-mêmes sont-elles autre chose que la consolidation vitale 
d'habitudes sociales ? En somme, la première tâche, et la plus importante, qui incombe au chercheur des sources de ce Nil, consiste à remonter le courant séculaire des inventions, à noter les affluents dont il se grossit sur sa route, à indiquer la fatalité des pentes qui l'ont alimenté ; et, quand cette besogne sera finie, il sera temps alors de s'amuser à composer le calendrier du génie, l'horloge du génie, la géologie ou la météorologie du génie.

Les calendriers sont à la mode actuellement. Après l'ingénieux calendrier du crime, dû à $M$. le docteur Lacassagne, nous avons eu celui du suicide et plusieurs autres. Celui du génie, j'en conviens, n'a rien de plus surprenant que les précédents, et je crois même qu'il renferme comme eux une grande part de vérité, contre laquelle je n'ai nulle raison de m'inscrire en faux. Il y a, pour chacun de nous, des saisons inspiratrices qui se reproduisent aux mêmes mois de l'année. D'après Lombroso, le printemps et l'été verraient mûrir toutes les moissons et toutes les vendanges de l'esprit. Je n'entre pas dans le détail de ses statistiques. Mais je crois qu'il convient ici de ne pas confondre deux choses bien distinctes : la production des œuvres d'art et celle des travaux scientifiques ou spéculatifs. Si les premières s'épanouissent plus volontiers pendant les mois d'enivrement extérieur, de soleil, de beautés naturelles, ajoutons de vacances, le philosophe et le savant ne retrempent-ils pas la vigueur de leur esprit dans la saison froide qui épure et recueille la pensée ? A cela on aurait beau objecter que Galilée découvrit les anneaux de Saturne en avril, et que la première idée de la découverte du nouveau monde vint à Colomb en mai et juillet, il pourrait rester des doutes sur la portée de telles observations, surtout si l'on remarque, au sujet de l'une d'elles, que les découvertes astronomiques ont dû forcément être plus fréquentes pendant la belle saison puisque, si les nuits sont plus courtes, elles sont beaucoup plus limpides.

On peut se faire une idée, ce me semble, assez exacte des variations en plus ou en moins que traverse au cours des diverses saisons l'inspiration philosophique, en consultant à ce sujet M. Ribot. Je le remercie d'avoir bien voulu dessiner pour moi, très approximativement, la courbe annuelle des manuscrits qui lui sont envoyés pour la Revue philosophique depuis quinze années qu'elle vit et prospère. Un manuscrit de ce genre, il est vrai, n'est jamais mis à la 
poste qu'un certain temps après qu'il a été terminé, et sa composition est assez lente. Mais on peut, sans trop d'inexactitude, reporter, en moyenne, à un mois en arrière de la date de l'envoi, l'époque où l'auteur était dans le feu de son travail. Or, la courbe des envois montre une forte dépression qui commence brusquement à l'époque des vacances, fin juillet, juste au moment des grandes chaleurs, et ne se termine qu'en octobre. En octobre et novembre, ce tracé se relève lentement, lance une vive poussée en décembre, s'abaisse un peu en janvier (à cause du jour de l'an sans doute), mais monte très haut en mars et se maintient à peu près jusqu'en juillet où, pendant une courte période avant les départs pour les vacances, elle fait jaillir une vive arête. Cela signifie qu'en novembre et février, aussi bien qu'en avril, mai, juin, les philosophes travaillent beaucoup, et qu'ils ne font pas grand'chose en juillet, août, septembre et octobre. Si je compare ce résultat avec celui que figure, en regard de la page 98 de I'Uomo di genio, un tableau graphique exprimant la courbe annuelle des créations géniales, j'y vois des différences importantes. Dans ce tableau, l'un des plus hauts pics est en septembre, le plus profond ravin est en février; novembre et décembre sont bas. - M. Ribot a eu l'obligeance de m'adresser un autre document : " c'est la statistique des lettres, me dit-il, reçues par la Revue depuis le jour où a paru le ler numéro. Je parle des lettres concernant la rédaction non l'administration, le spirituel non le temporel. » Pour chaque année, il y a deux chiffres seulement, un pour chaque semestre; puis le total. Le total ne varie guère, les chiffres semestriels varient davantage, mais tantôt le premier l'emporte tantôt le second, on ne voit point l'un des semestres affecter une supériorité constante, quoique variable, à l'égard de l'autre. Quant à la distribution des lettres par mois, « rien de plus irrégulier » m'assure M. Ribot ; « tantôt une pluie, tantôt rien ». Aucune influence saisonnière ne paraît ici se faire sentir.

N'importe, j'admets une action, quelle qu'elle soit, de la température sur les manifestations du talent humain. J'admets aussi en principe le calendrier insurrectionnel pour ainsi dire, que $M$. Lombroso dresse pour le comparer à son calendrier génial et au calendrier criminel. Il est intéressant d'apprendre que, soit dans notre Europe moderne, soit dans l'antiquité, soit même au moyen âge, le maximum des révoltes ou des révolutions a eu lieu dans les mois les plus chauds de l'année, et, bien qu'il y ait des exceptions à la règle, et 
que par exemple, (v. le tableau de la p. 51), dans notre Europe, de 1793 à 1884, sur 37 révolutions d'ordre politique, 16 aient eu lieu au printemps et en été, 21 en hiver et en automne, on ne peut méconnaître une certaine relation entre les périodicités des manifestations révolutionnaires et la gravitation de la terre autour du soleil. - Mais le sens de telles remarques ne se revêt qu'à mesure qu'elles se multiplient. Car ce n'est pas seulement en révoltes, en traits de génie, en crimes passionnels ou sanglants, que les mois chauds sont particulièrement féconds ; c'est encore en productions industrielles, et en consommations de tout genre, en fabrication de discours et de lois, en guerres aussi, en victoires et en défaites, en luttes électorales, etc. Tous ces calendriers économiques, militaires, politiques, parlementaires, veulent être rapprochés. Et leur rapprochement laisse entendre avant tout ceci, que les plus longs jours et les plus chauds, soit à cause de leur longueur, soit à cause de leur chaleur, ce qui n'est pas clair, sont liés à un redoublement d'activité de la vie sociale.

\section{III}

$\underline{\text { Retour à la table des matières }}$

Mais revenons à Jacoby. C'est une source. En même temps qu'il découvrait et démontrait la liaison entre l'intensité de la vie urbaine dans chaque département et sa génialité, il s'efforçait de rattacher celle-ci à la couleur politique de ce département. Cette idée, beaucoup moins heureuse que l'autre, n'en a pas moins reçu quelques confirmations apparentes sous la forme que l'ingénieux investigateur lui a donnée. Il a montré, dans un grand nombre de cas, pour les départements groupés dans certaines provinces, que leur fertilité en hommes remarquables était en rapport avec le chiffre des non fournis par eux au plébiscite de 1870. Ce succès partiel tient au choix singulièrement favorable de ce scrutin. Si la comparaison eût porté sur nos autres luttes électorales, elle n'aurait point confirmé l'hypothèse d'où semblait partir Jacoby, à savoir qu'une présomption de talent, d'originalité inventive, s'attache à l'adoption d'une opinion politique déterminée. M. Lombroso, en reprenant cette idée et la poussant à 
bout suivant sa manière, a précisé la nature de cette opinion politique qui, d'après lui, serait l'opinion républicaine, en France du moins. Mais Jacoby ne dit rien de pareil, ce n'est pas dans une cocarde positive, c'est dans une cocarde simplement négative qu'il a cherché le signe révélateur d'une aptitude aux innovations géniales. Au plébiscite de 1870, l'esprit d'opposition et d'indépendance sous toutes ses formes, républicaine, socialiste, légitimiste, orléaniste, s'exprimait par les non. Rien d'étonnant, par suite, à ce que leur chiffre fût dans une certaine mesure proportionnel à la proximité des grands centres et à la densité de la population, et, par conséquent, puisque deux quantités proportionnelles à une troisième sont proportionnelles entre elles, à la génialité de chaque département. Encore y aurait-il beaucoup à dire à ce sujet. Mais, quand la République commence à s'établir et à s'asseoir dans un pays, est-ce faire preuve d'indépendance et de tendance aux nouveautés, n'est-ce pas seulement montrer de la prudence ou du bon sens, ou parfois de la docilité, que de s'y rallier ? Et y a-t-il la moindre raison de penser que la promptitude à prendre le vent, à s'orienter vers le pôle gouvernemental, peut servir à mesurer la vocation aux voyages de découvertes sur des mers inconnues? Sans parti pris, comparons attentivement les six cartes de France où l'on nous a figuré, par départements, la distribution des races, le caractère plat, collineux ou montagneux du sol, la génialité, la répartition des votes politiques en conservateurs et républicains, la densité de la population, enfin, la nature agricole, industrielle, ou agricole et industrielle à la fois, des occupations. Ce qui m'y frappe, c'est que les départements conservateurs sont en majorité les départements agricoles ou semiagricoles, groupés à l'ouest et en partie an nord, tandis que les régions républicaines sont industrielles. La comparaison des cartes 4 et 6 le prouve, malgré force exceptions. Quant au rapport entre la génialité et le républicanisme, il me frappe bien moins, et je ne puis voir dans les coïncidences que présentent à cet égard les cartes 3 et 4 que l'action de la vie urbaine sur les deux phénomènes à la fois. M. Lombroso observe lui-même que l'opinion républicaine prévaut là où la population est le plus dense. Cette remarque, par laquelle il vient confirmer Jacoby, aurait dù lui faire reconnaître le rôle majeur des grandes villes et de leur contagion exemplaire en matière électorale.

Par exemple, plus je regarde, et moins j'aperçois le parallélisme prétendu entre la carte orographique et la carte électorale. « La 
montagne, nous dit M. Lombroso, favorise la génialité et les tendances républicaines. " Je cherche en vain la preuve de cet aphorisme, en contradiction absolue avec le fait, démontré par Jacoby, que la génialité est en rapport avec la densité de la population, très clairsemée, on le sait, dans les pays montagneux. J'avais cru jusqu'ici, d'autre part, que les montagnards, par leur genre de vie sédentaire et domestique, étaient enclins au conservatisme politique ou religieux. L'histoire le démontre, en particulier l'histoire de la Grèce, que M. Lombroso invoque pourtant (p. 62) à l'appui de son idée. Du reste, quelques pages plus loin, il oublie celle-ci. Ces cités de l'intérieur, dont les philosophes grecs louaient l'esprit traditionaliste, en opposition avec le tempérament révolutionnaire des cités du littoral, étaient situées dans les parties montagneuses ou dans les vallées hautes et encaissées de la Grèce. Il dit lui-même (p. 105) des Doriens, que, « ayant habité les régions montagneuses, ils sont restés attachés à la tradition. »

On pourrait croire, d'après ce qui précède, que M. Lombroso est un républicain ardent, malgré l'éloge qu'il fait quelque part de la monarchie de Savoie. Mais, en vérité, je crois qu'un jeune homme docile et confiant serait bien embarrassé s'il consultait Il delitto politico sur le choix d'un parti politique. Avec qui fera-t-il bien de vote ? Avec les monarchistes ? Mais ils abondent en France là où la malaria est le plus répandue, dans les pays marécageux, «Landes, Creuse, Charente-Inférieure, Vendée ». De plus, les monarchistes sont surtout brachycéphales, très dénués de génie. ${ }^{1}$ Faut-il donc être républicain? Ce n'est pas sûr. Les départements conservateurs sont ceux où la mortalité est la moindre, et où les hommes sont les plus robustes, les plus grands de taille. Ce sont aussi les plus fertiles en céréales. Le progrès du républicanisme correspond à celui de la folie. Il y a là de quoi réfléchir. Est-ce que, par hasard, le dernier mot de la sagesse serait de voter par bulletin blanc?

Il montre, p. 102, que la race cimbrique en France est entièrement monarchique. De là, il devrait suivre, naturellement, d'après la liaison cent fois alléguée par L. entre monarchisme et absence de génie, que la race cimbrique est la moins générale des races françaises. Mais, p. 103 , il nous apprend que «le génie prédomine là où prévaut la race belge et cimbrique. » Je ne comprends plus. Je suis fâché d'apprendre la supériorité des races blondes sur les races brunes ; est-il vrai cependant qu'Hector a été vaincu parce qu'il était brun et qu'Achille était blond ? (p. 97). 
M. Lombroso s'est laissé entraîner à quelques-unes des illusions que je lui reproche par sa préoccupation de ce qu'il appelle le misonéisme. Par misonéisme il entend l'horreur systématique, instinctive et innée, de toute innovation, effroi sacré qu'il se croit forcé, bien malgré lui, de reconnaître comme l'attribut normal, nécessaire et universel, des masses humaines ${ }^{1}$. Il suit de là que les révélations quelconques du génie, dont le philonéisme pour ainsi dire est le caractère propre, sont des anomalies, comme celles de la folie. Plus une région est géniale, donc, plus elle doit être réputée à priori novatrice, rebelle ou révolutionnaire en politique. Mais, s'il en est ainsi, M. Lombroso ne devrait-il pas songer, que toute résistance à un entraînement électoral, à une majorité triomphante, dénote de la liberté d'esprit? Ignore-t-il la dose de hardiesse intellectuelle que suppose l'ascension au-dessus des nuages de l'opinion jusqu'aux cimes élevées d'où s'aperçoit la raison de l'irrationnel apparent, la justification des institutions historiques? Si le monde humain ne datait que de cinq ou six mille ans, je comprendrais cette présomption de M. Lombroso paraît attacher à toute nouveauté politique. Mais, depuis que l'antiquité prodigieuse du passé social apparaît à nos yeux et que l'origine des civilisations recule dans les temps géologiques, il n'est plus permis d'être si prompt à croire que quelque chose d'absolument nouveau et en même temps de plus viable, de plus utile et de plus vrai que ce qui a précédé, puisse être encore découvert, après tant d'expériences sociales accumulées, en fait d'institutions et de principes politiques; il y a lieu, au contraire, de garder une certaine méfiance à l'égard de tout ce qui se flatte d'être neuf en ces matières, et de se demander si de prétendues nouveautés ne sont point telles précisément parce qu'après avoir été bien des fois expérimentées dans les civilisations antérieures, elles ont été rejetées chaque fois ensuite et remplacées par des vieilleries plus conformes à la nature des choses. Il en est de l'art politique comme de l'art en général, où tout changement n'est pas progrès, et dont le point de perfection impossible à franchir a plusieurs fois été atteint, dans certaines de ses branches au moins, au cours de l'histoire. En parlant ainsi, je ne crois

Comme exemple de ce misonéisme national, il cite le peuple français, qui depuis Strabon, est demeuré le même, "vain, belliqueux, amoureux des nouveautés ». Ici la contradiction est tellement forte qu'il faut l'attribuer à un lapsus calami. 
nullement céder à une inspiration rétrograde et réactionnaire. Mais je conclus de ces considérations que, lorsque des hommes comme Laplace et Taine, par exemple, au prix d'un grand effort émancipateur, retrouvent les litres du passé, ou quand un critique vigoureux tel que M. Brunetière recompose et redresse la statue des maîtres classiques, on n'est pas en droit de leur attribuer, comme le fait M. Lombroso, un misonéisme larvé, de les traiter en esprits inconséquents, parce qu'ils apportent des pierres neuves à de vieilles digues qu'on ébranle et qu'ils cherchent à raffermir. Sont-ils misonéistes ou philonéistes ? Peu importe ; ce sont des talents et des capacités en somme et supposons que les esprits de cette trempe abondent dans un département ou qu'ils y donnent le ton, vous verrez la majorité y revêtir la couleur conservatrice, (ce qui ne veut pas dire monarchiste nécessairement, au moment actuel). M. Lombroso, d'ailleurs, insiste souvent sur cette vérité que l'homme de talent on de génie, opposé sur un point, sur un seul point, au misonénisme des foules, est lui-même, sur tous les autres points, par une compensation inévitable, d'un misonéisme renforcé. Le conservatisme politique ne saurait donc être pris, à priori, et sans autre explication, pour une marque de stérilité artistique, agricole ou scientifique. Si l'on entre dans cette voie, où s'arrêtera-ton ? Hoeckel, à une certaine époque, évaluait le degré de civilisation des races et des nations d'après leur conversion plus ou moins rapide et générale à la religion darwinienne ; ce qui semblait l'autoriser alors à placer la France bien au-dessous de l'Allemagne, de l'Angleterre et de l'Amérique. A son exemple, le savant criminaliste italien ne serait pas éloigné de penser quelque part (p. 131 et 145) que l'empressement à accepter ses idées sur le type criminel peut servir à mesurer la génialité des divers pays. "L'idée socialiste fleurit, dit-il, en Russie, et l'école pénale italienne (la nouvelle) a en Russie ses principaux fauteurs ». Les Russes sont donc à la tête des peuples. Au contraire, ajoute-t-il, « la France. l'Espagne et l'Amérique du Sud, peuples si fréquemment en état de sédition, comptent de très rares créateurs de véritables révolutions politiques et scientifiques ». La France mise au même rang que l'Amérique du Sud, et citée comme exemple de stérilité imaginative et révolutionnaire ! Au reste, un peu plus loin, il écrit: "Nous voyons parmi nous, les hommes les plus avancés concevoir subitement et adopter les nouvelles idées, y compris celles de la nouvelle école pénale, mais se comporter dans la vie publique bien moins correctement que les cléricaux, d'idées assez courtes, mais 
de conscience intègre $»$. Je cite ce passage comme un échantillon des surprises qui attendent le lecteur presque à chaque page de Il delito politico.

M. Lombroso est à la fois trop sévère et trop bienveillant pour l'esprit de conservation en général. Trop sévère en le qualifiant misonéisme, ce qui est une manière dénigrante et toute négative de le comprendre. Trop bien veillant en le regardant comme le seul état normal des sociétés. C'est oublier que l'accueil hospitalier fait aux nouveautés étrangères est aussi une de leurs fonctions non moins normales, quoique discontinue et intermittente. $\mathrm{Si}$, au lieu de faire pivoter ses idées sociologiques autour de l'idée du nouveau et de créer une antithèse inféconde entre l'amour et la haine du nouveau, il eût pris pour notion centrale l'idée d'imitation et constaté la distinction universelle entre l'imitation du nouveau et l'imitation de l'ancien, il aurait évité bien des erreurs où son point de vue l'a entraîné. Il se fût gardé, d'abord, de considérer l'attachement à la tradition et à la coutume ou l'engouement pour les innovations contemporaines comme des caractères immuables, inhérents à une race ou à un peuple ; il eût pu voir, en effet, l'alternance de ces deux formes plus complémentaires que contradictoires de l'imitation. Il eût constaté sans nul étonnement que les peuples ou les départements les plus conservateurs aujourd'hui ont été à un époque antérieure très novateurs, et vice versa ${ }^{1}$. En comparant un certain nombre de cartes électorales d'un même pays à diverses époques avec un même nombre de cartes géniales de ce pays, aux mêmes époques successives de la France par exemple, dans le courant de ce siècle, il eût sans nul doute vu les premières différer entre elles beaucoup plus profondément d'une date à l'autre que les secondes, en sorte que, si quelque coïncidence semblait apparaître entre l'une des premières et l'une des secondes cet accord momentané et transitoire devait être jugé en grande partie fortuit ou s'expliquer par l'intervention d'une cause étrangère.

Les Ioniens ne sont pas toujours novateurs, ni les Doriens toujours conservateurs. Les premiers sont conservateurs en Asie-Mineure, les seconds sont novateurs en Sicile et dans la Grande-Grèce, M. Lombroso explique ces prétendues anomalies par les croisements de races. Je me demande comment les croisements des Doriens, nés conservateurs par hypothèse, avec des races autochtones encore plus routinières, en tant que sauvages ou barbares, aurait pu donner des résultats diamétralement contraires aux tendances des deux races progénitrices. 
En chacun de nous, a côté de l'habitude, sorte de misonéisme physiologique, existe le caprice ; à côté du penchant à se répéter, le penchant à innover. Le premier de ces deux besoins est fondamental, mais le second est l'essentiel, la raison d'être de l'autre. Il n'y aurait point de nouveautés possibles s'il n'y avait point de routines durables ; c'est la persistance des types spécifiques qui rend seule viables et même imaginables les variations individuelles. La lutte entre l'habitude et le caprice, qui se sont mutuellement indispensables, dure toute la vie de l'individu; mais il est à remarquer qu'elle commence par le triomphe du penchant novateur, et qu'elle se termine, dans l'extrême vieillesse, par la victoire définitive du penchant routinier. Il en est de même dans la vie sociale, bien que notre auteur semble croire précisément le contraire. C'est au plus ancien début des sociétés qu'il place le règne du misonéisme absolu, d'après l'observation superficielle des sauvages. Il estime que l'horreur du nouveau sous toutes ses formes est le propre des esprits faibles, femmes et enfants, à commencer par les animaux. Or, en ce qui concerne ces derniers, je veux bien l'en croire sur parole quand il nous affirme qu'une poule blanche peinte en vert a excité après ce changement de couleur une vive répulsion dans tout le poulailler; mais je ne puis m'empêcher de penser que, parmi les plus révolutionnaires des hommes en train de prendre un bain dans une rivière ou de figurer in naturalibus devant un conseil de révision, l'arrivée d'un homme nu tout vert ne laisserait pas de provoquer aussi un mouvement de répugnance. Ne confondons point l'horreur du nouveau et celle de l'anormal. Quant aux femmes, sans parler des enfants, leur facilité à s'imbiber des nouvelles modes non seulement en fait de toilette, mais de sentiments, d'idées, de mœurs, est incroyable quoique parfois dissimulée sous des dehors trompeurs. S'il y a chez elles beaucoup de survivances religieuses et morales, de pratiques qui jadis leur ont été enseignées par notre sexe (car tous les fondateurs de religions, et tous les apôtres, ont été des hommes et ont eu des hommes pour premiers fidèles,) cela tient simplement à la loi de l'imitation du supérieur par l'inférieur, qui s'est appliquée ici comme partout. La femme a toujours imité l'homme, dont elle a toujours senti la supériorité ; il n'est donc pas surprenant que sa religiosité, fille de celle de l'homme, lui survive un temps. D'ailleurs, quand les femmes emboîtent le pas des insurgés ou des révolutionnaires, elles vont plus loin qu'eux. M. Lombroso est 
embarrassé (p. 227 et s.) pour concilier l'exemple des tricoteuses de guillotines, des pétroleuses, des dames nihilistes, voire même des doctoresses russes, avec le misonéisme soi-disant essentiel à la nature féminine. Mais si, avec moi, on ne voit dans le penchant à suivre les nouvelles modes qu'une forme de l'imitation, on ne sera pas surpris que ce goût alterne chez les mêmes personnes avec le culte des vieux usages, des aïeux et du foyer. Et on concevra facilement que la femme, précisément parce qu'elle est très imitatrice, soit tour à tour dévote du passé jusqu'à la routine aveugle, et enthousiaste d'actualités jusqu'aux pires extravagances. Je ne dirai rien des sauvages; mais je ferai remarquer que l'admiration superstitieuse, la vénération enthousiaste des peuples barbares pour les diverses formes de la folie, baptisées souvent prophétisme et sainteté, ne s'accorde guère avec cette aversion pour les nouveautés, c'est-à-dire pour les singularités, qu'on leur attribue trop libéralement. La noble folie qu'aime le barbare, c'est celle qui accentue l'individualité, qui en fait une exception singulière et puissante à la règle commune. Il oublie ses prêtres, représentants de la règle, pour courir au prophète et à l'ascète, représentants de l'exception.

\section{IV}

\section{Retour à la table des matières}

Ce qu'il y a de plus fâcheux peut-être dans la manière dont $\mathrm{M}$. Lombroso entend le misonéisme, c'est qu'il est conduit par là à regarder toute invention, toute innovation, comme une anomalie morbide, compagne de la folie, puisque la routine est le seul phénomène normal, la santé et le salut des nations. Il ne distingue même pas entre les inventions qui sont conformes et celles qui sont contraires à l'esprit général de la société où elles éclosent. C'est pourtant cette distinction fondamentale, quoique souvent délicate et subtile dans le détail, qui seule peut justifier et expliquer l'opposition sur laquelle il insiste si fort sans parvenir à l'élucider, celle des insurrections et des révolutions, ou pour mieux dire celle des crises de destruction et des crises de renouvellement. Les révolutions vraiment 
rénovatrices sont, comme il le dit très bien, non le contraire de l'évolution sociale, mais son expression la plus nette et la plus forte. Le succès rapide et durable d'une idée politique ou religieuse nouvelle et brusquement importée dénote qu'elle était appelée, cherchée à tâtons depuis longtemps par les intelligences inquiètes, hantées des problèmes dont elle offre une solution inattendue. Le révolutionnaire, ou pour mieux dire, le régénérateur, heurte un rocher de préjugés, comme le simple insurgé ; mais de ce choc il sort une source, un flot de convictions antérieures et accumulées qu'il a fait jaillir. L'insurgé frappe, et rien ne jaillit; c'est un Moïse avorté. Il n'est pas d'insurgé qui, en d'autres temps n'eût pu être un révolutionnaire, et vice versa Luther, venu cent ans plus tôt, avant la découverte de l'imprimerie, ou né en Espagne au lieu de naître en Allemagne, eût péri sur le bûcher comme Jean Huss. Il n'a manqué non plus à Jean Huss pour être un Luther que d'être né à propos. - Voilà bien, ce me semble au fond, la vraie différence entre les rébellions et les régénérations sociales. Voilà bien la pierre de touche, indiquée par le bon sens, dont il faudrait commencer de faire usage avant de rechercher dans quels climats, dans quelles saisons, sous quelles latitudes, avec quel indice céphalique, etc. l'un de ces phénomènes est plus fréquent que l'autre. Notre auteur croit pouvoir décider, en vertu de certaines statistiques, que (p. 377) « les révoltes s'observent plus fréquemment dans les pays à altitude très élevée et très chauds, en temps de disette, ou chez les peuples brachycéphales et bruns, et sont en rapport très étroit avec l'alcoolisme et les saisons chaudes ", tandis que » les révolutions, plus rares dans les pays très chauds, plus fréquentes dans les mois chauds (chose un peu étrange), surtout pour les créations géniales, se développent pourtant à l'inverse des rébellions, dans les pays modérément froids, secs surtout dans les pays de montagnes et de collines, rarement dans les plaines et sur les sols volcaniques,.. et sont en rapport avec la haute stature de la race ». Mais pour être en droit de poser ces conclusions, très curieuses à coup sûr, ne faudrait-il pas préalablement expliquer sur quel principe on s'est appuyé pour dresser les listes de révoltes et de révolutions qui ont servi de fondement à ces calculs, pour classer dans une liste plutôt que dans l'autre beaucoup de faits historiques diversement appréciés ? M. Lombroso ne nous dit pas le principe qui l'a guidé dans cette délicate opération. Tout à l'heure, nous l'avons vu mettre sur le même rang la Révolution française et les Vêpres siciliennes ; cela est un peu hardi, même de la part d'un Italien. 
Au demeurant, je n'entreprendrai pas de discuter les propositions ci-dessus et d'autres semblables, malgré quelques timides objections que j'aurais peut-être à y opposer. C'est en songeant à l'Egypte et à la Mésopotamie ancienne, à la Chine, à la Russie, que M. Lombroso attribue aux pays de grandes plaines un caractère anti-révolutionnaire. Mais il ne songe pas aux phases de bouleversements gigantesques traversées par ces peuples avant leur époque d'apaisement sur laquelle s'arrêtent de préférence les yeux de l'histoire; il méprise trop les exceptions à sa règle présentées par la République Argentine et la Pologne, si agitées, quoique situées dans des pays d'une extrême platitude. Il dit, au sujet de la République Argentine, que cela tient « à la sécheresse de l'air, au débordement de la vie urbaine, à l'imitation des révolutions européennes ", trois considérations dont deux au moins ont leur valeur. Mais, par malheur, aucune des trois n'est applicable à la Pologne avant le partage. Je ne suis nullement surpris, pour ma part, de voir une nouvelle société en pleine fièvre de croissance, comme La Plata, se convulsionner souvent, et il y a des raisons de croire que toutes les sociétés destinées à un grand avenir, à un large développement territorial, qui se sont formées dans le haut passé, c'est-à-dire celles qui ont eu pour berceau une belle vallée, les vallées du Nil, de l'Euphrate, du fleuve Amour, ont été convulsionnaires de la sorte à leurs premiers débuts. Mais, en vieillissant, la plaine argentine se calmera comme s'est apaisée au XVIIe, au XVIIIe siècle, la plaine hollandaise, maintenant si tranquille, autrefois si tourmentée. - Il est à remarquer, à ce propos, que toutes les civilisations de l'ancien et du nouveau monde ont bâti leur nid dans une plaine on sur un plateau. Si donc il était vrai que les révolutions, j'entends les vraies et heureuses révolutions, ont pour théâtre habituel les collines ou les monts, il s'ensuivrait que révolution et civilisation seraient deux termes incompatibles, formant antithèse complète. Peutêtre Metchnikoff, le savant et profond révolutionnaire, auteur de « La civilisation et les grands fleuves historiques ", ne serait-i1 pas de cet avis. Et je crois qu'il aurait raison. Si révolution veut dire innovation féconde, propagée et durable, toute civilisation est un faisceau de révolutions entassées et tassées. Par les lois de l'imitation, - si, par hasard, ma propre chimère ne m'abuse - se résoudrait aisément une apparente difficulté que $\mathrm{Il}$ delitto politico présente au lecteur attentif. 
Mais je crains bien qu'en agitant ces questions avec notre auteur, nous ne perdions de vue, comme lui, notre véritable sujet. Il s'agit, en somme, de caractériser le délit politique et le délinquant politique, de dire dans quels cas nous avons devant nous un délit et un délinquant de cet ordre. Serons-nous suffisamment éclairés à cet égard quand nous saurons en quoi l'insurrection et l'insurgé diffèrent de la révolution et du révolutionnaire ? Non, à moins de révolter la conscience humaine en subordonnant l'appréciation morale et juridique d'un acte à son succès ou à son échec. Une conspiration éclate. Les conspirateurs sont-ils des régénérateurs ou des rebelles? L'avenir le dira. S'ils réussissent, on les saluera grands hommes ; s'ils échouent, on les fusillera. Sans doute, ils échoueront ou ils réussiront, le plus souvent, non toujours, suivant leur contradiction ou leur accord avec les idées et les tendances de leur milieu. Mais leur entreprise même prouve qu'ils ont cru s'accorder avec elles, pouvoir compter sur elles. Or, s'ils se sont abusés, de quoi sont-ils coupables? De leur erreur. Mais là n'est pas la question. Dès le moment où ils ont pris les armes, et avant le dénouement de leur tragédie, l'homme de pensée et de cœur se croit le droit de juger leur conduite et de ne pas attendre, comme la foule, le résultat final, pour les applaudir ou les tuer. Me direz-vous que c'est là un droit imaginaire, un pur préjugé ? Si vous me disiez cela, M. Lombroso, je ne vous croirais pas, car, d'un bout à l'autre de vos livres, vibre énergiquement la fibre honnête de l'indignation ou du mépris contre toute sottise même applaudie, contre toute méchanceté même réussie ; c'est cela surtout qui attache à votre lecture, qui fait passer par-dessus tous les paradoxes et toutes les étrangetés. Vous avez beau dire, de bouche, que mérite et démérite ne signifient rien, qu'il est puéril de blâmes, et de s'indigner, je vous vois avec plaisir flétrir à chaque page toute infamie et protester contre tout fait qui a donné tort au droit. Qu'un autre en cela vous accuse d'inconséquence, parce que vous êtes déterministe ; je le suis aussi et je prétends rester 
logique en m'indignant à l'occasion. Je me persuade même l'avoir prouvé. Droit, devoir, vice, vertu, bien, mal : notions toujours jeunes, patrimoine commun de tous les systèmes. "Quel pacte de ces mots nous a déshérités ? " pourrions-nous dire avec le poète. Donc, il nous reste permis de nous demander, à la vue de cet ouvrier qui monte sur une barricade un fusil à la main, de ce régicide ou de ce présidenticide qui va mettre le feu à une bombe, s'il est ou non, et jusqu'à quel point il est coupable. N'est-il pas manifeste qu'il s'agit pour cela de scruter son cœur, avant tout, et d'y lire le sentiment qui l'anime; de savoir si son mobile a été égoïste ou généreux, lâche ou héroïque ? Tel révolutionnaire, qui a combattu dans le sens de l'avenir, et à qui l'avenir dresse des statues, n'a été qu'un vil scélérat, concussionnaire et souillé de sang. Tel insurgé, acharné à un impossible idéal, à une cause perdue d'avance, chimérique ou prématurée, et, pour ce, pendu, guillotiné, fusillé, brûlé, suivant les temps et les lieux, est un héros qui a fait pleurer ses bourreaux mêmes de pitié et d'admiration. Ce que je dis là n'est peut-être pas politique, mais c'est moral ; et la morale, c'est, je l'espère bien, la politique de l'avenir. La nouvelle école italienne de droit pénal s'est fait honneur en signalant, à propos des homicides ordinaires, l'importance majeure et en partie méconnue de la nature du mobile. Elle voudrait, avec raison, voir substituer cette considération à celle de la préméditation, dont on abuse. Mais c'est surtout, me semble-t-il, aux crimes politiques qu'il conviendrait d'appliquer cette doctrine. Si les meurtres passionnels sont dignes d'une indulgence particulière, cela est surtout vrai de ceux qu'une passion, non pas individuelle comme l'amour ou la jalousie, mais patriotique ou humanitaire, a inspirés. Cette passion est un danger, je le veux, et il importe d'en prévenir les nouveaux éclats, mais, si l'on n'a égard en la châtiant qu'à l'utilité de "faire un exemple », et si l'on croit faire acte de profond homme d'État en ordonnant telle ou telle exécution capitale contre laquelle vont se soulever des protestations « sentimentales », on commet une erreur sanglante, qui devient plus grave et plus évidente chaque jour.

Les crimes politiques sont le dernier asile où ait régné jusqu'à nous l'utilitarisme pénal pur; et l'on peut là le juger à l'œuvre. Frapper un rebelle dans la mesure où l'État croit avoir intérêt à le faire, sans tenir le moindre compte du caractère vil ou noble de sa rébellion : telle a été la règle de conduite des chefs d'État dans tous les temps, même 
aux époques où l'on se flattait de proportionner la pénalité ordinaire au degré précis de culpabilité, de responsabilité morale. Mais notre siècle inaugure en ceci une ère nouvelle, qu'il est aisé de caractériser par le contraste du présent et du passé à deux égards, la peine de mort et l'extradition. Jadis, la peine capitale était un très important appareil social dont il ne nous reste plus qu'un organe rudimentaire; elle fonctionnait partout et continuellement; mais n'était-ce pas surtout en matière politique qu'elle déployait tout son luxe d'atrocités, qu'elle trônait comme dans son domaine propre ? Il semblait qu'on eût pu la déloger de partout ailleurs sans avoir l'idée de l'assiéger dans ce dernier retranchement. Aujourd'hui, c'est ici précisément qu'elle a été supprimée, pendant qu'elle subsiste pour les crimes de droit commun. Même interversion en fait d'extradition. Les premiers traités par lesquels les États anciens ont stipulé l'échange de leurs criminels avaient trait aux criminels politiques; ceux-ci ont été extradés longtemps avant qu'on ait songé à saisir par delà les frontières les vulgaires assassins. Dans notre siècle, au contraire, l'extradition atteint les délits graves de droit commun pendant qu'elle épargne habituellement les délits d'ordre politique. Je ne sais quelle explication physique ou physiologique de ces deux grands faits aurait fournie M. Lombroso, s'il les avait remarquée. Pour moi, j'y vois la suite des progrès immenses qu'a faits l'assimilation réciproque des nations civilisées en étendue et en profondeur; elle a commencé par les classes supérieures qui, en devenant semblables, ont eu les premières le sentiment de leur solidarité, de leur communauté d'intérêt; puis elle a gagné les dernières couches du peuple, et l'intérêt commun des gouvernés a fini dès lors par prévaloir même sur celui des gouvernants. Quoi qu'il en soit, du reste, il résulte au moins du double contraste indiqué, que le crime et le criminel politiques, loin d'être l'objet d'une horreur exceptionnelle, comme cela s'est vu au XVIIIe siècle, lors de l'attentat de Damiens, ont actuellement le privilège de provoquer l'indulgence ou la faveur universelle. Ce qui prouve que l'humanité en s'éclairant ne devient pas de plus en plus utilitaire, quoiqu'on en dise : eu effet, si rien n'est plus généreux souvent que le mobile du conspirateur, rien n'est plus dangereux d'ordinaire que sa tentative, rien n'est plus ruineux ni plus destructif que son succès. Ni Pranzini, ni Prado, ni Eyraud n'ont fait au public qui demande leur tête autant de mal que les condamnés de la Commune dont il a réclamé l'amnistie. 
C'est que le public est psychologue sans le savoir, beaucoup plus que sociologue; et il trouve, avec raison, la psychologie de l'insurgé bien plus intéressante que celle du brigand ordinaire. Mais il faut avouer que souvent il est dupe des mots, ici comme ailleurs, et qu'il se hâte trop de ranger parmi les délinquants politiques des scélérats n'ayant rien de politique que le nom ${ }^{1}$. Dans un chapitre des plus instructifs, M. Lombroso nous montre combien de fois cette confusion a dû être faite. Passant en revue (p. 268 et s.) les régicides célèbres, Orsini, Fieschi, Hoedel, etc., il énumère les condamnations pour délits de droit commun qui avaient été, avant leur attentat, encourues par eux-mêmes ou par leurs complices. Elles sont nombreuses. Il fait la même remarque, non seulement d'après Despine et Maxime du Camp, mais d'après Cluseret et Vallès, relativement aux hommes de la Commune. Il l'étend aux chefs jacobins. Il ne perd pas une si belle occasion d'utiliser son type criminel. Si, malgré moi, je ne gardais toujours quelque méfiance à l'endroit de ses statistiques, je ne pourrais m'empêcher d'être frappé d'un fait qu'il avance : la proportion des individus porteurs de ce fameux type est, d'après lui, beaucoup plus considérable parmi les insurgés que parmi les révolutionnaires; elle est très forte là où la cause du soulèvement est injuste, elle est très minime quand la révolte est légitime. Ainsi, sur 521 martyrs de l'indépendance italienne, il compte seulement trois stigmatisés de cette espèce; tandis que, sur 50 photographies de membres de 1a Commune, il y en a 6, et, sur 8 pétroleuses, 4. Mais les lunettes du patriotisme n'auraient-elles pas, peut-être, altéré sa vision ? Parmi nos grands agitateurs français, il trouve Mirabeau très beau, il est vrai, mais son nez de travers lui paraît suffire à le classer dans la catégorie des individus typés, à côté de Marat, de Carrier, etc. Il découvre beaucoup d'épileptiques au nombre des novateurs: Mahomet, par exemple. De là une nouvelle névrose dont il a voulu être le parrain et qu'il a baptisée épilepsie politique. Remarque plus sérieuse: le nombre extraordinaire de fous dans les rangs révolutionnaires. Luther,

Nous savons tous à quelles conditions l'affaire la plus simple du monde est réputée affaire politique et comme telle, soustraite à la juridiction du bon sens et du sens moral. Il suffit qu'elle intéresse de près ou de loin un homme politique, ou qu'elle soit censée pouvoir exercer une influence quelconque sur le résultat d'une élection, fût-ce une élection municipale. Remarquons que l'augmentation des affaires politiques ou qualifiées telles est un symptôme grave, un signe certain de perturbation sociale. 
Savonarole, ont eu de vraies hallucinations; Masaniello, Cola de Rienzi, fous dangereux; le dernier, mégalomane. Châtel, Jacques Clément, Poltrot, autant d'hallucinés. Ravaillac, en frappant Henri IV, obéissait au délire de la persécution. Pendant la Révolution française, Théroigne de Méricourt, aliénée ; sous la Commune, la folie règne ; voir à ce sujet le livre du Dr Laborde. Beaucoup de fous parmi les insurgés de l'Amérique du Sud. John Brown, l'apôtre de l'émancipation des esclaves en 1859, était atteint de folie héréditaire. Fou aussi, Hong-Sion-Tucen, le révolutionnaire chinois (M. Lombroso voit donc bien que la Chine, malgré ses vallées, a eu ses révolutions) qui, vers le milieu de ce siècle, a rêvé de christianiser le Céleste Empire et y a suscité de grands troubles. Fou encore, le fondateur d'une nouvelle religion qui, en 1862, s'est formée parmi les sauvages de la Nouvelle-Zélande (preuve que le prétendu misonéisme des sauvages n'est pas sans exception). C'était, paraît-il, un nommé Horopapera, en relations continuelles avec l'archange Gabriel.

S'il en est ainsi, nous devons nous attendre à voir l'esprit de révolte et de révolution, dans une nation ou dans une classe, en rapport avec la fréquence des cas de folie dans cette population. Il doit donc être plus répandu et plus intense dans les villes que dans les campagnes, dans les pays en train de se civiliser (je ne dis pas dans les pays très anciennement civilisés et assis en leur civilisation établie, tels que la Chine ou 1'Égypte) que chez les peuples barbares. En voyant progresser d'un même pas, dans notre Europe, l'aliénation mentale et l'agitation novatrice, on ne saurait douter de ce parallélisme ni hésiter à l'expliquer par des causes principalement sociales.

Le seul fait que l'esprit révolutionnaire a ses accès et ses apaisements, qu'il souffle tantôt du nord, tantôt du midi, qu'il se promène d'Orient en Occident, ou d'Occident en Orient, prouve clairement qu'il ne tient pas à des causes physiques ou physiologiques, au climat ou à la race, qui ne changent pas. S'il dépendait principalement de ces conditions, il serait fixe et constant comme elles. Jusqu'à Luther, comme on peut le voir notamment dans le Précis de l'histoire de l'Eglise d'Occident par Charles Schmidt, la plupart des grands hérésiarques chrétiens ont pris naissance dans le midi de l'Italie, ou de la France, foyer de la civilisation et de la richesse européenne au moyen-âge; et c'est parce que la découverte de 
l'Amérique et celle de l'imprimerie ont eu pour effet graduel de transporter à l'ouest et au nord le courant commercial et civilisateur, que l'hérésie, comme le génie, s'est mise à éclore, depuis le XVIe siècle, sous une latitude plus élevée. Au XIVe siècle, quand éclataient ces épidémies révolutionnaires par imitation de plèbe à plèbe, que Lombroso a remarquées, et qui ont sévi de 1378 à 1394, les plèbes de Rome, de Florence, de Palerme, ont servi de modèle aux communes allemandes, aux hussites de la Bohème, aux bourgeois suisses. C'est toujours la nation ou la classe la plus brillante qui est imitée. Par cette même loi de l'imitation du supérieur s'explique un autre fait, que cite notre auteur : Jusqu'à la moitié du siècle actuel en Russie, les révoltes et les conspirations étaient localisées dans les hautes classes ; c'étaient des événements de Palais. Mais, depuis, le régicide est descendu peu à peu dans les couches profondes de la nation. Chez nous, l'exemple des révoltes a été donné à la bourgeoisie et au peuple par les chefs aristocratiques de la Fronde, dont la tradition s'est perpétuée jusqu'en 1789 et a eu pour représentant le plus illustre le comte de Mirabeau. Si M. Lombroso eût tenu compte de cette loi, il eût été moins surpris d'un phénomène qu'il se donne beaucoup de mal pour expliquer: comment se peut-il faire que, la noblesse étant essentiellement misonéistique d'après lui, il y ait toujours eu, mais surtout jadis, tant de nobles à la tète de toutes les révolutions ? Ses efforts pour résoudre ce problème insolubles sont curieux. Mirabeau est représenté comme un dégénéré névropathe ! La vérité est que, loin d'avoir le misonéisme pour caractéristique essentielle, la noblesse, en ses jours de splendeur, est toujours amie des nouveautés, même des nouveautés qui tendent indirectement, par exemple les idées des encyclopédistes et de Rousseau au dernier siècle, à ébranler son pouvoir.

Mais c'est assez critiquer M. Lombroso. Malgré tout, son livre est très intéressant, précisément peut-être parce qu'il ressemble un peu trop à une forêt vierge. Disons-le en finissant, M. Lombroso est un des agitateurs les plus passionnés mais les plus sincères qui existent. C'est, à sa manière, un impulsif. Une forte excitation intérieure le pousse constamment, non à commettre des crimes, mais à pourfendre des ennemis intellectuels qui l'assiégent, et qui, toujours taillés en pièces, se redressent toujours sur leurs pieds, comme cela se voit dans les poèmes orientaux. Il lui sera beaucoup pardonné, non pour avoir beaucoup aimé, - car il me semble exécrer cordialement ses 
adversaires, - mais pour avoir beaucoup cherché, sinon trouvé toujours, ce qui serait vraiment trop de bonheur. 
Gabriel Tarde, Études pénales et sociales (1892)

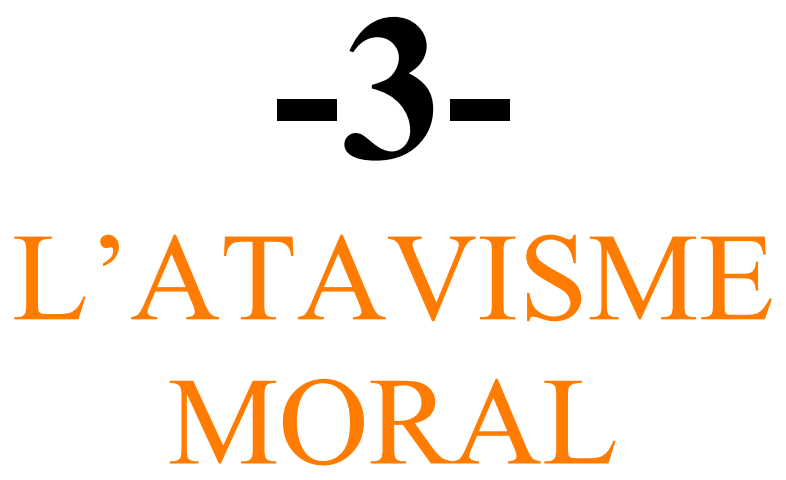

I

$\underline{\text { Retour à la table des matières }}$

C'est un vrai plaisir de discuter avec un esprit sincère et calme, aux convictions sans passions, aussi désintéressées qu'arrêtées, dont la fixité se déploie en une variété inépuisable d'ingénieux développements, servis par une vaste érudition. Tel est M. Colajanni, et voilà pourquoi, bien que je me félicite hautement d'être d'accord avec lui sur tant de points, et de pouvoir m'appuyer souvent sur le résultat de ses solides recherches en statistique, je ne sais si je ne suis pas tout aussi ravi de l'occasion qu'il m'offre aujourd'hui de le contredire un peu à propos de ses idées sur l'atavisme moral des délinquants. 
Mais, avant tout, que je commence par louer comme il convient son beau livre sur la Sociologia criminale ${ }^{1}$. Jamais la question du type physique des criminels, ni celle des rapports du crime avec la folie, l'épilepsie, la dégénérescence, l'hérédité, n'avaient été vues de si près, ni sous tant de faces différentes, ni éclairées à la lumière de tant de chiffres et de documents pris un peu partout, toujours aux bonnes sources. De cet examen consciencieux il se dégage la preuve que les causes sociales du délit l'emportent immensément sur ses prédispositions naturelles. Mais il semble que par sa thèse sur l'atavisme moral l'auteur se mette en contradiction partielle avec ce résultat général de ses travaux. Montrons en quelques mots ce que la position prise par lui et défendue avec talent a de singulier.

Le délinquant, à ses yeux, est-il un fou ? Non, (v. p. 407). Est-il un fou moral spécialement? Non plus. Est-il un épileptique ? Pas davantage. Est-il un malade? Singulière maladie qui, sous d'autres latitudes, constituerait une excellente santé ! Est-il un dégénéré ? Un régénéré plutôt, en un certain sens, s'il est vrai que la moralité ait été un éloignement du type mental primitif de l'humanité et que l'immoralité nous y ramène. Un tableau de l'Italie par régions où figurent les chiffres de la délictuosité comparés à ceux des réformes de conscrits pour défaut de taille et pour divers vices corporels de nature éminemment dégénérative, nous fait voir qu'il n'existe aucun lien entre la criminalité et la dégénérescence. Ces recherches très minutieuses (p. 300-317) aboutissent à cette conclusion : les provinces italiennes qui se distinguent par la santé physique et la parfaite conformation organique se signalent aussi par leur supériorité criminelle, et là, au contraire, où la dégénérescence sévit, la moralité relative règne! Qu'est-ce donc alors que le criminel ? M. Colajanni répond en reprenant la première thèse de Lombroso, mais en n'en retenant que la moitié. Le criminel est un néo-sauvage ou un néobarbare, un revenant du temps de nos ancêtres éloignés. Seulement, gardez-vous de voir en lui un sauvage au sens physique du mot; il ne l'est qu'au sens moral. L'atavisme physique ici est une explication doublement illusoire, et parce qu'elle suppose gratuitement l'existence d'un type physique propre aux délinquants, et parce que, si ce type physique était réel, composé comme on nous l'assure d'une collection

1 La Sociologia criminale, del D Napoleone Colajanni (Catania, Filippo Tropea, 1889 ). 
de malformations et de honteux stigmates, sa similitude avec les traits corporels de nos premiers parents serait la moins vraisemblable des hypothèses. Mais l'atavisme moral peut et doit se soutenir; car rien de plus analogue, moralement, que les sauvages encore existants et nos criminels civilisés, et, pour fortifier ce rapprochement, nous pouvons le compléter par l'analogie des deux avec les enfants, reproduction passagère du passé moral de nos races, et avec les gens du peuple, retardataires de la civilisation. Entre parenthèses, cette dernière considération, sous la plume d'un socialiste démocrate, ne manque pas d'originalité.

Mais comment, dira-t-on peut-être, le délinquant peut-il être une réapparition ancestrale du sauvage ou du barbare moral, s'il ne l'est aussi du sauvage ou du barbare physique ? Comment peut-il se singulariser à ce point par la nature de ses sentiments et de ses actes, si rien, dans les formes de ses organes et surtout de son cerveau ou même de son crâne, ne le particularise, au moins dans la majorité des cas ? Est-ce que tout caractère mental n'est point nécessairement lié à un caractère corporel ? Est-ce que toute variation mentale n'entraîne pas ou n'implique pas une variation corporelle ? Voilà précisément ce que notre auteur conteste. Il élargit, il élève l'étude du type criminel en la faisant rentrer, comme un simple cas particulier, dans l'étude générale de la corrélation entre la fonction et l'organe. Pour lui, toute fonction n'est pas liée à un organe spécial, du moins à un organe que nos yeux et nos instruments d'observation puissent atteindre. ${ }^{1}$ Cela est vrai, avant tout, des fonctions nerveuses qui ne sont pas toutes, il s'en faut, localisées ni localisables dans des compartiments déterminés du cerveau. En outre, le lien entre l'organe et la fonction, quand il existe, provient de ce que la fonction à la longue s'est fait son organe et continue à se le faire, mais non de ce que l'organe s'est fait et se fait sa fonction. Ce point de vue trouve son application et sa confirmation en sociologie même où c'est évidemment la guerre qui fait le militarisme

Au sujet du défaut de relation entre les troubles de la fonction et la malformation de l'organe, Colajanni aurait pu citer Féré, son contradicteur cependant en ce qui concerne la criminalitédégénérescence : «Les hystériques, nous dit celui-ci (Dégénérescence et criminal. p. 72, en note) qui présentent plusieurs des conditions physiologiques de la criminalité (troubles de la sensibilité et de la motilité, excitabilité excessive, etc.), et qui souvent se laissent aller à des impulsions délictueuses (voleuses aux étalages, vitrioleuses, etc.), sont souvent remarquables par la régularité de leur conformation physique et un petit nombre seulement offre des stigmates anatomiques ». 
et non vice versà, et où la nature de l'activité dominante, agricole, commerçante, industrielle, donne aux institutions leur caractère propre, de même que 1'évolution des littératures imprime aux langues son cachet.

- Ainsi, en admettant qu'il y eût un signalement anatomique lié aux anomalies psychiques des malfaiteurs, ce n'est pas à lui qu'il faudrait demander le secret de leurs inclinations. Mais ce lien est imaginaire ; c'est tout au plus si l'on a pu localiser cérébralement les facultés des sens et certaines facultés plus hautes, mais élémentaires encore ; il n'est pas sûr que celle du langage mérite le siège où Broca l'a confinée ${ }^{1}$; au moins est-t-il sûr que l'intelligence et la mémoire sont disséminées dans tout le cerveau, au lieu d'y être claquemurées quelque part : quant au sens moral, à l'instinct moral, au caractère moral, de quelque nom qu'on l'appelle, il est, de toutes les fonctions de l'âme, la moins susceptible de localisation, et c'est une étrange idée de vouloir la loger à droite ou à gauche, plus près ou plus loin du front. Autant vaudrait loger la tristesse ou la joie, comme on l'a essayé, dans les régions temporales et sphénoïdales. Ou plutôt l'idée d'enfermer la moralité dans une circonvolution quelconque serait bien plus ridicule encore ; le sens moral est de date trop récente pour avoir eu le temps de se faire un organe spécial... Aussi n'y a-t-il rien de plus indépendant des changements physiques subis par une race que les changements de sa moralité. Il ne faut donc pas nous étonner si, d'après le témoignage des savants les plus autorisés, la constitution physique et spécialement crânienne de chaque race humaine est restée fixe depuis des centaines ou des milliers de siècles, malgré le progrès ou la variabilité extraordinaire de sa capacité intellectuelle et de ses qualités morales. Broca nous apprend que «l'homme contemporain, par ses caractères morphologiques fondamentaux, ne diffère point de l'homme préhistorique dans le sein d'une même race » et il conclut que «l'évolution physique n'est point parallèle à l'évolution psychomorale. » (v. p. 233 et s.)

Cependant cette 1ocalisation a reçu tout récemment encore de nouvelles confirmations. 


\section{II}

\section{$\underline{\text { Retour à la table des matières }}$}

Telle est la thèse de M. Colajanni. Sans vouloir discuter toutes ces propositions, nous nous permettrons quelques réflexions éparses sur certaines d'entre elles avant d'entrer au cœur de notre sujet. Pour apprécier le jugement sévère porté par notre autour sur les idées anthropologiques des nouveaux criminalistes, il importe d'examiner si son scepticisme à l'égard des localisations cérébrales est fondé ou non. L'anthropologie criminelle, en effet, n'est qu'une phrénologie nouvelle. Peut-être fait-elle de la phrénologie sans le savoir. Or, après avoir passé en revue toutes les objections élevées contre la théorie des localisations, toutes les hypothèses, souvent contradictoires, émises à ce sujet par plusieurs savants, M. Colajanni se prononce, non sans raison, en faveur de l'opinion de Brown-Sequard sur le cerveau considéré comme une fédération de cellules, chacune complète en soi, mais spécialisée, de plus en plus à mesure que se resserre le lien fédératif. Ainsi, à la localisation des fonctions cérébrales se trouverait substituée la spécialisation des fonctions cellulaires du système nerveux. Il est certain que cette interprétation toute sociologique d'un problème biologique est ici fort heureuse, et nous n'avons qu'à suivre la métaphore de Brown-Sequard pour voir un peu plus clair dans cette obscurité. Supposons donc que, sans distinguer isolément les individus humains, les producteurs humains, un observateur de la Lune, ou, ce qui revient au même, un statisticien bien clos dans ses chiffres, aperçoive en gros les manifestations de l'activité humaine dans un État, c'est-à-dire, les divers genres de production agricole, industrielle, littéraire ou autre. Il ne manquera pas de remarquer que dans tel canton se localise l'industrie du fer, dans tel autre la fabrication de la toile, du coton, de la soie, de la musique wagnérienne ou de la poésie décadente ; et il se hâtera peut-être trop tôt de conclure que chacun de ces articles est le monopole exclusif de chacun de ces petits territoires, d'ailleurs assez mal délimités toujours. Mais une observation plus attentive ne tardera pas à lui prouver que chacun de 
ces cantons, s'il vient à être privé du secours fourni par ses voisins à la suite d'une épidémie ou de ravages quelconques survenus dans ceux-ci est capable à la rigueur de fabriquer lui même, tant bien que mal, la plupart, je ne dis pas la totalité des marchandises dont il a besoin. De là une distinction importante ; c'est qu'il y a des industries qui sont essentiellement localisées, et d'autres qui, essentiellement aussi, ne le sont pas, parce que, sans doute, elle sont très primitives, ou bien parce qu'elles répondent à des besoins très urgents, la boulangerie et la poterie par exemple. Quoique très récente, une industrie devenue très nécessaire serait, il est vrai, dans le même cas : par exemple, la fabrication des locomotives ou des télégraphes électriques. On peut être sûr que, si un petit État européen, qui reçoit aujourd'hui de l'étranger des locomotives ou des appareils télégraphiques, venait à être privé de cette importation, il y supplérait aussitôt en fabriquant sur place ces articles compliqués, aussi impérieusement requis par les exigences modernes que le pétrin du boulanger ou la roue du potier. Mais en somme, et malgré cette exception, les industries les plus localisées sont les plus nouvelles. - Eh bien, si une distinction analogue est applicable aux industries du cerveau, à ces fameuses facultés dont on a tant cherché l'emplacement, si les unes sont attachées à un domaine circonscrit et disparaissent sans retour après sa destruction, tandis que les autres se reconstituent tant bien que mal après la lésion ou l'ablation de leur territoire préféré : est-ce qu'il n'y a pas lieu de supposer aussi que ces dernières, celles auxquelles est dévolu le privilège de l'ubiquité cérébrale, - la mémoire, l'intelligence, la moralité, - sont les plus anciennes, les plus primitives, la troisième aussi bien que les deux autres, et même plus encore, car elle est moins indispensable à l'individu? Ainsi, si l'on admet avec M. Colajanni l'origine moderne de la moralité, on a droit de s'étonner, précisément à cause de cela, qu'il lui refuse un siège cérébral ; et, en prouvant qu'elle n'en a pas, il tend à rendre probable son ancienneté. Mais, ce n'est là, je l'accorde, qu'une présomption légère, et à fleur de sujet, en attendant mieux.

Je me demande comment notre auteur concilie avec son grand principe de la fonction cause de l'organe, le contraste supposé par lui entre la variabilité morale et intellectuelle de l'humanité et la permanence physique du type humain, du crâne et probablement du cerveau humain, depuis les temps géologiques. Comment se fait-il que 
cette variabilité, continuée depuis tant de milliers d'années, n'ait pu entamer sensiblement cette permanence? Il y a ici, je crois, une contradiction véritable. - Quant à la difficulté de concilier la permanence en question avec la loi de l'évolution, elle peut s'expliquer ingénieusement, si l'on suppose, avec Morselli et d'autres anthropologistes, que, à partir de l'apparition du langage et du lancement de la nef humaine sur l'océan social, la source des transformations simplement physiologiques a dû s'arrêter en nous, parce qu'elle a été remplacée avec avantage par la fontaine nouvellement jaillie de découvertes nées du contact social, accumulées et répandues par le langage. Idée séduisante et profonde, au fond de laquelle on peut voir - si l'on veut bien se placer à mon point de vue théorique, - la commune nature des innovations vitales et des inventions sociales, l'explicabilité de celles-là par leur similitude avec celles-ci. En ce sens, donc, la fixité physique de nos races civilisées serait due précisément à leurs modifications mentales; et, en général, il serait permis d'avancer que, dans une espèce vivante quelconque, la fixité, si surprenante, de certains caractères typiques est due en grande partie à la mutabilité de certains autres où le besoin de nouveauté inhérent à chaque for-me de la vie s'est donné carrière. ${ }^{1}$ Le monde social serait donc un débouché remarquable ouvert au besoin de nouveauté propre à l'espèce humaine et plus intense en elle qu'en aucune autre, peut-être parce qu'étant le plus élevé des volcans vivants par où s'échappent les forces du monde, elle exprime ce qu'il y a en elles de plus profond. Mais je crois qu'il faut se garder de confondre ici la variabilité sociale, qui n'est pas douteuse, avec la variabilité morale qui est en grande partie hypothétique; et l'observation précédente gagnerait à être rapprochée d'une idée de Darwin que M. Colajanni cite quelque part. Les organes et les fonctions les plus complexes, les plus nobles, sont, d'après l'illustre naturaliste, les moins variables. Cela s'applique avant tout au cerveau et aux fonctions du cerveau. Chose merveilleuse, en vérité, que ce qu'il y a de plus sensible au moindre souffle extérieur soit ce qu'il y a de plus résistant aux plus grandes tourmentes, que ce qu'un rien émeut soit ce que rien n'ébranle ! N'est-ce pas, qui sait ? parce que la richesse même de ses propres modulations assure la

C'est ainsi que socialement, la fixité (relative) de la langue est proportionnelle à la variabilité de ses emplois, aux progrès de la littérature et des sciences. Les langues sauvages sont bien plus variables, et de même les religions sauvages, que les langues et les religions civilisées. 
durée à un thème organique ou fonctionnel fondamental, en prolongeant sa raison d'être?

Plus un motif musical a de complexité et d'ampleur, c'est-à-dire de variabilité, et plus il lui est permis de se répéter indéfiniment. Quoi qu'il en soit de cette manière de voir, rien de plus variable individuellement que les formes du crâne, et rien de plus immuable dans la moyenne des cas. Rien de plus variable non plus que les idées de l'esprit, que les passions ou les penchants du cœur, source nécessaire de toute moralité, et rien de plus immuable, dans une race donnée, que son esprit et son cœur. Sans doute l'horizon de l'esprit s'est étendu incessamment; sans doute, le domaine du cœur et de la morale, le cercle des hommes réputés nos semblables, et comme tels jugés dignes de nos sympathies et de nos devoirs, s'est toujours élargi ; mais la virtualité intellectuelle ou cordiale est restée la même, concentrée ou déployée n'importe; et si haut que la lecture des plus vieux documents littéraires, des plus antiques documents linguistiques, nous permette de remonter un peu sûrement dans l'âme de nos aïeux, je ne dis pas de sauvages qui n'ont jamais été nos parents, nous sommes surpris de la facilité avec laquelle, après un peu d'exercice, nous nous mettons au pas de leur intelligence, et plus encore au diapason de leurs sentiments.

Le cœur assurément, d'Homère à nous, des patriarches hébreux à nous, a moins varié encore que l'esprit, bien que l'esprit ait gardé au fond la même constitution. Il en est, je crois, du préjugé scientifique courant sur l'immoralité, l'insensibilité, l'improbité natives de nos premiers pères à nous, peuples civilisés, comme de la tentative faite, il y a quelques années, pour démontrer que le sens des couleurs et des sons s'était modifié depuis les temps homériques, et qu'Achille ou Hector ne discernaient que deux ou trois teintes là où notre oeil en aperçoit cinq ou six. Il a fallu que l'évolutionnisme renonçât enfin à ce corollaire apparent de ses théorèmes ou de ses axiomes capitaux; et ceux-ci n'y ont rien perdu de leur force.

M. Colajanni appuie son hypothèse sur des faite tels que ceux-ci : il connaît un gentilhomme sicilien qui, d'une exquise sensibilité pour les maux des personnes de sa caste, est profondément insensible aux souffrances des roturiers. Mais je connais aussi force paysans, qui, 
très honnêtes avec d'autres paysans, ne cherchent qu'à rouler le bourgeois; je connais force gens passionnés en politique qui, très dévoués à leurs coreligionnaires politiques, commettraient sans scrupule toutes les indignités contre leurs adversaires. En cela tous ces gens là, il est vrai, rappellent les peuples primitifs, par la concentration intense de leurs affections et de leur moralité dans un champ étroit. Mais ce n'est pas là de l'atavisme ; c'est chose sociale et nullement vitale, une persistance coutumière et traditionnelle, assez fréquente dans un milieu insulaire et clos, tel que la Sicile ou la Corse, des sentiments d'un autre âge.

\section{III}

$\underline{\text { Retour à la table des matières }}$

Cela dit, examinons de plus près l'atavisme moral conçu par $\mathrm{M}$. Colajanni comme l'explication unique de toute criminalité. Il ne se borne pas, en effet, à expliquer de la sorte, comme Mante-gazza, certains crimes étranges et archéologiques d'aspect, «blocs erratiques moraux »; il prétend expliquer pareillement tous les genres de délits, même les plus modernes, malgré la difficulté de rattacher notre corruption d'ultra-civilisés, nos abus de confiance, nos escroqueries raffinées, nos attentats à la pudeur, à l'âge de la pierre éclatée ou même polie. En outre il entend l'atavisme (p. 476) dans le sens rigoureux, biologique du mot. Il ne veut pas qu'on se contente de voir dans le criminel, avec M. Lacassagne, un simple arriéré moralement, un traînard de l'armée civilisée en marche. Il admet cependant que le criminel provient, en général, des milieux retardataires ; mais, ajoutet-il, les penchants criminels sont l'exception, même dans les classes les plus inférieures de nos sociétés, et c'est de cette exception qu'il faut rendre compte par l'hérédité à longue portée.

Or, je comprendrais qu'on eût recours à cette interprétation des faits s'il ne s'en présentait pas d'autre, plus naturelle et plus vraisemblable, je veux dire celle de la tératologie morale. Dons son bel ouvrage sur l'Hérédité psychologique, M. Ribot cite comme 
exemple des faits contraires à la règle de l'hérédité, et, par suite, de l'atavisme, l'apparition soudaine, dans une famille honnête et normale, de certaines anomalies morales, de vices, de tendances criminelles. Ainsi, où $\mathrm{M}$. Ribot voit se révéler la force novatrice, révolutionnaire même, d'innéité, M. Colajanni n'aperçoit en jeu que la force conservatrice ou plutôt prodigieusement rétrograde de l'hérédité la plus renforcée. Lequel des deux a dit vrai ? A priori, il se peut qu'on donne raison à l'un comme à l'autre ; combien de fois les novateurs n'ont-ils fait que rééditer le passé ! Que d'inventions réinventées en ce monde ! Il est possible que les causes tératologiques aient simplement servi à dégager l'influence atavistique. Quand, par suite d'une digue, à laquelle on peut comparer une cause tératologique, obstacle apporté au cours de l'évolution, un fleuve est empêché de couler dans son lit actuel, il se remet quelquefois à couler dans son ancien lit, même abandonné depuis des siècles. Quand, par suite d'une famine, certaines classes pauvres cessent de pouvoir manger du froment, leur nourriture nouvelle, elles se remettent à manger du seigle ou du maïs. Quand, après une guerre, tous les ponts d'une rivière ont été détruits, on revient aux anciens bacs. Ici, et dans tous les exemples de ce genre qu'on pourrait citer, il y a quelque chose qui est, socialement, l'équivalent de l'atavisme, c'est-à-dire l'imitation à distance comme l'atavisme est la génération à distance ${ }^{1}$. Mais d'autres fois, il n'y a rien de pareil, malgré des similitudes vagues et trompeuses. Quand, sous l'Empire romain de la décadence, les statuaires ont peu à peu dévié des traditions du grand art, de l'art adulte et consommé, leurs productions de plus en plus grossières, où ils parvenaient de moins en moins, malgré leurs efforts, à reproduire les modèles des maîtres, ont souvent présenté une vague ressemblance avec les ébauches informes de la sculpture archaïque. Est-ce à dire qu'ils aient songé à imiter celles-ci ? Si l'imitation n'a rien à faire ici, n'est-il pas à croire aussi bien, dans le cas où certaines monstruosités anatomiques reflètent confusément quelque caractère propre à l'animalité inférieure ou au passé même de la race, que la génération n'a rien non plus à faire là ?

L'erreur de Lombroso est de prendre fort souvent des faits d'imitation pour des faits d'atavisme. Je n'ai pas été le seul à lui reprocher cette confusion. Je trouve le même reproche développé dans une leçon de M. Manouvrier à l'École d'anthropologie. (Voir cette leçon dans la Revue de l'École d'anthropologie, août 1891). 
La question est donc de savoir si les ressemblances qu'on prétend reconnaître entre les difformités morales des malfaiteurs et l'état moral de nos ancêtres primitifs, sont, prouvées soient-elles, du premier genre ou du second. Admettons même pour un instant qu'elles soient du premier. Encore faut-il avoir égard à une observation que me suggère un passage de Darwin sur les caractères latents des êtres vivants. Nous devons croire, nous dit-il ${ }^{1}$, qu'une grande quantité de caractères susceptibles d'évolution dorment cachés dans chaque être organisé, sorte de panspermie interne qui rend inutile, à vrai dire, l'hypothèse de la réinvention, émise ci-dessus. Ces possibles dont il s'agit ont tous été réalisés à des époques antérieures. Mais il faut un accident, une cause nouvelle, pour déterminer la réapparition de l'un d'eux parmi les milliers d'autres qui ne réapparaîtront jamais. En d'autres termes, parmi tous les atavismes possibles, qui sont innombrables, pourquoi celui-ci et non celui-là ou tel autre s'est-il réalisé ? Voilà ce qu'il importe de préciser. Cet enfant naît cruel, fourbe, imprévoyant, paresseux, et vous dites qu'en cela il ressemble à des sauvages, ses ancêtres supposés. Je le veux bien; mais, parmi ses ancêtres, il ne compte pas que des sauvages féroces, perfides, incapables de prévoyance et de travail; il compte aussi, et en plus grand nombre peut-être, des sauvages doux, intelligents, francs, laborieux, des barbares navigateurs intrépides ou héroïques guerriers et vassaux fidèles, ou paisibles laboureurs. Pourquoi ressemble-t-il aux pires de ses aïeux et non aux meilleurs? Pour des raisons où l'hérédité assurément n'entre pour rien.

Mais de quel droit, au surplus, verrions-nous dans une monstruosité morale qui rend criminel, c'est-à-dire insociable, un spectre évoqué de nos sociétés antiques ou préhistoriques ? L'interprétation tératologique a sur l'interprétation atavistique bien des avantages, celui-ci, entre autres, d'expliquer très simplement pourquoi la criminalité native est plus fréquente dans les classes pauvres et incultes. Il faut y voir une suite des conditions défavorables où se produit dans ces milieux la grossesse des femmes. Les recherches savantes de Marro ${ }^{2}$ l'ont conduit, on le sait, à donner une origine intra-utérine à la plus grande partie des anomalies présentées par les

Variation des animaux et des plantes, tome 2, p. 64.

2 Caratteri dei delinquenti. 
malfaiteurs. D'autre part, « Isidore Geoffroy Saint-Hilaire, nous dit M. Ribot, constate que les femmes des classes pauvres, obligées de se livrer, lors même qu'elles sont enceintes, à de pénibles travaux, et les femmes non mariées, forcées de dissimuler leur grossesse, donnent bien plus souvent que d'autres naissance à des monstres. " Une objection très juste que $\mathrm{M}$. Féré oppose à l'hypothèse de l'atavisme physique me paraît s'appliquer aussi bien, et mieux, à l'atavisme moral. «Il faut remarquer, dit-il, que les traces de dégénérescence, telles que manifestations névropathiques ou vésaniques, scrofules, etc., qui se rencontrent si souvent chez les criminels, n'ont rien à faire avec l'atavisme, qu'elles semblent plutôt exclure, puisqu'elles sont incompatibles avec une génération régulière. » Je dirai de même : la bassesse, la cruauté, le cynisme, la lâcheté, la paresse, la mauvaise foi, qu'on observe chez les criminels, ne sauraient leur provenir de la majorité de nos communs ancêtres primitifs ${ }^{1}$, puisqu'elles sont incompatibles avec l'existence et la conservation séculairement prolongée d'une société régulière, aussi incompatibles assurément avec cette santé et cette fécondité sociales que les névroses et les scrofules peuvent l'être avec la santé et la fécondité physiologiques.

M. Colajanni semble compter un peu, pour appuyer son hypothèse de l'atavisme moral, sur une autre hypothèse émise par M. Sergi, celle de la formation du caractère moral en chacun de nous par une superposition d'habitudes et de tendances accumulées comme des alluvions successives par les innombrables générations de nos ancêtres, puis, après notre naissance, par les événements de notre vie. Dans cette théorie, les tendances de plus antique date sont aussi les plus fondamentales et les plus fixes; ce sont elles, par suite, qui sont remises à nu quand des causes accidentelles ont aminci ou enlevé, comme il arrive chez les grands criminels, les couches supérieures et relativement, récentes. On reconnaît sans peine dans cette stratification du caractère de même esprit qui a suggéré à $M$. Ribot sa stratification de la mémoire, opinion du reste tout autrement

Distinguons bien d'ailleurs entre l'hérédité ordinaire et l'atavisme. Le dégénéré, moral en physique, est en général un héréditaire (voir à ce sujet la thèse du Dr Legrain sur la folie héréditaire des dégénérés); en remontant dans sa parenté rapprochée, on découvre presque toujours l'explication de ses anomalies; et c'est précisément pour cela qu'il est utile d'enjamber ses parents et je ne sais combien d'autres générations pour demander à des ancêtres fabuleux 1e secret de ses dépravations. 
fondée en fait. Pour apprécier à leur véritable valeur, réelle à coup sûr, ces essais de stratigraphie psychologique et d'autres semblables, il convient d'abord de se rappeler une remarque importante de Darwin. Dans l'ouvrage déjà cité ${ }^{1}$ il prouve que la fixité des caractères n'a aucun rapport avec leur ancienneté. « Lorsqu'un caractère surgit, dit-il, il peut quelquefois se fixer très fortement d'emblée ». S'il en est ainsi, la loi de M. Sergi me paraît atteinte à sa racine. En second lieu, la géologie du moi, pour ainsi parler, serait décevante si elle ne tenait compte d'un élément essentiel et prépondérant, je veux dire de cette harmonie profonde qui combine en nous les traits psychologiques, d'ailleurs très multiples et très fortuitement rassemblés, qui nous constituent. Les couches successives de la mémoire ne sont pas juxtaposées à demeure comme des terrains; elles sont à chaque instant soulevées et combinées par la finalité instinctive qui les fait servir à nos desseins spirituels. De même, nos habitudes et nos tendances, ces souvenirs organiques d'anciennes actions, ne sont pas rapprochées en nous comme les feuillets d'un livre, et notre caractère n'est pas seulement la collection de ses souvenirs-là ; il est leur emploi d'une certaine espèce, caractérisée par la nature des fins innées ou acquises qui prédominent en nous, et secondairement des convictions majeures qui s'associent à elles pour leur tracer la route. Or, c'est par la nature de nos plaisirs et de nos douleurs propres, c'est-à-dire de nos sensations sui generis, que cette nature de nos fins innées ou acquises est déterminée; et, dans la spécification de nos plaisirs ou de nos douleurs, notre tempérament individuel, formé d'une combinaison d'apports héréditaires où l'élément atavistique est absolument noyé, joue le rôle prépondérant. Entre parenthèses, ce que je viens de dire explique pourquoi le mot caractère a été bien choisi pour désigner notre genre de volonté, plutôt que notre genre d'intelligence. Notre genre d'intelligence est déterminé, il est vrai, par la nature de nos croyances fondamentales, comme notre genre de volonté par celle de nos désirs principalement. Mais la source de nos croyances est presque entièrement objective, extérieure à nous, et leur nature, par suite, dépend surtout des informations accidentellement offertes à notre esprit, tandis que la source primitive de nos désirs est subjective, jaillie des profondeurs de notre organisme particulier. Il n'est donc rien qui nous individualise et nous caractérise à ce point.

Variation des animaux et des plantes, t. 2. p. 65. 


\section{IV}

$\underline{\text { Retour à la table des matières }}$

M. Colajanni nous présente, en outre, sa thèse de l'atavisme moral comme se rattachant à la prétendue loi générale d'un parallélisme entre la phytogenèse et l'ontogenèse, entre la série des transformations de l'espèce ou de la race à laquelle un individu appartient et à la série des phrases embryonnaires ou infantiles qu'il est obligé de parcourir avant d'atteindre sa forme définitive. Effectivement, on nous dit que, par divers traits psychologiques, et surtout moraux, le criminel ressemble à l'enfant; et, s'il était vrai que l'enfant, conformément à la loi ci-dessus, fût la reproduction abrégée, atténuée et temporaire, de nos premiers pères, on pourrait dire la même chose du criminel. Mais d'abord, que vaut la loi dont il s'agit? Bien que Broca en ait fait jadis une critique très sagace, elle paraît s'appuyer sur un nombre respectable de faits. Toutefois ne sont-ils pas susceptibles d'une autre explication? La nécessité qui oblige l'ovule fécondé, pour devenir l'être adulte en n'importe quelle espèce végétale ou animale, à traverser un certain nombre minimum de phases intermédiaires, estelle comparable à la routine d'une mémoire d'écolier qui ne saurait se rappeler le dixième vers d'une fable sans avoir préalablement récité les neuf premiers; ou n'est-elle pas plutôt analogue à la raison géométrique et mécanique, impérieuse mais mystérieuse au fond, qui force un corps, pour se déplacer, à se mouvoir? Je m'explique. Pourquoi, s'il vous plaît, un corps qui veut substituer à son emplacement $\mathrm{A}$ un autre emplacement $\mathrm{M}$ ou $\mathrm{N}$, est-il dans l'impossibilité de disparaître brusquement en $\mathrm{A}$ et d'apparaître aussitôt en $\mathrm{M}$ ou $\mathrm{N}$, et doit-il obligatoirement parcourir au moins toutes les positions intermédiaires $\mathrm{B}, \mathrm{C}, \mathrm{D}$, etc. minimum qui s'appelle une ligne droite joignant le point $\mathrm{A}$ au point $\mathrm{M}$ ou $\mathrm{N}$ ? Je n'en sais absolument rien ; mais je sais qu'on nomme espace la collection complète et systématisée de ces minima, de ces séries de positions rationnellement enchaînées les unes aux autres comme par une sorte de déduction 
rigoureuse et inexplicable, de logique physique. Quoi qu'il en soit, quand un certain nombre de mobiles, les uns après les autres, à partir d'un même point $\mathrm{A}$, visent le même point $\mathrm{M}$, s'ils suivent à peu près le même chemin, ce n'est pas que les suivants imitent les précédents ou soient en rien influencés par l'itinéraire de ceux-ci; c'est qu'une nécessité commune et supérieure s'impose à tous et les contraint de marcher selon des directions plus ou moins parallèles. Tout ce que peuvent faire les suivants, s'ils veulent utiliser l'expérience des précédents, c'est d'arriver au but par un chemin de plus en plus rectilinéaire; et c'est précisément ce que semble faire la vie embryonnaire dans son évolution où se répète vaguement, en s'y abrégeant beaucoup, l'évolution de l'espèce. Mais, au-delà d'un certain degré marqué par la rectilinéarité complète, l'abréviation devient impossible. Est-ce qu'il y aurait aussi des rectilinéarités évolutives pour ainsi dire, des minima d'états vivants à traverser par force, par une nécessité rationnelle et nullement par une simple moutonnerie traditionnelle, pour passer en droite ligne, pour ainsi dire, de l'état ovulaire à l'état définitif? Est-ce que la Vie conçue dans sa plénitude, comme la totalité de toutes les formes organiques réelles et possibles et le système complet de leurs rapports nécessaires, ne serait pas une sorte d'espace invisible, de Raison et de Logique cachée, comme la Géométrie et la Mécanique ? Ce n'est qu'une vue de l'esprit, il est vrai ; mais la répétition prétendue de la phytogénèse par l'ontogenèse n'est aussi qu'une conjecture; et, entre les deux, entre celle qui fait de l'évolution vivante un enchaînement, déductif et celle qui en fait un ressassement machinal, laquelle justifie le mieux le labeur immense de la Vie ? - Or, pour revenir à notre sujet spécial, si l'on admet ma manière de voir, il pourrait fort bien y avoir similitude morale de l'enfant et du délinquant, ajoutons même de l'homme du peuple avec nos ancêtres reculés, sans qu'il y eût le moins du monde atavisme.

Mais y a-t-il même similitude ? Non. Spencer se croit autorisé par ses études sur les sauvages encore subsistants, rebut manifeste de l'humanité, à nous tracer de l'homme préhistorique (il dit l'homme et non pas les hommes, comme si tous les hommes s'étaient alors ressemblés) un portrait que notre auteur reproduit sans hésitation. Il nous peint cet homme imaginaire, ancêtre commun par hypothèse de tous les peuples civilisés et de toutes les tribus sauvages, comme "paresseux, vaniteux, imprévoyant à 1 'excès, nerveux, volubile, 
variable en ses émotions, fixe en ses habitudes, opposé au changement, étourdiment cruel et, avant tout, impulsif. " Acceptons ce signalement pour un instant. Mais en quoi s'applique-t-il aux plèbes de notre âge ou d'une époque historique quelconque? Partout, au contraire, le vrai peuple est laborieux, modeste, économe (c'est-à-dire très prévoyant), musculeux et point nerveux, taciturne, aussi tenace dans ses sentiments que dans ses coutumes, et inoffensif tant qu'on ne l'irrite pas. S'il est, comme les sauvages, religieux et respectueux envers les autorités, double reproche que M. Colajanni lui adresse, on ne peut en tous cas le rapprocher du délinquant par ces deux côtés. Celui-ci, comparé aux gens honnêtes de sa classe et de son pays, est remarquablement irréligieux et irrespectueux. - Passons à l'enfant. En vérité, nos anthropologistes criminels ne sont pas tendres pour lui, et le noir portrait qu'ils nous en tracent ne rappelle en rien un tableau de Greuze. Sa petite âme est, à leurs yeux, une mixture de tous vices et de tous crimes en herbe. Si cet âge est sans pitié, comme l'a dit le plus mauvais père de tous les poètes, ils le lui rendent bien. Pourtant, ce qui me frappe le plus en observant les enfants, c'est l'extrême dissemblance de leurs caractères. J'en connais beaucoup qui n'ont nulle inclination au mensonge ni au larcin, qui sont doux pour les bêtes, peu portés à la colère, etc. Ils sont égoïstes, c'est vrai, mais leur égoïsme irréfléchi, qui a un si grand charme de naturel, ne serait-il pas l'expression de leur premier devoir vital, de leur vraie moralité à eux, qui consiste à croître aux dépens d'autrui ? L'explication de leur turbulence, de leur légèreté, de leur insouciance, dites, si vous voulez, de leur gracieuse ingratitude habituelle, et de leurs autres prétendus défauts ordinaires, nous est trop clairement fournie par l'utilité fonctionnelle de ces traits psychologiques pour qu'il y ait lieu d'invoquer ici l'hypothèse de l'atavisme. On peut admettre cette hypothèse quand il s'agit d'expliquer des organes ou des caractères jadis utiles, devenus inutiles, et reproduits machinalement par une réminiscence sénile de la vie; on ne le peut à propos d'organes et de caractères nécessaires, indispensables ${ }^{1}$. Supposez un enfant tranquille, rassis, serviable, toujours préoccupé des intérêts d'autrui, soucieux de l'avenir, "vertueux et sensible », et vous verrez que tant de préoccupations l'empêcheront de grandir. Par l'égoïsme de l'enfant,

Il est à noter que M. Pérez, avec sa compétence hors ligne, se prononce contre l'explication atavistique du moral de l'enfant. 
ou plutôt par la limitation très étroite du cercle de sa sympathie, s'exprime et se satisfait le besoin d'expansion vitale, source de toute fécondité et de toute générosité même sociale, aussi bien que par l'abnégation et le dévouement de l'homme fait. Dans un organisme encore grandissant, ce besoin fondamental trouve à se satisfaire par sa croissance même, sans génération au dehors; et cela est vrai des organismes sociaux eux-mêmes, des petits États forcés de grandir pour durer, des tribus sauvages ou barbares d'abord, qui révèlent sous le nom de patriotisme un égoïsme collectif(je ne dis pas individuel) toujours si nécessaire, mais plus nécessaire à leurs débuts que plus tard, et perdant de son intensité âpre à mesure que leur action extérieure peut se substituer à leur élaboration intérieure, en la continuant. Inversement, l'égoïsme des vieillards se justifie de la même manière, puisque, dans un organisme en voie de déclin, toute l'énergie subsistante doit s'employer à se retenir sur cette pente, conformément au même vœu d'expansion vitale, qui se transforme ici en vœu stérile de non-refoulement vital. Entre les deux termes opposés de l'enfance et de la vieillesse, l'âge adulte, pour les sociétés comme pour les individus, est l'heure prédestinée des beaux dévouements à autrui, des colonisations et des abnégations fécondes. Les lecteurs de Guyau reconnaîtront dans le besoin d'expansion vitale dont je parle l'idée-mère de ses beaux travaux.

Pour bien comprendre les traits moraux et intellectuels de l'enfant, il faut les comparer aux traits similaires présentés par tous les petits de l'animalité, surtout de l'animalité supérieure. Ce que dit Agassiz quelque part (dans l'Espèce), que le sexe féminin, depuis le premier jusqu'au dernier échelon du règne animal, reste semblable à lui-même et frappe d'un même timbre psychologique, partout reconnaissable à sa grâce propre, les femelles de tous les animaux, cette remarque très juste s'applique aux petits de tous les animaux. À côté du " féminin éternel » et universel, il y a l'enfantin non moins éternel, non moins universel. Petits chiens, petits chats, petits singes, petits éléphants, poulains, ânons, etc.. tous ont, et doivent avoir, la même étourderie, la même frivolité, le même amour du jeu, les mêmes caprices où leurs forces s'exercent. Plutôt que de l'atavisme, n'y a-t-il pas du prophétisme pour ainsi dire dans leur genre de vie ? Comme le petit chat joue à la souris et le petit chien de chasse arrête, ainsi l'enfant se prépare, par ses façons de jouer, aux guerres, aux alliances, aux 
marchés de l'homme fait. Voit-on se dépenser, après tout, plus d'égoïsme dans une cour de collège que dans une assemblée parlementaire ou dans un champ de manœuvres? Je n'en sais rien ; mais le trait qui me paraît dominer chez l'enfant civilisé, c'est sa sociabilité, son horreur de la solitude.

Il n'a pas de plus grand plaisir que de se réunir à ses camarades, de former avec eux des groupes et des associations hiérarchiques, avec un embryon de discipline. Si l'on veut qu'il reflète le passé de la race, eh ! bien, soit; il en résulte que nos ancêtres ont été extrêmement sociables, disciplinés, gais, amis des fêtes, point féroces ni larrons ${ }^{1}$. La criminalité infantile est infiniment faible, M. Colajanni est forcé de le reconnaître et embarrassé pour l'expliquer. Si les enfants étaient aussi mauvais qu'il le suppose, ils pourraient facilement, malgré leur faiblesse physique, grâce à nos armes à feu et à nos engins de toute sorte, et malgré leur crainte des châtiments, qu'on nous dit excessive, ce qui se concilie mal avec leur imprévoyance jugée extrême, tuer les personnes qu'ils détestent ou voler avec effraction et escalade ce qu'ils convoitent. La preuve qu'ils le pourraient c'est qu'en fait certains enfants, ni plus ni moins intelligents ou rebutes que d'autres, commettent des meurtres audacieux, des incendies. Mais il est certain, et digne de remarque, que cette précocité criminelle, quand elle se révèle de la sorte, a le plus souvent des causes sociales et non physiologiques. C'est en effet dans les milieux urbains très denses et très civilisés, non ruraux et arriérés, que la criminalité des mineurs va en augmentant. A Paris elle croît d'une manière effrayante.

Dans son ouvrage si substantiel sur les Criminels, le Dr Corre observe que chez les races non civilisées, l'enfant naît remarquablement intelligent et bon, moralement supérieur à ses parents. L'hypothèse de l'atavisme moral aurait ici pour conséquence de nous faire croire à la bonté, à l'intelligence, à la moralité des premiers ancêtres de ces races. 
Reste la question principale de savoir si, mieux que les plèbes et les enfants, les délinquants ressemblent aux sauvages, nos ancêtres présumés. On ne peut douter que le délinquant rural par excellence, le, brigand, si peu semblable d'ailleurs au délinquant des grandes villes, ne rappelle à quelques égards le sauvages spencérien. Encore faut-il se demander ici, avant d'invoquer l'atavisme, si les traits moraux qu'on remarque chez le brigand, et qui sont chez lui des vertus professionnelles, sont innés ou acquis. J'objecterai donc à M. Colajanni l'observation très fine qu'il fait (p. 227), en réponse à Lombroso, relativement à l'insensibilité physique et morale des malfaiteurs. Il y voit, comme dans l'insensibilité du chirurgien aux douleurs de ses patients, l'effet graduel d'une longue pratique criminelle, et non sa cause. Mais avant tout, il importe de vérifier si l'esquisse que Spencer nous trace de l'homme primitif en général convient en particulier à ces hommes primitifs qui ont tressé le premier berceau de nos sociétés civilisés.

Si nous voulons nous faire une idée de nos ancêtres, au point de vue moral et intellectuel, qu'avons-nous besoin d'aller fonder nos inductions sur les dépravations et les superstitions grossières des sauvages actuels? ${ }^{1}$ Pourquoi ces êtres stupides ou méchants, pourquoi même les meilleurs d'entre eux, dont l'inaptitude au progrès est rendue manifeste par leur persistance séculaire dans la sauvagerie, par leur évanouissement devant la civilisation, nous représenteraient-

«Les hommes préhistoriques d'après Bagehot, devaient avoir des sentiments et des impulsions que les sauvages actuels n'ont pas ; certains restes d'instincts qui les aidaient dans la lutte pour l'existence se sont effacés à meure que la raison est venue. Des faits journaliers nous montrent encore cette influence de la raison sur l'instinct. » Guyau, Problèmes de l'esthétique contemporaine p. 138). S'il en est ainsi, pourquoi l'instinct moral, n'aurait-il pas été l'un des instincts nécessaires à la pose des premiers fondements de sociétés, plus tard dissous, je ne dis pas par la raison quand il s'agit de sauvages, mais par les calculs de l'égoïsme développé dans la guerre perpétuelle et sans merci ! 
ils les premiers promoteurs des progrès qui ont abouti à nous ? Pour connaître ceux-ci, adressons-nous directement à ces groupes nombreux de savants qui étudient leurs vestiges de toutes sortes, qui retrouvent leur âme dans leurs tombes et leurs temples fouillés, dans les racines de leurs idiomes rapprochés et comparés, dans leurs mythes, leurs coutumes, confrontés curieusement. Consultons à ce sujet les archéologues de la Langue ou de la Religion, ou du Droit, ou de l'Art; tous s'accorderont à doter nos plus lointains aïeux de pitié et de justice, de mansuétude et d'activité laborieuse, en même temps que de bravoure et de fermeté. Qu'ont rencontré de plus primitif M. de Laveleye et Sumner-Maine au fond de nos institutions juridiques européennes ? Une organisation toute communiste de la propriété, ce qui suppose essentiellement une mutuelle sympathie, une disposition à la confiance et à la fraternité, conditions indispensables de tout communisme analogue. Aussi M. Letourneau, ${ }^{1}$ témoignage non suspect, signale-t-il chez toutes les tribus pastorales ou agricoles qui vivent ou vivaient en état de communauté, chez les Peaux-Rouges par exemple, chez les Gropas et les Koupnis d'Asie, " le développement de sentiments altruistes » la probité instinctive et la douceur des mœurs. "Les Koupnis, nous dit-il, ont, à quelques pas de leurs villages, dans une position abritée, des greniers communs, où l'on rassemble tout ce qui est considéré comme ayant de la valeur en denrées, provisions, etc. Ces magasins sont dépourvus de protection, néanmoins il est sans exemple qu'on y commette un larcin, même en temps de disette ». Dans un voyage de découvertes aux origines de la famille dans nos races élevées, qu'a trouvé M. Fustel de Coulange ? Une intensité de vie domestique et religieuse, une énergie de vertus patriarcales, de piété filiale, de justice élémentaire, qui excitent son admiration, et sans lesquelles n'eût jamais été possible ni concevable le foyer antique, ni plus tard la cité antique ; n'a-t-il pas fallu l'amour du père poussé jusqu'à l'adoration pour transformer sa tombe en autel et son souvenir en culte sacré ? ${ }^{2}$ Demandez aux sinologues ce qu'ils pensent des anciens chinois, aux égyptologues ce qu'ils pensent des plus anciens égyptiens, à M. d'Arbois de Jubainville ce qu'il pense

Voir son Évolution de la propriété, p. 67, 134 et ailleurs.

2 Voir ce que dit M. Fustel de Coulanges dans la Cité antique sur l'antique morale de la famille. Il faut tenir compte du parti-pris, trop exclusif, de l'auteur. Assurément nos premiers aïeux souvent en guerre ou en chasse guerrière, ont connu et pratiqué d'autres devoirs que les devoirs de la famille. 
des plus anciens Celtes, à Tacite, à Homère, à la Bible ce qu'il faut penser des anciens Germains, des anciens Hellènes, des anciens Hébreux, au point de vue de la moralité ; ils vous répondront en vous citant des échantillons d'activité, de constance, de loyauté, d'empire sur soi ou de sacrifice de soi, auxquels vous trouverez difficilement rien à comparer parmi nous. Le témoignage des philologues, puisé à des sources tout autres, viendra confirmer le leur: celui de Pictet, entre mille, dans ses Origines indo-européennes ${ }^{1}$.

Certainement si l'on admettait les théories de Morgan et de MacLennan, d'ailleurs assez contradictoires entre elles, sur la famille primitive, si l'on accordait à ces auteurs, sans nulle preuve, que la promiscuité la plus absolue aurait régné à l'origine, chose exceptionnelle même chez les bêtes vivant en société, et que le rapt aurait été la première forme du mariage chez nos pères, l'infanticide des petites filles la première forme du sentiment maternel ou paternel ; si toutes ces monstruosités étaient gratuitement acceptées, il faudrait bien croire à l'immoralité native de nos ancêtres. Mais ces théories me semblent avoir été si complètement réfutées, par M. Sumner-Maine notamment, et plus récemment par Starcke dans sa Famille primitive, que je crois pouvoir les écarter sans réponse. Je renvoie le lecteur aux Études sur l'histoire du droit, du premier de ces deux auteurs, où ils trouveront tout un chapitre magistral consacré à prouver par une accumulation de documents des plus solides, empruntés aux races supérieures les plus diverses, que la «famille patriarcale» a été le point de départ commun, le seul commencement connu de toute civilisation, - je ne dis pas, il est vrai, de toute évolution sociale, et c'est une distinction importante dont l'oubli pourrait fausser la thèse de Maine. Cette toute-puissance du pater-familias antique, hindou, romain, grec, slave, celte, germain, ajoutons chinois, - complétée par l'égalité de tous ses sujets et la démarcation nette, sorte de fossé de fortification, creusé entre eux et le reste du monde, même parent, par l'idée de l'agnation, coexistait avec la communauté de village et ses règles compliquées. Cette communauté était une association de

Quant aux archéologues de l'âge de la pierre polie ou éclatée, Ils ne nous apprennent rien de précis sur la moralité de ceux qui ont pu être nos ancêtres. Toutefois il est permis, comme l'a fait M. Joly dans son livre Intitulé Le Crime, de puiser dans les faits amassés par eux quelques raisons de croire que les hommes de ces périodes géologiques n'étaient dépourvus ni de pitié ni d'équité. 
familles entre lesquelles le communisme régnait, (quoique la chose soit discutable et discutée) mais dont chacune à part était régie patriarcalement. Or, soit pour ce communisme, soit pour cette vie patriarcale, la condition préalable et indispensable était une haute dose de moralité innée. Avant d'accuser de dureté le régime de la patria potestas et de l'agnation, on doit songer que le père de famille avait commencé par être fils de famille et, comme tel, plié aux habitudes de respect, de vénération, de dévouement domestique. Ce qu'il y a de dur et de cruel en apparence dans la constitution de la famille patriarcale n'est que l'effet de son caractère défensif et militaire : elle doit donner tout pouvoir à son général, elle doit se clore hermétiquement comme un camp retranché. D'ailleurs quel esprit de solidarité et d'abnégation réciproque ne suppose pas l'égalité des enfants! Quelle docilité affectueuse et respectueuse ne suppose pas la puissance suprême exercée par le père, par le plus vieux, c'est-à-dire par le plus faible, devant lequel tous les forts s'inclinent! Observons qu'avant tout, et dès les plus hauts temps, le pater familias est juge, et juge très juste, si l'on regarde ce qui se passe en Chine et ailleurs où l'équité des tribunaux domestiques est l'objet d'éloges unanimes. Ajoutons que la communauté de village, partout où elle subsiste encore, est exclusive de cette anomalie monstrueuse que nous appelons l'indigent. Ce problème du "paupérisme", sur lequel nous écrivons tant de brochures stériles, n'a reçu jusqu'ici aucune solution égale à celle-là en efficacité. Et, pour que l'homme des âges reculés l'ait découverte et pratiquée, je me persuade qu'il a dû être équitable et compatissant. Quant aux vertus qui consistent dans l'empire sur soi-même, courage, constance, héroïsme de l'ascète indien ou du sauvage torturé, il n'est pas possible de les refuser aux hommes primitifs. Tout au plus peut-on en atténuer le mérite sous le prétexte d'une impassibilité physique à la douleur dont on les dote arbitrairement pour se dispenser de les admirer.

Dira-t-on que, par ces sondages archéologiques, nous ne descendons pas assez bas dans les ténèbres de la préhistoire ? Alors, plongeons tout de suite aux dernières profondeurs, regardons de près l'anthropoïde ou ce qui en subsiste, le grand singe. M. Colajanni est forcé de constater, d'après du Chaillu, Brehm et d'autres observateurs (p. 463) « la pieuse coopération, la mutuelle assistance et l'héroïque abnégation » dont les sociétés simiennes nous donnent d'admirables 
exemples ${ }^{1}$. Et l'on voudrait que les premières sociétés humaines eussent été fondées sur tous les instincts criminels ou vicieux !

Mais ce ne sont pas seulement les singes, ni même les mammifères ni même les vertébrés, ce sont tous les animaux, qui lorsqu'ils s'essayent à la vie sociale, les abeilles, les fourmis, les termites entre autres, pratiquent stoïquement, héroïquement, leurs devoirs, dictés par leur morale aussi rigoureuse que bizarre, et déploient en mille occasions les plus beaux sentiments de fraternité, d'aide réciproque, de courage au poste de combat, ainsi que tant d'autres vertus connues des seuls naturalistes. Qu'on relise les Sociétés animales de M. Espinas et l'on y trouvera à chaque page la preuve de ce que j'avance. $M$. Delboeuf, qui s'est tant occupé de la psychologie des bêtes et qui fraternise continuellement avec des crapauds, des lézards, des couleuvres, fait grand cas de leur bonté et leur prête toutes sortes d'autres qualités. Encore s'agit-il là d'espèces non sociables, mais seulement apprivoisables, car quelle espèce ne l'est? Mais combien, chez les espèces sociables, la même remarque se trouve-t-elle applicable à fortiori! Quoi d'étonnant, après tout, puisque, sans sociabilité préalable, c'est-à-dire sans moralité instinctive, il ne saurait y avoir de société ? En toute espèce sociable, donc, l'individu naît bon et moralisable dès le début. - Mais quelle espèce ne tend, n'aspire à se socialiser? Dans son Système de politique positive, oeuvre de folie peut-être, mais de géniale folie, Auguste Comte revient à plusieurs reprises sur cette importante idée, que l'aspiration à la vie sociale est le voeu de toute vie organique, vœu le plus souvent déçu quand il n'est pas servi par les conditions voulues de bonté, d'esprit d'union et de sacrifice, mais toujours renaissant d'un bout à l'autre de l'échelle animale, jusqu'à ce qu'enfin il se réalise pleinement en nous. Idée confirmée du reste, au-delà de toute prévision, par les travaux

Nous pouvons Invoquer un fait très significatif que M. Colajanni nous fournit lui-même dans une note de la page 388. Le cerveau du foetus humain ressemble à celui des jeunes anthropoïdes. Or, c'est dans cette première phase de sa vie où il ressemble le plus physiquement à l'homme que l'anthropoïde montre aussi « une Intelligence et une douceur assez voisines de celles de l'homme» qualités qu'il perd plus tard à mesure qu'en se développant son cerveau, par une sorte de régression, s'éloigne davantage de la forme humaine. Que peut-on Induire de là, atavistiquement? Que l'ancêtre commun de l'homme et du singe présentait un degré de douceur et d'intelligence, c'est-à-dire de moralité innée d'où le singe s'est écarté Irrémédiablement, et l'homme temporairement dans quelques-unes de ses phases sauvages. 
contemporains, tels que les Colonies animales de M. Perrier. D'autre part, je suis frappé de voir qu'un des penseurs les plus sagaces, un des plus profonds moralistes de ce temps, Guyau ${ }^{1}$, a cru nécessaire de chercher dans le monde vivant les germes et les premiers exemples de la morale pour donner à celle-ci une base objective suffisante. Rien de plus facile si l'on pose en principe que vitalité et socialité c'est même chose au fond, et si, partant de là, on songe au penchant universel, éternel, qui porte tous les êtres vivants, animaux ou plantes mêmes, depuis les végétaux ou les animaux unicellulaires jusqu'à nous, à s'associer pour former soit des organismes simples, proprement dits, soit ensuite ces organismes d'organismes, ces organismes du second degré qu'on appelle des sociétés. Mais ce caractère essentiellement social de tout ce qui est vital, nous ne l'apercevons, dans toutes les espèces autres que les nôtres, que superficiellement et du dehors. Par analogie, nous devons croire que, si nous pouvions pénétrer dans ces États hermétiquement clos à nos observations, nous y découvririons des vertus sœurs de nos vertus. Jugeons des cellules vivantes par leurs actes, et nous ne pourrons nous empêcher de louer leur serviabilité réciproque, leur activité, leur docilité, leur soumission à la règle commune, aux traditions de leur passé, leur profonde honnêteté en un mot. La nôtre est simplement fille de la leur. Et l'on supposerait gratuitement, après cela, sans l'ombre d'une preuve, comme un à priori évident, que l'ancêtre des nations les plus haut placées sur le faîte européen de la civilisation était égoïste, cruel, indisciplinable, paresseux, voleur, incendiaire, anarchiste! Et, quand un individu remarquablement pervers, insociable, naît parmi nous, on invoquerait l'atavisme pour expliquer ce phénomène ! Pour moi, je comprendrais, plutôt l'inverse. Quand dans nos agglomérations urbaines d'égoïsmes et d'utilitarismes en conflit, il surgit un cœur dévoué, noblement généreux, je comprendrais qu'on vît en lui l'image des lointains aïeux dont le sang et la sueur ont fait notre bien-être. L'héroïsme, voilà peutêtre le véritable atavisme moral.

Morale anglaise contemporaine, in fine. 
Gabriel Tarde, Études pénales et sociales (1892)

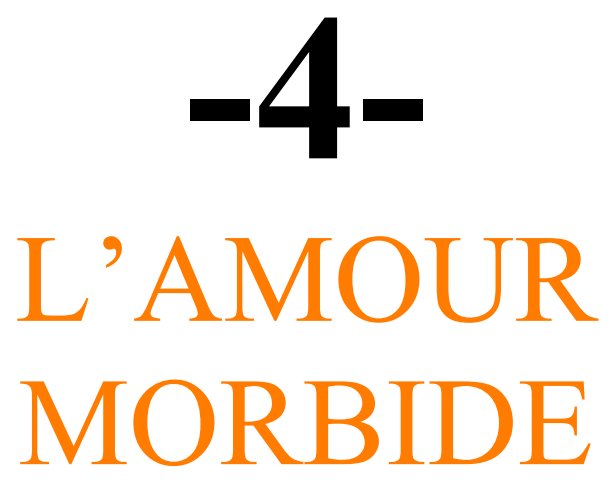

$\underline{\text { Retour à la table des matières }}$

L'amour morbide ! Mais, dira-t-on peut-être, quel est donc l'amour qui n'est pas une maladie? N'est-il point toujours une fièvre qui modifie les battements du pouls, gène ou accélère la respiration, trouble l'esprit? Il nous aveugle sur les défauts de l'objet aimé, il nous montre en lui des beautés imaginaires, et, par cette double hallucination négative et positive, par ce délire compliqué des sens et du cerveau, nous pousse au désespoir, à la ruine, au crime, à la mort. Il nous y pousse, s'il ne nous y précipite pas toujours. Si normal qu'il soit, supposez-le jeune, beau, mutuel, épanoui au soleil du luxe et de l'art, il n'est jamais, après tout, qu'une faim vorace de chair humaine toute vive, une variété d'anthrophagie qui va se développant avec la civilisation; et jamais, en ses accès, il ne fait qu'arrêter tout travail, éteindre toute curiosité, amortir toute noble passion, nourrir un monstrueux égoïsme à deux. L'amoureux, comme le malade, est 
nécessairement paresseux, incurieux, inactif, indifférent à ce qui n'est pas son mal; et n'est-ce pas là le pire des malades, celui qui ne redoute rien tant que de guérir?

Mais, à ceux qui feraient cette objection spécieuse et peu sérieuse contre le titre de cet article, je recommande la lecture du dernier ouvrage de M. Laurent pareillement intitulé ${ }^{1}$. Ils y verront clairement, s'ils l'ignorent, la distance qui sépare l'amour ordinaire de ses extraordinaires aberrations. Je ne range point, parmi ces anomalies amoureuses, la passion exagérée d'un étudiant naïf pour une prostituée de bas étage qu'il veut épouser, ni, en général, les excès de prodigalité, de crédulité, de docilité, où tombe un amant trop enthousiaste. Mais, quand des officiers supérieurs de notre armée s'éprennent d'une vieille proxénète du demi-monde ; quand des hommes d'une situation élevée se font surprendre par la police en train de couper des cheveux de femmes dans une foule parce que leur volupté suprême est le contact de ces nattes féminines; quand d'autres n'ont pas de plus grand plaisir que de baiser des mouchoirs ou des bottines de femmes, ne sent-on pas qu'il n'y a pas à comparer ces extravagances aux plus déraisonnables excès de l'amour de Léandre pour Héro ou de Roméo pour Juliette? Je ne sais pourquoi, dans sa liste d'aberrants, M. Laurent oublie de faire figurer les pédérastes. Même dans son trop rapide historique des maladies de l'amour, il ne mentionne pas l'amour grec. Est-ce avec intention ? La rapide diffusion à diverses époques, la renaissance si fréquente, l'extension si frappante en toutes les sociétés vieillies, des modes de saphisme ou de l'autre méprise sexuelle, lui en auraient-elles imposé ? En aurait-il conclu qu'il pourrait bien y avoir au fond de ces choses dites contre nature, quelque chose de trop naturel au contraire et que la morale seule peut extirper du cœur civilisé ? Ou bien jugerait-il plutôt que ce sont là des cas de tératologie et non de pathologie mentale, des monstruosités plus que des maladies ? Une monstruosité a beau se répandre, elle n'en reste pas moins telle; et, alors même que dans un pays presque tout le monde serait boiteux ou bossu, la bosse ou la claudication ne laisseraient pas d'y être des déviations du type humain. Au reste, la froideur habituelle du pédéraste pour les femmes ou de la lesbienne

L'Amour morbide, par le Dr Émile Laurent, ancien interne à l'infirmerie centrale des prisons de Paris (Paris 1891), petit volume où la solidité de la science se joint à l'agrément du style. 
pour les hommes dénote assurément l'atrophie maladive d'un sens indispensable, et peut être rapprochée d'autres faits analogues, morbides à coup sûr : on a remarqué que les amoureux enragés des statues, dans les jardins publics, sont très froids à l'égard des femmes, ainsi que les adorateurs de certaines beautés ou de certaines particularités féminines détachées du tout. - Mais, d'autre part, il faut se garder de prendre pour des maladies toutes les audaces périlleuses, parfois grotesques, auxquelles la surexcitation de leurs sens entraîne certains individus, notamment ceux qui se livrent à des manœuvres hardies sur les jolies femmes dans une foule compacte. Pendant une audience à laquelle j'assistais et qui avait attiré au fond de la salle (c'était un jour de foire et de pluie) un public nombreux de cultivateurs, une jeune paysanne se retourna tout à coup en apostrophant de la belle façon un garçon de vingt ans, qui déguerpit à toutes jambes. Nous apprîmes qu'il venait d'ébaucher sur elle, à tergo, et depuis un instant, - avec sa demi-complicité peut-être jusque-là ? un attentat des plus étranges en un lieu pareil et en un pareil moment. Était-il fou ? Pas plus que le héros de l'Immortel qui, avec une jeune veuve, profane semblablement le caveau de son mari. Il avait pris l'occasion aux cheveux, n'importe où.

Cependant, en quoi consiste au juste la différence entre l'amour normal et l'amour morbide? Y a-t-il seulement une différence de degré ? Non. J'ai comparé tout à l'heure l'amour à l'appétit. Soit; mais il y a aussi une faim morbide, celle qui, par exemple, pousse des hystériques ou des aliénés à manger du papier trempé d'eau de Cologne, à avaler des immondices, etc. Cette faim-là, si faible qu'elle soit, n'en est pas moins maladive; tandis que la faim d'un naufragé a beau être intense et lui faire dévorer de la chair crue, elle n'a rien que de conforme aux besoins de l'organisme et aux fins de l'espèce. Il y a aussi une haine morbide, par exemple l'aversion injustifiable inspirée par nous à certains originaux qui ne nous connaissent pas mais se mettent à nous détester à cause de la forme de notre nez ou du son de notre voix ou de nos manières. Même très faible, cette antipathie dénote une tare mentale.

Pareillement, entre le normal et le morbide en amour, il y a une différence non pas de degré mais de nature. 
Quelle est-elle encore une fois ? Suivant notre auteur, le caractère distinctif de l'amour normal est d'être l'harmonie d'un besoin et d'un sentiment, d'une impulsion physique et d'une attraction morale. Il y a rupture d'équilibre soit par l'amour platonique et l'érotomanie qui exaltent le sentiment en comprimant le besoin, soit à l'inverse par l'amour purement animal. Le chapitre consacré à ce sujet est intéressant; mais je crains qu'il n'épuise pas la question. Elle est complexe. En fait, la plupart de nos assassins urbains et de leurs maîtresses s'aiment harmoniquement, au sens où notre auteur entend ce mot : l'objet qui les charme répond à la fois, et à merveille, par sa lascivité ou sa robustesse de formes, à leurs besoins d'orgie, et, par sa perversité, par ses vices hardis, à leurs sentiments immoraux. L'accord est parfait dans la musique amoureuse de ces cœurs de coquins. S'ensuit-il que leurs passions soient normales, et que le succès exorbitant de certaines femmes médiocrement jolies mais vicieuses, et précisément parce qu'elles sont vicieuses, auprès de quelques déséquilibrés ou dégénérés inférieurs ou supérieurs, n'ait rien de pathologique?

Il y a, je crois, à distinguer ici les conditions non seulement physiologiques et psychologiques, mais encore morales et sociales de l'amour correct. Et pareillement les maladies de 1'amour sont de deux sortes : les unes physiques, les autres sociales. Ces dernières éclosent dans toutes les sociétés déclinantes, où souvent ce qu'il y a d'antisocial dans l'âme d'une personne est ce qui passionne en secret pour elle, où les excentriques se disputent la main des vitrioleuses ou empoisonneuses acquittées. L'amour vraiment normal, par suite, très rare, je dois l'avouer, du moins à l'état de normalité parfaite, est celui où non seulement les fins vitales de la génération et de la pureté des races, mais les fins sociales de la grandeur patriotique, de la conservation familiale, de la pureté des mœurs, sont poursuivies ensemble. Or, à quelle condition ces deux sortes de fins s'accordentelles ? Elles s'accordent quand l'objet aimé : 1• est, non pas un simple fragment d'une personne - son oeil, sa main, son oreille, ou même ses formes corporelles en entier, détachées de son être mental - mais toute cette personne, sous son double aspect psychique et physique, et, 2 quand, en elle, ce ne sont pas ses facultés anti-sociales ou ses fonctions anti-physiques qu'on aime mais bien les formes et les 
penchants les plus propres à perpétuer, à enrichir le double héritage du passé, à accroître la prospérité de la famille et de la nation.

Sans doute, même dans le cas le plus normal, il arrive souvent que l'amour s'attache de préférence à tel ou tel côté de la personne chérie, ou, plus souvent même, qu'il en fasse le tour par une sorte de gravitation amoureuse. La constance en amour est rarement autre chose qu'un voyage autour de l'amie, un voyage d'exploration et de découvertes toujours nouvelles, en somme, une inconstance circulaire qui revient sur soi jusqu'à épuisement de force. Il est de fait que l'amant le plus fidèle n'aime pas deux jours de suite la même femme de la même façon. Mais, en ces variations mêmes, tournantes et continues, se révèle l'attrait central et total qui les anime, et, pour être morbide, l'équilibre n'est pas moins réel. - Je sais bien aussi que rarement l'amour entre au cœur par l'éblouissement d'un groupe complet de perfections où rien ne détonne; d'ordinaire, nous mettons un certain temps, après avoir vu plusieurs fois une femme dont nous devons être un jour follement épris, à passer par dessus les imperfections qui nous déplaisent en elle, et à démêler un détail d'elle qui nous frappe, nous revient sans cesse, nous poursuit. C'est son oreille, par exemple, c'est la ligne de ses sourcils, c'est la volute de sa lèvre supérieure ou une singularité légère de son tour d'esprit. " $\mathrm{Ce}$ trait de beauté nous fixe, nous détermine », dit excellemment $\mathrm{La}$ Bruyère. Mais prenons garde d'assimiler ce fait habituel aux phénomènes exceptionnels présentés par les fétichistes de l'oreille, du nez, de la main, ou du vice. En effet, ce «trait de beauté » que nous saisissons n'est que le bout par lequel nous nous mettons à dévider aussitôt tout nu écheveau de charmes imaginaires ou cachés qui se révèlent à nos yeux; et bientôt, transfigurée, la personne est toute aimable de pied en cap. Illusion, il est vrai, mais illusion aussi nécessaire que décevante, plus féconde que toutes les vérités; et si l'on veut l'appeler délire et folie, j'y consens, mais qu'on nomme alors délire et folie aussi bien toutes les illusions non moins profondes et beaucoup moins douces qui servent d'assises fondamentales aux sociétés, avec force mensonges.

Il est à remarquer du reste que, dans nos jugements sur les femmes inspirés par l'amour que j'appelle normal ou plutôt par l'aptitude à ressentir cet amour, nous nous accordons assez bien, du moins dans 
les limites d'une même couche sociale et d'un même pays. Parmi les innombrables combinaisons de contours et de teintes où se joue le génie intérieur de chaque race humaine, il en est un petit nombre qui s'approchent de l'idéal de beauté latent dans le cœur des hommes; et la preuve que cet idéal n'est pas de pure fantaisie, qu'il a sa raison d'être générale et non simplement individuelle, c'est que, dans les mêmes milieux sociaux ce sont toujours les mêmes femmes qui font retourner et tourner toutes les têtes. En cela, donc, effet sans doute de l'hérédité combinée avec l'éducation et la suggestion ambiante, les membres d'une même société se ressemblent fort. - Au contraire, l'amour morbide est suscité par les objets les plus divers; et ce qui excite le plus tel aberrant laisse totalement froids tous les autres. Autant d'aberrants, autant d'aberrations. Ce que chacun d'eux nomme beauté, ses collègues l'appellent laideur.

Autre observation. Par le fait même que l'amour normal, en sa complexité compréhensive, embrasse la plénitude de son objet, il affecte l'amant tout entier, âme et corps, aspirations et appétits. Il n'en est pas ainsi de l'amour morbide. J'emprunte à M. Laurent qui l'a emprunté lui-même aux docteurs Charcot et Magnan, l'exemple de ce détraqué qui, depuis son enfance, est obsédé de temps en temps par la passion érotique des clous de souliers de femme, et qui «à 18 ans, était agité par un frémissement voluptueux lorsqu'en passant devant les boutiques de cordonniers il voyait mettre des clous à des chaussures de femmes ». Souvent, « en dehors de toute excitation, il voit ses idées se présenter à son imagination. Il tâche de les chasser; alors elles le harcèlent comme des furies. » La surexcitation cérébrale va quelquefois jusqu'à produire des hallucinations. C'est surtout dans les moments où il lutte contre ses pensées et contre les entraînements qui les accompagnent; il lui semble alors qu'un second être lui est juxtaposé et lui fait entendre, par des paroles qui lui retentissent dans le cerveau, que toute résistance est inutile. .. Quand il a succombé, et que, désespéré, il prend la résolution énergique de ne plus céder, il croit entendre, toujours dans son cerveau, comme une voix qui lui fixe le jour où il cédera de nouveau. Lorsque ce jour approche, il redouble de précautions pour éviter tout ce qui pourrait aider à sa chute; il y met de l'amour-propre; c'est comme un duel entre l'être étranger et lui ; mais, le jour arrivé, une sensation de langueur s'empare de toute sa personne, son intelligence s'obscurcit, et la crise ne peut être 
évitée... » Il y a là une auto-suggestion évidente autant qu'irrésistible ; et, comme dans tous les cas d'auto-suggestion, on peut dire que la personne s'est rompue en deux, que l'un de ses fragments est devenu l'instrument passif et irresponsable de l'autre. Irresponsable pourquoi ? Parce que l'automate suggéré n'est point la personne habituelle et vraie, mais une autre qu'elle, et je dis une autre précisément parce qu'elle n'en est qu'un débris. Il faut donc plaindre et non blâmer ce malheureux quand il succombe ; et s'il venait à commettre un délit pour la satisfaction de son désir insensé, il faudrait l'absoudre.

Mais jamais, je le répète, dans les plus violentes exaltations de l'amour normal, cette scission de la personne, cette fragmentation de l'individualité, n'a lieu. Il déploie jusqu'en son fond le plus replié toute la personne, il ne la dénature pas. Il montre, comme par un fort grossissement, tout ce dont un homme est capable, tout ce dont il peut être à bon droit jugé coupable, car c'est bien lui qui le veut, dans le plein déploiement de son vouloir et de son désir. Il ne pousse au meurtre que le cruel, il ne pousse au vol que le fourbe. De là cette conséquence importante, que les crimes passionnels, - qu'on pourrait nommer passionnants aussi bien, à raison de leur accueil par le public, -engagent d'ordinaire la responsabilité morale de leurs auteurs. En effet, c'est toujours un amour de l'espèce normale, jamais une passion pathologique, qui les provoque. Le public ne s'intéresse guère aux vrais malades, pas plus à ceux de l'amour qu'aux autres. Aussi les artistes et les écrivains, qui cherchent à flatter ses goûts, se gardent-ils bien de choisir leurs modèles parmi les aberrants. Nulle aberration érotique n'a inspiré un roman, ni un tableau, ni une pièce de théâtre ${ }^{1}$, pas même une comédie bouffonne. Imagine-t-on une comédie roulant sur l'amour d'une bottine virginale possédée, perdue, reprise, etc., ou sur la passion érotique d'un vieillard pour une petite fille de 7 à 8 ans ? On peut s'étonner, à première vue, que les amateurs du nouveau quand même aient négligé cette source de renouvellement esthétique. Mais, à vrai dire, elle est moins riche qu'elle n'en a l'air, et il est à croire que, si par hasard, on osait l'utiliser, elle serait vite tarie. L'amour normal est tout autrement varié grâce à son unité même, et sans parler du petit grain de folie qui s'y mêle le plus souvent, non sans agrément du reste.

Je n'oublie pas les poésies consacrées à l'amour grec. Mais c'était alors une aberration généralisée. L'exception confirme la règle. 
Gabriel Tarde, Études pénales et sociales (1892)

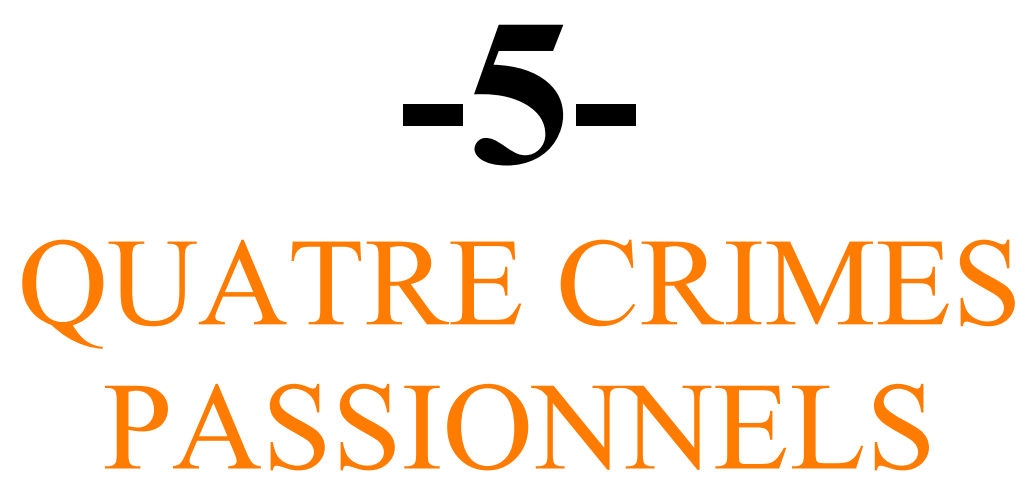

$\underline{\text { Retour à la table des matières }}$ 
Gabriel Tarde, Études pénales et sociales (1892)

\section{-5- Quatre crimes passionnels}

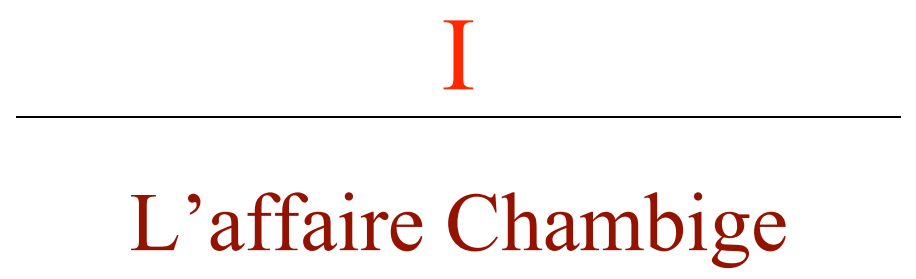

$\underline{\text { Retour à la table des matières }}$

Les débats qui ont eu lieu devant la Cour d'assises de Constantine en novembre dernier ont excité dans toute l'Europe un intérêt passionné d'une nature aussi exceptionnelle que l'affaire elle-même. Ce n'était pas dans le gros public, comme il arrive d'ordinaire, c'était dans le monde lettré et philosophique, que l'émotion était forte. Il y avait, à ce moment-là, un théâtre judiciaire pour tous les goûts : les plus grossiers trouvèrent à se satisfaire dans l'affaire Prado ; les plus raffinés, dans l'affaire Chambige. C'est ainsi que, le dimanche, on a à choisir entre un drame du boulevard et une tragédie des Français. Nous savions depuis longtemps que l'amour est le plus terrible et le plus fécond des dramaturges, tour à tour burlesque et sanglant, comique et tragique au suprême degré, et excellent dans tous les genres ; jamais preuve plus frappante de cette vérité n'a été fournie que dans les deux causes, diversement célèbres, dont je viens de parler. On y voit, par exemple, une ingénue espagnole, enamourée à première vue d'un aventurier hâbleur, d'un voleur assassin, au point de 
lui tout sacrifier; on y voit une des plus jolies et des plus charmantes femmes du monde algérien, d'une irréprochable vertu, d'une réputation parfaite, mère de famille accomplie, heureuse épouse, s'éprendre d'un jeune homme de 21 ans au point de faire tout à coup et sans hésitation un pacte avec elle-même et avec lui, par lequel elle donne, pour deux heures de bonheur trouble, son honneur, sa vie, toutes ses affections passées. - Mais ne faisons pas plus longtemps à Chambige, si peu d'égards qu'il mérite, l'injure excessive d'accoler son nom à celui de Prado ; il faut lui savoir gré plutôt d'avoir apparu au moment où ce charlatan sanguinaire faisait sa parade sur son tréteau d'un instant et de l'avoir aussitôt fait descendre de son piédestal. Les Prado sont fréquents, Chambige est, par bonheur, unique. Entendonsnous bien, cependant. Tout se répète ici-bas, et même là-haut: «l'Univers se répète », dit mélancoliquement Guyau en songeant, d'après l'analyse spectrale, que les étoiles sont constituées comme notre soleil. A plus forte raison est-il vrai de dire que l'amour se répète, même en ses plus extraordinaires manifestations, et qu'il a le droit de se répéter, puisqu'il est éternel. Aussi n'est-il rien de moins rare, notamment, que de lire, à la troisième page des journaux, le récit d'un de ces doubles suicides, ou, si l'on veut, de ces suicides réciproques, d'amants, dont Chambige et sa malheureuse amie ont grossi la martyrologe. Les Amants de Montmorency ne sont nullement une invention d'Alfred de Vigny. Il n'est pas même très exceptionnel que l'un des deux héros de ces mutuelles exécutions, l'homme le plus souvent, survive à l'autre. Mais ce qui singularise l'affaire dont je parle, c'est un ensemble de circonstances éminemment instructives et propres à éclairer la psychologie de notre temps : le mystère qu'on y a vu et celui qu'on a voulu y voir, en dépit de l'évidence des faits; avant tout, chez le principal personnage, l'acuité d'une passion qui trouve le moyen d'être sincère et littéraire à la fois et de s'exalter en s'analysant ; chez l'héroïne, jusqu'au jour suprême, la profondeur de la dissimulation mesurée à celle de l'honnêteté et de l'amour, la fascination de l'étrange et du morbide en raison même du bon sens antérieur, et peu à peu, par la force d'une suggestion qui, pour n'avoir rien d'hypnotique ni d'hystérique apparemment, n'en était pas moins irrésistible, l'intrusion d'une nouvelle âme grandissante dans une ancienne âme refoulée; puis, le mobile inouï du commun suicide: non pas le désespoir, l'épuisement de toutes les ressources matérielles, la faim, mais chez le jeune homme, la logique à outrance du pessimisme 
ambiant compliqué peut-être d'une impulsion héréditaire, et, chez la jeune femme, le désaccord senti de ses deux âmes, le désir et l'impossibilité de les concilier, le besoin intense de mourir après pour se croire le droit d'aimer avant; enfin le drame final, ce délire déchirant, cette affreuse idylle, cette sanglante oaristys dans une villa sous le ciel de l'Afrique, à deux pas d'amis discrets et demi-souriants qui, se promenant, en attendent la fin et sont si loin de la prévoir. Ce n'est pas tout: après la catastrophe, les poursuites judiciaires, extrêmement rares en cas pareils ; et, qui plus est, le verdict du jury, sans parler des appréciations non moins surprenantes de la Presse. Maintenant, la question est vidée pour le grand public : mais, pour nos lecteurs, c'est, ce me semble, le moment où l'intérêt commence et où la réflexion peut s'exercer utilement, de sang-froid, sans parti-pris, sur les singularités que j'indique.

Je dois à l'obligeance de M. Lacassagne, quelques détails fournis sur l'adolescence de Chambige par deux de ses anciens condisciples, qui ont passé huit années avec lui au pensionnat de la Seyne, près de Toulon, grand pensionnat dirigé par les Maristes. «Dans le cours de ses études ; écrivent-ils, il ne s'est jamais fait remarquer; dans les classes inférieures, il occupait plutôt la seconde moitié. Arrivé en Humanités, il faisait souvent des narrations en vers, assez mauvais du reste, de l'avis du professeur. (Ajoutons, de son propre avis, car dans ses notes de prison, il confesse ses très mauvais vers d'alors, mais « sur de très beaux sentiments ». Très beaux ? peut-être ; un peu faux sans doute). En rhétorique, il était classé dans les premiers pour le discours français. Toutefois son style était étudié, prétentieux ». Est-ce prétentieux ou consciencieux qu'il faut dire, ou simplement conscient de l'effet produit et de l'effet cherché, ce qui est la marque propre du littérateur-né ? N'importe. La prédestination au décadentisme se voit ici, et il est également visible déjà que cette maladie du style en gestation se lie à une maladie bien plus grave de l'amour-propre, congestionné, qui, pour se préserver et pour se dilater, s'isole : celleci, comme celle-là, est peut-être un effet de ce subjectivisme artificiel, où faute d'un suffisant régime scientifique, tombe un esprit plus soucieux de ses impressions que de leur objet, de soi-même que de l'Univers, et des mots que des choses. Chambige enfant était susceptible et boudeur. Il se fâchait rouge quand, à raison de ses oreilles très grandes, rabattues en avant, - un des caractères marqués 
de son visage sur sa photographie, - on l'appelait Midas. De bonne heure il a révélé ce goût des coteries jalousement closes, qui est le symptôme habituel des blessures ou des enflures de l'orgueil, mais aussi, ajoutons-le, des attachements passionnés et dévoués du cœur. Il « s'attachait à un nombre très restreint de camarades qu'il fréquentait exclusivement. Il se lia particulièrement avec un élève, fort laid mais très intelligent, qui était l'objet des tracasseries de tout le monde. » Un jour, il joua « à la perfection » un des premiers rôles dans une tragédie de collège, moins dramatique vraisemblablement que la pièce criminelle où, peu d'années après, il devait tant faire parler de lui. Par le timbre impressionnant de sa voix, - que les reporters des assises ont aussi remarqué plus tard, - il frappa aussi tout le monde. Dans l'histoire de son amour-propre, ce fut là un événement important. En voici un autre qui, dans l'histoire de son cœur, a pu avoir une importance aussi grande, si je suis bien renseigné. Mais j'ai besoin de quelques circonlocutions pour être exactement compris. On nous dit qu'à l'époque où il faisait sa seconde, c'est-à-dire à l'âge des précoces pubertés, "une de ces liaisons qui se font au collège entre camarades» parut modifier profondément son caractère 1 . " Il devenait rêveur, il correspondait journellement avec son ami, souvent en vers. Il paraissait prendre la chose très au sérieux et conserva cette intimité tant qu'il resta au collège ». Bien que j'aie souligné le mot liaisons, le lecteur se méprendrait tout à fait sur ma pensée s'il y cherchait d'infamantes insinuations qui n'y sont pas. Et, à ce sujet, je voudrais que, lorsque par hasard, on touche à ce point délicat, on se gardât de confondre sous les mêmes vocables répugnants les choses les plus dissemblables dont les unes vraiment font tort aux autres. Les aberrations de l'amour naissant, telles qu'elles éclosent dans nos écoles de garçons ou de filles, comme autant de fleurs vénéneuses et vivaces, n'ont presque rien de commun. - je parle des maisons moralement surveillées, - avec ces corruptions et ces dégénérescences monstrueuses de l'amour usé qui sont la flore infecte des prisons et des maisons de tolérance. Il y a aussi loin des premières aux secondes que d'un bégayement à l'argot. Celles-ci sont une déviation complète et voulue des sens; celles-là, le plus souvent platoniques dans

N'est-ce pas à cela qu'il fait allusion dans ses notes, quand il dit que la « crise mélancolique de la puberté en (1883-84), fut pour lui hors de toute proportion et presque exclusivement intellectuelle »? 
l'acception primitive du mot, une simple indécision de frontière entre l'amitié et l'amour, encore indistincts, à l'aube du cœur qui s'éveille. Je me souviens avoir vu, avec stupeur, de pareils attachements si forts et si immaculés, si inconscients en leur ingénuité, que je ne saurais me résoudre à les assimiler aux autres. J'accuse ici l'internat qui rend à un certain âge ces confusions du cœur presque inévitables ${ }^{1}$; l'internat, ce bagne des innocents, cette culture intensive de tous les vices qui se qualifie éducation. Peut-être est-ce une nécessité de notre vie moderne, comme le gymnase était une nécessité de la vie hellénique ; et c'est pourquoi l'amour grec aussi, ce fils du gymnase, a droit à quelque indulgence en vertu des considérations qui précèdent : mais ce n'en est pas moins un séminaire de dépravation, un orthopédie morale au rebours. Quand vient l'âge d'aimer, l'amour collégien, trouvant la porte fermée, frappe à la fenêtre, et, pour ses débuts, tombe dans un quiproquo.

Rien de plus excusable, soit, mais rien de plus fâcheux que de débuter ainsi. Apprendre la musique sur un piano faux, avoir pour premier modèle de dessin des lithographies pleines de fautes d'anatomie, s'initier à la poésie par l'imitation de vers boîteux et contrefaits, cela n'est pas plus propre à fausser l'oreille, l'œil et le goût que les intimités de pensionnaires à fausser le sentiment. En général, le mauvais pli donné de la sorte à la sensibilité s'efface, il est vrai ; mais jamais tout à fait; il en reste le goût de l'anomalie. Et, plus la lésion première a été vive, c'est-à-dire plus l'âme a été affectueuse et sincère plus le vestige de cette incorrection initiale se fait sentir.

Ainsi préparé, Chambige entre dans la vie. Je le tiens pour une des victimes les plus lamentables de l'internat. N'oublions pas d'ailleurs,

Dans un article de la Revue Scientifique (2 septembre 1871) M. Sainte Claire-Deville adresse ce reproche à l'internat avec preuves à l'appui, et fait à ce sujet un rapprochement intéressant avec ce qui se passe dans les troupeaux d'animaux domestiques où la séparation des sexes est habituelle et prolongée. Voir aussi l'ouvrage récent de M. Saunié sur la Réforme de l'instruction nationale. L'auteur s'associe pleinement aux critiques de M. Sainte-Claire-Deville sur ce côté trop négligé de nos moeurs scolaires. Mais l'un et l'autre ont eu en vue exclusivement le cas, trop fréquent du reste, où les tendances antiphysiques se donnent pleine satisfaction chez l'enfant. C'est le cas le plus simple et le plus grossier. Je ne m'occupe que de celui où ces erreurs du coeur s'arrêtent au platonique, et je regrette que, sous cette forme, elles n'aient attiré l'attention d'aucun observateur. Bien que Lamartine, dans l'épisode de Régina de ses Confidences les ait poétisées sous leur expression féminine, leur danger n'est peut-être pas beaucoup moindre que celui des autres équivoques plus répugnantes. 
qu'il avait une prédisposition, peut-être héréditaire, aux troubles nerveux, et qu'en 1883 il dut être soumis, pendant trois mois, dans un établissement médical de Bordeaux, à un traitement hydrothérapique. Il va former maintenant d'autres coteries et d'autres liaisons dans sa vie libre ; mais elles se ressentiront de celles de sa captivité. Notez qu'il avait 21 ans au moment où il a aimé Mme. G., et que ses impressions d'adolescence, malgré son passage au régiment (où le chiffre énorme de ses punitions révèle l'horreur que le second internat de la caserne lui inspirait), n'avaient pas eu le temps de se dissiper. Au surplus, je ne donne cette appréciation que comme une conjecture, peut-être sans fondement suffisant. - Peut-on s'étonner qu'il soit entré d'emblée, étant étudiant, dans une de ces sociétés d'admiration mutuelle à trois ou quatre que le quartier latin a de tout temps fait fleurir? Ces sociétés y procèdent en droite ligne des petits groupes d'écoliers, qu'on voit se pelotonner contre eux, agressifs ou défensifs, exclusifs toujours, dans les cours de nos collèges, à l'écart de leurs camarades. C'est dans ces groupes, abris fortifiés des natures nerveuses, des meilleures âmes parfois, que l'on apprend à considérer la société extérieure comme une ennemie, à moins que ce ne soit comme un public étranger dont on est le théâtre. L'internat, dit-on, forme le caractère : oui, le caractère de ceux qui n'en ont pas, mais il déforme le caractère de ceux qui en ont un. Par l'intensité excessive autant qu'artificielle de la vie sociale qu'il impose à des organisations délicates, il la leur fait sentir douloureusement, odieusement, il tue en elles le sentiment social en voulant le forcer, et les oblige à se clore en soi. Rien n'est plus propre, dès lors, à nourrir abusivement l'égoïsme que ce prétendu apprentissage de la société. L'individualisme révolté d'un grand nombre de nos contemporains tient sans doute à cette cause, comme le socialisme asservissant des autres tient à la cause inverse, de même origine. - Encore si, pour tempérer son subjectivisme, à défaut du sentiment social, Chambige avait eu, dans le milieu religieux où il avait été élevé, le mysticisme ! C'est toujours un frein et une limitation pour le moi mystique en ses dilatations, de se trouver en face du grand Moi divin, comme pour le Pharaon des bas-reliefs de se trouver en présence d'Osiris ou d'Horus. Mais Chambige, on nous l'apprend, malgré ce qu'il nous dit lui-même à cet égard dans ses confidences publiées, n'a jamais tourné son exaltation naturelle du côté dévot. Ses condisciples du moins ne s'en sont jamais aperçus. 
Quand on a pris l'habitude scolaire de la solitude systématique à trois ou quatre, ou à deux, l'amour, s'il survient ensuite sous sa forme vraie, doit naturellement exagérer et renforcer encore un de ses traits les plus marqués, l'oubli du monde extérieur. Cette éclipse de l'Univers, qui est le météore caractéristique de la passion, devient totale et durable, au lieu d'être partielle et momentanée. Elle et Moi. Moi et Elle, et c'est tout; au-delà il n'y a plus rien. Les enfants, le mari, la famille, le devoir, l'honneur, cela n'est qu'un songe aussitôt évanoui que né, et infiniment trop faible pour alimenter le moindre remords. Ce n'est pas que toute moralité soit abolie : à défaut d'objet réel, vivant et vivifiant, le dévoûment s'en crée de factices et de funestes; à défaut d'une notion large et humanitaire du Devoir, d'une sympathie ample et profonde pour nos semblables, le besoin qu'on a de se grandir à ses propres yeux suscite un idéal de beauté, de sublimité intérieure, qu'on a lu quelque part dans Alfred de Vigny ou ailleurs, et l'on s'immole à ce fantôme. Et, en pleine audience, avec une audace trop peu remarquée, on appelle héroïsme cette immolation! Il serait plus vrai de dire que dans les âmes déséquilibrées dont je parle, déséquilibrées c'est-à-dire détachées du pôle social et désorientées, le courage a ses aberrations fatales et inévitables, comme l'amour; ses dépenses et ses prodigalités de force dévoyée, comme l'amour. On a été cruel quand on a jeté l'épithète de lâche à un homme qui s'est tiré deux coups de pistolet dans la bouche, s'est manqué de l'épaisseur d'un millimètre, et n'a pu s'achever: plus de justice est due à son action, qui mérite seulement l'épithète d'insensée et, aussi, de criminelle.

Une grande pitié surtout est due à celle qui l'a aimé jusqu'à en mourir. Épargnons-lui même l'irrespect d'une analyse trop prolongée et du reste inutile. Est-ce la douleur de deuils récents qui les a rapprochés, qui a servi en elle de préparation, puis de prétexte, à un attachement tendre, accueilli sous le masque de la bonté, au désir trompeur d'être l'amie quasi maternelle d'un jeune homme sans direction, la Muse idéale d'un poète d'avenir? Qu'est-ce qui l'a subjuguée, à l'insu de tous et d'abord à l'insu d'elle-même, chez ce rêveur sinistre, chez cet énigmatique causeur ? Est-ce sa tristesse, estce sa jeunesse, est-ce sa poésie, est-ce son obscurité ou son affectation à la mode ? Peu nous importe, on n'explique pas l'amour, on le constate; toujours il se déguise pour entrer chez une femme vraiment 
honnête, toujours il se dissimule pour y rester et y grandir; il se couvre de ses meilleurs sentiments et les détruit, il lui cache ce qu'il y a de pire dans son objet et s'en nourrit. Mais quoi qu'il en soit, quand il nous maîtrise il nous dénature. Un grand amour, pourrait-on dire, est toujours une âme nouvelle qui entre en nous, une condition seconde où la vue d'une personne nous place brusquement. faisant tomber le rideau de notre vie ordinaire, de nos occupations et de nos préoccupations oubliées soudain. Mais jamais cette vérité n'a été plus frappante que dans le cas de Mme G., jamais l'empire absolu de la passion sur une âme n'a été plus mystérieux, plus semblable à cette suggestion hypnotique dont on a pu sans trop d'invraisemblance émettre l'hypothèse ici, bien qu'à vrai dire rien ne la démontre ${ }^{1}$. Ce n'est donc pas dans la vie antérieure de cette femme honnête et charmante, aussi douce et aussi bonne que jolie, qu'il faut chercher l'explication de son malheur; elle est, elle, beaucoup plus encore que Chambige, un cas pathologique : elle est morte d'une maladie qui lui a été inoculée du dehors. Félida, à mon avis, ne sortait pas plus d'ellemême en passant à son second état que Mme. G. en voyant apparaître son fascinateur étrange qui l'ensorcelait par je ne sais quel charme, une tournure particulière de l'esprit, peut-être une certaine nuance du regard, un timbre de voix singulier. Sans doute, dans les derniers temps, elle était facile à hypnotiser ; peu de jours avant sa mort, elle avait eu des syncopes, elle s'était elle-même endormie ou fascinée en regardant un objet brillant; mais c'est prendre l'effet pour la cause que d'attribuer à cet état son entraînement et sa chute. Elle était, je crois, devenue hypnotisable parce qu'elle était depuis longtemps affolée d'amour, et non vice versa. Et qu'est-ce que l'hypnotisme, en somme, comparé à l'amour, pour la force hallucinatoire et persuasive, pour la

\footnotetext{
Ce n'est point, je dois la reconnaître, l'avis de M. Delboeuf, juge si autorisé. Dans le journal de Liège, du 21 novembre 1881, sous le pseudonyme d'Argand, il se prononce pour une hypothèse ingénieuse, permise du reste à un hypnotiseur de sa force, rompu à tous les maléfices de la nouvelle sorcellerie. "Il me paraît, dit-il, qu'il n'y a rien de plus facile que d'abuser d'une femme mariée hypnotisable, si elle aime son mari. On lui fait croire que l'on est le mari. De là l'air souriant de la morte... Chambiqe est peut-être sincère quand il affirme que Mme. G. l'aimait il a pu le croire ». Rien de plus facile que de se faire passer pour le mari de la femme que l'on aime! Il faut être Jupiter auprès d'Alcmène pour trouver la chose aisée. Jupiter aurait-il fait de l'hypnotisme sans le savoir ? - dans l'ouvrage récent de M. Liégeois sur la suggestion (Doin 1889,758 pages), qu'on lise le compte rendu de toutes les affaires où l'hypnotisme a joué un rôle certain ; on n'en verra aucune qui, de près ou de loin, ressemble à la nôtre, à moins qu'on ne veuille assimiler à l'affaire Castillan (v. p. 337 et s.), tous les cas de séduction et d'irrésistible entraînement d'amour.
} 
grandeur inaperçue des révolutions intérieures qu'il opère! Une personne qui cesse d'aimer se souvient des extravagances et des folies qu'elle a commises pendant la durée de sa possession érotique, à peu près comme, au réveil, on se rappelle les appétits dépravés ou les crimes horribles dont on s'est rendu coupable en rêve. Au degré près, cette aliénation passagère est le caractère de tous les amours; mais il est porté au plus haut point d'intensité chez Mm. G. Aussi, qu'on ne vienne pas opposer au récit de Chambige, comme un argument irréfragable, la tranquillité apparente de cette femme, la lettre enjouée qu'elle écrivait à sa mère, le cours régulier de sa vie domestique, un moment avant son départ en voiture avec son amant, brusquement, sans un baiser, même à ses deux petites filles ${ }^{1}$. Ce n'est pas seulement par la duplicité féminine, éternelle, insondable c'est surtout par la dualité psychique essentielle à la passion folle, que cela s'explique à merveille. L'obsession amoureuse en elle, comme il arrive toujours, avait des intermittences, ses deux personnes alternaient et pendant les assoupissements lourds et de plus en plus courts du moi morbide, le moi sain et habituel reprenait sa routine mécanique. Mais, une dernière fois, l'autre, en sursaut, s'est réveillé et on sait les conséquences qu'a eues son réveil. Pour moi, quand Mme. G. était emportée en voiture avec Chambige vers la villa de Sidi-Mabrouck, ce n'était pas elle, c'était une demi-aliénée qui passait, et je la juge à peu près irresponsable de ce qu'elle va faire. J'en vois la preuve dans ce qui précède et dans ce qui suit, dans ce brusque oubli de ses enfants au départ et dans la monstruosité de leur souvenir ensuite sous la forme du regret de ne les avoir pas amenés, -dans la soudaineté de sa décision terrible et dans l'indécence inouïe de l'exécution. Cette chrétienne zélée veut mourir comme une païenne, et l'effondrement de son christianisme est si profond, et si subit, que ce n'est pas surtout un signe du temps qu'il convient d'y voir mais un symptôme manifeste de sa folie. Qui plus est, cette protestante un peu prude veut mourir nue, et ne s'aperçoit pas qu'elle est nue, et il est curieux de noter l'unanimité des femmes à se récrier ici contre l'énormité de ce scandale. Tout cela se tient cependant, s'enchaîne et s'entr'éclaire. Que ce désordre ou plutôt ce nouvel ordre révolutionnaire d'esprit tienne à

Les domestiques déclarent que tous deux, Chambige aussi bien que Mme. G. avaient l'air tranquille et naturel en partant pour la villa. Or, nous savons à quoi nous en tenir sur la tranquillité réelle de Chambige à ce moment. Pourquoi son amie n'aurait-elle pas eu le même calme? 
une grave maladie de foie révélée par l'autopsie, ou simplement à la passion, au cap orageux de la trentaine, peu nous importe; l'essentiel est qu'il est évident. Une fureur de dépravation abominable, inexplicable, semble être entrée au coeur de cette femme vertueuse ; il lui faut l'ivresse compliquée d'angoisse, spasme et râle mêlés, être souillée et être tuée tout ensemble, et s'il se pouvait, tuer aussi. C'en est trop vraiment, cela ne peut être qu'un cauchemar de malade, mais, par malheur, un cauchemar réalisé.

Toutefois, jusque dans nos rêves les plus insensée ou les plus horribles, il entre quelque part de nous, et c'est à la madame G. honnête et normale que j'attribue en partie la conception du dénouement tragique de son églogue. L'idée, sous forme hypothétique, en avait d'abord souri à son imagination et à sa vanité de femme, où commençait à s'exercer la contagion morbide de son ami. «Ce serait une grande beauté, avait-elle dit, de mourir ainsi, on nous admirerait ». Puis quand ce mauvais germe a eu grandi, pris racine et force, elle a dû le fortifier encore en voyant dans ce suicide rêvé comme fin d'orgie, une expiation épuraratrice de l'affreuse joie achetée à ce prix. Tant cette antique notion de la pénalité expiatoire est ancrée au fond des consciences! En route vers la villa, quelque lueur de bon sens a pu s'entrevoir encore comme un pâle crépuscule à l'horizon de leur double démence. Tous deux, dit le cocher « avaient l'air triste ». On le serait à moins. Quelque horreur, dirait-on, se mêle encore à l'invincible attrait de la boucherie volontaire où ils courent, effrayés et forcés de la vouloir. Mais à peine ont-ils mis les pieds dans la chambre, la perturbation mentale est complète, surtout chez elle. « Elle me fit, dit-il, jurer sur la tête de ma mère et de ma petite soeur de la tuer. Cela maintenant peut paraître monstrueux, mais cela me parut alors avoir un caractère sacré. » Le sauvage qui tue par piété filiale ses parents âgés ne sent pas autrement. En vérité, quand un accusé allègue de tels récits pour sa justification, leur monstruosité même, indépendamment de tout autre considération, me porte à admettre sa véracité. Il insiste sur un autre détail significatif; elle ne voulait pas, dit-il, le laisser sortir un seul instant de la pièce où ils étaient même pour passer dans la pièce d'à côté " parce qu'elle aurait peur si elle restait seule. » Cette horreur de la solitude, cet effroi de soi, a quelque chose d'étrangement enfantin et fou. « Elle répétait: ne t'en va pas, j'ai peur! » Si Chambige a imaginé cela et tant d'autres 
petits détails étrangers à la vie commune, indice frappant de déséquilibration, il n'est pas simplement un artiste, il est un aliéniste de première force. Mais alors je m'étonne qu'il soit en même temps un avocat si maladroit. Qu'on lise les notes écrites durant sa détention et qu'on les compare aux confessions plus ou moins littéraires de véritables assassins, par exemple à celles que cite M. Henri Joly dans son livre sur le Crime, le contraste est grand. Il y a là des délicatesses d'analyse et d'expression presque inconciliables avec la grossièreté de l'âme scélérate. Ce qui m'atteste le mieux la sincérité de l'auteur c'est la recherche évidente de l'effet, la prétention du style, assez beau par endroits, où l'on sent bien que, dès les premières lignes, le littérateur oublie profondément l'accusé. "Plus encore que les femmes, dit-il, j'aimais le mensonge. Dieu fit le monde, et en le voyant si laid, il donna au monde l'illusion. Ce que nous blasphémons sous le nom de mensonge, nous l'adorons sous le nom d'idéal, » Voilà un bel éloge du mensonge qu'un menteur n'aurait jamais eu la naïveté d'écrire, d'écrire pour se blanchir! Je sais bien que dans le milieu spécial où le littérateur psychologue vivait, on trouvait tout naturel d'exprimer l'idée qu'il serait doux de commettre un crime pour se donner la sensation de l'assassinat. Mais voilà encore une chose qu'un assassin n'eût jamais dite ni pensée, encore moins imprimée.

On peut m'objecter, il est vrai, que si le bouleversement de l'âme par l'amour peut aller, chez la femme, jusqu'à transformer une puritaine en bacchante, il peut aussi transformer un amoureux en assassin. Sans doute, mais les circonstances du fait autorisent-elles cette dernière hypothèse ? Non, ce me semble ; outre que, chez un homme raffiné d'esprit, ne fût-il pas élevé de coeur, l'association antique de l'amour et de la mort, devenue un lieu commun de la poésie et de la science, se présente exclusivement sous la forme du suicide précédé par la débauche, comme dans Rolla, nullement sous celle du viol suivi de meurtre; en dehors même de cette considération, rappelons-nous ce cocher qui, durant toute la scène, n'a entendu aucun bruit de voix ni de lutte, les volets demi entr'ouverts comme pour le demi jour de l'alcôve, non largement ouverts, comme il l'eût fallu pour faire des recherches domestiques dans un appartement, et tant d'autres 
points fort bien relevés par l'avocat de Chambige ${ }^{1}$. Il n'est pas jusqu'à l'air souriant et tranquille de la morte, - car peut-on dire que ce fût un faux air encore, celui-là, comme son apparence de tranquillité de tout à l'heure sous les yeux de ses domestiques ? - qui ne me semblât une sorte de certificat posthume donné par elle à la version de son ami, si du moins il n'y avait pas à se méfier de cette constatation. Mais M. Lacassagne me fait observer à ce propos le penchant qu'on a, en regardant le visage d'un mort, à lui prêter une expression imaginaire. «Pour ce qui est des doubles suicides, nous a-t-il ajouté, j'en ai observé un certain nombre, des amants qui se sont noyés ensemble après s'être ligotés, d'autres qui ont bu le poison dans un même verre, d'autres qui se sont asphyxiés par le charbon. J'ai en aussi à examiner des assassinats-suicides, l'amant tue sa maîtresse et se fait ensuite justice. Sur ces victimes, ou ces épouses de la mort si j'ose dire, je n'ai jamais lu sur les traits du visage les traces d'une dernière pensée ou d'une dernière consolation. » À l'inverse et pareillement, « j'ai observé plus de cinquante cadavres de personnes assassinées, me dit-il encore, et j'ai remarqué que l'effroi, la terreur n'étaient nullement figés sur la figure. » Il n'y aurait donc à tirer aucun argument ni pour ni contre de la physionomie qu'a paru avoir Mme G. morte aux yeux des premiers observateurs, trop profondément émus pour bien observer. Je ne puis me défendre cependant de penser qu'ils ne se sont pas trompés entièrement et que le sujet de leur surprise, ce repos des traits, cette attitude du corps et des mains, confirme, plus qu'il ne l'infirme, le récit de sa mort avec ses particularités déchirantes, le revolver assujetti sur sa tempe par sa propre main, et cette dernière parole : «Oh ! comme tu vas me faire souffrir!», qui me rappelle, je ne sais pourquoi cet enfant de 14 ans montant à la guillotine sous la Terreur et demandant au bourreau : « Me ferez-vous beaucoup de mal ? " Est-ce là des mots qu'on invente?

En faveur de l'accusé, d'ailleurs, et de la victime elle-même, il y a beaucoup mieux à invoquer que tout ce qui vient d'être dit; il y a à tenir grand compte du milieu algérien où ce drame s'est déroulé. Je ne parle pas seulement de ce ciel et de ce soleil, de ce climat, ni même du sang africain, je parle surtout de ce bazar colonial où se juxtaposent

Quelle maladresse aussi de nous apprendre qu'en rentrant dans la chambre il lui avait parlé violemment. Il pouvait bien se dispenser de ce détail, le cocher n'ayant rien entendu. 
pêle-mêle des immigrants de tous pays avec leurs morales et leurs immoralités hétérogènes, dont le contact mutuel a pour conséquence le relâchement général des mœurs et l'indulgence extraordinaire de l'opinion. Les colonies, en fusionnant les civilisations, amollissent les cœurs, aussi ont-elles la spécialité des passions extrêmes. On a beau s'individualiser, se recroqueviller en soi-même, on subit inconsciemment l'action de la société environnante comme le poisson la pression de l'eau.

Malgré tout, me permettrai-je de blâmer les poursuites exercées par le Parquet de Constantine ? Non, elles s'imposaient nécessairement ; et, si j'ose ici exprimer un avis contraire à celui que le Ministère public à éloquemment développé, qu'il a fait triompher devant le Jury, c'est que je m'adresse à un public spécial auquel on peut parler en toute liberté d'esprit sans égard à la règle res judicata pro veritate habetur. Cette fiction nécessaire, qui doit dominer toutes les discussions de la Presse partout ailleurs, ne serait pas à sa place dans ce recueil. Il est vrai que le Ministère public poursuit rarement les amants échappés par hasard à une tentative de mutuel suicide. M. Enrico Ferri remarque avec beaucoup de justesse, dans son Omicidiosuicidio, que, malgré le nombre considérable de faits semblables relatés par les journaux quotidiens, les recueils de jurisprudence criminel en mentionnent à peine un de loin en loin comme ayant donné lieu à une instruction. Par la même raison, bien que tous les jours nous lisions les procès-verbaux de duels terminés par une blessure ou la mort de l'un des deux adversaires, il est extrêmement rare que les duellistes soient poursuivis. Pourquoi serait-on plus sévère dans le premier cas que dans le second ? Est-ce que, ici comme là, le consentement donné par la victime à son propre homicide n'innocente pas le meurtrier? Est-ce qu'il ne l'innocente pas dans le cas du double suicide encore plus que dans celui du duel, puisque, dans celui-ci, la victime a simplement accepté sans la désirer le moins du monde l'éventualité de la mort par autrui, tandis que, dans celui-là, elle a demandé, elle a exigé impérieusement l'exécution immédiate de l'homicide dont l'auteur à ses yeux est son bienfaiteur ? On comprend donc sans peine que, d'ordinaire, les magistrats refusent d'assimiler ces faits à des assassinats. Mais dans l'espèce, il y avait, certes, assez d'obscurités sur la vraie nature de l'acte, pour motiver une accusation. 
Ce qu'il y a de navrant, c'est de songer que, pour dissiper ces obscurités, pour résoudre ce problème de pathologie cérébrale compliqué de psychologie amoureuse, et trancher les difficiles questions de responsabilité morale et sociale posées de la sorte, on a dû s'adresser à une douzaine de colons quelconques, à un Jury! Si jamais le Jury ${ }^{1}$ a été radicalement incompétent ratione materioe et aussi bien ratione loci, c'est bien dans cette affaire, qui ressortissait évidemment à la juridiction, non du sens commun et populaire, mais du sens subtil, aiguisé, et méritait d'être évoquée, comme elle l'a été de fait, par le tribunal supérieur des psychologues et des lettrés, voire même des journalistes, tous plus ou moins experts en matière pareille.

Cette Haute-Cour, à la grande majorité des voix, a réformé le verdict des jurés de Constantine, elle a déclaré, non qu'Henry Chambige n'était pas coupable ni punissable, mais qu'il n'était pas coupable d'assassinat, et qu'il ne pouvait être puni, si la logique et la justice ont quelque valeur, par ce même jury qu'on voit tous les jours, régulièrement, acquitter les duellistes, cela va sans dire, et aussi les maîtresses abandonnées qui vitriolent ou assassinent par vengeance leurs amants, et tant d'autres malfaiteurs pires encore! Il y aurait lieu cependant d'approuver pleinement la condamnation de Chambige, si elle eût signifié, de la part du jury, la renonciation à son ancienne jurisprudence si favorable aux meurtriers et surtout aux meurtrières, et l'intelligence tardive du besoin de protéger la vie humaine contre la passion. Même en acceptant toute la version de Chambige, je le crois condamnable dans une large mesure. Aussi tout le monde, en réprouvant le verdict, a-t-il approuvé en somme l'arrêt de la Cour d'assises, où il est aisé de voir, si on lit à travers les lignes, que l'opinion des magistrats a loin d'avoir été celle des jurés relativement à la manière dont les faits incriminés ont eu lieu. C'est la sagesse de la magistrature, en réalité, nullement celle du jury, qu'on a louée en jugeant la condamnation de Chambige juste et suffisante. Le jury en a été si peu satisfait que son chef, - chose incroyable, - a cru devoir aller, après l'arrêt, rendre visite, à $\mathrm{M}$. G, et lui exprimer l'indignation de ses collègues contre l'indulgence de la Cour... En quoi cependant consiste, selon nous, la culpabilité de Chambige ? La question ne s'est pas présentée devant le jury algérien, car, a n'en pas douter, s'il eût

\footnotetext{
1 Il est vrai que les Assises ont été présidées avec une distinction rare par M. Zill des Iles.
} 
admis le récit de l'inculpé, il eût rendu un verdict d'acquittement. Devant la Presse, la question a été vaguement agitée. Malheureusement, c'est ici que la Presse a déliré à son tour, et il serait trop long de relever les jugements inattendus prononcés par les hommes les plus graves. L'un a décidé que le crime du malheureux consistait... à avoir compromis la littérature et la poésie en personne. Il y a ceci de vrai, que le fait d'avoir versifié et lu Schopenhauer a dû lui compter comme une bien mauvaise note aux yeux des jurés. D'autres, et ils sont nombreux, l'ont jugé criminel parce qu'il y avait eu un pacte entre son amie et lui et qu'en ratant son suicide il avait manqué envers elle à la promesse de ne pas lui survivre. C'est inouï le succès qu'a eu cette belle sentence dans les journaux mondains où la violation des devoirs les plus certains, domestiques ou autres, est réputée une simple plaisanterie, mais où "l'engagement d'honneur » intervenu entre nos deux amants à été aussitôt reconnu comme la plus inviolable des dettes sacrées. En général, on s'est accordé à flétrir la prétendue lâcheté de ce jeune homme qui, dit-on, n'a pas eu le courage, qui, en réalité, n'a pas eu la force physique, après la prodigieuse dépense qu'il venait d'en faire, de se tirer un troisième coup de revolver. Il faudrait bien pourtant s'entendre avec soi-même une bonne fois. Lâche qui se tue, dit-on tous les jours, c'est convenu. Et les mêmes qui répètent ce lieu commun, disent maintenant: lâche qui ne se tue pas. Il serait peut-être bon de choisir. Je me permets d'ajouter que, si la vie est la meilleure des choses, comme le public en est convaincu, il y a du courage à rejeter la vie, et qu'ainsi l'optimisme banal du public est en contradiction avec l'une de ces deux opinions banales. M'expliquera-ton enfin la sévérité générale des moralistes pour le suicide en regard de leur indulgence générale pour le duel ?

Il est remarquable que personne, à propos de notre affaire, n'ait songé à discuter la question capitale de savoir si, et à quelles conditions, on a le droit d'ôter à quelqu'un la vie sur sa demande ou avec sa permission. Chose étrange, l'immense majorité des criminalistes, d'après M. Ferri, admet à la fois que le suicide n'est pas un délit et que la participation au suicide d'autrui est délictueuse. En vain, Carmignani compare ce contraste, pour le justifier, à cet autre, que le fils voleur de son père n'est pas passible de poursuite, tandis que le complice du fils est traité comme délinquant. L'assimilation n'est qu'ingénieuse et sans justesse. Ici, comme partout, l'école ontologique 
crée des distinctions où elle voit des abîmes de profondeur et qui se comblent sans beaucoup de peine. Par exemple, entre le cas où, sur deux amants qui cherchent à s'asphyxier ensemble devant le même réchaud, l'un est sauvé à temps, et le cas où, sur deux amants résolus également à mourir ensemble, l'un tue l'autre et ne parvient ensuite qu'à se blesser lui-même, la différence est énorme d'après Carrara; nulle, d'après Ferri. J'incline à l'avis de ce dernier, car les deux termes extrêmes, d'ailleurs si rapprochés, peuvent être réunis par une suite de chaînons intermédiaires et ambigus. Mais il me semble que; avant tout, il y aurait à prendre en sérieuse considération, - comme le veulent ailleurs avec tant de raison les partisans des nouvelles idées, la nature des motifs déterminants, aussi bien pour l'appréciation du suicide que pour celle de l'aide prêtée au suicide d'autrui. Sans entrer dans trop de détails, je serais porté à excuser entièrement l'homicide compatissant, le coup de grâce donné à un blessé inguérissable et en proie à des douleurs atroces, par son camarade supplié ; j'excuserais beaucoup moins l'homicide fanatique, l'obéissance sauvage à une loi religieuse qui ordonne d'immoler des victimes humaines même avec l'adhésion de celles-ci, comme cela s'est vu en Russie de nos jours. Mais que dire de l'homicide amoureux commis par Charnbige? Socialement, les excès de l'amour sont plus dangereux encore que les excès du fanatisme ; le fanatisme, après tout, n'est que l'attachement à un ancien lieu social des plus énergiques, mais qui à la longue est devenu trop étroit; l'amour, quand il dépasse un certain degré et franchit une certaine limite, est l'une des forces les plus dissolvantes contre lesquelles aient à lutter les sociétés quelles qu'elles soient. Le malheur est que la répression la plus dure ne saurait prévaloir contre l'indomptable élan de cette rébellion anti-sociale, et que par suite l'impunité ici ou la punition reviennent à peu près au même au point de vue de l'exemple. Est-ce à dire qu'alors il soit irrationnel de punir? Oui, si l'on pousse à bout la logique de l'utilitarisme et du rationaliste pénal, entendu dans un sens, à mon gré, trop étroit, sans égard aux sentiments éternels et invincibles du cœur humain qui exigent satisfaction par la peine, et, s'ils ne l'obtiennent pas, sauront bien se satisfaire sans la peine.

L'affaire dont nous nous occupons, en effet, serait très propre à faire toucher du doigt le vice de bien des théories accréditées en pénalité. Si le châtiment appliqué aux crimes de passion n'est 
nullement exemplaire ni intimidant, comment se fait-il néanmoins que le public, même cultivé et désintéressé, exige qu'ils soient châtiés ?

En grande partie, sans qu'on en ait conscience d'ordinaire, on cherche à donner par là satisfaction aux voeux profonds d'une famille outragée. Ici, exceptionnellement, on a eu conscience, ce semble de la convenance qu'il y a toujours à ne pas perdre tout à fait de vue que la justice pénale, si elle n'est ni ne doit être une vindicte publique, s'est substituée à la vindicte privée dont elle est la délégation, et ne saurait oublier cette origine sans nous ramener à la barbarie sous prétexte de raffinements juridiques. 
Gabriel Tarde, Études pénales et sociales (1892)

\section{-5- Quatre crimes passionnels}

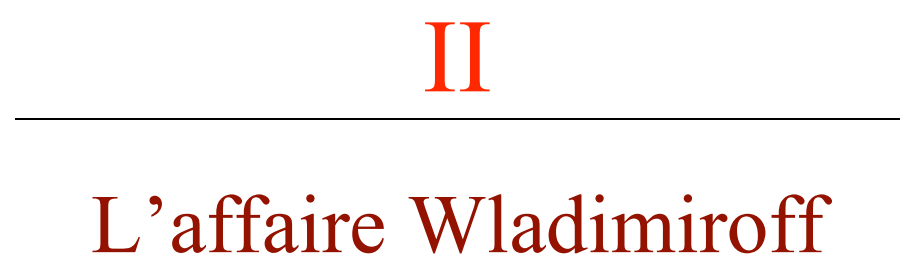

(mars 1891)

On a fait beaucoup d'honneur à Wladimiroff, car tout est relatif, en le comparant à Chambige. Il y a cette seule ressemblance entre les deux qu'ils ont l'un et l'autre tué leur maîtresse et expliqué la chose en disant qu'ils voulaient se tuer après. Mais, dans l'affaire algérienne, il semble que la victime ait elle-même demandé la mort et qu'on se trouve en présence d'un de ces cas de suicides doubles, si fréquents à notre époque érotique où le meurtre même est amoureux; dans le drame de Ville-d'Avray, il est certain que Mme D... n'a pas le moins du monde conçu le romanesque dessein de mourir d'amour, qu'elle n'a pas aimé avant le coup fatal, malgré la version du meurtrier démentie par l'expertise médico-légale, et que ce jeune misérable, quoiqu'il en dise, n'a pas eu l'intention sérieuse, un seul instant, de se suicider comme l'a tenté Chambige. Tous deux détraqués, je le veux bien, malgré l'abus qu'on fait de ce mot; mais leur détraquement diffère du tout au tout. L'un, beau ténébreux, psychologue aux phrases entortillées comme la queue du serpent d'Eve, poursuit un morbide idéal de sensation aiguë et unique en soi ; l'autre, bellâtre vulgaire, 
parfait gentleman selon la formule, banalement « distingué », n'a rien conçu, en fait d'idéal, si ce n'est celui, tout à fait pratique et nullement maladif, de s'enrichir par un beau mariage. Rien de moins anormal assurément qu'un pareil dessein; rien de plus sensé, rien de plus normal, si j'en juge par sa fréquence, malheureusement. L'avoir poursuivi par des moyens en apparence extravagants, par toutes sortes de brutalités et d'indélicatesses, est-ce là même une anomalie ? Non, puisque ces moyens ont réussi, ou failli réussir, en dépit de tous les obstacles. Ce séducteur, en somme, a bien joué son rôle, et sa violence l'a autant servi que sa fatuité, jusqu'au moment où elle l'a perdu en le poussant à un crime absurde. Mais cette absurdité de l'acte suffit-elle à dénoter chez l'agent une sorte de folie qui entraînerait sa demiirresponsabilité ? Voyons cela.

Ce qui mérite véritablement le nom de détraqué, car visiblement cela se détraque, c'est la famille, c'est la société telle qu'elle se révèle à nous dans les milieux où nos crimes passionnels éclosent. Je songe à l'affaire Fouroux et à bien d'autres. On voit là, autour du criminel, un personnel aussi étrange que lui, et appartenant aux classes supérieures : des femmes élégantes et qui boivent de l'absinthe, dans les intervalles de la morphine ou de la cocaïne ; des maris de comédie qui pardonnent tendrement à leur femme en lui écrivant qu'elle a été le jouet de la «fatalité » ou qui la rendent morphinomane pour éteindre ses désirs ; des pères qui sont de vénérables sigisbés de leur fille, ou qui demandent 6.000 francs pour consentir au mariage insensé de leur fils; des tantes devant qui leur nièce tutoie son amant sans qu'elles s'en formalisent; des femmes légitimes qui écrivent charitablement à la maîtresse de leur mari, mariée elle-même, d'être moins dure pour lui, de ne pas le tromper, d'avoir égard à ses exigences jalouses en faisant lit à part conjugalement ${ }^{1}$; enfin une manière de comprendre les relations domestiques qui déroute absolument toutes les vieilles idées. Est-il surprenant qu'un enfant né pervers, s'il est élevé dans un pareil milieu, devienne un monstre d'égoïsme, d'immoralité et parfois de cruauté ? C'est le cas de notre héros. La nature l'a fait débauché, vaniteux, irascible, menteur; l'éducation a développé à outrance tous ces mauvais germes, et après une enfance, une adolescence passées à se faire chasser de tous les établissements où on l'a mis, il est devenu

Voir une affaire jugée en janvier ou en février 1891 devant le trib. correct. de la Seine 
escroc en attendant d'être assassin. A l'aide de véritables manœuvres frauduleuses, où sa vanité trouvait son compte, il se fait prêter 3.000 francs par la mère d'un de ses amis. Russe avec cela et bénéficiant de notre russomanie (que je partage du reste), il est une variété réussie du genre rastaquouère qui est à la mode de nos jours. Le rastaquouéirisme lui-même n'est qu'une des formes de cette épidémie qui sévit parmi nous comme à toute époque de renouvellement, le prestige de l'étranger.

Tel est l'homme qui, à première vue, foudroie le cœur de cette pauvre Mme D... Elle aussi me fait l'effet d'avoir été élevée d'une singulière façon, par ses parents d'abord ${ }^{1}$, par son mari ensuite. Jolie, gracieuse, consciencieusement gâtée par son père comme le sont plus ou moins, à l'heure qu'il est, toutes les jolies personnes, elle est, nous dit-on, excellente mère de famille, à cela près que le garnement dont nous venons de parler lui fait totalement oublier sa charmante enfant âgée de 14 ans. Elle a eu le malheur d'épouser un homme qui, réduit à l'impuissance par suite d'une maladie, n'a rien imaginé de mieux que de la morphiniser pour lui adoucir les amertumes d'une abstinence forcée. Est-ce bien exact? Ou ne faut-il pas supposer aussi bien que, en voyant son mari prendre de la morphine, elle a voulu se piquer ellemême, par esprit d'imitation ? Quoiqu'il en soit, il ne paraît pas que la morphine ait été pour elle un bien merveilleux éteignoir de concupiscence, pour employer une expression ecclésiastique ; une allumette plutôt. Elle voit, pour la première fois, Wladimiroff, et aussitôt prend feu, accepte ses rendez-vous, répond à ses lettres. C'est là un bel exemple du coup de foudre, phénomène auquel Stendhal consacre un intéressant chapitre de son livre sur l'Amour. Il se trompe pourtant en exagérant le caractère exceptionnel du fait. La plupart des amours naissent ainsi, brusquement, sans préparation, par une simple action de présence. Quand un jardinier de mon pays, à la suite d'un orage, constate la mort d'un de ses arbres fruitiers en train de perdre ses feuilles subitement desséchées, il dit qu'il a été touché par l'éclair « éclairé », invisiblement et silencieusement. On peut dire la même

Intéressé à se vieillir artificiellement comme d'autres à se rajeunir, Wladimiroff imagine de se faire passer pour l'enfant naturel de sa tante. Cette invention montre assez sa profonde démoralisation ; mais il est regrettable aussi pour la famille de sa fiancée qu'il ait eu lieu de croire par là se rehausser à ses yeux, comme si l'on eût mieux aimé s'allier à un fils naturel de 24 ans qu'à un enfant légitime de 20 ans seulement. C'est pousser loin le mépris des préjugés. 
chose d'un jeune homme, d'une jeune femme ${ }^{1}$, qui a changé d'humeur et sèche sur pied depuis un dîner, une soirée, une rencontre quelconque. Seulement, le plus souvent, la raison sert à tenir secrets et inaperçus ces foudroiements intérieurs et à les amortir; mais la morphinomanie de Mme D.. . l'a empêchée d'avoir cette profondeur féminine de dissimulation. L'éclair qui l'a frappée a été visible à tous les yeux, et d'abord à ceux de Wladimiroff. Celui-ci n'a pas manqué de nourrir et d'exploiter comme il fallait cette belle passion. Il l'a nourrie de coups, de brutalités, de soufflets donnés en pleine rue, de scènes de jalousie à propos des amies mêmes, trop tendrement embrassées, d'aménités dans le genre de celle-ci : "vous tuez les mouches à dix pas ", et de fallacieuses promesses telles que celles de conduire la future comtesse à la cour de Russie. Les amours croissent parfois comme les popularités, moyennant beaucoup d'insolence combinée avec force mensonges. Fouroux le savait bien, lui qui a eu autant de succès auprès des foules qu'auprès des femme ${ }^{2}$.

Par malheur pour notre séducteur, les renseignements pris sur son compte par la famille de Mme D...., avant tout consentement au mariage projeté, ont été si détestables que le père lui-même de la malade a dû, pour la première fois de sa vie, résister au caprice de sa fille. Elle a fini par ouvrir les yeux à la vérité ; mais son cœur restait pris. Ballotée entre les suggestions de ses parents et sa passion persistante pour son amant, elle penchait tantôt à droite tantôt à gauche, contradiction incarnée, anarchie psychologique comparable à ce palimpseste du moyen-âge où se superposait à l'Art d'aimer d'Ovide un sermon sur la chasteté. Je voudrais bien savoir ce qu'était devenu en ce conflit ce fameux libre-arbitre qui est réputé le pouvoir absolu du moi. En ce prétendu autocrate il m'est impossible de voir autre chose ici qu'un automate ou, si l'on veut, un monarque constitutionnel

L'observation s'applique surtout aux femmes. Chez nous, il y a toujours entre l'admiration et le désir de la possession, qu'il s'agisse de meubles, de décorations, de situation sociale, d'amours, un Intervalle de temps plus ou moins long. Chez la femme point. Ce qu'elle admire - regardez-la aux vitrines des bijoutiers, - elle veut l'avoir aussitôt. Ajoutons que la trépidation des wagons prédispose certaines femmes, surtout si elle sont déséquilibrées, à des accès de passion Intempestive.

2 Pourtant l'engouement populaire semble être encore plus aveugle que 1'amour, Madame D...., malgré tout, a gardé assez de bon sens pour comprendre qu'elle devait refuser le mariage à Wladimiroff tandis que le suffrage universel de Toulon a voté obstinément pour Fouroux. Et nunc, plebes, intelligite; erudimini, qui possidetis terram. 
chargé de contresigner toutes les décisions changeantes et contraires de ses ministres successifs.

Mais Wladimiroff était-i1 plus libre ? Ses résolutions avaient-elles mieux le caractère d'une option entre plusieurs volontés possibles ? Non, il ne m'en coûte pas de reconnaître, tout en le jugeant très coupable, que son crime, à raison de sa nature et des circonstances où il s'est trouvé placé, a été inévitable. Il exploitait financièrement sa maîtresse ; mais il était encore plus vaniteux et violent que cupide. Peut-être même était-il surtout flatté de ses largesses, comme ces amants du XVIe et du XVIIe siècles, dont Brantôme et Bussy-Rabutin nous parlent complaisamment. Ce mariage qu'il convoitait si fort, ce mariage avec une femme de douze ans plus âgée que lui, qu'il savait infidèle, avec une femme que le médecin d'un de ses amis lui avait dit n'être pas mariable, faisait luire à ses yeux la perspective de briller dans le monde encore plus que de s'enrichir. Aussi, quand, devant un refus formel, ses rêves de fortune s'écroulent, sa cupidité est encore moins blessée que sa vanité, et sa violence s'exaspère. Il tente un dernier effort et se résout, si cette tentative échoue, à tuer la pauvre femme. À quoi lui servait cet assassinat? dira-t-on. A rien, sinon à se venger et à décharger son exaspération; mais c'est assez pour une nature de cet ordre. Il achète donc, avec le prix d'une bague de fiançailles qu'elle lui avait donnée, un revolver à cinq coups pour la tuer. Au rendez-vous fatal elle se rend, la malheureuse, de peur qu'il ne se tue pour elle ! Car de ces deux menaces « je vous tuerai et je me tuerai ensuite », elle n'a pris garde qu'à la seconde, elle oublie la première avec cet admirable abnégation du cœur féminin que l'amour pousse aux plus aveugles excès de la bonté. Et, pendant plusieurs heures, à Ville d'Avray, au bord de l'eau, il essaie de fléchir cette volonté jusqu'alors si docile, à présent galvanisée par les obsessions familiales, et résistante obstinément. Elle consent cependant à le suivre dans une chambre d'auberge; il y redouble ses instances. Lui at-elle alors proposé, comme il l'affirme, de vivre avec lui librement? et a-t-il repoussé cette offre, qui n'était pourtant pas à dédaigner par un jeune homme de vingt ans ? C'est bien possible. Ce qui est certain, c'est qu'il ment en affirmant qu'à cette heure il a eu ses faveurs. Comme il devait être d'humeur amoureuse en cette crise de colère et de dépit ! Quoiqu'il en soit, elle a persisté dans son refus de se marier. Quelle incroyable opiniâtreté ! Il n'en revenait pas. Elle, cette créature 
à lui, son jouet, sa chose, elle se permettait de lui échapper et de se reprendre ! Son bien lui était volé, il avait tout droit sur l'esclave révoltée, et il ne lui restait plus qu'une manière de lui prouver qu'elle lui appartenait encore, c'était de disposer d'elle en la détruisant : jus abutendi. Orgueil ulcéré, fureur déchaînée, férocité réveillée en sursaut, lui commandaient cet acte absurde, d'une très logique absurdité. Il tire donc un premier coup de revolver, et la manque. Un second; il la manque de nouveau. Après une courte pose, durant laquelle il est aisé de se figurer la terreur, l'horreur peintes sur le visage de la victime, la troisième détonation se fait entendre; et, comme il avait eu le temps de mieux viser, ou comme si sa main s'affermissait à mesure qu'il tirait, cette fois-ci la balle frappe à la tête. Puis une quatrième balle atteint la tête encore.

Le revolver était déchargé ; car précédemment une balle avait été tirée contre un arbre par Mme D... elle-même. Il ne restait donc plus à Wladimiroff un seul coup dont il pût faire usage contre lui-même, pour achever l'exécution du dessein qu'il prétend avoir conçu. $\mathrm{Si}$, réellement, il avait voulu se suicider, ne se serait-il pas réservé une balle au moins ? A cela il répond qu'il avait mal compté les coups de son arme, qu'il croyait avoir un revolver à six coups et non à cinq. C'est inadmissible. Quand on achète un revolver pour tuer et se tuer, quand on tient à cet achat au point de l'avoir fait avec le prix d'un bijou donné par une femme qu'on dit aimer, il est impossible qu'on n'ait pas examiné cette arme avec assez d'attention pour savoir le nombre exact de ses coups. Dieu sait s'il était occupé et préoccupé de ce revolver ! Au départ pour Ville-d'Avray, il allait oublier, sans la soubrette Clary, son pardessus et son parapluie, mais non cet instrument de meurtre.

$\mathrm{Au}$ demeurant, qu'il ait eu, avec la volonté préméditée de l'homicide, quelques velléités vagues de suicide, tout juste assez fortes pour lui faire illusion à lui-même sur leur sincérité, et que la force nerveuse lui ait fait défaut au dernier moment, c'est possible à la rigueur; le Dr Lacassagne est porté à le croire ; mais peu importe. Je consens à ce qu'on lui accorde, à raison de ce doute, comme le jury, les circonstances atténuantes. Il n'en est pas moins vrai qu'il a tué sciemment et volontairement cette femme, poussé par un mobile antisocial au premier chef, non la vengeance de l'honneur blessé, non 
l'emportement de la passion folle et désintéressée, mais la rage de la cupidité déçue, de la fatuité offensée, du despotisme rendu féroce par une rébellion. Et, ce que j'ai tenu à montrer, c'est que le crime ainsi commis résulte de la situation et de l'état psychologique de l'agent comme une conclusion sort des prémisses. Wladimiroff, étant donné son caractère (majeure) révélé par les espérances et les déceptions qui ont suivi sa rencontre avec Mme D ... (mineure) devait nécessairement l'assassiner (conclusion)

Eh bien, je dis que sa responsabilité morale, - si morale et responsabilité ont un sens, ce qui n'est pas niable, - a précisément pour cause cette nécessité. Supposez un autre Wladimiroff en face d'une autre Mme D ... ou même d'une femme quel conque qui lui résiste après l'avoir bercé d'un rêve pareil, le dénouement sera identique. Laissez Wladimiroff en liberté, acquittez-le sous prétexte qu'il ne jouissait pas de son libre arbitre, et, d'après ce précédent, nous avons lieu d'affirmer que, dans mille autres circonstances de la vie journalière, sa nature, mauvaise et perverse, lui fera commettre des actions plus ou moins préjudiciables à autrui, plus ou moins criminelles ou délictueuses. En lui, en sa propre personne, et non en une personnalité adventice et morbide, commensale du même cerveau, réside la cause efficiente, l'énergie potentielle si vous aimez mieux, de nombreux crimes ou délits, qui attendent seulement une occasion pour éclore. Voilà pourquoi j'applaudis à la condamnation qui le frappe. $\mathrm{Ne}$ m'objectez pas qu'après tout Wladimiroff ne s'est pas fait lui même, qu'il est une simple résultante de facteurs physiques, climatériques, biologiques, sociologiques, momentanément concentrés en son activité individuelle. De quel droit refusez-vous à ce qui est individuel le titre de réel ? De quel droit jugez-vous les éléments plus vrais que leur combinaison? Pourquoi ne voulez-vous voir dans l'individu que la dissémination, antérieure à lui, des atomes et des molécules, dont il est l'agrégat inexplicable, au lieu de ne voir à cette poussière d'autre raison d'être que sa concentration sous forme animée ? Espace, temps, matière, force, sommes-nous bien sûrs que cela soit, et qu'en savonsnous si ce n'est ce que nos sensations individuelles, ce que nos efforts individuels, ce que nos croyances et nos désirs individuels, nous en apprennent? Qu'est-ce qui permet de dire que Wladimiroff ne s'est pas fait lui-même, qu'il a été fait par autrui ou par quelque autre chose que ce soit? Le distinguer de ses soi-disant causes comme s'il était 
leur effet, postérieur à elles et extérieur, c'est concevoir le rapport du moi à ses conditions organiques et essentielles, et de l'organisme à ses fonctions constitutives, comme s'il s'agissait du rapport de l'ouvrier à l'œuvre, du fabricant au fabriqué. Est-ce qu'il pouvait y avoir quelque chose d'autre que Wladimiroff avant qu'il ne fût ? Pour différer, il faut exister ; rien, donc, en lui n'a préexisté à vrai dire ; et dire que ce qui est devenu lui, dans l'éternité passée était autre que lui, c'est déjà le poser comme existant. Et, de fait, n'était-il pas déjà visé comme une cible fatale, ou plutôt recelé comme une virtualité latente, par cette multitude d'êtres et de forces qui de tous les points de l'étendue et de la durée se sont rencontrés pour le faire apparaître ? Il n'est donc pas simplement dépositaire, il est vraiment propriétaire, passagèrement je le veux, de la réalité qui est en lui, qui est lui, qui fait siens tous ses actes conscients, volontaires, conformes à son orientation caractéristique.

Voilà pourquoi il n'est pas permis de regarder la conduite humaine comme un vain jeu d'une éternelle magie et de sourire en esthéticien au spectacle des vertus et des vices, des dévoûments ou des crimes, sans enthousiasme ni indignation. Le blâme et l'approbation du moraliste atteignent quelque chose qui n'a rien d'illusoire; et la conscience qui atteste la profondeur de son objet ne se trompe pas en ceci.

Mars 1891. 
Gabriel Tarde, Études pénales et sociales (1892)

\section{-5- Quatre crimes passionnels}

III

\section{Les affaires Weiss et Achet}

J'ai reçu il y a longtemps un livre dont je m'accuse de n'avoir pas encore parlé, ni peut-être remercié l'auteur ; ingratitude d'autant plus blâmable que cet ouvrage est des plus instructifs, des plus fortement pensés, des plus troublants pour la conscience. Le souvenir m'en est revenu il y a quelque temps en songeant à ce merveilleux crime d'AïnFezza qui a tant fait couler de sang d'abord, d'encre ensuite, et qui mérite bien quelques réflexions rétrospectives. Par amour du contraste, on peut le comparer au drame de Chantelle, ce vulgaire assassinat d'un notaire riche et galant par une jolie femme endettée.

Il n'y a pourtant pas un rapport bien étroit, ce semble, entre l'ouvrage de M. Paul Moriaud sur le Délit nécessaire ${ }^{1}$ et les deux faits monstrueux imputés à Mme Weiss et à Mme Achet. 
Mais, en y regardant de près, on s'aperçoit que presque toutes les difficultés soulevées par le problème pénal se ramènent à celle dont s'occupe l'écrivain genevois. Le délit nécessaire, ou plutôt légitime, ou bien, pour employer une autre expression de l'auteur, "l'état de nécessité », qu'est-ce ? C'est le genre très vaste dont la légitime défense n'est qu'une espèce particulière et rare. Un voleur, le couteau à la main, s'avance vers moi la nuit pour m'assassiner; je le préviens en déchargeant sur lui un coup de revolver qui le tue : légitime défense. La vie de ce malfaiteur m'appartient parce qu'elle est un obstacle à la mienne à raison de ses intentions meurtrières rendues manifestes. Mais combien de fois arrive-t-il, que la vie d'un homme, même le plus inoffensif des hommes et le moins agressif, soit un obstacle à la vie d'un autre! Un incendie éclate à côté de moi, je me précipite dans un escalier étroit où deux personnes ne peuvent passer de front; un paralytique est là, qui entrave mon passage ; si j'attends qu'il ait passé, je suis étouffé avec lui ; ai-je ou n'ai-je pas le droit de le pousser brutalement au risque de le tuer? M'accorder ce droit n'est-ce pas inhumain et sauvage ? Me le refuser, n'est-ce pas nuisible à l'intérêt social et condamner deux hommes à la mort au lieu d'un seul ? Il semble que, au point de vue utilitaire, cette dernière considération doive paraître prépondérante. Et toutefois je remarque qu'elle n'a point paru telle au plus utilitaire des peuples. En 1884, le jury anglais a eu à se prononcer sur le sort des trois matelots qui avaient survécu au naufrage de la Mignonette. Quatre s'étaient sauvés sur un radeau; mais, après vingt-quatre jours de navigation, mourants de faim, il délibérèrent sur la terrible question de savoir qui serait mangé. La majorité décida que ce serait le mousse Parker, en sa qualité de garçon sans famille; il eut beau protester, on l'égorgea, on le dévora, on s'abreuva de son sang, et, grâce à cet affreux viatique, les trois anthropophages ont pu vivre assez pour être sauvés à temps. Il a été démontré que, sans cela, ils auraient tous péri, y compris le mousse. Qu'a décidé le jury? Rien; il a « laissé à la Cour du banc de la reine le soin de trancher la question ». Quant à cette Cour, elle a condamné les accusés à mort, (peine que la reine a commuée en six mois de prison). En France, on a été plus indulgent pour les naufragés cannibales de la Méduse en 1816. Ils n'ont pas été poursuivis. 
Je veux bien qu'ici la justice française ait eu raison, en cela d'ailleurs conforme à une très ancienne jurisprudence ${ }^{1}$. Mais il faut aller plus loin. Sur un canot de sauvetage il n'y a plus place pour moi, à moins que je ne jette à l'eau de vive force l'un de ceux qui y sont installés. Si je pratique dans ce cas la maxime « ôte-toi de là que je m'y mette », suis-je punissable ? Ici, la Société est désintéressée en apparence, puisqu'il lui importe peu que Pierre ou Paul survive, l'un ou l'autre devant périr. Si la vie de Pierre vaut celle de Paul, pourquoi Pierre serait-il dans l'obligation de sacrifier à la vie de Paul sa propre vie, - ou, ce qui revient en apparence au même, de ne pas sacrifier la vie de Paul dont le sacrifice est nécessaire au salut de la sienne ? Les accidents de chemin de fer, les incendies, les catastrophes de tout genre que le progrès de l'industrie multiplie, soulèvent chaque jour des questions anxieuses de ce genre.

Un pas de plus, la logique nous y oblige. Si nous admettons que la certitude de mourir à moins que je ne tue me donne le droit de tuer, pourquoi n'admettrions-nous pas aussi bien que le simple danger de mort où je me trouve me permette un acte d'où résulte un danger de mort égal ou inférieur pour autrui que, par exemple, pour éviter une fluxion de poitrine, je puis légitimement m'emparer du pardessus d'un homme qui a aussi la poitrine délicate et l'exposer, en plein hiver, faute de ce vêtement, à être atteint de la maladie même que je veux m'épargner ? Si l'on a appelé vol nécessaire et absous comme tel, au moyen-âge même, le vol d'aliments fait au détriment même d'un affamé par un autre affamé, est-ce que la soustraction de ce pardessus ne mérite pas aussi bien ce nom ? Ce n'est pas tout. Même quand il n'y aura ni certitude ni danger de mort, ne suffit-il pas d'une grande souffrance physique ou morale pour m'autoriser à infliger à autrui une souffrance égale ou moindre, s'il m'est impossible d'échapper à la mienne autrement que moyennant la sienne ? On voit les conséquences où entraîne ce point de vue : il n'est presque point de vol qui ne puisse être légitimé par-là, puisque tout vol est une exemption de douleur ou une acquisition de plaisir obtenue par le moyen d'une douleur infligée ou d'un plaisir retranché à autrui, et qu'il n'est presque point de cas où il soit possible de démontrer que le mal fait à la

M. Moriaud cite un jugement d'acquittement, rendu en 1610 dans l'île Saint-Christophe à l'occasion d'un fait analogue. 
victime l'emporte sur le mal évité au voleur. Ce n'est pas tout encore. Même quand le mal d'autrui n'est pas la condition sine quâ non de l'absence du mien, il peut en être le moyen le plus aisé ou le moins difficile, le plus à ma portée ; de fil en aiguille, en suivant cette pente, on se trouvera conduit à une classification des délits qui a échappé jusqu'ici aux criminalistes et que je leur recommande: les délits nécessaires, les délits simplement utiles (au délinquant), et enfin les délits superflus. Cette dernière catégorie, tout à fait exceptionnelle, comprend ceux qui ont coûté à leur auteur plus de peines, à égal profit, que ne lui en eût coûté l'exercice d'une profession honnête.

Je ne m'attarderais pas à ces déductions paradoxales (qu'on aurait tort d'imputer à M. Moriaud, car je m'en accuse), si elles n'étaient propres à faire toucher du doigt l'insuffisance du calcul utilitaire des biens et des maux sociaux donné pour unique appui à la morale et au droit, du moins quand on restreint ce calcul à l'intérêt social actuel sans tenir compte de l'avenir. L'erreur implicitement contenue dans les considérations successives déroulées plus haut consiste à croire ceci : toutes les fois que la balance actuelle des biens et des maux, des plaisirs et des douleurs ressentis à la fois par les membres du corps social, est favorisée ou du moins n'est pas inclinée davantage du mauvais côté par l'effet d'une action, cette action est légitime. Cette balance est une sorte de somme algébrique, où les quantités positives (plaisirs) et les quantités négatives (douleurs) s'additionnent ensemble, quelle que soit la diversité des individus qui les éprouvent au même instant, et cette somme ne change pas si une souffrance ou une joie donnée est supprimés chez l'individu A et simultanément produite chez l'individu $\mathrm{B}$. Il est difficile d'échapper à cette conséquence si l'on est persuadé avec Bentham que, sous le mot droit, il n'y a rien ou il n'y a que des idées de douleurs et de plaisirs. Et de fait, quand on y cherche autre chose, en dehors des vaines entités à l'usage de la scolastique juridique, on est bien embarrassé ; et qu'y trouve-t-on de plus, après réflexion? A mon avis, on y trouve aussi, et surtout, des volontés et des croyances, par lesquelles nous nous imaginons viser simplement et juger agréable ou pénible, bon ou mauvais, ce qu'en réalité nous créons tel; des volontés et des croyances non pas individuelles, mais sociales, c'est-à-dire héréditairement ou contagieusement suggérées à l'individu par ses aïeux ou ses contemporains, par l'air ambiant de son pays et de son siècle. Les 
problèmes soulevés par la question, en apparence secondaire, du délit " nécessaire », problèmes qui embrassent en réalité tout le domaine pénal et même civil, puisqu'il s'agit toujours en toute action criminelle ou honnête, d'opter entre deux biens ou deux maux, inhérents à la même personne ou à plusieurs personnes différentes; ces problèmes sont insolubles si l'on oublie la solidarité des compatriotes dans la vie et dans la mort, la nécessité fréquente d'immoler non pas seulement l'intérêt individuel à l'intérêt général, mais souvent l'intérêt général du moment à l'intérêt plus général encore des générations futures, conformément parfois aux prescriptions dogmatiques, aux impératifs catégoriques, des générations passées.

Mais laissons là ces difficultés transcendantes. Revenons. Quelles que soient mes réserves au sujet de l'indulgence abusive où l'on se trouverait conduit par les déductions utilitaires indiquées ci-dessus, il faut mettre à part le cas de mort certaine faute d'homicide. Car l'intérêt de vivre est si infiniment supérieur à tout autre qu'il ne souffre de comparaison avec aucun autre, pas plus que l'infini, en mathématiques, n'est comparable à une quantité finie quelconque. Or, à ce cas, ne devons-nous pas assimiler ceux où une personne ne saurait sans attenter à la vie d'autrui, sauvegarder un bien auquel elle est plus attachée qu'à la vie même, - par exemple l'honneur s'il s'agit de certains hommes, la pudeur s'il s'agit de certaines femmes ? Mais si ce point est accordé, de quel droit refuserait-on d'ajouter à cette liste un intérêt si souvent plus cher que l'honneur et la pudeur, - je veux dire l'amour?

C'est par ce point d'interrogation que nous sommes ramenés tout droit à Aïn-Fezza. Voici une jolie empoisonneuse, non par cupidité comme les Brinvilliers et les Voisin, mais par amour. Elle aime follement comme elle est aimée ; l'audace incroyable de ses rendezvous avec son amant à deux pas du lit de son mari, ses lettres brûlantes, son complet bouleversement d'âme à partir du moment où le bel ingénieur a apparu dans sa vie, sa mort tragique enfin, tout prouve la folie de sa passion. Jeanne Daniloff a 24 ans, elle est sous ce ciel algérien fatal aux Chambige ; elle est hystérique, et elle est russe, de cette race à laquelle nous devons, grâce à l'importation trop brusque de notre civilisation, les Wladimiroff, beaucoup moins intéressants qu'elle, et les nihilistes autrement passionnés, mais non 
plus fortement. - Remarquez que ce n'est pas la race que j'accuse, car le vrai russe c'est le moujik, qui ne donne pas dans les extravagances amoureuses ou politiques, et a le bon sens tenace de nos paysans; mais c'est le greffage hâtif d'une civilisation étrangère sur une race simple et forte qui est dangereux. - Fille de nihiliste elle-même, élevée au gré des vents qui l'ont jetée dans les milieux les plus divers, parmi des savants, des littérateurs, des femmes galantes, Jeanne a préludé par des attachements courts et violents à ses cinq années d'heureux mariage où l'ardeur de son tempérament semble s'être amassée dans le repos du foyer pour rendre plus terrible l'explosion finale. Elle voit un jeune homme, et, dès ce jour, elle ne s'appartient plus. Tout ce qu'il veut, il faut qu'elle le fasse, si insensé que ce soit. Il se glisse la nuit dans la chambre conjugale, près du lit où dorment les deux époux, réveille Jeanne et lui dit : viens ! et elle le suit dans la pièce voisine. «Il m'était, dit-elle, impossible de lui résister. » Elle a fait tous ses efforts, comme le lui a dit le président des assises, pour briser ses relations avec lui. Elle n'a pu. Elle a appelé son mari à son secours. Tentative désespérée ! L'amour a vaincu. Chez elle, chez son amant, l'adultère exalté s'élève à la hauteur d'un sacrement soumis à une sorte de rituel, il implique des serments sacrés écrits sur des carnets, une remise de bagues, l'inscription de dates commémoratives. Il suppose, avant tout, une concentration, une convergence, invincible de tout l'être vers un autre être et l'impossibilité de vivre sans lui. Roques parti, Jeanne Daniloff ne vivait plus que par l'espérance de le revoir.

Donc, son amour, c'est sa vie ; et, d'autre part, elle est convaincue que le seul moyen qui lui reste de reposséder son amant c'est d'assassiner son mari. En effet, elle a essayé de divorcer, mais, en vain elle fait des scènes domestiques, l'homme de coeur qui l'a épousée par passion et qui subit aussi la contagion de cette nature délirante, l'adore trop pour consentir jamais à une rupture. De deux choses l'une, donc : le tuer ou mourir. Il semble qu'elle ait hésité, que l'idée fatale du poison ait mis du temps avant de s'implanter en elle. Enfin, c'est résolu : elle l'empoisonne par l'arsenic.

Je me demande ce qui manque à cette résolution pour réunir les conditions du délit nécessaire, et si ce n'est pas le cas d'appliquer la théorie de l'état de nécessité pour juger de sa valeur. Je sais bien que les procédés mis en oeuvre par Jeanne Daniloff sont odieux. Cette 
affreuse comédie qu'elle joue pendant plusieurs jours au pied du lit de son mari, ces gouttes de poison versées et ces caresses prodiguées, ces précautions infinies pour effacer toute trace de son forfait, et, dans ses lettres à Roques, cette unique préoccupation, cette unique peur de n'avoir pas assez de «remède », c'est-à-dire d'arsenic, et « de ne pouvoir aller jusqu'au bout » : il y a bien là de quoi faire prendre en horreur cette vipère féminine au venin subtil, cette femme qui n'a pas un instant de pitié pour son mari torturé par elle, cette mère qui ne songe pas à ses enfants. J'accorde qu'elle serait plus sympathique si, dans un moment d'exaltation, elle eût déchargé son revolver sur son époux. Peut-être, probablement même, le jury l'eût-il alors acquittée. Mais, après tout, la question du genre de mort est secondaire, et, si l'on part de ce principe que, la vie d'une personne valant celle d'une autre, la nécessité de tuer pour ne pas mourir excuse l'homicide en général, je ne vois pas pourquoi elle n'excuserait pas en particulier l'empoisonnement, surtout de la part d'une femme.

Je ne fais pas de paradoxe. Je maintiens que, si le système social des droits et des devoirs n'est et ne doit être que la consécration des besoins naturels, organiques, comme il n'est pas de besoin naturel plus impérieux que l'instinct de conservation, l'individu n'a jamais le devoir de se laisser mourir pour respecter la vie d'autrui. Je dis que, si l'on part de ce principe, trop légèrement accueilli et répété partout, l'acte de Jeanne Daniloff n'est point punissable et qu'elle ne saurait être réputée coupable. Quant à moi, je tiens son acte pour criminel parce que j'adopte un principe différent et plus complexe, parce que je crois qu'aux besoins de source organique s'ajoutent des besoins de source sociale, des instincts sympathiques, désintéressés, généreux, nés de l'association des hommes et, plus que tous les autres, consacrés par des obligations juridiques ou morales. Ce n'est pas au soldat seulement, c'est au citoyen quelconque, voire même à la citoyenne, que la société impose le devoir de savoir mourir et de mourir parfois pour sauver ses frères. Si elle ne pouvait se passer de Roques, Jeanne Daniloff n'avait qu'à absorber elle-même le poison qu'elle distillait à son mari. Le suicide lui eût été un préservatif de l'homicide au lieu d'en être le complément ${ }^{1}$. Pourquoi ne l'a-t-elle pas fait, elle, si

Remarquer, en effet, qu'il y a des cas où il faut tuer ou se tuer et non pas seulement tuer ou mourir. Dans ces cas là, si l'on prohibe le suicide, on commande l'homicide. Il faut bien se 
familiarisée avec l'idée de la mort violente et de l'amour sanglant, elle qui a vu il y a quelques années un de ses amoureux se tuer pour elle, et qui a trouvé cela tout naturel ? Pourquoi la répugnance au meurtre lâche et martyrisant n'a-t-il pas suffi à la décider au suicide, et ne s'y est-elle déterminée qu'après l'exemple qui lui en a été donné par son amant et après la mort de l'enfant fruit de l'adultère ? Parce que l'égoïsme forcené des sens était le fond de cette nature ; et aussi parce que, chez les âmes même les plus tragiques, comme paraît l'avoir été celle-là, l'amour de la vie résiste longtemps à la tentation d'échapper aux maux de la vie. Dans sa prison, elle s'accuse d'être lâche. "Car il n'y a pas à dire, écrit-elle, je le suis, je voudrais vivre ! L'anéantissement complet me fait horreur, et je ne puis vivre ! » Elle écrit cela à la veille du jour où elle va, en dépit de la surveillance la plus active, avaler de la strychnine. Cet exemple montre, entre parenthèses, qu'il n'y a pas, à vrai dire, d'impulsion au suicide ; il n'y a qu'une expulsion hors de la vie, même dans le cas de folie, par la violence des maux qu'on souffre et contre laquelle lutte obstinément l'instinct du salut. Une grande pitié par suite, est due à celui ou à celle qui succombe dans ce duel intérieur. Cette pitié toutefois, dans le cas actuel, ne doit pas aller jusqu'à nous faire regretter la condamnation dont l'accusée a été frappée ni même l'inexorable refus de pardon prononcé contre elle par son mari, aux cruels applaudissements du public. Ce double verdict était à coup sûr mérité ; car si Jeanne Daniloff eût accompli impunément son dessein criminel, il ne m'est pas prouvé, quoi qu'elle en ait dit, qu'elle se fût suicidée ensuite; il est plus probable que, enhardie plus tard par l'impunité, elle aurait récidivé et fait subir à Roques un jour le sort de son prédécesseur. Mais, malgré tout, il est impossible de ne pas voir dans le suicide, malheureusement tardif, de cette femme, l'explication de son âme, la révélation de son énergie, de sa sincérité, de ses souffrances, de la fatalité des sentiments toutpuissants qui l'ont poussée au crime. C'est dire, du reste, qu'elle s'y est poussée elle-même, car ces sentiments c'était elle, et rien ne lui était plus essentiellement propre que de sentir ainsi.

rappeler ceci, que la prohibition absolue, et sans restriction, du suicide, rend quelquefois l'homicide nécessaire. Elle est sous-entendus dans beaucoup de cas par "l'état de nécessité » de M. Moriaud. 
Cette affaire a soulevé incidemment une question qui se rattache aussi, par un certain côté, au problème du Délit nécessaire. Un ami du mari de Jeanne Daniloff s'est aperçu qu'elle l'empoisonnait, il en a acquis la conviction personnelle, et, pour la faire partager à la justice, il a intercepté à la poste, soustrait frauduleusement pour appeler les choses par leur nom, une lettre adressée par l'empoisonneuse à son amant. Quid, au point de vue moral et juridique, de cette action? Il s'agit là aussi d'un délit dont la nécessité a paru se faire sentir à celui qui l'a commis, et s'est en effet révélée après l'ouverture de la lettre. Sans cette violation hardie de correspondance, M. Weiss serait mort maintenant. Roques et sa maitresse savoureraient un bonheur assaisonné peut-être par le souvenir de leur complicité criminelle. Vaudrait-il mieux que cette lettre n'eût pas été violée, que cet exemple dangereux des avantages d'un pareil viol n'eût pas été donné, au risque de provoquer avec les meilleures intentions du monde mille imitations abusives, inutiles et funestes de ce précédent? Qui le sait? qui le saura jamais? En tout cas, il faut reconnaître que, si le vol nécessaire au voleur est parfois justifiable, à plus forte raison doit-on légitimer celui qui est nécessaire à la société, à la sécurité publique. Seulement y avait-il vraiment nécessité ? Et l'impunité d'un coupable n'est-elle pas préférable socialement au danger d'un encouragement donné à l'infraction d'un devoir reconnu?

- J'avais dit que je parlerais aussi du crime de Chantelle. Mais je n'ai pas le courage d'y toucher maintenant. Il me semble que je ferais subir au cadavre de Jeanne Daniloff un outrage posthume en la comparant à Mme Achet, cette veuve cupide qui, pour payer ses dettes, tend à un vieux notaire libertin un guet-apens mortel. L'argent ici, non l'amour -nullement la pudeur - a été le mobile. Il est curieux de voir, par les appréciations que portent sur cette sinistre créature, même après l'assassinat, en pleine audience, les personnes de son entourage, jusqu'où peut aller l'hypocrisie féminine. (Corruptio optimi pessima). - "C'était la femme la plus doute qu'on puisse voir » dit le juge de paix. "Mme Achet, dit Mme L. avec des larmes dans les yeux, était pleine de douceur et de gentillesse. " $\mathrm{Au}$ moins le souriceau de La Fontaine, quand il dépeint à sa mère le chat qu'il a vu venir avec " une humble contenance, un modeste regard» a-t-il la perspicacité d'ajouter : « et pourtant l'œil luisant, » L'œil luisant de Mme Achet, apparemment, n'avait pas échappé à son adorateur du 
notariat; car, plus pénétrant, mais ne croyant pas sans doute prophétiser si juste, il disait quelques jours avant le crime, en parlant d'elle et de sa sœur: «Ces femmes ne valent pas plus l'une que l'autre. Quelqu'un qui se hasarderait une nuit à aller sans défiance là-bas, pourrait bien avoir le sort de Gouffé. »- Certes, si l'on pouvait admettre un instant la version de l'accusée, à savoir que, forcée dans ses derniers retranchements par les entreprises juvéniles de ce vieillard, elle a cédé aux transports de sa pudeur révoltée, on pourrait absoudre cette Lucrèce qui tue Collatin au lieu de se poignarder ellemême. Ce serait encore un crime nécessaire. Mais il est inutile de prouver, après les antécédents de Mme Achet, que sa pudeur ne lui était pas plus chère que sa vie. - A l'occasion de cette affaire, les mauvais plaisants ont pu rire un peu de l'attitude des quatre médecins experts, en contradiction les uns avec les autres, comme les docteurs du Médecin malgré lui. Si l'on y réfléchit cependant, on verra là la preuve non de l'inutilité de l'expertise, mais de la nécessité d'en confier la charge à des médecins spéciaux, expérimentés, instruits, non au premier médecin local qui apporte dans l'exercice de sa mission des préoccupations étrangères parfois à la recherche pure de la vérité. 
Gabriel Tarde, Études pénales et sociales (1892)

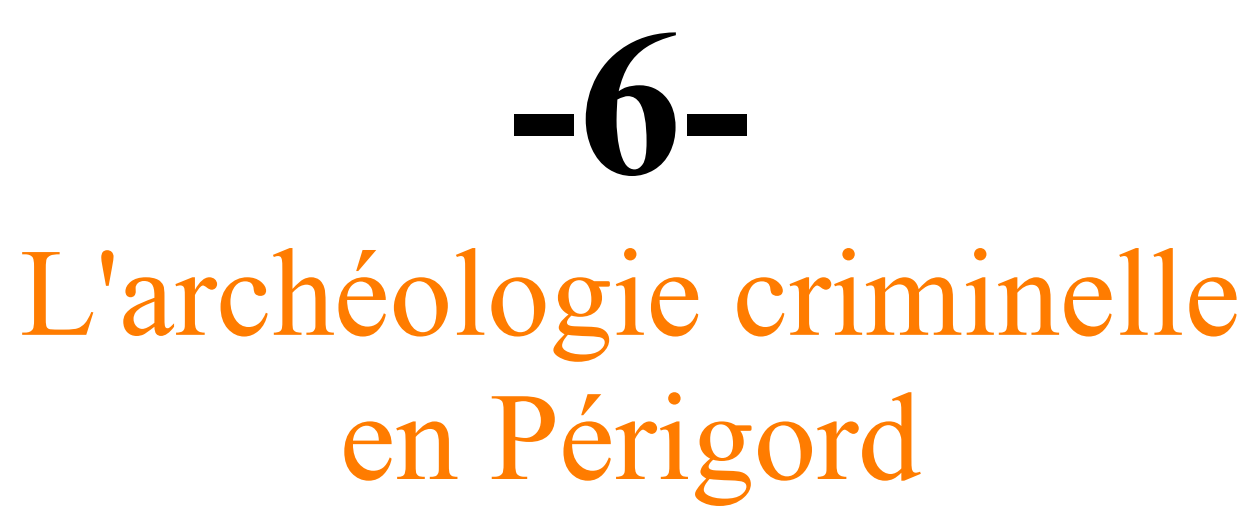

$\underline{\text { Retour à la table des matières }}$

Il est vraiment bien fâcheux que les criminologues aient en général si peu de goût pour l'archéologie, et que les archéologues ignorent tout ce qui est sociologie, criminologie ou anthropologie quelconque. Qui perd le plus à cette séparation étanche de deux ordres de recherches parallèlement poursuivies sans nul contact fécond ? Je n'en sais rien. D'un côté, le criminaliste qui se dit et se croit évolutionniste ment à sa prétention en négligeant d'étudier l'histoire du crime puisée aux sources mêmes, authentiques et précises. La criminalité d'ancien régime sur laquelle abondent les documents, peut seule éclairer la nôtre, et c'est une mauvaise plaisanterie de demander l'explication de celle-ci à la préhistoire ou aux anthropoïdes avant de s'être adressé d'abord à un passé infiniment plus instructif pour deux raisons, parce qu'il est plus récent, et parce qu'il est plus lumineux. Mais, d'autre part, quel dommage de voir tant de consciencieux fouilleurs d'archives 
dépenser des trésors de sagacité à déterrer et déchiffrer des manuscrits pour résoudre des questions d'importance frivole ou secondaire, sans jamais se soucier de ce qui devrait les préoccuper par dessus tout: l'archéologie morale !

Je me disais cela, il y a quelque temps, en ayant le plaisir d'entendre, avec M. Lacassagne, notre ami le Dr Corre nous développer ses projets d'étude et de publication sur le crime d'ancien régime à Brest. Une idée analogue à la sienne s'était déjà présentée à moi, et, si je l'ai longtemps écartée, c'est, l'avouerai-je, par paresse. A première vue, l'idée de faire une fouille d'ensemble dans les amas de procédures criminelles légués par les anciens tribunaux de la France, a de quoi épouvanter. Mais, depuis ma conversation avec M. Corre, j'ai songé qu'en réalité ce travail est moindre qu'en apparence, du moins si on l'envisage sous un aspect un peu différent de celui qui séduit si fort, et non sans raison, notre collègue de Brest. À ses yeux, il convient de se plonger directement dans l'étude des vieux dossiers, de les parcourir tous, et d'en éventrer quelques-uns à fond pour essayer de ressusciter ainsi d'anciens malheureux condamnés à la pendaison et à la roue. Il est certain qu'il y a là des mines psychologiques à exploiter, et, pour s'en convaincre, il suffit de lire, par exemple, dans la Police sous Louis XIV par Pierre Clément, les chapitres sur la Brinvilliers et la Voisin. Cependant n'est-il pas à craindre qu'en suivant exclusivement cette méthode, excellente, je n'en doute pas, entre les mains d'un esprit philosophique tel que celui de son auteur, ses imitateurs ne se laissent entraîner à l'attrait fatal des crimes d'exception, des curiosités, des singularités monstrueuses, et à l'oubli des délits moyens, habituels, ordinaires, où se peint sous des couleurs plus ternes, je le veux, mais plus exactes, la physionomie criminelle du passé ?

Aussi m'a-t-il semblé qu'il y aurait peut-être avantage à utiliser en même temps des travaux déjà exécutés en grande partie par les archivistes départementaux de notre pays et qui répondent précisément au besoin d'information sur la délictuosité pour ainsi dire normale de jadis. On sait que chaque chef-lieu de département français possède un archiviste, dont la tâche, assez ingrate, consiste à inventorier exactement, à résumer succinctement, les archives de tous les arrondissements centralisés à la Préfecture. On sait aussi, ou plutôt il est regrettable qu'on ne sache pas assez, que beaucoup de ces 
inventaires-résumés ont déjà été publiés. Or, parmi les pièces analysées, celles qui ont trait au fonctionnement de la Justice criminelle d'avant 1789 ou 1790, occupent une grande place. Pourquoi ne pas feuilleter un peu ces utiles recueils comme nous étudions les registres officiels de notre statistique judiciaire, assurément bien plus arides ?

Pour donner un échantillon de ce qu'on trouve dans ces livres vierges quand on se donne la peine de les déflorer, je vais demander au lecteur ami la permission de le conduire à Sarlat,en Périgord, ma patrie, à Périgueux pareillement, et de l'introduire dans deux vieux bâtiments obscurs et pittoresques de ces deux villes, l'Hôtel du Sénéchal et du Présidial.

Si nous pouvions faire revivre le personnel de ces deux tribunaux, et leur fonctionnement, photographier l'une de leurs audiences, peutêtre serions-nous moins étonnés de certaines singularités, que nous ne nous y serions attendus.

Dans la magistrature, où tous les dehors se conservent d'âge en âge, rien en somme n'a beaucoup changé extérieurement, ni le costume, sauf la perruque, ni le langage baroque, ni même la procédure, et, quant aux traits physiques des juges aussi bien que des justiciables, ils devaient certainement ressembler à ceux de mes compatriotes actuels, qui portent souvent les mêmes noms, et, souvent aussi, j'en ai fait la remarque en lisant, exercent le même métier ou du moins appartiennent à la même classe sociale. Il serait curieux, en revanche, de pouvoir soulever la calotte des crânes et scruter les fonctions spirituelles de leurs porteurs. $\mathrm{Si}$, anthropologiquement, ceux-ci sont restés les mêmes, leur transformation psychologique a été profonde. Les sentiments moteurs des âmes et leur orientation ont changé du tout au tout. Prenez le juge d'alors et comparez-le au juge d'aujourd'hui. Une de ses énergies dominantes et constantes était la conviction qu'il était né juge ${ }^{1}$ comme le roi était né roi, qu'il y avait en lui un certain droit immanent de juger ses semblables. Rien de

À la vérité, il avait acheté son office, mais perce qu'il avait eu la droit de l'acheter, comme appartenant par sa naissance à la corporation judiciaire, fils, petit-fils, arrière-petit-fils de magistrats. 
pareil à présent heureusement. Mais l'avantage était que cette fierté était une force contre la pression du pouvoir, une garantie d'indépendance. Et, de fait, je m'aperçois que Sénéchal et Présidial, au risque d'encourir les terribles vendettas héréditaires d'alors, frappent indistinctement les plus hautes têtes féodales de leurs sentences draconiennes. À la lecture de ces impitoyables arrêts, on sent, sous cette férocité, une impartialité courageuse par laquelle Présidiaux et Parlements se valaient et rivalisaient de méritoire orgueil. Et, certes, je ne veux pas dire que, par ce trait, mes collègues et moi, nous contrastions avec nos prédécesseurs; mais enfin il me semble que notre indépendance à nous a quelque chose de moins frappant ou de moins héroïque. Autres différences bien plus accusées : le magistrat ancien, précisément parce qu'il était très fier du corps auquel il appartenait, professait le dédain de l'avancement, et se souciait peu d'échanger sa robe de conseiller à son Présidial contre celle de conseiller au Parlement voisin; mais d'ailleurs il tenait fort à monter en grade socialement, c'est-à-dire à s'anoblir de plus en plus. M'est-il permis de faire observer que, par ce mépris de la hiérarchie professionnelle et ce culte de la hiérarchie sociale, il est la vivante antithèse $\mathrm{du}$ magistrat contemporain, avec sa rage d'ascension judiciaire et son air égalitaire? Autre différence. La question des préséances, qui passionnait autrefois, est devenue insignifiante maintenant; ou, si elle renaît encore çà et là ; c'est sous une forme infiniment plus facile à résoudre, puisqu'elle n'intéresse plus que la vanité individuelle. Jadis elle intéressait surtout la vanité corporative ; et l'on a vu, par exemple, le Présidial de Sarlat plaider pendant 50 ans contre le tribunal de l'Élection pour savoir lequel des deux aurait la première place à l'église. L'amour-propre collectif de nos administrations actuelles est devenu beaucoup moins irritable, bien que leurs membres ne laissent pas d'avoir leur petit amour-propre particulier. Dirai-je enfin que je n'ai pu lire tant d'arrêts de condamnation à la pendaison et à la roue pour de simples vols, les procès faits à la mémoire des protestants morts dans l'impénitence finale, et tant d'autres procédures extravagantes ou odieuses, sans me féliciter de pouvoir opposer à la sévérité atroce, à la foi fanatique, à l'austérité puritaine de la magistrature ancienne, l'indulgence même excessive, la tolérance même sceptique, l'anémité même relâchée des nouveaux magistrats ? 
Si une révolution s'est accomplie dans l'âme des juges malgré l'identité de leurs robes, de leurs rabats, de leurs toques, de leur installation sur une estrade entre un greffier et un membre du Parquet, l'âme des justiciables n'a pas subi de moindres changements, comme nous allons le voir. - Mais un mot d'abord sur les documents dont nous allons nous servir. L'Inventaire pour Sarlat est encore incomplet et inédit; une partie cependant est déjà imprimée, et je dois à l'obligeance de son auteur la communication des bonnes feuilles ${ }^{1}$. Je les ai étudiées spécialement, mais j'ai complété cette étude par celle de l'Inventaire pour Périgueux, qui est complet et beaucoup plus volumineux. Je ferai de fréquents emprunts à ce dernier. Dans l'ensemble il diffère peu du précédent et donne lieu aux mêmes considérations, à cela près que le premier, d'une couleur plus accentuée, témoigne de mœurs encore plus rudes, qu'abritait mieux sans doute contre l'importation de la civilisation relative du Nord une région plus accidentée. J'ai aussi utilisé quelque peu les inventaires de l'Agenais et du Quercy.

J'ai cru pouvoir traiter pêle-mêle des procédures criminelles déroulées devant le Sénéchal ou devant le Présidial. Bien que les délits les plus graves ressortent plus spécialement au Présidial, tribunal d'appel, et que la proportion des plaintes pour homicide et pour vols importants y soit plus forte, les deux juridictions rentrent l'une dans l'autre et font souvent double emploi. Le Sénéchal, comme le Présidial, s'occupe de meurtres, de sacrilèges, etc., et condamne à l'étranglement, à la pendaison, à la roue, à l'amende honorable.

Cala dit, entrons en matière. Pour bien comprendre l'étendue ou la profondeur des changements moraux et sociaux opérés depuis deux ou trois siècles dans le petit pays dont il s'agit, considérons séparément : 1 les délits, fréquents aujourd'hui, qui brillaient autrefois par leur absence complète ou presque complète; $2 \bullet$ les délits, fréquents autrefois, qui ont disparu ou qui n'en sont plus ; $3 \bullet$ les délits communs au présent comme au passé, mais qui s'y présentent en proportions

Disons en passant que ce travail de M. Villepelet, secrétaire général de la Société archéologique du Périgord, est un modèle du genre, par la précision, la clarté, l'exactitude et le choix intelligent des citations intercalées çà et là, les plus propres à exprimer l'âme même des textes résumés. 
différentes et avec des caractères distincts, effets de mobiles tout autres. - Après quoi, nous parlerons des pénalités.

Commençons par les délits absents ou rarissimes. Les viols d'abord, et les attentats à la pudeur : il y en a 3 ou 4 à peine, presque tous commis par des adultes sur des adultes, un seul (p. 143), par un adulte sur un enfant. Point d'outrages publics à la pudeur. Les formes raffinées et astucieuses du vol, escroqueries, abus de confiance, banqueroute ${ }^{1}$, paraissent aussi faire défaut. Presque point d'infanticides, et ce crime inspire tant d'horreur, à raison de sa rareté en partie, qu'il est puni beaucoup plus sévèrement que l'homicide. Rarement le meurtrier est puni de mort, il ne l'est que lorsqu'il a été en même temps voleur; mais la fille où la femme qui a tué son enfant est sûre du gibet. «Guill. Deladeuil, défenderesse, prisonnière, accusée par le Procureur de la juridiction de Ladouze du crime d'infanticide, est condamnée à être pendue et étranglée par l'exécuteur de la haute justice sur la place publique d'Entre-les-deux-villes, à une potence qui y sera dressée, et son corps sera brûlé et mis en cendres; mais, avant de procéder à l'exécution, la cour criminelle (le Présidial de Périgueux) ordonne qu'elle sera mise à la question et torture pour savoir par sa bouche le fait des complices ${ }^{2}$. » Cet arrêt est de 1592, mais jusqu'à la fin du XVIIIe siècle la jurisprudence sur ce point n'a pas varié. A côté, on peut lire un grand nombre de lettres de grâce obtenues par des assassins.

Je ne vois, dans l'Inventaire de Sarlat, le mot de banqueroute prononcé qu'une fois, et encore peut-être improprement (p. 142), à propos d'une plainte « de Messire Armand de Beaumont, seigneur comte de..., contre Pierre Thibal, sieur de la Coste, à qui il a affermé pour 500 livres sa forge de Beyssac et le moulin en dépendant, et qu'il accuse de banqueroute frauduleuse (1733) ». Noter qu'à cette époque le Périgord était semé de forges, toutes éteintes maintenant.

2 Inventaire du Périgord, $\mathrm{p} 41$. 
Une seule fois, l'idée de folie apparaît dans l'Inventaire de Sarlat (p. 157) : c'est surprenant si l'on veut que la criminalité et la folie soient indissolubles.

En somme, il est manifeste que ce bilan criminel de l'ancienne population périgourdine nous la peint beaucoup plus dépourvue d'astuce et de sensualité que ne l'est la nôtre.

\section{II}

$\underline{\text { Retour à la table des matières }}$

Voyons les crimes qui ne sont plus ou qui n'en sont plus. Combien y en a-t-il, des plus monstrueux jadis, qui sont tombés au rang de délits, de contraventions, de faits licites! Il est parlé une fois du " crime de maquerellage », d'autres fois du crime de fornication, du crime de luxure, du crime de scandale; à chaque page, du crime de blasphème ou de non-catholicité, rarement, mais parfois, du crime d'adultère, du crime de duel, et surtout du crime de chasse ! D'office, et sans nulle plainte maritale, l'adultère était poursuivi. En 1685 (Périgueux), le procureur du roi, «demandeur en crime d'adultère commis avec scandale par la tolérance du mari », fait condamner les trois coupables au bannissement hors du ressort de la sénéchaussée et à une amende. Au nombre des plus grands forfaits, il fallait compter le blasphème et l'infraction aux commandements de l'Église. En 1696, plainte du Procureur du roi « contre Gabrielle Frenon, fille de ministre (nous sommes au lendemain de la révocation de l'Edit de Nantes), et contre Jeanne Madranges, sa nièce, accusées d'avoir contrevenu aux ordonnances et règlements relatifs à l'observation des fêtes de l'Église catholique, notamment en lavant et faisant laver la lessive le jour de saint Laurent, fête chômée ». Deux pages plus haut, je vois des paysans dénoncés pour avoir joué aux quilles pendant vêpres ; d'autres pour avoir fait du bruit hors de t'église pendant la messe, pour n'avoir pas salué une croix en passant, pour avoir donné à manger et à boire 
dans une auberge un jour de fête ${ }^{1}$. En 1659, un maître tailleur a poussé l'irréligion jusqu'à travailler chez lui, « en présence de son père, de son métier, le jour de la Pentecôte, et pendant la messe », et l'information, faite à la requête du Procureur du roi, nous apprend que cette action inouïe "a causé un grand scandale dans la paroisse » (Périgueux).

En 1594, - il est vrai que l'esprit de la Ligue vit encore, - « Thony Rousseil, accusé du crime de lèse-majesté divine, est condamné à faire amende honorable un jour d'audience à Périgueux et devant la porte de l'église Saint-Paul de Serre, à l'issue du service divin, ayant la tête et les pieds nus, en chemise, la hart ${ }^{2}$ au cou et une torche de cire allumée à la main du poids d'une livre et à déclarer qu'il a blasphémé contre la majesté de Dieu et scandaleusement proféré les paroles suivantes sur le saint sacrement de l'autel : «Tu le manges tout et bois tout, grand bien te fasse ! Dieu aie l'âme du défunt et Saint Michel les tripes », propos dont il se repent et demande pardon à Dieu, au Roi, à la Justice et au curé de sa paroisse : l'accusé aura ensuite la langue percée avec un fer rouge, puis sera fouetté de cordes jusqu'à effusion du sang... et paiera en outre une amende de vingt écus. " Un siècle après, la sévérité contre les blasphémateurs n'avait pas diminué ; loin de là. En 1683 (Périgueux) un accusé, convaincu " d'avoir blasphémé le saint nom de Dieu » est condamné, d'abord, à une amende honorable dans le genre de la précédente, à cela près que la torche sera du poids de deux livres, et qu'au front le malheureux portera un écriteau avec ces mots : blasphémateur ordinaire ; mais, en outre, l'arrêt ajoute que « il sera ramené dans les prisons pour être livré entre les mains de l'exécuteur de la haute justice et être par lui conduit à jour de marché la corde au col, en chemise, torse nue et pieds nus », et recommencer la même confession publique de son péché ; après quoi, il sera " conduit dans le même état à la place de la Clautre et y sera attaché au carcan pendant l'espace de quatre heures; et ensuite sera

Ce n'est pas seulement contre des personnes du peuple que de telles dénonciations ont eu lieu, c'est aussi et même plus souvent qu'on ne l'aurait supposé, surtout au cours du XVIIIe siècle, contre des membres de la noblesse ou de la magistrature. En 1725, je vois une plainte du curé de Laroque-Gajac, petite commune du Sarladais, contre un magistrat de Sarlat. "qui a été irrévérencieux dans sa chapelle, (dans sa chapelle à lui, auteur de ce méfait) en causant scandaleusement, un jour de Fête-Dieu, avec des demoiselles et des jeunes gens. »

2 La hart, on le sait, était la corde qui servait à étrangler les criminels. 
mené et conduit à la chaîne pour y être attaché et servir de forçat dans les gallères du Roy pendant cinq années... » On voit que le Présidial de Périgueux se conformait au vœu, exprimé par Colbert, de voir les cours de justice garnir de rameurs les galères de Sa Majesté.

Mais, dès le commencement du XVIIIe siècle, je ne découvre plus de poursuites contre ce crime, apparemment démodé déjà. Le blasphème n'est plus poursuivi qu'accessoirement, quand il accompagne des coups à l'adresse du curé ou toute autre violence. Le voleur sacrilège est puni comme sacrilège, mais surtout comme voleur. En 1737, par exemple (Périgueux), plainte du prieur-curé de Miremont contre un nommé Blondel « qui le menaça publiquement de coups avec mille blasphèmes ». En 1746, un prêtre, un menuisier et un journalier sont «accusés du crime de sacrilège et de vol de vases sacrés, commis dans l'église paroissiale de la ville de Brantôme, avec effraction extérieure à la porte de la dite église ». En 1779 encore, divers particuliers «accusés du crime d'exhumation et de profanation commis dans l'ancien cimetière de Cubjac », le sont en même temps d'avoir tenu des discours impies et scandaleux ... ». Après cette date, les blasphémateurs périgourdins m'ont l'air d'avoir été complètement impunis. L'Encyclopédie a fait son oeuvre.

Parmi les crimes qui n'en sont plus, et qui, il faut l'espérer, n'en seront plus jamais, on peut bien compter, je pense, celui de professer une religion contraire au culte officiel. Les années qui ont suivi la révocation de l'Édit de Nantes (1686) abondent, dans toute notre région, en persécutions contre les protestants et leurs pasteurs. En 1689, il est dit incidemment dans une procédure de Périgueux que, « en exécution des ordres du roi et de messieurs de la cour présidiale, Jean Darpès, huissier.., s'est rendu dans la ville de Mussidan pour faire prisonnier le sieur Mizambini, ministre de la R. P. R. ${ }^{1}$ et le conduire dans les prisons de Périgueux ». On ajoute que, " au moment où il l'emmenait, le nommé Laubaire, de Mussidan, accompagné de plusieurs autres, voulut le lui enlever et le menaça de l'assommer s'il ne relâchait pas leur ministre... » La même année, à Sarlat, plainte du procureur du roi contre Jean Tresfeilh et le nommé Duverger, son gendre, "nouveaux convertis », qui ont tenu des « discours insolents,

De la religion prétendue réformée. 
séditieux, contraires à la religion et au bien de l'Estat, marquant leur esprit de révolte et leur attachement à l'ennemi juré de l'Église et de l'Estat, et caché des armes au lieu de les remettre, ce qui peut faire connaître leur intelligence avec le prince d'Orange, ennemi capital de la couronne ». Comme toujours, la politique se mêlait aux questions de conscience, et, quand la persécution, à force d'excès, paraissait avoir tué ou blessé le patriotisme dans l'âme du persécuté, elle se croyait justifiée par là, par son propre effet.

On sait que, longtemps avant 1686, le fatal édit de Louis XIV était pressenti et, malheureusement, demandé par cette tyrannie anonyme qui s'appelle vox populi ${ }^{1}$. La magistrature, aussi bien que le clergé, était entrée dans «le mouvement», et je me persuade que les Membres du Parquet les plus éclairés, les plus avancés de leur temps, ne devaient pas être les derniers à se signaler par des poursuites telles que la suivante. En 1680, «Jean Gommar, ministre de la ville de Mussidan (Mussidan était un boulevard du protestantisme en Périgord), est accusé par le procureur du roi, d'avoir avec des complices : 1 fait sonner la cloche du temple pendant qu'on célébrait le service divin dans la chapelle de Notre Dame du Roc ${ }^{2}$, au mépris de la religion catholique, et troublé la procession; 2 - fait une assemblée particulière avec les anciens du consistoire pour violenter l'esprit de sa fille qui voulait embrasser la religion catholique ; $3 \bullet$ commis une impiété envers la Sainte-Vierge... etc. » Pour ces méfaits, cet honnête pasteur a été condamné à 600 livres d'amende, « applicables aux réparations de la chapelle de Notre-Dame du Roc » et il a dû s'étonner d'en être quitte à si bon marché. - Les abjurations

On en trouvera des preuves dans La police sous Louis XIV, par Pierre Clément (1866) «En 1682, le garçon d'un marchand de vin du faubourg Saint-Marcel, professant comme son patron la religion réformée, avait reçu un coup mortel dans une rixe. Un vicaire de SaintMédard l'alla voir et ne put le décider à se confesser. "Le menu peuple, dit un rapport de police, en ayant « eu connaissance, s'assembla en un moment au nombre de 7 à 800 , et, étant « devant la porte du blessé, ils firent toutes les violences qu'on se peut « imaginer, frappèrent à coups de pierres, bâtons et règles, contre les portes, «qu'ils rompirent à quelques endroits cassèrent toutes les vitres, s'efforcèrent «d'entrer dans la maison s'écriant: Ce sont des huguenots et des parpaillots "qu'il faut assommer mettre le feu aux portes, s'ils ne nous rendent le blessé. » L'arrivée d'un commissaire mit la populace en faite.

2 Dans les milieux théocratiques, de telles poursuites paraissent toutes naturelles. De nos jours encore, dans l'Inde, suivant Sumner-Maine, on a vu des arrêts de la justice anglaise « autoriser des prêtres à se dire lésés dans leur propriété et leur honneur, parce que, à un moment donné de leurs cérémonies, une cloche (d'une autre pagode) avait tinté dans leur voisinage ». (His. du droit, trad. fr., p. 63). 
arrachées aux protestants, par toutes sortes de moyens militaires ou pécuniaires, étaient rarement sincères et fréquemment rétractées, surtout au moment de la dernière maladie ; ces rétractions donnaient lieu à des poursuites soit contre le relaps, soit contre sa mémoire. En 1697, (Périgueux) Jeanne Favard, damoiselle, « en présence des officiers de la juridiction qui en dressent procès-verbal, du curé et de trois témoins », déclare qu'elle veut « vivre et mourir dans la religion prétendue réformée, qu'elle avait ci-devant abjurée ; » et le procureur du roi, en vertu de la déclaration royale du 26 avril 1686, requiert qu'il soit permis de l'arrêter pour lui faire son procès. En 1702, un marchand hollandais, naturalisé français, qui avait abjuré le calvinisme, meurt dans la sénéchaussée de Périgueux ; le procureur du roi informe pour savoir dans quelle religion il est mort. Le 17 février 1701, 35 habitants de Villefranche-de-Belvès (Sarlat) avaient signé une abjuration solennelle. Quelques mois après, l'une des signataires, Esther de M., a refusé de se confesser dans sa dernière maladie, et « déclaré qu'elle voulait mourir dans sa religion ; " après sa mort, « le procureur du roi demande que le procès soit fait à sa mémoire. »En 1703, autre procès de même nature contre la mémoire d'un autre signataire mort dans des conditions analogues.

Ces procès faits à des morts nous étonnent. Ils n'étonnaient personne ${ }^{1}$ à une époque où la foi en l'immortalité posthume était générale et profonde. Notre étonnement sur ce point peut servir à mesurer le déclin de notre foi. - Peut-être sera-t-on curieux cependant de savoir à quelle pénalité venaient aboutir de telles poursuites. Voici un échantillon des sentences qui les clôturaient dignement. En 1740, un arrêt du Sénéchal de Sarlat « condamne la mémoire de Marie de S..., convaincue du crime d'apostasie, et ordonne qu'elle demeurera éteinte et supprimée à jamais; comme aussi la condamne à une amende des deux tiers des biens envers le roi, et aux dépens ». Ce n'étaient pas là, on le voit, des condamnations platoniques, et une condamnation à la pendaison ou à l'étranglement par effigie eût été

Ce n'était pas seulement pour cause d'apostasie, mais pour tout autre cause, que la mémoire des morts pouvait être incriminée. En 1752, je vois la mémoire d'un homme "accusée de subornation de témoins ». 
préférable pour les héritiers ${ }^{1}$. - Mais, en 1740 encore, en plein XVIIIe siècle, des arrêts pareils !

Et pourtant le zèle persécuteur, en Périgord, paraît avoir été bien tiède, comparé à l'ardeur de persécution, qui a sévi dans l'Agenais. L'Inventaire de la Sénéchaussée d'Agen en fournit la preuve abondante. On y peut voir d'abord l'intensité des passions religieuses dans ce pays. Une affaire d'homicide nous éclaire là-dessus. Elle nous montre avec quel acharnement protestants et catholiques, dès 1673, se disputaient l'âme des gens. Un sieur Daniel Bourgié, bourgeois de Castelmoron, calviniste, a abjuré sa religion; quelque temps après, sollicité par ses anciens co-religionnaires, il s'est, nous dit-on, « laissé extorquer une déclaration portant qu'il révoquait son abjuration ». Nouveau siège alors des catholiques qui le pressent de rétracter sa rétractation, et il est sur le point de céder quand il est assassiné ; et qui accuse-t-on, qui parait-il naturel d'accuser de son assassinat? Le ministre et les anciens de la R. P. R. et cinq autres individus » qui ont voulu l'empêcher ainsi de commettre ce nouvel acte de faiblesse. - Si, vingt-trois ans déjà avant la révocation de l'Edit de Nantes, la surexcitation des partis et des sectes à Agen atteint ce degré, on doit penser où elle est montée au lendemain de ce coup d'État autocratique. En 1687, 38 accusés, dont 19 détenus et 17 défaillants, sont condamnés par le Présidial d'Agen » pour avoir assisté aux assemblées nocturnes qui sont faites pour la R. P. R. ». Quant aux 19 défaillants, qui ont eu la bonne idée de s'enfuir, ne les plaignons pas trop; une exécution par effigie n'est pas pour leur faire peur au-delà des frontières. Mais l'un des 19 détenus, le chef, est condamné d'abord à faire amende honorable dans le costume traditionnel, puis à être pendu et étranglé ; et, préalablement, à subir la question, dont le résultat déterminera le sort des 18 autres prisonniers. Jusqu'en 1717, les poursuites vexatoires ou sanguinaires se poursuivent devant ce même tribunal. A cette dernière date, sur quatre accusés, convaincus de suivre la R. P. R., un est condamné à être pendu. Notons, à l'article des vexations, une information contre plusieurs personnes, coupables

On comprend que la perspective de pareils traitements ait mis en fuite les suspects. Aussi, je ne m'étonne pas de voir en 1700 (Sarlat), un malheureux apothicaire protestant, dont la maison venait d'être investie, la nuit, par un sergent porteur d'un décret de prise de corps contre lui, s'échapper en chemise et nu-pieds, "par une masure d'eyrial», tandis que sa femme, n'ayant pas eu le temps de se sauver, cachait sous sa jupe les Psaumes de Marot. 
d'avoir assisté à l'enterrement d'une " nouvelle convertie » ensevelie dans son enclos; et, en 1703, des poursuites contre "Prignan de Malerbe, nouveau converti, qui faisait profession de manger publiquement et avec escandale de la viande... les jours défendus ». Bien entendu, les procès aux mémoires ne manquent pas non plus.

Ce terrible présidial d'Agen était impitoyable non seulement pour les calvinistes endurcis, mais encore pour les prêtres catholiques qui, çà et là, s'efforçaient d'adoucir un peu la rigueur des ordonnances. En 1714, il condamne aux galères à perpétuité un curé dont tout le crime consistait à avoir béni, sans les formalités dilatoires requises, le mariage de 40 "nouveaux convertis ». Apparemment, ils étaient mariés déjà suivant le rite protestant, et le bon curé n'a pas eu le cœur de prolonger indéfiniment la séparation canonique des conjoints. L'arrêt ajoute que le mariage de ces "nouveaux mariés », parmi lesquels sans doute il se trouvait de vieux époux, est annulé, et il leur est fait « inhibition et défense de se hanter et fréquenter, sous peine de punition exemplaire ». Un autre curé, à la même époque et dans la même sénéchaussée, est puni de quelques années de galères pour une complaisance analogue.

Admirons, en passant, cette expression de " nouveaux convertis », parfois de " nouveaux catholiques » appliquée à des gens qui le sont si peu, convertis et catholiques, et que l'on condamne précisément pour ne l'être pas. Ils ne l'étaient pas, cela est vrai, mais ils étaient censés l'être, puisque le roi voulait qu'il en fût ainsi ; c'est là un de ces «mensonges conventionnels » dont toute société a faim et soif depuis le commencement du monde, une de ces fictions hypocrites qui, même en se contredisant elles-mêmes, persistent à s'affirmer.

Crime d'apostasie, crime de fidélité à sa religion, crime d'humanité envers des hérétiques: combien d'espèces criminelles, maintenant éteintes, ont surgi durant les persécutions contre les protestants ! Il convient d'en signaler encore une autre, qui malheureusement est destinée à revivre plus tard : le crime d'émigration. En 1689, je vois à Agen, une Moïse Lacoste, accusée d'avoir favorisé la fuite de " nouveaux convertis » hors du royaume ; en 1701, en 1702 encore, je vois des poursuites semblables, notamment contre un individu coupable «d'avoir logé un étranger qui conduisait des nouveaux 
convertis hors du royaume ». A Sarlat et à Périgueux, pareillement. Moins d'un siècle après, d'autres émigrés, parmi lesquels se trouveront les descendants des persécuteurs, seront traqués de la même manière.

Si l'on doutait, malgré les attestations de l'histoire, que de telles poursuites aient été approuvées, réclamées même par le peuple français, il suffirait de quelques lignes empruntées à nos documents, pour nous édifier sur le fanatisme despotique des foules de ce tempslà et de tous les temps. En 1763 (Périgueux), plainte «de Léonard Bramand, laboureur, contre le sieur Rousset, curé d'Augignac, qui lui a refusé la communion ». En 1768, plainte des prieur-curé et chanoines réguliers du prieuré de Saint-Jean de Côle contre les nommés Baricot et Pradel qui les ont injuriés et menacés parce qu'ils ne voulaient pas faire de processions un jour d'orage ». Voilà des ecclésiastiques beaucoup plus prudents et moins superstitieux que leurs ouailles : ils ont dû lire les traités d'électricité, alors à la mode, et ont peur de la foudre. Mais surtout voilà des griefs contre le clergé qui assurément ont fait leur temps.

A tout le monde, classes dirigeantes ou masses dirigées, paraît faire défaut la notion la plus élémentaire, je ne dis pas de la liberté de conscience seulement, mais d'une liberté individuelle quelconque. Je suis surpris que d'une telle disposition d'esprit, d'une telle lacune mentale et si universelle, ne soit pas éclos dès lors le socialisme d'État. Il en était la conséquence logique, imminente. Peut-être doiton considérer la Révolution française et le siècle de troubles émancipateurs qui l'a suivi, comme un simple retard apporté à l'éclosion de cet oeuf redoutable. En 1716, le greffe de Périgueux enregistre une circulaire ministérielle invitant le Procureur du roi à faire exécuter les ordonnances «qui défendent aux hôtes et cabaretiers de tenir leurs cabarets ouverts les dimanches et jour de fêtes, et à toutes personnes de marcher la nuit dans les rues des villes, bourgs et villages du ressort de la cour de Bordeaux $»$. On trouvait cela tout naturel, d'interdire à toutes personnes de sortir la nuit. Rien de surprenant, par suite, si on lit de temps en temps des passages dans ce genre: « dénonciation (en 1755) du promoteur du diocèse au procureur du roi contre M. de Ch. de Chant., et demoiselle Marie V..., qui vivent ensemble en la ville de Mussidan sans être unis par le lien d'un légitime mariage ». Elle aurait fort à faire, l'autorité ecclésiastique ou 
autre qui s'amuserait de nos jours à dénoncer de pareils délits. Lisons encore : vers 1740, "Jean Bazinette, médecin-chirurgien, est dûment convaincu du crime de fornication suivi de grossesse et d'accouchement» le tout de complicité avec «demoiselle Marie-Robert de N..., bourgeoise de Périgueux ». Cependant l'air du siècle est venu jusqu'à nous : ce chirurgien galant n'est condamné pour son crime qu'à des dommages-intérêts envers la personne qu'il a séduite.

Mais on ne plaisante pas, en général, sur le chapitre des mœurs ; et, quand un ecclésiastique est répréhensible à cet égard, ce qui est assez fréquent alors, c'est lui surtout qu'on n'épargne pas. Le Procureur du Roy, en 1745 (Périgueux), informe contre M• Antoine Gatignol de Lantis, sieur de Labagie, prêtre, curé de la paroisse d'Antonne, accusé du crime de scandale. Un autre prêtre, en 1764, est accusé du crime de luxure. Un autre, en 1742, est « accusé du crime de rapt par séduction et inceste spirituel avec scandale ». Inceste spirituel, cela signifie sans doute le crime de fornication commis avec une filleule ou une pénitente.

Tout le monde s'arrogeait de bonne foi un droit, un devoir de surveillance morale sur la conduite de son prochain, et d'abord de ses voisins. Quand un acte, désapprouvé par la coutume, tel que le mariage d'une veuve, se produisait dans une ville ou un bourg, la honte en rejaillissait sur l'entière population de la localité, qui, pour s'en laver, infligeait un châtiment expiatoire aux auteurs du fait scandaleux, et aussi à leurs parents, et même à leurs alliés, en vertu de cette notion de la responsabilité familiale qui est innée dans le cœur des foules. L'épouse Jardel, de Sarlat, en 1787, se plaint « des injures et excès commis à son préjudice par la nommée Campagnac... ${ }^{1}$ et autres quidams, qui sont venus faire un charivari à sa porte, ont cherché à l'enfoncer et l'ont insultée, sous prétexte qu'un de ses beauxfrères se mariait avec une veuve du faubourg de la Bouquerie. " ${ }^{2}$

\footnotetext{
Le texte porte : « la nommée Campagnac, dite M... de Poule.» Ce genre de surnom ordurier était fréquent autrefois dans nos campagnes; et je le note ici comme indice de la grossière gauloiserie d'esprit qui s'y marque.

2 La réprobation contre les secondes noces se manifestait de bien d'autres façons. Parmi les jeux publics qui, traditionnellement, avaient lieu à Sarlat en carnaval et qui n'ont disparu qu'en 1790, je remarque le jeu de la cruche cassée, dont la présidence, ironique et injurieuse assurément, était imposée à la dernière veuve remariée dans l'année.
} 
N'est-il pas permis de voir, dans cette vieille coutume des charivaris abusifs, et dans beaucoup d'autres manifestations traditionnelles, non moins attentatoires aux libertés de l'individu, une survivance, un dernier débris de l'étroite discipline qui, d'après nos érudits, étreignait ensemble, dans les temps primitifs, les villageois agglomérés en communauté de village ? L'existence de ces groupes communistes, à une certaine époque (d'une ancienneté, je crois, fort exagérée) n'est pas douteuse, sinon en Germanie, du moins dans l'Inde, en Russie, chez toutes les nations slaves. Nous a-t-on assez vanté le mir russe, le town-ship saxon, la Zadruga, etc. ? Il existait, peut-être en Germanie, quoique Fustel de Coulanges le conteste et avec une grande force, mais à coup sûr en d'autres pays ${ }^{1}$, un droit, au profit des voisins, de racheter le bien acheté par un étranger, comme il existe encore dans notre code civil un droit pareil au profit des cohéritiers dont l'un a vendu à un étranger sa part héréditaire. Ce retrait vicinal en quelque sorte semblait dénoter entre les voisins un lien comparable à celui que le retrait successoral atteste encore entre les membres d'une même famille, ou à celui que le retrait seigneurial, sous l'ancien régime, révélait entre le seigneur et le vassal. - Eh bien, je ne veux pas pour le moment discuter ces thèses ou ces hypothèses; mais je ferai observer que, s'il en est ainsi, les menus faits dans le genre de celui dont l'épouse Jardel se plaignait à Sarlat en $1781^{2}$ sont propres à nous faire envisager les communautés de villages sous de nouveaux aspects, beaucoup moins enchanteurs que l'apparence idyllique sous laquelle on a l'habitude de nous les présenter.

Ce droit de censure que s'attribuait tout le voisinage, à plus forte raison appartenait-il à la parenté. Au père en premier lieu. Au dixhuitième siècle même, en nos provinces méridionales, l'autorité du pater familias gardait sa saveur archaïque et toute romaine. Les actes d'émancipation, si âgé que fût le fils, se faisaient toujours, disent les procès-verbaux, en la forme solennelle d'autrefois, le fils à genoux et les mains jointes devant le père qui lui délie les mains. Un des crimes

Voir l'Histoire du Droit par Dareste (1889).

2 Autre histoire de charivari. En 1786, un habitant des Eyzies se plaint d'un charivari épouvantable qui lui a été fait parce qu'il a été battu par sa femme et que néanmoins il refuse de se laisser promener processionnellement sur un âne, la tête tournée vers la queue de l'animal. Les habitants des Eyzies, on le voit, voulaient se montrer dignes de leurs ancêtres troglodytes. 
les plus noirs était celui de rapt, d'enlèvement d'une fille dans le but de se marier avec elle contre le gré de ses parents. Le ravisseur avait la tête tranchée et le corps mis en quartiers par le bourreau. Soyons donc assurés que, en 1713, quand un magistrat de Sarlat a porté plainte au Sénéchal contre une fille de conduite légère « qui est allée dans un de ses domaines y suborner son fils, Me Guillaume L..., avocat en la cour, et le porter à concupiscence ", personne, en Sarladais, n'a ri de lui, ni de ce grand fils, avocat, prétendûment suborné par une fille. Soyons même certains que, en 1708, la plainte d'une femme "contre sa belle-sœur, qui mène une vie scandaleuse », et, beaucoup d'autres plaintes semblables émanées de parents quelconques, ont eu l'approbation générale.

$\mathrm{Au}$ fond, sous ces exagérations ou ces étrangetés, éclate dans toute sa force un sentiment dont il ne nous reste plus que l'ombre évanouissante, un sentiment des plus purs, des plus nobles, le seul capable peut-être de lutter avec succès contre l'entraînement des passions et des convoitises : le sentiment de l'honneur familial. Mais il faut reconnaitre que ses manifestations sont parfois extraordinaires. Voici, par exemple un enlèvement qui s'offre à nous sous des couleurs très romanesques, dans la plainte à laquelle il a donné lieu, en 1696 (Périgueux) de la part de la personne enlevée. "Dame Catherine des Cars, veuve de messire Jacques d'Abzac, seigneur de Mézière et de Villars » se rendait de son château de la Renaudière à la ville de Nontron, quand, près du château de Lage, apparaissent «trois hommes à cheval qui la saisissent violemment et la conduisent au village de Mondonnet. Quand la nuit fut venue, il arriva six ou sept autres personnes à cheval, parmi lesquelles il y avait un prêtre et une personne masquée. » On la mit en croupe derrière un valet " après lui avoir lié les mains et les pieds ", et on l'emmena de maison en maison jusqu'au château de Plieux, dans la sénéchaussée de Lectoure, « où on la renferma dans un trou, et où elle fut traitée avec la dernière cruauté. »- Or, pourquoi tout ce dramatique appareil, cette mise en mouvement d'une machine si compliquée et si mystérieuse ? Tout simplement parce que la mère de la dame des Cars avait ouï dire « qu'il courait de fâcheux bruits sur le compte de sa fille » dans la ville de Nontron, et elle voulait bon gré malgré lui faire quitter ce séjour de perdition. C'est sur son ordre que l'enlèvement avait eu lieu. La jeune femme a eu beau dire ensuite «qu'étant veuve elle était maîtresse 
d'elle-même », ce n'est pas sans peine qu'elle a fini par obtenir de la justice, visiblement mal disposée pour elle, la fin de la séquestration maternelle.

On ne me pardonnerait pas d'avoir oublié, dans l'énumération der crimes fossiles, le crime de sorcellerie. Mais mon excuse serait qu'il figure bien rarement dans les documents dont je fais usage. Ils ne remontent pas pour la plupart, plus haut que les premières années du XVIIe siècle; le bel âge des sorcières est déjà passé. A Sarlat, il n'en est pas fait mention, ce qui ne laisse pas de m'étonner, car la croyance aux sorciers n'y a pas tout à fait péri dans les villages reculés, et, il y a deux ans, j'y ai fait condamner pour escroquerie un empirique de Donne, qui guérissait toutes les maladies de sa clientèle, nombreuse et même choisie, par les procédés magiques les plus variés, y compris le paiement d'une somme de 7, 14, 21 francs ou autre multiple de 7. Quoiqu'il en soit, je n'ai pu trouver à cet égard dans l'Inventaire de Sarlat que la mention suivante. En 1713, un chanoine régulier du chapitre de Saint-Cyprien porta plainte contre Bertrand R..., écolier, âgé de quinze ans, " qui s'est vanté de faire danser toutes les filles de Saint-Cyprien et particulièrement la nommée Jeanne Rouchon, et de s'en faire suivre partout au moyen d'une herbe enchanteresse nommée le matagot, placée par lui dans le missel, un jour où le plaignant disait la messe... " Mais, dans l'Inventaire de Périgueux, je trouve une condamnation, une seule, contre un sorcier, sous la date de 1599. Convaincu du crime " de sortilège », il est condamné à être pendu et étranglé à un gibet, » puis son corps sera brûlé et mis en cendres. » En outre, sous la date de 1778, il est question incidemment du «sorcier Pierre », mais on ne dit pas qu'il soit poursuivi. - C'est seulement en se transformant et revêtant une couleur plus positive que l'incrimination de sortilège réapparaît de temps à autre. En 1784, je remarque une information contre un seigneur de Feuillade et son domestique «accusés d'avoir empoisonné l'eau de la fontaine des Pradelles.» Cette imputation populaire de l'empoisonnement des fontaines, si fréquente aux époques de troubles, n'est-elle pas la dernière phase où aboutit l'évolution de la sorcellerie ?

L'Inventaire de Cahors renferme aussi une belle affaire de sorcellerie, et à une date déjà avancée : le Quercy était sans doute en retard sur les provinces voisines. Jean Lacan et Jeanne Pégourié, en 
1661, sont accusés des «crimes de sacrilèges, sortilèges et autres maléfices ; » mis à la question, ils avouent tout et le reste. Jean Lacan confesse "être allé au sabbat, y avoir vu le démon, avoir, en sa présence, foulé aux pieds le Saint-Sacrement et avoir obtenu de l'argent ainsi que la faculté de voyager avec une extrême rapidité, ce qui lui a permis de visiter le royaume d'Espagne. » Jeanne Pégourié s'accuse "d'être allée au sabbat, d'y avoir vu le démon, d'avoir été même connue charnellement par lui, etc. » Interrogés de nouveau, à l'effet de savoir «si les tourments de la question ne leur ont pas fait déclarer des maléfices qu'ils n'auraient pas commis », ils persistent dans leurs dires. Comme de juste, ils sont pendus et étranglés, puis leurs corps sont brûlés et les cendres jetées aux vents. C'était réglé. Ne nous hâtons pas de maudire leurs juges; après de tels aveux, répétés, confirmés, leur conscience devait être en parfait repos: pouvaient-ils deviner, à deux siècles et demi de distance, l'hypnotisme, la suggestion, la théorie de l'hallucination, la médecine mentale ? Pour nous, la persistance même de ces déclarations aussi insensées que sincères complète la preuve du délire de leurs auteurs; mais, aux yeux des magistrats de l'époque, elle devait paraître la démonstration irréfutable de leur culpabilité. Observation qui pourrait nous donner à réfléchir à nous-mêmes, magistrats contemporains.

Un genre d'attentats fréquemment renouvelé au XVIIe siècle, au XVIIIe siècle même, c'est l'attaque à main armée et le pillage des châteaux, non par des bandes de brigands, mais par des châtelains voisins qui ont à se venger d'une offense ou à réparer une injustice prétendue. C'est, évidemment, le dernier reste des guerres privées du moyen-âge. J'en fais juge le lecteur. En 1683 (Sarlat), noble François de Mellet, écuyer, possesseur du château de Mellet, se plaint du seigneur de Rouffignac et de dame Marguerite de la Morelie, «qui, accompagnés de 30 ou 40 personnes armées d'épées, de pistolets et de fusils, se sont emparés par force et violence du château, ont rompu et enfoncé les coffres, pris 2,000 livres d'argent et pour 100 louis d'or de hardes, habits, linge, etc.. » - En 1698, plainte de dame Catherine de Montesquieu, contre noble Pierre de Vassal, sieur de Caumont, et Charles de Vassal, son fils, "qui, accompagnés d'une dizaine de personnes armées d'épées, de pistolets et de fusils, sont venus la nuit enlever tous les blés et les fruits qui se trouvaient dans la grange de sa métairie de la Genèbre ». - En 1702 (Périgueux), je lis deux faits 
semblables. L'un est révélé par la plainte de Messire Marc de Vassal, seigneur de Belle-garde, qui, " pendant qu'il était à Castillonnès, a eu son Château de Bellegarde pillé et dévasté » par une trentaine de gens, notamment par «les sieurs de Saint-Dizier, Pedeville et PeyCharnaud. L'autre fait est encore plus étrange : c'est une mère qui monte à l'assaut du château de son fils Charles de Saint-Astier, seigneur des Bories, « se plaint de ce que la dame des Bories, sa mère, en compagnie de.. ses laquais, d'une fille de chambre... et de plus de vingt autres personnages, tous à cheval, armés, est venue, pendant son absence, heurter avec des pierres à la porte située au bout du pont de l'entrée du château, et a voulu la faire ouvrir de force, ordonnant à ses complices d'aller chercher des haches et des échelles pour rompre les portes, escalader les murailles et prendre le château ». Voilà une terrible mère, d'un type perdu,fort heureusement. Elle avait, à coup sûr, dans les veines, du sang des preux. J'ai regret à dire que le succès ne répondit pas à tant de vaillance; et quelques pierres, jetées du dedans sur les assiégeants, les mirent en fuite. - Si, de mère à fils, on se traitait ainsi, qu'était-ce entre gentilshommes non-parents ? En 1696, Françoise de Chabans, demoiselle, se plaint de ce que, le 21 février de cette année, «, une centaine de personnes à elle inconnues, armées de pistolets, fusils, hallebardes, faulx, bâtons ferrés et autres instruments de cette nature, sont venues entourer sa maison, criant qu'elles voulaient la brûler, en tuer et rnassacrer tous les habitants. Tous se mirent en devoir d'exécuter leur dessein... La plaignante s'étant adressée à un certain personnage qui conduisait la troupe et lui ayant demandé pourquoi il venait à main armée assiéger et démolir sa maison, celui-ci répondit qu'il était un des domestiques du comte de Ribérac et qu'il avait ordre de faire cet attroupement, d'enfoncer les portes et d'abattre les murailles... » Ce comte de Ribérac était, du reste, un vieux féodal attardé dans son siècle, un baron des Adrets au petit pied. Son nom revient plusieurs fois. Un médecin, qui a le malheur d'habiter sous la terrasse de son château, et qui, il ne sait pourquoi, a encouru sa haine, tremble devant ses menaces de mort et demande, avec supplication, « à être mis sous la sauvegarde du roi et de la justice ». Du haut de sa terrasse, le comte lui fait journellement lancer des pierres et autres projectiles par ses domestiques. Un peu plus loin, nous voyons qu'il a pris en exécration un huissier, parce que celui-ci, dans un acte signifié, l'a qualifié simplement de messire. «Depuis ce temps, le comte - qui avait commencer par le souffleter - 
a donné l'ordre à ses domestiques de l'arrêter partout où ils le trouveraient et de le mener dans les prisons de son château, ce qui a obligé le plaignant de se retirer dans la paroisse de Ponteyrand pour se mettre à l'abri des violences. Dix ou douze domestiques du dit seigneur, armés d'épées et de mousquetons, l'ont cherché par les chemins pour l'enlever... » C'est la dernière convulsion de la féodalité expirante sous le salutaire despotisme du grand Roi. Mais, jusqu'à la fin, le fier ribéraquois narguera la justice royale, et, en 1714 encore, nous apprenons par une plainte d'Adrien de Beaupoil de Saint-Aulaire, marquis de Fontenille, qu'une bande de gens mal famés « lui a enlevé un troupeau de moutons et de brebis par ordre du comte de Ribérac ».

Ces enlèvements de bestiaux, accomplis hardiment, en bande, et par esprit de vengeance plutôt que de cupidité, sont l'un des exploits les plus renommés chez les peuples primitifs. Même quand le vol de troupeaux a un mobile essentiellement cupide, comme chez les brigands siciliens qui pratiquent l'abigeato, le caractère de razzia militaire qui s'y attache leur prête un certain lustre. Et de nos jours encore, dans les pays les plus civilisés, le vol d'un cheval dans une écurie, d'une paire de bœufs dans une grange, a une couleur archéologique qui ne permet pas de confondre son auteur, bohémien ou bandit, avec un simple voleur d'argent, bien que le bétail, à l'époque où le cheptel est le seul capital (pecunia, pecus), ait commencé par être la seule monnaie en circulation. - Or, entre le pillage effronté de tous les troupeaux d'une vallée par une tribu barbare, et les vols de poules qui se commettent encore journellement dans nos campagnes, il y a mille transitions successivement parcourues à mesure que le bétail volé diminue en taille et en nombre, et que le nombre aussi comme la qualité sociale des voleurs va s'amoindrissant. Le comte de Ribérac tenait un bon rang sur cette échelle : il était assurément plus près de Cacus, ravisseur des génisses d'Hercule, que de nos détrousseurs de poulaillers. Mais, de son temps, son action en cela n'avait rien d'exceptionnel, et, après lui, les vols de bétail, tout en se décolorant peu à peu et dérogeant de leur noblesse première, ne laissent pas de se présenter souvent sous des aspects originaux qui les distinguent des nôtres. Le bétail était donc une richesse à part, une richesse vivante et sacrée. Je lis cette phrase incidente : «le jour de saint Roch, jour de la bénédiction des bœufs... » Voler ces bœufs bénis, cela ne tenait-il pas autant du 
sacrilège que du vol ? Avant tout il y fallait une audace rare, digne d'un meilleur emploi. En 1726 (Sarlat), plainte d'un sieur de Ponteille, du village de ce nom, près Carlux, "contre les nommés Giraud Escarotte et Guillaume E... ${ }^{1}$, gens mal famés, du bourg de SaintJulien Lampon, qui, à l'imitation des pirates écumeurs de mer, lui ont volé ses meilleurs bœufs les plus gras, dans ses prés, leur ont fait traverser la rivière, et les ont emmenés au lieu de Fénelon, paroisse de Sainte-Mondane, où on les trouva avant qu'ils n'aient eu le temps de les égorger ». En 1757, le procureur du roi, à Sarlat, informe «contre une troupe de brigands, ayant pour chefs un nommé Saint-Pierre et son fils, qui s'est répandue du côté de Terrasson où elle vole des chevaux et des bourriques ». Des bourriques, c'est déjà moins noble ; on sent la déchéance graduelle de ce crime jadis si bien porté.

Mais je reviens aux sièges minuscules de châteaux dont je parlais tout à l'heure, copie ridicule des faits d'armes qui ont illustré les du Guesclin et les sires de Coucy. Eux-mêmes à leur tour ont été copiés, et c'est certainement à leur imitation qu'ont eu lien force pillages et saccagements de simples maisons roturières. A mesure que la noblesse abaissée se rapprochait davantage des classes inférieures, celles-ci se sentaient plus à l'aise pour donner libre cours au désir qu'elles avaient toujours eu de l'imiter. Elles imitaient son luxe et ses vices, c'est bien connu, et j'en trouve la preuve, par parenthèses, dans une affaire de vol. En 1720 (nous sommes sous la Régence), une Marie de Tapinoix, «marchande de la ville de Sarlat», porte plainte contre «Jean Vilatte, sieur de la Plaine, son apprenti » qui lui a volé de l'argent dans ses tiroirs à l'aide de fausses clefs, pour l'employer, non pas comme feraient les apprentis de nos jours, à s'amuser et faire la noce, mais à acheter « des habits de drap d'Elboeuf avec boutons d'argent, des bas de soie de plusieurs couleurs, des escarpins, etc. ». C'était une vraie frénésie imitative qui, des vices, s'étendait naturellement aux délits. En 1701 (Sarlat), un chirurgien du bourg de Faux, Jean Cabanet, en butte à la haine d'une famille Tarneaux du Gondal, est assiégé un jour par ses ennemis dans sa maison qu'ils essayent de démolir, et «le curé du lieu de Faux est obligé de faire sonner le

Je ne transcris pas ce dernier nom, encore porté par une famille du même lieu qui a été impliquée il y a quelques années dans une grande affaire d'homicide. Le bourg de SaintJulien-Lampon s'est longtemps signalé par sa criminalité violente et sa férocité corse. Les caractères y sont aussi abruptes que les sites. 
beffroi pour faire cesser ce désordre " En 1738, un certain Louis Henry, "maître bâtier ", à la tête d'une centaine de gens " armés de barres et de bâtons » - non plus de hallebardes ni de mousquetons, - va un dimanche, pendant vêpres, au bourg de Terrasson, enfoncer les portes d'une maison appartenant à un autre maître bâtier, " démolir les murailles du jardin et enlever tous les meubles... »- Nos cambrioleurs actuels, ces spécialistes qui dévalisent pendant la nuit les villas ou les hôtels inhabités, ne seraient-ils pas le dernier avatar des féodaux du moyen-âge, dévaliseurs de châteaux forts, et métamorphosés d'abord en comtes de Ribérac puis en maîtres hâtiers de Terrasson? D'ailleurs, le cambriolage proprement dit n'était pas inconnu au XVIIIe siècle. Deux riches habitants de Sarlat se plaignent, en 1746, «de certains quidams qui sont entrés avec effraction dans leur maison » et y ont volé un lit garni.

Il tarde peut-être au lecteur de voir l'amour jouer un rôle quelconque en toute cette criminalité d'où il semble absent, tandis qu'il occupe une si large place dans la nôtre. A vrai dire il n'est pas aussi étranger aux crimes d'ancien régime qu'on pourrait la supposer de prime abord ; et, s'il y apparaît rarement, quand il apparaît c'est avec une violence caractéristique. Comment expliquer autrement que par une frénésie de passion ce crime de rapt, si fréquent jadis, et si audacieusement entrepris au risque de la décapitation ? Je remarque aussi force effraction de couvents qui dénotent un amour intense. Par exemple, en 1701, la supérieure du couvent de Sainte-Claire, à Périgueux, a eu beau faire dire au sieur Gerbaud de la Sénédie, par la soeur portière, " de ne plus rendre de visites au parloir à la demoiselle Laulanié, fille de $\mathrm{M} \cdot$ Nicolas Laulanié, procureur au siège de cette ville », celui-ci ne s'est pas découragé pour si peu; il «s'est mis fort en colère, disant qu'il reviendrait dans huit jours et brûlerait la communauté ». Effectivement, quelques jours après, il entrait de force au monastère, après " avoir brisé les grilles des deux arcades » et non sans avoir proféré « des paroles outrageantes pour les religieuses ». On ne dit pas s'il a brûlé le couvent.

Mais je m'aperçois que le bris de clôture est loin de rentrer dans la catégorie des crimes et délits paléontologiques pour ainsi dire dont je viens de passer la revue. Il peut me servir de transition à la section suivante. 


\section{III}

\section{$\underline{\text { Retour à la table des matières }}$}

Arrivons aux méfaits, de beaucoup les plus nombreux, qui se reproduisent même de nos jours, et n'ont pas cessé d'être incriminés. Mieux encore peut-être que les précédents, ils peuvent servir à caractériser leur époque ; car, s'ils sont restés en apparence les mêmes, en réalité ils ont changé d'âme pour la plupart, et leur proportion numérique s'est grandement modifiée comme leur mobile et leur mode d'exécution.

Il me faut, malheureusement, renoncer à l'espoir d'extraire de nos documents les éléments d'une statistique, même embryonnaire, qui permettrait de décider si, à population égale, la criminalité d'ancien régime l'emporte ou non, numériquement, sur la nôtre. Si l'on s'en rapporte aux Inventaires des Sénéchaussées et des Présidiaux, elle aurait été très inférieure à celle qui l'a suivie. En effet, pour ne parler que de Sarlat, j'ai compté que, de 1676 à 1790. le Sénéchal avait reçu 38 plaintes pour homicides, 110 pour vols, 230 pour coups et blessures, et le Présidial, 11 pour homicides, 36 pour vols, 7 pour coups et blessures. En réunissant les deux, le total ne s'élève qu'à 49 homicides, 146 vols, 237 coups et blessures. Ce sont là des chiffres infinitésimaux pour un siècle et quart. Le Parquet de Sarlat, j'en ai fait un relevé pour les années $1880,1881,1882,1883,1889,1890$, a reçu pendant ces six années seulement, 1676 procès-verbaux pour vols, 484 pour coups et blessures, et poursuivi 6 homicides ${ }^{1}$.

Mais cette comparaison perd la plus grande partie de sa valeur si l'on remarque, d'une part, que la dent des rats et les ravages du temps ont détruit une notable quantité des archives judiciaires dépouillées

Le chiffre annuel des meurtres et assassinats a beaucoup diminué depuis quelques années dans cet arrondissement où il passait, récemment encore, pour considérable. Nos grand criminels se réfugient maintenant dans les grandes cités environnantes, à Bordeaux notamment. 
par nos archivistes ; d'autre part, que les justices seigneuriales, et aussi les officialités, devaient retenir un certain nombre d'affaires, des moins importantes à la vérité. Devons-nous ajouter que beaucoup de crimes, et particulièrement d'homicides, ont échappé à toute poursuite, à toute dénonciation même, par la terreur que leurs auteurs inspiraient? En 1712 (Périgueux) le procureur du roi informe «contre une bande de voleurs et de vagabonds qui exploitent la paroisse de Chalais et les paroisses voisines, commettent tant la nuit que le jour toutes sortes de vols, d'exactions, et même de meurtres et d'assassinats, sans que les habitants osent s'en plaindre de peur d'être égorgés. " Cependant c'étaient là des faits exceptionnels, quoique le brigandage paraisse avoir été plus fréquent jadis qu'à présent. En remontant plus haut, jusqu'à la Fronde, jusqu'aux guerres de religion du XVIe siècle, nous avons lieu de croire que, dans ces périodes d'anarchie, les crimes de sang ont dû pulluler. Il est vrai que nos documents sarladais sont postérieurs à la Fronde ; mais il semble que, chez nous, les suites de ces troubles se soient prolongées socialement bien au-delà de leur apaisement général au point de vue politique. En ce qui concerne Périgueux, du moins, j'en trouve la preuve dans ce curieux passage ${ }^{1}$. En 1676, le procureur du roi requiert information contre deux hommes qui, "comme la plupart des paysans de la juridiction, au mépris de la dernière déclaration du roi, portent des armes à feu en labourant et faisant paître des bœufs, s'attroupent et chassent ordinairement, s'en vont armés dans les marchés et lieux publics, et commettent des meurtres et assassinats qui demeurent impunis ». Partout où l'on voit ce pittoresque amalgame de la charrue et du fusil, en Sicile, en Corse, on peut être sûr que les crimes de sang abondent. Toutefois il est très improbable que cet état d'insécurité, à l'époque dont il s'agit, en plein règne de Louis XIV, ait duré longtemps et se soit généralisé dans notre province. Mais, en revanche, j'ai des raisons de penser que le Sénéchal et le Présidial étaient souvent, même à des époques rapprochées de nous, mal servis par leurs auxiliaires. En 1770, le Procureur du roi est averti que l'exercice de la

Pour Sarlat, j'en trouve l'indice assez significatif dans le préambule des lettres de grâce accordées en 1675 à un apothicaire qui, en se défendant dans une rue de la ville de SaintCyprien, avait tué d'un coup de pistolet Bernard de Montesquiou : ce préambule nous apprend que, depuis plus de quarante ans, cette famille de Montesquiou tyrannisait les habitants de la ville et seigneurie de Saint-Cyprien, achetées par eux jadis, durant la Ligue, à un archevêque de Bordeaux 
justice dans la ville et juridiction de Montignac est dans le plus grand désordre et que le crime y reste impuni " par la négligence, tolérance ou connivence des officiers (de police judiciaire), jusques au point qu'on y a vu commettre des assassinats, des meurtres, des infanticides et des vols » sans nulle poursuite.

Même en faisant la part la plus large aux considérations qui précèdent, je garde l'impression, malgré tout, après la lecture de mes documents, qu'il y avait autrefois, dans notre région, hormis les périodes de guerre civile, moins de vols et même peut-être moins d'homicides, quoique beaucoup plus d'actes de violence 1 qu'aujourd'hui. Quant aux attentats à la pudeur, ils étaient beaucoup moins nombreux, sans aucun doute : j'en compte à Sarlat 7 pour la durée plus que séculaire que l'on sait. Pour les infanticides, de même. J'en ai compté à peine trois ou quatre. De nos jours, rien que pour les 6 années ci-dessus indiquées, je trouve 19 attentats à la pudeur, la plupart commis sur des enfants, crime ignoré de nos aïeux; et je trouve aussi 7 infanticides ${ }^{2}$.

Une chose me paraît certaine en tout cas, c'est qu'il y avait fort peu de duels jadis, à partir de la fin du XVIIe siècle. Je n'en ai compté que 5 en tout dans l'inventaire de Sarlat, et à peu près autant dans celui de Périgueux. Par exemple, ils sont presque tous sanglants et mortels. En 1701, je vois le procureur du roi instruire au sujet du meurtre commis sur la personne de feu Jean Lavergne, à Saint-Cyprien, après un défi et combat de quatre à quatre à armes égales. $»$ Ce combat quatre à quatre prouve que les témoins se battaient encore à cette date. Je sais bien que la peur d'encourir la haine des duellistes ou de leur famille empêchait souvent les personnes qui avaient connaissance d'un duel

Je dis beaucoup plus d'actes de violence; ce n'est pas que la comparaison du chiffre des plaintes pour coups autorise à première vue cette conclusion, mais Il faut considérer que, précisément parce que nos aïeux étaient portés aux voies de fait, comme le prouve la proportion relative des plaintes de ce chef, Ils se montraient Indulgents à réprimer ce genre de délit et ne prenaient la peine de le signaler à la justice que s'il atteignait un assez haut degré de gravité.

2 Dans une visite officielle faite à la prison de Sarlat en 1783, Il est constaté que le nombre des prisonniers est de 12 en tenant compte du fait qu'on incarcérait préventivement autrefois dans beaucoup de cas où la liberté provisoire est de règle aujourd'hui, on doit voir dans ce chiffre, assurément très bas, la preuve que la criminalité sarladaise, à la fin du XVIIIe siècle, était peu élevée. 
d'en avertir la justice. Mais, d'autre part, la justice était vigilante et inexorable contre les spadassins. En somme, Voltaire a raison de dire qu'à partir des édits de Louis XIV contre le duel, il a presque disparu du sol français où il s'était si solidement implanté jusqu'à Louis XIII et à la Fronde. A n'en pas douter, ce merveilleux résultat est dû à 1'intelligence autant qu'à la sévérité de la répression inaugurée. Je vois en 1681, le «crime de duel» puni de la pendaison et de la strangulation, jusqu'à ce que la mort s'ensuive, - par effigie, il est vrai ${ }^{1}$-, mais d'autres fois, c'est pour tout de bon que les criminels de cet ordre étaient punis et étranglés, sans parler d'une forte amende.

Ce qui montre également à quel point le combat singulier était tombé en désuétude, c'est le nombre assez grand de gentilshommes ou de gens vivant noblement qui portaient à la connaissance des tribunaux les insultes, les soufflets même reçus par eux, pour en demander réparation judiciaire. Dans les procédures criminelles du Présidial de Périgueux, figure un procès-verbal dressé en 1697 « à la requête de Joseph de Gravier, écuyer, sieur des Combes du Puygrand, qui demande à la justice d'informer sur le soufflet qu'il a reçu, les menaces de coups de bâton et les injures qui lui ont été adressées dans l'église de Saint-Front, aux vêpres, par M. M• Chabaneys, sieur du Claux, conseiller magistrat au siège présidial de Périgueux 2 ». Parfois, l'autorité saisie, et spécialement compétente pour ces affaires d'honneur, était la cour des maréchaux, devant laquelle Oronte, dans le Misanthrope, porte son litige avec Alceste. En 1696, requête est présentée au Sénéchal de Périgueux par le seigneur de la Tiffardière, cornette au régiment royal de Roussillon-cavalerie, qui a été grièvement outragé par Antoine Mérilhon, «soi-disant avocat en la

1 A Sarlat de même, en 1725, deux archers convaincus du «crime de duel» sont condamnée par coutumace, «à être pendue et étranglés jusqu'à ce que la mort naturelle s'ensuive, à une potence croisée qui, pour cet effet, sera dressée par l'exécuteur de la haute justice à la place de l'Endrevie, du côté où le susdit crime a été commis, ce qui sera exécuté car effigie sur un tableau qui sera attaché à cette potence. » Je dois ajouter que, lorsque la condamnation était bel et bien sérieuse, le condamné obtenait le plus souvent sa grâce.

2 Le texte ajoute : « ayant une cravate au cou et habillé en cavalier ». C'était, en effet, une grave Inconvenance à cette date, et digne d'être signalée, que de ne pas porter le costume traditionnel des magistrats quand on appartenait au corps judiciaire. Chaque corporation alors restait encore claquemurée en des usages et des uniformes distincts, et c'est seulement au XVIIIe siècle, comme nous l'apprend Voltaire, excellent observateur des mœurs, que ces barrières des diverses classes sortes de douanes Intérieures des départements sociaux, sont tombées. 
Cour ». Ce dernier, nous apprend la requête, «lui a donné un soufflet ». L'affaire avait été d'abord portée devant M. de Campagnac, lieutenant des maréchaux de France, « qui commit Messire Charles de Peyrot, seigneur de Joffrenie, pour procéder à une enquête... Mais, comme c'est un cas royal, l'outrage ayant été fait à une personne de qualité, la Cour doit en connaître. » Ainsi, de jeunes gentilshommes, des militaires de ce temps-là, si chatouilleux sur le point d'honneur, jugeaient honorable de laver dans l'encre des greffes et non dans le sang des combats un affront tel qu'un soufflet. Nos démocrates en auraient honte, et, en plein Parlement français, montrent infiniment plus de respect pour un préjugé féodal.

J'ai dit plus haut que, d'après mon impression à la lecture de nos documents, la criminalité du passé aurait été numériquement inférieure à la nôtre. À l'appui de cette conjecture, je me permets d'invoquer un catalogue de même nature, mais beaucoup plus ancien encore, le Registre criminel de Saint-Martin-des-Champs ${ }^{1}$. Cette abbaye exerçait le droit de haute et basse justice, au moyen-âge, dans une juridiction fort étendue, évaluée à 30,000 feux, ce qui laisserait supposer une population de 150,000 justiciables, tant à Paris qu'au dehors. Mettons 100,000 si l'on veut, en supposant quelque exagération dans le chiffre précédent. A Paris même, l'autorité judiciaire du monastère s'étendait sur 26 rues. D'autre part, ce recueil contient la liste des poursuites criminelles qui ont eu lieu de 1332 à 1357 ; cinq années manquent complètement il est vrai, et neuf autres en majeure partie. Ce recueil n'est donc complet que pour 11 années. Mais il l'est pour elles. Or, ce qui m'étonne ici, comme dans mon vieux Périgord, c'est la faiblesse des chiffres qu'on obtient en y comptant les diverses catégories de délits. J'y ai trouvé 151 affaires de coups et blessures, parmi lesquelles force coups de couteau, et aussi des coups de pied dans le ventre de femmes enceintes ; 56 vols, 15 meurtres, ce qui est bien peu pour une population urbaine ou suburbaine si tumultueuse ; 7 viols ou graves attentats à la pudeur, dont 3 sur enfants, fait exceptionnel jadis, mais où l'on voit que la capitale de la France a toujours donné l'exemple de la civilisation la plus avancée; 6 blasphèmes; 2 fausses monnaies, et rien que 4 suicides! Le tout je le répète, pour 11 années au moins, et pour une

Paris, Léon Wilheim, éditeur, 1877. 
population de plus de 100,000 personnes! Aujourd'hui pour une population égale, en France, je ne dis pas même à Paris, on aurait environ 250 suicides et 1,100 vols (en 1888 il y a eu 37,505 vols sur une population de 38 millions d'hommes). Quant aux homicides, le chiffre serait à peu près égal, mais à Paris il serait supérieur. Je sais bien que, à raison des causes énumérées ci-dessus et notamment de l'enchevêtrement des juridiction royales et seigneuriales dans le passé, les chiffres du Registre de Saint-Martin doivent être sensiblement grossis. Doublons les, si l'on veut. Ils n'en resteront pas moins encore étonnamment faibles, même en ce qui a trait aux faits de violence. $\mathrm{Si}$, par le dépouillement d'autres recueils de même sorte, on arrivait à un résultat pareil, il y aurait lieu, je crois, d'attribuer en majeure partie à l'effroi universel des horribles pénalités, terrestres ou posthumes, redoutées par nos aïeux, la minime proportion de leurs méfaits. Il ne resterait plus qu'à se demander, comme conclusion pratique, si les théories utilitaires ne nous obligent pas dès lors à rétablir la question et la roue, sans parler d'autres supplices infernaux. La douleur de quelques malfaiteurs peut-elle balancer, dans les plateaux de l'arithmétique morale de Bentham, les maux épargnés par elle à tant d'honnêtes gens ? Et toutefois quel est celui de nous qui ne protestât contre le rétablissement de peines atroces, fussent-elles démontrées efficaces? Cela prouve, soit dit en passant, que la considération de l'utile, même de l'utile social, ne suffit pas, - et qu'il y a une esthétique morale.

- Malgré tout, nos inventaires périgourdins, je le répète, et bien qu'ils ne soient pas seuls à paraître attester la faible criminalité de nos ancêtres, ne se prêtent pas encore à une comparaison numérique réellement scientifique entre la criminalité du passé et celle du présent. Mais il ne s'en suit pas que le dénombrement des crimes anciens, d'après nos inventaires, soit sans intérêt. On peut puiser, dans cette statistique archéologique, les éléments d'une comparaison instructive avec elle-même, c'est-à-dire rechercher la proportion numérique de certaines grandes catégories de délits comparées les unes aux autres, et voir si ces mêmes classes de délits se présentent encore de nos jours en proportions semblables ou notablement différentes. J'ai essayé ce travail en ce qui concerne Sarlat. Du premier coup d'œil, il est visible que le chiffre des actes de violence était, relativement à celui des vols, beaucoup plus fort aujourd'hui que 
maintenant. Aujourd'hui, d'après les chiffres indiqués plus haut, il y a trois ou quatre fois plus de vols que de coups et blessures; jadis, il y avait près de deux fois plus de coups et blessures que de vols. On vient de voir même une proportion plus forte dans le Registre de Saint-Martin : près de trois fois plus d'actes de violence que de vols. Cela tiendrait-il à ce que ce registre est plus ancien et que la violence aurait été en diminuant depuis le Moyen-Age? Il faudrait d'autres comparaisons pour autoriser une réponse précise. Toutefois ce simple rapprochement suffit déjà pour attester la double élaboration psychologique qui s'est opérée durant l'ancien régime et poursuivie de l'ancien régime à nous : l'adoucissement des mœurs et l'affaiblissement des caractères ou de certains principes, moins de grossièreté et plus d'astuce.

Ce premier aperçu assez vague se précise, prend physionomie, si l'on entre dans le détail des faits. D'abord, remarquons que la plupart des homicides sont des meurtres d'impétuosité comme disent les Italiens; on en a la preuve par les circonstances où ils se produisent, si brièvement qu'elles soient indiquées, et même par les instruments de leur exécution. Un paysan est accusé (Sarlat, 1777) d'avoir tué un de ses voisins, " au cabaret, avec un chenêt de fer battu. » Il est clair que le meurtrier, après boire, et dans une querelle, a pris le premier objet en fer à sa portée ; et le malheur a voulu qu'il ait trouvé sous sa main l'un de ces lourds landiers des cuisines antiques, massue redoutable s'il en fut. Ailleurs (Agen) c'est avec un coup de faucille, ou avec un coup de fourche, qu'un homme est tué au cours d'une discussion, dans les champs, cela va sans dire; ou encore d'un coup de boule, en jouant aux quilles. - Quand l'homicide paraît prémédité, c'est la haine, c'est la vengeance, ce n'est presque jamais la cupidité, qui l'a inspiré. La tentative d'assassinat que je vois relatée en 1677, comme ayant été commise sur la personne du procureur du roi lui-même et de ses deux fils par plusieurs personnes de la noblesse, dans un grand chemin, ne peut certainement être attribuée qu'à des animosités suscitées par quelques poursuites, et elle paraît se rattacher aux troubles de la Fronde, si antérieurs qu'ils soient. Voici la note : "plainte de M. Jean de Ladieudie, procureur du roi au siège de Sarlat et de ses deux fils, contre Jean-Jacques de Montesquiou, ci-devant dit l'abbé de Fages, se faisant à présent appeler le marquis de Sainte Colombe, et Bernard de C... sieur de Beyssac, et un cavalier inconnu, qu'ils accusent 
d'assassinat prémédité contre eux, sur le grand chemin de Dôme à Sarlat... » Cette route, qui traverse un haut plateau désert, a été à diverses époques le parcours préféré de plusieurs bandes de brigands. - Il est question, en 1690 (Sarlat), d'une procédure instruite à Fénelon contre le baron de M... et le sieur de Gaumiers pour le meurtre d'un batelier. En 1721, le seigneur de Vimières se plaint du baron de Monclard qu'il accuse de l'avoir assassiné, en lui tirant un coup de fusil par derrière et en le frappant de coups de barre sur la tête et au bras gauche, dans un endroit isolé du chemin de Veyrignac à Gaulejac (Sarlat). Evidemment l'idée du vol a été étrangère à ces crimes.

Je ne crois pas non plus qu'elle ait présidé au drame monastique qui nous est révélé par une poursuite dirigée en 1753, à Périgueux, contre quatre individus. Dom Gibon, prieur de Badeix, fut trouvé mort un jour au couvent de Peyrouse, le corps percé de neuf coups de couteau. Le couteau ensanglanté était fiché dans un trou du mur. Quatre personnes furent accusées de ce meurtre : un domestique du défunt, le valet du prieur de Baschaud, un domestique de l'abbaye de Peyrouse, et Louis Borie, sieur des Barrières, maître chirurgien. N'estil pas permis de supposer que ces quatre personnes ont été les instruments de rivalités, ou de vengeances claustrales? - Cette procédure, outre son intérêt dramatique, est curieuse au point de vue l'instruction criminelle du passé. Les accusés ayant allégué que dom Gibon avait bien pu se suicider, l'expertise médico-légale fut confiée à plusieurs groupes de médecins, deux de Paris, trois de Montpellier, quatre d'Angers, et cinq de Tours - gradation numérique assez bizarre - sans compter des médecins de Périgueux et de Limoges, et il fut établi par leurs rapports que l'hypothèse du suicide devait être écartée. J'ai lu ces rapports. Il m'ont frappé par la sobriété, la clarté, la justesse du raisonnement. Sur les neuf coups de couteau, deux avaient percé le cœur ; les experts font remarquer avec raison que chacun de ces deux coups devait provoquer des convulsions et une syncope qui n'eût pas laissé au blessé, dans l'hypothèse du suicide, la force de récidiver et de planter ensuite son couteau dans le mur. - Rarement l'amour semble avoir été l'inspiration des meurtres ; peut-être cependant, si l'on en juge par un détail romanesque, a-t-il provoqué le crime suivant, en 1681. "La cour présidiale (Périgueux) condamne Fronton Tridar, détenu dans les prisons de la Conciergerie, convaincu de crime d'assassinat commis dam un bois sur la personne d'une jeune fille 
travestie en garçon, à être rompu vif sur un échafaud... qui à cette fin sera dressé sur la place publique de la Clautre, et ensuite à être exposé sur une roue qui sera élevée sur le grand chemin de Périgueux à N. D. des Vertus, la face tournée vers le ciel, pour y demeurer jusqu'à sa fin. De plus, l'accusé devra payer 100 livres au roi et aumôner 50 livres au curé de N. D. des Vertus qui emploira cette somme à prier Dieu pour l'âme de la défunte. »

Rassurons-nous un peu cependant sur le sort du malheureux Fronton Tridar. Il est fort probable qu'il aura été gracié. C'est seulement quand le vol est joint à l'assassinat que les atroces condamnations de la justice ancienne sont exécutées. Une chose remarquable, en effet, c'est son extrême sévérité pour le vol et son indulgence pour l'homicide quand il n'a pas le vol pour but. Il en est ainsi dans tous les présidiaux et toutes les sénéchaussées à ma connaissance. Je vois le sénéchal de Périgueux, en 1551, condamner plusieurs meurtriers à une simple amende, et, quelques lignes plus loin, condamner un voleur à être pendu et étranglé. Un contraste pareil s'offre presque à chaque page. Des centaines de fois, on voit, à côté de sentences qui envoient à la potence et à la roue un faussaire, une simple servante, une couturière coupable d'avoir volé du linge à sa patronne, et, tout à côté, l'entérinement d'une lettre de grâce dans le genre de celle-ci : "Entérinement (1545) des lettres de grâce et rémission octroyées à Bertrand Rouchon pour raison de l'homicide de feu Jean de Lamothe ; mais à la charge pour ledit prisonnier, de payer la somme de cent sols tournois qui sera destinée à faire prier Dieu pour le salut de l'âme du défunt. » Jamais cette pieuse amende n'est oubliée. Parfois il s'y joint l'obligation de payer aux pauvres une certaine somme. Ces lettres de grâce, qui se répètent jusqu'à la fin de la monarchie, ne sont jamais accordées dans le cas de vol, à ma connaissance du moins; je ne me souviens pas en avoir vu pour d'autre cause que l'homicide ou des faits de violence. Notez qu'il ne s'agit nullement d'homicides involontaires; car, dans ce cas, on a toujours soin de mentionner cette particularité essentielle. Mais, sans nul doute, il s'agit d'un meurtre impétueux, et, entendue de la sorte, la fréquence de ces grâces à une époque de si sévère répression vient à l'appui de l'idée que l'homicide, depuis deux siècles a lentement mais profondément changé de nature, de vindicatif devenu cupide, d'emporté calculé. 
Un contraste aussi frappant que le précédent, entre la justice du passé et la nôtre, c'est qu'on punissait jadis l'infanticide bien plus rigoureusement que l'homicide. Le présidial de Périgueux, en 1592, condamne Guil. Deladenil, convaincue du crime d'infanticide, à être pendue et étranglée, après avoir été mise à la question; son corps devra être brûlé et mis en cendre.

Remarque importante que, du reste, les citations précédentes ont pu suggérer au lecteur: les homicides ont très souvent pour auteurs des personnes appartenant à la noblesse ou aux classes supérieures qui se modelaient sur elles. De nos jours les meurtriers se recrutent à peu près exclusivement dans la lie du peuple. ${ }^{1}$.

Autre remarque applicable à l'ensemble des crimes ; beaucoup plus fréquemment qu'aujourd'hui, les méfaits étaient commis en troupe, par des bandes spontanément formées et d'ordinaire plus nombreuses que ces associations de malfaiteurs qui de nos jours se forment encore exceptionnellement. Celles-ci, du reste, transformation de compagnies de brigands qui habitaient jadis les cavernes des rochers et ont établi aujourd'hui domicile dans des tavernes de faubourgs, ne doivent pas être confondues avec les attroupements passagers et accidentels dont je parle, et dont on a pu voir plus haut des exemples à propos de charivaris et de pillages. En veut-on d'autres ? Le curé de Roquépine (Périgueux, 1692) se plaint de Marie Simonet, Jean Fauchereau son fils et autres, qui, « attroupés et armés, ont la nuit brisé les portes de sa maison, l'ont frappé de coups de couteau et de bâton et laissé comme mort, couvert de sang ». - Un arrêt du parlement de Bordeaux, en 1785, dans une affaire civile, intentée par « le syndic des propriétaires de la prairie de Saint-Michel » près de Martel, lui avait donné gain de cause, apparemment contre les habitants de la paroisse qui alléguaient, je pense, un droit de passage coutumier. C'est un des innombrables conflits soulevés par les disputes des communaux. Or, en dépit de cet arrêt, on voit un habitant de Saint-Michel, bientôt suivi de beaucoup d'autres, tous armés de fusils et de bâtons, et menaçant de tuer les propriétaires, mener pacager un grand troupeau dans cette prairie, non

Pour ceux qui m'ont fait l'honneur de lire ma Philosophie pénale (Storck, 1891, 2e édition), ce contraste s'expliquera naturellement par les lois de l'imitation. 
sans y faire un dégât considérable. Mais ici le rassemblement peut s'expliquer par l'intérêt commun ${ }^{1}$. Ailleurs il n'a d'autre explication possible que l'autorité, absolue encore, exercée par le père sur ses enfants, par l'aîné sur ses cadets ${ }^{2}$, par le maître sur ses domestiques ou sur ses métayers, ou bien le lien de fraternité, de solidarité encore étroite, qui unissait les voisins d'un même bourg, les membres d'une même corporation. Pour commettre une razzia ou un assassinat, comme pour labourer son champ ou laver sa lessive, un homme trouvait toujours sous sa main des auxiliaires aveuglément dévoués. Le lien féodal d'homme à homme subsistait, bien qu'amoindri. À présent, notre émancipation individuelle à outrance, notre pulvérisation sociale, à côté de beaucoup d'effets destructeurs, a eu au moins cela de bon d'isoler le malfaiteur, de le livrer à ses propres ressources personnelles, faute de confiance dans son entourage. Car telle est bien la principale cause de cet individualisme criminel, pour ainsi dire, dont nos statistiques nous montrent la progression depuis un demisiècle : il est, avant tout, lié à notre individualisme social, et, comme on voit, il n'y a pas lieu de s'en féliciter outre mesure.

Il y a d'autant moins à s'en applaudir que, en vertu de la même cause, si le crime en général reste individuel, il tend aussi à redevenir collectif de temps en temps, mais alors sur une échelle immense, très supérieure à ce que les temps passés ont jamais vu. Détaché de sa famille, de son bourg, de sa confrérie, l'individu ne s'en rattache que plus aisément à ces hordes confuses d'hommes que roule aujourd'hui en larges courants d'émeutes, de manifestations, de grèves, de ligues internationales, l'impulsion d'un meneur quelconque. Pas de milieu

Pareillement, il n'y a pas à être surpris de voir, en 1733, se manifester par une petite émeute locale la haine habituelle des ouvriers du lieu contre les ouvriers étrangers. Une dame de Condat avait appelé, pour dépiquer son blé, quelques paysans limousins. Aussitôt, 150 habitants de cette localité, "armés de piques et de hallebardes » se ruent contre eux, les blessent, les garrottent et les conduisent dans les prisons de la Commanderie, où il les gardent nuit et jour.

2 En 1692, Messire Louis de Carbonières de Jayac, doyen de l'église cathédrale de Parlet, porte plainte contre « M. Jean-Alexandre de C. de J , chanoine de ladite église, qui a essayé de l'étrangler et menacé de le faire tuer par ses cadets, de ce que le plaignant a été pourvu du prieuré du Padhilac». Il faut maintenant aller dans les gorges du Caucase, ou dans d'autres pays sauvages pour retrouver intacte cette autorité de l'aîné sur ses frères. Dans sa Maison des morts, Dostoïevski nous dépeint avec sa pénétration habituelle une sympathique figure de jeune forçat. Inoffensif et doux par nature, qu'un ordre de son aîné avait poussé à commettre un assassinat. 
maintenant entre le crime commis par un seul et le crime commis par une foule innombrable. Ce n'est pas que le passé ait ignoré les émeutes et les révoltes populaires. Je les trouve au contraire, en des temps réputés paisibles, bien plus fréquentes qu'on n'aurait pu le supposer. Il n'est pas rare de rencontrer des mentions dans le genre des suivantes. Un juge de la juridiction de la Renaudie (Périgueux, 1695) et son lieutenant, prisonniers, sont convaincus « du crime de rébellion à justice faite avec tocsin et émotion populaire ». En 1690 (ibidem) « frère Jacques Chaslet, prieur de Saint-Jean-de-Verleine, expose que, déjà en 1664, les habitants de la paroisse de Saint-Paul s'étaient assemblés en armes avec des épées et des bâtons et avaient enlevé par force les offrandes apportées par dévotion à la chapelle du prieuré, et que, tout récemment encore, ils se sont attroupés, armés de fusils et de pistolets, et ont enlevé plusieurs offrandes, entre autres plus de vingt agneaux et d'autres oblations. Ils ont tiré un grand nombre de coups de pistolet. " A Cahors, en 1741, il est question d'une procédure contre divers habitants du lieu de Théminette accusés du crime d'attroupement formé avec port d'armes, sédition, émotion populaire et démolition de maison.

Mais, on le voit, ces émotions restaient localisées; et, à la différence de ce que nous venons d'observer pour le temps présent, mille degrés intermédiaires établissaient la continuité entre le crime de L'individu isolé et le crime des masses. Quand une partie d'un bourg s'ameutait pour aller piller un monastère, ce phénomène n'était, en somme, que l'agrandissement d'un fait plus habituel et du même ordre, au degré près, à savoir du soulèvement de toute une maison, maître et valets, père et enfants, patron et ouvriers, pour exécuter le dessein criminel conçu par son chef. C'est qu'en effet les foules d'alors ne ressemblaient guère, - sauf dans quelques capitales, et pas même toujours ici, - aux foules d'aujourd'hui. Elles se composaient de gens apparentés ou agrégés depuis longtemps, unis entre eux par des liens antérieurs très étroits ; à présent, elles se composent d'éléments épars, fortuitement rassemblés, comme les grains de sable des dunes. De là une grande différence entre elles, au point de vue de la responsabilité qui pèse sur le monstre anonyme aux mille têtes, et qui doit se répartir entre elles, quand il les a fait toutes participer à une même orgie de sang, d'incendie ou de vol. Il devait être plus facile jadis de découvrir les vrais meneurs, investis d'une autorité non pas transitoire, mais 
permanente; il devait être plus licite par suite, de circonscrire la culpabilité collective et de frapper les chefs seuls. Bien plus légitimement qu'aujourd'hui, on aurait pu, en faveur des masses, plaider l'entraînement irrésistible de la suggestion, de l'exemple donné par le supérieur prestigieux.

- En fait de vols, je remarque la fréquence, qu'on n'aurait pu prévoir, des vols sacrilèges dans les églises. C'est que les trésors des églises, bien plus riches qu'aujourd'hui, surtout relativement aux caisses des particuliers bien moins remplies de numéraire, devaient tenter beaucoup plus la cupidité des malfaiteurs. En ces âges de foi, restée toute vive parmi les populations rurales, quelle émotion, quelle horreur sacrée devait étreindre le cœur du voleur au moment où, la nuit, par effraction, il franchissait le seuil d'un sanctuaire, et mettait la main sur un ostensoir, sur un calice ! Un vieux routier du crime, dont je lisais cet hiver les mémoires manuscrits, avoue n'avoir jamais violé de nuit le domicile d'un honnête citoyen sans ressentir au cœur une sensation étrange et presque voluptueuse qui lui rappelait les palpitations de l'adolescence à sa première possession féminine. Combien plus forte encore, plus déchirante, plus fascinatrice, devait être pour un croyant impie et bandit cette satanique volupté de violer la maison de Dieu! - Mais citons quelques exemple. En 1783, un individu, natif de la paroisse de Rocamadour, lieu du fameux pèlerinage, est accusé d'avoir volé cinq nappes d'autel dans différentes églises. En 1758, un prisonnier, convaincu d'avoir volé, la nuit, les vases sacrés de l'église de Cussac, de les avoir brisée et offerts à un marchand juif de Bergerac, est condamné à l'amende honorable, au poing coupé, à la roue, aux cendres jetées au vent. Il fallait de l'audace ou l'empire d'une fascination bien puissante pour affronter de tels châtiments. J'espère, pour l'honneur de mon ancien Présidial, qu'il aura montré plus de pitié envers une pauvre revendeuse qui, en 1733, «a volé un plein tablier de noix sur les noyers du cimetière, destinés à fournir l'huile qui brûle devant le Saint-Sacrement. » - Je lis fort peu de vols d'argent, un seul me frappe par son importance, le vol d'une lettre contenant 5,800 livres, en 1709. Je ne trouve mentionné qu'un seul vol à la tire, commis en 1765, à la foire de Terrasson. Il est question de plusieurs bandes de voleurs. En 1761, un nommé Transquinian, qualifié « chef d'une bande de voleurs » est condamné 
ainsi que ses deux valets, à la question ordinaire et extraordinaire, suivie de la pendaison et de la strangulation.

- Arrivons aux faits de violence : c'est, avons-nous dit, la note caractéristique de ces voix qui nous parlent du passé. Mais à vrai dire, qu'avons-nous besoin de revenir sur ce sujet? N'avons-nous pas fourni déjà assez de preuves de l'impétuosité qui éclatait à chaque instant dans la conduite de nos aïeux ? Encore quelques citations cependant. Elles montreront que nulle classe de la société n'échappait à ces habitudes de vivacité extrême, et que l'exemple, ici comme ailleurs, était donné par la noblesse, surtout par la noblesse militaire, sinon par le clergé. Une plainte nous apprend qu'en 1717, le seigneur de Laxion «bat et renverse devant la petite porte de l'église de Corniac » un conseiller au Présidial de Périgueux. Il y avait en 1762, à Sarlat, un M. de Ravillon, capitaine au régiment de Vaubrecourt, qui n'était pas commode à vivre. Un jour, je ne sais pourquoi, il poursuit furieux, avec une épée à la main, le fils d'un notaire, et celui-ci en est réduit à chercher asile dans le ruisseau infect qui traverse la ville, ponté presque partout. Une autre fois, il escalade la maison de campagne du même notaire, et ne parle de rien moins que de l'assassiner. Les simples soldats auraient cru manquer de respect à leurs capitaines en ne se montrant pas aussi irascibles et belliqueux avec les civils. Nombreuses sont les plaintes contre les garnisons de passage, qui terrorisent les habitants. Même les invalides sont insolents. Deux époux marchands sarladais, en 1778, se plaignent d'un « soldat invalide » qui est venu chez eux les forcer à lui donner du vin, « insultant, menaçant la femme et lui disant cent fois qu'il voulait l'éventrer depuis la bouche jusqu'au nombril. » On avait beau être galant, on ne se gênait pas toujours pour battre les femmes, ou du moins sa femme. Un sieur de L., en 1752, en battant la sienne, lui a plongé de toute sa force, s'il faut en croire la plainte, son bâton dans le ventre. Du reste, l'habitude de bâtonner et de souffleter est si générale qu'elle atteint les femmes elles-mêmes. Nous apprenons par une plainte, qu'en 1686, la dame de Veyrignac, Flore de Ch., jetait des couteaux et des assiettes à la figure de son époux et le prenait par les cheveux. Les dames ne se bornaient pas à traiter de la sorte leur maître et seigneur; elles étendaient les mêmes procédés aux autres hommes. Une demoiselle F., en 1784, insulte et soufflette sur la place publique de Belvès, un médecin. Un magistrat de Périgueux se plaint, en 1724, 
de ce qu'une demoiselle A. D. R. lui a donné, « un grand coup de poing sur le nez, et l'a menacé de coups de bâton. » Je vois une dame, en 1689, qui, dans un salon de Périgueux, donne un soufflet à une autre. Ce sont là des traits cueillis au hasard entre mille. - Pourtant, je connais force descendants ou descendantes de ces gens si violents et d'une éducation si sommaire : il n'y a pas de personnes mieux élevées, plus inoffensives, d'un savoir-vivre plus parfait en général. De leurs aïeux ils ont les traits, non les moeurs. A quoi tient ce changement? A une cause physiologique ou à des causes sociales? Il n'est pas difficile de répondre.

Les curés aussi brillent peu par la douceur du caractère. Il est fait mention plusieurs fois, vers 1730, d'un archiprêtre de Daglan qui ne se contente pas de "mener une vie scandaleuse » avec les femmes de ses paroissiens ; un jour il jette au lieutenant criminel de l'officiel, un verre de vin au visage et le provoque en duel. Assez souvent les ecclésiastiques ont des querelles entre eux, soit au sujet de la perception des dîmes qu'ils se disputent ${ }^{1}$, soit surtout pour des questions d'amour-propre et de vanité. Une vanité puérile, inimaginable, est le principal levain qui fait fermenter continuellement la pâte de cette sensibilité française d'autrefois. Les moindres honneurs royaux, ecclésiastiques, municipaux, donnaient lieu à des rixes, parfois grotesques, entre le prédécesseur et le successeur. En 1696, dans une cérémonie, l'ancien et le nouveau maire d'Issigeac se prennent aux cheveux et s'enlèvent réciproquement chapeau et perruque. Ces susceptibilités troublaient même, ou plutôt spécialement, les offices religieux. En 1761, «Messire Michel d'Abzac de Ladouze, chanoine de l'église cathédrale de Périgneux, porte plainte contre Messire Faure des Romains, chanoine et archidiacre de ladite église qui, voulant placer pendant l'office son aumusse ${ }^{2}$ sur le dossier de la stalle du requérant et malgré lui, finit par le prendre aux cheveux et lui donner plusieurs poussades et deux coups de poings sur les épaules en le traitant d'inpertinent, d'insolent et de coquin. » Un vicaire de Notre-Dame des Soubiroux de Cahors se plaint, en 1729, de

Trois ou quatre affaires ont trait aussi à des conflits violents provoqués par la dîme entre les curés et leurs paroissiens. On y voit la force de mécontentement populaire contre cet impôt en nature.

2 Aumusse, fourrure que certains chanoines portent sur le bras. 
frère Jean, des Cordeliers, lequel « alors que le suppliant conduisait un enterrement, en chape, étole et bonnet carré, l'a pris par les cheveux du derrière de la tête et a fait divers efforts pour le renverser en disant : Allons, b...! »- Messire Arnaud de Puybertrand, curé de N. D. du Roc, se plaint, en 1719, du chapelain de l'hôpital de Mussidan « qui a soulevé toute la populace, femmes et enfants et usa de toutes sortes de violences pour l'empêcher de prendre possession de son bénéfice. » Nombre de fois, le nouveau titulaire d'un bénéfice se trouve empêché d'en prendre possession par les cabales de son prédécesseur.

À chaque page on voit les graves problèmes de préséance mettre la perturbation partout, notamment dans les processions. En 1674, le premier consul de la ville de Lisle et le marquis de Monségur se disputent l'un des cordons du poële à la procesion du SaintSacrement; ils se saisissent «à la cravate». Grand tumulte, comme on l'imagine, «et la procession n'eut pas lieu». En 1716, nous sommes informés par une plainte du curé de Nontron contre le sieur Laborderie, lieutenant de la juridiction, que celui-ci «dans une procession en l'honneur du sacre du roi donna un coup de poing à Mathieu Fage, l'un des sacristains, et lui renversa sa perruque. » La plainte d'un autre curé, en 1729, nous fait savoir qu'un sieur de Lestaillades, sa femme et sa servante, ont troublé le service divin parce que « le dit Lestaillades, prétendait avoir le privilège comme ses ancêtres, de porter le bâton du dais, du côté le plus honorable, en la procession du Très-Saint-Sacrement. »

Une chose à noter, car elle contraste singulièrement avec ce qui se passe sous nos yeux, c'est la mauvaise intelligence qui semble régner entre le curé et le seigneur, entre le presbytère et le château. Ils sont souvent en guerre ouverte. Rien que pour Sarlat, sur les 230 plaintes pour violence j'en ai compté 43 qui sont portées par des prêtres contre des personnes nobles ou notables de leur voisinage. En veut-on des échantillons? Plainte en 1708, (Sarlat) du curé de Jayac contre «Messire de Carbonnières de Jayac, seigneur justicier du dit lieu, qui l'a menacé, l'a insulté, lui a tué son chien, a fait sonner le carillon pendant une heure pour honorer les convives du château, et enfin a maltraité le requérant lorsqu'il est allé fermer l'Église.» Plainte en 1726, (Périgneux) «de très haut et très-puissant seigneur César- 
Phébus-François comte de Bonneval, contre les religieux de SaintJean de Côle qui ont biffé ses noms et qualité de seigneur de la paroisse sur une cloche neuve, dont il a fourni le métal et dont il est le parrain, qui ont sonné le tocsin à plusieurs reprises pour exciter une sédition populaire et ont poussé le peuple à mettre le feu au château. » En 1778, après un procès avec la famille d'Allemans, le curé de la paroisse de Champniers est condamné «à présenter l'eau bénite et le goupillon au sieur et dame d'Allemans et à l'aîné de leur maison, à leur banc, toutes les fois qu'il fera l'aspersion d'eau bénite; à faire présenter par le sonneur de cloches et le bedeau le pain bénit au sieur et à la dame d'Allemans et enfin à les encenser à leur banc toutes les fois qu'il brûlera de l'encens, à la messe et aux vêpres, au moment où l'on fait l'encensement au peuple, »

Les cérémonies du culte semblent, au XVIIIe siècle, n'avoir d'autre intérêt pour la noblesse que l'exercice de ses privilèges. En général, sa tenue à l'église laisse à désirer; et si l'on doutait des progrès que l'irréligion avait fait dans les classes supérieures avant de se répandre au-dessous d'elles, on trouverait dans nos documents force témoignage de son irréligiosité au moins extérieure. Je me souviens avoir lu dans un sermon du XVIIe siècle que, à cette époque déjà, à Paris, il n'était pas rare de voir un jeune gentilhomme, entrant à l'église au milieu de la messe, embrasser une demoiselle coram populo. Cet exemple parisien a été suivi. En 1696, (Sarlat) un curé porte plainte « contre le sieur de Labrande et ses enfants, entre autres le sieur de Nadaillac et le petit chevalier qui l'ont maltraité en diverses rencontres et ont causé du scandale dans son église, en caressant la demoiselle L. du C. nonobstant sa résistance. " Ne nous étonnons donc pas si, un jour de mardi gras, qui excuse toutes les licences, nous voyons, dans une campagne arriérée même, à Berbières, un bachelier en droit et les deux fils du lieutenant et du procureur d'office, « danser dans les prés, masqués, ayant des manteaux comme ceux des Récolets et tournant la religion en dérision. » -Et maintenant il n'est personne de plus pieux que les petits-neveux de ces impies, comme il n'est personne de plus poli que les petits-neveux de ces matamores !

Inutile d'ajouter que toutes les classes participent à la brutalité des moeurs dont j'ai donné des spécimens pour les classes dominantes. De nos jours, quoi de plus courtois que les relations des greffiers avec les 
juges, et en général des autorités entre elles ? Jadis il n'en était pas de rnême. En 1731, le greffier de la juridiction de Saint-Cyprien se plaint de son juge Me Guillaume Jarlan sieur de la Carrières, "qui l'a menacé de coups de pied dans le ventre et lui a donné un coup de fouet dans la rue, lui reprochant d'avoir remis en son absence une procédure à Me Bertrand R. 》 - Je sais bien que, parmi les médecins d'aujourd'hui, quand ils se disputent la clientèle d'une petite ville, ne règne pas toujours un esprit de confraternité tout à fait parfaite. On aurait cependant de la peine à voir se reproduire la scène qui suit, et qui nous est retracée par une plainte (1717, Cahors) d'un maître chirurgien et consul perpétuel de Cahors. Pendant qu'il était en train de sonder un malade atteint d'une rétention d'urine, deux de ses confrères survenant «se sont rués sur lui, l'ont traité de sot et d'ignorant, lui ont déchiré ses manchettes, l'ont poussé hors de la chambre du malade et lui ont fermé la porte au nez en disant qu'ils voulaient eux-mêmes faire l'opération parce que c'était une de leurs pratiques. » Les anciens médecins sarladais, j'ai peine à le confesser, ont été même plus âpres au gain que ceux du Quercy. Croirait-on qu'en 1674 il y avait, à Sarlat, une doctoresse en chirurgie, « Marie Bourdet damoiselle de Daubigny », ayant déjà professé son art «avec honneur dans plusieurs villes du royaume »? Cette jeune personne, qui devançait, on le voit, de deux siècles nos femmes-médecins d'à présent, ne paraît pas avoir eu à se louer de ses confrères masculins. « On menace continuellement de la tuer et de la chasser de la ville, » et tous les chirurgiens du lieu avec leurs apprentis «sont venus armés de marteaux pilons en fer, bistourtiers ${ }^{1}$ et autres instruments enfoncer les portes de sa boutique, briser les parements, les vitres et les instruments, notamment quatre bassins, coffres, chaises et autres meubles, même un miroir qui coûtait deux louis d'or, comme aussi ils lui ont emporté un petit cocomart ${ }^{2}$ d'étain sonnant, une perruque toute neuve, etc. » Vraiment, nos docteurs actuels sont plus galants pour leurs rivales en jupons.

Il ne faut pas être surpris, après cela, si les huissiers sont quelque peu brutaux. J'en vois un, en 1755, maltraiter fort rudement une femme enceinte contre laquelle il instrumente : il lui donne un coup de

Bistortier, pilon en bois à long manche.

2 Coquemar, pot pour faire bouillir de l'eau. 
poing au sein et un coup de pied dans le bas ventre. Du reste, ces malheureux étaient excusables dans leurs brutalités, qu'on leur rendait avec usure. Rien de moins confortable que la vie d'un huissier d'ancien régime. Les gentils-hommes le rouent à coup de bâton, les militaires menacent de l'éventrer ou font mine de «vouloir le percer avec une broche de la cheminée » ou de « lui jeter un pot sur la tête. » Il n'est pas jusqu'aux curés parfois qui ne le battent.

\section{IV}

$\underline{\text { Retour à la table des matières }}$

En résumé, la criminalité d'ancien régime, prise dans son ensemble, diffère de la nouvelle par des caractères importants. Des crimes ou des délits, destinés de notre temps à une brillante carrière, banqueroutes, escroqueries, abus de confiance, viols sur des enfants, infanticides, je ne parle pas même des suicides, - y apparaissent à peine, ou y font complètement défaut. D'autres, aujourd'hui disparus, soit parce qu'ils ne sont plus incriminés, soit parce qu'ils ne se produisent plus, y sévissent encore, avec une intensité, il est vrai, décroissante: blasphème, sacrilège, sorcellerie, etc. Et, même à l'égard des faits délictueux ou criminels qui se continuent du présent au passé, les dissemblances sont telles, comme proportion numérique, comme procédés d'exécution, comme qualité d'exécutants, que, certainement, l'anthropométrie lombrosienne elle-même, si elle pouvait s'appliquer aux meurtriers et aux voleurs d'autrefois, ne parviendrait pas à les confondre avec nos assassins et nos larrons. Que l'on prenne la peine de feuilleter les volumineux documents dont je viens d'extraire la moëlle, en partie du moins; et que l'on parcoure ensuite rapidement un recueil de plaintes parvenues à l'un de nos Parquets ou un registre de nos jugements et de nos arrêts criminels. Cette comparaison suffira pour faire sentir le contraste des couleurs entre la délictuosité violente de nos pères et la délictuosité astucieuse de leurs petits-neveux. 
Est-il nécessaire d'ajouter que, sous l'ancien régime même, la criminalité a subi des transformations, sensibles à la lecture denos inventaires ? Çà et là, quand ils remontent aux guerres religieuses du XVIe siècle, on voit les teintes s'assombrir et se colorer de sang. Encore sont-elles adoucies trompeusement par ce fait que la justice, en beaucoup de points, fut alors suspendue. Dans un procès soutenu en 1617 devant les « Parlements de Nérac et de Castres, » un habitant de Périgueux a eu besoin de se faire délivrer un certificat constatant que « la ville de Périgueux a été prise par des gens de guerre et du parti de la R. P. R. le 6 août 1575 et fut reprise par les habitants de ladite ville catholique le 28 juillet 1581 : pendant lequel temps il ne s'exerçait de justice, et messieurs les juges présidiaux furent contraints d'aller tenir la cour en la petite ville de Saint-Astier où il se faisait fort peu d'expéditions, à cause que les chemins n'étaient libres. Comme aussi la présente ville se déclara pour la Ligue depuis le mois de janvier 1590 et continua en même état jusqu'à la fin de l'année 1594 ; pendant aussi lequel temps la justice ni le commerce ne s'exerçaient que fort peu, à cause des troubles. ") Que de brigandages alors, que d'exactions et de pillages impunis! Les chroniques locales en font foi. Les représailles de parti à parti ont été terribles et prolongées. Le mouvement calviniste s'étant propagé d'abord dans la noblesse de notre région, il est permis de croire, d'après ce qu'on sait de son esprit d'autrefois turbulent et factieux ${ }^{1}$, que les questions de religion ont été trop souvent pour elle un prétexte à batailler, à traiter en ennemi l'ami de la veille, en étranger le voisin, et à le tuer et le piller en conséquence. Imaginez une troupe de chasseurs passionnés qui, dans un pays peu giboyeux, se prendraient pour gibier les uns les autres : telle est la parfaite image des politiciens de tous les temps. L'histoire des prises et reprises de villes, dans notre province, pendant toute la seconde moitié du seizième siècle, est une orgie de massacres et de pillages où les criminels-nés ont eu beau jeu. Les révolutions, on le sait, sont les saturnales du crime; malheureusement, elles en sont aussi les oubliettes, et il est dans la nature des plus grands forfaits de se faire oublier ou excuser sous prétexte de politique.

Le Périgord, d'après de Thou, regorgeait de noblesse factieuse; et l'histoire du pays, notamment la conspiration de Biron sous Henri IV, confirme pleinement cette assertion. 
La Fronde aussi, on l'a vu, a laissé trace de son passage dans nos documents ${ }^{1}$. Mais, à partir de la belle époque de Louis XIV, les mœurs deviennent moins sanguinaires, quoique toujours violentes, et, si force coups s'échangent, surtout des coups de poing, ils sont rarement mortels. A mesure qu'on descend vers la Révolution, cependant, le murmure des mécontentements grossit et se fait entendre par instants. La perception des rentes féodales, comme celle des dîmes, devient tumultueuse. En 1747, le sieur Dubos, chargé de percevoir les arrérages de rente des tenanciers sur la terre de Carves, porte plainte contre plusieurs femmes qui lui «ont arraché des cheveux, donné des coups de bâton, jeté une poignée de cendres dans les yeux et la bouche pour l'empêcher de crier, et finalement lui ont pris les papiers qu'il portait à l'audience de la justice de Carves pour les jeter au fond d'une mare... » Mais la rivalité et la haine des classes remontent plus haut encore. En 1727, je vois cinq paysans de Simeyrols, "armés de gros bâtons et de massues » pénétrer dans l'enclos d'une maison noble " pour y chercher un paysan qu'on y aurait recélé, suivant eux ». Ils ne se retirent qu'en grondant et menaçant. C'est par ces petites expéditions rurales que se préparaient peu à peu les grandes journées révolutionnaires. Dans les cabarets, des précurseurs de Rabagas, commencent à pérorer dès 1740. A cette date, le comte de Bourdeilles se plaint « du nommé Desvaux, soi-disant avocat, homme violent, dangereux, qui tient contre lui, dans les cabarets, les propos les plus atroces, et qui notamment a attaché au portail du château de Bourdeilles une affiche ou placard contenant de mauvaises rimes ou des vers séditieux et obscènes tendant à révolter les habitants de la terre de Bourdeilles contre leur seigneur. » C'est un demi-siècle avant la Révolution que s'étalait sur les murs de cette petite ville cette protestation rimée contre l'ancien régime.

Nos documents s'arrêtent au moment où l'ère révolutionnaire s'achemine vers sa phase sanglante. Dans les dernières pages la fermentation des esprits se laisse clairement apercevoir au fond des campagnes les plus arriérées. Nous apprenons par une plainte « du Procureur du Roi en la maréchaussée générale de Guyenne », qu'en

Dans d'autres documents, je vois mentionné l'assassinat de Pierre de Labrousse, vieillard de 82 ans, ancien lieutenant-criminel, en septembre 1653, dans une sédition populaire qui eut lieu à Sarlat. La vengeance privée, sous couleur politique, parait avoir été le mobile du crime. 
1790 des habitants de Vallojoux, Sergeac, Saint-Léon et Thonac, petites paroisses du canton de Montignac, armés et rassemblés au nombre de 300 environ, " vont se transportant chez les particuliers, de préférence chez les seigneurs et chez les curés, où ils mettent tout à contribution, jusqu'à enlever les grains qu'ils trouvent, à les forcer à donner leur argent, les menaçant d'incendier leurs châteaux, se permettant même de faire feu sur les personnes. " Le Procureur du Roi les accuse d'exercer toutes sortes de brigandages: "ainsi attroupés, ils plantent au milieu des places publiques et devant les châteaux et maisons des seigneurs, des arbres d'une grande hauteur, dont quelques-uns ont la forme de potence, et en haut desquels ils placent un balai, une mesure de grains, une radoire, un crible, et de plus un écriteau portant quittance de rentes. Ensuite, ils cherchent à enlever les girouettes placées sur les châteaux ou maisons particulières, et, en cas de résistance, de la part des propriétaires, ils se portent envers eux à de graves excès, et même jusqu'à l'incendie. » Ces désordres ont eu lieu en janvier 1790. Nous comprenons qu'une autre plainte, sous la même date, parle d'un «bureau de vexations tortionnaires, créé à Montignac. » Ces attroupements se répétaient partout avec une frénésie imitative qui est la circonstance atténuante de leurs meneurs eux-mêmes : ceux-ci pourtant étaient traités par la justice prévotale avec une rigueur où se continue l'esprit des Présidiaux. En 1790, le Prévot général de la Maréchaussée de Guyenne condamne le chef d'une de ces bandes pillardes et dévastatrices à être pendu et étranglé ; et deux de ses complices sont condamnés, l'un à cinq ans de galères, l'autre à un an de prison. - Mais arrêtons-nous; il faudrait, pour continuer, empiéter sur le champ de M. Taine, qui ne laisse pas grand chose à glaner après lui.

Encore un mot, pour finir, sur le fonctionnement des anciens tribunaux et l'exécution de leurs peines. Une chose me frappe, d'abord, c'est le nombre des magistrats. Dirai-je qu'il y en avait alors quatre ou cinq fois plus qu'aujourd'hui ? Non, ce ne serait pas assez dire. Le Présidial de Périgueux, par exemple, dont la juridiction s'étendait, il est vrai, sur toute la Sénéchaussée de Bergerac et aussi sur partie de celle de Saint-Yrieix, comptait en 1584 trois présidents, dix-huit conseillers, un procureur du roi et deux avocats du roi : plus tard, le nombre des conseillers fut réduit à douze ou treize. A Sarlat, à peu près mêmes chiffres. Notez que, à côté de ces Présidiaux si peuplés, - 
sans compter leur barreau composé de 36 avocats inscrits encore en 1788 , et de seize procureurs, - il faut compter les «conseillers en l'Élection », membres presque aussi nombreux d'un tribunal administratif et fiscal ; et, au-dessous, dans chaque petite seigneurie, le juge seigneurial. Somme toute, surtout si l'on a égard à l'accroissement de la population, notre personnel judiciaire a été se réduisant dans des proportions énormes, et, si l'on y réfléchit, excessives. À présent la plus vive préoccupation d'un ministre de la justice semble être de supprimer des tribunaux, de diminuer le personnel judiciaire autant que possible. Dans les autres ministères, la tendance est inverse : créer sans cesse de nouvelles fonctions et de nouveaux fonctionnaires. Il en est ainsi, je suppose, parce que la fonction essentielle de l'État, la seule même que les économistes classiques lui reconnaissent avec la défense militaire du territoire, c'est la Justice. Rogner tous les ans, dans nos budgets, la part de l'essentiel, au profit de celle de l'accessoire, c'est imiter les femmes qui font des économies de linge pour avoir une plus belle robe. Mais on dirait que notre démocratie courrait un grave péril si les magistrats épargnés jusqu'ici par cette manie extraordinaire d'économie de sièges n'étaient pourchassés de leurs derniers loisirs, surchargés d'affaires, bourrés de procédures jusqu'au cou. Au moment où tous les ouvriers réclament et obtiennent la diminution de leurs heures de travail, ces exigences sont singulières. C'est s'abuser, d'ailleurs, que de confondre le travail d'un juge avec celui d'un maçon et de payer le premier à tant l'heure d'audience comme l'autre à tant le mètre carré de maçonnerie. Le juge, d'après nos pères, et en cela ils avaient raison, doit être avant tout un travailleur faiblement occupé, car on ne juge bien qu'autant que juger est un plaisir et non une fatigue, et il n'y a rien de plus dangereux qu'un magistrat trop pressé, surtout à l'audience correctionnelle. La leçon du passé sur ce point pourrait être entendue avec profit.

Ce n'est pas que je propose les juges anciens pour modèles en tout ${ }^{1}$; les juges seigneuriaux du moins. En 1696 (Périgueux), une

\footnotetext{
Il me sera permis cependant de louer une dernière fois leur impartialité courageuse. En voici un trait qui me frappe. En 1611, au moment où, Henri IV venant de mourir, la fermentation des guerres religieuses recommençait, le lieutenant général de la Sénéchaussée de Sarlat, François de Gérard, est appelé à décider, après enquête et contre-enquête, après avoir oui « le promoteur du diocèse en ses observations ", si l'église réformée de Salignac doit être réputée légalement établie. Or, ce magistrat était un fervent catholique ; Il était le beau-frère de
} 
femme mariée porte plainte « contre le juge et le procureur d'office de Badefol qui, par violences et menaces, après l'avoir renfermée dans un cachot du château de Badefol, l'ont forcée à déclarer qu'elle était enceinte des oeuvres, d'abord du nommé François, puis d'Etienne Lapeyre, bourgeois, son maître... » Voilà comment procédaient extrajudiciairement, les juges ${ }^{1}$, et le cas qu'on faisait de la présomption pater is est quem nuptiae demonstrant.

On a pu remarquer, outre la cruauté des peines, leur diversité et aussi leur étrangeté. Les exécutions par effigie jusqu'à ce que mort s'en suive devaient être un spectacle assez grotesque, et si plusieurs fois, comme on l'assure, le condamné par coutumance a pu assister, caché derrière une fenêtre, à sa propre pendaison de la sorte, il lui a été permis d'en rire un peu, quoique peut-être il n'ait guère abusé de la permission. L'amende honorable, en chemise, et un cierge à la main, en pleine église et en plein tribunal, à laquelle le diffamateur était soumis, n'était pas non plus sans côté plaisant. En 1679, par exemple, le Sénéchal de Sarlat condamne «messire Jean de Calvimont, seigneur de Saint-Martial, etc., " à déclarer " solennellement», le Corpus Domini présent, dans l'église paroissiale de Sarlat, à l'issue de la grand'messe, que Léonard Clarat, clerc, « est innocent d'avoir tiré aux pigeons et d'avoir tué iceux... » C'est que la chasse alors, de la part d'un roturier, était un grand crime. - Le bannissement hors du ressort de la juridiction était aussi cruel jadis que peut l'être aujourd'hui l'exil hors de France, sinon la déportation. Mais on voit

l'évêque de Sarlat, un Salignac-Fénélon; il était sûr de plaire à la population sarladaise, en grande majorité catholique, en refusant l'estampille officielle au groupe et au temple protestant dont il s'agit. N'importe, il résiste à ces influences, et déclare l'église réformée de Salignac légalement établie. - Quant à l'intelligence professionnelle, le magistrat ancien pourrait aussi, bien souvent, servir de modèle. Dans une brochure relative à une expertise médico-légale qui eut lieu à Bologne en 1665, le Dr Augusto Setti (Rome, 1891), exprime une vive admiration, et très justifiée, pour la pénétration, l'ingéniosité, la finesse dont le magistrat instructeur du XVIIe siècle a fait prouve en ses multiples et pressantes questions. Il rend hommage aussi, comme j'ai dû le faire plus haut. à l'habileté des experts (il s'agissait d'une affaire d'empoisonnement très délicate), malgré les lacunes forcées de leurs connaissances chimiques.

1 Et voici comment les particuliers imitaient les magistrats. En 1676, plainte de Léonard Lagrosse, forgeron « contre le sieur de Beyssac et son valet et autres, qui, armée de pistolet et de fusils, auraient enlevé ledit Lagosse, lui auraient bandé les yeux pour le transporter dans une caverne et lui auraient mis une corde au cou, pour lui faire avouer qu'il avait tué la jument et pris le cheval du sieur de Beyssac. » N'est-ce pas là, visiblement, un délit suggéré par les procédés habituels de la justice d'alors, par la question? 
l'abus qu'entraînait cet échange de leurs malfaiteurs auquel se livraient les diverses cours criminelles. A partir de 1680 environ, les condamnations aux galères se multiplient et paraissent se substituer souvent aux condamnations à mort. Quant à l'emprisonnement, ce devait être, comme toujours, une peine aussi terrible pour le conscrit du délit que bénigne pour le vieux routier. La surveillance était à peu près nulle dans les prisons, si j'en juge par la fréquence des évasions ${ }^{1}$, et aussi des églogues pénitentiaires. Je vois à Périgueux, notamment, en 1748, un prisonnier et une prisonnière accusés du crime de commerce adultère « continué au mépris de la justice dans les prisons royaux de la ville de Périgueux », et, en 1757, un autre couple de détenus accusés du crime de commerce incestueux. La vieille gaîté française n'abdiquait pas ses droits dans ces locaux malpropres. On y avait l'habitude de fêter joyeusement le carnaval ; si bien qu'à Sarlat, on prenait des mesures de police (1783) contre la « dissipation » que cette époque de l'année y occasionnait. Naturellement, on s'y battait; qui plus est, on y battait quelquefois le geôlier et même sa femme. En 1706, « le concierge de la prison de Sarlat, qui a reçu l'ordre de laisser promener dans la cour et les chambres Boucher de L..., (accusé d'assassinat), se plaint de ce que celui-ci, faisant le maître à la prison, lui tue ses poules, bat sa femme à coups de pied et à coups de poing, et, ayant mis dans son parti les soldats du régiment de Romainval, prisonniers, qui ont la même liberté, lui lance des pierres dès qu'il paraît dans la cour, de sorte qu'il a manqué d'être tué deux ou trois fois ${ }^{2}$. 》

Gardons-nous cependant de trop nous apitoyer sur ces geôliers d'autrefois. Comme valeur morale, ils devaient être à peu près à la hauteur des bourreaux; et j'observe qu'en 1781 le bourreau de Sarlat a été condamné, pour faits de violence accomplis en dehors de ses fonctions, par habitude sans doute, aux galères à perpétuité.

Assez souvent aussi, des bandes d'émeutiers forçaient les portes des prisons pour mettre en liberté un de leurs amis. La mise en liberté sous caution était assez fréquemment pratiquée, nous semble-t-il. On la voit aussi souvent mentionnée dans le Registre criminel de SaintMartin.

2 Relativement à la nourriture des prisonniers, je trouve, en 1716, un bail au rabais des fournitures de pain dans les prisons: l'adjudication a lieu en faveur d'un boulanger qui « s'oblige à fournir du pain bien conditionné a chacun des prisonniers, du poids de 28 onces, à raison de 2 sols le pain ». 
Je termine ces notes éparses par un spécimen des signalements anciens. Il manque un peu de précision. On signale, en 1733, « deux personnages, l'un désigné par le nom de sergent dans la compagnie du sieur de la Martonie, figure de grande taille, veste bleue, le visage enflammé, le poil ardent, une perruque en façon de bonnet, un chapeau bordé d'argent. » Nous sommes loin des envois de photographies et du bertillonnage..

Il y aurait bien d'autres citations à extraire des vieux papiers où je me suis plongé pour en donner aux lecteurs un simple aperçu. J'ai laissé parler les textes, m'abstenant de réflexions le plus possible. Mais il importe cependant de faire observer, en finissant, que l'on aurait de l'ancienne société une idée beaucoup trop sombre si l'on se bornait à la considérer sous son aspect criminel. Si l'on jugeait la nôtre d'après les livres de nos parquets, quel tableau s'en ferait-on ? L'ancien régime $\mathrm{a}$ eu, à côté de ses espèces éteintes de crimes, sa flore caractéristique et non moins éteinte de beautés et de vertus, et mes compatriotes sarladais, spécialement, commettraient une grave erreur s'ils se persuadaient que tout, dans leur état social actuel, est préférable à celui de leurs pères. La violence des mœurs, par exemple, ne fait pas toujours obstacle à l'amour de l'art et à une certaine finesse de goût. Les mémoires de Benvenuto Cellini nous en donnent une preuve entre mille. Or, certes, je ne veux pas comparer Sarlat à Florence ou à Venise, mais, au point de vue artistique, je note dans l'un de nos inventaires, qu'à Sarlat en 1782 il existait deux peintres italiens nommés Ramelli et Lange, et que ce dernier avait la spécialité de nettoyer les tableaux, c'est-à-dire de les restaurer. Je dois, hélas ! constater qu'à présent il ne vient plus de peintre ni d'Italie ni d'ailleurs se fixer dans cette petite sous-préfecture ; et, à coup sûr, le métier de nettoyeur de tableaux n'y nourrirait personne. 
Gabriel Tarde, Études pénales et sociales (1892)

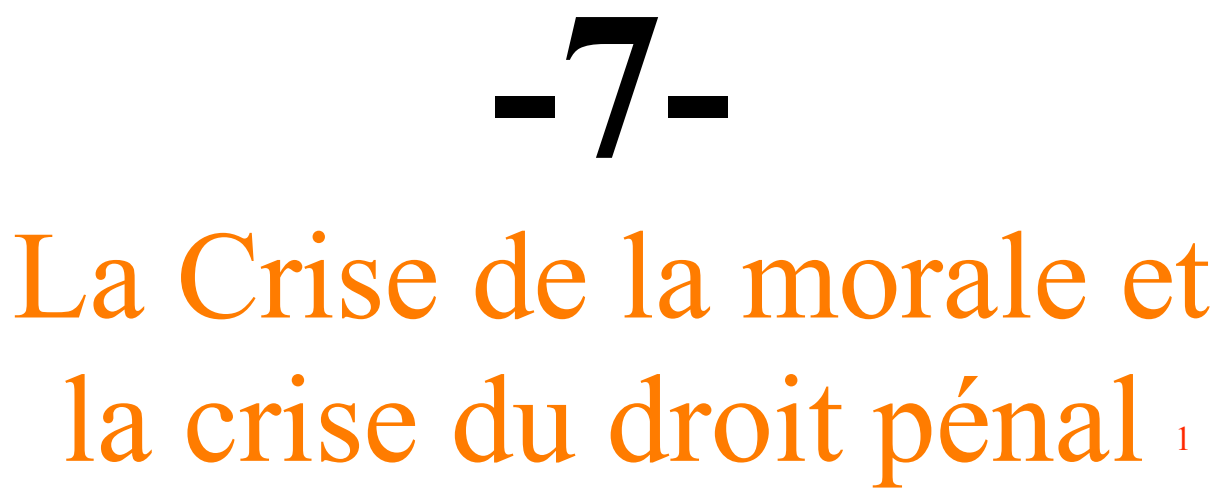

(Octobre 1888)

La crise du droit criminel à notre époque n'est qu'une des formes des plus saillantes par lesquelles fait éruption dans les faits sociaux ou dans les théories sociales cette grande crise de la morale qui trouble actuellement les coeurs. Ce ne sont pas quelques observations anthropologiques de crânes ou de cervaux, ni quelques enregistrements statistiques, qui ont suffi à ébranler les antiques fondements de la pénalité, à susciter de tous côtés, ce qui ne s'est pas encore vu, des ouvriers âpres à la destruction et à la reconstruction du droit pénal sur de nouvelles bases. Pour être bien compris, le mouvement révolutionnaire qui agite les criminalistes italiens ou français, et qui se fait

Article de revue générale paru dans la Revue Philosophique d'octobre 1888. Cette étude, malgré sa date un peu ancienne, ou plutôt à cause de cela même, m'a paru propre à montrer, par sa comparaison avec l'étude suivante, le travail qui s'est opéré dans les esprits sur le sujet dont il s'agit au cours des dernières années. 
sentir par une secousse salutaire au sein même de l'école dépositaire des traditions, doit être rattaché à cette anxiété, à cette angoisse universelle des consciences éclairées dont les travaux de MM. Fouillée et Guyau, de M. Beaussire, de M. Renouvier même, ont été l'expression en France. Les progrès du néo-criticisme sont peut-être, à vrai dire, le symptôme le plus frappant de cette déséquilibration des âmes, comme les progrès du despotisme sont souvent l'indice révélateur des périls qui s'accumulent autour d'un gouvernement. Avec l'intolérance désespérée du croyant qui sent sa foi chanceler autour de lui et la proclame d'autant plus impérieusement, le maître éminent de l'école rajeunie de Kant fait du devoir un dogme appuyé sur la seule volonté, le soustrait aux morsures de la raison, et veut que la science des réalités se subordonne à la foi en cet idéal. Si cette foi est contredite par le déterminisme scientifique, tant pis pour les déterministes. Mais les efforts faits en ce sens, avec tant de vigueur, $\mathrm{du}$, reste, tant de hauteur d'âme et de talent, pour relever les digues de l'impératif catégorique, prouvent que le déluge des idées contraires croît toujours. Dans ce déluge, M. Fouillée cherche un port; il croit le trouver dans la théorie des idées-forces. La liberté du vouloir, fondement indiscutable de la responsabilité morale d'après lui comme d'après l'école traditionnelle, serait une de ces idées qui constitueraient elles-mêmes la condition essentielle de leur graduelle réalisation, à peu près comme la réalité de Dieu, d'après saint Anselme, était impliquée dans la notion de sa responsabilité. Je doute qu'après avoir été ballotté par la Critique des systèmes de la morale contemporaine 1 sur l'orageuse mer de nos doutes moraux, le lecteur de cette belle odyssée métaphysique ne trouve pas un peu décevante et stérile l'Ithaque où il aborde enfin. À moins d'admettre, comme l'a admis un jour Claude Bernard en passant, par distraction sans doute, qu'il puisse y avoir " un déterminisme de la liberté », c'est-à-dire un ensemble de conditions cérébrales d'où la liberté, au sens métaphysique du mot, pourrait jaillir, chose aussi impossible, à mon avis, que la création d'un être incréé; à moins d'admettre cette contradiction dans les termes, on ne voit pas comment une décision volontaire pourrait un jour, soit par l'effet même de l'idée de liberté, soit autrement, devenir moins déterminée qu'elle ne l'est par le concours des circonstances internes réunies. Tout ce qu'on voit nettement, c'est que la proportion

Réédité en 1887 (F. Alcan). 
de ces dernières peut et doit aller croissant; et c'est ce qui nous intéresse, à vrai dire. Mais la proportion croissante des conditions intérieures du vouloir, qu'est-ce ? Le progrès de la liberté ? Non, dites plutôt le progrès de l'identité personnelle. Or, appliquée à l'identité et non à la liberté, la thèse de $\mathrm{M}$. Fouillée serait, je crois, susceptible d'une interprétation très propre à justifier sa confiance en elle.

Reconstruire la théorie morale à neuf : telle à été, malgré tout, la haute et ardue tentative de M Fouillée. Telle a été aussi celle de son ami, que la grande famille philosophique a eu la douleur de perdre. Tous deux ont travaillé, et l'un d'eux est mort à cette oeuvre, pendant que, de l'autre côté des Alpes, une pléiade de criminalistes s'efforçait avec plus de fougue, mais non avec plus de sincérité, non avec cette émotion contenue et condensée, si persévérante et si pénétrante, d'accomplir une tâche plus précise, mais semblable. Certes, il y a loin de la méthode de ceux-ci, de leurs mesures crâniennes ou de leurs courbes graphiques, à la méthode syllogistique de ceux-là ; il y a plus loin encore du naturalisme des uns à l'esthéticisme des autres, de l'esprit, au fond, éminemment pratique et quelque peu draconien qui caractérise les novateurs italiens, à cette poésie refoulée et intarissable, féconde en délicatesses d'images ou en ingéniosités d'idées, qui dissimule parfois sous son charme la profondeur habituelle à l'auteur d'une Morale sans obligation ni sanction. Livre singulier, rêve doré peut-être, mais dans le sens où l'on dit les vers dorés de Pythagore. Nul n'a fouillé plus à fond les racines du devoir; nul n'a mis plus à nu leur fragilité. Il a bien vu que le sacrifice au devoir implique la foi à quelques hypothèses, un risque couru par la volonté et la raison. Mais cela même l'électrise, et, jugeant toutes les âmes d'après la sienne, il estime que la perspective d'un si beau danger envisagé face à face, sans nulle illusion, est propre à redresser le ressort moral. Il eût dit vrai, je crois, si, complétant et rectifiant sa pensée, il eût ajouté que la foi à l'hypothèse choisie, pour être efficace, doit être pleine, et, partant illusoire, et que la suggestion ambiante, la contagion d'un milieu social imprégné de cette croyance fondamentale (disons aussi de quelque désir non moins fondamental) est nécessaire pour produire ce degré de conviction. L'individu qui est seul à croire ce qu'il croit ne croit jamais bien fort. 
Il faut rendre cette justice aux évolutionnistes (en morale héritiers des utilitaires, sous bénéfice d'inventaire d'ailleurs) qu'ils n'oublient jamais l'origine et la nature toute sociologique du devoir. Ce point de vue prête à toutes leurs théories morales un intérêt et une importance qui, en dépit d'étranges lacunes, expliquent leur succès. Prenons pour exemple l'Évolution de la morale par M. Letourneau ${ }^{1}$. Je n'ai pas à en rendre compte. Cependant cet ouvrage nous achemine par une pente naturelle aux travaux récents des criminalistes ; car le crime historique ou préhistorique y déborde. L'évolution de l'immoralité, comme il convenait du reste, y tient une place énorme. Sur les formes successives du délit, sur la transformation de la peine et de la responsabilité collective ou individuelle ; on y trouve une foule de renseignements et de documents puisés aux bonnes sources. L'auteur, par certains côtés, échappe à l'école matérialiste dont il professe les principes; il se sépare aussi de Spencer par son mépris de la «morale industrielle et mercantile » que vante si fort l'illustre anglais, trop favorable à l'industrialisme de sa nation. Il rend justice au passé même militaire. "Si nous honorons le courage, si, même au sein d'une civilisation énervante, mis en face d'un péril, nous entendons encore au fond de notre conscience une voix nous crier qu'il est bien de faire front, que la fuite est honteuse, qu'il faut savoir mourir, c'est que, des milliers et des milliers de fois, nos ancêtres, depuis les plus lointains, ont risqué leur vie, en tenant ferme devant le danger, devant l'ennemi animal ou humain. Si le vol est considéré comme un acte déshonorant... c'est que, des milliers d'années durant, il a été interdit, blâmé par la morale et puni par les lois avec une sévérité souvent atroce. » Fort bien, mais si la morale n'a pas d'autre appui que cette impulsion héréditaire, d'autre raison à invoquer que cette " voix » des aïeux, il ne faut guère s'étonner des progrès de la démoralisation. Leur lenteur seulement est surprenante et prouve qu'il y a ici à compter avec un autre élément, avec une conception intellectuelle de l'ordre social qui va se précisant dans les esprits et se généralisant, à mesure que la dissolvante analyse affaiblit les instincts moraux passés dans le sang. Il y a bien en tout matérialiste enthousiaste un idéaliste, mais un idéaliste sans le savoir.

Ce préambule est long, mais en vérité, il m'en coûte un peu de revenir à nos criminels et même à nos criminalistes. Il est vrai qu'il

Delahayes et Lecronier, éditeur, 1887. 
s'agit ici d'une fermentation d'idées qui tend manifestement à déborder hors de son berceau, hors de l'enceinte des écoles, et à passer de la période d'agitation à une phase d'action pratique et réformatrice. Cette tendance toujours plus accentuée est le fait important qui nous paraît se dégager, et des travaux accomplis dans le chantier des novateurs, et des critiques auxquelles ils ont donné lieu, de l'écho qu'ils ont eu au dehors.

Parlons d'abord de ces travaux. Le mot est ambitieux, car il n'a paru depuis un an aucune publication qui mérite d'être mise au rang des Nuovi Orizzonti, de l'Uomo délinquente, de la Criminologia. Mais M. Garofalo a donné une édition française de ce dernier ouvrage où les magistrats et les avocats, s'il en est qui lisent autre chose que Dalloz annoté, apprécieront, je n'en doute pas, à côté de quelques italianismes de style, une sobriété de langage qui n'a rien d'italien, et chez un membre du parquet, une hardiesse de vues, un goût des sciences naturelles, une combinaison de finesse psychologique et de force logique, d'esprit juriste et d'esprit naturaliste, qui n'ont rien de judiciaire. - M. Lombroso, d'autre part, a réédité son Uomo di genio revu et amplifié, et qui est susceptible du reste de s'accroître indéfiniment, si l'auteur espère fortifier sa thèse sur la quasi-identité du génie et de la folie en multipliant les anecdotes sur les traits d'extravagance échappés aux hommes supérieurs. Des deux procédés de Victor Hugo, l'énumération et l'antithèse, Lombroso affectionne le premier, et il excelle à en tirer des effets surprenants, contre lesquels on est obligé assez souvent de se défendre, en se rappelant qu'après tout il faut autre chose qu'une série de coïncidences pour établir légitimement, d'après les canons de l'induction, un lien de causalité ou d'identité. La méthode qui consiste à faire de l'ordre avec du désordre, à fonder une règle sur une collection d'exceptions, se déploie là avec une ampleur et un intérêt extraordinaires; et si j'en parle, c'est que cette lecture aide fort à se tenir en garde contre certaines précipitations de jugements qu'on rencontre aussi dans l'Homme criminel. Puis, les deux livres se complètent, l'un cherchant à prouver que l'homme de talent est un fou, l'autre que le délinquant est un fou lui-même ou un sauvage. La folie serait ainsi le confluent ou la liaison du génie et du crime. Jamais cette thèse, déjà ancienne, n'avait été étayée d'illustrations et de considérations si propres à la faire admettre à première vue. Un mauvais plaisant, compatriote de l'auteur (on n'est 
jamais trahi que par les siens), y a répondu par une brochure où il prétend prouver que l'éminent professeur de Turin, ce pseudoaliéniste, précisément sans doute à raison de son grand talent, est luimême un aliéné. Laissant de côté ces plaisanteries d'un goût douteux, bornons-nous à faire observer pour le moment que les hommes supérieurs où une époque salue sa propre image agrandie, son portrait générique ${ }^{1}$, sont équilibrés ou détraqués, sains ou morbides, suivant qu'elle-même est paisible ou orageuse, sage ou troublée, c'est-à-dire suivant que les formes traditionnelles de l'imitation y prédominent sur ses formes nouvelles, les suggestions du passé intérieur sur les excitations du présent et de l'étranger. Le moment le plus favorable à l'éclosion, à l'illumination d'une pléiade de génies purs, exempts de toute démence, est cette phase trop courte où un afflux antérieur d'innovations perturbatrices est en train de se consolider en une coutume nouvelle, plus souple et plus large. Tel est le traditionalisme rationaliste pour ainsi dire, du siècle de Louis XIV ou du siècle de Périclès. Je ne crois pas que M. Lombroso ait à puiser beaucoup de traits d'aliénation mentale, pour la prochaine édition de son ouvrage, dans la vie des grands hommes littéraires, politiques, scientifiques de ces temps-là. Ce que je dis des fous d'une époque donnée ne pourraitil pas se dire aussi de ses criminels ? Un siècle d'agités, comme le nôtre, ne doit-il pas compter une proportion d'aliénés, parmi ses malfaiteurs, supérieure à celle que présentaient les bagnes du XVIIe siècle ? C'est possible. Quoi qu'il en soit, n'est il pas évident qu'avant de conclure du particulier au général, il importe, ici et là, d'avoir égard à l'influence des causes sociales, à ces grandes ondes historiques de hausse ou de baisse cérébrale qui impriment à la psychologie de chaque période son cachet spécial ?

En attendant, un élève de Lombroso, le docteur Salvattore Ottolenghi, de Turin, nous sert sa brochure sur le squelette et la forme du nez chez les criminels, les fous, les épileptiqnes et les crétins, toute

\footnotetext{
A propos de portraits génériques, M. Lombroso a dans ces derniers temps, photographié synthétiquement, suivant la méthode de Galton, quelques têtes de voleurs et d'assassins, et dans une lettre reproduite par la Revue scientifique (9 juin 1888), il prétend que ses photographies composites présentent quelques traits de l'homme sauvage. Par malheur, il semble résulter de sa lettre que plus les photographies élémentaires sont nombreuses, moins le résultat est accusé : c'est le contraire, ce me semble, qui devrait avoir lieu si le type criminel était réel au même degré que le type mongol ou chinois.
} 
bourrée de chiffres, de tableaux, de courbes graphiques. Ce serait une erreur de croire qu'il n'y a rien d'intéressant à voir dans le nez d'une tête de mort. Débarrassé de sa partie charnue et cartilagineuse, il révèle à l'observateur certaines anomalies de structure que le nez vivant dissimule, et qui, d'après $M$. Ottolenghi, seraient plus fréquentes chez les délinquants et les aliénés que chez les honnêtes gens de même race. Or, ces anomalies sont, nous assure-t-on, d'origine atavistique. Le malheur est, que pour leur attribuer ce caractère, il faut chercher l'ancêtre de l'homme d'où elles proviendraient, bien au-delà des primates, parmi les mammifères les plus inférieurs, les rongeurs. «Cela, dit l'auteur qui a l'air de se féliciter de cette rencontre, donnerait raison à ceux qui, avec Albrecht et avec Benedickt (première manière), se fondant sur l'anatomie comparée, jugent l'homme de beaucoup inférieur aux singes et assez voisin des insectivores. » N'importe, il est instructif d'apprendre que les malfaiteurs ont 48 fois sur 100 le nez de travers, tandis que les normaux l'ont seulement 6 fois sur 100. Mais ce qui m'étonne bien davantage, c'est que les criminels en général, et les meurtriers en particulier, se font remarquer par la fréquence du nez rectiligne et long. Lombroso ne nous avait-il pas dit, cependant, que l'assassin avait surtout le nez aquilin ? La brochure de M. Ottolenghi n'en est pas moins une curieuse et instructive contribution à l'étude du type criminel, problème non résolu à la vérité, mais posé en termes de plus en plus précis. - Il y a moins d'anthropologie, et plus de psychologie, souvent même très fouillée, mais un peu délayée, notamment au sujet de l'invasion lente de l'idée homicide (p. 161 et s.), dans le volume que vient de faire paraître M. Rizzone Navarra, avocat, sous ce titre : Delinquenza e punibilita. Mais c'est tout à l'heure que j'aurais dû en parler, à propos de rééditions d'ouvrages publiées par les chefs de la nuova scuola. En effet, ce livre ne fait lui même que les rééditer et sous une forme moins attrayante. M. Navarra est plus 1ombrosien que Lombroso. Comme M. Ottolenghi, il va loin dans ses excursions paléontologiques à la recherche des origines. Pour atteindre celles de l'homicide, il croit devoir remonter jusqu'à la dionée attrape-mouches, qui, paraît-il, toute plante qu'elle est, déploie une certaine astuce et montre même une animosité profonde contre l'insecte qu'elle pince entre ses feuilles, (p. 10). La sensitive aussi, avec son irritabilité notoire, destinée à repousser tout contact, révèle un instinct criminel embryonnaire. C'est le germe qui, développé peu à peu, est devenu la 
criminalité humaine la plus monstrueuse ; - Ainsi, voilà l'irritabilité vivante conçue comme le point de départ du crime. Vraiment, il est à regretter que le plus illustre et non le moins solide des criminalistes français - je veux dire Voltaire - ne puisse sortir un moment de sa tombe pour nous donner le spectacle de l'ébahissement que lui causerait une telle proposition. Je crains fort que le grand railleur ne se dédommageât sur M. Navarra, avec usure, des éloges prodigués par lui à Beccaria, son compatriote, et qu'il n'eût de la peine à voir dans Delinquenza e punibilità un arrière-rejeton naturel des Délits et des peines. Il se tromperait pourtant, et ces étrangetés ne sont point justiciables de son rire. Il y a bien quelque chose, au fond, dans les assimilations étonnantes de M. Navarra. Seulement, si l'on veut à tout prix expliquer les choses sociales par les vitales, le clair par l'obscur, ne semble-t-il pas que l'irritabilité des tissus vivants doit être considérée comme le principe de l'action défensive contre toute attaque, c'est-à-dire de la pénalité et non du délit? - Autre petite observation, que je me hasarde timidement à formuler. Notre auteur reconnaît que l'anthropoïde ancêtre de l'homme a dû être peu féroce, peu criminel en somme, puisqu'il était frugivore comme le singe. Le singe a des habitudes patriarcales, il vit bourgeoisement avec sa femme et ses enfants. Mais, s'il en est ainsi, est-on bien venu, après cela, à nous présenter la férocité, l'immoralité, le crime, comme des phénomènes d'atavisme? N'est-ce pas plutôt l'esprit de famille, l'amour conjugal, les vertus domestiques, qui devraient passer pour des cas de retour à la vie de nos antiques aïeux ? - J'observe aussi, et non pas seulement à propos de M. Navarra, un certain penchant, trop fréquent dans l'école évolutioniste, à se payer de distinctions vagues. «En gravissant l'échelle animale, nous voyons peu à peu se développer et se déterminer une série de bonnes actions; de même, et plus aisément encore, nous voyons s'étendre et se précipiter une série d'actes mauvais. » D'autre part, on tient pour certain que les individus mauvais, les criminels, sont séparés des individus bons, qualifiés normaux, par tous les traits du corps, du crâne et du visage, voire même par le nez. Mais le malheur est que plus on s'efforce de préciser ce signalement anatomique des uns et des autres, plus se trouble et se brouille à nos yeux, dans cette grande crise de la morale dont j'ai parlé plus haut, la distinction du bien et du mal. 
Ce n'est pas de ce côté, décidément, que l'école nouvelle peut espérer des progrès durables, et ses chefs commencent à le comprendre. M. Ferri, depuis qu'il est député, a fort bien su reconnaître, avec la souplesse et la netteté d'esprit qui le caractérisent, l'orientation qu'il convenait de donner au vaisseau de sa doctrine pour le faire aborder au terrain des faits législatifs. Il est curieux de comparer Ferri législateur à Ferri conférencier ou théoricien; trois hommes en un seul. Ce n'est pas qu'ils se contredisent précisément; mais combien le dernier, en traduisant les deux autres dans ses discours à la Chambre italienne, les transpose habilement, les modifie et les simplifie ! Lisez, par exemple, ses discours, fort applaudis, des 26 et 28 mai 1888. Il est si loin, maintenant, de contester l'efficacité des peines qu'il attribue expressément la moindre criminalité de l'Angleterre, sa criminalité décroissante qui la distingue avantageusement de tous les autres États, à sa sévérité répressive. - Il n'est plus question de type criminel, d'atavisme, de Darwin, fort peu de statistique même. "Un code ne saurait être le triomphe d'une école, d'une doctrine préconçue »; l'homme d'État ne doit avoir qu'un but: «l'organisation légale de la défense des gens honnêtes contre les délinquants. " Rien de plus sensé, et, à la faveur de cet exorde, l'orateur fait passer une foule d'aperçus très justes sur la réforme pénitentiaire, devenue le vrai champ de bataille des théories pénales en Italie. Ferri n'est pas partisan du régime cellulaire ni de la peine de mort. - Dans ce même ordre pratique d'idées, nous signalons la Riparazione alle vittime del delitto, par M. Garofalo, écrit développant cette idée souvent émise, et avec raison, par l'auteur, que la plus efficace des peines, pour les petits délinquants, consisterait en dommages-intérêts prononcés d'office et payés obligatoirement en argent ou en travaux. - Louons encore Polizia e delinquenza in Italia, par M. Alongi, l'auteur d'une intéressante monographie sur la maffia sicilienne. Ces études de police importent à la psychologie criminelle par la même raison que l'art de la chasse, pratiqué par des Leroy, a servi aux progrès de l'ornithologie et de l'histoire naturelle en général.

Pendant que l'école positiviste d'outre-mont continue son évolution, l'école française rivalise avec elle d'activité et se distingue par le caractère solide, sérieux, modéré, de ses recherches. Les Archives d'anthropologie criminelle du docteur Lacassagne apportent tous les deux mois des contributions importantes, soit aux problèmes 
de criminalité par des articles tels que ceux de M. Bournet sur la criminalité corse (à rapprocher de En Corse, par Paul Bourde, livre tout plein d'informations), soit aux questions relatives à la preuve judiciaire par des monographies sur le Dépeçage criminel de $\mathrm{M}$. Lacassagne sur le fonctionnement du service des signalements anthropométriques de M. Bertillon, sur l'hypnotisme et la médecine légale de Ladame, soit enfin aux questions si délicates de responsabilité par une magistrale théorie de la responsabilité, incomplète à notre sens, mais remarquable surtout dans sa partie historique 1, de M. Paul Dubuisson, etc. Aux écrits publiés dans ce recueil peuvent être rattachés ceux qui émanent des élèves de son savant directeur, par exemple, de l'Empoisonnement criminel par le docteur Georges Benoist. On y voit, par l'histoire de ce crime, fort bien traitée, à quel point le courant de l'imitation est prépondérant dans la direction choisie par les instincts malfaisants, et aussi combien le déplacement de ces courants dans un sens ou dans l'autre, vers le poignard, l'arme à feu ou le poison, vers les poisons animaux, végétaux ou minéraux, dépend d'une découverte qui a rendu relativement moins efficace ou plus dangereux l'emploi d'un procédé antérieurement adopté. Pourquoi le règne des douze Césars es-il marqué par une épidémie d'empoisonnement ? Pourquoi faut-il ensuite « aller jusqu'au moyen-âge pour retrouver une nouvelle recrudescence de ce crime ?» On peut hardiment conjecturer que les découvertes d'une Locuste, puis celle des alchimistes, répondent à la question. On s'en assurera si l'on se rappelle que l'importation (équivalente à une découverte là où elle a lieu) du sublimé corrosif, du vitriol et de l'arsenic, par la Brinvilliers, la Voisin et leurs émules, en plein midi de Louis XIV, a suffi pour susciter à la cour du grand roi, et de là dans toute la France, une nouvelle poussée de ce crime éminemment contagieux. Au début de notre siècle, les découvertes de la chimie inorganique ont provoqué une recrudescence d'empoisonnements, toujours effectués à l'aide de poisons minéraux, mais surtout de l'arsenic, jusqu'à ce que la découverte par Marsh, en 1835, de l'appareil qui porte son nom, eût opposé une première digue à ce courant. Rejetés dès lors sur le phosphore, les empoisonneurs ont été dépouillés de cette nouvelle arme par l'appareil de Mitscherlich. Actuellement, leur nombre est fort diminué, mais on constate avec

Dans le Lyon-Médical du 24 juin et du 5 juillet dernier, ont paru deux intéressants articles de M. le Dr Henry Coutagne, sur La folie devant nos codes. 
effroi que les substances d'origine végétale, dues aux découvertes de la chimie organique, commencent à prendre faveur parmi eux; la digitaline, la strychnine, l'acide prussique, font leur entrée, et régneront jusqu'à l'apparition de nouveaux appareils propres à compléter les précédents.

$\mathrm{Au}$ premier rang des travaux français, il faut ranger - avec un article de M. Topinard sur l'anthropologie criminelle, publié dans la Revue d'anthropologie (15 nov. 1887) ${ }^{1}$ et où l'hypothèse du crimeatavisme ainsi que celle du crime-folie sont vigoureusement combattues au profit de la thèse du type criminel considéré comme un type professionnel - la brochure de M. Féré sur Dégénérescence et criminalité dont les lecteurs de la Revue philosophique ont eu la primeur. M. Féré n'admet pas les types professionnels; il combat également l'explication atavistique du délit, mais il adopte l'explication pathologique et lui prête le secours de son talent. Il se rattache non à Lombroso, mais à Morel. La criminalité native n'est à ses yeux qu'une des formes de la dégénérescence, et l'une des plus inférieures, car elle ne s'associe jamais au génie. Les « stigmates de la dégénérescence » observés chez tant de névropathes sont précisément ces traits défectueux du crâne, du visage et du corps que le professeur de Turin prête au criminel-né : prognathisme, strabisme, assymétrie de la face, etc. Du reste, « en ce qui concerne les circonvolutions cérébrales, personne ne peut dire quelle est la forme normale » et « on ne peut, dans l'état actuel, établir aucune relation entre une anomalie, cérébrale et la criminalité ou la folie. » En somme, le criminel est un fou, et M. Garofalo a fait de vains efforts, en niant la folie morale, pour établir une démarcation nette entre l'aliénation et la criminalité. Ceci posé, s'ensuit-il que le criminel doive être considéré comme irresponsable, ou même comme moins responsable que l'homme normal ? Nullement, car l'homme normal n'est ni plus ni moins libre que l'aliéné ; de là cette conséquence qu'il faut les considérer comme également irresponsables ou comme également responsables. Pour des raisons évidentes d'utilité, l'auteur se prononce en faveur de cette dernière opinion. En outre, « au point de vue social, on peut diviser les

Cet accord de M. Topinard (j'ajoute de M. Manouvrier) avec les vues que j'ai exprimées il y a longtemps à ce sujet m'est plus précieux que cet auteur ne paraît pas en avoir eu connaissance ; car il me traite en adversaire, erreur qu'il a reconnue plus tard. 
dégénérés en deux catégories : les improductifs et les destructeurs. » Les improductifs sont les paresseux, les infirmes, les malades; les destructeurs sont les délinquants. Tous ces "déchets sociaux" doivent être éliminés de diverses manières, D'ailleurs, la nature se charge en partie de cette oeuvre d'assainissement; les aliénés, les vicieux se cherchent, s'accouplent, et par l'accumulation héréditaire de leurs anomalies, aboutissent promptement à la stérilité; la dégénérescence court à l'impuissance.

C'est net et logique ; on pourrait dire : c'est raide. Mais d'abord, est-il vrai que le criminel soit, physiologiquement, un dégénéré ? je ne sais pas de plus beaux hommes que les tyrans et les condottieri italiens du moyen-âge, souillés de tous les vices et de tous les crimes. La dégénérescence est à la race ce que la décadence sénile est à l'individu. Le vieillard décadent (tous les vieillards ne le sont pas) est caractérisé par cette faiblesse irritable qui est la meilleure définition des dégénérés. Il boit, il s'excite de toutes manières pour ranimer sa force éteinte, et n'atteint, par cette excitation factice, qu'un plus complet épuisement. Cependant voit-on cette déchéance s'unir en lui à une criminalité plus prononcée ? Voit-on des personnes, honnêtes toute leur vie, manifester des penchants au vol ou au meurtre à partir du moment de leur déclin? Non; on n'est même pas en droit d'expliquer par le ramollissement sénile la fréquence des attentats aux mœurs commis par les vieillards sur des enfants. En effet, n'est-ce pas toujours comme conclusion d'une vie de débauches qu'un vieillard se livre à ces excès punis par la loi ? Ses antécédents, plus que son affaiblissement, l'ont poussé à ce genre de crime. Si donc la vieillesse ne conduit pas au crime, pourquoi la dégénérescence y conduirait-elle ceux qui n'y seraient pas prédisposés par d'autres causes?

Au demeurant, peu importe ; et, cela fût-il admis, est-ce qu'il serait permis de confondre, au point de vue de l'imputabilité, d'une part, les dégénérés criminels avec les fous proprement dits, sous prétexte que les uns comme les autres présentent des anomalies, et, d'autre part, les uns et les autres avec les normaux, sous prétexte que les actes des seconds comme ceux des premiers sont déterminés, assujettis à des lois ? Je ne puis le croire. Cette double assimilation n'est légitime que, si l'on persiste à faire reposer nécessairement la responsabilité morale, individuelle, sur le libre arbitre, suivant le préjugé traditionnel ; mais 
les conséquences mêmes auxquelles on est amené par là prouvent l'urgence de réformer cette antique notion. $\mathrm{Si}$, au contraire, on donne pour fondement à la responsabilité l'identité personnelle ${ }^{1}$, on reconnaîtra l'opportunité de distinguer avec soin le cas où une action, (libre ou non, ce n'est pas là la question) est conforme au caractère inné de l'individu, et celui où elle lui est contraire. Dans le premier cas, l'individu en répond, parce qu'elle lui appartient; dans le second, non. Or, qu'est-ce qui appartient plus exclusivement, plus véritablement à un homme que son anomalie congénitale, c'est-à-dire sa particularité distinctive, serait-ce une forme de perversité spéciale ? La normalité de l'honnête homme lui est moins propre, en un sens, puisqu'il la possède indivisément avec la majorité de ses semblables, que cette anomalie de naissance ne l'est au voleur ou à l'assassin, à l'ivrogne ou au débauché. La folie proprement dite, au contraire, est l'insertion, durant la vie, d'un nouveau caractère, parasitaire et rongeur, sur le caractère primitif. Voilà pourquoi j'ose prétendre que la folie morale, bien que son existence soit indéniable, est mal nommée. Il y a une autre raison, c'est que cette anomalie cérébrale rend l'individu impropre à remplir les fins sociales, mais non les fins individuelles de son activité, en quoi elle diffère des troubles intellectuels et sensoriels. Mais ajoutons que cette insociabilité innée suffit à établir aussi une différence radicale entre les soi-disant fous moraux ou les fous véritables et les cerveaux sains, au point de vue même de la responsabilité. - Au surplus, on abuse un peu de ce mot anomalie. Après tout, les déviations du type normal lui sont essentielles, puisqu'elles ne sont autre chose que ces variations individuelles postulées et non expliquées par Darwin, source obscure et toujours coulante sans laquelle ces cristallisations de la vie, ces stalactites zoologiques ou botaniques, que nous appelons des types, n'auraient jamais apparu, ne se maintiendraient pas même, et à coup sûr ne sauraient progresser dans la voie de leurs métamorphoses. Il n'est point de paradoxe qui ne soit ou ne puisse être la vérité de demain ; il n'est point d'anomalie qui ne soit ou ne puisse être un type normal dans l'avenir. Pourquoi ? parce que la différence est l'alpha et l'oméga des choses ; parce que les éléments sont essentiellement différents, et

Je dis l'identité, en dépit de la diversité des actes. A travers les actions les plus hétérogènes, le caractère individuel, virtualité profonde, reste identique comme une formule algébrique à travers ses applications les plus dissemblables. 
non essentiellement identiques, comme on se le figure d'ordinaire par habitude de juger homogène ce qu'on voit en masse et de loin. Sans doute, tout type régulier, une fois fixé, est un appareil répétiteur et tend à comprimer les tendances séparatistes des éléments sous son joug de fer; mais la preuve que le "génie de l'espèce » en cela est insensé ou criminel - comme la plupart des génies, si l'on en croit Lombroso et Moreau de Tours, - la preuve que la voie de répétition uniforme, de régularité plate, d'honnête médiocrité, est contraire à la nature des choses, c'est la loi de l'évolution. Cette loi ne signifie rien ou elle atteste que la seule raison d'être de la répétition, en tout ordre de réalités, c'est la variation à laquelle elle sert à la fois d'obstacle et d'appui. Par l'anomalie qui la constitue, l'individualité, c'est-à-dire la réalité par excellence, incarnation momentanée d'un élément-chef (c'est du moins l'idée que j'aime à m'en faire), s'empare d'un type, l'emploie et le tord à son usage ou à son image; et de la sorte les crimes, les excès, les chefs-d'œuvre, émanés de cette anomalie, sont bien siens dans toute la force du terme. N'oublions pas, enfin, de signaler la dernière publication française de M. Macé, Un joli Monde, et les Deux Prostitutions, de M. Carlier, livres abondants en renseignements de nature à faire toucher du doigt les liens étroits du vice et du délit. De ce tableau de notre corruption morale on pourrait rapprocher, parmi les publications italiennes, la Corruzione politica, de M. Colajanni, où l'auteur tâche de prouver que le milsonisine n'est pas un chancre exclusivement inhérent au tempérament français ni à la forme politique de la France actuelle. Nos remerciements au savant sicilien.

Après avoir montré, trop succinctement, les progrès intrinsèques, pour ainsi dire, des nouvelles idées, il me reste à parler de leur progrès entrinsèques. Ils sont de deux sortes. D'abord ils consistent dans cette diffusion du dehors dont témoigne, entre autres signes, la fondation récente d'une instructive Revista d'antropologia criminel à Madrid, sous la direction du Dr Alvarez Taladriz qui va ensemencer et développer dans tous les pays de langue espagnole les germes d'idées apparus en France ou en Italie. Mais surtout ils consistent dans un autre genre de propagation plus cachée, par-dessus les murs des école adverses et non les frontières des États voisins, qui se manifeste par des symptômes significatifs, en Italie notamment, par le livre de $\mathrm{M}$. Innamorati sur les Nuovi Orizzonti e l'antica scuola italiana et par 
celui de M. Alimena sur la Premeditazione ${ }^{1}$, en France aussi, ce me semble, par le Devoir de punir de M. Eugène Mouton, et les Principes du droit de M. Beaussire. Jetons un rapide coup d'œil sur chacun d'eux.

M. Innamorati, professeur de droit pénal à Pérouse, appartient à l'école de Carrara, le dernier et le plus illustre héritier de Beccaria. Il en est fier; il dit en parlant d'elle " l'école nationale » et il expose ses doctrines sur un ton de respect et de foi. Mais comme on sent bien qu'il se défend contre la séduction de l'hérésie ambiante ! Il s'excuse presque, au début, de ne pas s'être rallié à la nuova scuola, et il semble avoir pris la plume tout exprès pour en donner les raisons. Il s'efforce de prouver, en premier lieu, que les Pères de son Église, les Romagnosi, les Carmignani, les Carrara, ne se contredisent jamais sur le fond des dogmes ; mais, en second lieu, il tâche de montrer que les cadres de ses maîtres sont assez larges ou assez élastiques pour accueillir sans se rompre l'intrusion inattendue des nouveaux faits et même des nouvelles idées et se les assimiler. La conciliation éclectique et hospitalière est sa note dominante. Est-ce que l'étude directe des délinquants ne peut pas se concilier avec l'étude abstraite des délits considérés comme «entités juridiques" dont les « ontologistes « du droit pénal classifient dans leurs tableaux synoptiques les espèces, variétés et sous-variétés ? Après tout, parce qu'on fait un cours de clinique dans les hôpitaux aux jeunes médecins pour leur faire connaître les malades, on ne se croit pas dispensé de leur enseigner à la faculté ce que c'est que la maladie. En droit civil, on n'a pas l'idée de renoncer à l'étude de la vente, du louage, des contrats quelconques, pour celle des vendeurs, des locataires, des contractants. « Il faudrait donc un code pénal particulier pour chaque délinquant! » D'ailleurs, en admettant les circonstances atténuantes ou aggravantes du délit envisagé in abstracto, est-ce que l'école classique n'ouvre pas la porte aux recherches de la pathologie mentale et de la médecine légale ? Enfin, est-il nécessaire de substituer la responsabilité sociale, fondée sur l'utilité générale, à la responsabilité morale ? Non, les deux n'en font qu'une ou plutôt celle-ci enveloppe celle-là ; les prescriptions de la législation, dont le délit est la violation punissable, sont

J'ajoute par la Pena di morte de M. Carnevale (Bocca, éditeur, Turin, 1888), livre où se montrent quelques côtés peu aperçus d'une question épuisée. 
comprises dans les préceptes de la morale, «comme un petit cercle dans un grand. » L'ordre moral excède, mais embrasse l'ordre social.

Tout cela est juste et parfois très finement dit ; mais, en somme, ce que l'auteur démontre le mieux, sans y prendre garde, en nous faisant passer en revue les riches collections d'idées étiquetées de son école, c'est l'urgence qu'il y avait à renouveler l'air de ce musée, à y faire circuler la vie par un changement de méthode. Une bonne classification, comme l'entendaient les anciens naturalistes, un bon rangement des tiroirs scientifiques ne saurait être l'idéal de la science. Je comprends l'étude du délit in abstracto si c'est pour en faire la morphologie comparée, ou la paléontologie historique ou préhistorique, mais non l'ontologie scolastique. D'ailleurs cette abstraction se comprend d'autant moins chez les classiques, qu'ils accordent moins d'importance aux considérations sociales ${ }^{1}$. L'œuvre d'art considérée à part du public et de l'artiste en même temps est un pur néant. Si l'on fait abstraction du public, c'est-à-dire du plus ou moins de succès d'une oeuvre, et si l'on prétend faire reposer le degré de son mérite sur un autre fondement, alors il faut d'autant plus avoir égard au tempérament et au caractère, à la vie et à l'âme de l'artiste. De même, moins vous ferez de sociologie, plus vous devrez faire de psychologie en droit criminel, si vous ne voulez avoir pour domaine les inania regna de Virgile. Autrement dit, si, pour apprécier la gravité d'un crime, on prétend qu'il n'y a pas à tenir compte de l'alarme sociale, on aura une raison de plus de s'attacher aux antécédents et à la nature du délinquant. Juger le délit par rapport au délinquant et non au public, c'est, à vrai dire, le point de vue proprement moral ; en sorte que, par l'usage et l'abus même qu'elle en fait, l'école positiviste se montre bien plus soucieuse de morale qu'elle ne le croit elle-même. C'est elle pourtant, qui, étant si préoccupée en outre de l'intérêt social, si habituée à juger le délit par rapport au public, pourrait se permettre de négliger les considérations anthropologiques. Mais, faisant oeuvre de sociologie et de psychologie à la fois, elle donne au délit le sens le plus concret qu'il comporte.

À quel point le tort fait à autrui y est jugé secondaire, on ne peut juger par ce trait. Il s'est trouvé des criminalistes (p. 57) pour décider qu'un homme devait être poursuivi pour vol quand, croyant s'emparer de la chose d'autrui, il s'emparait de sa propre chose, et pour adultère quand il possédait sa femme, croyant posséder la femme de son voisin. 
Veut-on avoir un échantillon des discussions auxquelles on se livrait complaisamment dans le sein de l'école classique avant l'inoculation du virus darwinien? Par exemple, page 121, je lis une controverse sur le point de savoir si l'arrêt d'acquittement ou de condamnation doit être rangé parmi les modes naturels ou les modes politiques d'extinction de l'action pénale. Car naturel s'oppose à social. "Qui ne sent la différence entre la mort naturelle de l'accusé et le déroulement d'un procès criminel jusqu'à son terme ? "Pourtant, dire qu'un verdict affirmatif ou négatif est un mode politique d'extinction de l'action que la société avait contre l'auteur d'un crime », cela est difficile à comprendre, d'après $\mathrm{M}$. Innamorati, et je suis pleinement de son avis. Que faire ? Il propose une solution propre à tirer tout le monde d'embarras. Volontiers, dit-il, il qualifierait la sentence absolutoire ou condamnatoire de "mode judiciaire » d'extinction de ladite action. Effectivement, mode judiciaire est on ne peut plus judicieux. - Autre grave question encore, celle de décider si la récidive doit être traitée au chapitre de la quantité des délits ou de leur degré. M. Innamorati penche pour la quantité, et il motive sa préférence, assez brièvement du reste. Ce passage sur la récidive, qui est pourtant une des plus sérieuses préoccupations de notre temps, est remarquablement court. L'école ontologique a ses raisons pour ne pas insister sur cette considération. $\mathrm{Si}$, en effet, le délit doit être examiné à part du délinquant, à plus forte raison le délit doit-il être examiné à part d'un autre délit. M. Mouton est bien plus logique que M. Innamorati sur ce point; car il ne veut pas que la récidive soit une cause d'aggravation de peine. - Ce n'est pas que le livre du savant professeur de Pérouse n'ait un réel mérite et n'offre un sérieux intérêt ; mais, vraiment, après des passages comme ceux qui précèdent, on s'explique le succès de I'Uomo delinquente et des Nuovi Orizzonti. Ne finissons pas sans rendre à $\mathrm{M}$. Innamorati cette justice qu'il se prononce contre le jury, cette juridiction sans appel, là précisément où l'appel serait le plus nécessaire, c'est-à-dire dans les causes les plus graves.

M. Alimena n'appartient, ce me semble, à aucune école ; mais on sent bien qu'élevé dans l'ancienne, il a respiré l'air de la nouvelle, excellente condition pour entrer dans ce que nous appellerions en France l'école historique. Le sujet qu'il a choisi, la préméditation, est un de ceux sur lesquels les novateurs se rencontrent avec le jury. Depuis le droit romain, tous les codes des peuples néo-latins et des 
nations habituées à les imiter ont attribué à la préméditation, comme circonstance aggravante de l'homicide, une importance qui, dans la plupart des cas, est injustifiable, quoique l'auteur s'efforce habilement de la justifier : c'est un bel exemple de moutonnerie législative. Dans la famille des législations anglo-saxonnes, notamment dans les lois anglaises, le code de Malte et le code anglo-indien, cette distinction de l'homicide simple, du meurtre, et de l'homicide prémédité, de l'assassinat, n'est pas connue, mais elle est remplacée par une distinction encore plus déraisonnable, celle du manslaugher et du murder ${ }^{1}$. Il y a murder, c'est-à-dire assassinat, dans le sens anglais, d'après un jurisconsulte éminent de la Grande-Bretagne consulté par notre auteur (p. 61), quand un homme entre chez son voisin pour lui voler une poule, tire un coup de fusil destiné à ce volatile et par hasard atteint un homme : le caractère malicieux du mobile qui l'animait, le vol, suffit pour le rendre coupable de la forme la plus grave de l'homicide. N'est pas murder, en revanche, dans le code anglaisindien, l'homicide provoqué, l'homicide commis dans une rixe, et aussi la participation au suicide d'autrui pourvu que le suicidé ait atteint dix-huit ans. Quelle preuve plus forte du pouvoir inhérent à l'entraînement imitatif, que le fait de voir reproduite expressément par la jeune Amérique des État-Unis l'idée si bizarre de ranger sous le même vocable murder l'assassinat tel que nous l'entendons, l'homicide volontaire simple, et même l'homicide involontaire quand il est commis au cours d'un vol ou d'un autre petit délit quelconque ? Bien mieux, cette autre singularité de la législation anglaise que l'homicide est réputé murder jusqu'à la preuve du contraire, énormité si opposée au libéralisme britannique, se reproduit dans presque tous les codes américains du Nord. - Or, quoique moins contraire à la raison, notre manière de graduer l'homicide est loin d'être satisfaisante elle-même. Comment se fait-il que l'idée si simple de faire consister l'aggravation du meurtre, non seulement dans sa délibération préalable, mais encore et surtout dans la nature des motifs sous l'empire desquels, délibéré ou non, il a eu lieu, ne soit venue à aucun législateur ? ${ }^{2}$ N'est-ce pas

1 Notons spécialement le code de 1870 pour le Panama, État de la Colombie. L'indulgence de ce code est, en outre remarquable. L'homicide simple y est puni de 4 à 6 ans de réclusion, l'homicide prémédité de 6 à 10 ans au maximum. Ici un autre genre d'imitation s'est ajouté au précédent : le législateur s'est inspiré du libéralisme émollient qui régnait il y vingt ans.

2 Elle s'est présentée cependant au législateur de l'Islam. Dans une très intéressante et très consciencieuse Étude sur la théorie du droit musulman, par Savvas Pacha, ancien ministre de 
surprenant, quand on voit cette idée se présenter inconsciemment, mais régulièrement à l'esprit de tous les jurés, de telle sorte que, n'ayant nul égard en général au fait de savoir si le meurtrier a préconçu son crime, ils sont surtout préoccupés de connaître si c'est la jalousie, l'honneur, la vengeance ou la cupidité qui l'animait ? C'est pour redresser cette erreur législative que, d'accord ici avec la jurisprudence inconsciente du jury, les nouveaux criminalistes, M. Garofalo notamment, ont repris la thèse déjà ancienne de $\mathrm{M}$. Holtzendorff et mis en relief, au nom de la psychologie, la considération négligée et prépondérante des motifs. Ils ont montré ce qu'il y a d'énorme à voir dans la passion le contre-pied de la préméditation : d'ordinaire, la passion prémédite et la préméditation est passionnée. La durée de la préméditation pourrait souvent servir à mesurer l'intensité de la passion, c'est-à-dire, si cette passion est légitime, non immorale, non contraire à la droite nature humaine, le degré d'indulgence que mérite le meurtrier.

L'espace me manque pour suivre dans ses délicates analyses psychologiques et dans ses excursions historiques M. Alimena. Son livre est une volumineuse et complète monographie que tous les criminalistes voudront connaître. Ils y trouveront le résumé de toutes les législations du globe sur le sujet traité, et une abondance d'informations statistiques dont je regrette de ne pouvoir donner des extraits. J'observe pourtant qu'ici plus qu'ailleurs les illusions d'optique arithmétique, pour ainsi parler, sont à craindre. En lisant, par exemple, que, en Allemagne, les homicides par cupidité sont trois fois plus souvent prémédités que simples, et les homicides par haine ou vengeance, au contraire, deux fois plus souvent simples que prémédités ${ }^{1}$, il ne faut pas perdre de vue, que, les meurtres cupides excitant bien plus l'indignation des parquets, on est plus souvent porté à leur appliquer la circonstance aggravante de la préméditation. En fait, il y a bien peu de meurtres volontaires, par amour même, qui ne soient pas prémédités, au moins conditionnellement. Le mari qui tue sa femme surprise en flagrant délit avait sans nul doute prémédité de

Turquie (Paris 1892), je lis ce qui suit : «Les motifs qui décident l'homme à agir, ont dans l'islamisme une importance plus grande que dans tout autre législation. Elles forment, en ce qui concerne la rémission et l'atténuation des peines, une règle de conduite pour les juges. Le Prophète a dit que les actions soient jugées d'après les déterminations ».

1 Une statistique de Quételet donne à peu près les mêmes résultats pour la France. 
la tuer s'il la rencontrait avec un homme dans telle ou telle circonstance.

Le Devoir de punir, par M. Eugène Mouton, ancien magistrat, est un livre original. D'abord, ce qu'il y a de meilleur, c'est la tête et la queue, la préface et l'appendice : la préface où l'auteur dénonce avec verve toutes les sources sociales de délit qui ont jailli à l'époque contemporaine et qui expliquent le débordement du fleuve criminel ; et l'appendice, où on lit l'intéressant compte-rendu d'une mission scientifique faite en Suède et en Norvège par M. Mouton, au point de vue des résultats obtenus par le régime cellulaire dont il dit merveille. Il n'appartient, lui non plus, à aucune école, mais en dépit de son originalité, il reste imprégné des traditions de l'ancienne; il poursuit toujours cette pierre philosophale des fils de Beccaria, l'équation entre la peine et le délit. Malgré cela, il est sympathique aux anthropologistes criminels. "De telles recherches, dit-il, ne peuvent qu'être accueillies avec reconnaissance, puisque, touchant au point capital de l'imputabilité du délit, elles sont faites pour donner plus de puissance et de lumière au concours que la justice a toujours demandé à la médecine légale. » Il a retiré de sa longue expérience des parquets cette impression plusieurs fois répétée qu'il y a des ressemblances effrayantes entre les criminels et les aliénés, " comparaison que les membres du ministère public peuvent souvent faire quand ils ont des maisons de fous à visiter périodiquement dans leur circonscription. Les «souverains du royaume du mal» sont, suivant lui comme suivant nous, "l'imitation et t'hérédité ». Il aime aussi, en touriste amateur, à remonter aux origines, mais pas si haut que M. Navarra. Il se contente de prendre pour point de départ de la pénalité, de l'instinct du châtiment, " le premier soufflet donné par le premier des pères, irrité, au premier des fils, désobéissant ». Mais, à regret, je me vois forcé de me séparer de lui ; car, si je le suivais partout où il mène son lecteur, je n'en finirais plus.

Pour un autre motif, je dois être bref aussi au sujet du beau livre que M. Émile Beaussire vient de publier sur les Principes du droit : il ne touche au droit pénal, en effet, que dans un de ses chapitres. Je laisse donc à d'autres le soin de louer comme il convient, dans l'ensemble de cette oeuvre, la compréhension pénétrante, la profondeur claire de la pensée, et l'élévation simple du ton. Tout ce 
que je tiens à faire observer, c'est que le spiritualisme éclairé de l'auteur fait bon accueil aux nouveautés étrangères. Il " admire comme très ingénieuse les théories qui prétendent reconnaître des types héréditaires de criminels », il admet des délinquants-nés ; il concède aux aliénistes que « le vieux paradoxe de la folie universelle, si l'on en fait une question de degrés, de nuances, est bien près d'être justifié par les recherches de la psychologie contemporaine ». N'oublions pas d'ailleurs que l'école spiritualiste, autant vaut dire libérale, n'a pas attendu l'avènement du positivisme pour protester, par la bouche de M. Franck, contre la théorie de l'expiation donnée comme fondement aux peines, et pour proposer au législateur de substituer, la responsabilité purement sociale à la responsabilité morale. Seulement les positivistes excluent celle-ci, parce qu'ils la nient; les spiritualistes, tels que M. Lévy-Bruhl, par exemple, parce qu'ils la mettent trop haut pour ne pas la mettre à part. Il n'en est pas moins curieux de voir l'écrivain que je viens de citer, dans son Idée de la responsabilité, fonder le droit pénal sur l'utilité, à l'exclusion de l'idée de justice, par suite de son culte même pour cette dernière notion, et je ne puis me défendre de soupçonner dans cette thèse une inspiration du dehors. $M$. Beaussire n'admet pas d'ailleurs cette théorie utilitaire, et, à ses yeux, le droit de punir se fonde en quelque sorte (p. 131) sur le devoir d'être puni, conception très singulière à première vue et que l'on pourrait regarder comme un habile effort pour faire rentrer le droit pénal luimême dans sa formule générale du droit considéré comme la garantie du devoir. Ce n'est pas du droit naturel, en effet, c'est plutôt du devoir naturel que part $\mathrm{M}$. Beaussire dans sa critique des législations. En y réfléchissant, on trouve à cette manière d'entendre les rapports de la morale et du droit un grand fonds de vérité, et si, on la compare à celle de $\mathrm{M}$. Innamorati, on sentira le progrès de l'une à l'autre. La morale n'est plus au droit ce qu'un grand cercle est à un petit cercle intérieur, mais ce qu'une source est à son bassin. Ce point de vue, à mon avis, demanderait à être complété par des considérations qui montreraient que, si la morale individuelle est antérieure aux législations vivantes et leur sert de fondement nécessaire, elle a son origine sociale et non à proprement parler naturelle dans plusieurs couches de législations et de coutumes mortes sans lesquelles ce que nous sentons généralement comme devoir ne serait senti comme tel par personne. Il n'en est pas moins certain que la nature de l'homme le prédestinait à la vie sociale et au sentiment de certains devoirs ou de certains droits imposés par 
chacune des phases de l'évolution sociale; c'est la violation de ces droits ou de ces devoirs anciens et consolidés qui doit seule donner lieu aux poursuites criminelles, la violation des droits ou des devoirs artificiels ou superficiels, non sentis directement, non naturels si l'on veut, donnant ou devant donner ouverture à de simples procès civils. Ce sera toute ma réponse à la très bienveillante critique qui m'est adressée par M. Beaussire (p. 125) au sujet de ma définition du délit, incomplète parce qu'elle était incidente. 


\section{-8- \\ Études criminelles \\ et pénales}

Je ne sais si je m'abuse, si je prends mes désirs pour la réalité, mais il me semble que la crise du Droit pénal commence à devenir moins aiguë, et laisse entrevoir déjà la probabilité de certaines solutions conformes à des idées que j'ai eu l'occasion d'exprimer souvent. Pour faire partager cette impression, je n'aurai, je crois, qu'à feuilleter rapidement force livres ou brochures qui encombrent ma table de travail où ils s'accumulent depuis bientôt dix-huit mois.

Tout d'abord, il est à noter que les deux grandes sources de Jouvence, où les études pénales ont puisé abondamment et trouvé un rajeunissement inespéré, à savoir la méthode anthropologique et la méthode statistique, donnent des signes d'épuisement. Ce n'est pas à dire qu'elles tarissent ; loin de là, elles coulent toujours plus fort, mais l'une et l'autre de ces deux fontaines, la première surtout, paraissent 
avoir déjà donné, en fait de résultats généraux, tout ce qu'on pouvait momentanément attendre d'elles. Certes, je sais bien que $M$. Lombroso ni ses élèves n'ont rien perdu de leur ardeur à mesurer fiévreusement des crânes, des pulsations, des réflexes rotuliens, et l'Archivio di psichiatria continue à en magasiner cette volumineuse moisson de chiffres. Mais si j'entends toujours le bruit du moulin, je ne vois guère plus la farine. Tout est dit, pour l'instant, sur le type criminel ; il reste acquis que le criminel par tempérament n'est plus un mythe et qu'il abonde en anomalies de divers genres, physiques ou psychiques; mais il faut convenir que ce signalement un peu vague n'a pu encore être précisé. Le besoin s'est fait sentir, dans l'école lombrosienne elle-même, de tourner les recherches d'un autre côté ; aussi, a-t-on vu paraître, comme complément, en apparence, mais en réalité comme suite de l'Archivio, une nouvelle Revue, la Scuola positiva, dirigée par M. Fioretti, inspirée de l'esprit de Ferri et de Garofalo, bien plus large et compréhensif, malgré tout, que le point de vue du maître. La Sociologia criminale de Colajanni, maintenant député socialiste au Parlement italien, a été un coup violent pour les théories de cette école ; elle a donné lieu entre les deux champions des causes sociales et des causes naturelles du délit, à une polémique des plus vives, où, si je suis bien renseigné, les applaudissements de la galerie, c'est-à-dire de la presse, n'ont pas été pour le célèbre professeur de Turin. Aux colères et aux déraisonnements (ire e spropositi) de ce dernier, son adversaire a répondu par des démentis sanglants, des raisons et des faits, ce qui lui a valu de la part de $\mathrm{M}$. Lombroso, l'épithète de pseudo-sociologue. Cela ne prouve pas grand'chose ; un des collègues de $\mathrm{M}$. Lombroso ne l'a-t-il pas traité lui-même de pseudo-aliéniste, sans diminuer en rien par là sa réputation, ni son mérite ? M. Morselli est, certes, un anthropologiste de distinction; cependant le remarquable programme de son cours de criminologie, fait à l'université de Gènes, indique nettement ses préférences pour l'explication sociale du crime. Je traduis un passage entre plusieurs : "Nécessité de substituer le concept sociologique au pur et simple concept bio-anthropologique du délit... » Nous pouvons citer encore, comme preuve de la diffusion du point de vue sociologique en criminologie, une incisive brochure du professeur Mosca, revisore à la Chambre des députés italienne, à propos de Colajanni, dont il combat d'ailleurs les idées socialistes. Enfin, nous venons d'apprendre, par un article-programme de M. Emmanuel Carnevale, 
dont le titre est significatif, Una terza scuola di diritto penale, qu'une phalange de criminalistes distingués dont il fait partie est en train de fonder une troisième école de droit pénal, également éloignée du conservatisme classique et du naturalisme lombrosien. "Colajanni, Pugliese, Alimena, Vaccaro, Impallomeni et quelques autres » sont ses fondateurs. Il suffit de citer ces noms pour dire à quelle source puisera de préférence ce "positivisme critique». Il se préoccupera de trouver à la science pénale, de même qu'à la science sociale en général, son fondement propre au lieu de l'asservir aux sciences naturelles sous prétexte de l'élargir; et il prêtera attention aux progrès des idées socialistes au moins autant qu'à celui des études anthropologiques. Il est inutile d'ajouter que toutes nos sympathies sont acquises aux éminents initiateurs de ce mouvement.

Quant à la statistique, elle a l'avenir pour elle, sans nul doute, et elle est destinée à résoudre plus tard, définitivement, bien des problèmes qui nous divisent. Mais il faut attendre pour cela que bien des années d'enregistrements arides et monotones, aux oscillations faiblement significatives, aient passé sur nos têtes. M. Virgilio Rossi, dans une intéressante petite brochure (I qermi dellastatistica Milan, 1891) nous fait l'archéologie de la statistique ; il nous apprend, que ce n'est pas aux Chinois mais aux Romains qu'il faut en attribuer la paternité. Plus pratique, et non moins érudit, M. Bodio, l'éminent statisticien dans une «communication sur l'organisation de la statistique pénale en Italie » (Rome, 1890), nous offre un essai, fort méritoire et instructif, de statistique comparée, mais il nous initie en même temps aux «difficultés qui s'opposent aux comparaisons internationales dans cette branche » de la science. Des années s'écouleront avant que ces difficultés soient résolues ${ }^{1}$. En attendant, on se lasse de répéter toujours les mêmes banalités tristes, que le crime et le délit augmentent, que la récidive progresse, que la marée du suicide ne s'arrête pas. Pour varier, la dernière statistique criminelle parue (celle de 1888!) essaye, bien timidement dans le rapport officiel, de se présenter sous un aspect plus favorable. À prendre les chiffres en bloc, délits vrais et délits factices mêlés et confondus, il y

En corrigeant les épreuves de ce livre, je reçois une brochure, fort étudiée de M. Bosco, sur la delinquanza in Italia. Une certaine amélioration y est signalée dans la criminalité Italienne, depuis 1885 , mais non en ce qui concerne les vols. Je recommande la lecture de ce substantiel écrit, de source quasi-officielle. 
$a$, en effet, une légère diminution sur l'année précédente ; mais si l'on prend à part les délits et les crimes vraiment dignes de ce nom, assassinats, meurtres, vols, escroqueries, abus de confiance, il y a hausse graduelle et continue. Vraiment, dans cette statistique, malgré la meilleure volonté du monde, je ne trouve rien de consolant et de rassurant qu'un point, étranger, il est vrai, à notre sujet, mais que je signale avec bonheur aux hommes de finance. C'est la diminution notable et progressive des frais de justice criminelle. Les affaires criminelles ont eu beau se multiplier sans cesse, il a suffi au garde des sceaux de recommander à la magistrature plus de vigilante économie pour que, au lieu de croître comme on aurait dû s'y attendre, les frais aient diminué d'année en année, depuis cinq ou six ans. Pour les affaires d'assises, le montant moyen des frais avait été, en 1886, de 356 francs par affaire ; il n'a plus été que de 328 francs en 1887, et de 296 en 1888. En matière correctionnelle, où le calcul se fait par individu, on relevait une moyenne de 19 francs 19 centimes par prévenu de délit commun en 1886 ; ce chiffre tombe à 16 francs 90 centimes en 1887 et à 15 francs 81 centimes en 1888. Au total, les frais se décomposent en deux portions, celle qui est recouvrable sur les biens des condamnés et celle qui ne l'est pas. La seconde est insignifiante, elle a seulement baissé de 269,025 francs en 1886 à 262,808 francs en 1888. Mais la première, de beaucoup la plus considérable, a décru bien plus rapidement; en 1886, elle était de 6,116,755 francs; en 1888, elle n'est plus que de 4,963,523 francs. Combien ce phénomène budgétaire est propre à nous rassurer pour les finances françaises! Car, assurément, il n'est pas contestable que le budget de la justice criminelle est le plus indispensable avec celui de la guerre, et en même temps le moins élastique de tous les budgets de l'État; il se prête infiniment moins que celui des travaux publics, du commerce, de l'agriculture, etc., à des suppressions de dépenses, vu le caractère urgent et capital des besoins auxquels il répond. Par suite, il est évident que, le jour où on le voudra bien, le jour où l'esprit d'économie, j'allais dire outrée, qui règne au ministère de la justice et qui devrait régner là beaucoup moins qu'ailleurs, puisque la justice est la plus essentielle des fonctions de l'État, aura envahi contagieusement tous les autres ministères l'un après l'autre, ce jour-là on pourra compter à fortiori sur des excédents budgétaires merveilleux dans tous les chapitres du budget. Mais fermons la parenthèse. 
La vérité cependant m'oblige à dire qu'il y a en Europe une statistique consolante et tout à fait rassurante, j'allais dire réjouissante : c'est celle de Genève, qui vient d'être l'objet d'une monographie très étudiée par M. John Cuénoud, ancien directeur de la police genevoise ${ }^{1}$. Cette petite république peut singulièrement faire envie sous ce rapport à sa grande voisine. Pendant que toutes les autres villes européennes importantes achètent leurs progrès matériels au prix de leur moralité déclinante, de leur criminalité grandissante, la cité de Calvin a vu baisser rapidement, de 1818 à 1885 (date où s'arrêtent nos informations), le chiffre de ses crimes et aussi de ses délits. Est-ce à dire qu'elle soit restée à l'écart du mouvement de notre civilisation ? Répondons par chiffres. De 45,000 habitants en 1818, sa population s'est élevée à 107,000; elle a un peu plus que doublé. Sa circulation, sa fièvre locomotrice, a décuplé. Et voici qui est plus probant encore : pour cette population simplement doublée, il y a six fois plus de pharmaciens, cinq fois plus de médecins et d'avocats. Eh bien, malgré des signes si évidents de modernisation, et quoique "Genève soit à Lyon ce que Bruxelles est à Paris, un port de salut pour les banqueroutiers, un asile d'impunité pour les débiteurs de mauvaise foi », la grande criminalité a diminué, de 85 pour 100 en égard au progrès de la population, et la délictuosité, dans des proportions à peu près égales, surtout depuis 1879. Il est vrai que, si l'on entre dans le détail des chiffres, on constate une certaine augmentation numérique des homicides et des vols, mais très inférieure à celle que déplorent les nations principales de l'Europe. Il y a, notamment, six fois moins d'homicides qu'à Paris. D'autre part, si l'on décompose la population totale en ses éléments, on voit que le contingent de la population d'origine genevoise dans ces résultats est très inférieur à celui de la population immigrée, qui a quadruplé depuis 1822 et représente les deux tiers, ou peu s'en faut, du total des habitants ${ }^{2}$. Ce qui est surprenant, ce n'est pas qu'ici comme partout la colonie étrangère se distingue à son désavantage, c'est que le contraste ne lui soit pas plus désavantageux, c'est qu'elle-même ait été se moralisant; et je ne puis attribuer cet heureux phénomène, si

La Criminalité à Genève au XIXe siècle, avec tableaux synoptiques et graphiques (Genève, $\mathrm{H}$. Georg, 1891).

2 La population rurale, qui, exception rare, grandit encore plus vite que la population urbaine, se moralise ou se décriminalise encore plus rapidement. 
exceptionnel, qu'à l'action lente, assimilatrice, moralisatrice, des natifs sur les immigrants. La gravité des moeurs, l'austérité même des habitudes, ajoutons la tournure religieuse des esprits et des consciences, ont décidément $\mathrm{du}$ bon, et ce serait puérilité que de méconnaître l'efficacité de ces causes dans le spectacle que nous donne ce pays de liberté consolidée, de vieille démocratie.

\section{II}

$\underline{\text { Retour à la table des matières }}$

Anthropologie et statistique ayant pour le moment, je le répète, dit leur dernier mot, l'heure est venue, ce semble, de travailler sur ces données, de construire avec ces matériaux. Aussi voit-on apparaître çà et là des essais de synthèse, parmi lesquels une place d'honneur est due à Crime el suicide du Dr Corre ${ }^{1}$. Cet ouvrage, de 654 pages compactes, vraiment trop dense et trop débordant de faits et d'idées pour être résumé, n'est pas une compilation, mais une élaboration profonde et complexe. L'auteur est médecin, naturellement; car c'est dans le corps médical maintenant, à quelques exceptions près, que s'élaborent les idées destinées à renouveler le droit pénal de demain. $\mathrm{Ne}$ nous en étonnons pas trop, cependant. Au fond, il en est toujours ainsi, c'est toujours de l'étranger, au sens national ou professionnel, ou religieux, ou politique du mot, que nous viennent les idées rénovatrices. Les médecins sont en train d'importer de nouvelles doctrines juridiques, par la même raison que des chimistes tels que Pasteur leur ont enseigné à eux-mêmes de nouvelles doctrines médicales, par la même raison que les nouvelles méthodes ou machines agricoles, à l'usage des propriétaires ou des paysans, sont dues à des ingénieurs ; que les nouvelles idées socialistes, à l'usage des ouvriers, sont dues à de vils bourgeois; que l'invention de la poudre, à l'usage des

Crime et Suicide, par le Dr Corre. (Paris. Doin, 1894). Me sera-t-il permis de mentionner aussi! parmi les essais de synthèse ma Philosophie pénale dont la $2 \mathrm{e}$ édition vient de paraître? 
militaires, a été due, nous dit-on, à un moine ${ }^{1}$, enfin par la même raison que les idées des criminalistes italiens, pour rentrer dans notre sujet, leur viennent d'éléments anglais ou français, et n'en sont pas moins le ferment rénovateur des théories pénales qui éclosent en Angleterre, en France, en Hollande, en Belgique, en Russie.

Le Dr Corre, comme d'autres, a été stimulé par l'action de cette levure étrangère, mais il a réagi d'une façon très particulière. " Médecin par profession, sociologiste par tendance et par goût », et même, ce qui ne gâte rien, un peu, beaucoup archéologue, il ne s'est pas borné, comme il le dit modestement, à «se cantonner dans l'observation » des faits ; et, s'il a publié de très instructives monographies sur le Crime en pays créole ${ }^{2}$, on sent constamment chez lui la préoccupation d'idées générales qu'il soumet à l'épreuve des faits observés. Dans son examen des « facteurs individuels, sociologiques ou cosmiques du crime et du suicide » il ne rejette a priori aucune des explications fournies : ni la folie, ni la dégénérescence, ni l'atavisme, ni son opposé l'infantilisme, ni l'action du climat, de la saison ou de la race ; il fait la part de tout avec une largeur synthétique, un peu trop éclectique peut-être, où se reflète une nature des plus sympathiques, des plus hospitalièrement ouvertes aux idées d'autrui. Mais, avec toute l'école française, il admet, il démontre la prépondérance des facteurs sociaux, et il abonde à ce sujet en développements ingénieux, en documents curieux, en aperçus multiples, tels que le suivant, que je glane entre mille: "La survivance d'anciennes mœurs, dans les milieux et au contact des milieux les plus civilisés, n'apparaît pas seulement chez des individus ou des familles isolées; elle se manifeste chez des races très compactes, chez des fractions de races transplantées. Les Annamites, a-t-on dit avec beaucoup de justesse, sont des adeptes de la civilisation célestiale, arrêtée pour eux au XIVe siècle ; nos créoles des Antilles et de la Réunion, sous maints rapports, sont demeurés des Français des XVIIe et XVIIIe siècles ; les habitants de Port-Mardick sont toujours des Bretons de Paimpol, au coeur d'un pays flamand; les Prussiens de Friedrichsdorf sont, par les mœurs et

On peut lire sur la série d'inventions accumulées dont l'invention de la poudre n'est que le dernier terme, éclatante fleur d'une tige obscure, l'étude récente de M. Berthelot (Revue des Deux Mondes, 15 août 1891). Il n'y a rien qui confirme, il est vrai, mais rien qui contredise la légende de l'invention monacale.

2 Storck, édit, Lyon. 
même un peu par le langage, des Français pétrifiés de l'an 1687. Que, dans ces foyers particuliers, certains crimes se produisent avec des caractères de rudesse ou de superstition qui rappellent les façons ancestrales, sera-t-on bien fondé à parler d'atavisme, et ne serait-on pas davantage autorisé à admettre l'effet d'une continuation d'habitudes et de croyances, parallèle à une évolution ambiante plus avancée? » Je suis très heureux de constater que, sur l'influence puissante «de l'imitation, de la suggestion, de la contagion», le $\mathrm{Dr}$ Corre s'accorde pleinement avec moi, et sur bien d'autres points encore. Mais, encore une fois, je n'ai pas la prétention de résumer ici, en quelques lignes, un livre où tout est à lire.

Le livre du Dr Xavier Francotte 1 , professeur à l'université de Liège, sur l'Anthropologie criminelle, est une sorte de manuel de cette nouvelle science, un simple travail de «vulgarisation », comme le dit l'auteur dans sa préface. L'exposition des faits et des doctrines y est lucide et complète. La critique en est impartiale. Les conclusions y sont nettement favorables à l'interprétation avant tout sociologique du crime et du criminel. "Certes, l'ensemble des traits du type criminel est imposant et considérable. Mais cette abondance, cette profusion cherche en somme à dissimuler la faiblesse et l'insignifiance des caractères pris en particulier. Est-il un de ces caractères qui n'ait été battu en brèche et dont la valeur n'ait été contestée ? » Il y a en tout homme un penchant qui se développera si l'éducation ne le réfrène. « S'il était besoin de fournir une preuve des funestes conséquences du défaut d'éducation, on la trouverait dans ce fait, constaté par Raux, à savoir que, sur 385 jeunes détenus, 223 appartenaient à des familles incomplètes, privées du père et de la mère ou de l'un des deux. ${ }^{2}$

Un esprit analogue règne dans les écrits de M. Prins, l'éminent criminaliste belge ${ }^{3}$, et dans le bulletin de l'Union internationale de Droit pénal, rédigé en français et en allemand, où se reflète l'opinion dominante en Allemagne, en Belgique et en Hollande

L'Anthropologie criminelle, par le Dr Xavier Francotte.

Nos jeunes détenus, Storck, édit. Lyon.

3 Voir notamment de lui sa Note sur la réparation dans le système répressif (Bruxelles, 1891). 
principalement ${ }^{1}$. Pour l'Espagne, nous croyons trouver dans un livre tout récent, écrit avec une rare élévation de style et un talent original, l'expression des idées en voie de formation dans la jeunesse intelligente de ce pays. La Crisis del Derecho penal, par M. César Silio ${ }^{2}$, s'ouvre par une belle préface de M. Alvarez Taladriz qui a été, dans la Revue dont il est le directeur, l'initiateur de sa nation aux nouveautés criminologiques. Une chose me gêne pour dire tout le bien que je pense de l'ouvrage de M. Silio, c'est tout celui qu'il dit des miens en divers passages. Aussi, par affectation d'ingratitude, vais-je m'attacher surtout aux points par lesquels nous différons d'avis. Sa nuance personnelle est une sorte de spiritualisme positiviste où se sent l'influence profonde de la foi religieuse refoulée, réfugiée au Cœur. Il reproche à Turati, avec raison, et avec quelque indignation, le mépris où il tient « la résignation chrétiennement idiote ». Son principal grief contre les anthropologistes italiens, c'est leur matérialisme plutôt que leur déterminisme. Il croit au libre arbitre d'ailleurs, mais il reconnaît qu'on ne saurait plus appuyer la morale sur ce fondement. « Absolument sans motif, dit-il, est l'alarme que ressentent ou affectent de ressentir certains esprits devant le déroulement graduel et la propagation des doctrines de la nouvelle école. Même en tenant pour certain, comme nous, que l'homme est un être libre, les multiples limitations de cette liberté, l'impossibilité de préciser ses degrés, la difficulté de distinguer entre les actes libres et non libres, la nécessité enfin de la défense sociale, sont des raisons plus que suffisantes d'abandonner le critère de l'École classique et d'affirmer avec l'école italienne le fondement purement défensif de la pénalité : Salus populi suprema lex esto. » Comment l'âme généreuse de 1'auteur n'a-t-elle pas reculé devant l'énormité des conséquences qu'entraîne son adoption précipitée de l'utilitarisme pénal ? Appuyer la responsabilité sur le salut public, c'est la supprimer; et je comprendrais fort bien, si la négation du libre arbitre entraînait ce corollaire, l'alarme, nullement factice, nullement sans motifs, des consciences éclairées. Mais, comme je l'ai dit d'ailleurs, la responsabilité morale a d'autres appuis. Quant à la considération de l'utilité générale, de la volonté sociale

Un autre auteur belge, M. Mans, encore attaché aux Idées de l'école classique, bien qu'il fasse grandement l'éloge de l'anthropologie criminelle et de l'utile fermentation qu'elle entretient dans les esprits, a publié une intéressante brochure sur le Droit de punir (Alcan, 1891).

2 La Crisis del Derecho penal, par César Silio y Cortès (Madrid, Fuentes, y Capdeville, 1891). 
pour mieux dire, c'est sur elle qu'il faut faire reposer l'incrimination de certains actes et non de tels autres. Ne pas confondre les caractères objectifs qui rendent un acte punissable, abstraction faite de son auteur, avec les caractères subjectifs qui rendent coupable dans certains cas et non dans tous les cas l'auteur d'un acte punissable. Or c'est l'incrimination des actes qui doit être avant tout utilitaire, mais non l'incrimination des agents. Cette distinction est élémentaire, mais essentielle, et elle a été si souvent méconnue que je me permets de la rappeler.

M. Silio a été séduit, plus peut-être que de droit, non abusé à fond cependant, par le fameux type criminel. Comment son spiritualisme s'effaroucherait-il de cette conception puisqu'elle a eu pour père le $P$. Niquetius, jésuite du XVIIe siècle, précurseur oublié de Lombroso ? Le vir audax de cet anthropologiste en soutane rappelle singulièrement 1'uomo delinquente. "Os exertum, aspera frons, supercilia arcuata, nasus longior, dentes longi, breve collum, brachia longiora quae genua attingant, etc. »

\section{III}

$\underline{\text { Retour à la table des matières }}$

À propos de l'influence du climat, qu'il est porté à exagérer, $\mathrm{M}$. Silio engage avec moi une discussion longue et courtoise où il apporte des documents statistiques nouveaux. Mais je crois qu'au fond sa conviction, fondée en apparence sur des chiffres, l'est en réalité sur ce raisonnement a priori: la chaleur réveille tous les instincts, les mauvais comme les bons; " elle donne le venin aux reptiles", elle déchaîne toutes les passions violentes; donc les climats chauds, de même que les saisons chaudes, doivent faire prédominer la criminalité par violence. Je réponds : c'est possible, et même, dans un certain sens, c'est probable ; ce qui est certain, en tout cas, c'est que l'énergie solaire ne se perd pas, mais elle peut aussi bien se dépenser en surcroît de travail qu'en surcroît de délits, et elle peut aussi bien s'accumuler en vin, soleil de l'hiver, ou en alcool, soleil des pays froids, qu'en 
excitation nerveuse directement reçue, et produire, par l'alcoolisme septentrional, des effets comparables à ceux du nervosisme méridional. En tout cas, si l'influence de la chaleur peut bien avoir pour effet d'accroître le nombre des homicides passionnels, en quoi peut-elle agir sur le progrès des assassinats cupides, froidement réfléchis, qui, précisément, sont le crime caractéristique de notre âge ? Aussi voit-on la carte de l'homicide se teinter autour des grandes villes, quelle que soit leur latitude. Il est vrai que la courbe annuelle, saison par saison, du même crime, présente un relèvement accentué en été ; et il semble qu'ici la température joue un certain rôle. Comment donc, m'objecte l'auteur, puis-je, en admettant cette action saisonnière de la chaleur, me refuser à admettre son action climatérique ? N'est-ce pas là une contradiction ? - Non, je ne crois pas m'être contredit. Je n'ai pas dit que le relèvement de l'homicide en été est dû exclusivement à la température; il peut l'être aussi et même plutôt à l'allongement des jours qui multiplie les travaux et les rencontres de personnes. Il se peut cependant, je l'accorde volontiers, que le passage du froid de l'hiver à la chaleur de l'été ait sur l'organisme humain une action qui le prédispose à certains genres d'activité criminelle ou honnête ; et, parmi nos populations européennes, - car je n'ai parlé que de l'Europe; parmi les créoles, d'après les statistiques de Corre, l'influence thermique s'exerce en un sens précisément inverse, signe évident que la force du soleil, ici comme là, là comme ici, est soumise à une direction étrangère, aiguillée à gauche ou à droite par la race ou le milieu social - parmi nos populations européennes, disais-je, cette action de la saison chaude -succédant à la saison froide pousse à l'homicide plus qu'au vol. Mais s'ensuit-il que le climat chaud doive agir nécessairement comme la saison chaude, c'est-à-dire que la supériorité fixe de la température moyenne, à laquelle l'organisme s'adapte à la longue, ait une efficacité semblable à celle d'une élévation progressive et périodique de la température quotidienne ? Je le veux bien encore, soit. Toutefois, il y a cette différence entre l'influence de la saison et celle du climat, que celle-ci peut être et est en fait contrebalancée par des influences d'ordre social, tandis que celle-là ne saurait l'être, puisque l'état social d'un peuple donné reste le même d'une saison à l'autre, tandis que, d'une latitude à l'autre, d'un peuple à l'autre ou même d'une province à l'autre, l'état social diffère souvent du tout au tout. Il ne faut donc pas s'étonner que l'influence thermique, si elle se fait sentir sous forme climatérique, aussi bien que 
sous forme saisonnière, apparaisse ici et non là dans les enregistrements statistiques; car, dans le premier cas, si elle existe, elle est recouverte par des causes d'un autre ordre.

À la vérité, M. Silio nous présente deux cartes statistiques de l'Espagne, l'une relative à la répartition des homicides, l'autre à celle des crimes contre la propriété ; et il est certain que, dans l'ensemble, malgré force exceptions, les provinces du Nord se distinguent par la prédominance des délits cupides, les provinces du Sud par la prédominance des crimes de sang. Je ne suis pourtant pas bien frappé de ce contraste qui me paraît devoir s'expliquer avant tout par la civilisation plus avancée des régions septentrionales et urbaines. Mais, sans entrer dans le détail d'un examen qui nous conduirait à approfondir l'histoire et la géographie de la péninsule espagnole, bornons-nous à noter l'embarras extrême où se trouve M. Silio quand, après avoir comparé ses deux cartes, il trace les deux courbes des deux criminalités, de 1884 à 1889, et les compare à leur tour. Chose étrange, et vraiment bien inexplicable à son point de vue - il le reconnaît - les courbes sont parallèles. Comment concilier ce parallélisme avec l'inversion apparente qui semble résulter des rapprochements des cartes ? Comment, si vraiment les cartes ont prouvé, comme l'auteur le suppose, que les causes favorables aux crimes contre les personnes, l'élévation de température notamment, sont défavorables aux crimes contre les biens, les courbes maintenant viendraient-elles prouver au contraire que les mêmes causes, thermiques même, favorisent ou contrarient à la fois les deux sortes de criminalités? Aussi, M. Silio est-il persuadé que le phénomène du parallélisme où se heurte sa thèse est exceptionnel et accidentel.

Il n'en est rien cependant; ce qui est exceptionnel et accidentel, ou plutôt simplement apparent, c'est l'inversion des cartes. En France, où nos statistiques sont faites avec un scrupule et un soin minutieux dont les statistiques péninsulaires, je le crains, n'approcheront pas de longtemps, nous avons, pour nous éclairer, les cartes et les courbes dressés officiellement par M. Yvernès. Regardons-les.

1 Les cartes des deux criminalités, l'une contre les personnes, l'autre contre les biens, jointes au rapport de 1880, mais résumant la statistique d'un demi-siècle, nous montrent une distribution de teintes 
à très peu près égales; les départements septentrionaux, surtout la Seine, la Seine-Inférieure, le Nord, l'Aisne, le Finistère, l'Ille-etVilaine, etc., sont également remarquables par leur noirceur sur les deux, ainsi que les départements de l'Ouest et du Midi où sont de grandes villes du littoral, la Loire-Inférieure, la Gironde, les Bouchesdu-Rhône. Au contraire, la plupart des départements du centre, montagneux ou ruraux, Cher, Creuse, Corrèze, Lozère, Haute-Loire..., brillent par leur blancheur, ainsi que les départements alpestres de l'Est, Basses-Alpes, Hautes-Alpes, Savoie, Haute-Savoie, Ain. - La même similitude, et encore plus frappante, s'observe entre deux autres cartes pareilles d'Yvernès, jointes à l'année $1887^{1}$, et exécutées suivant une idée plus large et plus juste, en ce sens qu'elles groupent ensemble les délits et les crimes et graduent leurs teintes d'après le rapport de la criminalité de chaque département à sa population. L'une et l'autre, aussi bien celle qui a trait aux crimes et délits par violence que celle qui concerne les crimes et délits par cupidité, a des teintes très foncées dans les régions septentrionales, essentiellement urbaines et civilisées, et dans les parties urbaines et civilisées du littoral, des teintes très claires à l'inverse dans les régions centrales, orientales, méridionales, partout où domine l'élément rural et arriéré.

Notons, en passant, que, sur toutes les cartes statistiques, qu'il s'agisse de la richesse proportionnelle des départements, de leur activité commerciale, de la valeur vénale de leur sol, de leur degré d'instruction, de leur densité de population, aussi bien que du nombre de leurs crimes, de leurs suicides, de leurs divorces, etc., les teintes les plus foncées, exprimant les chiffres les plus gros, s'observent dans le Nord. De là on peut être conduit, par précipitation de jugement, à généraliser trop vite cette idée paradoxale, que la progression du crime, du suicide, des morts accidentelles, etc., est liée indissolublement à la civilisation, qu'il ne faut donc ni s'en étonner ni s'en affliger outre mesure, et qu'il est superflu de prétendre rompre ce lien naturel en luttant contre la marée du Délit. Un villageois raisonnerait exactement de la même manière, si, voyant sa rivière, d'abord basse et limpide, grossir peu à peu après des pluies et se salir en même temps, il en concluait que la saleté d'un cours d'eau est nécessairement proportionnelle à son volume et à sa hauteur. Il n'aurait qu'à attendre

Elles résument une période décennale. 
quelques jours pour voir, souvent, quand le fleuve grossi s'est maintenu à son niveau supérieur, le limon tomber, et l'eau retrouver sa limpidité première. Actuellement, notre civilisation, en sa montée rapide, après des pluies de découvertes, présente les caractères d'un débordement; mais soyons sûrs qu'en se fixant elle se filtrera. Rappelons-nous la statistique genevoise de tout à l'heure.

2 Au rapport officiel de 1880 est joint un tableau graphique qui résume en deux courbes la marche, année par année, de la criminalité violente et de la criminalité cupide pendant un demi-siècle. Or, ces deux courbes françaises, précisément comme les deux courbes espagnoles correspondantes, présentent une même allure générale, malgré des inversions accidentelles à certaines dates. Un autre tableau graphique, joint à l'année 1887, et qui fait porter la comparaison entre les deux natures de délictuosité aussi bien qu'entre les deux natures de criminalité proprement dite, donne lieu à la même observation.

On le voit, toutes les cartes et toutes les courbes d'Yvernès, pour la France, rendent témoignage dans le même sens et s'entre-confirment; et elles s'accordent pareillement avec les courbes espagnoles, mais non peut-être, semble-t-il, avec les cartes espagnoles. Qu'en conclure ? sinon qu'il y a lieu de n'accueillir qu'avec réserve ces dernières ou du moins l'interprétation qu'on nous en donne.

Mais c'est trop insister assurément sur un des côtés erronés, instructifs néanmoins, du livre de M. Silio. Tout ce qu'il dit du rôle des causes sociales, dont il reconnaît expressément la supériorité ( $\mathrm{p}$. 212 et s.), est du reste excellent. Il n'est point porté à outrer la portée de leur côté économique. Il montre, par une statistique, que les classes aisées contribuent aux 19 centièmes de la criminalité espagnole, bien qu'elles soient loin de représenter une fraction égale de la population totale du pays. Or M. Garofalo, on le sait, a cru dégager une conclusion semblable des statistiques italiennes. La misère ne serait donc pas la cause principale du délit. - Principale, soit, mais bien importante! - Pas plus que moi, M. Silio n'admet la prétendue inversion entre la marche du suicide et celle de l'homicide. Il est d'avis que le graphique annexé par Ferri à son Omicidio-Suicidio pour prouver sa thèse prouve justement le contraire ; et, à l'appui de la thèse opposée, il apporte un document statistique relatif à l'Espagne. On y 
voit, de 1884 à 1889, les deux courbes du suicide et de l'homicide figurer des oscillations presque semblables.

Il nous explique, incidemment, pourquoi, pendant que la récidive est d'environ 50 pour 100 dans la plupart des pays civilisés d'Europe, elle paraît n'être que de 9 pour 100 en Espagne : c'est que la récidive, dans la statistique espagnole, est entendue dans un sens très étroit qui s'applique seulement à une faible partie des délinquants qualifiés par nous, et fort justement, récidivistes.

\section{IV}

$\underline{\text { Retour à la table des matières }}$

Maintenant, si l'on veut bien revenir en France et voir exprimer avec précision, mesure et sagacité, l'opinion dominante des médecins français relativement aux nouvelles idées pénales, il convient de lire l'Anthropologie criminelle ${ }^{1}$ par le Dr Dortel. Les idées de Lombroso $\mathrm{y}$ sont soumises à un examen consciencieux où se condensent les critiques de MM. Brouardel, Lacassagne, Motet, Magnan, Manouvrier, etc. Laissons-le résumer lui-même son travail : «1・ Le criminel-né, tel que l'a conçu et décrit Lombroso, n'existe pas : aucun caractère anthropologique nettement défini n'a pu lui être reconnu. $2 \cdot$ Des anomalies par lesquelles il a cru pouvoir le distinguer il n'en est aucune de premier ordre qui soit congénitale, comme l'exigerait la théorie: elles sont le plus souvent imputables à des processus pathologiques banals. 3- Les caractères psychiques, loin de préexister à la criminalité, sont au contraire pour la plupart la conséquence de la vie de prison ou de la pratique du crime. 4 Le criminel n'est ni un fou, ni un fou moral, ni un épileptique à impulsions nocives. " Comme on le voit par le 3•, l'auteur n'est pas éloigné d'admettre avec nous un type professionnel du criminel d'habitude. Il rappelle (p. 69) notre hypothèse à cet égard. "Est-ce à dire, comme on l'a tenté, qu'il

L'Anthropologie criminelle et la Responsabilité médico-légale, par le Dr Emile Dortel (J. B. Baillière, 1891). 
pourrait exister un type criminel comme il existe un type de savant, un type militaire, un type ecclésiastique ? Celui qui dès longtemps est voué aux mêmes occupations subit peu à peu l'influence de son travail même. Et si on admet que les criminels se reproduisent avec leurs tendances nocives, chaque génération accentuerait encore le type avec les traits qui le distinguent ${ }^{1}$. Et il se serait peu à peu établi ainsi un type criminel. Cette conception n'est pas incompatible avec l'idée que nous nous faisons du criminel. Néanmoins elle nous semble faire encore trop large la part du fatalisme déterministe. » Je ne comprends pas bien cette dernière critique. On est déterministe, ou on ne l'est pas. Si on l'est, on doit juger que la manière dont un homme est constitué, à un moment donné, combinée avec les circonstances extérieures où il se trouve à cet instant, détermine son acte; et peu importe à ce point de vue que sa constitution soit semblable ou non à celle d'autres hommes, qu'elle se conforme à un type ou exprime une variation originale; la détermination de l'acte n'est ni plus ni moins nécessaire dans un cas que dans l'autre, puisque, si original ou si banal qu'on soit, on ne s'est jamais fait tout seul. La question n'est donc pas de savoir, pour apprécier la responsabilité d'une action - car ce problème est l'objet propre du livre de M. Dortel - si cette action a été plus ou moins nécessairement déterminée, mais bien quelle est la nature, interne ou externe, du déterminisme d'où elle résulte.

Je vois avec plaisir que $M$. Dortel fait très large la part de l'imitation dans le développement des habitudes criminelles et aussi dans la formation d'une sorte de type pénitentiaire, décrit par $\mathrm{M}$. Gauthier avec beaucoup de verve. Les prisonniers «ont été l'objet d'une sélection; enfermés pour des motifs analogues, ils sont en quelque sorte poussés par leur vie même, à se copier, à s'imiter, à se

Ce n'est pas encore là toute ma pensée. Non seulement, quand les professions sont héréditaires - comme elles le sont neuf fois sur dix, même dans nos démocraties - l'hérédité sert ainsi à consolider vitalement un trait d'origine sociale; mais, en outre, quand les professions sont librement recrutées, il est présumable que chacune d'elles est recherchée par des gens présentant certaine goûts et certaines aptitudes semblables, par suite certaines similitudes de fonctions physiologiques liées à ces caractères psychiques, et certaines similitudes de traits anatomiques liées à ces fonctions. Il est donc probable qu'une statistique portant sur d'assez grands nombres, dégagera pour chaque profession la prédominance de ces traits et de ces fonctions, aussi bien que de ces aptitudes et de ces goûts. 
modeler inconsciemment les uns sur les autres ${ }^{1} \gg$. - Il ne croit pas à la folie morale (p. 86). Appeler fous moraux certains individus, parce qu'ils présentent des caractères propres aux criminels par nature; puis se donner la peine de composer un long chapitre, comme l'a fait Lombroso, pour établir que les criminels par nature et les fous moraux ont beaucoup de traits communs, c'est, à ses yeux, perdre son temps. Car « il s'agit d'une seule et même catégorie de sujets. Ces sujets sont caractérisés par différents traits : les uns les appellent des criminels, les autres des fous. Ce n'est pas prouver que le crime est la folie morale que de remarquer qu'ils se ressemblent. Il serait difficile qu'il en fût autrement : ce sont les mêmes, désignés de façon différente. Ce qui importerait, ce serait de savoir si on doit considérer l'habitude du crime, le goût en quelque sorte maladif que certains êtres ont dès l'enfance pour le mal, comme une perversion fatale de l'intelligence, un délire dont le sens moral fait tous les frais » (p. 80). Est-ce un délire? Voilà la question, d'après notre auteur. Or « des écrivains autorisés (p. 86), Pinel, Pritchard, Nicholson, Maudsley, Camarria s'accordent à reconnaître, que, dans la folie morale, l'intelligence est intacte, sans hallucinations ni illusions, et même sans défaut ni désordre d'aucune espèce. Nous avons tenu à citer ces lignes qui sont décisives, car, hallucinations, illusions, désordre, tout l'aliéné n'est-il pas là ? » Ce raisonnement est juste si l'on part du principe qu'il n'y a pas de folie sans trouble intellectuel. Mais c'est là précisément ce qui est en question. Il me semble qu'on pourrait réserver le nom de folie morale à ces perversions du caractère qui font rechercher le mal pour le mal, le meurtre pour le meurtre, le vol pour le vol, indépendamment de tout mobile, et bien que l'intelligence soit encore ou paraisse être encore intacte.

Tout à fait dans le même esprit ${ }^{2}$, la brochure de M. le Dr Henri Thierry sur la Responsabilité atténuée creuse aussi le problème qu'indique suffisamment son titre. M. Thierry, élève de M. Brouardel comme M. Dortel, est à la fois médecin et avocat près la cour d'appel de Paris. A ce double titre, chose rare, il réunit les conditions voulues

Il explique de la sorte la criminalité infantile et présente à ce sujet (p. 141) de très judicieuses considérations.

2 «La thèse récente de $\mathrm{M}$. Dortel, dit M. Thierry, a fort bien exprimé les opinions de l'école française. » 
pour traiter à fond son sujet. Sur M. Lombroso et ses idées, il est sévère. « Dernièrement, au Palais, dit-il, nous voyions défiler en cour d'assises sept criminels. Un seul avait le type de Lombroso, et des trois juges deux offraient des stigmates indéniables." Le savant professeur de Turin, qui n'est jamais à court, pourra répondre, il est vrai, qu'il y a des criminels latents en toque et en robe. Son mérite, à le juger impartialement, est d'avoir été un grand agitateur de questions qu'il a cru résoudre, mais qui sont toujours à l'étude.

L'historique de la responsabilité est fort bien tracé par M. Thierry. Il aperçoit une certaine similitude de phases entre les deux évolutions successives de cette notion qui, effectivement, dans les temps connus, a évolué deux fois, une première fois d'Homère à Socrate, à Platon, à Zénon, une seconde fois des théologiens du moyen-âge à Descartes et à Kant (en passant par les légistes et les humanistes de la Renaissance, que l'auteur oublie). Aux temps homériques, en effet, les bonnes ou mauvaises intentions des héros, et en général des hommes, sont réputées des inspirations soufflées par un dieu bienveillant ou hostile ; c'est Athéné qui inspire à Ulysse ce qu'il fait de bien, c'est Jupiter qui inspire à Ajax une idée funeste, "les poèmes homériques sont d'un bout à l'autre des histoires de suggestion, où les guerriers jouent le rôle de sujets dociles, et les dieux celui d'opérateurs qui s'amusent. » Ce qui n'empêche pas les héros de l'Iliade ou de l'Odyssée de revendiquer la récompense de leurs actions utiles ou d'accepter le châtiment de leurs actions nuisibles, tout comme s'ils en étaient les auteurs. - Pareillement, au moyen-âge, tous les exploits mystiques d'un saint, toutes les bonnes oeuvres d'un homme quelconque, sont censées l'effet de la grâce divine, mise en mouvement par quelque grand patron céleste ; tous les crimes des pécheurs sont suggérés par le diable. Les chroniques monacales du temps, - par exemple, celle du moine de Vaulx-Cernay, à laquelle je songe en ce moment, entre mille autres - sont toutes pleines de suggestions angéliques ou diaboliques. Néanmoins, on trouve juste que le privilégié de la grâce soit récompensé par une félicité éternelle, et que l'hypnotisé du démon soit voué à d'éternels supplices. - Puis viennent, en Grèce, les philosophes, les sophistes, Socrate ; dans notre Europe chrétienne, les romanistes, les humanistes, Descartes, et Descartes comme Socrate consomme une révolution morale qui consiste à intérioriser dans l'agent le 
principe de ses actes volontaires, à éliminer l'intervention des personnages surnaturels dans les décisions de la personne.

Il ne faudrait pas pousser à bout cette comparaison; elle est acceptable pourtant dans ces termes, et ce n'est pas la première fois que nous voyons la période homérique comparée au moyen-âge féodal. Littré, par exemple, nous avait déjà montré entre l'état social d'où l'époque homérique est éclose, et celui qui a enfanté nos chansons de gestes, des ressemblances assez surprenantes. Mais, comme rien ne se répète en histoire si ce n'est pour se varier, la responsabilité telle que l'entendent Socrate et Platon ne ressemble guère à l'idée que s'en font les cartésiens. Platon est, dans nombre de passages, déterministe. Platon, qui le croirait ? est un précurseur de Lombroso par son explication toute pathologique du vice et du délit ${ }^{1}$. «Les maladies de l'âme, est-il dit dans le Timée, naissent de l'état du corps... Personne n'est mauvais volontairement, mais c'est par quelque vice dans la constitution du corps, et par une mauvaise éducation, que l'homme mauvais est devenu ce qu'il est. Or c'est là un malheur qui peut arriver à tout le monde... Les humeurs produisent dans l'âme toutes sortes de maladies..., une variété infinie de tristesses sombres et de chagrins, comme aussi d'audaces et de lâchetés. »

C'est Aristote qui, par réaction contre Platon, a formulé le premier avec netteté l'idée du libre arbitre. On voit ici la théorie du libre arbitre succéder à celle du déterminisme, tandis que, dans les temps modernes, a lieu la succession inverse. Mais, au fond, nous voyons surtout que ce qui importe ici, ce n'est pas de savoir si la personne sera douée ou non d'un mystérieux pouvoir d'initiative première, c'est de savoir si c'est en elle qu'on placera soit cette initiative supposée, soit la combinaison originale de forces extérieures qui, sous le nom de décision volontaire, en est l'équivalent au point de vue pratique, relatif et humain. Et, de fait, de Descartes comme de Socrate ont découlé les doctrines les plus contradictoires sur ce point, quelques-uns de leurs élèves affirmant, quelques autres niant la liberté. Il est plus intéressant, à notre avis, de remarquer que l'idée du libre arbitre, en fin de

M. Thierry emprunte la citation suivante (et bien d'autres que je ne reproduis pas) à un travail inédit de son ami M. Gérard-Varet sur Platon. 
compte, a conduit Descartes comme elle avait conduit le stoïcisme ${ }^{1}$, à considérer la responsabilité comme un absolu qui ne comporte pas de degrés. Le libre arbitre est " tout entier présent ou tout entier absent. » Donc on doit être entièrement responsable ou entièrement irresponsable. «De ce point de vue, les idées de Pascal, de Bossuet, qui plaident l'un et l'autre en faveur de récompenses et de châtiments éternels, deviennent légitimes et logiques. » Ce que dit là $\mathrm{M}$. Thierry des spiritualistes chrétiens est aussi vrai des spiritualistes antiques, des stoïciens, aux yeux desquels il n'y a point de petite faute.

M. Thierry estime, au contraire, avec presque toute l'école française, ajoutons avec un grand nombre de législations étrangères, comme il le prouve dans un chapitre très substantiel, que la responsabilité comporte des degrés. Chaque jour se propage cette manière de voir, si conforme au sens commun, et il est remarquable qu'après avoir débuté, et attiré l'attention par la prétention d'éliminer l'idée de responsabilité, le mouvement novateur, en se développant, aboutit à la développer, à déployer toute la richesse et la complexité de cette notion. Parmi les États qui admettent, outre l'irresponsabilité absolue à raison de la folie ou d'autres circonstances justificatives, une demi-responsabilité, on peut citer le Danemarck, la Grèce, l'Italie. Dans le nouveau code pénal italien, le texte relatif à la responsabilité atténuée est une des meilleures innovations (art. 47, 48, 51 et autres). D'après l'article 51, l'atténuation de culpabilité existe en faveur de « celui qui a commis le fait sous une impulsion de colère ou d'intense douleur ». M. Thierry ne veut pas que l'on confonde avec la responsabilité atténuée les circonstances atténuantes prévues par la loi française ; et, théoriquement, il a raison. Mais, en fait, et pratiquement, le juge interprète la loi comme si elle avait trait aux conditions subjectives, pathologiques même, d'où résulte la diminution de responsabilité, aussi bien qu'aux circonstances objectives dites atténuantes. La France peut donc être comptée parmi les États qui ont donné une certaine satisfaction au voeu de M. Thierry.

Je sais bien que, à certains égards, le stoïcisme est déterministe ; mais le christianisme des Pascal, des Bossuet eux-mêmes l'est aussi, au point de vue de leurs idées sur la grâce et la prédestination. Ils n'en sont pas moins pénétrés (je n'ai pas à expliquer leurs contradictions) de l'idée, qui leur est commune, que l'homme, en agissant volontairement, pourrait, s'il le voulait, agir autrement, et a voulu comme il l'a voulu et parce qu'il l'a voulu. 
Ce vœu est destiné à se réaliser de mieux en mieux. De nos jours, Papavoine serait acquitté et enfermé pour la vie dans un asile d'aliénés criminels. «Il suffit de lire les débats pour être certain que cet homme avait obéi à une impulsion épileptique. Les juges trouvaient alors son crime d'autant plus grand qu'il avait tué sans motif. » La liste s'allonge sans cesse des états impulsifs produits non par l'épilepsie seulement ou l'hystérie ${ }^{1}$, mais par la période menstruelle chez la femme, et, dans les deux sexes, par diverses maladies à contrecoup cérébral, fièvre typhoïde, fièvres éruptives, impaludiques, syphilis, etc., par des blessures à la tête, par des accidents de chemin de fer en particulier. Dans ces terribles catastrophes, on ne compte que les morts et les blessés : mais combien d'autres victimes qui, sans nulle lésion visible au dehors, ressentiront l'effet périodique ou continuel de la terreur d'un instant et en resteront frappées à fond, sujettes à des accès d'hypocondrie ou d'irritabilité maladive. "Le souvenir de l'accident, dit le Dr Guillemaud (Des accidents de chemins de fer et de leurs conséquences médico-judiciaires, Storck, 1891) est extrêmement vivace. Il imprime aux sentiments un caractère tout particulier et provoque pour les motifs les plus futiles une sorte d'angoisse insurmontable et même de véritables accès de terreur. " Exemple, entre mille, de cette périodicité psychologique qui fait qu'aucune sensation, comme disait Goethe, n'est fugitive. «Le caractère subit de profondes modifications; le malade devient triste, taciturne; il recherche la solitude, se renferme en lui-même, est hanté par des idées noires. Tout cela, sans motif. » Souvent, cet état ne se déclare qu'un certain temps après la catastrophe. Il arrive aussi que l'atteinte cérébrale est moins profonde quand elle s'accompagne d'une blessure extérieure. «Erichsen fait remarquer à cet égard que, si la violence du choc s'est épuisée en causant une fracture, une luxation, l'élément nerveux se trouve ménagé d'autant. De même, dit-il, une montre en tombant est plus rarement atteinte dans les pièces du mouvement, si le verre a été brisé par le choc. »- On s'est demandé si les douleurs de l'accouchement n'expliquaient pas, dans un petit nombre de cas, l'infanticide, suite d'une névrose spéciale. On peut se demander si, chez certaines voleuses de magasins, la vue de l'objet de toilette ne

Au sujet de l'hystérie, nous avons à recommander le livre de M. le Dr Colin, élève de Charcot, sur l'État mental des hystériques (Rueff et Cie, 1890). Ce travail, d'après M. Charcot (pourrait s'intituler: De la réhabilitation des hystériques au point de vue moral. - A quand la réhabilitation morale des épileptiques? 
produit pas une tentation morbide comparable à celle que la vue de leurs nattes de cheveux ou de leur mouchoir produit chez l'érotomane qui les suit par derrière, ou à celle de ce malheureux (cité p. 89 et suiv.) qui, en voyant un rasoir, ne pouvait résister au désir de tuer sa femme qu'il adorait. Il n'est pas d'homme, si normal soit-il, qui ne traverse à certaines heures un de ces cyclones intérieurs appelés amour, désespoir, vengeance, colère ; et quand l'accès érotique notamment se réveille en nous, c'est un délire des sens, du sens moral, du coeur, une aberration de tout l'être délicieusement avili.

Quand on a lu les rapports médico-légaux, si approfondis, de MM. Motet, Garnier, Brouardel, Magnan, cités par M. Thierry, ou bien l'étude du Dr Régis sur les neurasthénies psychiques, sur ces affaiblissements de la volonté qui provoquent une sorte de monoïdéisme obsédant et tyrannique, on ne doute plus de la nécessité d'établir des asiles spéciaux pour les criminels irresponsables ou à peine responsables mais non moins dangereux. Entre autres exemples qui prouvent l'urgence de cette création, rappelons cet ingénieur qui, « ne réussissant pas dans ses inventions, prend en haine l'Ecole polytechnique, et, sans rime ni raison, s'en va tirer sur des élèves qu'il ne connaît même pas; on l'arrête, la justice impuissante le passe à l'administration trop bienveillante qui le rend à la liberté. Il recharge son revolver quelque temps après, tue un homme du plus grand mérite, l'ingénieur Raynaud », et, traduit en cour d'assises cette fois (pourquoi cette fois plutôt que l'autre ?) est condamné à sept ans de réclusion. C'était, évidemment, trop et trop peu ; car il méritait non d'être absous, mais d'être interné indéfiniment, jusqu'à guérison constatée et complète ${ }^{1}$.

La petite brochure du Dr Charpentier sur la Responsabilité légale et la Séquestration des aliénés persécuteurs, Paris, 1891, et l'important travail du Dr Allaman sur les Aliénés criminels, Paris, 1891, ont trait encore au même ordre de questions et prouvent clairement la nécessité d'introduire la réforme dont il s'agit. Le Dr Allaman s'est tout inspiré, et nous l'an félicitons, des idées de Maudsley 
C'est encore le problème de la responsabilité qui est étudié, et sous un de ses aspects les plus ardus, les plus importants, les plus négligés néanmoins, par M, Scipio Sighele, dans sa brochure sur la Foule délinquante ${ }^{1}$. Le choix seul du sujet est déjà une heureuse trouvaille. Il s'agit d'apprécier moralement et pénalement les actes commis par des groupes très denses de personnes sous l'empire de l'entraînement mutuel. Pour cela il importe avant tout de bien comprendre la nature de la fermentation psychologique à laquelle ce rassemblement passionné et fortuit donne lieu. Essayons donc de faire un peu de psychologie follesque. Très justement, l'auteur critique l'idée émise par Spencer, que les caractères de l'agrégat social seraient la simple somme des caractères présentés par chacun de ses éléments pris à part. Nos assemblées politiques, en séance, n'applaudissent-elles pas, ne votent-elles pas bien souvent, des sottises dont la plupart de leurs membres, pris à part, rirait ? Le jury en bloc ne commet-il pas des verdicts réprouvés ensuite par chacun des jurés ? Même observation pour les jurys de peinture ou de musique. D'autres fois, mais plus rarement, c'est l'inverse. Dans un bel élan d'enthousiasme - par exemple, pendant la nuit du 4 août - les assemblées déploient une générosité collective dont presque tous leurs membres, sinon tous, sont incapables isolément.

Il n'y a pas somme, il y a produit; il n'y a pas toujours produit seulement, il y a combinaison parfois, création de caractères tout nouveaux. Il y a produit, je crois, quand le groupe est homogène, composé d'individus à très peu près semblables, dont les caractères similaires se fortifient dans ce cas par reflet réciproque. Il y a Combinaison créatrice quand le groupe est hétérogène, parce qu'alors l'un de ses éléments devient prépondérant par propagation contagieuse

1 La Folla delinquente, par scipio Sighele, Fratelli Bocca, Turin, 1891. 
de son caractère individuel qui se généralise, ou bien parce que la mise en rapport de ces individus dissemblables suscite en chacun d'eux la révélation de caractères latents jusque-là, réalise des virtualités profondément cachées dans leur cœur. Ce dernier cas, d'après M. Sighele, est celui du jury, d'une représentation théâtrale, d'une réunion électorale, collections incohérentes de gens très divers de métier, de classe et d'éducation. Je ne trouve pas qu'ici l'hétérogénéité soit bien marquée, du moins si l'on fait une distinction qui paraît avoir échappé à $M$. Sighele. L'hétérogénéité relative, en effet, et non absolue, importe seule à considérer. Si dissemblables que soient d'autre part les éléments d'une réunion, ils peuvent être dits homogènes quand ils se ressemblent au point de vue de l'idée, du but de la curiosité, de la passion, de la conviction, qui est l'âme de leur réunion. A ce point de vue, rien de plus homogène qu'une réunion d'électeurs du même parti; et même, en général, qu'une salle de spectacle, où le plus souvent on est unanime à applaudir ou à siffler.

D'ailleurs, les rassemblements dont il s'agit n'ont rien de commun avec la foule proprement dite, dont la caractéristique me paraît consister d'abord dans la spontanéité de sa formation, par la contagion d'une émotion qui envahit de proche en proche tous les passants, et ensuite, ou par suite, dans l'intolérance de la majorité qui s'y soulève en un instant et n'y souffre pas de minorité opposante. Donc, par définition, une foule est toujours ou ne tarde jamais à être parfaitement homogène dans le sens parfait du mot. Il n'en est pas moins vrai que les similitudes ou les diversités, à d'autres égards, des individus qui la composent, ont aussi leur importance. Est-il vrai comme M. Sighele semble le croire, que la dissemblance de ces derniers soit un mal, et leur ressemblance un bien ? C'est au contraire l'hétérogénéité du corps social qui fait sa solidité, étant donnée une fois pour toutes son orientation collective vers un même pôle. La vie sociale paisible et prospère est un échange imitatif de produits, de besoins, de sentiments, d'idées dissemblables. En s'organisant, nous le savons, les individus se différencient, et ils ont dû se différencier pour s'organiser. Une foule est d'autant plus redoutable qu'elle est plus homogène en ce sens. Les émeutes urbaines ou rurales doivent à cette particularité leur danger; les émeutes des grévistes spécialement, parce qu'elles consistent en soulèvements, d'ouvriers similaires. 
La présence seule d'un de nos semblables suffit à produire en nous, normalement, une légère augmentation de notre force d'émotion et de volonté, de même que la vue de la lumière accroît légèrement, notre force musculaire. Nous n'avons pas plus conscience de cette action psychologique que de cette action physique; et, de même qu'il a fallu l'emploi du dynamomètre pour révéler à $\mathrm{M}$. Féré la seconde, il nous faut, pour bien comprendre la première, utiliser les observations expérimentales faites sur les aliénés ${ }^{1}$. Dans la brochure du Dr Régis que je citais tout à l'heure, je viens de lire cette petite remarque jetée en passant. Voici un malade atteint de la folie du doute, ou pour parler plus exactement, de l'indécision ; il lui est impossible, malgré tous ses efforts de volonté, de se décider à ouvrir une porte, à reboutonner son pantalon. Cela lui est impossible s'il est seul ; mais, "si on intervient, quel que soit le moment, l'obsession cesse », le malade ouvre la porte, se reboutonne, «car on sait que les obsédés puisent dans la présence des personnes étrangères... un appui moral, c'est-à-dire l'appoint de volonté qui leur fait défaut quand ils sont seuls ». Cette action de présence, qui se révèle ici avec évidence, mais qui n'est pas moins réelle, n'en doutons pas, quoique inaperçue, dans la vie ordinaire, nous explique par là même la puissance des foules. En lisant ce passage, je me suis rendu compte pourquoi, dans les inventaires d'arrêts rendus par des sénéchaux ou des présidiaux, sous l'ancien régime, j'ai souvent remarqué la fréquence de délits commis par de petites bandes de paysans non malfaiteurs. Au lieu de se disperser, comme ils le feraient aujourd'hui, pour marauder, piller, incendier, commettre des actes de violence, ils se réunissaient alors (car, s'il y avait en ce temps-là, moins souvent de grandes foules, il y avait bien plus fréquemment de petites foules), et cela n'a pas laissé de m'étonner un peu. Mais je présume maintenant en songeant à l'observation du Dr Régis que, pour acquérir l'audace d'affronter les épouvantables pénalités d'autrefois, les candidats au vol, à l'incendie, au meurtre, étaient obligés de se mettre plusieurs ensemble, de se donner du cœur les uns aux autres.

Mais un grand rassemblement d'hommes n'a pas seulement pour effet psychologique d'outrancier l'intensité des émotions et des

Ajoutons : et les études faites sur les sociétés animales. Rien de plus instructif à cet égard, que les remarques de M. Espinas, sur la contagion et le grossissement des émotions dans le sein d'un guépier, quand la sentinelle a annoncé l'apparition d'un ennemi. 
passions qui s'y multiplient les unes par les autres, et dont les plus fortes, les plus hardies, les plus dangereuses, d'habitude et par force, l'emportent; en outre - et cette très juste remarque est faite par M. Sighele - un sentiment tout nouveau naît de là dans la conscience de chacun : à savoir le sentiment d'une toute-puissance extraordinaire et subite, redoublé par celui d'une impunité presque assurée. Or Jacoby nous a appris le degré d'ivresse mentale, d'alcoolisme intellectuel, que produit l'omnipotence chez les parvenus au pouvoir suprême, et même parfois chez ses détenteurs traditionnels, surtout quand ils ont la tête peu solide. Il en est de même des multitudes. Leur force les affole. C'est « un vin trop fort pour la nature humaine, comme dit M. Taine : le vertige vient, l'homme voit rouge et son délire s'achève par la férocité. » - Encore faut-il, bien entendu, pour que la foule aille aux derniers accès, ou même jusqu'au simple meurtre ou au pillage, qu'elle soit en majorité composée d'individus vicieux, tels que souteneurs, ivrognes, repris de justice.

Toutefois, dirons-nous avec M. Sighele que l'action de la foule sur ses membres, ou mieux des meneurs sur les menés dans une foule, est inférieure en énergie à celle de l'hypnotiseur sur l'hypnotisé ? Et si l'on a pu refuser à la suggestion hypnotique elle-même le pouvoir de transformer un honnête homme en assassin ou en voleur, dénieronsnous à plus forte raison ce pouvoir à la suggestion follesque ? Je répondrais volontiers par un distinguo. En tant qu'elle agit sur les sentiments, la volonté, le caractère, la suggestion par la foule me parait souvent l'emporter en puissance sur la suggestion par l'hypnotisme, mais celle-ci a incontestablement une action plus grande sur l'intelligence et les sens. L'influence hypnotique est plus brillante et plus superficielle; l'autre est plus obscure et plus profonde, quoique passagère aussi.

L'appréciation et la répartition des responsabilités, quand il s'agit d'un crime collectif, tel que l'assassinat de M. de Moneys par les paysans d'Hautefaye, un jour de foire, ou l'assassinat de l'agent de police Vincenzini par une bande de la Commune, soulève des difficultés que M. Sighele s'efforce de résoudre. En cela, il donne un excellent exemple à nos tribunaux et à nos cours d'assisses qui ne me paraissent pas s'être donné autant de mal que lui pour dénouer ce problème. Et pourtant c'est bien souvent qu'il se pose devant nos 
magistrats: il n'est pas une grève, il n'est pas un soulèvement populaire quelconque, qui n'amène devant les juges ou les jurés trois ou quatre, cinq ou six co-auteurs de violences commises de complicité avec des centaines et des milliers d'autres individus non traduits en justice et souvent tout aussi dignes d'y figurer. Sortis du courant puissant où ils ont été pris, ou qu'ils ont paru conduire, ces quelques naufragés de l'émeute, épaves d'une vague à présent évaporée, sont tout changés, tout ahuris de ce qu'ils ont fait; et le juge ou le juré qui les voit ainsi, en cet état d'isolement où ils sont manifestement maîtres de leur pensée et de leur conduite, et aussi bien dépourvus de tout prestige sur autrui, est porté à les juger toujours ou beaucoup plus ou beaucoup moins coupables qu'ils ne le sont. Il ne songe pas, en effet, à les replacer en ce milieu enfiévrant et momentané, en cet ouragan qui les a poussés ou qu'ils ont déchaîné. Il est trop porté à considérer un meurtre collectif comme une simple somme d'actes individuels et à croire chacun des inculpés capable de faire seul tout ou partie de ce qu'il a fait pendant l'émeute.

Mais peut-être me dira-t-on: Après tout, ce phénomène est bien moins exceptionnel qu'il ne semble; est-ce que l'individu même en agissant seul, n'est pas mû, à notre insu et à son insu, par une foule invisible et innombrable, celle de ses ascendants, de ses compatriotes, de ses éducateurs, dont les influences combinées, emmagasinées dans son cerveau, localisées peut-être en des cellules distinctes, se réveillent en sursaut et toutes ensemble à certains moments, véritable multitude intérieure fourmillante et fermentescible sous un crâne ? Or, de deux choses l'une : ou, dans ce cas, nous dirons qu'il faut n'avoir nul égard à ces complices cachés et insaisissables et concentrer toute la culpabilité sur le seul auteur que nous puissions saisir ; mais alors la logique nous oblige à décider de même dans le cas d'une émeute et à faire peser l'entière responsabilité du meurtre collectif sur les deux ou trois émeutiers, sur l'émeutier unique parfois, que nous parvenons à découvrir. Ou bien, à l'inverse, nous déciderons que l'émeutier arrêté doit supporter seulement une part, une faible part de la culpabilité collective, et alors, pour être conséquents, nous devons admettre que le criminel isolé doit bénéficier d'une atténuation analogue, à raison des suggestions multiples qui l'ont déterminé au mal. 
En fait, la justice pénale a successivement choisi ces deux alternatives ; la première jadis, quand le conspirateur découvert entre mille payait pour tous, et quand on punissait un malfaiteur quelconque sans égard aux circonstances atténuantes; la seconde à présent, et de plus en plus à mesure que s'accréditent des idées analogues à celles de MM. Thierry et Dortel sur la responsabilité atténuée.

Encore est-il bon de faire observer que l'assimilation précédente pèche, évidemment, par un point: les influences complexes de la foule cérébrale que chacun de nous porte en soi, ont été assimilées, identifiées plus ou moins à nous-mêmes, tandis que les impulsions de la foule extérieure sont étrangères au moi. A ce même point de vue, il importe de ne pas confondre une secte et une foule. Une secte est une foule triée et permanente, comme le groupe de tendances agrégées qui constituent la personne; une foule est une secte très mêlée et très passagère. Les sectes se recrutent comme les foules, un peu au hasard, dans des classes, des familles, des nations différentes, en tout cas sans exception de famille ni de classe habituellement; mais elles font subir à leurs conscrits un temps d'épreuve et de noviciat; une foule reçoit des recrues aveuglément et sans préparation. Aussi les sectaires doivent-ils être jugés plus responsables que les émeutiers, pour des actes de même nature. Je condamnerais plus sévèrement un camorriste qu'un gréviste pour un assassinat commis dans des circonstances semblables. L'esprit de secte, - et aussi bien l'esprit de clan, comme en Corse, ou l'esprit de parti - exerce une action lente, continue et profonde, qui refond l'être, mais que l'être s'approprie; l'esprit de foule traverse l'âme comme un orage l'air. Les sectaires sont aux émeutiers ce que les criminels par tempérament ou par métier sont aux criminels par occasion ou par colère. La délictuosité des foules est toujours impétueuse, explosible; il n'y a pas d'individu aussi sujet à « s'emballer » qu'une foule, même composée de gens assez froids. La délictuosité des sectes est plus calculée, plus préméditée, plus réfléchie, ce qui ne veut pas dire d'ailleurs moins passionnée. Une foule peut massacrer des prisonniers ou des otages, piller des églises ou des palais ; une secte seule peut organiser ces massacres ou ces pillages.

Les foules pourraient servir - et je regrette que M. Sighele n'y ait point songé - à contrôler les idées lombrosiennes sur l'importance 
prépondérante des influences de race et de climat, des facteurs biologiques et physiques, dans la production des crimes. Si cette prépondérance est réelle, c'est surtout dans les crimes de foules qu'elle doit se manifester avec évidence. Une foule, et même une secte, étant un être toujours beaucoup moins organisé et centralisé qu'un individu, les influences diverses qui agissent sur elle s'y font sentir plus indépendamment les unes des autres, de manière à se détailler en quelque sorte aux yeux du spectateur, et les influences extérieures la dominent davantage parce qu'elles rencontrent une moindre résistance interne. La pluie et le soleil, l'hiver et l'été, ont une action directe sur la formation des rassemblements extérieurs de personnes, condition première des attroupements séditieux. Quant à l'action de la race, elle peut être masquée ou neutralisée le plus souvent dans l'individu par la variation individuelle qui lui est propre, mais, dans un groupe d'hommes de même race, les variations individuelles se compensent comme dans une photographie composite, et le type moyen tend à prévaloir. Il est vrai que, lorsque les délits individuels eux-mêmes sont étudiés en masse, par la statistique, la compensation des variations individuelles a lieu aussi, mais d'une façon plus abstraite et moins frappante. Et d'ailleurs cette considération n'est pas applicable à l'influence du climat et de la saison, qui, même observée à travers les gros chiffres du statisticien, doit toujours être beaucoup moins efficace en fait de délits individuels qu'en fait de délits collectifs, par suite de la raison donnée plus haut. Si donc cette efficacité, dans le cas des foules, nous paraît surpassée ou seulement même contre-balancée par celle des causes sociales, nous devrons a fortiori ne plus révoquer en doute la supériorité de celle-ci dans l'explication du délit individuel.

Or il est bien certain que l'heure, la saison, le climat, le froid ou le chaud, la sécheresse ou l'humidité de l'atmosphère, la race surtout, jouent un rôle important dans les excès de la folla delinquente. Ce n'est jamais la nuit que commencent les émeutes : les grandes journées ne sont que bien rarement les grandes nuits. Dans le Midi, les émeutes ont une autre couleur, une autre impétuosité d'allures que dans le Nord; en Orient qu'en Occident. Un meeting anglais est plus calme qu'une réunion électorale de France ou d'Italie. Comparez l'enthousiasme délirant du public, dans un théâtre de Florence, quand apparaît une actrice en vogue, aussitôt ensevelie sous des avalanches 
de bouquets et de sonnets, à la froideur d'une représentation belge ou hollandaise. - Mais, en somme, n'est-il pas évident que les foules, avant tout, sont soulevées et mues par des passions politiques, religieuses, par la nouvelle d'un désastre militaire ou d'un acte du pouvoir, par la parole d'un tribun ou d'un moine, par la contagion puissante des idées du moment, par les précédents historiques ? Il est possible que les foules révolutionnaires, comme a essayé de le démontrer Lombroso dans son Délit politique, se soulèvent de préférence en été ; mais suivez une à une toutes celles qui sont nées à Paris, cyclones sanglants, depuis le 14 juillet 1789 jusqu'à la fin du Directoire, vous verrez que leurs vraies causes n'ont rien à voir avec la température, et qu'il faut les chercher dans l'atmosphère morale de l'époque, dans un confluent de circonstances historiques, de fleuves d'exemples et de traditions qui sont venus déboucher à la Révolution française. Vous verrez que chaque émeute se modèle sur les précédentes, que sans celles-ci elle ne serait pas. Vous pourrez faire les mêmes remarques sur les troubles de la Fronde ou de la Ligue, entrecoupés de si longs intervalles de temps où rien ne parvenait à émouvoir, en aucune saison, ce même peuple qu'un rien ameute en ces temps de mode insurrectionnelle. L'observation s'applique avec plus de force encore aux sectes. Pendant la Révolution, le Jacobinisme est pareil d'un bout à l'autre du territoire et d'un bout à l'autre de l'année ; les clubs jacobins, hiver comme été, au Nord comme au Midi, à l'Est comme à l'Ouest, ont même langage, mêmes procédés sanguinaires. On en peut dire autant, mutatis mutandis, des sectes religieuses quelconques qui ne changent guère malgré le changement de latitude ou de longitude...

Mais je ne vois pas pourquoi je discute avec M. Sighele. Il est peut-être, au fond, de mon avis, et plus qu'il ne le croit lui-même, si j'en juge par une petite monographie de lui que je regrette de ne pouvoir analyser en détail, tant elle est riche de documents et d'aperçus instructifs ${ }^{1}$. La criminalité romaine, dont il nous donne un échantillon à propos de la petite ville d'Artena, située dans les anciens États pontificaux, mérite un examen à part, comme la criminalité corse ou sicilienne. Pendant que l'Écosse a moins d'un homicide annuel sur 100,000 habitants, que la France en a 2, que l'Italie dans

Un paese di delinquenti nati, par Sciplo Sighele, Fratelli Bocca, Turin, 1890. 
son ensemble en a 12 , Artena en compte 61 et demi ; et elle compte 145 vols qualifiés (toujours sur 100,000 habitants) pendent que l'Italie en a 3 ou 4. A quoi tient cette criminalité extraordinaire, inouïe ? M. Sighele nous dit-il que cela tient à la forme crânienne des habitants, à leurs anomalies corporelles, à la fréquence des cas d'épilepsie parmi eux ? Rien de pareil. Fort sensément, comme un archéologue eût pu faire, il remonte à leur passé et nous transcrit un acte du XVIe siècle d'où il résulte que les mœurs criminelles des Arténiens sont de date très ancienne. Il lui plaît de donner le nom d'atavisme à cette tradition de brigandage ; mais il est évident qu'ici l'expression d'atavisme est purement métaphorique ou signifie seulement la consolidation en instincts innés de mauvaises habitudes contractées par des générations successives et transmises en majeure partie par l'éducation. Du reste, l'auteur confesse que l'hérédité ici «n'explique point l'origine première du phénomène et qu'il faut la chercher dans le caractère de ces habitants du Midi et dans les vicissitudes historiques auxquelles ils ont été sujets. " Suivant lui, et probablement avec raison, il faut attribuer la formation des associations de malfaiteurs d'Artena aux mêmes causes (sociales, nous le savons) qui ont fait pousser les champignons vénéneux de la Maffia et de la Camorra sur le tronc pourri des anciennes institutions siciliennes et napolitaines. Enfin, il déclare formellement, n'en déplaise à mon ami Ferri, que la cause « socialement la plus importante », du brigandage effréné, devenu un métier avoué, et assez productif, est ou a été «l'impuissance démontrée de l'autorité à découvrir les coupables et à les punir ». Dès le moment où les exécutions ont commencé - il est vrai qu'il y a fort peu de temps - les brigands se sont mis à réfléchir.

\section{VI}

$\underline{\text { Retour à la table des matières }}$

L'ouvrage de M. Paul Moriaud, avocat à Genève, sur le Délit nécessaire ${ }^{1}$, nous fait aborder un terrain nouveau : il ne s'agit plus des conditions subjectives de l'irresponsabilité, mais de ses conditions objectives. L'auteur d'un délit peut être irresponsable, soit parce qu'il a

\footnotetext{
Du Délit nécessaire et de l'Etat de nécessité, Genève et Paris, 1889.
} 
été en proie à une surexcitation morbide ou à un entraînement contagieux en l'exécutant, - nous venons de voir cet aspect de notre sujet, - soit parce que ce délit n'en est pas un, à raison des maux qu'il a empêchés et qui sont égaux ou supérieurs aux maux causés par lui. C'est, par exemple, le cas de la légitime défense ; mais la légitime défense n'est qu'une espèce du genre beaucoup plus vaste fort savamment et profondément traité par M. Moriaud. N'est-il permis de tuer ou de blesser quelqu'un que pour se défendre contre son injuste agression? N'est-on pas excusable d'avoir tué ou blessé quelqu'un qui ne nous attaquait pas, mais dont la mort ou la blessure était la condition sine qua non de notre salut personnel, comme lorsque dans un bateau de sauvetage surchargé et prêt à périr, un des naufragés en jette un autre à l'eau pour alléger l'embarcation, ou, de peur de mourir de faim avec son compagnon d'infortune, le tue et le dévore ? Cette question de droit n'est pas purement oiseuse, elle a été soumise parfois à l'appréciation des cours criminelles, qui l'ont jugée diversement. Elle aurait déjà pu se présenter plus haut à notre attention, à propos des délits de foules. Il est arrivé peut-être quelquefois qu'un massacre ait été commis par une multitude, quoique tous ses membres l'aient réprouvé au fond du cœur, mais parce que chacun d'eux a été convaincu, d'après l'attitude des autres, que, s'il refusait de participer au meurtre collectif, il serait massacré lui-même. Robespierre, d'après Mme Rolland, était terroriste par peur. Combien de férocités collectives ne sont que des collections de lâchetés! Or, dans ces caslà, dirons-nous que les massacreurs étaient " en état de nécessité », pour parler le langage de M. Moriaud?

Entre deux maux il faut choisir le moindre, entre deux biens il faut sacrifier le moindre ; cela est évident. Mais quel est le moindre ? Aux yeux du législateur qui prévoit ce conflit - et dont toutes les décisions, à vrai dire, sont provoquées par le besoin de résoudre un conflit pareil ${ }^{1}$, plus ou moins intense et inquiétant, - le bien moindre, c'est l'intérêt d'un seul individu quand il se trouve en lutte avec l'intérêt, égal ou même un peu inférieur, de plusieurs autres individus, ou avec l'intérêt jugé très supérieur, d'un seul individu même; c'est enfin

Aussi M. Moriaud dit-il fort bien que le législateur est souvent lui-même "en état de nécessité » Il aurait pu dire toujours. L'état de nécessité, en effet, tel qu'il le conçoit, tel qu'on doit le concevoir, n'est pas une exception, comme il parait le penser ; il est la règle. 
l'intérêt présent d'un ou de plusieurs individus, d'un très grand nombre d'individus, quand il fait obstacle à l'intérêt majeur non pas même d'autres individus vivants, mais d'autres individus à naître, au bonheur des générations futures, à l'avenir de la patrie ${ }^{1}$. Aux yeux de l'individu, $\mathrm{j}$ 'entends de l'individu égoïste, étranger aux inspirations du mi-lieu social, c'est tout différent. Son intérêt, à lui, si faible soit-il, est toujours supérieur à l'intérêt le plus pressant de plusieurs centaines ou de plusieurs milliers de ses semblables. Seulement, à mesure que cet individu se civilise, s'imprègne des idées ambiantes, sympathise et fraternise plus intimement avec ses compatriotes, la notion de l'intérêt général tend à dominer sa raison avant même d'avoir subjugué son cœur, et à y former les principes directeurs, obéis ou non, de sa conduite. Il y a un législateur en lui.

Le point de vue du juge est souvent, trop souvent même, intermédiaire entre celui du législateur et celui de l'individu. Le juge tient compte, et jusqu'à un certain point doit tenir compte, en appliquant les principes légaux, des combats intérieurs qui ont mis aux prises, dans le cœur de l'accusé, deux biens hostiles, et produit la défaite du bien préféré par la loi. Suivant que le juge sera plus ou moins éclairé et pénétré de sa mission, il sera plus ou moins accessible à ces considérations personnelles. Le magistrat, à cet égard, diffère avantageusement du juré. - À vrai dire, la préoccupation du juge doit être tout autre que celle du législateur. Celui-ci ne doit se préoccuper que du conflit des biens et donner toujours raison au bien réputé le plus grand, d'après les maximes régnantes dans un temps et un pays donnés; cet intérêt préférable à ses yeux, il le sacre droit, il sacre devoir le respect de ce droit. Le droit et le devoir sont l'armure et l'arme du bien choisi. J'ai tâché de montrer ailleurs ${ }^{2}$ que le devoir ainsi compris, d'une façon toute positive, était simplement la conclusion d'un syllogisme moral, c'est-à-dire téléologique. Or, il arrive fréquemment que, après que le conflit de deux biens a pris fin par la consécration d'un devoir, ce devoir lui-même entre en conflit

Évidemment les lois relatives aux exceptions à l'inviolabilité du domicile, aux expropriations pour cause d'utilité publique, ordonnent le sacrifice d'un bien à un autre bien jugé plus grand. Mais toute loi fait de même; il n'est pas une disposition légale au titre des servitudes rurales ou urbaines, des successions, des donations, etc., qui, en délimitant des droits rivaux, ne sacrifie plus ou moins un bien à un autre.

2 Qu'on me permette de renvoyer à ma Philosophie pénale, p. 23 et suiv. 
avec un autre devoir, et aussi bien le droit corrélatif avec un autre droit. La vie morale est pleine de ces batailles de devoirs; quelques moralistes essayent de le nier, mais la plupart le reconnaissent, quoique ce soit là une terrible objection contre l'impératif catégorique. Si le devoir est un commandement absolu, comment deux ordres absolus et contraires peuvent-ils nous être donnés en même temps par la même autorité souveraine? Dans ma manière de voir, rien de plus simple que ces contradictions d'obligations : les conclusions de deux syllogismes ordinaires peuvent se heurter et se heurtent en fait très souvent sur le champ de bataille de la délibération interne, ou à l'audience civile et criminelle. Eh bien, c'est au juge qu'il appartient, dans ce dernier cas, de faire triompher le droit ou le devoir le plus cher au législateur, sans s'inquiéter habituellement de savoir si ce droit ou ce devoir de prédilection incarne et garantit la somme de bonheur la plus forte. S'il en était autrement, combien de fois n'absoudrait-on pas les voleurs, les escrocs, les adultères, etc., en prouvant que le plaisir goûté par eux à dérober ce qu'ils ont pris, l'emporte, et parfois beaucoup, sur le plaisir que goûtait le possesseur de la chose soustraite!

Car il se peut que les biens en conflit soient égaux (ou paraissent l'être) et que cependant les devoirs relatifs à ses biens soient inégaux. Ce serait le cas, suivant M. Moriaud, quand un homme se voit acculé à la nécessité de tuer quelqu'un pour sauver sa propre vie. Sa vie est un bien et la vie d'autrui un bien réputé égal. Néanmoins le devoir de respecter la vie d'autrui ${ }^{1}$. est supérieur au devoir de conserver notre vie propre. Pourquoi supérieur? On n'en peut trouver socialement qu'une raison, c'est que la lésion du droit de vivre d'autrui, opérée par moi volontairement, entraînerait non un mal plus grand, mais un danger de maux ultérieurs, possibles ou probables, plus grand que la lésion volontaire par moi-même de mon droit de vivre. En effet,

Remarquons que la nature de ce devoir, comme de tout autre, diffère d'après la nature des prémisses dont il est la conclusion. " Je veux que ma tribu reste en paix avec la tribu de cet homme : or, si je tuais cet homme, nos deux tribus se battraient ; donc, je dois ne pas le tuer. » Voilà le devoir de ne pas tuer, tel qu'il est le plus souvent compris chez les barbares. " Je veux mon salut éternel ; or je serais damné si je tuais ; donc je dois ne pas tuer.» Voilà le devoir religieux, dans le sens le plus bas du mot. " Je veux faire ce que Dieu, que j'aime, désire de moi, or il me dit d'aimer tous les autres hommes comme mes frères; donc je dois ne pas attenter à leur vie. » Voilà le devoir religieux dans une acception plus haute, non la plus haute encore peut-être..., etc. 
l'exemple de l'homicide "nécessaire » est tout autrement à redouter que l'exemple du suicide par amour du prochain. Qu'un homme immole sa vie à celle d'un de ses semblables, cet acte d'héroïsme comptera toujours peu d'imitateurs et entraînera peu d'abus, ou, s'il devient par hasard contagieux, ce sera un bien social immense que le refoulement puissant d'égoïsme acquis au prix de quelques existences, glorifiées par leur mort; tandis que la légitimation d'un homicide commis " en état de nécessité » crée un précédent destiné à propager le meurtre et à développer l'égoïsme. Est-il possible, en outre, de laisser l'individu, juge dans sa propre cause, décider qu'il a droit à sacrifier la vie de son semblable ${ }^{1}$ ?

M. Moriaud reconnaît, du reste, la supériorité du devoir de respecter les vies étrangères sur celui de conservation personnelle. Mais alors comment est-il d'avis (p. 264) que le Droit, « émanant de la volonté générale, ne peut que se désintéresser d'un conflit de biens égaux »; que « le principe d'égalité le lui commande », qu' « il ne doit pas protéger un individu aux dépens d'un autre »? Je ne puis admettre que la loi, ici, se sépare de la morale, et que l'État «s'il ne peut approuver l'homicide, ne puisse prêcher le suicide, dont les résultats immédiats sont aussi fâcheux pour lui ». Immédiats, soit; mais n'oublions pas la considération si importante de l'exemple. Je ne puis admettre non plus, et pour une raison analogue au fond, que, entre deux biens individuels inégaux, la loi doive toujours ordonner ou autoriser l'immolation du moindre. Elle ne peut pas m'obliger à me laisser couper un doigt pour sauver la main d'autrui ; elle ne peut pas me permettre de couper la main d'autrui pour sauver mon bras. Elle peut cependant, si le sacrifice de mon étable est nécessaire, dans un incendie, pour conserver la grange d'autrui, autoriser la destruction de mon étable. Pourquoi cela ? Apparemment parce que les membres de chacun de nous lui appartiennent autrement et plus profondément que ses immeubles ou ses meubles. Quand il ne s'agit que de nos propriétés extérieures, on comprend fort bien «l'expropriation pour cause d'utilité privée », phénomène fréquent, dit avec raison l'auteur; les règles relatives à l'accession des choses mobilières en sont un

Il y a des cas où le sacrifice de la vie est un risque professionnel accepté d'avance. Le soldat doit mourir à son poste, le matelot doit se sacrifier au passager (voy. à ce sujet un curieux arrêt américain, p. 303), le guide montagnard au touriste, etc. 
exemple frappant. Mais il serait plus exact de dire que l'utilité privée est ici sanctionnée par le législateur parce qu'il est d'utilité publique qu'elle le soit. En somme, les raisons qui ont fait édicter l'expropriation pour cause d'utilité publique sont précisément les mêmes qui font légiférer sous mille noms et sous mille formes l'expropriation pour cause d'utilité privée. Et ces raisons sont, en définitive, la supériorité évidente, écrasante, d'un bien sur un autre. Bien entendu, il n'est question que de deux biens possédés par deux individus différents. S'ils sont possédés par le même individu, le conflit, purement interne, est du ressort de l'hygiène ou de la morale.

S'il en est ainsi, tout ce qui tend à changer, comme degré d'intensité et comme étendue de diffusion, la proportion relative des divers besoins naturels ou factices et des diverses croyances, c'est-àdire à modifier la valeur relative des divers biens, tend à transformer en délits des actes licites, ou en actes licites des faits délictueux. L'incrimination est donc fonction (au sens mathématique) de l'évolution scientifique, industrielle et religieuse, qui bouleverse la hiérarchie des désirs et des opinions. "Il est certain, dit très bien M. Moriaud, que la société et les individus attachent une importance très différente à la conservation des différents biens. La loi pénale en est le prix courant, a dit justement Jhering; l'élévation de la peine dont la loi frappe la lésion d'un bien est un indice certain de sa valeur aux yeux des hommes d'une époque et d'un pays donnés. " C'est le côté économiquement intéressant du Droit pénal. Supposons que le désir de locomotion aille en diminuant dans notre pays, qu'il revienne au point où il était au moyen-âge ; il pourra être question alors d'ériger en délit le fait de transporter des voyageurs en chemins de fer, à cause de la gravité des catastrophes éventuelles. A présent, le besoin de déplacement est si impérieux et si général que le nombre des accidents de chemins de fer aurait beau doubler, quadrupler, décupler, on voyagerait quand même en wagon. C'est surtout quand le conflit des biens, comme ici, a lieu entre un bien actuel ou certain et un bien futur, simplement probable, que le problème de leur valeur relative est compliqué et que le champ est ouvert à l'arbitraire des appréciations. "L'éducation du soldat entraîne des dangers multiples que l'État connaît : les insolations, les suites de fatigues exagérées, les accidents divers, dans la cavalerie surtout, l'essai d'engins destructifs, sont cause de morts nombreuses. Chaque année un certain nombre de citoyens - 
la statistique montrerait peut-être la fixité relative de ce chiffre - sont sacrifiés, non pas au salut, mais à l'éventualité du salut de la patrie. De même dans la défense contre les fléaux naturels : l'État lui-même organise les secours contre l'incendie et sait que, pour sauver souvent de simples choses, des maisons, le pompier exposera sa vie; il le désire même, il ordonne des exercices préliminaires dangereux, ici aussi sacrifiant des vies à l'éventualité du salut d'autres vies. Et le flottage et la construction des clochers, des ponts, des routes de montagne ! Et l'exploitation des mines! Et toutes les industries insalubres où l'ouvrier abrège sa vie de moitié ! Actes dangereux, que la loi approuve, qu'elle doit approuver, parce que le dommage qui en résulte est compensé, et au-delà, par leur utilité sociale.» il y a corrélation entre le degré de probabilité du bien poursuivi par le sacrifice d'un autre et le degré de légitimité de ce sacrifice. M. Moriaud pose à ce sujet des sortes de théorèmes juridiques.

Dans ses aperçus de législation comparée, il fait ressortir l'étendue très variable du droit de légitime défense dans les divers pays. En Allemagne, il est abusif. Les criminalistes français "n'autorisent guère le meurtre de l'agresseur que pour la défense de la vie », les criminalistes allemands l'autorisent pour la défense « du bien le plus insignifiant; les quelques voix qui se sont élevées contre cette morale du meurtre sont restées sans écho ». Suivant l'auteur, cela provient de ce que «un peuple de mœurs sévères et respectueux des formes établies reconnaîtra un droit de défense plus étendu qu'un peuple de mœurs faciles et de caractère indulgent ». La facilité de mœurs et l'indulgence de caractère sont de bien bonnes choses si elles engendrent la générosité et compriment la barbarie.

\section{VII}

$\underline{\text { Retour à la table des matières }}$

Il me reste peu de place, malheureusement, pour parler de beaucoup d'autres ouvrages tout à fait dignes d'étude. Mais je me reprocherais d'avoir passé sous silence les Attentats à l'honneur, par 
M. Emile Worms ${ }^{1}$, professeur à la Faculté de droit de Rennes. M. Beaussire, un des premiers, dans ses Principes $d u$ Droit, avait signalé en termes énergiques l'insuffisance criante de la protection que nos lois accordent à notre bien le plus précieux, l'honneur. La question du Duel, si ardue et si piteusement abordée par nos juristes, tient tout entière là. La persistance, la recrudescence même, de cette féodale coutume du combat singulier en pleine démocratie, est une honte pour nos codes et nos législateurs. Louis XIV a pu, en plein XVIIe siècle aristocratique, ce qu'ils disent ne pouvoir. "Quel dommage, dit éloquemment $\mathrm{M}$. Worms, que la société qui adresse ses clameurs à la loi, n'y éveille aucun écho ; que les balles de pistolet échangées dans les duels traversent tant de cœurs, sans que le législateur semble touché par aucune d'elles! Chaque coup revient à un reproche amer, à une accusation formidable, et personne ne sent de responsabilité peser sur ses épaules. » Et plus loin : « N'y a-t-il donc pas d'autre chemin conduisant à la réconciliation que celui où les adversaires se rencontrent le pistolet au poing ? N'y a-t-il pas de pont jeté sur l'abîme qui les sépare ? » Mais je ne veux pas revenir sur ce problème du Duel, que j'ai étudié longuement ailleurs ${ }^{2}$.

Je n'en finirais plus si j'abordais avec $M$. Vaccaro la discussion des importantes considérations indiquées et rapidement approfondies dans sa petite brochure sur l'Utilita nel diritto penale classico. Ce titre ne dit pas le sujet de ce travail, qui a pour objet de montrer la fragilité des deux fondements donnés successivement au Droit de punir, à savoir d'abord, la prétendue volonté de la nature, postulat imaginaire du Droit naturel, la plus chimérique des utopies, et ensuite le principe de l'utilité, donné par Bentham pour règle suprême à la conduite. D'une part le darwinisme est incompatible avec le droit naturel : si une loi de la nature veut la lutte des êtres et l'extermination des faibles au profit des forts, il faut cesser de dire que la nature veut l'harmonie des êtres, circonscrits respectivement dans la sphère de leurs «droits ». D'autre part, le darwinisme n'est pas moins contraire au benthamisme qui prétend faire naître l'harmonie générale et le plus grand bonheur commun de la mêlée des rivalités et des hostilités individuelles. Si la loi naturelle est que « chacun se procure le plus de plaisirs possible et

Didier, 1890, in- 8 de 332 pages.

2 voir plus haut [Dans l'édition numérique, voir le premier fichier. JMT.]. 
se soustraie le plus possible à la douleur », la conséquence forcée sera, sous n'importe quel gouvernement, que les gouvernants, conformément à cette loi, feront tout ce qu'ils pourront « pour se donner le plus de jouissances égoïstes, aux prix des plus grands sacrifices imposés aux gouvernés. » Cette conséquence de l'utilitarismes n'a pas tardé à être tirée aux États-Unis où les associations de grands capitalistes, qui sont le vrai gouvernement, ont exploité, à leur profit, par la vénalité des pouvoirs publics, les masses électorales. Il faut lire là-dessus Choses d'Amérique, par Max Leclerc (1891). On a commencé par ériger en axiome que toutes les fonctions, toutes les positions officielles devaient être attribuées, tous les quatre ans, aux créatures de la coterie triomphante. Les gens accommodants trouvaient la chose logique, sinon honnête. Puis cela n'a pas suffi ; on a fait des lois, par exemple celles sur le protectionnisme, uniquement dans l'intérêt de cette coterie. C'était encore plus malhonnête, mais encore plus logique. Si intelligent de ses intérêts que soit le peuple américain, il s'est laissé duper le mieux du monde, jusqu'à ces derniers mois. Cet exemple peut n'être pas inutile à rappeler. - Mais prenons garde à ne pas diffamer la nature humaine : tôt ou tard, en Amérique comme en Europe, elle finit par se révolter contre l'injustice, ou par en rougir. La nature humaine en effet, a une inclination innée à l'ordre et à la paix, elle est essentiellement sympathique et sociable, comme l'est en son fond la nature de tout être vivant, car tout organisme n'est-il pas une association harmonieuse? L'association pour la vie est l'alpha et l'oméga de la nature; la lutte pour la vie n'en est que le moyen terme et le procédé passager. Voilà pourquoi il y a, dans la vieille et séculaire hypothèse du Droit naturel, une âme de vérité que $M$. Vaccaro a tort de méconnaître et que Spencer a eu raison de dégager. Par les «vœux de la nature», par les «commandements de la nature », comme par les » commandements de Dieu », les grands moralistes de tous les temps, depuis les jurisconsultes stoïciens de Rome, qui ont renouvelé et transfiguré rationnellement, grâce au jus naturae, le Droit quiritaire, jusqu'aux fondateurs du Droit des gens au XVIe siècle, jusqu'aux évangélistes des Droits de l'homme en 1789, tous se sont-ils donc payés de vains mots? Non, tous, ce me semble, ont exprimé de la sorte, avec plus ou moins de bonheur et d'exactitude, cette conviction très plausible, qu'il y a au cœur des choses comme au cœur de l'homme, une profonde bonté immanente, source cachée de nos inclinations fréquentes au «bien», de nos 
orientations spontanées, en tant de races et de lieux différents, vers cet équilibre seul stable des intérêts que nous appelons la Justice. Mais, encore une fois, je n'ai pas le temps de discuter ${ }^{1}$.

Je n'ai pas encore dit un mot des travaux accomplis sous l'impulsion toujours féconde du Dr Lacassagne. Mais, à dire vrai, il est plus facile de les louer, que de les résumer, tant ils sont pleins et denses. La brochure du maître sur l'affaire Gouffé, nous détaille le tour de force exécuté par l'identification du plus fameux des cadavres mutilés. L'étude sur la submersion, de M. Paul Barlerin touche à un sujet qui, s'il n'est pas à l'ordre du jour, mériterait bien d'y être. Le tableau de la page 27 fait voir que la moyenne des morts, qualifiées accidentelles, par submersion n'a cessé d'augmenter depuis cinquante ans ; en 1836-1840, la moyenne annuelle était de 2.887 : en 1881-86, elle s'est élevée à $3.910^{2}$. Or, l'embarras est grand, dans beaucoup de cas de décider si la submersion est la conséquence d'un suicide, d'un homicide ou d'un simple accident, «En l'absence de lésions, nous dit M. Barlerin, les présomptions sont que l'individu est tombé à l'eau vivant, accidentellement ou volontairement (voilà le hic), et l'expert doit simplement déclarer que la mort est le résultat de l'asphyxie par submersion. » Alors le procureur de la République classe sans suite et inscrit sur son registre : Ni crime ni délit. Mais, combien de fois des crimes odieux échappent ainsi à la justice! Dans son appendice, l'auteur reproduit douze rapports émanés des docteurs Lacassagne et Coutagne dans des espèces délicates. J'observe que six de ces rapports, fort bien faits du reste, aboutissent à des conclusions données par l'expert comme dépourvues de certitude. Par exemple ( $\mathrm{p}$. 186) : «Il est impossible d'affirmer les causes de la mort, qui semble, cependant, en l'absence de lésions et blessures, être due à un accident «; ou bien (p. 187) : « La mort... est probablement le résultat d'un suicide ou d'un accident $»$, etc.

À ceux qui désirent connaître le malfaiteur photographié au vif et instantanément, je recommande les ouvrages du Dr Laurent,

\footnotetext{
Je me borne aussi à indiquer une étude remarquable de M. Alimena sur le Giudizio d'accusa nella legislazione inglese (Turin, 1890).

2 Le nombre des morts accidentelles en général s'est élevé un peu plus vite encore; il a passé de 6192 à 13,205 en 1885 .
} 
notamment son livre volumineux, aussi documenté qu'agréable à lire, sur les Habitués des prisons ${ }^{1}$. Impossible, par malheur, d'en faire un compte rendu en quelques lignes et même en quelques pages. L'Année criminelle (1891) et l'Amour morbide (1891) du même auteur se recommandent par les mêmes qualités. L'amour morbide! En voilà encore un sujet plein d'à-propos! La proportion grandissante des crimes d'amour dans notre société contemporaine donne raison aux physiologistes qui voient un lien étroit entre l'instinct générateur et l'instinct destructeur. L'amour et le meurtre ; antithèse tout autrement vraie que l'antithèse banale, si chère aux poètes, sur l'amour et la mort! Le Dr Laurent fera bien de songer à un nouveau livre sous ce titre : l'Amour meurtrier. L'amour est, de toutes les forces naturelles, y compris la force des vents, des torrents et des marées, celle que la société capte le moins. Au contraire, la civilisation la déchaîne, et, en la surexcitant, la stérilise. Chose étrange, que ce puissant dissolvant des liens sociaux progresse avec la société. Ne semble-t-il pas que, à mesure que le besoin de procréation se fait moins sentir, et que la population arrive à son apogée numérique, l'amour devrait décroître ? Quand on songe à l'évolution habituelle de l'amour, depuis l'adolescence jusqu'à l'extrême vieillesse, aux immondes excès où il aboutit fatalement, à ses effets désastreux sur les plus hautes fleurs du cerveau, on se dit qu'une société adulte et déjà mûre devrait à tout prix l'arrêter sur sa pente, comme l'individu parvenu à la même saison de la vie. Il en est de l'amour comme de la poésie : il vient vite un âge où, ce qui en reste, il serait bon de le refouler en soi, de le moissonner en vert, pour féconder la pensée et l'activité, - si on en avait le courage. Évidemment, notre Europe ne l'a pas, pas plus que ne l'a eu l'Empire romain, jusqu'au jour où le besoin s'est fait sentir en lui de la réaction chrétienne contre ses débordements de prostitution et de pornographie. Pouvons-nous espérer - ou redouter - en vertu de la loi du rythme universel chère à Spencer, - quelque réaction analogue au XXe siècle?

Volume de 616 pages avec planches et figures, préface du Dr Lacassagne (Storck, Lyon 1890). 
Je ne saurais mieux finir que par l'étude lucide, pénétrante, définitive du Dr Régis sur les Régicides ${ }^{1}$, l'un des meilleurs travaux de la collection lyonnaise. Comme il n'est rien qui ne se falsifie en ce monde, il y a de faux régicides, persécutés imaginaires devenus persécuteurs et simulant un attentat sur un prince, sur un président de république, sur un ministre, pour se faire rendre justice en attirant ainsi l'attention sur eux. Quant aux vrais régicides (ou présidenticides, cela revient au même), ils présentent des traits frappants de ressemblance morale, physique même, à travers la diversité des temps et des lieux. Chez eux apparaissent souvent les stigmates de la dégénérescence. La plupart sont jeunes au moment de leur premier attentat ; aucun n'a dépassé trente ans. Ils sont tous mystiques, et d'un mysticisme le plus souvent héréditaire. Ils ont des hallucinations qui les poussent au glorieux crime de leurs rêves, et des hallucinations parfois étonnamment semblables entre elles. Voici, par exemple, celle de Jacques Clément, racontée par Palma Cayet. « Une nuit, étant dans son lit, Dieu lui envoya son ange en vision, lequel avec une grande lumière se présenta à lui et lui montra un glaive nu en lui disant ces mots : «Frère Jacques, « je suis messager du Dieu tout-Puissant, qui te viens accertener «que par toi le tyran de France doit être mis à mort; pense " donc à toi, comme la couronne du martyre t'est aussi préparée... » Cela dit, l'ange disparut. Voici maintenant comment un anarchiste contemporain, de l'espèce des régicides, a raconté au $\mathrm{Dr}$ Régis lui même sa vision récente. "La nuit, au milieu d'un cercle de lumière, un être surnaturel m'est apparu sous la forme de l'archange Michel, tenant en main une épée flamboyante. " Je suis, m'a-t-il dit, le Génie de la Révolution; il faut «que tu meures pour tes principes comme Jésus-Christ et Pranzini. Puis le génie a disparu, laissant après lui comme une traînée lumineuse ». Est-il possible, comme le fait remarquer M. Régis, de rencontrer deux faits morbides plus entièrement semblables chez deux êtres différents, à trois cents ans de distance ? Autres similitudes encore. Tout impulsifs qu'ils sont, ces hallucinés sont essentiellement préméditatifs, ce qui n'empêche pas leur acte réfléchi, calculé, logique, d'être l'effet d'une obsession maladive et irrésistible. Aussi sont-ils incorrigibles, et c'est pitié

Les Régicides dans l'histoire et dans le présent, par le Dr Régis (Bibliothèque de criminologie, Storck-Masson, Lyon-Paris, 1890), brochure de 97 pages avec vingt portraits de régicides. 
perdue que de les gracier. L'erreur où le public et même les historiens, tels que Michelet, tombent souvent à leur sujet, c'est de leur supposer des complices cachés, dont ils auraient été les instruments. Il est prouvé que Ravaillac, notamment, n'en avait pas, qu'il n'était nullement l'agent du duc d'Epernon. Après une étude personnelle de la question, M. Régis en est absolument convaincu : «Avec FontenayMareuil, Ponchartrain, P. Mathieu, Voltaire, on ne doit voir dans Ravaillac qu'un fanatique, qu'un mélancolique, auteur et exécuteur d'un dessein ignoré, et, en dehors de son mobile de folie et de fureur religieuse, désintéressé ». N'attribuons même pas une importance trop grande à l'action indirecte, puissante néanmoins, que des prédications ardentes ou des articles de journaux incendiaires peuvent avoir eue sur la direction prise par la folie d'un malheureux. C'est surtout l'exemple d'un précédent du même genre, l'exemple de Judith ou de Brutus, entre autres, qui décide la volonté malade à l'acte fatal ... En somme, je crois que, si après avoir lu le volumineux Delitto politico de Lombroso, on lit la mince brochure du Dr Régis, on sentira mieux tout le prix de la clarté française, sans méconnaître d'ailleurs aucunement le mérite des grands brasseurs d'idées, même un peu confuses et mal étreintes.

J'omets bien d'autres travaux de l'École de Lyon; les auteurs me pardonneront cette négligence forcée. Mais, en post-scriptum, je crois devoir appeler l'attention de mes lecteurs sur une voie nouvelle de recherches que cette École va incessamment inaugurer et qui ne saurait être poursuivie sans la coopération d'un grand nombre de chercheurs simultanés ou successifs. Il s'agirait d'ajouter aux deux grandes mines ouvertes et exploitées, ai-je dit, par les nouveaux criminalistes, c'est-à-dire aux études anthropologiques et statistiques, une troisième mine, à peu près inexplorée jusqu'ici, et digne pourtant de fouilles profondes, à savoir l'exhumation archéologique des innombrables dossiers criminels enfouis dans les nécropoles de nos archives, non seulement à Paris, mais dans tous les chefs-lieux de nos départements. Il y a là d'immenses matériaux accumulés à exploiter. On verrait alors l'anthropologie criminelle fort heureusement complétée par ce que l'on pourrait appeler l'archéologie criminelle. Après quoi, l'histoire du crime en France pourrait réellement être abordée. Elle restera inabordable jusque-là, à moins de se tenir sur les hauteurs de vagues généralités. 
Gabriel Tarde, Études pénales et sociales (1892)

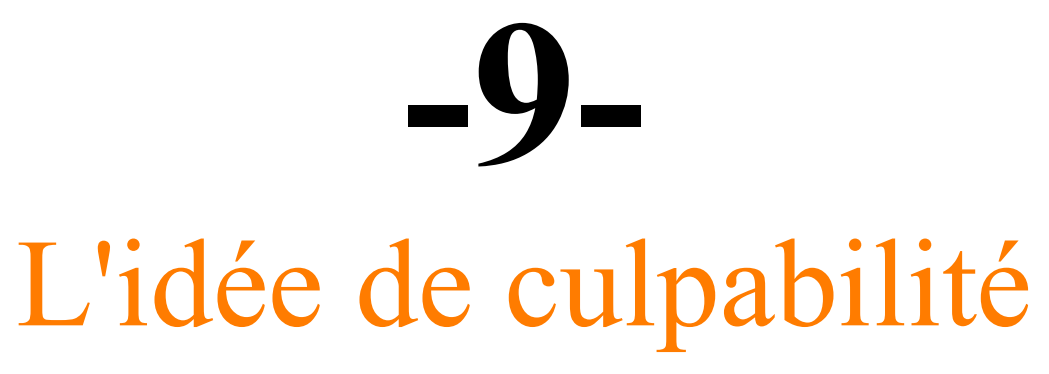

I

Tous les trois mois devant nos cours d'assises, et tous les jours dans la conscience des médecins-experts, des magistrats, des philosophes, se pose le problème de la responsabilité morale des malfaiteurs. Il n'a jamais été plus ardu ni plus hardiment discuté. Y at-il vraiment des coupables ou ne faut-il voir dans nos condamnés que des malheureux ou des malades, des damnés par prédestination héréditaire et anatomique, sinon des hypnotisés parfois ? L'hypnotisme, il est vrai, dans une affaire célèbre, est intervenu sans succès ; mais il est loin d'avoir dit son dernier mot. D'ailleurs, si la suggestion criminelle est tout au plus une simple possibilité difficilement réalisable en pratique, l'hérédité des aptitudes, bonnes ou mauvaises, n'est pas un vain mot; le lien étroit du physique et du moral, toujours serré de plus près par nos physiologistes et nos psychologues, n'est pas une chimère. Il s'agit de savoir si, à la lumière de ces vérités, la 
notion de culpabilité doit disparaître, ainsi que le veulent de savants criminalistes d'Italie et d'ailleurs, et comment elle pourrait être remplacée, ou bien si elle peut être renouvelée et conciliée avec des idées en apparence hostiles, ou enfin si, par un volontaire aveuglement, elle doit être maintenue de force, imposée comme un dogme socialement nécessaire, quoique scientifiquement insoutenable?

Qu'on ne s'étonne pas trop de me voir accueillir cette troisième et dernière solution, à la vérité révoltante, celle de la foi sans bonne foi, parmi les hypothèses qui méritent examen. De tout temps les peuples ont couru non seulement à la « servitude volontaire, » mais à l'erreur volontaire et à demi consciente, quand servitude ou erreur ont paru salutaires. Si l'on comptait tous les illustres et parfois généreux imposteurs, hommes d'État, oracles, thaumaturges, historiens, penseurs même, si l'on passait en revue toutes les générations ou toutes les classes qui ont plus ou moins menti paternellement, afin que les générations suivantes ou les classes inférieures fussent sincèrement abusées, on serait effrayé de la grandeur du rôle social dévolu au mensonge, père de l'illusion. Y a-t-il un seul gouvernement qui soit parvenu à s'établir sans légendes accréditées par des impostures historiques sur ses origines? Même de nos jours, nos bulletins de guerre mentent, nos programmes électoraux mentent, nos journaux mentent, le tout dans un intérêt patriotique ou politique, après tout, secondaire. Comment se ferait-on scrupule de mentir dans un intérêt humain de premier ordre, s'il était démontré que cela fût indispensable, c'est-à-dire que, sans la croyance au libre arbitre, affirmée en dépit de tout argument, la société ne saurait subsister? N'en doutons pas, pour un professeur qui crierait tout haut : périssent les colonies plutôt qu'un principe! il se trouverait mille gens raisonnables qui se diraient tout bas: périssent tous les principes plutôt qu'une colonie ! Ce serait le cas, pour les cœurs les plus droits, de se demander si, en somme, vérité signifiant accord possible ou actuel des esprits, société par suite, et non pas seulement accord d'un esprit avec lui-même, une notion antisociale peut être vraie, à proprement parler. Quelque doute de ce genre n'explique-t-il pas peutêtre la propagation des doctrines de $\mathrm{M}$. Renouvier sur la liberté personnelle dans le monde pensant de notre époque contemporaine ? 
Il importe donc au plus haut point de décider si nous allons être acculés à cette nécessité déplorable: nous aveugler, nous tromper nous-mêmes ; s'il n'y a pas d'autre issue pour nous que cette impasse. Suivant M. Fouillée, déterministe pourtant, le sentiment trompeur de notre liberté est une illusion de naissance, comme les catégories de l'espace et du temps, et elle nous est donnée pour notre bien, fantôme idéal qui nous mène, dit-il, à sa propre réalisation dans l'infini. Mais, à la différence des deux autres grandes formes de notre sensibilité, auxquelles il la compare, celle-là n'est pas invincible : ils sont rares, extrêmement rares, les sceptiques qui parviennent à se réveiller «du sommeil dogmatique, » en ce qui concerne l'étendue et la durée, et à se persuader que nous attribuons faussement aux objets ces qualités illusoires, comme nos sensations de lumière et de couleur. Nombreux, au contraire, et en nombre toujours croissant, sont les esprits désabusés du libre arbitre; nombreuses sont les volontés qui, en agissant, prennent conscience des mobiles et des motifs, des majeures et des mineures de ces syllogismes intimes dont la décision est la conclusion. Or, autrefois, les réveils de ce genre étaient clairsemés, un ou deux par siècle; à présent, dans certains milieux, précisément les plus savants et les plus influents sur l'esprit public, ils s'opèrent en masse. Est-ce là un danger social ?

Non. Le danger social, c'est de perpétuer une équivoque, une association d'idées qui a fait son temps. Si l'on s'obstine à définir la culpabilité de telle manière qu'elle implique la liberté d'indifférence, le miracle psychologique, il est certain que, le libre arbitre ôté, la culpabilité s'évanouit, et il ne reste plus qu'à asseoir la pénalité sur l'utilité générale. L'égoïsme collectif de la société, car c'est là le vrai nom de l'utilitarisme, a beau n'être pas plus respectable aux yeux de l'individu que ne l'est l'égoïsme privé, c'est-à-dire l'utilitarisme individuel, au regard de la société, n'importe, il faut en venir là et travailler à reconstruire le droit pénal, ou plutôt la thérapeutique criminelle, sur cet unique fondement. Il faut concéder à M. Enrico Ferri, le brillant champion de l'école positiviste au parlement italien, qu'il est logique en niant absolument, l'imputabilité morale, en refusant de voir dans le délit autre chose qu'un préjudice et une alarme. Les spiritualistes se récrient quand de telles propositions sont énoncées, et d'autres semblables; mais ils oublient que leurs anathèmes retombent en partie sur eux, qu'ils ont leur bonne part dans 
ces erreurs, que c'est leur faute si leurs adversaires se sont vus ou crus conduits à ces extrémités par le préjugé spiritualiste, écho d'un principe théologique, relatif aux liens indissolubles des notions de liberté et de responsabilité. Plus on accréditera ce faux dogme, et plus, sans le vouloir, on favorisera les progrès de l'école qu'on croit combattre, et qui s'offrira inévitablement comme le seul refuge ouvert aux défenseurs éclairés de l'ordre social. On a assis la morale tout entière sur le libre arbitre : droit et devoir, justice et injustice, bien et mal, tout est censé reposer là-dessus ; on nous l'a dit et redit cent fois. Aussi, qu'arrive-t-il ? Dès qu'un jeune homme, au sortir du collège, s'avise de raisonner sur le principe de causalité, sur l'axiome, - assez mal compris, - de la conservation de l'énergie, et sur la doctrine de l'évolution, il se reconnaît déterministe ; et aussitôt, avec une horreur sacrée, avec une épouvante d'abord douloureuse, il croit voir s'écrouler en son cœur toute la dignité de la vie humaine, il se croit forcé de tomber dans le nihilisme moral. Plus d'un pourrait décrire cette angoisse mentale, si le philosophe avait, comme le poète, le droit de dire je ; mais il ne l'a pas, car le moi des poètes est un nous, non le sien. Plus tard seulement, habitué au séjour de son abîme imaginaire, et pareil au Jacques le fataliste de Diderot, «qui ne connaissait ni le nom de vice, ni celui de vertu, » il « haussera les épaules » avec une certaine gaîté « quand il entendra prononcer les mots récompense ou châtiment. » Il en est des femmes comme des jeunes gens. Discutez devant elles le libre arbitre; il y a fort à parier que la plus intelligente vous objectera: "Mais alors, si je suis née vicieuse, pourquoi me blâmer? Est-ce moi qui me suis faite ainsi ?» Elle n'en prétend pas moins, du reste, avoir droit à de l'admiration pour sa beauté, qui n'est pas non plus son oeuvre, aux artifices près. Avec la même précipitation outrancière de jugement, familière à l'esprit juvénile et à l'esprit féminin, l'esprit italien, - qui joue effectivement, dans le grand salon de l'Europe, le rôle de la «femme supérieure, " enthousiaste, agitatrice, très radicale d'allures, très diplomate au fond, un peu prompte à exagérer la nouveauté à la mode pour se l'approprier, - se jette, à peine éveillé au darwinisme, dans la négation de toute notion éthique. Combien faut-il que cette influence du génie national, j'allais dire du sexe national, soit puissante pour avoir entraîné M. Ferri luimême, esprit d'ailleurs des plus virils, aussi pondéré et compréhensif que brillant; sans compter M. Garofalo, l'éminent magistrat! Mais en France pareillement, et partout où le déterminisme, sous sa dernière 
forme, l'évolutionisme, a pénétré il a fait les mêmes ravages moraux, malgré de moindres écarts de langage. Or, encore une fois, je comprends le scandale soulevé par les hardiesses que je signale. Mais à qui la faute ? A ceux qui ont donné pour tout soutien au temple de l'éthique une colonne vermoulue.

La liaison étroite des deux idées de culpabilité et de liberté a sa raison d'être chez les théologiens ; sous la plume d'un moraliste et d'un sociologue, elle ne se comprend pas. Tâchons de nous représenter l'émotion attachée à l'idée du péché dans l'âme d'un puritain écossais, d'un janséniste et même d'un de ces grands stoïciens, si religieux, qui étaient les casuistes de l'antiquité ; tous, cependant, plus ou moins teintés de nécessitarisme, soit dit en passant. Ce sont eux qui auraient eu le droit d'invoquer le postulat du libre arbitre, et, s'ils ne l'on pas fait, je m'explique bien que d'autres, pénétrés de la même impression profonde en face du crime, aient requis ce principe. Quand, par ce mot coupable, on entend infiniment haïssable, damnable éternellement, il va de soi que la culpabilité absolue ainsi entendue suppose une causalité absolue elle-même, c'est-à-dire l'action d'une cause première, d'une spontanéité créatrice, née ex abrupto et ex nihilo : ou le libre arbitre ne veut rien dire, ou il signifie cela. J'admets encore que, pour motiver les atroces pénalités de nos aïeux, réalisation terrestre de l'enfer dantesque, où se révélait une horreur du crime, une profondeur de vertueuse haine contre le criminel, étrangère aux honnêtes gens d'aujourd'hui, l'hypothèse du libre arbitre était indispensable. Le problème de la culpabilité, en effet, se lie à celui de la causalité ; l'une doit se proportionner à l'autre et se modeler sur l'autre. Pour satisfaire donc aux exigences d'une conscience qui affirme la possibilité d'une criminalité infinie, d'une faute non pas relative aux temps et aux lieux, à telle ou telle fraction de l'humanité, voire à l'humanité tout entière, mais d'une faute en soi pour ainsi dire, éternelle et ineffaçable, noircissant l'âme à fond et à jamais, il a bien fallu doter l'âme d'un pouvoir à la hauteur d'une telle chute. Au surplus, expliquer comment ce pouvoir d'option vraie, de « premier commencement, » comme dit excellemment M. Renouvier, c'est-à-dire de création, en désobéissant au Dieu créateur, peut ne lui pas faire échec, ce n'est pas là mon affaire. Quoi qu'il en soit, est-ce bien une culpabilité pareille que nous avons à justifier maintenant ? Non, la transformation profonde des peines et leur extrême 
adoucissement expriment assez le changement qui s'est opéré dans les consciences et qui tend même, en s'accentuant, à un singulier excès. Si le champ de nos indignations, pour ainsi parler, s'est fort étendu, embrassant à présent, grâce à la presse, les crimes et les criminels du monde entier, au lieu de se cantonner dans ceux d'une petite région, l'intensité de nos indignations, en revanche, a prodigieusement décru, à part le cas de mutuelle surexcitation dans les foules exaspérées et en train de lyncher. Aussi, de nos jours, être coupable, être responsable moralement, c'est simplement être blâmable jusqu'à un certain point et, comme tel, punissable, par un groupe plus ou moins étendu de personnes, par toute l'humanité, si l'on veut, mais à des degrés divers ; c'est être propre à susciter dans ce groupe une certaine indignation, du mépris, ou tout au moins une pitié toujours à un certain degré flétrissante, et, par choc en retour, à ressentir parfois dans son propre cœur le sentiment du remords avec une force variable. Est-il donc nécessaire, pour trouver juste l'idée d'une culpabilité limitée et relative ainsi définie, d'attribuer à la volonté de l'homme autre chose qu'une efficacité elle-même limitée et relative ? En deux mots, pour juger quelqu'un coupable, en ce sens très clair et très usité, avons-nous besoin d'imaginer qu'il a exercé une causalité libre, et ne nous suffit-il pas qu'il ait mis en jeu sa causalité propre ? Son acte ne lui est-il pas suffisamment imputable dès qu'il apparaît que son acte est sien?

Dût-il être maintenu pour les usages de la vie courante, de la petite morale habituelle, je crois que le libre arbitre, tel qu'il est conçu de nos jours dans les écoles, devrait être tenu à l'écart de la question pénale. Ce n'est plus là le libre arbitre vigoureux et tout-puissant de nos pères, réputé capable de résister aux plus forts ouragans du cœur. De capitulation en capitulation, délogé un peu partout, il. s'est vu réduit à s'atténuer, à se raffiner tellement pour se faire accepter encore, que de tout son ancien domaine il ne lui reste presque rien. Il n'apparaît plus, nous dit-on, que dans le moment de la délibération intérieure. Pour M. Delboeuf, l'un de ses plus ingénieux défenseurs, il n'est qu'une faculté dilatoire, un veto suspensif. Presque personne n'ose plus tirer argument en sa faveur du sentiment énigmatique et illusoire qu'on dit en avoir. Qu'on lise Liberté et Déterminisme de M. Fouillée, un livre qui épuise son sujet, et l'on verra le libre arbitre se retrancher dans le cas d'une alternative réfléchie et paisible, d'une indécision de la volonté ou même du jugement, et se présenter là 
comme un poids additionnel jeté on ne sait d'où dans la balance des mobiles et des motifs ${ }^{1}$. Ces mobiles et ces motifs étant toujours supposés ou très faibles ou très peu inégaux, le poids additionnel n'a besoin que d'être très léger pour être prépondérant.

Mais est-ce bien là l'hypothèse où nous place l'âme criminelle dans le moment immédiatement antérieur au crime ou à sa résolution ? Ici les plus tragiques passions entrent en scène, lors même que le malfaiteur a fait preuve d'une cruauté froide au service d'une âpre cupidité. Quand une fièvre de jalousie exalte un amant, quand le ressentiment poignant d'une injure fait prendre à un Corse son fusil, quand l'ambition politique arme des conspirateurs, ou même, à l'autre extrémité de l'échelle des délits, quand une femme est tentée de voler dans un grand magasin un objet de toilette dont elle s'éprend, je vois bien là des combats intérieurs qui s'engagent, lutte très inégale toujours, entre des appétits violents et des scrupules débiles ; mais des délibérations, une chambre du conseil intime où l'on discuterait poliment, posément, où l'on s'ajournerait pour délibérer de nouveau plus tard, en vérité je n'en vois pas l'ombre; et le veto suspensif ni le poids additionnel n'ont rien à faire là. Nous sommes à mille lieues des conditions exigées pour le fonctionnement du libre arbitre nouveau, simple instrument de laboratoire, pour ainsi dire. Si donc on veut faire, bon gré mal gré, reposer sur lui la responsabilité morale, on doit, quelque partisan qu'on soit de cette idée scolastique, acquitter la plupart des malfaiteurs, - à moins qu'on ne leur applique les idées de MM. Lombroso, Ferri et autres, qu'on est mal venu dès lors à critiquer.

J'indique simplement pour mémoire une tentative ingénieuse et désespérée de sauvetage du libre arbitre, imaginée par M. Bergson dans ses Données immédiates de la conscience, livre d'une analyse psychologique très délicate. 
Voilà pourquoi je me suis permis de chercher si la responsabilité morale, définie comme il a été dit plus haut, n'avait pas quelque autre appui possible que son fondement traditionnel ou conventionnel, assez peu antique à vrai dire ${ }^{1}$. La condition essentielle et suffisante, selon nous, de la culpabilité, c'est que l'acte reproché émane de la personne même, volontaire et consciente, non malade, non aliénée, cause causée, soit, mais cause pourtant, saillante et irréductible, et que cette personne soit restée, jusqu'à un certain point, la même depuis le délit. Il faut, en outre, que l'auteur de l'acte soit et se reconnaisse plus ou moins le compatriote social de sa victime et de ceux qui l'accusent. Ainsi, il y a en réalité deux conditions : à savoir, un certain degré d'identité personnelle persistante chez le malfaiteur dans l'intervalle de l'acte à l'accusation, et un certain degré de similitude sociale sentie ou reconnue entre sa victime et lui, entre lui et ses accusateurs. - Faisons remarquer que ces conditions de la culpabilité de l'agent ne doivent pas être confondues avec celles de la criminalité de l'acte. Bien entendu, il est nécessaire, avant tout, que celles-ci se rencontrent dans le fait incriminé, c'est-à-dire qu'il soit qualifié et réputé délictueux. Quant à l'explication de ce dernier caractère, nous n'avons pas à la donner ici. Mais on se tromperait en pensant qu'elle est exclusivement

Voir Revue des Deux Mondes du 1er juillet 1890, article de M. Brunetière intitulé - Une nouvelle théorie de la responsabilité à propos de notre Philosophie pénale. Voir aussi Archives de l'anthropologie criminelle du 15 janvier 1891, article du Dr Corre sur le même sujet. Je suis très heureux d'avoir obtenu pour ma théorie de la responsabilité, entre autres adhésions, celle de deux esprits aussi profondément dissemblables que le sont MM. Brunetière et Corre ; l'un spiritualiste, l'autre positiviste d'éducation et de tendance, ils doivent à leur égale indépendance intellectuelle le mérite de juger sans parti pris les idées nouvelles. Je devais d'ailleurs m'attendre à être critiqué, sans être le moins du monde compris, par la plupart des spiritualistes et des positivistes, également pénétrés du préjugé que je combats, la fausse et séculaire association entre les notions de liberté et de culpabilité. - J'ajoute que, lorsque le premier germe de ma théorie de la responsabilité fut posé dans ma Criminalité comparée. M. Zaborowski, dans la justice, s'est empressé de lui donner son assentiment et de voir en elle la seule solution possible scientifiquement acceptable, d'un problème inquiétant. 
ou même toujours principalement utilitaire. On en aura la preuve en parcourant la liste des actions regardées et punies comme les plus criminelles dans la suite des temps et la diversité des nations. Ce ne sont presque jamais les plus nuisibles à l'intérêt général, mais bien les plus contraires à la volonté générale, expression complexe non des intérêts seulement ni surtout, mais aussi, et en premier lieu, des croyances religieuses ou philosophiques. Si le plus grand crime, chez les anciens Persans, était d'ensevelir les morts, et, chez les Grecs, de ne pas les ensevelir, ce n'est pas que le plus grand intérêt pratique de ces peuples fût relatif aux usages funèbres; mais leur religion attachait le plus grand déshonneur des vivants à l'inobservation des coutumes concernant les morts. Le plus grand crime, au moyen-âge, était la sodomie ; le brigandage n'était rien auprès de cet acte honteux, à coup sûr moins préjudiciable à autrui, mais des plus opposés à l'esprit chrétien et à son apothéose de la chasteté. La criminalité d'un acte ne se proportionne donc pas, dans un lieu et un temps donnés, au préjudice social qui s'ensuit, pas même au préjudice supposé et imaginaire, comme dans le cas de la sorcellerie; car les sociétés, comme les individus, se font honneur de s'interdire des actes qu'elles jugent déshonorants, tout en reconnaissant leur innocuité. Cette importance des considérations esthétiques, appliquées à la conduite humaine, est-elle destinée à s'amoindrir de plus en plus, et celle des considérations utilitaires à grandir ? Il n'y a nulle raison historique ni philosophique de le penser. Avec le progrès de la civilisation, ce n'est pas l'intérêt collectif seulement, c'est l'idéal collectif, politique ou religieux, national ou social, qui s'accentue et prend conscience de luimême. Et la chaîne des utilités, en fin de compte, est suspendue à l'attrait du but final, du beau spécial, qui détermine son déroulement.

Mais revenons aux conditions de la culpabilité. Occupons-nous de l'identité personnelle d'abord. Cette exigence en suppose deux : que l'acte ait pour cause saisissable une personne, c'est-à-dire qu'il ait été voulu, et que cette personne n'ait point subi d'altération trop profonde, au point de vue de ses rapports avec ses semblables, pour être demeurée la même dans le sens social du mot. 
La personne, le moi, est. $\mathrm{Si}$ «je suis libre» est contestable et contesté, " je suis » est indiscutable et à peu près indiscuté ${ }^{1}$. Quelques nihilistes de la philosophie peuvent bien nier de bouche leur propre existence, leur propre différence individuelle, mais ils se contredisent en parlant, ils témoignent contre eux-mêmes par 1'étrangeté même de leur prétention. En tout cas, c'est leur matérialisme ici, ou l'espèce très singulière de leur matérialisme, qu'il faut accuser, ce n'est point leur déterminisme. Il y a un déterminisme des faits de conscience, comme il y a un déterminisme des mouvements extérieurs auxquels ils sont liés; la discussion qui porte sur la nature de ce lien et sur la valeur relative de ses deux termes est étrangère aux débats sur l'universelle détermination. On peut, sans cesser d'être déterministe, préférer la doctrine des idées-forces à celle des idées-reflets ${ }^{2}$, refuser de voir, dans une conscience qui s'allume un jour parmi des mouvements nerveux, un simple épiphénomène, inutile et inefficace, autant qu'inexplicable, dont l'absence n'eût rien changé au cours de l'évolution phénoménale ${ }^{3}$. On peut, sans croire le moins du monde au libre arbitre, et en se pénétrant au contraire de l'idée d'une nécessité universelle, d'une nécessité vivante et finale jointe à une nécessité physique et causale, repousser une conception qui supprime à la conscience toute raison d'être et fait de la réalité par excellence une vaine superfluité. Or, si l'on n'envisage l'agent d'un crime que comme un petit tourbillon de mouvements cérébraux, compris et noyé dans le grand tourbillon cosmique, je comprends qu'on refuse à cet être, qui n'en est pas un, à ce point d'intersection de facteurs physiques, non seulement toute liberté, mais toute individualité. Dès lors, quelle absurdité de le juger coupable, de le vouer à la réprobation? On ne blâme ni n'approuve, on n'aime ni ne hait, un mécanisme simplement physique. Il n'en est pas de même des mécanismes «à ressort

Aussi ne puis je comprendre l'objection que me fait M. Henri Joly dans son Combat contre le vice (p 26). «Un esprit subtil (cet esprit subtil, c'est moi) a cru récemment devoir substituer l'idée de personne à l'idée de liberté comme fondement de la responsabilité pénale. C'était se donner une peine bien Inutile. Métaphysiquement, l'idée de personne est au moins aussi obscure ou obscurcie que l'idée de liberté ; pratiquement, la liberté est aussi évidente et aussi respectée que la personne. » Les trois assertions soulignées sont manifestement erronées.

2 Voir l'Évolutionisme des idées-forces, par M. Fouillée. Paris, 1890.

3 Épiphénomène est un néologisme commode et qui a eu du succès. Tout ce que nos savants ne peuvent expliquer, ils le relèguent dans cette nouvelle catégorie des faits, inventée à leur usage. Je lisais dernièrement ces lignes d'un anthropologiste embarrassé pour donner une explication biologique du crime: "En un mot, le crime est là comme toujours un épiphénomène, un accident dans la vie de certains sujets. 
mental, » pour employer l'expression de M. Fouillée. Est-ce que des mécanismes animés, dans leurs relations mentales et sociales, ne peuvent pas, ou plutôt peuvent ne pas se haïr ou s'aimer, se blâmer ou s'approuver, puisque la haine ou l'amour, l'approbation ou le blâme, sont l'expression spéciale de leurs accords ou de leurs conflits de volontés, comme la joie et la douleur expriment leurs accords ou leurs conflits avec les choses ? Ni la nécessité, ni la continuité même des phénomènes solidaires de l'univers, ne signifient la confusion universelle. Tout enchaîner, ce n'est pas tout brouiller.

Au demeurant, nous n'oublions pas que nécessité et liberté, - ce dernier terme pris dans une acception toute métaphysique, étrangère au sens des moralistes, - sont deux idées corrélatives. Ces lois, en effet, auxquelles ont dit que tout obéit, sont-elles donc des ordres ? Si elles ne sont pas des ordres d'un législateur divin, que peuvent-elles être, sinon des habitudes que se sont formées à la longue les réalités, les originalités élémentaires ? Dans cette dernière hypothèse, elles impliqueraient donc des initiatives cachées dont elles seraient les moyens d'action plutôt que la raison d'être ; et, sous la nécessité des phénomènes, il y aurait nécessairement les libertés primitives des éléments, dissimulées par leur multitude même. Qui sait, en outre, si le moi, en ce qu'il y a de singulier, de sui generis, ne serait pas le reflet et l'expression supérieure de ce fond des choses ? Qui sait si, en vertu de cette similitude symétrique des extrêmes, mystérieux besoin de la nature, ce qu'il y a de plus élevé et de plus lumineux dans les phénomènes ne nous révélerait pas ce qu'il y a en eux de plus obscur et de plus profond ? C'est possible, mais c'est là une simple conjecture métaphysique, et, sur une base si fragile, bâtir la morale, quand nous avons à côté un terrain si solide, ne serait-ce pas courir le plus inutile et le plus redoutable des dangers?

Même à supposer que le moi n'implique absolument rien de simple et d'élémentaire, qu'il soit en entier un composé, le moi est, donc il agit ; l'un implique l'autre. Je comprends qu'on le nie, je ne comprends pas que, l'affirmant, on le dise inerte. Sa force, cependant, me demandera-t-on, d'où lui vient-elle ? Elle lui vient de mouvements qui lui sont liés, qui sont peut-être lui-même sous une autre face, qui ne seraient pas s'il n'était pas, de mouvements où s'enregistrent et se conservent toutes les forces extérieures qu'il s'est appropriées, qu'il a 
faites siennes ${ }^{1}$, le soleil, les aliments, les aptitudes héréditaires, les influences sociales de tout genre, religieuses, professionnelles, domestiques, politiques, courants innombrables de traditions ou de modes entre lesquels il s'est décidé conformément à son caractère peu à peu déformé ou réformé. Ce domaine, en partie son oeuvre, comment l'a-t-il acquis ? Pourquoi le grand Tout est-il morcelé, pulvérisé en atomes ou en monades, et comment se peut-il faire que, du simple contact de ces termes, un terme supérieur ait pu jaillir, plus réel qu'eux-mêmes, unité née d'une somme, petit monde croissant et grandissant dans le grand monde ? Peu importe, après tout. Ce morcellement et ces accroissements, cette existence d'êtres composés, qui existent puisqu'ils acquièrent, sont un fait, au même titre que le rapport de cause à effet, beaucoup plus mystérieux.

« J'ai, donc je suis, » aurait dû dire Descartes. Il y a trois verbes fondamentaux et irréductibles, être, avoir et faire. Le malheur des philosophes est d'avoir trop spéculé sur le premier et sur le troisième, sur la substance et sur la causalité, pas assez ou point du tout sur le second ${ }^{2}$. La fécondité des sciences proprement dites tient à ce qu'elles ont mis au premier rang de leurs préoccupations les propriétés des choses. Rien de plus clair que ces mots, avoir ou ne pas avoir, acquérir ou perdre. Rien de plus obscur que ces autres mots, cause et effet, actif et passif; et rien de plus ambigu. On peut, avec une égale apparence de raison, dire " que le déterminisme universel abaisse tous les êtres au rang d'effet ${ }^{3}$, » et dire qu'il élève tous les êtres au rang de cause. Mais ce qui est certain, c'est que le mien et le non mien font deux. Or, fondée sur l'identité personnelle, la responsabilité soulève simplement la question de savoir où s'arrête le domaine du moi;

Autre chose, remarquons-le, est la prédestination des âmes par une volonté divine qui aurait d'avance voulu leur vouloir, autre chose leur prédétermination (ce qui ne veut pas dire leur prévision, ni même leur prévisibilité) par le jeu de lois et de forces qui, sans le vouloir et sans le savoir, les auraient suscitées. Dans le premier cas, on peut prétendre que mes actes, même volontaires, ne m'appartiennent pas, qu'ils appartiennent au premier voulant, à Dieu. Mais, dans le second cas, mon vouloir est mien, car, avant d'être, nouveauté inattendue, il n'avait jamais été. Il est ma création, dans le sens comédien du mot, qui ne manque pas de vérité.

2 M. Herbert Spencer a fait exception, au moins dans sa magistrale formule, ou il réduit, toute évolution à des acquisitions de matière compensée par des pertes de mouvement. La clarté d'une telle conception, aussi nette que le doit et l'avoir des compatriotes commerçants de l'illustre sociologue, en explique peut-être en partie le prodigieux succès.

3 Le mot est de Guyau, déterministe pourtant. 
fondée sur la liberté, celle de savoir où finit son pouvoir, chose infiniment plus obscure.

Que puis-je ? que ne puis-je pas ? Je l'ignore. Pourrais-je, ne pourrais-je pas résister à des tortures comme celles qu'ont subies les templiers ; et, si j'avais été à la place de Jacques de Molay, aurais-je ou n'aurais-je pas pu m'empêcher d'avouer des crimes imaginaires, de dénoncer d'imaginaires complices ? Je n'en sais rien, le témoignage de ma conscience ne peut m'éclairer en rien à ce sujet. Je peux bien savoir, d'après l'expérience des limites de mon courage, ce que j'aurais pu si j'avais voulu ; j'ignore si j'aurais voulu et pu vouloir. Mais je sais bien que la contrainte exercée sur ma volonté par ces atroces souffrances aurait eu une origine étrangère, extérieure à mon être. Je sais, au contraire, que mes désirs d'habitude sont bien à moi, d'autant plus à moi qu'ils sont plus enracinés, plus habituels, plus irrésistibles ; et, quand je cède à l'une de ces contraintes intérieures, non moins puissantes parfois que la précédente, je sens que ma décision forcée est tout à fait mienne, d'autant plus mienne qu'elle a été plus forcée. C'est le cas du criminel de race et de profession. Si la responsabilité est fondée sur le libre arbitre, il n'y a plus lieu de faire cette distinction; interne ou externe, la force déterminante a entraîné irrésistiblement la volonté ; il n'en faut pas davantage pour disculper moralement les plus dangereux et les plus féroces malfaiteurs. On voit déjà, par ce contraste des deux solutions, que la substitution de l'identité à la liberté comme fondement de la morale n'est pas une simple question de mot, une transposition insignifiante. On gagne à ce changement un accroissement de clarté, de précision, de solidité, de justice.

Le plus haut point de la responsabilité-liberté semble attaché à l'état d'une personne qui n'est pas faite encore, mais qui se fait, dont tous les éléments, désirs et croyances, en voie de formation et d'agrégation, en état d'équilibre instable, non rattachés entre eux, non enchaînés dans un système de coopération et de mutuelle assistance, laissent à l'hypothèse du fiat créateur un champ d'opération apparente d'autant plus vaste. Les criminels les plus coupables, ce seraient les adolescents; les moins coupables, ce seraient les récidivistes, les grognards du crime ou du délit. Mais le zénith, l'apogée de la responsabilité-identité, c'est au contraire l'âge où se réalise la 
perfection du système intérieur, la stabilité de son équilibre par la prépondérante définitive d'une idée ou d'une passion autour de laquelle tout gravite dans l'âme et qui trouve, hors de l'âme, dans un milieu social conforme ou conformé à ses fins, une occasion de se déployer. On est d'autant plus coupable à ce point de vue, qu'on est plus adapté à soi-même et à son milieu (ce second côté de la question sera examiné tout à l'heure), c'est-à-dire qu'on est plus mûr et plus vraiment soi. On l'est d'autant moins qu'on est moins formé à raison de sa jeunesse, ou plus déformé et plus déséquilibré à raison de son aliénation mentale. Entre les deux extrêmes de l'équilibre complet et de la complète déséquilibration, s'interpose une échelle immense de degrés traversés par chacun de nous dans sa longue période de croissance et de décroissance. Notre personne, en effet, est une harmonie qui se fait ou se défait sans cesse par une suite continuelle de duels intérieurs entre des opinions contradictoires ou des penchants incompatibles. Elle se fait par ces conflits, quand ils se terminent par la victoire de l'opinion ou de la tendance la plus propre à fortifier notre accord avec nous-mêmes et avec notre milieu; elle se défait par ces mêmes luttes, quand l'issue en est inverse. Mais, dans les deux cas, si les deux adversaires à la fois sont nôtres, quoique inégalement nôtres, il y a lieu de porter sur notre décision, - fatale, n'importe, - un jugement de réprobation ou d'approbation morale. Un jeune voleur, surpris la nuit en flagrant délit par un témoin, hésite à le tuer, combattu entre le désir d'éviter le châtiment, d'emporter son butin, et sa répugnance à verser le sang. Quel que soit son choix, sa détermination sera bien à lui, et, comme telle, très coupable dans un cas, quelque peu méritoire dans l'autre.

C'est une erreur de regarder la personne comme simplement spectatrice des combats qui se livrent en elle et qui sont elle; le déterminisme ne dit point cela, on le lui fait dire à tort; il permet de penser, on vient de le voir, qu'elle est actrice dans ses guerres civiles ou ses discussions intestines, animant les deux parties ensemble à poursuivre le rétablissement et la consolidation de son équilibre rompu. Mais, quand un despote ou un bourreau violente ma volonté, c'est alors une guerre extérieure qui s'engage entre lui et moi ; si je lui résiste, ma décision est mienne ; elle ne l'est pas si je lui cède de force, elle appartient à ce tortionnaire comme l'acte de la somnambule à son hypnotiseur. Ici s'élève, à la vérité, la question de savoir si j'ai pu 
résister, mais cela ne veut pas dire si j'ai été libre. Cela veut dire si mon énergie disponible de volonté, au cas où il m'aurait plu de faire donner pour ainsi dire ma vieille garde de courage, était ou non à la hauteur des circonstances. C'est là une question de fait, difficile d'ailleurs à trancher; mais, s'il est prouvé que j'étais plus courageux par nature, qu'il n'eût fallu l'être pour faire front à la coercition du dehors, je dois être jugé coupable d'avoir cédé, car je donne lieu de penser que j'ai pactisé avec mon ennemi, que j'ai été bien aise d'être contraint, pareil à ces dames du temps de Brantôme qui, dans une ville prise d'assaut, se réjouissaient intérieurement d'être violées, parce qu'elles pouvaient pécher alors en sûreté de conscience. Jusqu'à quel point étaient-elles coupables d'être « victimes » de pareils viols ? Elles l'étaient, évidemment, d'autant plus que la violence était moindre et leur courage naturel plus grand. Leur degré de liberté supposée n'entre pour rien dans cette appréciation.

À ce point de vue, s'évanouissent mille difficultés qui ont paru presque insolubles aux théoriciens du libre arbitre, celles que présente, par exemple, la responsabilité des hypnotisés. L'âme de ces rêveurs est comme un champ de bataille où la lutte a brusquement cessé par le sommeil de tous les combattants, à l'exception d'un seul, au gré de l'hypnotiseur qui dispose ainsi de la victoire. L'âme mutilée à ce point, dépouillée de son domaine presque tout entier, n'est plus elle-même, et ses actes, si libre qu'elle se sente, - car elle se sent libre, exactement comme nous, - sont les actes de l'hypnotiseur. Encore faut-il remarquer que, même dans l'assoupissement le plus profond de nos autres facultés, notre caractère moral, ce que nous avons de plus intime en nous, veille encore d'ordinaire ; et il est fort rare qu'un acte immoral, commandé à une somnambule honnête, soit accompli. Si cependant, par exception, - chose admissible en théorie, non encore démontrée en fait d'une manière indiscutable, - un crime était commis par suite d'une suggestion hypnotique, il y aurait lieu à l'acquittement de l'agent, à la condamnation de l'inspirateur. M'objectera-t-on que, s'il en est ainsi, et si, au fond, tous les mobiles auxquels nous cédons dans notre vie normale sont le résumé d'influences multiples reçues de divers côtés dans notre passé, et condensées en nous, sortes de suggestions enchevêtrées, nous ne sommes dès lors jamais responsables? Mais ce serait oublier la distinction capitale du mien et du non mien. Dans l'âme passive et crédule de l'enfant, de l'adolescent 
un peu moins, du jeune homme moins encore, toute parole paternelle ou magistrale, tout exemple du dehors, a quelque chose de suggestif, je le veux ; mais si, à sa première apparition, chaque besoin nouvellement importé y a eu l'air exotique et dépaysé parmi les autres, il acquérait, à mesure qu'il s'y acclimatait avec les autres et s'y naturalisait, des droits à en être réputé partie intégrante. Suggéré d'abord, puis identifié de mieux en mieux au moi, il est entré ainsi dans le cercle ou plutôt dans les cercles concentriques de la personne, et a, par suite, de plus en plus engagé la responsabilité de celle-ci.

On peut me faire d'autres objections. On peut me dire : si nous devons être jugés coupables de certains de nos désirs, traduits en actes, par cela seul qu'ils nous sont propres, et d'autant plus coupables que ces désirs nous sont plus profondément, plus anciennement inhérents, pourquoi ne serions-nous pas jugés coupables aussi de nos croyances personnelles, traduites en discours, et d'autant plus qu'il s'agirait de convictions plus anciennes et plus fortes ? L'objection n'est pas seulement spécieuse, elle est sérieuse à quelques égards. Mais, avant toute réponse, les doctrinaires du libre arbitre devront se garder d'en triompher, s'ils veulent bien se souvenir que les délits et les crimes d'opinion sont vieux comme le monde, que la ciguë chez les Grecs, les bûchers au moyen-âge, les massacres en masse au XVIe siècle, les septembrisades ou l'échafaud il y a cent ans, en tout temps les spoliations, les destitutions et les calomnies, ont été les pénalités réservées à ce forfait inexpiable d'avoir un credo à soi, contraire au credo général. Une telle unanimité séculaire à proclamer coupables tous ces hérétiques politiques ou religieux, qu'on avouait pourtant n'avoir pas été libres d'ordinaire d'adopter d'autres croyances, n'estelle pas la preuve manifeste que l'idée de la responsabilité-liberté est une notion d'école, étrangère au sentiment instinctif du genre humain ? En revanche, nous avons le droit d'invoquer ici à notre point de vue ce fait certain que, lorsque l'hétérodoxie dont il s'agit a paru être l'effet momentané d'un accès d'ivresse ou de folie, d'un démon tentateur, en un mot, d'une cause extérieure à la personne, jamais elle n'a été sérieusement incriminée. - Il n'en est pas moins vrai que l'incrimination de croyances sincères et de leur expression précise est une aberration ; mais pourquoi ? Pourquoi est-il permis tout au plus à une société de bannir parfois, à raison du trouble qu'ils lui causent, les apôtres de certaines idées dissolvantes on dissonantes, mais jamais de 
les flétrir, ni même de les blâmer ? Pourquoi serait-ce une criante injustice de réprimer par les mêmes procédés l'expression d'une foi dangereuse et la réalisation d'un désir mauvais, alors même que l'une serait aussi préjudiciable que l'autre à l'intérêt général ? Ce n'est pas à la doctrine du libre arbitre qu'il faut demander de répondre, car elle convient que les désirs ne sont pas moins nécessités que les croyances. Ce n'est pas à la doctrine utilitaire non plus ; car des actes également nuisibles sont pareillement répressibles à ses yeux. Mais, à nos yeux, cette distinction se justifie par plusieurs motifs. D'abord, nos opinions sont la surface mouvante, nos passions le fond stable de notre être ; celles-ci nous caractérisent bien plus essentiellement que celles-là ; aussi l'ensemble de nos penchants a-t-il été fort bien nommé« notre caractère. » On appelle erreur, dans un milieu donné, le nonconformisme des opinions; perversité, le non-conformisme des passions. Or, l'erreur et la perversité ont beau être nécessitées l'une et l'autre, il y a cette différence entre les deux, que la seconde, corruption de la volonté, nous est inhérente à fond, et que la première, viciation de l'intelligence, tient surtout à des influences extérieures.

Mais, en second lieu, il est bon de se souvenir que la responsabilité morale, dans notre manière de voir, suppose, avec la personne identique à soi-même, la personne semblable à son milieu, dans une mesure plus ou moins large. C'est une condition secondaire, mais nécessaire et dont nous parlerons bientôt. Le concours des deux est exigé ; ainsi nous replaçons le problème dans la complexité du réel, et, au lieu d'envisager scolastiquement l'acte en lui-même, abstrait de l'agent et du milieu, nous nous efforçons de rattacher intimement l'acte à l'agent, l'agent à son milieu, inséparables dans une théorie vraie, puisqu'ils le sont en fait. Eh bien, à cet égard, il faut remarquer que l'assimilation imitative, contagieuse d'homme à homme, dans une société, envahit souvent l'esprit avant d'avoir pénétré au cœur. Le malfaiteur et l'homme vicieux ont opposé une résistance invincible à la contagion de l'honnêteté relative qui les entoure, mais ils n'en partagent pas moins les idées régnantes, et, en particulier, les jugements ambiants sur la moralité ou l'immoralité des actions. En faisant le mal, donc, ils sont forcés de se condamner eux-mêmes, ou bien ils ont commencé par là avant qu'une longue accoutumance du crime ou du vice ait étouffé en eux tout sens moral. Rien de semblable chez les dissidents intellectuels ; ceux-ci jugent vrai ce qu'ils croient, 
tandis que les autres jugent mauvais ce qu'ils font. Il n'y a donc pas à les confondre. Je conviens qu'il est irrationnel de s'indigner contre un sectaire, contre un délinquant politique, qui commet de bonne foi, en croyant faire une action louable, un acte qualifié crime par la loi, comme il est irrationnel de s'irriter contre quelqu'un qui se trompe de bonne foi. Mais il est rationnel de s'indigner contre un malfaiteur comme de s'irriter contre un menteur, soit qu'il mente à autrui ou qu'il se mente à lui-même en se faisant suggérer par son propre cœur des croyances de complaisance adaptées à sa justification. Dans une certaine mesure, en effet, - comme les théologiens n'ont pas manqué d'en faire la remarque, - on croit parce qu'on veut croire ; et, dans cette même mesure, on peut être réputé blâmable de ses erreurs intéressées.

Ainsi entendue, la question de la responsabilité morale, ce nous semble, s'élucide et se complique à la fois. Elle est plus claire, parce que les notions qui lui servent de fondement le sont aussi. Elle est plus complexe, puisqu'elle a trait non à une abstraction, à un acte pris à part, soustrait à toute son atmosphère intérieure ou externe, mais à une réalité concrète et vivante. Il s'agit d'une responsabilité relative et variable qui ne méconnaît pas la solidarité de toute une existence dans le crime d'un instant, ni la demi-complicité de tous dans le crime d'un seul. Étant réelle, elle comporte des degrés sans nombre. La responsabilité fondée sur le libre arbitre, au contraire, si l'on veut être logique, n'en comporte pas. On est bien, il est vrai, plus ou moins fort; mais la force qu'on a ne peut pas être plus ou moins non déterminée en agissant. Elle l'est ou elle ne l'est pas ; il n'y a pas de milieu. Si l'on peut être dit plus ou moins libre en un sens, cela signifie que le champ de manœuvre de l'indétermination, le nombre d'actes où elle peut s'exercer, s'élargit ou se resserre ; mais, relativement à un acte donné, elle est tout entière ou elle n'est point. Ce n'est point là le caractère d'une réalité.

Mais revenons à la notion de l'identité personnelle. En résumé, pour que mon acte me soit imputable, la première condition est qu'il appartienne à ma propre personne; ce n'est pas le cas des actes produits sous le coup de ces «maladies de la volonté et de la personnalité » Si bien étudiées par M. Ribot, quand une sorte d'âme parasite, qui traverse et trouble comme une comète mon ciel intérieur, 
périodique et réglé, vient rompre l'unité de son système ${ }^{1}$. Mais il ne suffit pas que mon acte émane de ma personne même, il faut aussi qu'il émane de ma personne restée la même au fond, depuis l'heure de son accomplissement. Car si ma personne avait changé, soit par le réveil d'un accès d'alcoolisme, soit par la guérison ou l'évolution même de ma folie, aliénation en voie d'altération continuelle, soit enfin par ma conversion morale, souvent possible en dépit de Schopenhauer et de nos naturalistes, je ne pourrais plus être réputé coupable de ce qui aurait cessé de m'appartenir. La persistance du souvenir de l'acte chez son auteur importe, mais importe moins que la persistance du caractère de l'agent. Je puis attribuer à mon passé une faute dont je me souviens, mais non à mon présent, si je ne suis plus capable de la commettre. Inversement, supposons un homme, qui, immédiatement après avoir commis un crime de sang-froid et sans nulle impulsion morbide, en aurait perdu tout souvenir. A supposer que cette amnésie totale fût possible et pût être démontrée, serait-il à bon droit jugé coupable de ce meurtre ou de ce viol dont il semble qu'il se soit dessaisi en quelque sorte par le bénéfice de son oubli ? Oui, sans nul doute, et je verrais même dans la profondeur de cet oubli l'indice d'une nature foncièrement criminelle, trop habituée à faire le mal pour y prendre garde.

Il est vrai que, comme la liberté, l'identité personnelle a trouvé des contradicteurs, mais infiniment moins nombreux et moins sérieux. Elle n'en eût jamais compté un seul, si ces deux idées n'avaient paru à plusieurs liées ensemble. Le discrédit de l'une a quelque peu rejailli sur l'autre. Elles n'en sont pas moins absolument distinctes, et leur liaison tient simplement à ce que l'identité est la réalité intime dont le sentiment nous suggère l'illusion de la liberté. Le moi, en effet, est porté à se sentir plus immuable qu'il ne l'est réellement. Identité, après tout, signifie toujours changement, mais changement négligeable, comme repos veut dire, en mécanique, mouvement négligeable, à

Les naturalistes, trop préoccupés des caractères anatomiques et physiologiques, pas assez des caractères psychologiques, se refusent à croire que la personne puisse changer. Le sujet n'a-til pas conservé les mêmes traits, le même corps ? Mais les moindres nuances psychologiques, pour peu qu'elles se répètent et se fortifient, ont plus d'importance véritable que les différences les plus saillantes des organismes vivants. Il y a des transformismes moraux plus certains que la transformation des espèces; il y a plus loin souvent d'une personne à soi même, après une lésion ou une maladie cérébrale, ou après une conversion, qu'il n'y a loin d'une espèce à une autre espèce vivante. 
raison de sa lenteur ou de sa nature étrangère au problème. Le moi ne fait pas assez cette distinction. Il n'a pas conscience d'avoir changé moralement, il ne prévoit pas devoir moralement changer ${ }^{1}$, il croit en général avoir toujours été et devoir toujours demeurer, comme caractère, identiquement ce qu'il est; et comme il s'étonne, malgré cette identité absolue, d'avoir dans de nombreuses occasions agi autrement qu'il n'agirait dans le présent, il en conclut que, à côté de ses décisions passées, seules effectuées, coexistaient ses décisions actuelles à l'état virtuel. La contre-épreuve de cette explication nous est fournie par le contraste de notre conscience intellectuelle avec notre conscience morale, à cet égard. Quand nous nous rappelons nos opinions passées, même contraires à nos opinions présentes, nous n'avons jamais l'illusion de croire que nous aurions pu librement avoir des opinions différentes. Nous ne nous croyons pas assurés non plus d'affirmer toujours ce que nous affirmons aujourd'hui. Pourquoi ? Parce que nous avons conscience de nos changements intellectuels, surface de notre esprit, bien plus que de nos changements moraux, fond de notre être. Voilà pourquoi nous avons l'idée de notre libre arbitre moral, non de notre liberté arbitre intellectuel; étrangeté frappante qui me paraît valoir la peine d'être remarquée. L'un pourtant n'est ni plus ni moins soutenable que l'autre, et, de fait, la logique a conduit $\mathrm{M}$. Renouvier et ses disciples à admettre que le jugement luimême, "la certitude, » est «un état psychique résultat d'un acte libre. »

Un sentiment qui ne nous trompe pas, qui nous traduit exactement notre permanence à la fois et notre transformation commencée, hâtée

\footnotetext{
Nos amis et nos connaissances s'aperçoivent bien mieux que nous de ces changements, qu'ils reconnaissent à des signes certains. Le déchiffrement de ces signes et leur lecture aisée sont l'art de l'aliéniste. C'est à lui qu'il conviendrait de demander la solution du problème relatif à l'identité personnelle de l'accusé et à son degré, au lieu de lui demander si et jusqu'à quel point l'accusé a été libre ; car c'est cela qu'on entend à présent encore en lui demandant si et jusqu'à quel point l'accusé est responsable moralement. Chose remarquable à cette question de responsabilité ainsi posée et comprise, l'expert judiciaire, tout déterministe qu'il est le plus souvent, répond toujours ; et comme on ne peut avoir l'irrévérence de penser qu'il parle pour ne rien dire, il faut bien admettre qu'il fait reposer ou à son insu la responsabilité morale sur une autre considération que celle du libre arbitre auquel il ne croit point. Ne seraitce point la considération de l'identité ? - Je ne me fais pas illusion, d'ailleurs, sur les difficultés inhérentes, dans bien des cas, à l'appréciation de l'identité personnelle. Mais l'identité corporelle même est-elle toujours facile à constater ? Etait il aisé d'identifier les restes mutilée de Gouffé, comme est parvenu à le faire le docteur Lacassagne?
} 
par lui, c'est le sentiment de la honte et du remords au souvenir de nos actes mauvais. Et si la honte et le remords, qui sont le blâme et l'indignation dirigés contre soi-même, sont justifiés, le blâme et l'indignation, honte et remords extérieurs exprimés par le châtiment, seront rendus aussi légitimes. La peine alors pourra être considérée comme l'équivalent du repentir. Le repentir est la peine intérieure du coupable qui se condamne lui-même; la peine est le remords imposé du dehors au coupable condamné par autrui. L'un est requis à défaut de l'autre. Quand il se trouve un criminel qui se repent à fond, qui souffre intérieurement et est bien aise de souffrir à cause, de sa faute, on devrait ne pas le punir si l'abus d'un tel précédent n'était à craindre. Or, qu'est-ce que le remords ? C'est la douleur sui generis que j'éprouve à reconnaître, en songeant à une faute de mon passé, que mon moi actuel est la continuation de mon moi antérieur, malgré la différence sentie des deux. Cette souffrance m'atteste, en même temps que ces deux personnes sont la même personne et qu'elles sont différentes ; ce qui est le mystère habituel et courant des choses. Elle accompagne l'effort par lequel j'expulse ou je tâche d'expulser de mon domaine actuel, de mon mien présent, ce souvenir poignant, pour éviter toute rechute ultérieure. Mais en quoi ce désir d'expulsion, d'épuration personnelle, pourrait-il être supprimé ou même diminué par la croyance au déterminisme intérieur? Loin de là, je rougis d'autant plus de mon acte passé, que je me crois plus sûr, si une tentative pareille se présente, de n'y pas retomber, conviction qui est la négation de ma liberté dans l'avenir. De même, plus nous sommes convaincus qu'un de nos ennemis, à raison de sa haine et de sa méchanceté, n'a pas pu ne pas nous faire volontairement le mal qu'il nous a fait, et plus nous nous sentons indignés contre lui. Au surplus, les positivistes italiens qui, sous prétexte qu'ils sont déterministes, nient le devoir et la culpabilité, contestent le droit à l'indignation et à la réprobation, de quel droit admettent-ils la légitimité de la reconnaissance et recommandent-ils la pitié ? Si le soulèvement des cœurs contre un assassin est irrationnel, pourquoi l'explosion de la reconnaissance publique envers un grand bienfaiteur, ou de l'admiration générale pour un homme de génie, le serait-elle moins ? Qu'est-ce que ce scrupule de flétrir un voleur ou un meurtrier et à plus forte raison de prononcer le mot rebattu de vindicte publique, chez certains publicistes qui, dans leurs polémiques, dans leurs vendettas 
de plumes acharnées s'échauffent si fort? Ne serait-il licite de s'indigner que contre les honnêtes gens?

\section{III}

$\underline{\text { Retour à la table des matières }}$

Une autre condition, ai-je dit plus haut, est exigée pour que l'indignation dont il s'agit soit naturelle et justifie la pénalité où elle s'exprime : il faut que l'auteur d'un acte volontairement nuisible à autrui ait en commun avec sa victime et ses accusateurs des traits de ressemblance sociale assez nombreux et assez frappants pour créer entre eux et lui et leur faire sentir une sorte de consanguinité sociale plus ou moins étroite. Plus elle sera étroite et sentie comme telle (deux choses distinctes, mais équivalentes), et plus, son acte restant le même, sa culpabilité croîtra. Au point d'assimilation fraternelle où les peuples éclairés de la terre sont parvenus de nos jours, grâce à l'héritage d'une même civilisation romano-chrétienne, grâce à l'échange belliqueux ou pacifique des idées, des mœurs, des industries, des arts, à l'agrandissement des états et à leurs relations multipliées, l'horizon moral des meilleurs d'entre nous et des plus cultivés s'est prodigieusement élargi. Nous avons peine à nous persuader qu'il fut des temps où le plus honnête homme regardait le meurtre et le pillage de l'étranger comme un acte de chasse. Nous sommes enclins à juger inné notre cosmopolitisme de conscience parce que nous oublions les étapes séculaires de sa formation, l'un des progrès historiques les plus réguliers et les plus remarquables. Pourtant, même aujourd'hui, un Anglais instruit qui a tué un nègre africain pour se donner le plaisir de photographier une scène de cannibalisme, se sent-il coupable et doit-il être jugé coupable au même degré que s'il avait traité de la sorte un de ses compatriotes ? Non, assurément. Les plus honnêtes Chinois croient licites contre un Français, et les plus honnêtes Français contre un Chinois, bien des choses qu'ils se reprocheraient de tenter contre un des leurs. Mais cette inégalité de culpabilité sentie et réelle qui tient à la différence des civilisations diminue à mesure que l'une de ces civilisations emprunte 
davantage à l'autre, ou, ce qui revient au même, à mesure que ces deux peuples se connaissant mieux, apprennent à sentir mieux leurs ressemblances préexistantes sous mille rapports. Contre les indigènes d'une île nouvellement découverte ${ }^{1}$, il n'est pas de traitement barbare que les voyageurs ne se soient permis sans scrupule et réciproquement; jusqu'au moment où ils se sont reconnus jusqu'à un certain point semblables, socialement semblables, et, comme tels, frères en humanité. Quels sont ceux parmi nous dont la responsabilité morale s'étend à l'humanité tout entière, et embrasse parfois l'animalité dans son large cercle? quels sont ceux qui s'infligent à eux-mêmes ou méritent de la part d'autrui un blâme sévère quand ils font souffrir sans nécessité un animal, domestique ou même sauvage ? Ce sont les savants qui ont poussé l'étude des êtres vivants assez loin pour sentir la profondeur de leurs similitudes, et non seulement de leur parenté, mais de leur solidarité presque sociale dans cette grande fédération qu'on appelle la faune terrestre ${ }^{2}$.

Que de guerres, de conquêtes, d'annexions violentes et assimilatrices, il a fallu pour en venir là ! Mais surtout quelle action lente et ininterrompue de l'imitation internationale ou intranationale, sous tous les rapports! Plus haut nous remontons dans le passé et plus nous voyons se rétrécir le champ moral de nos pères, la limite au-delà de laquelle ils ne reconnaissaient en fait ni devoirs ni droits, quelles que fussent leurs maximes verbales. Au moyen âge, cette extrême limite n'excédait guère la chrétienté, immense domaine déjà; sous les empereurs romains, la romanité (romanitas de Tertullien), territoire un peu plus restreint; au siècle d'Alexandre, la Grèce et une faible partie de l'Asie par lui conquise; au temps d'Épaminondas, le petit monde hellénique ; avant lui, la petite sphère athénienne pour l'un, spartiate pour l'autre, béotienne pour un troisième. Et auparavant, en un temps dont parle Thucydide, époque de brigandage réciproque entre cités voisines et entre bourgs voisins, de piraterie réciproque entre îles rapprochées, chacun blottissait pour ainsi dire sa conscience en son petit endroit, limitant toute l'humanité reconnue par lui aux remparts de son nid d'aigle, à la palissade de sa tribu ou de sa famille. En outre,

Ou d'une portion de l'Afrique tout récemment explorée.

2 Mais le lama hindou qui tue une fourmi est plus coupable encore, car il croit frapper en elle une âme humaine et indienne transfigurée. 
et en même temps que s'accomplissait, de la famille primitive à nous, le développement graduel et extraordinaire de la responsabilité morale en surface, elle se développait en profondeur, supprimant les barrières des classes, des professions, des sexes, ajoutant par exemple, au champ de la conscience grecque, l'esclave ou la femme hellènes après le barbare asiatique. Il est clair, d'ailleurs, que, appliquée à ces groupes d'hommes de plus en plus nombreux et divers, elle devait se compliquer pour s'adapter à des relations humaines plus diversifiées. En s'élargissant donc, la morale s'enrichissait par force comme la législation ${ }^{1}$.

C'est pour n'avoir pas eu égard à cette marche envahissante de l'imitation, et à cette extension parallèle du sentiment de la fraternité sociale et morale, que les criminalistes des écoles nouvelles ont trop exclusivement fait dériver la pénalité de la vengeance. La justice pénale se rattache en partie aux vendettas des primitifs, c'est certain, et elle retient certaines traces de cette origine; mais elle a aussi une autre source plus profonde et plus pure que les considérations précédentes nous font toucher du doigt. Il en résulte, en effet, que, si l'évolution historique a étendu et ne cesse d'étendre le domaine où s'exercent le remords et la réprobation, elle n'a pas créé ces sentiments. Avant qu'elle les eût pour ainsi dire délayés sur le monde entier, ils se concentraient avec intensité dans leur berceau familial ; ils se resserraient et se cachaient là, où nos yeux, à une telle distance de nous, ne peuvent plus malheureusement les bien distinguer, si ce n'est par induction, quand un voyageur par hasard, plus observateur et

Remarquons que deux transformations inverses, dont l'idée de culpabilité à chaque moment est la résultante, s'opèrent à la fois ; pendant que la similitude sociale sentie va s'élargissant sans cesse, au point d'embrasser déjà l'humanité tout entière et même l'animalité domestique et supérieure, l'autre condition de la responsabilité, l'identité personnelle, va se resserrant, grâce aux découvertes de la médecine mentale. Supposez ces deux changements parallèles poussés à bout ; le champ de la culpabilité se sera singulièrement agrandi d'un côté, rétréci de l'autre ; nous serons jugés irresponsables (comme plus ou moins aliénés ou déséquilibrés ou dégénérés héréditaires, etc.) de beaucoup de crimes, parricides même et fratricides, dont nous aurions été jugée coupables jadis ; mais nous serions jugés coupables d'une foule de crimes qui, commis au préjudice d'étrangers, nous auraient mérité l'absolution de nos pères ou de nos lointains aïeux. - Est-ce à dire pourtant qu'il viendra un moment où par le fait même que la similitude sociale sera universellement sentie, la considération de cette seconde condition de la responsabilité cessera de jouer un rôle quelconque dans le jugement moral? Non, car toujours on sera tenu envers son prochain, envers son compatriote le plus rapproché à des égards et à des devoirs spéciaux. Une théorie complète de la responsabilité morale exige donc et exigera toujours la synthèse des deux conditions indiquées. 
plus sagace que les autres, après un long séjour dans une tribu de sauvages réputés féroces, s'étonne d'y découvrir, dans les bornes étroites de leurs rapports mutuels, des notions et des émotions morales d'une énergie non soupçonnée. Pourquoi nous en étonner du reste, quand l'observation nous montre que les éléments dont ces idées et ces sentiments sont la combinaison, c'est-à-dire la bonté naturelle, l'attachement affectueux aux siens, le chagrin après leur avoir fait du mal, se montrent même dans les espèces ${ }^{1}$ animales tant soit peu sociables ? Or, s'il en est ainsi, est-ce que primitivement, lorsqu'on était victime d'une offense ou d'un préjudice volontaire causé par autrui, on a dû et pu réagir de la même manière, soit que l'auteur appartint, soit qu'il fût étranger à la tribu dont on était membre ? Évidemment non. La différence, alors radicale, des deux cas, devrait être nécessairement marquée dans la nature de la réaction consécutive. Quand on avait à sévir contre un agresseur étranger pour empêcher le retour de son agression, on exerçait une vengeance pure et simple. Il y avait alors colère, irritation, alarme d'amours-propres et d'intérêts, mais indignation, non. C'est seulement à l'occasion des délits commis dans l'intérieur de la tribu, des fratricides, des querelles intestines, que le sentiment du repentir d'une part, de la réprobation indignée de l'autre, avait lieu d'éclater; et l'autorité du père justicier ou du prêtre sacrificateur intervenait toujours pour arrêter les représailles en leur substituant une peine proprement dite, infamante ou expiatoire, signe public de l'indignation publique ou purification de la souillure spirituelle. Car la distinction du pur et de l'impur appliquée à l'âme est très énergique chez les primitifs autant que la même distinction entendue au sens corporel l'est peu, ce qui serait inexplicable dans l'hypothèse de leur immoralité prétendue; et l'impureté du cœur, mal comprise je le veux, mais vigoureusement sentie, expression figurée de leur contrition, leur répugne aussi fort que la saleté physique leur

\footnotetext{
Voir Espinas, Sociétés animales, passim. -Voir aussi la Politique positiviste d'Auguste Comte. Darwin, dans sa Descendance de l'homme (t. I, p. 78 et suiv.), cite aussi beaucoup de traits qui prouvent les sentiments affectueux des animaux sociables les uns pour les autres. Mais il fait de vains efforts pour expliquer par la concurrence vitale et la sélection naturelle l'apparition de ces sentiments. La sélection n'a pu fonctionner, en tout cas, qu'à partir du moment où, au milieu d'une espèce composée, par hypothèse, d'individus absolument égoïstes jusque-là, aurait apparu cette bien étrange variation individuelle, un individu prenant plaisir au plaisir d'un autre. Et je me demande en quoi cette étrangeté lui aura servi personnellement. Il me semble plutôt que, par la sélection naturelle, on rend compte des exceptions si nombreuses à l'instinct de sympathie, telles que celles qui sont relatées p. 80 du même volume.
} 
est indifférente. L'inverse se remarque chez beaucoup de civilisés. Pour expliquer les trésors du temple de Delphes, on disait en Grèce, dès la plus haute antiquité, que les loups y avaient apporté l'or, «car on comprenait sous ce nom, nous dit Curtius ${ }^{1}$, les hommes inquiets, errants, souillés de meurtres, qui, par l'entremise des prêtres, avaient recouvré la paix de l'âme et le droit de vivre avec leurs semblables "), c'est-à-dire avec le groupe étroit de leurs concitoyens. Cette préoccupation pénitentiaire est si grande parmi les populations sauvages que, chez elles, toute souffrance, toute maladie, toute infortune est souvent considérée comme le châtiment d'une faute inconnue commise depuis la naissance ou dans une vie antérieure.

Mais je m'aperçois que je me heurte ici à une erreur des plus accréditées et qui m'oblige à quelques mots d'explication. On lit partout, partout on répète, même en dehors de l'école d'anthropologie criminelle, que la vengeance et le talion sont la source primitive, unique, de la justice pénale, qu'à 1'origine, crime signifiait préjudice matériel purement et simplement, que châtiment voulait dire coup rendu, et qu'il n'y avait nulle trace d'un sentiment moral en tout cela. A première vue, cette thèse s'appuie sur les documents, les observations, les inductions les plus multiples ; un coup d'œil jeté sur l'Évolution juridique de M. Letourneau, par exemple, pourra suffire à s'en rendre compte. Mais, si l'on regarde de près, on s'aperçoit de la profonde méprise où l'on est tombé ici, par suite d'un étrange oubli. On n'a pas pris garde que tous les crimes dont s'occupent les législations anciennes ou les coutumes juridiques des barbares sont des crimes commis de tribu à tribu, de clan à clan, de famille à famille, c'est-àdire contre une personne étrangère au groupe social du malfaiteur. Si les lois primitives ne traitent pas des crimes intérieurs de la tribu, du clan, de la famille, c'est que ceux-ci étaient souverainement frappés par le chef de ce petit État, aussi clos alors et impénétrable en soi que les monades de Leibniz. Nous savons cependant, à n'en pas douter, qu'il existait, dans chacun de ces groupes fermés, un tribunal domestique, comme il en existe encore chez les Ossètes du Caucase, cette peuplade où le droit primitif semble s'être perpétué au cœur des montagnes pour le bonheur des juristes archéologues. Des tribunaux pareils, des cours d'assises familiales, existent aussi en Chine, ce pays

Histoire de la Grèce, t. Il. 
des séculaires survivances; et on les découvre en tout pays inculte où l'on prend la peine de les rechercher.

Or, M. Dareste, dans son magistral ouvrage, récemment paru, sur l'Histoire du Droit, observe avec raison que l'existence de cette justice paternelle a été trop souvent, trop complètement passée sous silence, et que cette omission a eu des conséquences fâcheuses, par exemple celle de rendre inexplicable la prétendue impunité du parricide au temps de Dracon. Si le sévère législateur athénien n'a rien dit de ce crime, est-ce, comme on l'a naïvement pensé, parce qu'il n'admettait pas sa possibilité ? Non, c'est que « le parricide était un crime commis dans l'intérieur de la famille et qui, par conséquent, ne pouvait donner ouverture de la vengeance. La seule peine possible était l'excommunication et l'exil. La plupart des lois barbares gardent le même silence que la loi athénienne, et apparemment par la même raison ${ }^{1}$. " Ainsi, point de vengeance, point de talion en ce qui concerne les délits intrafamiliaux; en revanche, une peine flétrissante, déshonorante; caractère que n'a pas le talion vindicatif à la suite des crimes extérieurs. Le meurtrier tué par vendetta de la tribu offensée n'est pas déshonoré par cette exécution ; jamais ses fils n'en ont rougi, comme, parmi nous, les fils d'un guillotiné. - Mais je ne veux pas insister sur ces considérations, qui demanderaient à être développées si elles ne nous éloignaient de notre sujet. Un dernier mot cependant. Par un côté essentiel, la criminalité externe, même aux temps les plus primitifs, ressemble à la criminalité interne. Dans l'une comme dans l'autre, le crime est une brouille, soit entre deux familles, soit entre deux parents d'une même famille ; et la peine, vengeance dans un cas, châtiment flétrissant dans l'autre, a toujours pour but d'aboutir à la réconciliation soit des deux familles (ou des deux clans, ou des deux tribus), soit des deux parents. Je vous ai tué un parent, vous m'en avez tué un; je vous ai volé un bœuf, vous m'avez volé une vache; nous sommes quittes. Cela est si vrai que le couronnement d'une procédure criminelle, chez les Ossètes, c'est un festin de réconciliation, cérémonie pénale très singulière à nos yeux sans doute, mais qui n'en est pas moins

Il me sera permis d'exprimer le plaisir que j'ai eu à voir une autorité telle que celle de M. Dareste prendre en passant cette idée sous son patronage. Je l'avais indiquée aussi dans les Archives d'anthropologie criminelle de M. Lacassagne, n• du 17 mai 1889. J'y faisais remarquer que, chez les primitifs, il y a deux peines toujours, comme il y a toujours deux prix des mêmes articles, l'un pour le compatriote, l'autre (excessif et arbitraire) pour l'étranger. 
pratiquée chez beaucoup d'autres peuples non civilisés. Il s'agit là de deux familles qui se réconcilient. Mais, à plus forte raison, nous devons être certains que, lorsqu'un membre de la famille avait subi la peine infligée par le père, - excommunication temporaire, coups de bambou comme en Chine, etc., - il y avait un festin de réconciliation aussi. La différence était que, dans le premier cas, le repas solennel était une sorte de dîner de gala diplomatique, qui met fin à la rupture de relations officielles entre deux États, tandis que dans le second cas, la Cène devait avoir un tout autre caractère, et bien plus touchant; et, si les documents législatifs ne nous disent rien à cet égard, c'est que, précisément à cause de leur nature intime, de tels spectacles sont interdits au regard de l'observateur étranger. - Le malheur de notre pénalité, à nous, est que jamais il ne vient un moment où le condamné ayant subi sa peine est reçu dans les bras de la société qu'il a offensée, et s'entend dire solennellement: Ta faute est effacée, reviens parmi nous ! Nous avons bien une procédure de réhabilitation, mais combien froide et paperassière ! Il faut avoir été membre d'un Parquet pour le savoir. Quel est parmi nous le pendant du festin de réconciliation usité chez les pauvres montagnards du Caucase? Serions-nous plus barbares que ces barbares? Et nous nous persuaderions après cela, que c'est nous qui avons inventé le sentiment moral, le repentir et le pardon!

Le remords et la réprobation, donc, en ce qui concerne les attentats intérieurs de la tribu ou de la cité, - l'acte de vengeance en ce qui concerne les attaques de tribu à tribu, ont été le point de départ de deux évolutions qui se sont côtoyées assez longtemps et ont influé l'une sur l'autre, mais qui ont fini par diverger complètement. De l'un de ces termes provient notre justice pénale, de l'autre, nos institutions militaires. La guerre, fille de la vengeance, en est l'organisation, vendetta collective, régularisée et systématisée. On parle toujours de vengeance ou de représailles militaires, sans que personne se récrie, pas même ceux qui ne peuvent supporter, et avec raison, l'expression démodée et en tout temps inexacte de vindicte publique. Mais la pénalité est pour ainsi dire l'organisation de la pénitence et de l'indignation, devenue peu à peu de la compassion méprisante. Rattachée à ces sentiments plutôt qu'au sentiment de la vengeance, auquel cependant elle a emprunté quelque chose, et même beaucoup trop, aux âges de barbarie, en lui prêtant en retour quelque vague 
caractère de justice, elle se comprend mieux, ce me semble, et, à coup sûr, tout autrement. La vengeance ne distingue pas entre l'ennemi et son frère, elle tue celui-ci pour la faute de celui-là, ils font partie de la même tribu, de la même horde, de la même armée ; cette identité non pas personnelle, mais familiale ou nationale, suffit à ses yeux pour légitimer ses coups ${ }^{1}$. En tant que vindicative, la justice pénale, elle aussi, a souvent dédaigné de s'attacher à l'identité individuelle et a admis une sorte de culpabilité collective, inhérente aux membres de toute une famille, par exempte à celle des Alcméonides à Athènes pour la faute d'un seul qui avait violé le droit d'asile de Pallas. Après la mort de Crésus, on expliqua son désastre par le crime de son aïeul Gygès qui avait conquis le trône en commettant un meurtre. Mais, à part ces exceptions, bonnes, du reste, à jeter du jour sur l'importance de la notion d'identité, bien ou mal comprise, et à montrer son lien indissoluble avec celle de la culpabilité, le justicier a de tout temps cherché à frapper l'auteur individuel d'un crime et l'a déclaré seul coupable, quoiqu'il ait fait ou laissé retomber sur ses parents, par la confiscation notamment, les conséquences déplorables de sa culpabilité. La peine, si elle est le corrélatif et le substitut extérieur du remords intérieur, le remords de ceux qui n'en ont d'autre, est, comme la vengeance, une souffrance infligée, mais une souffrance voulue moins par un calcul d'utilité sociale, que par le besoin d'exprimer la honte d'avoir un frère qui nous déshonore. Si nous nous refusons à concevoir une pénalité autrement que comme douloureuse, tandis que nous admettons très bien la possibilité, d'une médication agréable, c'est que le repentir ne saurait être que douloureux. Il me semble que les phases successives de la pénalité s'accordent avec ce point de vue. L'adoucissement et surtout la transformation séculaire des peines qui, toutes physiques et positives au début, se sont spiritualisées à la longue et sont devenues simplement privatives, ne correspondent-ils pas aux changements opérés dans l'expression du repentir aux divers âges des peuples, depuis le repentir des sauvages et des barbares

\footnotetext{
Napoléon, en bon Corse qu'il était, sentait ainsi : «Un prince de la maison de Bourbon a été pour quelque chose dans la conspiration de Cadoudal donc j'ai le droit de faire tuer un prince quelconque de cette famille." Tel a été son raisonnement en faisant assassiner le duc d'Enghien, et son acte a été si conforme au sentiment corse de la responsabilité familiale, qu'il n'a jamais pu concevoir l'émotion suscitée par cette mort tragique. (Voir les Souvenirs de M. de Barante à ce sujet).
} 
exprimé par des coups, des mutilations, des blessures volontaires ${ }^{1}$, jusqu'au repentir civilisé qui a pour signe unique la tristesse d'une attitude humiliée ? Le sauvage contrit se déchire le corps, verse son propre sang; le civilisé repentant peut bien se tuer, car il y a des suicides par remords, mais sans se faire mal ou en se faisant le moins de mal possible. Il n'y a pas de milieu pour ce dernier entre le repentir qui est une souffrance morale, non physique, et le repentir qui le condamne à mourir. De même dans nos pénalités modernes, il n'y a presque plus de châtiments corporels, de flagellations, de bastonnades, de tortures ; il n'y a pas de milieu entre la prison assez confortable, seulement déshonorante, et la peine de mort réduite au minimum de douleur.

Telle est, brièvement résumée et incomplètement, une notion de la culpabilité qui, tout étrangère qu'elle est à l'idée du libre arbitre, me paraît donner pleine satisfaction à la conscience, s'accorder avec l'état des sciences et trouver sa confirmation historique dans l'évolution des sentiments moraux aussi bien que des institutions pénales. Pratiquement, elle a, ce me semble, l'immense avantage de rompre un lien factice, mais des plus périlleux, entre une hypothèse métaphysique plus ou moins plausible, mais de plus en plus combattue, et une idée morale nécessaire qui, malheureusement, devient inefficace dès le moment où elle cesse d'être certaine et incontestable. Les deux fondements que nous avons cru pouvoir lui donner sont à l'abri de toute sérieuse attaque, l'identité personnelle est un fait, la similitude sociale un autre. Avec ce fil conducteur, il est aisé de se retrouver dans le dédale des difficultés offertes par les perturbations mentales de la folie, de l'hypnotisme, de l'alcoolisme, de la sénilité, etc. A première vue, on pourrait croire que les deux conditions indiquées se développent en raison inverse l'une de l'autre, que plus on s'identifie à soi-même par la cohésion croissante de la enduite, et plus on devient dissemblable à son milieu social. Mais il n'en est rien; l'homme est devenu un animal si essentiellement sociable que sa personnalité se trouble en s'isolant, s'accentue en s'ouvrant largement aux influences, aux sympathies, aux exemples du dehors. Son originalité se nourrit de son impressionnabilité. C'est par l'étude prolongée des modèles, oeuvres magistrales ou créatures vivantes, que le peintre fait son style.

Les anciens Aztèques se saignaient cruellement eux-mêmes pour les moindres peccadilles. 
Aussi, toutes les causes qui diminuent, resserrent et mutilent, ou paralysent entièrement notre faculté d'assimilation sympathique envers autrui, ont-elles pour effet parallèle d'entraver notre identification avec nous-mêmes. La folie qui nous aliène nous désassimile aussi bien, et sa plus ordinaire manifestation est un égoïsme extravagant. Peut-être m'objectera-t-on que, s'il en est ainsi, la culpabilité des malfaiteurs doit être en général bien faible, puisque, donnant la preuve de leur insociabilité, de leur défaut de sympathie, de leur dissemblance avec la société honnête, ils doivent être réputés dépourvus d'équilibre mental, de stabilité personnelle. Mais je ne recule pas devant cette conséquence, en ce qui concerne un certain nombre de malfaiteurs, déséquilibrés ou demi-fous plus dignes du cabanon que de la cellule. Quant à la plupart des délinquants, c'est une erreur de se les représenter comme des êtres à part, sans nulle similitude avec nous. Sous bien des rapports, très nombreux même, ils nous imitent, ils nous empruntent nos mœurs, nos vices surtout, nos vanités, nos cupidités, nos erreurs, le plus souvent aussi nos jugements moraux par lesquels ils se voient forcés de se condamner eux-mêmes. Ils sympathisent donc avec nous plus qu'ils ne pensent et que nous ne pensons. Car il y a toujours quelque amour ou quelque respect, conscient ou inconscient, au fond de l'imitation, comme il y a toujours de l'imitation ou une tendance imitative au fond du respect ou de l'amour ${ }^{1}$. Ces êtres dégradés font donc partie, malgré tout, de notre société qu'ils exploitent, et dont l'exploitation est la carrière où ils déploient leur individualité. Il est donc juste et logique de voir dans la majorité des malfaiteurs, non pas des malades ou des infirmes, mais des coupables, et de les punir comme tels, d'après le degré variable, nullement chimérique, de leur culpabilité. - Cela dit à l'adresse des spiritualistes d'une part, des positivistes de l'autre, je ne vois pas en quoi cette solution d'un problème épineux pourrait offenser les premiers ou mériter le reproche d'éclectisme que lui ont adressé çà et

C'est la raison pour laquelle j'ai toujours attaché une importance si grande à l'imitation et à la similitude sociale, son effet. Ce n'est pas en tant que les hommes s'utilisent réciproquement, comme les économistes sont trop enclins à le penser, que les hommes font partie de la même société ; pour se rendre les plus grands services, ils sont souvent forcés de se différencier les uns des autres si profondément, par la régime des castes ou par la division du travail poussé à l'excès, qu'ils cessent de se traiter en compatriotes sociaux; et ils ne se sont jamais peut être tant entre-servis que lorsqu'ils ont divorcé socialement. Non, c'est en sympathisant réciproquement, et, par suite, en s'imitant les uns les autres, qu'ils sont vraiment cosociétaires. 
là les seconds. Cet effort pour sauver l'idée de culpabilité trahirait-il, comme l'ont insinué ces derniers, un reste de spiritualisme ou de christianisme inconscient et se survivant au cœur, chose grave à leurs yeux ? Je croirais plutôt que dans leur obstination, à vouloir détruire cette notion vieille comme le monde, antérieure à toutes les philosophies et peut-être à toutes les religions, il y a l'action d'un préjugé inspiré par une conception toute théologique de la coulpe et du péché. Seulement, comme je l'ai montré, les théologiens avaient de puissants motifs pour appuyer la responsabilité morale sur le libre arbitre, et les positivistes n'en ont aucun en supposant comme eux, et d'après eux, que, le libre arbitre supprimé, la responsabilité morale s'évanouit. Revenons au sens humain des choses, à leur sens antique ressaisi et précisé ; voyons des coupables là où cette épithète est le mot propre, clair et net; cela ne peut gêner en rien les anthropologistes dans l'examen anatomique et physiologique des criminels, ni les statisticiens dans l'étude numérique des crimes; mais cela ôtera tout prétexte aux attaques passionnées ou aux plaisanteries plus ou moins spirituelles dont ils sont parfois l'objet, et cela ouvrira à leurs instructives recherches, fécondes en documents intéressants l'accès de beaucoup d'esprits distingués dont l'entrée leur est barrée et le sera toujours, non sans quelque apparence de raison, s'ils s'obstinent à nier l'idée morale. Ce dont il y a lieu d'être frappé, c'est que, en dépit de ce paradoxe, les doctrines des nouveaux criminalistes se soient propagées dans le monde entier, en France même ${ }^{1}$, avec une rapidité si grande et toujours croissante. Rien ne montre mieux l'opportunité de leur apparition, l'universalité du besoin auquel elles répondent, leur vérité sous certains rapports essentiels, et la vanité des traits légers décochés contre elles par leurs adversaires.

Il est à remarquer, d'ailleurs, que l'école française, fondée à Lyon par le docteur Lacassagne, se distingue nettement par sa sagesse, par son caractère pratique et solide, de l'école italienne. 
Gabriel Tarde, Études pénales et sociales (1892)

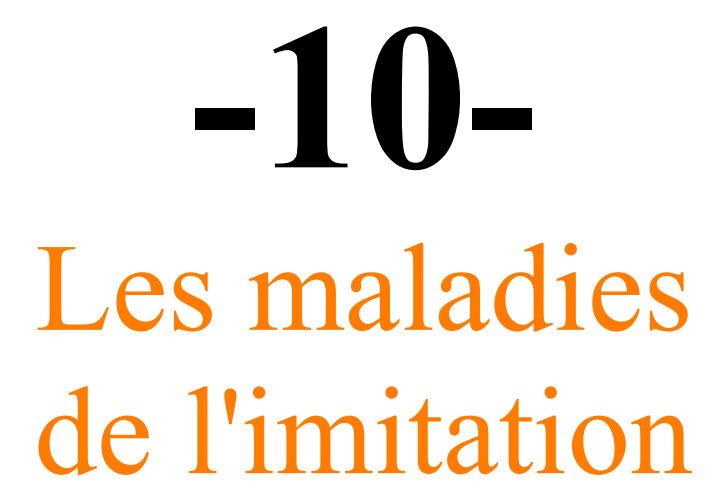

I

$\underline{\text { Retour à la table des matières }}$

Qu'est-ce que le rapport social de deux organismes, à l'exclusion des relations simplement mécaniques, physiques, physiologiques qu'ils peuvent avoir entre eux, telles qu'une contagion épidémique, par exemple, ou l'étouffement d'un homme dans une foule trop compacte ? Élémentairement, c'est une action d'un cerveau sur un autre cerveau; action qui doit commencer, naturellement, par être unilatérale avant d'être réciproque, et par être immédiate et directe avant d'être indirecte et médiate. Nous savons, d'ailleurs, par l'étude approfondie de l'hypnotisme dans ces dernières années, à quelle profondeur descend et pénètre dans l'intimité des tissus, en certains cas exceptionnels, cette action d'un esprit sur un autre esprit : d'où nous pouvons induire que, dans tous les cas, même les plus ordinaires, elle est plus profonde qu'elle n'en a l'air, et comporte une large part 
d'inconnu. Mais toute action d'un cerveau sur un autre est-elle de nature sociale? Non; le lion et son dompteur ne sont point associés, ni même le maître et l'esclave, aussi longtemps du moins que l'esclave obéit par force et que sa servitude n'est point volontaire, ce qui d'ailleurs finit toujours par arriver. Quand elle est volontaire, il est vrai, une sorte d'association unilatérale, incomplète encore, commence à s'établir entre le maître et lui ; qui sait même ? entre le dompteur et le lion, si celui-ci subit la fascination quasi hypnotique de celui-là. Pourquoi ? Parce que l'idée du maître, la volition du maître ont passé dans l'âme de l'esclave, l'idée et la volition du dompteur dans celle du lion, comme un modèle passe dans sa copie. Il y a eu là imitation interne, inconsciente ou consciente n'importe, comme, lorsque l'esclave reproduit les gestes, l'allure, l'accent du maître, il y a imitation extérieure.

Voilà bien, élémentairement, le rapport social cherché ${ }^{1}$. Le caractère d'être imitatif est le propre de tout acte vraiment social, à l'exclusion de tous autres. Plusieurs êtres appartenant à des espèces identiques ou différentes peuvent être utiles les uns aux autres, avec ou sans réciprocité, et former de la sorte, soit par l'union sexuelle, soit par l'allaitement, soit par la domestication ou le parasitisme, ou la réduction en esclavage, des agrégats de diverse nature. Mais, tant que la manière dont ils se rendront service ne consistera point en pensées et en actions enseignées, c'est à dire modelées sur des pensées et des actions semblables, émanées de l'un d'eux et communiquées aux autres, ou transmises aux uns et aux autres par imitation de quelque auteur commun mort ou vivant, leur liaison n'aura rien de sociologique. Au contraire, dès que la condition indiquée viendra à être remplie, et elle le sera quand ils parleront la même langue ou des langues parentes, quand ils professeront la même religion ou des religions de même origine, ou adopteront le même credo philosophique, ou auront reçu une commune éducation scientifique, industrielle, artistique, ils auront beau se combattre au lieu de s'entr'aider, ils auront beau rivaliser et se haïr au lieu de se concerter et de s'aimer, la sociologie aura à s'occuper de leurs relations. La similitude imitative est si bien le fondement caractéristique du lien

Je renvoie, pour le développement de ce point, à mon livre sur les Lois de l'Imitation, étude sociologique (Alcan, 1890). 
social (quoiqu'elle ne suffise pas à produire la cohésion sociale, la nation, l'État), que chacun de nous se sent lié plus étroitement avec ses collègues et ses confrères de la même administration, de la même industrie, du même art, c'est-à-dire avec ses rivaux pourtant et ses adversaires qu'avec ses fournisseurs ou ses clients. Ce devrait être l'inverse, si société voulait dire avant tout et uniquement mutuelle assistance. En général, plus on se ressemble et plus on se heurte et se nuit; plus on diffère et plus on est apte à s'entre-servir. Les économistes, s'ils poussaient à bout leur théorie de la division du travail et de la spécialisation des aptitudes, nous ramèneraient tout droit au régime des castes, qui est le nec plus ultra de la mutuelle exploitation utilitaire des hommes par les hommes, - aussi bien, parfois, des classes supérieures par les inférieures que de celles-ci par celles-là. Mais, en dépit des avantages économiques attachés à cette différenciation graduelle des professions et des classes, la civilisation nous conduit à leur fusion progressive, et, au risque de compromettre l'ordre social, elle fortifie ainsi, malgré tout, le lien social. Il n'en est pas moins vrai que, des ressemblances imitatives une fois formées entre les hommes, cellules d'un même tissu social pour ainsi dire, il reste à organiser ces divers tissus en les employant à la poursuite d'un but commun. De là, la difficulté du problème que les nations ont à résoudre. Il s'agit pour elles de rendre les concitoyens de plus en plus semblables les uns aux autres, tout en leur permettant de s'utiliser réciproquement de plus en plus ; il s'agit pour elles, en d'autres termes, de concilier avec un maximum d'exploitation mutuelle un maximum d'imitation mutuelle, deux choses qui cependant paraissent s'exclure de prime abord. Il n'est pas de société, petite ou grande, qui ne se soit persuadé un jour ou l'autre, toujours illusoirement en définitive, avoir résolu ce problème ardu, mais seulement dans quelque coin privilégié, signalé ensuite à l'admiration ambiante et imité pour son malheur. Tous les peuples ont cherché à réaliser, dans une communauté de choix, dans une élite qui a le plus souvent affecté la forme d'une communauté religieuse, où l'imitativité sévit à l'état aigu avec une intensité superlative, la vie idéale, telle qu'ils l'ont comprise à raison de leurs idées et de leurs besoins. En Grèce, c'était la confrérie des mystères d'Orphée, où tous les initiés étaient égaux et semblables autant que solidaires; an moyen âge, les couvents, plus tard, la chevalerie, ou bien l'élite albigeoise qui s'intitulait les Parfaits. En Polynésie, c'est la secte des Aréoï, association étroite, essentiellement 
érotique, sur laquelle on peut voir de piquants détails dans Letourneau (Évolution de la morale). Dans notre Europe moderne, c'est le groupe des courtisans qui entouraient un monarque à certaines époques de beau luxe. Peu à peu, par imitation, ce groupe s'est grossi ou reflété dans des groupes inférieurs et plus vastes; et, bien que ce cercle se soit déformé en s'élargissant, quelque chose de sa courbure première subsiste encore en chacun de ses dérivés actuels. Le corteggiano dont Castiglione (XVe siècle) nous trace ${ }^{1}$ le portrait dans son Dialogue s'est reproduit dans le gentilhomme français du XVIe siècle, dans l'honnête homme du XVIIe, dans l'homme bien élevé de nos jours; autant d'expressions équivalentes, dont la compréhension croissante, au point de vue du nombre des personnes auxquelles elles s'appliquent, montre le progrès continu de l'imitation depuis le commencement de l'ère moderne.

L'impressionnabilité imitative, la sociabilité proprement dite, est une de nos propriétés cérébrales les plus caractéristiques, les plus merveilleuses et les moins connues. J'ai déjà parlé de l'hypnotisme. On n'eût jamais cru, avant les expériences auxquelles il a donné lieu, qu'une cervelle humaine fût à ce point malléable et maniable par autrui, intangiblement et invisiblement. Je ne veux pourtant pas, poussant à bout l'idée de la suggestion sociale, voir en tout homme un hypnotisé mû par la volonté de ses ancêtres ou de ses contemporains, magnétiseurs collectifs. Mais si, malgré bien des analogies ${ }^{2}$, ce point de vue est inacceptable à la lettre, il nous aide à comprendre le sens caché, le sens vraiment pathologique, qu'il convient de donner au mot prestige par lequel nous expliquons tant bien que mal le pouvoir fascinateur exercé par un homme sur ses semblables. Toutefois, il n'est pas nécessaire qu'un homme soit doué de cette sorte d'empire occulte pour produire sur ses compatriotes un effet pareil, au degré près. La preuve en est fournie par cet état psychologique et physiologique singulier dont la singularité ne nous frappe que lorsqu'il se prolonge au-delà de l'adolescence ou de la jeunesse, mais par lequel nous avons tous passé, normalement, dans notre enfance et à notre première entrée dans une cour de collège ou dans un salon: l'intimidation.

\footnotetext{
Voir à ce sujet Boccace, par Henri Cochin (1890).

2 Voir mon livre ci-dessus cité, p. 86 et suiv.
} 
Il y a, entre l'intimidation et l'hypnotisation, à laquelle pourtant on peut la comparer pour l'expliquer, des différences remarquables. L'hypnotisation est l'action prestigieuse d'une individualité privilégiée sur une autre ou sur d'autres. On a vu parfois un fascinateur endormir à la fois dix, vingt, trente sujets. A l'inverse, l'intimidation est l'action prestigieuse, non moins perturbatrice d'ailleurs et paralysante dans certains cas, d'un groupe d'hommes sur un seul homme ${ }^{1}$. Ce dernier effet, comme on peut le remarquer aisément si l'on est né timide (ce qui ne veut pas dire craintif), est produit beaucoup moins par la qualité des personnes rassemblées que par leur nombre. La foule, dont la vue intimide le jeune orateur balbutiant devant elle, est un être impersonnel, ce semble, une collection d'individus dont aucun séparément n'intimiderait le moins du monde sa victime actuelle. On le dirait du moins. Mais il n'en est rien. Cet effet d'ensemble, en apparence impersonnel, n'est qu'une addition d'effets élémentaires exercés par des personnes; et cela est si vrai, que tel myope, non intimidé s'il voit son auditoire à travers son brouillard visuel où nulle physionomie ne se distingue, se trouble dès qu'il a mis son lorgnon sur le nez. Cela ne prouve-t-il pas que chacune de ces physionomies, isolément, a son action intimidante, à un degré, il est vrai, insuffisant pour être senti ? Ici pourrait se poser un problème analogue à celui que les scolastiques ont agité sur le point de savoir combien il faut perdre précisément de cheveux pour commencer à mériter l'épithète de chauve. Un jeune homme doit parler devant cinq personnes, il ne paraît pas intimidé ; devant cent personnes il le sera. Mais si le groupe des cinq premières s'est régulièrement grossi, à quel chiffre précis l'intimidation du malheureux a-t-elle lieu ? Cela dépend de bien des conditions, et je n'entrerai pas dans leur détail. Je ne rechercherai pas non plus si l'intimidation croît comme le logarithme de son excitation, c'est-à-dire du chiffre des personnes dont le rassemblement intimide. Elle me semble croître d'abord plus vite, puis moins vite. Mais peu importe. Il est certain que ce phénomène est graduel, et je n'en veux pas davantage pour être autorisé à conclure que tout homme, plus ou moins, exerce sur tout homme ce pouvoir impressionnant. Or

Quand un homme est à lui seul aussi intimidant qu'un grand auditoire, par exemple Napoléon $1 \mathrm{er}$, il est né despote. 
l'intimidé est éminemment suggestible, c'est à dire plastique mentalement, modelable au gré des exemples ambiants.

Comment se fait-il qu'aucun physiologiste n'ait encore songé, avec le sphygmographe, l'esthésiomètre, etc., en mains, à analyser l'état physique de l'intimidé ? À coup sûr, il en vaudrait la peine. Pâleur ou rougeur subite du visage, sueurs, palpitations, embarras de la parole et paralysie des gestes, sont des symptômes bien connus. Nerfs, muscles, charpente osseuse, circulation, respiration, tout est modifié profondément par la simple convergence de quelques regards sur un visage. Et remarquons que l'effroi, la crainte, l'espoir, l'admiration, l'amour, ou tout autre sentiment, n'entrent pour rien, essentiellement, dans ce phénomène. C'est une émotion dont le caractère est d'être tout à fait désintéressée. C'est une pure action de présence. Il y a là quelque chose de spécifique. - Allons plus loin : la présence même du groupe intimidant peut n'être pas nécessaire, ou peut cesser de l'être. Puisque, suivant nos psychologues, l'image, l'idée, le souvenir d'une sensation en est la reproduction affaiblie, nous devons croire que l'idée seule d'un groupe d'hommes qui nous a antérieurement intimidé suffit à nous intimider, plus faiblement il est vrai. Cette intimidation de reflet est de beaucoup la plus importante. C'est à elle qu'il faut attribuer les fléchissements intellectuels des penseurs qui, même dans leur cabinet, subissent à leur insu la fascination d'un public spécial ou de l'opinion populaire, et, à plus forte raison, ces capitulations de conscience, ces lâches complaisances de coeur ou d'esprit, ces aplatissements devant le succès, ces passives obéissances à des mots d'ordre tyranniques qui, à certains moments, signalent la dépression générale des caractères. On a beau être dispersés chacun chez soi, on se sent proches, et chacun, en songeant à tous les autres, est intimidé à la pensée de se mettre en opposition ou en dissidence avec cette foule qui le submerge et le subjugue.

En effet, l'intimidation naît du sentiment qu'on a d'être étrange en quelque chose et du besoin de mettre fin à cette étrangeté en revêtant la livrée commune. Un enfant, un homme est intimidé, quand, par son costume, par son accent, par ses manières, ou mieux par ses croyances et ses sentiments, il se croit dissemblable au public qui le regarde ou qui l'écoute. Tel, dans une réunion électorale, un homme seul de son bord; telle,parmi des femmes galantes, une honnête femme égarée ; 
ou, parmi d'honnêtes femmes, une femme galante. Ou bien, on est intimidé quand, par l'opinion orgueilleuse ou vaniteuse qu'on a de soimême et que les spectateurs ne partagent pas, on se sent isolé. Mais l'intimidation n'est pas seulement l'impressionnabilité excessive, maladive, de l'amour-propre, elle est aussi l'impressionnabilité non moins extrême de la volonté, du jugement, du cœur. Toutes les facultés sont troublées, et, avec elles, tous les organes, parce qu'elles ressentent le contact et la contagion déjà subjugante des amourspropres, des volontés, des jugements, des cœurs présents, en partie dissonants. Alors, entre le désir de se distinguer et le besoin de sympathiser, entre l'orgueil sauvage et l'instinct social, entre la liberté propre et l'autorité de tous, il y a conflit, et les progrès de l'intimidation marquent le triomphe croissant de la société sur l'individu qu'elle dompte. Quand la victoire est achevée, l'intimidation cesse, mais elle est remplacée par ce qui a l'air d'être son contraire et, en réalité, est son effet: la parfaite aisance d'un homme qui se meut dans son milieu comme chez lui, parce qu'il se sent en communion absolue d'idées, de désirs, de dehors, avec cette atmosphère humaine qu'il respire constamment et inconsciemment. Il n'est plus intimidé, il ne se souvient même plus de l'avoir été, il a oublié cette crainte révérentielle que, sous une forme quelconque et à un degré quelconque, le plus effronté des enfants n'a pas manqué de ressentir pour quelqu'un de ses parents, de ses maîtres, ou encore mieux de ses condisciples ; mais, de cette crise à laquelle nul n'échappe, de ce défilé angoissant qui est la porte d'entrée nécessaire de la vie sociale, il n'est sorti que révolutionné à fond dans tout son être moral. Ce qui le caractérise à présent, comme ce qui caractérise l'hypnotisé, c'est une disposition permanente et parfois morbide à recevoir l'empreinte d'autrui, c'est une complaisance inconsciente et incurable pour les opinions et les caprices d'autrui, penchant qui le pousse parfois, comme il pousse tant de somnambules, à dissimuler ses inclinations propres pour simuler des goûts, des sentiments, des idées conformes à ceux de la coterie plus ou moins large dans laquelle il vit.

Il y a deux manières, pour l'intimidé, en présence d'un auditoire, de mettre fin à l'étrangeté, à la dissemblance dont il a le sentiment : c'est, ou de se conformer à la manière d'être de cette foule, en flattant ses penchants, ses préjugés, sa vanité, ou de la conformer au contraire à sa manière d'être à lui, de lui faire partager ses idées, ses vœux, et 
l'opinion avantageuse qu'il a de lui-même. D'ordinaire, suivant le conseil éternellement vrai de la vieille rhétorique, l'orateur habile emploie ces deux procédés successivement, le premier d'abord, puis le second. Par quelques mots d'exorde insinuants et flatteurs, il se fait applaudir; et, dès ce premier applaudissement qui atteste sa consonance avec le public, sa timidité s'évanouit; son geste, son attitude, sa prononciation, sa diction, se fortifient et se modifient, et bientôt de magnétisé il devient, s'il est éloquent, magnétiseur. Grande maladie de l'imitation, en vérité, que cette puissance oratoire dans bien des cas ! Maladie double, où il faut distinguer, d'une part, la contagion de l'orateur sur chacun de ses auditeurs, et, d'autre part, la contagion de ceux-ci les uns sur les autres; car ils s'entre-communiquent l'effet qu'ils ressentent et, comme cet effet est le même, ce mutuel reflet en est la multiplication en chacun d'eux.

Chose à remarquer, l'intimidation, cet état qui dispose si puissamment à recevoir la contagion, n'est pas elle-même contagieuse. On n'est pas plus intimidé qu'on ne l'était parce qu'on voit d'autres personnes l'être aussi. Mais il n'en est pas de même des convictions ou des passions quelconques suggérées à l'intimidé, à l'homme social, quel qu'il soit, par son milieu. Or, quand la communication sympathique, quand le renforcement imitatif de ces convictions ou de ces passions s'opèrent suivant un crescendo plus rapide ou plus lent, plus étendu ou plus localisé qu'il ne conviendrait d'après les principes et les buts fondamentaux de la société dont il s'agit, ce sont là vraiment les grandes, les redoutables maladies de l'imitation. Ce n'est pas seulement dans les assemblées qu'elles éclatent, c'est encore dans les rues où passent des manifestations tumultueuses, où se dressent des barricades ; c'est parmi des populations éparses, dans de vastes nations engouées de quelque grand homme de pacotille, ou électrisées par la nouvelle télégraphique d'une guerre déclarée, d'une émeute triomphante quelque part. Démêler ici le normal du morbide n'est pas aisé. On ne se compromet pourtant pas beaucoup en avançant qu'un peuple est bien malade au sein duquel les affections d'ordinaire antisociales, haine, envie, soupçon, scepticisme, révolte, ambition même, sont beaucoup plus contagieuses que l'amour, l'admiration, la confiance, l'obéissance, le respect de quelque chose et de quelqu'un. 


\section{II}

$\underline{\text { Retour à la table des matières }}$

Maintenant, pour nous faire une notion plus large et plus complète de l'imitation et de ses troubles, nous devons essayer d'une comparaison psychologique. L'imitation, phénomène social protéiforme aux mille aspects linguistiques, dogmatiques, rituels, scolaires, professionnels, moraux, esthétiques, est à la société ce que la mémoire est à l'esprit d'après les psychologues de l'école expérimentale.

On a beaucoup trop comparé l'agrégat social à un organisme ${ }^{1}$. Peut-être les services que cette analogie a rendus, quand elle a été poursuivie par de grands esprits, sont-ils compensés par les erreurs et les puérilités où elle a conduit leurs disciples. En revanche, il me paraît certain qu'une société ressemble beaucoup à cet organe souverain, tout à fait à part, qu'on appelle le cerveau. Par le côté spirituel de leur fonctionnement, les cellules qui le composent sont en rapport vraiment social, ce qui explique le jour jeté par la sociologie dans les arcanes de la psychologie entendue à la façon des nouveaux psychologues. Nous avons tout lieu de penser que la masse cérébrale est à chaque instant traversée par des courants d'impressions qui se communiquent de cellule à cellule, se répètent, se multiplient, s'échangent, s'entre-croisent comme les ondes sonores dans l'air, luttant pour l'apparition ou la réapparition à la conscience. Par toutes les portes du cerveau, par les sens, une foule d'impressions nouvelles - nouvelles jusqu'à un certain point, et en cela comparables aux découvertes, aux innovations de tout genre qui cherchent à faire leur chemin dans le monde - se précipitent pour entrer. Un petit nombre, formant faisceau et système, $\mathrm{y}$ réussissent, et, depuis leur point d'origine, se répandent dans le peuple entier des cellules avec une rapidité que les

Voir à ce sujet notre étude Intitulée : Catégories logiques et institutions sociales, publiées dans la Revue philosophique. 
psychophysiciens ont mesurée parfois. Puis, après un moment d'éclat, comme les découvertes réussies après une période de célébrité, elles retombent dans l'obscurité de l'inconscience; mais alors, loin de s'anéantir, grossissent le trésor des souvenirs accumulés, de loin en loin reviviscents.

Or, s'il en est ainsi, nous ne devons pas être surpris que la mémoire, conservation et reproduction des souvenirs (et aussi bien des habitudes, souvenirs d'actes), soit une propriété universelle de toutes les impressions qui ont été une fois conscientes, et, comme telles, ont fait partie de ce que nous appelons l'esprit. En effet, ce ne peut être assurément qu'en se répétant, qu'en se reproduisant incessamment au dedans des éléments cellulaires, que l'impression s'y peut conserver, comme c'est seulement en se répétant, en se propageant d'une cellule à l'autre, qu'elle a pu arriver à la gloire de la conscience et qu'elle pourra y revenir ultérieurement ${ }^{1}$. Conscience et mémoire sont donc des phénomènes cérébraux de même nature, des reproductions; ils ne diffèrent que par le caractère intercellulaire ou intracellulaire de celles-ci. C'est précisément la différence que je remarque entre deux formes complémentaires et alternantes de l'imitation, et que, sous le nom d'imitation-coutume et d'imitation-mode, j'ai longuement développées ailleurs. Un esprit vit avant tout de souvenirs et d'habitudes, comme une nation de traditions et de coutumes, de vieux mots, de vieux dogmes, de vieilles institutions, de vieux métiers, de vieilles moeurs. Mais tout ce qui s'est ainsi enraciné coutumièrement a

Le cerveau est le siège d'un déplacement incessant de molécules que le cours de la nutrition enlève et remplace avec une grande rapidité. Et d'après Ribot, c'est à la vitesse même de ces substitutions qu'est due la fixation des souvenirs. En cela, il est d'accord avec les physiologistes, notamment avec Maudsley. "L'effet produit par une impression sur le cerveau, dit ce dernier, y est fixé et retenu parce que la partie quelle qu'elle soit, qui a été changée par cette impression est exactement représentée par la partie qui lui succède dans le cours de la nutrition. » - Supposez que la nutrition, c'est-à-dire le renouvellement incessant des cellules cérébrales, n'ait pas lieu, "l'effet de l'impression » s'userait vite, s'épuiserait, le souvenir ne durerait que fort peu de temps. - De même, la société est le siège d'un remplacement incessant des vieux par les jeunes, des anciens par des nouveaux, dans chaque corps de métiers ou d'art, dans chaque administration, dans chaque régiment, dans chaque foyer. Et c'est grâce à ce renouvellement vivant, que se perpétue avec une quasi-immutabilité chaque découverte ou chaque invention qui vient grossir le trésor du travail humain ou de l'activité humaine. Sans la communication des procédés, des rites, des dogmes, des mots, par l'enseignement et l'exemple, toutes ces choses ne tarderaient pas à tomber en désuétude ou en oubli. Leur transmission les fixe. C'est ainsi que les langues, les religions, les sciences, les lois, les métiers, les arts se conservent. 
commencé par être une innovation accueillie à la faveur d'une mode, si l'on me permet d'étendre et de modifier un peu l'acception usuelle de ce terme. La mode, ainsi conçue, est l'aliment intermittent et nécessaire de la coutume. Le penchant à s'engouer des exemples étrangers et contemporains, source des courants de mode en tout ordre de faits, n'est donc pas contraire, autant qu'on pourrait croire, au penchant à se régler sur les us des aïeux. C'est, à vrai dire, par le jeu alternatif de ces deux dispositions différentes, ou plutôt par les intermittences fécondes de l'une et la continuité salutaire de l'autre, que s'opère le progrès des sociétés, comme le progrès des esprits s'opère par la prépondérance alternative de l'observation et de la réflexion, de la perception et du raisonnement, de l'inglutition d'idées nouvelles et de la rumination d'idées anciennes. Dans cette vie de l'esprit, la mémoire est le fait, non pas unique, mais élémentaire et fondamental. C'est la logique individuelle, la finalité individuelle, comme l'a fort bien montré $\mathrm{M}$. Paulhan dans son profond livre sur l'Activité mentale ${ }^{1}$, qui règle en général le sort de nos souvenirs, efface les uns, éclaire les autres, et compose avec les souvenirs élus, tous ou presque tous d'accord entre eux, le système de nos états de conscience simultanés ou successifs. C'est la logique sociale, pouvons-nous ajouter, qui règle en général le sort des exemples reçus par mode ou conservés par coutume; c'est elle qui les organise en langues, en religions, en constitutions, en codes, en institutions, en industries, en arts. Mais, si la mémoire et l'imitation sans la logique ou la finalité spontanée qui les emploie seraient incomplètes et inutiles, la finalité sans la mémoire et l'imitation qui lui fournissent sa matière première serait impossible et inconcevable.

Alcan 1889. Voir aussi dans la Revue philosophique de fév. 1890, la belle étude sur la Concurrence des états psychologiques, par M. Binet. 


\section{III}

$\underline{\text { Retour à la table des matières }}$

Cela posé, on voit l'importance d'étudier cette action de cerveau à cerveau, tantôt volontaire et consciente, tantôt involontaire et inconsciente, comme pour la communication de l'accent, que j'appelle imitation; et l'on voit aussi que les études si approfondies des psychologues sur la mémoire peuvent, par analogie ou par contraste, nous servir en cela. M. Ribot a fort bien analysé et expliqué les maladies de la mémoire. Est-ce qu'elles ne seraient pas jusqu'à un certain point comparables aux maladies de l'imitation?

La difficulté ici est de préciser ce qu'il faut entendre par l'imitation normale de même que par la mémoire non malade. La mémoire peut pécher par défaut ou par excès, par amnésie (totale ou partielle) ou par hypermnésie. Elle a ses amnésies compensées par des hypermnésies ; tel est le cas de ces idiots qui ont une mémoire musicale extraordinaire. L'imitation pareillement a ses temps de torpeur ou de fièvre, de paralysie ou de surexcitation. Elle présente, en certains pays, des désuétudes brusques, compensées par des frénésies d'assimilation. Mais où commence l'exagération maladive de la disposition à se rappeler ou à oublier, à copier ou à ne pas copier autrui ? L'oubli, en effet, loin d'être une anomalie, est une condition de la bonne mémoire ; une grande maladie de la mémoire consiste à ne pas savoir oublier à propos, chose impossible à certains vieillards ${ }^{1}$. La mémoire saine suppose beaucoup d'oublis oppotuns ; l'imitation saine suppose

Il y a aussi des amnésies spécifiques, limitées à tel genre de souvenir : par exemple, aux dates, etc. Il y a, de même, des incapacités d'imiter qui se bornent à tel ou tel genre d'exemples. On voit des gens qui ont tout emprunté au pays où ils sont venus s'établir, tout, excepté l'accent. Si modernisée que soit une province, il est rare que, par quelque coutume locale persistante on ne sait pourquoi, en dépit de tout, parmi beaucoup d'autres bien préférables qui ont disparu, elle ne se montre étonnamment et exceptionnellement routinière. Ici, on a gardé la coiffure traditionnelle quoique laide, après que l'habit traditionnel, quoique charmant a été abandonné. Ailleurs, on a gardé des superstitions féroces, telles que le duel, après avoir fait litière des meilleurs institutions. Il est des tribus sauvages qui, en contact avec les civilisés, ne leur ont rien emprunté que l'alcoolisme. 
beaucoup de désuétudes utiles. Mais est-il prouvé qu'il soit utile, par exemple, aux Japonais actuels de désimiter leurs pères pour imiter fiévreusement les étrangers européens ? L'avenir décidera. Bien des fois, au cours de l'histoire, on a vu, sous forme religieuse il est vrai, mais peu importe, des conversions de peuples en masse à une civilisation nouvelle. La chrétienté du moyen-âge s'est formée et grossie par une suite de ces brusques transformations, de ces sortes de métempsycoses nationales. L'entrée successive des Bulgares, des Polonais, des Russes, de tous les peuples orientaux de l'Europe, dans la République chrétienne, a été accompagnée partout d'une de ces fermentations extraordinaires au spectacle desquelles un spectateur philosophe a toujours eu le droit de se demander : Est-ce un bien, estce un mal ? Il s'est trouvé que c'était un bien, puisque l'assimilation ainsi opérée a été durable, qu'elle a été se développant et se consolidant plus tard, et que plus les consciences s'assimilent par le triomphe d'une religion sur ses rivales, prélude à l'invasion des mêmes sciences, puis des mêmes besoins et des mêmes mœurs, plus le champ moral de la justice et de la fraternité, la sphère des droits et des devoirs s'élargit sur la terre, à travers tous les combats. Mais combien de fois est-il arrivé que ces enthousiasmes rénovateurs, destructeurs du passé, ont précipité la ruine des États et justifié les prédictions pessimistes des patriotes!

Quand, après l'érosion complète des croyances d'un autre âge, le culte où elles s'exprimaient et qui était leur exposition universelle et perpétuelle, subsiste dans les habitudes des populations, dirons-nous que c'est là une anomalie ? Proposerons-nous des remèdes énergiques ou violents contre cette persistance morbide de rites devenus routines, vêtements vides ou déguisements trompeurs, formules menteuses ou mortes? Mais tous les peuples qui ont prospéré et duré ont été malades en ce sens, et leur maladie a duré parfois des milliers d'années comme en Égypte, ou des siècles au moins comme à Rome. Ce qui serait anormal, bien plutôt, ce serait, à l'inverse du phénomène indiqué, la cessation soudaine des fêtes, des processions sacramentelles d'inhumation ou de mariage, dans un pays ou dans une province qui aurait gardé, au for intérieur, sa foi religieuse et rougirait de la traduire au dehors; ce serait surtout de singer les façons et le jargon de nouveaux sectaires avant de s'être pénétré de leur foi. Cela s'est vu à certaines époques révolutionnaires où, par mode, et non sans 
remords, on a affecté de ne plus paraître ce qu'on était encore et de paraître déjà ce qu'encore on était point. On a vu même, sous l'empire du respect humain, des barbares, restés barbares de cœur, renoncer à tous leurs usages traditionnels, traduction exacte et nécessaire de leurs besoins survivants, et copier les dehors du voisin civilisé avant d'avoir été atteints dans l'âme par le contact de la civilisation. Cette anticipation de l'imitation extérieure sur l'imitation interne a toujours été ce qu'il y a eu de plus superficiel et de moins vivace; la marche normale est le passage de l'imitation ab interioribus ad exteriora ${ }^{1}$, d'où il suit que, adoptés les derniers et à titre de conséquences logiques, les exemples externes doivent survivre aux premiers ou en ont le droit un certain temps; et ainsi s'explique, ainsi se justifie jusqu'à un certain point, le phénomène des survivances.

Il n'en est pas moins vrai qu'il vient un moment où la survie d'un culte à son dogme, d'un usage à son besoin, d'une institution à sa raison d'être, devient abusive et appelle une refonte des habitudes. Mais, encore une fois, il est difficile de marquer ce point, bien que, à certaines époques, tous les gens sensés s'accordent à reconnaître que leur pays est mûr ou n'est pas mûr pour telle ou telle réforme radicale.

Une mémoire saine, pourrait-on dire, est celle qui conserve tous les souvenirs utiles aux fins présentes ou futures de l'esprit, et rien que ceux-là, et qui les représente quand il faut. La mémoire d'un enfant, d'un vieillard, d'un convalescent qui vient d'avoir la fièvre typhoïde a perdu beaucoup de souvenirs précieux et se dépense parfois en prodigalités de réminiscences insignifiantes, inopportunément rappelées. - L'imitation ou plutôt l'imitativité saine est, de même, celle qui conserve toutes les inventions conformes à l'idéal actuel ou prochain et déjà pressenti de la société où l'on vit. Elle est liée à la force inventive, en effet, comme la mémoire saine est liée à la perception aisée et complète. Quand la perception et l'invention

Cette marche du dedans au dehors semble de prime abord contraire à l'observation. J'ai cru cependant la prouver dans mon livre plus haut cité. Voici encore un fait à l'appui : "À la fin du XVIIIe siècle, on pouvait encore apercevoir, sans doute, entre les manières de la noblesse et celles de la bourgeoisie, une différence ; car il n'y a rien qui s'égalise plus difficilement que cette superficie de mœurs qu'on nomme les manières ; mais, au fond, tous les hommes placés au-dessus du peuple se ressemblaient ; ils avaient les mêmes idées, les mêmes habitudes, les mêmes goûts, etc. » (Tocqueville, l'Ancien Régime et la Révolution p. 143). 
s'affaiblissent, la mémoire et l'imitation se troublent et s'altèrent. L'imitation propre aux tribus sauvages ou aux peuples décadents ou aux nations qui sortent de quelque longue convulsion, telle que la guerre de Cent ans ou les luttes religieuses du XVIe siècle, s'attache à beaucoup d'innovations vaines et frivoles, se détache de beaucoup de coutumes salutaires. Le type, ou l'un des types, à coup sûr, de l'imitativité normale, c'est l'Angleterre de notre siècle, avec son traditionnalisme ouvert, hospitalier aux nouveautés fécondes. Même à l'époque de son radicalisme le plus aigu, elle a montré une sagesse que beaucoup jugeront excessive. Tous les grands révolutionnaires anglais du XVIIe siècle ne l'ont été que par force. Pym, le premier général de l'armée parlementaire au début de la guerre civile, était fort attaché aux traditions laïques ou ecclésiastiques. Cromwell, qui lui succéda, était lui-même si conservateur que, comme son gendre Ireton, il persista longtemps, après la captivité du roi, à négocier avec lui pour éviter la suppression de la royauté. Les marques de respect sont prodiguées au royal prisonnier. On lui parle à genoux.

Jamais cependant la fidélité des Anglais à leurs coutumes nationales n'a été poussée au point de leur faire perdre de vue leurs intérêts nationaux ; et c'est en quoi elle diffère de la routine byzantine. On a raison de railler les Grecs du Bas-Empire qui, par habitude invétérée et maladie chronique, se disputaient pour des querelles de théologie abstruse au moment où Mahomet II assiégeait leur capitale. Un moine alors ameutait la foule contre les azymites, c'est-à-dire contre les papistes, et faisait perdre par là à l'héroïque empereur de Constantinople le bénéfice de l'union des deux Églises sollicitée et préparée par lui si politiquement. Mais, à dire vrai, les Spartiates, dont nul ne rit, n'ont pas montré moins d'extravagance quand ils ont différé de trois semaines l'envoi de secours contre les Perses avant la bataille de Marathon, parce que la religion interdisait aux troupes lacédémoniennes de se mettre en campagne au quartier de la lune où l'on se trouvait. On ne songe pas non plus à se moquer des Hellènes de toute nation qui, à cette même époque, ont laissé passer le moment favorable pour défendre avec succès les Thermopyles, à cause des Jeux Olympiques auxquels, avant tout, il importait d'assister. En revanche, peut-être les historiens de l'avenir s'amuseront-ils à nos dépens en relatant les questions qui passionnaient l'opinion et le monde parlementaire en France entre Sadowa et la guerre de 1870. - 
C'est ainsi que les historiens blâment ou louent, échos les uns des autres, aussi moutonniers dans leurs jugements que le sont les peuples dans leur conduite. Et cette moutonnerie de l'histoire, qui a accrédité tant d'erreurs, tant de mensonges conventionnels, n'est pas la moins pernicieuse des maladies que nous étudions.

\section{IV}

$\underline{\text { Retour à la table des matières }}$

En fait de mémoire comme en fait d'imitation, l'inexactitude est un défaut, l'exactitude un avantage. Sur ce point, il n'y a pas de doute possible. Quand l'inexactitude des souvenirs dépasse un certain degré et expose l'esprit à des confusions comme il arrive chez les personnes âgées, il y a là une anomalie morbide. On doit attribuer aussi un caractère pathologique à l'inexactitude des imitations quand elle tend à dénaturer son objet. Sous les noms d'altération phonétique, de corruption grammaticale, etc., elle joue un grand rôle en philologie. Chose remarquable, plus une nation se civilise et s'étend, plus se multiplie le nombre des bouches qui parlent une langue et le nombre des mots, des tournure de phrases, que chacune de ces bouches emploie ; et plus, malgré cette complication croissante, la répétition de chacun de ces mots, de chacune de ces tournures, devient précise, invariable, rituelle pour ainsi dire. Bien mieux, les termes les plus employés, les plus vieux mots de la langue, sont ceux qui se modifient le moins. Ce sont les peuplades les plus grossières, ce sont, parmi nous, les classes les plus illettrées, parlant patois, dans nos provinces méridionales, qui présentent les variations les plus rapides du langage. - Je sais bien que les linguistes sont portés à regarder les altérations phonétiques et grammaticales comme un phénomène normal, nécessaire même, sans lequel l'évolution des langues, leur graduelle adaptation aux besoins nouveaux de la prononciation et du parler ne se comprendraient pas. Mais je crois qu'ici on confond deux choses sous le même vocable altération. Un mot change, une règle de grammaire se modifie, soit par une accumulation de petits barbarismes, de petits solécismes échappés malgré l'intention de ne 
rien changer, soit par le succès d'une ou de plusieurs innovations dues (plus ou moins consciemment ou inconsciemment, n'importe) à d'heureux parleurs, imités en cela et de proche en proche, mais exactement imités en leur inexactitude même. Or n'est-ce pas aux soidisant altérations de cette seconde espèce qu'il faut faire honneur des progrès linguistiques, tandis que les altérations vraies n'ont jamais servi qu'à corrompre et abâtardir les langues ? Dans la formation des langues romanes, les deux causes paraissent avoir agi ensemble ou l'une après l'autre ; et c'est pourquoi, malgré leur originalité à certains égards et leur longue culture, ces idiomes ont mérité que le plus harmonieux d'entre eux fût appelé « doux bâtard du latin ». Il en est du conformisme en fait de langage comme en fait d'orthographe. Serait-ce un bien que l'orthographe française, par une suite de petites fautes insensibles et impunies, allât d'elle-même se modifiant à la débandade; et n'est-ce qu'ainsi qu'on peut espérer de la voir progresser en simplification et en adoucissement pour ainsi dire de l'écriture, comme les syllabes et les grammaires ont été se simplifiant et s'adoucissant pour la plus grande commodité du discours ? Il me semble, au contraire, qu'on ne saurait trop tenir à la rigueur de l'étiquette orthographique, et qu'elle n'empêche en rien une réforme intelligente de l'orthographe d'être tentée avec succès. Par suite de la discipline même, quasi militaire, à laquelle les plumes auront été longtemps habituées, cette réforme si elle parvient à se faire adopter d'une élite, sera assurée d'un triomphe rapide et d'un enracinement fécond.

Il y a aussi des altérations mythologiques ou religieuses d'où résulte la dégénérescence des religions, avant que, fixées par leur culture même, ainsi que les idiomes, elles se perpétuent presque inaltérablement comme le catholicisme depuis le concile de Trente. Il ne faut pas confondre cette dégénérescence avec le renouvellement des religions par des idées géniales d'hérétiques, d'apôtres, de prophètes, de papes. Autant vaudrait confondre la bizarrerie des mauvais penseurs dont la pensée ne doit son étrangeté qu'à la superposition de souvenirs altérés, déformés dans la mémoire, avec l'originalité vraie produite par d'heureux mariages entre des souvenirs très précis et très fidèles. C'est une grande erreur de penser qu'une Église, parce qu'elle est devenue une merveille d'uniformité et de centralisation, a perdu toute plasticité ; elle ne s'en prête que mieux à 
l'adoption rapide et universelle de nouveaux dogmes, de nouveaux rites. Tout entière dans la main de son chef, elle peut d'un jour à l'autre étonner le monde par la soudaineté de ses palingénésies.

Les constitutions et les législations peuvent donner lieu à des distinctions analogues. Est-ce par une suite continue d'altérations juridiques, d'inexactitudes dans l'application des textes et des formules, dans l'emploi des procédures, est-ce par une accumulation de petits progrès absolument inconscients et anonymes, comparables à la transformation spontanée des langues, telle que l'imaginent la plupart des linguistes que le vieux droit quiritaire est devenu le Code savant de Justinien? Nullement; c'est par une suite discontinue d'innovations très réfléchies que chaque préteur, au commencement de son année, inaugurait dans son Edit, et auxquelles les plaideurs, comme les jurisconsultes, se conformaient rigoureusement. À aucune époque le génie romain n'aurait supporté le vague, l'indécision, le défaut de rigueur en matière pareille; et cependant nulle part le droit n'a subi de transformations aussi heureuses ni aussi pro -fondes que chez ce peuple formaliste et procédurier, exact observateur de la loi. Soyons-en certains pourtant, si nous ignorions le rôle qu'a joué ici l'Édit du prêteur, il ne manquerait pas d'historiens pour nous parler de l'évolution spontanée du droit romain. - Il ne faut pas croire non plus que la constitution politique de l'Angleterre se soit développée, grâce à d'insensibles déviations des précédents, inconscientes et inaperçues des contemporains. Le peuple anglais n'est pas moins tenace ni rigide que le peuple romain en son conformisme coutumier; mais l'on peut nombrer et dater les initiatives royales ou parlementaires qui ont successivement, et très sciemment, modifié le vieil édifice constitutionnel. Autant de modifications, autant d'inventions accessoires très exactement imitées jusqu'à leur remplacement.

Tout s'altère, les métiers et les arts, aussi bien que les cultes et les vocabulaires, à certaines époques de paresse imitative. Le Bas-Empire a connu cette inexactitude généralisée des exemples industriels et artistiques; et l'on sait si ces altérations-là ont servi au progrès des industries, de la sculpture, de la peinture, des lettres. Après les Antonins, la sculpture décadente, à force d'incorrections, retourne aux gaucheries de son enfance. Elle ne meurt pas de témérité comme d'autres, de précipitation dans le nouveau quand même, dans 
l'invention à tout prix ; elle ne fait qu'imiter, mais elle imite de plus en plus mal, comme la versification de même date. Si, parmi nous, les bonnes règles de l'apprentissage en tout genre se perdaient, si les jeunes ouvriers se modelaient de moins en moins sur leurs aînés ou sur leurs patrons, avant de songer à les surpasser, la décadence de notre production serait proche. Le progrès industriel est d'autant plus rapide que chaque amélioration apportée aux secrets d'atelier, aux procédés de fabrication, aux machines, etc., est plus exactement copiée par ceux qui en ont apprécié les avantages. -Enfin, le progrès des mœurs s'opère, non à la faveur de ce laisser-aller moral qui produit la dissolution des mœurs anciennes sans préparer la formation de mœurs nouvelles, mais par la préoccupation générale de se conformer dans sa conduite aux meilleurs exemples, ou réputé tels, qu'on voit surgir autour de soi.

\section{$\mathbf{V}$}

$\underline{\text { Retour à la table des matières }}$

Ainsi, il n'est pas vrai que l'inexactitude des souvenirs et celle des imitations soient favorables à l'évolution mentale ou à l'évolution sociale; et voilà pourquoi, dans la période ascendante de l'esprit, à mesure qu'il évolue plus rapidement vers son apogée, ses souvenirs vont se précisant aussi bien que se multipliant; voilà aussi pourquoi, pendant la croissance des sociétés, à mesure qu'elles s'élèvent plus vite au sommet de leur civilisation propre, tout en elles prend un air plus régulier, plus précis, presque mécanique : leurs langues fixées, leurs religions dogmatisées, leurs théories arrêtées, leurs administrations centralisées et uniformisées, leurs produits de tout genre stéréotypés pour ainsi dire, sortis du même moule comme leurs idées et leurs besoins. Un train de chemin de fer est bien plus compliqué et bien plus progressif, bien plus prompt aux améliorations qu'une caravane ; cependant les caravanes qui se suivent se ressemblent beaucoup moins que les trains qui se suivent. De plus en plus, on s'évertue à refléter fidèlement les coupes d'habits, les coupes de vers ou de phrases à la mode, à saluer suivant l'angle exact d'inclinaison de la tête ou du corps 
qui est actuellement en usage dans les salons, à se mettre au ton de son atelier, de son bureau, de son administration quelconque, dans le plus menu détail, ou, si l'on poursuit une apparence d'originalité, à copier comme un fac-similé l'excentricité particulière sur laquelle on se modèle sciemment ou à son insu. Le scrupule de la fidélité imitative poussé jusqu'au tic et à la manie est si peu le caractère exclusif des sociétés naissantes, qu'en réalité il est fort peu répandu en elles et qu'il l'est beaucoup plus dans les civilisations avancées, formalistes et procédurières en tout. Mais ce n'est jamais cette rigueur de conformisme qui est par elle-même, je le répète, un obstacle au progrès; elle ne l'est que lorsqu'elle affecte l'imitation du passé, à l'exclusion de l'imitation du présent. Elle devient alors un rituel sacré et immuable; ce qui n'est pas toujours un mal, et ce qui, d'ailleurs, est un penchant encore plus développé au sein des civilisations mûres que parmi les barbaries adolescentes. Pour n'en citer qu'un exemple entre mille, quel est le fabricant de cartes à jouer qui oserait de nos jours introduire la moindre modification dans les noms ou les attributs consacrés des personnages et des quatre couleurs ? Il serait sûr de ne trouver aucun débit. Aussi des milliards et des milliards de cartes scrupuleusement identiques continuent depuis plusieurs siècles à se fabriquer sur notre continent si révolutionnaire, tandis que, au début du XIVe siècle, les transformations les plus considérables ont été apportées arbitrairement, avec la plus grande liberté, dans le nombre, la forme, les dimensions, les dénominations et les couleurs des cartes ${ }^{1}$. Dira-t-on que la sélection du meilleur ou du plus fort est pour quelque chose dans le triomphe définitif des particularités adoptées, et que ces royautés traditionnelles, non les moins dangereuses des monarchies, méritent le privilège qu'elles possèdent d'être respectées unanimement par les plus fougueux anarchistes des brasseries? Mais je ne vois vraiment pas en quoi il convenait mieux d'appeler Hector que de tout autre nom le valet de carreau. La vérité est que la fixation des types propagés, propagés à tort ou à raison, a été la condition de la multiplication et du développement savant des jeux, nouvelle issue, et bien plus récréative, donnée au besoin de variation. À l'origine, pendant que les types de cartes variaient d'une année à l'autre, les règles des jeux n'ayant pas non plus le temps de se fixer, l'art de jouer devait rester embryonnaire. Je ne puis me défendre de penser que les

Lacroix, Arts au moyen-âge, p. 244. 
constitutions et les législations sont aux industries et aux arts, et la grammaire, sinon l'orthographe, aux lettres, ce que les cartes à jouer sont au plaisir du jeu; sans leur stabilité assurée, point de renouvellement sérieux et profond.

L'imitation, comme la mémoire, peut être très lente, mais très tenace (c'est le cas des époques où la coutume règne à peu près seule) - ou très rapide, mais très fugace (c'est le cas des épidémies de mode momentanément envahissantes) - ou à la fois très lente et très fugitive - ou enfin très rapide et très persistante. De ces quatre combinaisons, la dernière est seule avantageuse de tous points et caractérise les civilisations consommées. La troisième est une anomalie complète, qui se montre au déclin des nations tombées dans l'atonie finale, et apparaît aussi, passagèrement, au lendemain de grandes catastrophes nationales. Il n'est pas donné à tous les peuples, au sortir d'une guerre de 1870 et d'une Commune de Paris, de voir se redresser brusquement le ressort de toutes les activités avec cette élasticité que M. Halévy, par exemple, a si bien peinte dans ses Notes et Souvenirs. À Athènes même et à Florence, après la grande peste, dans toutes les républiques italiennes, après cette série de convulsions sociales qu'elles ont traversées, on remarque une paralysie presque totale du travail, c'està-dire de la force d'imiter. C'est ainsi qu'à la suite d'accès épileptiques répétés, la mémoire s'affaiblit ou se meurt. Le génie alors a beau enfanter des merveilles, elles sont perdues pour la masse insouciante du public qui vit sur son fond d'habitudes, diminuées elles-mêmes et usées. Au demeurant, il convient de distinguer entre la perte accidentelle de certaines catégories d'imitations, c'est-à-dire l'interruption forcée de certains métiers, de certains arts, de certaines sciences mêmes dont tous les secrets ont été détruits avec leurs dépositaires par un fléau national, et la destruction de certaines espèces d'imitativités. Ici, la capacité est atteinte, bien que l'occasion de s'exercer subsiste. Là, c'est l'occasion qui manque à la faculté. De même, pour la mémoire, autre est l'effacement de certains souvenirs par un accident, autre est la suppression d'une certaine espèce de mémoire. Il y a des malades qui, ayant oublié tout ce qui précédait une certaine date, très intelligents d'ailleurs, sont portés à dater leur naissance de cette époque. Tels sont les Français de notre siècle qui font naître la France en 1789. Mais cela ne les empêche pas d'avoir gardé et même 
considérablement accru tous les genres d'imitativités qui brillaient chez leurs pères d'ancien régime.

Mais les deux premières des quatre combinaisons de caractères cidessus indiquées méritent de nous retenir un instant. Passons en revue les diverses maladies dont la coutume et la mode peuvent être atteintes, par excès ou par défaut, dans les différentes branches de l'activité sociale.

En ce qui concerne le langage, un purisme exagéré, rebelle à toute innovation, est aussi morbide qu'une fureur insensée de néologisme par importation de mots empruntés à des langues étrangères, vivantes ou mortes. L'affectation d'archaïsme n'est qu'une forme insidieuse du néologisme. Il y a des provinciaux qui affectent parfois de parisianiser leur accent ; mais cet accent postiche est un ridicule individuel qui ne court pas le danger de se généraliser. La contagion de l'accent suit d'ordinaire une marche très régulière et s'écarte rarement des voies les plus normales. L'accent est, plus encore que la prononciation, ce qui dans le langage se copie le plus fidèlement, du supérieur à l'inférieur, de la capitale aux provinces, de l'adulte à l'enfant, et, une fois communiqué, se consolide le mieux. L'accent parisien est-il resté le même depuis plusieurs siècles ? Je n'oserais l'affirmer, car la prononciation à laquelle il est lié a changé, comme le prouvent tant de mots qui rimaient jadis et qui ne riment plus. Mais, s'il se modifie, c'est avec une très sage lenteur, et, partout où il se répand avec une vitesse très suffisante, il s'enracine à demeure. - Il est curieux de penser que, si les provinces du midi de la France, au moyen-âge, avaient triomphé de celles du nord, toute la France aujourd'hui, du moins dans les classes instruites, gasçonnerait ou aurait l'accent provençal. Ce n'est donc pas à ses qualités particulières que l'accent de Paris doit sa diffusion, mais bien à des accidents historiques; et on voit par là clairement, soit dit entre parenthèses, à quelle profondeur descend en nous, à notre insu, jusque dans les intimités moléculaires de notre organisme pour ainsi dire, le prestige du pouvoir, puisque son action suggestive s'exerce même sur un phénomène aussi étranger à notre conscience et à notre volonté, aussi physiologique avant tout par son mécanisme, que la communication de l'accent. 
Passons aux religions. C'est sous cet aspect que se déploie le plus richement, mais aussi le plus notoirement, la pathologie de l'imitation. Les maladies de cet ordre, quand elles consistent en exagération coutumière, se nomment fanatisme ou bigoterie, suivant qu'elle portent plus spécialement sur la crédulité aveugle aux dogmes ou l'observance puérile des rites. Quand elles consistent, ce qui est plus rare, mais tout autrement important, en excès soudains de mode, elles se traduisent par ces rages extraordinaires et épidémiques de conversion, par ces soifs ardentes de nouveautés religieuses, par ces épidémies de pénitence (telles que celles des flagellants en 1310 et 1334, et d'autres pareilles, émanées de Florence, sous Savonarole), dont toutes les religions prosélytiques ont bénéficié à diverses époques, christianisme, boudhisme, islamisme. Quand on songe au nombre infinitésimal de néophytes que le zèle des missionnaires parvient à convertir en temps normal, dans l'intervalle de ces fièvres contagieuses, on doit reconnaître que, sans elles, jamais le christianisme de l'empire romain, jamais l'islamisation de la moitié de l'Asie et de l'Afrique, jamais la conquête spirituelle de l'Inde, du Thibet, de la Chine, par les apôtres de Bouddha, n'auraient été possibles ni même concevables. L'idée d'une religion universelle était ce qui, dans les prétentions du christianisme naissant, paraissait le plus chimérique aux Romains du second siècle de notre ère, à cette époque où, malgré la romanisation de tant de peuples, le morcellement des cultes était encore si grand. Ces Romains, il est vrai, ne réfléchissaient pas que si, au second siècle après la fondation de Rome, on avait prédit à tous les peuples riverains de la Méditerranée, toujours très morcelés jusque-là, qu'ils seraient un jour assujettis ensemble à un seul d'entre eux érigé en République universelle, le rire et les haussements d'épaules n'eussent pas manqué d'accueillir cette prédiction. L'erreur, en ce monde, est de ne pas s'attendre à l'inattendu. Les victoires merveilleuses des légions romaines étaient des anomalies comme les conversions en masse au culte du Christ. L'anormal a sa place voulue en histoire; il est des fièvres de croissances qui sont de bienfaisantes maladies. C'est par des formations sédimentaires entrecoupées de formations éruptives que la terre s'est constituée normalement, malgré le caractère anormal de ces dernières; c'est aussi par des alternances de routine coutumière et d'enthousiasme novateur que les assises religieuses se succèdent et se superposent. Précisément parce que le lien religieux sous ses formes 
multiples, philosophiques ou scientifiques parfois, est le lien social par excellence, c'est surtout par son côté religieux que l'homme en société est imitatif; et, par suite, il ne faut pas s'étonner de voir les deux grandes branches alternantes de l'imitation, la coutume et la Mode, aboutir ici à des exagérations opposées de développement plus extravagantes que nulle part ailleurs. Autant, par exemple, les Bretons sont tenaces depuis des siècles dans leur foi chrétienne comme ils l'avaient été jadis dans leur foi druidique, autant ils ont été prompts un jour, sous l'empire d'une exaltation prodigieuse et transitoire, à renier le druidisme et embrasser la croix.

À quel point cette exaltation a été vive et profonde en même temps chez tous les peuples qui tour a tour l'ont ressentie, on en jugera par l'observation qui suit: "Une loi remarquable, dit M. Sayous ${ }^{1}$, se dégage de l'histoire de la propagation du christianisme : des nations déjà converties (à peine converties) sort un apôtre qui va trouver une nation encore païenne, et cette nation une fois convertie produit un apôtre à son tour. Le moine romain Augustin avait conquis les AngloSaxons ; du peuple anglo-saxon sort saint Boniface, qui va conquérir les Allemands; du peuple allemand sortent des missionnaires qui se rencontrent avec ceux de Constantinople pour conquérir la Bohême ; enfin, des rangs des Tchèques de Bohême une fois convertis sort l'apôtre Vojtach. »

La philosophie et les sciences ont aussi leurs périodes alternatives de conservatisme et d'affolement. Après des temps régis par l'entêtement héréditaire de l'Université de Paris pour Aristote, on voit sévir l'engouement général pour Descartes. Dans un siècle où domine la disposition à se Modeler sur les aïeux, on ne doit pas plus être surpris des résistances opposées par les corps savants à la découverte de la circulation, ou à celle de la rotation du globe terrestre autour du soleil, qu'on ne peut s'étonner aujourd'hui, en notre siècle épris d'exemples exotiques et contemporains, de l'accueil enthousiaste fait à des hypothèses rapidement accréditées, saluées vérités, consacrées dogmes, se répandant en quelques années suivant une progression géométrique, et auxquelles la vitesse même de leur vulgarisation semble tenir lieu de démonstration. Je ne parle pas seulement de

Études sur la religion romaine et le moyen-âge oriental. - Ernest Leroux 1889. 
l'atomisme en chimie, du darwinisme en histoire naturelle, ni d'autres théories tout au moins très spécieuses et très fortes, mais de conjectures encore en ébauches, telles que, par exemple, le type criminel de M. Lombroso.

En politique, comme chacun sait, la singerie humaine s'exprime tantôt par un traditionnalisme servile qui ne supporte pas l'idée de la plus légère et indispensable réforme, tantôt par un radicalisme aigu qui est toujours, au fond, un besoin de copier quelqu'un ou quelque chose, seulement de copier un étranger ou un contemporain à la mode, une idée nouvelle et dans l'air, non les aïeux, non les anciennes idées. Cette frénésie est en train d'européaniser le Japon pendant qu'elle américanise certains pays d'Europe. L'histoire de la Grèce, l'histoire de Rome, l'histoire de France, l'histoire de tous les peuples, est remplie par le long duel, aux péripéties infinies, entre les populations maritimes ${ }^{1}$ et les populations continentales, ou entre les citadins et les ruraux, ou entre les progressistes quelconques et les conservateurs quelconques qui, sous des noms divers, ceux de Thémistocle et d'Aristide par exemple, de César et de Caton, etc., personnifient momentanément la lutte éternelle entre la mode et la coutume en fait de gouvernement. Il n'est pas de nation, si routinière soit-elle, qui n'ait ses heures de manies novatrices, c'est-à-dire importatrices du dehors ; l'Égypte elle-même n'eut-elle pas sa fureur d'hellénisation sous les Psammétiques ? Quand cette maladie atteint les têtes couronnées, on doit présumer qu'elle est bien répandue parmi leurs sujets. Or, c'est bien souvent qu'on la signale sur les trônes, où, du reste, aussi bien qu'au sein des foules, elle a souvent produit de bons effets. Nous lui devons, par exemple, au XVe siècle, la réforme monétaire de Charles

La vie des peuples pasteurs, dans le Sahara comme sur les plateaux de l'Asie centrale, partout, se passe en migrations circulaires, revenant à leurs points de départ, et comparables aux migrations des oiseaux ou aux voyages des navires de commerce. Si donc la vie maritime a de tout temps favorisé l'expansion des imitations de peuple à peuple, il a dû en être ainsi de la vie pastorale aux époques reculées où les caravanes jouaient le rôle commercial de nos vaisseaux. On objectera peut-être que rien n'est plus immuable au fond que les pasteurs nomades, Berbères ou autres. Mais il en est de même des matelots, des marins, qui n'en sont pas moins des véhicules d'idées et d'exemples extérieurs. Par eux, le pollen des civilisations assises, agricoles et continentales, est porté à d'autres et produit d'heureux ou malheureux croisements. Les tribus pastorales ont dû être jadis aux cités agricoles et industrielles ce que les abeilles sont aux fleurs. 


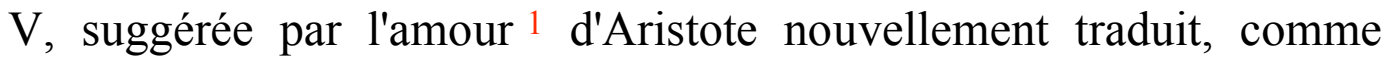
nous lui devons l'affranchissement des communes au XIIe siècle, à l'instar de l'une d'elles, dont l'exemple a couru tout le nord de la France ainsi qu'un feu de poudre. L'engouement qui, aux deux derniers siècles, poussait tous les principicules allemands à singer le roi de Versailles, ou qui, au commencement du nôtre, a poussé les chefs des républiques espagnoles de l'Amérique méridionale à caricaturer leurs collègues de la première République française, est de même nature, au fond, que les entraînements populaires des croisades, ou des fêtes de la Fédération en 1790. Beaux mouvements, célébrés pourtant avec assez d'inconséquence et un excès de lyrisme par les historiens qui croient y voir des explosions d'émancipation individuelle. Ce ne sont, en effet, que des ouragans d'imitation toute puissante, des accès inouïs de crédulité et de servilité aussi irrésistibles qu'inconscientes. Des historiens d'un tempérament opposé, à la Guizot, ont voué leur admiration aux peuples opiniâtres en leurs traditions séculaires. Un long fleuve de coutumes immuables est à leurs yeux le plus beau des spectacles. Au moins ces auteurs sont-ils logiques ; mais peut-être, en tout ceci, n'y a-t-il rien à admirer, et j'approuve ceux qui réservent leurs applaudissements pour l'éruption, très rare, d'une grande idée nouvelle dans un cerveau individuel.

Distinguons bien deux cas différents, subdivision de l'imitationmode. Il est des temps où les rois ne se piquent d'imiter que d'autres rois étrangers, plus grands, mais semblables à eux par la civilisation ou la religion, - où les aristocraties ne se règlent que sur l'exemple d'autres noblesses étrangères, plus brillantes mais analogues, celle d'Angleterre au moment de la Restauration sur celle de France, par exemple, - où les bourgeoisies ne copient que d'autres bourgeoisies, comme sous Louis le Gros, - où, enfin, les corporations, les confréries, les métiers, les écoles ne se préoccupent que de rivaliser avec d'autres corporations, d'autres confréries, d'autres métiers, d'autres écoles, florissantes au dehors, mais de même nature. Cette sorte d'imitation circonscrite et pour ainsi dire professionnelle, n'est pas celle qui excite

«C'est un fait acquis, dit M. Siméon Luce (Revue historique, mai-juin 1881), que l'influence des doctrines économiques d'Aristote domine l'histoire du règne de Charles V. C'est à cette influence qu'il faut attribuer la fixité des monnaies qui caractérise ce règne $»$. La Politique d'Aristote venait d'être traduite, et il s'était engoué de cette nouveauté. 
le plus, par ses excès, la verve des satiriques et le blâme des moralistes. Poussée à bout, cependant elle tend à creuser entre les classes et les professions différentes un fossé profond, dans le même État, pendant que, d'un État aux États voisins, elle supprime toute différence entre les classes et les professions de même ordre. Il s'ensuit une organisation où l'idée de caste tend à éclipser l'idée de patrie, où la différenciation anti-nationale marche de front avec l'assimilation internationale. C'est sous l'action longtemps continuée de cette imitation spéciale que, au XVIe siècle, les cours de France, d'Espagne, d'Italie, d'Angleterre, rivalisant de faste royal, étaient arrivées à un degré de similitude frappant déjà, ainsi que les noblesses de ces divers Pays, et aussi bien leurs clergés, pendant que la distance allait en augmentant, dans chaque pays, entre la cour et la noblesse, entre la noblesse et les classes inférieures. Supposez que le courant des exemples fût resté ainsi canalisé dans son lit étroit, de plus en plus prolongé, mais toujours aussi rétréci, et, malgré la beauté pittoresque de ce spectacle admiré des historiens artistes, vous verrez que nous aurions été nous éloignant du confluent démocratique où tous ces courants divers ont fini par déboucher. Mais cette supposition est inadmissible; en se prolongeant, ce fleuve devait nécessairement s'élargir. A force de chercher au loin, de plus en plus loin, des modèles brillants dans sa propre sphère sociale, on devait peu à peu en chercher hors de celle-ci; et de là des pastiches nombreux dont la comédie s'est souvent moquée, bien qu'ils aient ouvert des voies utiles. Au XVIIe siècle, toute l'Allemagne est pleine de roitelets qui jouent au grand monarque de Versailles, aussi ridicules à coup sûr que Clovis pouvait l'être habillé en consul romain, ou Chilpéric faisant des vers comme Néron, beaucoup plus assurément que ne l'était l'empereur allemand Frédéric II 1, dans ses libres importations de mœurs musulmanes en pleine Chrétienté. Mais ne rions pas trop; la Prusse a dû sa grandeur à cette manie du premier de ses rois. -A la même époque fleurit le type du bourgeois gentilhomme et de même celui de l'abbé musqué et galantin, de l'abbé-gentil-homme, comme plus tard celui du paysan demi-monsieur. Dès le XIVe siècle, les gens d'église, dit Quicherat, avaient un penchant prononcé à imiter les toilettes laïques, bien que, à l'inverse, la barrette ait été empruntée par

Le royaume normand de Sicile, transformé par Frédéric Il au XIIIe siècle, suivant la mode musulmane, a servi de modèle à beaucoup de principautés italiennes du temps. 
les laïques au clergé. -Or, si la vanité imitative de M. Jourdain a quelque chose de morbide, la prétention qui pousse aujourd'hui tant de gens à sortir de leur condition et à grossir la tourbe des déclassés, pépinière de malfaiteurs, n'est pas moins maladive. Mais, par là, se pelleverse le fond social à des profondeurs inconnues jusqu'à nous.

Les maladies de l'imitation, en matière de Droit, sont désastreuses. Là, une immobilité paralytique, un fétichisme absurde du passé, alterne avec des périodes d'activité législative intempérante et brouillonne. Mais passons.

\section{VI}

$\underline{\text { Retour à la table des matières }}$

Dans le monde économique, les excès de coutume ou de mode sont plus dangereux encore, comme chacun sait. Tantôt ce sont les producteurs, tantôt les consommateurs qui sont sujets à ces maladies contraires. Chez les producteurs d'abord, la ténacité routinière d'industries démodées qui ont perdu leur raison d'être, ou de prix et de salaires traditionnels, n'est pas ce qui cause le plus de mal ; peut-être la promptitude excessive à introduire partout une industrie nouvelle qu'on voit réussir quelque part 1 , à adopter partout un prix nouveau, qui quelque part est justifié, est-elle la source de ruines plus lamentables. De là cette périodicité de crises commerciales qu'occasionne la surproduction intermittente. Ce mot de crises, emprunté à la pathologie, vient ici naturellement sous la plume de tous les écrivains. Ce n'est pas qu'il n'existe aussi des crises religieuses, causées à certaines époques par une fermentation de nouveautés hérétiques ou philosophiques, découvertes scientifiques, philosophiques pareillement; n'en traversons-nous pas une, à cette heure ? Ce scepticisme

Cet empressement n'est point particulier aux Européens. Chez les peuples inférieurs, on remarque souvent un engouement grotesque qui leur fait oublier certaines fabrications où ils excellent supérieurement, pour se mettre à la mode. Les Polynésiens ont cessé de fabriquer leurs pirogues accouplées, si admirées des navigateurs d'autrefois, pour confectionner des canots à l'instar des nôtres, bien moins adaptés à leurs besoins. 
éclectique ou pessimiste qui se répand parmi nos contemporains, n'estce pas l'équivalent des faillites multipliées qui signalent les crises du commerce et de l'industrie ? Chaque esprit qui sombre dans le doute incurable fait banqueroute à la science et à la pensée. Il y a aussi, nous le savons, des crises législatives où les codes morts-nés se succèdent vainement, comme des sociétés anonymes pour la liquidation d'une entreprise impossible. Il y a enfin et surtout des crises morales, compliquées de crises esthétiques, où le bien et le beau désorientés cherchent leur pôle. Mais, de toutes ces crises, les plus visibles et les mieux étudiées sont celles qui frappent les commerçants et les industriels ; et c'est pour les guérir que les empiriques ou les chirurgiens ont imaginé toute sorte de remèdes, dont les plus préconisés à cette heure composent ce qu'on appelle le socialisme d'État. Malheureusement, les utopistes ou les souverains qui s'occupent de ces questions oublient que toutes leurs panacées seront des palliatifs, s'ils ne trouvent pas le moyen d'agir sur le régime et la pente du fleuve de l'imitation, et de changer son cours, non seulement parmi les producteurs, mais parmi les consommateurs.

Chez ces derniers, dont les goûts et les besoins, tour à tour incorrigibles et capricieux, font loi pour les premiers, il souffle parfois des vents, des ouragans de mode, qui renversent tout, et échappent à toute prévision comme à toute direction. L'histoire du costume abonde en illustrations de cette vérité. "Il est prouvé par d'irrécusables témoignages, dit Quicherat ${ }^{1}$, que l'usage du linge de corps, les larges chaperons à cornettes, les jaquettes froncées et bordées de pelleteries, les mahoîtres, les souliers à la poulaine, furent adoptés par les paysans. " Ainsi accoutrés, des paysans ne devaient être guère moins curieux à voir que des nègres africains en habit noir. Tous ces vêtements de luxe leur venaient des villes de leur voisinage, où ils les avaient admirés, et qui elles-mêmes les avaient reçues, dans le Nord, du Midi plus riche et plus civilisé, par la même raison qu'aujourd'hui, le Midi au contraire se règle sur le Nord. Aux XIIe, XIIIe et XIVe siècles, le foyer de la civilisation européenne était sur les rives de la Méditerranée, en Sicile principalement, en Provence, en Espagne, en Italie. De ces régions sont parties toutes les innovations, souvent excentriques et disgracieuses, mais toujours adoptées avec un

Histoire du costume en France. 
empressement frénétique, qui ont plusieurs fois révolutionné le costume au moyen âge. La révolution qui eut lieu en 1190 et qui inonda l'Europe de vêtements longs, encombrants, fastueusement incommodes - les robes de nos hommes de loi en sont le dernier vestige -provenait des Normands-Siciliens. La révolution de 1340, qui, en une année, substitua à cet excès d'ampleur les formes les plus étriquées, à l'exception des chapeaux, devenus au contraire gigantesques, prit naissance en Catalogne et en Italie. À cette époque, «les mêmes usages étaient communs à toutes les villes de la Méditerranée, depuis Barcelone jusqu'à Gênes ${ }^{1}$. ». Quand, au XVe siècle, Gand et Bruges devinrent les villes les plus riches du monde, quand la cour du duc de Bourgogne fut le centre le plus brillant de l'Europe, c'est de là que partirent les rénovations du costume, par exemple la mode du hennin, cette coiffure si bizarre, en 1428. Cette multitude d'édits, de décrets, de règlements anciens et modernes, qui ont interdit à telles classes de citoyens de porter tels costumes, aux sénateurs romains de s'habiller en Asiatiques, aux roturiers de s'habiller en seigneurs, etc., prouvent la force universelle et constante du penchant à se parer sur le patron d'autrui.

Cette force est encore attestée, dans certains cas, par l'incommodité et la laideur des modes copiées. Conçoit-on qu'au XIIIe siècle les femmes se soient maquillées en se jaunissant les joues avec du safran! Jusqu'où va la tyrannie de la mode ${ }^{2}$ ! Ce siècle, d'ailleurs, aimait le jaune ; il jaunissait le linge mis à la lessive comme nous le bleuissons. - La mode des vêtements longs au XIIe siècle, dont nous venons de parler plus haut, était ce qu'on peut imaginer de plus gênant. Le manteau, notamment, au lieu d'être attaché sur l'épaule droite, ce qui eût laissé au bras droit sa liberté, fut attaché sur l'épaule

Au XIIe siècle, l'usage de s'habiller en noir pour marquer le deuil n'existait qu'en Espagne, d'après Baudry, abbé de Bourgueil, écrivain du temps ; aux XIVe et XVe siècles, la France, l'Angleterre et d'autres pays avaient adopté cet usage dont l'origine méditerranéenne est ainsi attestée. Combien il a fallu que la violence du courant de la mode fût extrême pour avoir décidé les jeunes femmes à adopter cette couleur sévère! Il est vrai que le noir sied aux blondes.

2 Contre cette tyrannie est venu échouer le despotisme même de Louis XIV. Toute son autorité royale a été impuissante à faire proscrire de sa cour la mode des coiffures hautes de dames. En revanche, il suffit de l'apparition, à Versailles, d'une dame anglaise coiffée bas pour faire reléguer les coiffures hautes aux oubliettes. C'était en 1714, et le cyclone d'imitation-mode qui a labouré tout le XVIIIe siècle jusqu'au cataclysme final commençait à se faire sentir par le prestige croissant de l'étranger. 
gauche, ce qui entravait tous les mouvements du bras ouvrier. Notez que le siècle où ce costume insensé se généralisa si vite était un siècle remarquable par son activité remuante. Mais, précisément parce qu'il était très actif, très sociable, il était très imitatif...

Puisque nous parlons du costume, profitons de cette occasion pour remarquer les confirmations frappantes que son histoire vient apporter à quelques-unes des lois de l'imitation énoncées, en passant, ci-dessus. D'abord, nous y voyons toujours l'exemple descendre du supérieur à l'inférieur, c'est-à-dire des régions les plus civilisées, les plus prospères, les plus fertiles en inventions heureusement exploitées, aux nations plus arriérées et plus pauvres, et, dans chaque nation, des aristocraties, j'entends des aristocraties jeunes et partant novatrices, aux tiers états et aux plèbes. Ajoutons, ce qui surprendra notre siècle, des hommes aux femmes. L'homme n'a jamais été porté à imiter le costume féminin. Mais jadis, quand la supériorité masculine était écrasante et indéniable, la femme se paraît à l'instar de l'homme, et voilà pourquoi nous constatons que le guerrier primitif, et non sa compagne, est couvert de bijoux ${ }^{1}$. Le civil, anciennement, était porté à imiter le militaire. La chlamyde, vêtement militaire, devint, au IVe siècle, le manteau préféré des personnes de condition noble.

En second lieu, l'histoire du costume nous fournit des exemples sans nombre de cette alternance de la coutume et de la mode, ou plutôt de cette consécration de la mode en coutume, que nous avons érigée en loi générale. On s'aperçoit, à la résistance opposée par les prédicateurs du moyen-âge aux moindres changements dans la coupe ou l'étoffe des vêtements, que le costume ancien était devenu très cher et presque sacré aux populations. Cependant, ce costume lui-même, si l'on remonte à ses origines, a commencé par causer, à sa naissance, un scandale égal à celui que provoque sa disparition. On a la preuve que la coupe de cheveux traditionnelle des Bretons, conservée, de nos jours mêmes, avec un respect religieux, a été importée en Bretagne au XVe siècle : c'est la coupe mise en vogue par la cour de Louis XI. De même, les bonnets des Gauchoises « ne sont que les hauts bonnets du

Du reste, le costume féminin, à l'origine, était loin de différer autant que maintenant du costume propre à notre sexe. On est souvent, dit Quicherat, dans l'impossibilité, sur les bas reliefs, de distinguer si on a l'image d'un Gallo-Romain ou d'une Gallo-Romaine. 
temps de Charles VII », mis à la mode vers 1430. «Les bonnets de certains villages vendéens rappellent encore les larges atours de la reine Isabelle », etc. Voilà pourquoi - le rite n'étant qu'une habitude et toute habitude finissant par prendre un air rituel, comme l'a finement remarqué Guyau - nous ne devons pas être surpris de voir les soutiens attitrés du rite et de la tradition, prédicateurs, moralistes, conciles, au moyen âge et même dans les temps modernes, tonner contre les modes nouvelles, quelles qu'elles soient, et signaler comme l'indécence suprême une dérogation quelconque à des toilettes traditionnelles, qu'ils avaient pourtant maudites autrefois. Si les vêtements s'allongent, augmentent d'ampleur, comme en 1190, c'est la ruine des familles, c'est de la folie. S'ils se raccourcissent, comme en 1340, c'est une inconvenance sans nom, une immoralité criante. Tel seigneur, en se baissant, a laissé voir le haut de ses braies; là-dessus, toutes les foudres séculières ou ecclésiastiques sont lancées. Les cornes des coiffures de femmes étaient anathématisées, parce qu'elles rappelaient les cornes du diable ; les souliers à la poulaine, parce que leur pointe faisait songer à l'ergot du diable ! Mais, en 1480, quand ces dernières chaussures furent remplacées par des souliers à bout rond, plus commodes à coup sûr, les prédicateurs se scandalisèrent encore, et on fit à ce sujet des doléances sans fin.

Mais si nous y regardons de près, nous verrons qu'au fond ces jérémiades, pour être abusives, n'étaient pourtant pas aussi dénuées de fondement sérieux que nous pourrions le penser. Et cette considération confirmera ce que nous disions plus haut relativement à la marche normale de l'imitation, qui va des dedans aux dehors de l'homme, ab interioribus ad exteriora. En effet, si les costumes nouveaux, venus, avons-nous dit, des régions les plus civilisées et les plus émancipées intellectuellement de la chrétienté ou même de l'islam, du Midi d'abord, foyer de toutes les hérésies alors, plus tard du Nord, scandalisaient à ce point les gardiens du dogme, n'allons pas croire que ceux-ci, gens fort intelligents, aient obéi à une simple horreur instinctive du changement, à un misonéisme puéril, comme dirait M. Lombroso. Ils savaient ce qu'ils faisaient et ce qu'ils disaient, et leurs déclamations prouvent - ce dont témoignent d'ailleurs tant d'autres faits (le succès d'hérésies nombreuses, l'émancipation des communes, etc.) - que l'invasion des idées émancipatrices, d'origine méridionale, puis septentrionale, avait précédé et préparé l'invasion 
des mœurs et des toilettes nouvelles, de même source. Quand parut la mode des vêtements longs, inspirée aux Siciliens par le costume musulman, nous savons que déjà la science, les arts, les idées et les mœurs arabes avaient fait leur chemin dans l'Europe chrétienne, et que cette nouvelle importation orientale contribuait à accélérer leurs progrès. Les sermonneurs n'avaient donc pas tort de croire ces nouveautés « imaginées en dérision de Dieu et de la sainte Église. » Elles étaient apportées par un grand vent d'indépendance spirituelle. Sans cette raison-là, comment n'aurait-on pas ouvert les yeux à l'évidence, qui montrait la supériorité de la mode de 1340 sur l'ancienne? Le vêtement de cette date n'avait rien d'indécent, et, simple autant que commode, il était éminemment propre à l'action. Mais ces grands vents dont je parle ne soufflaient que par bouffées, au moyen-âge. Aussi, quand ils étaient apaisés, le changement qu'ils avaient produit dans les usages cessait de faire fulminer les autorités religieuses et bientôt même s'abritait sous leur protection, sans qu'il y eût là de leur part la moindre inconséquence.

Me reprochera-t-on de m'être tant attardé sur l'évolution du costume ? On devrait plutôt me savoir gré d'avoir ainsi détourné les yeux d'épidémies imitatives tout autrement graves, vraies névroses publiques, qui ont ensanglanté le monde: la longue traînée des jacqueries, les poussées successives des émeutes parisiennes, maillotins, cobochiens, etc., pendant la guerre de Cent ans ; la SaintBarthélemy, ses antécédents et ses suites, les septembrisades et tant d'autres horreurs... Éloignons-nous de ce fleuve de sang. Les maladies de l'imitation, relativement bénignes, celles qui ont trait aux usages de la vie commune, sont plus intéressantes peut-être, parce qu'elles sont plus fréquentes. Par exemple, on a peine à se figurer à quel. point a été tenace et indéracinable le ridicule usage des baisers de cérémonie entre hommes. De la cour des rois de Perse, à travers je ne sais combien de. vicissitudes, il a passé à la cour des empereurs romains, puis à celle de Louis XIV. Il a fallu un édit de Tibère pour mettre un frein, momentané seulement, à cette fureur d'embrassades grotesques. - Disons encore un mot d'une autre sorte d'usage, les voyages.

Non seulement les voyages favorisent le développement de l'imitation en tout genre, mais encore ils sont eux-mêmes une des 
formes les plus développées du besoin social d'imiter ses semblables. Les oiseaux ou les poissons migrateurs, qui se suivent à la queue-leuleu dans l'air ou dans l'eau, ne se copient pas plus docilement entre eux que les voyageurs humains, voire même les touristes, réputés pourtant si capricieux. Sous l'empire romain, comme à notre époque, les touristes allaient de ville en ville, de ruine en ruine, sur les pas les uns des autres, et, soit que la curiosité historique ou le dilettantisme artistique fût leur mobile apparent, la direction de leur instinct locomoteur appartenait en fait à la coutume ou à la mode, de même que la force de cet instinct était due en majeure partie à cette série de découvertes réussies, imitées, qui, en facilitant les transports, en avaient accru le besoin au point d'en faire oublier la source physique, c'est-à-dire le besoin tout animal de mouvoir les jambes.

Pourquoi des milliers de Romains nomades étaient-ils si curieux d'aller voir, à Sparte, le prétendu oeuf de Léda suspendu au plafond d'un temple, ou ailleurs une lance d'Achille, aussi authentique à peu près que l'épée de Roland, visitée à Roc-Amadour, de nos jours, par des pèlerins ? Pourquoi, en fait de beautés naturelles, n'appréciait-on alors que les rivages de la mer ou les plaines ondulées, jamais les montagnes, tandis que, de nos jours, on se précipite en Suisse et on fuit les vallées larges et sans pittoresque ? Pourquoi le courant de ces migrations, en apparence fantaisistes, en réalité moutonnières, traversait-il exclusivement la Grèce, l'Égypte, 1'Asie-Mineure (comme aujourd'hui l'Italie, l'Espagne, la Suisse), pendant que d'autres régions, très curieuses à voir, restaient oubliées ? "Non seulement, dit Friedloender, les steppes de la Russie, les mers arctiques, les merveilles de l'Afrique demeurèrent inexplorées, mais l'Inde même, ce pays des fables, paraît avoir peu tenté la curiosité des voyageurs romains. Bien que de grandes flottes marchandes naviguant pour le compte d'Alexandrie, fissent voile, chaque année, à la côte de Malabar, et que, par conséquent, l'occasion de visiter l'Inde ne manquât jamais, nous ne voyons pas que des voyageurs autres que ceux du commerce aient jamais pris part à ces expéditions. »

Le besoin d'imitation peut seul fournir réponse aux questions ici posées. - Tantôt c'est la mode qui dirige les touristes, même les touristes religieux, appelés pèlerins. Dans l'antiquité, il en était de même; mais c'était surtout les villes d'eaux qui bénéficiaient ou 
souffraient suivant les cas, des caprices de la mode. De nos jours quelle est, s'il vous plaît, la raison de la préférence générale accordée au Mont-Dore sur Cauterets, ou à Cauterets sur le Mont-Dore, ou à la Bourboule sur les deux? On va moutonnièrement où l'on voit son voisin aller (sans parler des réclames doctorales). - D'autres fois, c'est la coutume qui impose des itinéraires traditionnels: l'affluence périodique à de vieux sanctuaires, tels qu'Eleusis chez les anciens, ou les voyages périodiques des Grecs à Olympie...

\section{VII}

$\underline{\text { Retour à la table des matières }}$

En fait d'arts, les maladies de l'imitation, bien connues des critiques, sont: ou le fétichisme ultra-classique, ou l'extravagance moderniste de l'innovation à outrance, de la mode à tout prix. Je n'y insiste pas. On rira fort dans quelques années, de nos admirations actuelles, pour certaines musiques, certaines peintures, certaines littératures. - En fait de mœurs et de moralité, il y a à noter pareillement le culte superstitieux des nouvelles façons d'agir. N'en parlons ici que pour mémoire. Notons seulement l'alternance de la morale-mode et de la morale-coutume, leur lutte fréquente et le passage de la première à la seconde. La morale-mode, c'est l'honneur, écho intérieur de l'opinion contemporaine et étrangère. La moralecoutume, c'est le devoir, écho intérieur d'une voix plus profonde, d'une voix antérieure et antique, de la voix des aïeux. Mais tout ce qui est devoir n'a-t-il pas commencé par être point d'honneur?

Notons aussi l'inappréciable avantage que ce jeu alternatif a pour effet de produire : le nivellement graduel des morales locales, qui s'acheminent vers une ère de morale universelle et une, et, par suite, l'agrandissement continu du champ moral, qui, d'abord réduit aux limites de la horde, de la famille ou de la tribu, hors desquelles il n'y avait ni droits ni devoirs reconnus, ni salut ni pitié à attendre, finira par embrasser l'humanité tout entière et même l'animalité domestique. C'est là le bénéfice moral le plus net dont nous soyons redevables à la 
civilisation, c'est-à-dire à la culture intensive et extensive à la fois de l'imitation. Car tous les nivellements analogues que la mode et la coutume, en alternant, opèrent à d'autres points de vue, tous les agrandissements du champ religieux ou scientifique, du champ politique, du champ économique, du champ esthétique, auxquels elles travaillent sans cesse, concourent à cette oeuvre de la grande pacification future, dont nous pouvons déjà entrevoir l'aurore. Par là, nous sommes en possession d'une pierre de touche infaillible, applicable à tous les temps et à tous les lieux, pour juger de la valeur morale des hommes. On peut poser ce principe : toute conduite qui, dans une époque et un pays donnés, tend, par son exemple, à étendre un peu, si peu que ce soit, la frontière morale reconnue jusque-là, est digne d'éloges ; toute conduite qui tend à faire rétrograder et resserrer cette limite est digne de blâme. En vertu de ce principe, on ne saurait reprocher au citoyen antique l'étroitesse de sa notion du devoir, limitée aux remparts de sa cité. Car le domaine de cette notion et de ce sentiment n'avait jamais été auparavant plus large. Au contraire, chez ses ancêtres, il était plus étroit encore, borné à sa tribu. Mais on est en droit de s'indigner contre le politicien ou même l'homme d'État moderne qui, ayant vécu à une époque de large horizon moral, étendu à l'Europe entière ou à presque toute l'humanité, trace autour de sa petite coterie ou de son petit pays un cercle de Popilius, dans l'enceinte étriquée duquel il ramènerait peu à peu, si nous l'imitions, l'idée et le sentiment mutilés de la justice. - Epaminondas ne se préoccupait que du petit monde hellénique, et eût massacré sans scrupule ou réduit en esclavage tout l'univers barbare, si l'intérêt grec l'eût voulu. Mais il fallait autant de hauteur d'âme à un Grec du temps d'Epaminondas pour travailler sciemment et résolument, comme ce grand homme, dans le sens de la culture hellénique prise dans son ensemble, et non pas seulement dans un intérêt béotien, ou athénien, ou spartiate, qu'il en faut à un homme d'État de nos jours pour adopter une politique vraiment européenne et non pas exclusivement nationale. A ce compte, aucun des grands ministres de ce siècle n'est comparable au général thébain.

On le voit, en dépit de ces exagérations, grâce à elles parfois, l'imitation, à son insu, s'oriente vers un grand but lointain; elle tend au port vaste et souhaitable où tous les vaisseaux réunis de l'humanité ne formeront plus qu'une même flotte pacifique. Bien mieux, 
l'opération même du nivellement, à force de se prolonger, aboutira sans doute à renforcer en chacun de nous les traits de son originalité distinctive. On ne s'affranchit, en effet, de l'imitation que par la multiplicité des imitations, c'est-à-dire par la culture de l'esprit, qui consiste en une accumulation de connaissances enseignées. On imite de moins en moins par moutonnerie, de plus en plus par réflexion, à mesure qu'on se civilise. Mais ce changement lui-même est dû au développement de l'imitation. L'imitation élective, réfléchie, suppose qu'on a le choix entre des modèles différents, ce qui implique une foule d'inventions et de découvertes conservées moyennant une suite et une superposition de traditions.

On peut se demander lequel des deux excès opposés, de la mode et de la coutume, dont nous avons rapidement - et trop superficiellement - indiqué les principales variétés pathologiques, doit finalement prévaloir. Nous croyons que c'est le dernier. La mode sévit dans un temps donné et sous un aspect social donné - rarement sous tous les aspects sociaux à la fois - parce que ce temps, sous ce rapport, a montré une fécondité remarquable d'invention. Or, à mesure que les inventions et les imitations, qui en sont le rayonnement social, se multiplient, il devient de plus en plus facile, il est vrai, jusqu'à un certain point, mais de plus en plus inutile à la longue, d'inventer de nouveau. La facilité d'inventer croît à raison des croisements nombreux d'idées flottantes dans l'air, d'où la chance plus grande d'interférences heureuses. L'utilité d'inventer décroît, en revanche ; car à quoi bon se mettre en frais de génie quand on a sous la main tant de modèles excellents ? - De là deux penchants contraires, qui luttent dans le sein des civilisations avancées : un penchant à profiter de la facilité croissante des inventions pour innover sans fin, et même sans motif suffisant, et un penchant contraire à profiter du trésor d'idées géniales léguées par le passé pour se reposer en une activité délicieusement machinale. Entre les deux la victoire est fort disputée. De nos jours, en Europe, le premier l'emporte ; mais est-il probable qu'il triomphe toujours? Non, l'expérience de l'histoire, qui nous montre tant d'empires, tant de civilisations différentes, parvenus successivement, plus tôt ou plus tard, à l'équilibre mobile - Égypte, Chine, empire byzantin, etc. - ne nous permet pas de le croire. Déjà, dans nos beaux-arts mêmes et dans certaines branches de notre littérature, ne voyons-nous pas se révéler, sous des dehors 
d'imagination postiche, une véritable paresse d'esprit, habile à copier sans en avoir l'air et à démarquer le linge brodé d'autrui ? - La société, en son évolution, part de la stérilité imaginative et y retourne, mais sous des formes bien dissemblables. Chez les peuples qui se reposent dans leur civilisation consommée - la nôtre ne l'est pas encore, celle de Rome l'était déjà dès le second siècle de l'empire - on n'invente plus rien : l'empire romain après les Antonins, a vécu trois siècles, avec assez de prospérité parfois, ou du moins en continuant à assimiler ses peuples, et même les peuples voisins, sans d'ailleurs rien découvrir dans les sciences, dans les arts, dans le droit même. Mais les habitudes de travail, loin de se perdre, s'étendaient, en se déformant, il est vrai, peu à peu, et ne laissaient pas d'entretenir une prospérité grandissante en apparence, assez semblable à l'engraissement d'un eunuque. Tout autre est l'inertie intellectuelle des peuples barbares, tels que l'étaient les Germains avant leur contact fécond avec Rome. Ici, par paresse, on guerroie pour éviter le travail ; là, pour s'épargner la peine d'inventer, on imite ; et, pour s'épargner la peine de vouloir, on obéit...

Entre autres griefs, Sumner-Maine reproche au suffrage universel (il aurait pu reprocher encore mieux au jury) d'être essentiellement hostile au progrès et voué à un conservatisme absurde. Suivant lui, si le suffrage universel eût fonctionné depuis deux siècles sur toute la surface du monde civilisé, " il aurait certainement chassé la mulljenny et le métier mécanique, interdit la machine à battre, etc. ». C'est bien possible. Mais il se pourrait que cette maladie constitutionnelle des institutions démocratiques devint leur meilleure raison d'être dans l'avenir. Quant il sera temps que le flot des innovations superflues s'arrête et se solidifie immuablement, elles se chargeront de cette opération cristallisante... Mais, par bonheur, nous sommes encore loin de cette paix sénile. 


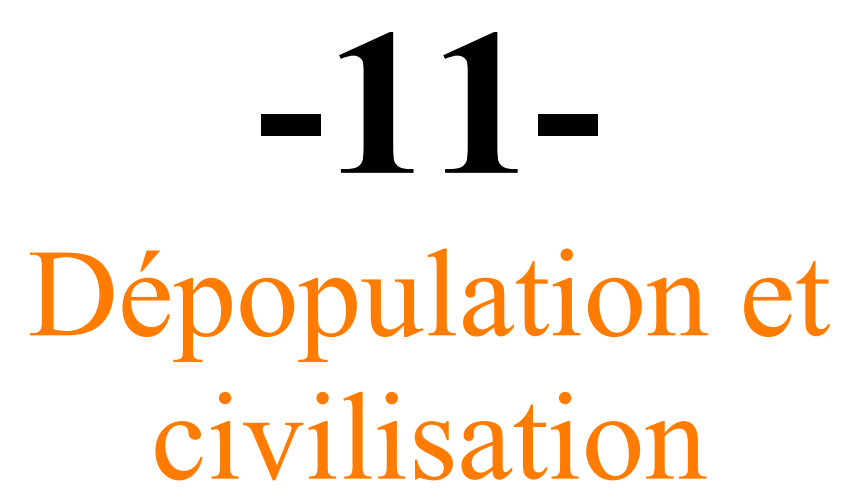

$\underline{\text { Retour à la table des matières }}$

Aussi longtemps qu'on s'est obstiné, en dépit de toutes les objections contraires, à expliquer le déclin relatif de la population française ou de toute autre par la stérilité des femmes, et celle-ci à son tour par des causes tirées de la race ou du climat, le problème de la population a paru appartenir en propre aux naturalistes; et l'on n'était pas exposé en l'abordant, au danger de faire de la politique. Mais si l'on tient pour démontré - et je pars de là - que les Français de France, par exemple, à la différence de ceux du Canada ou d'ailleurs, ont peu d'enfants parce qu'ils veulent en avoir peu, il reste à chercher la cause de cette volonté, opposée au désir naturel; et la question devenue toute morale et sociale, prend alors une tout autre envergure. Car il ne suffit pas d'apporter dans ce débat, comme le font les économistes, ces saints Jean-Baptistes de la sociologie, des considérations économiques; il n'est pas vrai que les raisons de cet ordre jouent un rôle 
exclusif ni même dominant. Loin de se régler sur les subsistances, les naissances sont souvent plus nombreuses dans les nations, les provinces, les classes les plus pauvres ; non pas toujours cependant, les peuples riches, tels que l'Angleterre, restant féconds quand ils ont gardé l'esprit de famille et de tradition avec la foi religieuse. En général, plus un peuple ou une fraction d'un peuple se civilise, plus sa natalité diminue. "Pauvreté, dit M. Dumont, ignorance noire, grossièreté et crédulité, voilà ce qui coïncide presque toujours, au moins en France, avec une natalité forte ${ }^{1}$ »; au contraire, "richesse, instruction, culte des arts, des lettres et de l'élégance, élimination de la croyance au surnaturel, en un mot tout ce qui constitue la civilisation est lié à une natalité faible ». Les départements de forte natalité sont tous montagnards : Auvergne, Bretagne, Pyrénées. De là Lombroso ne manquerait pas de conclure que la natalité est en raison directe de l'altitude. Mais M. Dumont explique le fait autrement : « les provinces les plus fécondes sont celles qui ont le mieux résisté à l'attraction de la civilisation centrale ». À l'inverse, les groupes départementaux à natalité très faible se distinguent par leur richesse, leur instruction, leurs lumières: Normandie, Gascogne, Bourgogne, Provence. Pourquoi en est-il ainsi ? Cela tient-il à l'essence même de la civilisation, ou à un caractère accidentel et passager de la nôtre, à un poison qu'elle nous apporte parmi tant de salutaires élixirs?

On conçoit que, formulé ainsi, le problème qui nous occupe se rattache à toutes les préoccupations du sociologue, à toutes les branches de la sociologie ; religion, politique, législation, mœurs, industrie, arts, tout s'y rapporte et il me faut tout d'abord louer M. Arsène Dumont, avec qui je vais causer un instant plutôt que de discuter, d'avoir mieux que personne compris la portée, la complexité, l'élévation d'un sujet trop souvent abandonné à de purs statisticiens. J'ai lu peu de livres plus profonds et plus attachants; le style, en sa sévère poésie, y reflète expressivement une pensée ferme, une âme pleine d'un noble idéal. Démocrate d'une trempe peu vulgaire, à l'effigie de Périclès et non de Cléon, cet auteur ne cache pas à ses amis les vérités dures, il montre aux démocraties leur écueil. Son ampleur d'esprit, d'ailleurs, n'est rien moins que du scepticisme ou de l'éclectisme; nous en verrons des preuves.

\footnotetext{
Voir son livre qui porte le même titre que cette étude, écrite à son sujet.
} 
Puisque la cause principale de notre dépopulation est une volonté propagée par l'exemple, pourquoi cet exemple dangereux a-t-il triomphé de la concurrence d'exemples opposés, si ce n'est parce qu'il a été jugé, et de plus en plus universellement jugé, propre à satisfaire des désirs eux-mêmes en voie de croissance et de propagation imitative ? Quels sont donc ces désirs funestes ? Pour M. Dumont, ils se résument en ce seul mot : l'idéalisme individuel. Devant l'individu fasciné, dans nos démocraties, surgissent toutes sortes d'échelles de perroquet et de mâts de cocagne, où pour la première fois il est autorisé à grimper, ce qui lui donne la rage de cette ascension. Hiérarchie sociale, niée de bouche, attestée de cœur, proclamée par l'envie et la haine même dont elle est l'objet, et, partant, entretenue par sa négation même; hiérarchie professionnelle ; hiérarchie militaire ; inégalité des fortunes, des rangs, du savoir, du talent, du luxe et de l'élégance ; autant de gradins superposés qui, comme en une vision de Jacob vulgarisée, éblouissent de leur prestige antique ou nouveau le citoyen égalitaire de nos sociétés. Cette épidémie de mégalomanie démocratique reçoit de notre auteur un nom assez original: la capillarité sociale. De même qu'en vertu de l'attraction capillaire chaque molécule de la sève des plantes s'élève de leurs radicelles à leur cime, ainsi, par un effort continu, travaille à monter du dernier échelon au plus haut sommet social, le moindre atome de nos plèbes. Cette soif de grandeurs imaginaires, que l'individu rêve pour lui tout seul, n'a rien de commun avec l'ambition qui, en d'autres temps, a fait désirer ardemment à certains l'élévation de leur famille ou la gloire de leur cité. Cet idéalisme national ou familial, loin d'entraver la fécondité, la favorisait. Mais, chez nos fonctionnaires, notamment, le prurit de l'avancement, la rage du déménagement, chez tout le monde la fureur de briller par la copie d'élégances coûteuses ou par la copie de ces copies, excluent le désir d'une progéniture encombrante. Les enfants sont des impedimenta dans cette course à l'assaut du plaisir, du pouvoir, de la richesse, du savoir même. Notre organisation sociale, visiblement modelée par cette frénésie, donne donc une prime au célibat. Je suis persuadé, comme M. Dumont, que la proportion des célibataires ou des mariés sans enfants est plus grande parmi les fonctionnaires, et aussi dans le personnel politique, que dans l'ensemble de la nation. Il est fâcheux que cette statistique n'ait pas été faite ; et je dirais que c'est surprenant, si l'importance de l'imitation en 
sociologie n'avait toujours été méconnue. Comment expliquer autrement que, au lieu de s'égarer parfois en tant de recherches stériles ou oiseuses de démographie, les statisticiens n'aient pas étudié à part la nuptialité et la natalité des classes qui donnent le ton et l'exemple aux autres dans les quatre cinquièmes du pays, c'est-à-dire dans les petites villes et les bourgs ? "Outre sa charge spéciale, dit très bien M. Dumont, chacun des principaux magistrats est devenu une espèce d'apôtre, chargé de propager les modes et les goûts de Paris, d'affecter grand air et suffisance, d'en imposer au peuple, d'éblouir les femmes et de frapper de respect le bourgeois. » On l'imite en tout, même en sa stérilité relative, condition sine qua non de son agilité. Cette influence déprimante des fonctions publiques sur la population a plus d'importance qu'on ne pourrait le croire.

Mais partout, même en dehors d'elle, sévit la manie de monter en grade, fondée sur l'erreur de croire trop aux grades, aux situations, et de ne pas assez tenir à son site propre, d'apporter en toutes choses la préoccupation écolière des places de composition. Les grands enfants que tourmente cette maladie du siècle sont fort joliment comparés aux saumons qu'un invincible instinct pousse à remonter une rivière et à se tuer contre un barrage plutôt que de ne pas sauter par-dessus. Tels « les individus, entraînés en haut par une force inconsciente, masquée à leur yeux par l'illusion du bonheur personnel, en subissent l'attraction jusqu'à la mort». De là, en partie, la progression des suicides. - En a-t-il toujours été ainsi, dans le passé ? Non, nous le savons. Le nivellement égalitaire a puissamment contribué à déchaîner ce fléau. "Quand deux ou plusieurs espèces (animales), circonscrites dans la même aire géographique, ont la même organisation, les mêmes mœurs et les mêmes besoins, la lutte entre elles est d'autant plus vive qu'elles sont identiques, car toutes veulent le même gîte pour s'abriter, les mêmes plantes pour se nourrir. Pareillement, plus une nation est égalitaire, homogène dans ses mœurs, ses lois, ses goûts, et ses aspirations, plus, d'autre part, la lutte sera âpre entre ses membres. Tous auront le même idéal, tous concourront aux mêmes emplois, viseront aux mêmes plaisirs, au même genre de vie. En conséquence, plus il y aura de concurrents, plus il y aura de vaincus, plus il y aura de douleurs, de tristesses et de désespoirs secrets. » 
Quel réquisitoire contre la démocratie ! Il est vrai qu'ensuite $\mathrm{M}$. Dumont s'efforce de la disculper. L'égalité démocratique, dit-il, n'exige pas la similitude d'éducation et, par suite, ne doit pas être rendue responsable des désastres causés par celle-ci. C'est juste ; et il est même certain que l'égalité, la solidarité surtout, supposent la dissemblance. Il aurait pu jouter que la similitude des membres d'une nation est plus apparente que réelle. Les déshérités se payent d'une vaine illusion, fondée sur la ressemblance approximative des costumes et des dehors de la vie, en se persuadant qu'ils sont semblables à l'élite sociale. Il y a là un mensonge des surfaces, un leurre, une grossière contrefaçon sur une vaste échelle, qui paraît être une des fictions les plus chères et les plus nécessaires au temps présent. Disons à ce propos qu'un fait mis en lumière avec beaucoup de sagacité par l'ouvrage qui nous occupe, c'est l'extrême dissemblance des communes souvent les plus rapprochées. La natalité, spécialement, est très restreinte dans tel village breton, exubérante dans le village voisin. " Ces différences démographiques, nous fait-on observer, sont incontestablement l'indice et la conséquence de divergences profondes dans la manière d'apprécier la vie, de concevoir le rôle de l'individu dans l'espèce, les exigences qu'il peut se permettre en fait de bonheur, de plaisirs et d'amusements, de culture intellectuelle ou esthétique. " Cela signifie, à notre avis, que la civilisation, j'entends par ce mot l'ensemble des foyers d'où émane la contagion imitative des nouveaux besoins d'art, de science, de confort, de luxe, rayonne à la façon de la chaleur, c'est-à-dire assez lentement, quoique avec une continuité ininterrompue. En été, de même, à deux pas d'un lieu brûlant, dans un pays pittoresque, on peut trouver une gorge très fraîche, et le moindre pli du sol creuse entre deux localités contiguës les plus grands écarts de température. ${ }^{1}$

Mais il n'en est pas moins vrai que l'assimilation des provinces et des classes dans nos États centralisés, où le même cliché central se

Cette considération, applicable a fortiori au passé, doit nous engager à n'accepter qu'avec réserve les évaluations archéologiques de la population française à diverses époques du moyen âge, basées sur le chiffre des feux de telle ou telle petite province. Cependant on est arrivé à certaines approximations; et, si l'on parcourt les premières pages de l'instructive brochure du marquis de Nadaillac sur le Péril national (1890), où les recherches sur ce difficile problème historique sont résumées et commentées, on y pourra voir que la civilisation et la population françaises, loin d'avoir été en raison inverse l'une de l'autre, ont baissé ou grandi simultanément. 
reproduit partout, s'est opérée dans notre siècle plus vite ou moins lentement qu'à nulle autre époque, grâce à la proclamation de l'égalité des droits, et qu'à son tour celle-ci s'est répandue avec l'aide de cellelà. Or, ce que M. Dumont voit très bien, c'est que l'égalité en droit et l'inégalité en fait, (p. 257) ont grandi parallèlement de nos jours ; mais ce qu'il ne voit pas, c'est que l'égalité en droit, en grandissant, à fait grandir l'inégalité en fait, par une connaissance nécessaire, non en vertu de circonstances accidentelles. En effet, l'égalité des droits ne serait pas toujours plus chère, elle serait la chose la plus indifférente du monde au cœur ambitieux de l'homme contemporain, si elle était autre chose que la possibilité d'accéder jusqu'au faîte d'une montagne de biens et de pouvoirs très inégaux, dont la hauteur, avec leur inégalité, s'accroît sans cesse. Ne doit-elle pas sans cesse s'accroître avec cette ambition dont elle n'est que la projection objective et imaginaire ? Cela doit être, au surplus, en vertu d'une autre fiction engendrée par le même principe. Puisque les droits sont égaux et que le sort des individus est dans leurs propres mains, on en conclut logiquement que le succès à présent est la vraie mesure de la valeur personnelle, de l'intelligence et de la moralité. C'est souvent tout le contraire, notre auteur le sait bien. N'importe; un des mensonges conventionnels de notre civilisation, pour employer le langage de Nordau, est que le pauvre l'est par sa faute, que le parvenu doit sa fortune à ses talents, et que le second, in petto, sinon ouvertement, a le droit de mépriser le premier. Ce mépris est d'une étoffe toute neuve. «Le mépris qui tombait jadis d'une classe supérieure sur une classe moins fortunée était supportable parce qu'il était collectif. Aujourd'hui le mépris, s'adressant à l'individu isolé, est devenu intolérable. »Par suite, l'arrogance des parvenus «va croissant». L'ambition, l'attraction capillaire, a donc été érigée en dogme ; c'est le premier des devoirs. Si, par hasard, quelqu'un s'amuse de mettre son orgueil à rester soi, à ne pas ramper pour monter, comme font les chenilles le long d'un piquet, il doit se résigner d'avance à être méprisé de tous. «En vain un homme calme et sensé veut-il rester immobile dans sa condition, faire son luxe de son indépendance, et posséder des loisirs en guise de superflu; on ne le laissera pas tranquille. Le désintéressement, la vie simple et fièrement indépendante, autant d'articles démodés, objets d'un dédain si sincère qu'on se ferait tort en en faisant trop de cas, » Être fonctionnaire, par exemple, et n'être pas solliciteur, c'est une anomalie qui rend légèrement ridicule. 
Faut-il croire maintenant M. Arsène Dumont quand il impute ces vices de notre démocratie, et la dépopulation qu'ils entraînent, à notre passé monarchique d'une part, et, d'autre part, aux deux sources pétrifiantes où nous aurions eu le malheur d'être trempés jusqu'ici : l'hellénisme et le catholicisme ? Il n'est pas douteux que le sceau royal ait laissé son empreinte à beaucoup de nos vanités et "à certaines formes de notre luxe »; mais quelle erreur de penser que l'uniformité d'idéal en fait de luxe et d'art a pour cause l'ancien régime! Rien de plus démocratique, au contraire. C'est très arbitrairement qu'on attribuerait à l'esprit démocratique la simplicité et la similitude de plus en plus grande des vêtements masculins (évolution qui a commencé à s'opérer depuis plusieurs siècles) et qu'on reprocherait à l'esprit monarchique les progrès parallèles dans le luxe des toilettes féminines, des ameublements et des habitations. On ne voit pas pourquoi, de ces deux progrès contraires, mais contigus et simultanés, l'un plutôt que l'autre aurait une origine aristocratique. La centralisation, par l'émigration rurale, par la fascination des capitales toujours plus éblouissantes, a fait cela : c'est elle, monarchique d'abord, démocratique ensuite, qui nous a imposé notre esthétique uniforme et compliquée. Et la centralisation est le fruit fatal de l'évolution politique sous toutes ses formes, du libre jeu de l'imitation et de la logique sociale.

Quant à notre éducation d'origine hellénique et catholique, est-il vrai que, sans elle, le citoyen de nos démocraties ne professerait pas ou professerait moins l'idéalisme individuel, autrement dit l'égoïsme ? Sommes-nous égoïstes, absorbés dans la préoccupation de notre but personnel, de notre développement particulier, parce que l'antiquité gréco-romaine n'a fait luire à nos ancêtres que leur gloire propre, et parce que le moyen-âge catholique nous a donné pour visée habituelle le salut, le salut de nous-même, abstraction faite du salut de nos concitoyens et de nos proches ? La justesse de cette explication ne me frappe point. Oublierons-nous que la cité antique a été une école de patriotique solidarité, et que le christianisme, dont le catholicisme après tout est la plus forte organisation, a pour âme essentielle l'extension à tout le genre humain du sentiment de la fraternité ? « Si le protestantisme, nous assure-t-on, est socialement moins nuisible que le catholicisme, c'est qu'il participe davantage de l'hébraïsme (qui 
développe l'idéalisme familial) et moins de l'hellénisme » Je ne m'aperçois pas cependant que, chez les peuples protestants, nos adversaires ou nos rivaux, chez ceux du moins qui sont nos égaux en civilisation, l'égoïsme soit moins développé que chez nous. La natalité des nations protestantes (à égalité de civilisation) n'est pas même plus forte que celle des nations catholiques; la plus forte natalité européenne est celle de la Russie, peu civilisée il est vrai, mais où règne le catholicisme grec, qui ne diffère en rien d'essentiel, à notre point de vue, du catholicisme romain. Toutes les grandes religions, le bouddhisme, l'islamisme, comme le catholicisme, ont orienté l'âme vers la même étoile polaire, le salut individuel ; et toutes ont obtenu par cette orientation d'admirables solidarités. L'individualisme, du reste, n'est point particulier à l'hellénisme et au christianisme; il est propre à toute doctrine de progrès, notamment à la doctrine révolutionnaire, qui doit affranchir l'individu des liens primitifs de la famille pour l'engager dans les nœuds d'une famille nouvelle. C'est une criante injustice de rejeter sur la religion de nos pères la faute de notre infécondité, quand il est manifeste, au contraire, et reconnu par de très libres penseurs tels que Guyau, que l'esprit chrétien retient sur la pente de son déclin, en Bretagne et dans tous nos départements dits arriérés, la population française.

Il est bon de relire de temps en temps l'Irréligion de l'avenir. Dans le chapitre intitulé la Religion et la Fécondité des races, où la question qui nous occupe est si profondément étudiée, le regretté philosophe avoue la salutaire influence des divers cultes, surtout du nôtre, et se demande avec inquiétude comment elle pourra être remplacée. C'est cette recherche inquiète que j'aurais voulu voir aborder par $\mathrm{M}$. Dumont, si sa passion antichrétienne ${ }^{1}$, surprenante d'ailleurs à ce degré dans un esprit de cette largeur et de cette élévation, ne l'avait empêché de concevoir une telle préoccupation. Pour avoir le droit de nier l'évidence même, pour fermer les yeux, par exemple, sur l'instructive comparaison entre la Bretagne et la Normandie, entre la fécondité du Breton croyant quoique prévoyant, et la stérilité du

Elle éclate souvent par des phrases telles que les suivantes: «Le christianisme, devenu catholicisme, puis cléricalisme, est la machine à énervement la plus parfaite que l'esprit pervers du mal et des ténèbres ait jamais inventée. » (p. 509) «Les relations habituelles des jeunes gens des deux sexes sont le remède le plus efficace contre l'ivrognerie, le cléricalisme, le progrès des naissances naturelles. » 
Normand incrédule ${ }^{1}$, il ne suffit pas de dire que le christianisme tend à remplir les couvents, à éloigner les jeunes gens du mariage, à remplacer le type maternel des vierges robustes de la Renaissance par celui des vierges de Lourdes, sans enfants sur les bras. Il ne suffit pas même de faire observer, avec raison du reste, que, à notre époque de foi déclinante, même chez les plus dévots, la peur de pécher en ne se conformant pas à la recommandation de croître et multiplier ne saurait l'emporter souvent sur la crainte de s'imposer des privations en obéissant à cet ordre divin mais ruineux. C'est peut-être, au contraire, précisément parce que la foi religieuse s'est affaiblie qu'elle produit sur la natalité les bons effets constatés par la statistique. La religion est un poison et un virus, soit ; mais M. Dumont ne sait-il pas qu'il est dans la nature des virus et des poisons de devenir remèdes en s'atténuant? Je suis porté à croire que, en sa ferveur initiale, le christianisme, inspirant l'horreur de la génération charnelle, a dû activer et non ralentir la dépopulation de l'empire romain, et même plus tard celle du moyen-âge en certains pays ; logiquement, il pousse au célibat. Mais, chose étrange quoique certaine, son effet pratique, contraire à sa conséquence logique, est de rendre le mariage fécond. Pourquoi cela? La réponse à cette question n'est pas pour déplaire, je crois, à M. Dumont. La fécondité plus grande des familles où s'est conservé l'esprit chrétien, ne provient pas seulement, ni surtout, de ce qu'elles sont préoccupées du rnultiplicamini biblique, mais bien de ce qu'elles ont gardé une foi vague en la Providence nourricière des petits oiseaux, et qui «bénit les nombreuses familles. » À vrai dire, notre catholicisme atténué, mitigé de scepticisme, réduit à une sorte de traditionnalisme moral, familial et social, agit surtout comme gardien de l'esprit de coutume, de l'esprit d'attachement aux mœurs des aïeux. Son influence directe, dérivée de ses dogmes, peut être fâcheuse; mais elle est peu de chose, comparée à son influence indirecte exercée par les traditions dont elle a pris la garde pour se soutenir dans sa faiblesse, et qui se sont formées dans le passé sous l'empire de sentiments laïques et profanes, souvent étrangers, parfois hostiles même, à ses principes. Le temple de Delphes, au temps d'Alcibiade, était de moins en moins le conseiller de la Grèce; mais il en était toujours le trésorier; là était le trésor d'Athènes, de l'Athènes railleuse et à demi sceptique qui s'était enrichie par sas victoires sur les Doriens

\footnotetext{
V. Irréligion de L'avenir à ce sujet, p. 274.
} 
religieux et dévots ou par son commerce avec les barbares impies. L'Église chrétienne, à présent, ressemble fort au temple delphique.

En quoi consiste donc son action sur la population? En ce qu'elle tend à perpétuer ou à raviver ce culte de la famille que $\mathrm{M}$. Dumont loue avec éloquence chez les habitants du Céleste Empire. C'est par ce penchant domestique et coutumier où elle incline le cœur du croyant, devenu aux trois quarts incrédule, que la religion lutte avec fruit contre le penchant opposé, qui est justement cet idéalisme individuel, cause de tous nos maux. Aimer quelque chose plus que la vie, quelque chose où l'on espère revivre ou se survivre; elle crée ou entretient en nous cette double force, condition du sacrifice. Le songe de l'immortalité, même après le réveil, nous laisse longtemps l'habitude de déployer le vol de nos désirs dans le champ de la durée plutôt que dans celui de l'étendue terrestre occupée pendant le court moment de l'existence. Qui se préoccupe aujourd'hui de ce que deviendront ses petits-fils et arrière-petits-fils ? Je n'aperçois maintenant un pareil souci que parmi ceux qui sont préoccupés de leurs ancêtres; et la plupart, dont on se moque, sont imbus de l'esprit ou du sentiment religieux. Or, il est évident que le progrès de la population est intimement lié à ce vœu de postérité, faisant suite à ce rêve d'éternité. Le malheur est, pour la civilisation contemporaine, principalement sous sa forme démocratique, que, à l'inverse de la religion, elle invite, elle habitue l'individu à pratiquer le carpe diem d'Horace, à restreindre sa prévoyance, de plus en plus vigilante, mais de plus en plus étroite, aux limites de son existence, à oublier les descendants aussi complètement que les aïeux. Mais cet individualisme est-il essentiel à l'idée que nous devons nous faire de la civilisation et de la démocratie ? Non. M. Dumont cite avec éloge et avec une vive sympathie (p. 393 et suiv.) un passage trop peu remarqué, et qui m'avait frappé moi-même, de la Cité chinoise, par M. Eugène Simon. Cet écrivain, qui connaît si bien la Chine, pays exubérant d'enfants, comme on sait, bien que civilisé et démocratisé tant de siècles avant nous, nous montre de quelle façon on est égalitaire là-bas. Taudis que nous nous payons de mots en proclamant de bouche l'illusoire égalité des individus, le Chinois croit à l'égalité vraie, à l'égalité des familles ; il n'est pas une famille si brillante actuellement, en effet, qui n'ait en dans son long passé, connu de tous, des membres obscurs; et il n'en est pas de si obscure qui n'ait eu dans la suite indéfinie de ses ancêtres 
quelque glorieux représentant ou ne puisse l'attendre des générations futures. Il y a compensation dans l'ensemble, et cela suffit à l'individu, quand l'individu a appris à se connaîtra, comme simple anneau d'une chaîne par laquelle seule il vaut et dont il ne peut sans honte se détacher. On n'a pas le droit de s'asseoir dans la rue; on n'a pas le droit de se reposer dans la vie et d'arrêter à soi, célibataire, le flot qui vous y a poussé.

Les Juifs, comme les Chinois, ajoutons comme les Américains, ces féconds démocrates, sont là pour protester contre l'idée que la civilisation et la démocratie même s'achètent au prix de la fécondité vitale. Civilisés et égalitaires, ils le sont aussi, et de très ancienne date, bien que leur civilisation soit toute d'emprunt et leur égalité d'origine théocratique. Mais toujours ils ont eu le culte du foyer, toujours ils ont puisé dans le souvenir des plus lointains aïeux le désir ardent de la postérité la plus reculée. Aussi, même dénationalisés, ils n'ont pas cessé de former une société spéciale et nombreuse, et ils ont survécu à tous leurs anciens vainqueurs, Égyptiens, Romains et autres. Ils ont eu beau se mêler à notre monde, ils ne s'y sont pas noyés, ils l'ont utilisé au profit du leur; et, soit dit en passant, leur exemple est assez propre à nous faire prévoir ce qu'il adviendra vraisemblablement des Chinois eux-mêmes quand ils auront été pénétrés et transpercés de toutes parts par l'influence européenne. Ils ne s'européaniseront jamais qu'à la chinoise ; et fussent-ils conquis et dispersés, ils formeraient toujours un jour la France chinoise ou l'Europe chinoise. Pourvu que les fils du Ciel ne survivent pas aux Français comme les Hébreux aux Romains !

Nous venons de voir M. Dumont osciller, hésiter, se contredire parfois, dans le diagnostic du mal qui l'inquiète ; ne nous étonnons pas si son ordonnance pèche un peu par l'insuffisance des remèdes. C'est la partie faible du livre, malgré la justesse et la profondeur de maints aperçus. Le remède, d'après ce que nous venons de dire, serait de nous convaincre sérieusement que la famille, la famille-souche, chère à Le Play, est la vraie molécule sociale, beaucoup plus que l'individu. Mais, pour être intense et fructueuse, cette conviction doit être générale ; et la difficulté est là. Car, comme notre auteur le dit très finement quelque part: "Nous n'avons, quoi que nous fassions, une qualité à un haut degré que si ceux qui nous entourent la possèdent euxmêmes »; et, pareillement, nous ne croyons bien fort à nos idées les 
plus démontrées que si notre milieu les partage. Comment cependant, espérer que la nôtre, qui se heurte à tant de préjugés contraires, se généralise jamais ? On peut croire cependant que, soutenue d'autre part et soulevée par les plus antiques besoins du cœur, elle se répandra d'elle-même le jour où l'émigration rurale vers les villes s'arrêtera. Mais quand s'arrêtera-t-elle ? Est-ce seulement quand le courant de la centralisation à outrance sera endigué ou refoulé ? Entreprise impossible; disons plutôt: quand ce débordement aura achevé son oeuvre. Et c'est en effet ce que propose à son insu M. Dumont. Pour combattre, pense-t-il, l'émanation (il appelle ainsi le rayonnement imitatif des capitales dans les États centralisés), il demande qu'on crée partout en province, jusque dans les moindres villes, des foyers de culture scientifique, artistique, qui dispensent d'aller prendre étincelle au feu parisien. Certes, c'est là un beau plan, et moins dispendieux et plus pratique, et beaucoup plus près de se réaliser, qu'on ne le croit communément. Mais cela, au fond, qu'est-ce, si ce n'est l'émanation poussée à bout, Paris multiplié en une foule de petits Paris à son image, sorte de multiplication des pains de l'esprit ? C'est ainsi que la centralisation politique aboutit naturellement à la centralisation intellectuelle ; le centre, à force de rayonner, se réfléchit et se disperse dans le cercle entier.

Mais toute la question n'est pas là. Il ne s'agit pas seulement de savoir comment le déclin de la population pourra être empêché, et le progrès de la population favorisé ; il est bon aussi de nous demander jusqu'à quel point ce dernier progrès importe à celui de notre humanité, qui est notre grand but. Posons-nous donc ce problème ardu. Qu'est-ce qui vaut le mieux, un monde qui nourrit le plus grand nombre possible de sociétaires médiocrement heureux, médiocrement riches, médiocrement instruits et cultivés, ou un monde qui élève au plus haut degré possible de savoir, de culture, de richesse, de bonheur, un nombre médiocre d'associés ? Le problème ainsi posé, remarquonsle, ne signifie pas que le perfectionnement interne des individus est toujours en opposition avec leur accroissement numérique, autrement dit, pour employer les expressions de M. Dumont, que la viriculture intensive est absolument opposée à la viriculture extensive. Ce n'est qu'à partir d'un certain chiffre de population assez élevé, variable d'après la nature des civilisations et les aptitudes des races, que cette opposition se produit; et aussi longtemps que la sève des inventions 
civilisatrices est en train de monter dans toutes ses branches, ces deux genres de viriculture se prêtent au contraire un mutuel appui, l'augmentation en nombre offrant plus de chances à l'apparition d'un génie exceptionnel qui fera l'ascension d'un pic supérieur, et les découvertes géniales permettant à un plus grand nombre d'hommes de vivre sur le même espace. Mais, au-delà d'une certaine densité de population, et quand le système d'une civilisation est à peu près achevé, complet, adulte, susceptible encore d'améliorations de détails, non de remaniements profonds, n'est-il pas alors manifeste que la société doit choisir entre ces deux fins, multiplier les vies ou élever la vie?

Ce problème, l'Empire romain et l'Empire chinois l'ont résolu, prématurément l'un et l'autre d'ailleurs, en deux sens contraires. Lequel des deux a eu raison? Il nous semble que, sans l'invasion des barbares, la solution romaine, disons aussi bien hellénique ou française, serait reconnue en somme supérieure à l'autre. La qualité des hommes importe, à coup sûr, plus que leur nombre, leur nombre n'importe qu'autant qu'il sert à développer leur qualité; ainsi le voulaient Platon, Aristote, et la plupart des sociologues grecs, qui ont fait tant de sociologie sans le savoir. Mais ils chiffraient par dizaines de mille le maximum numérique de leur république idéale, et, même à leur époque, ce chiffre était évidemment beaucoup trop bas. Maintenant, c'est par centaines de millions qu'il faudrait parler, si l'on se risquait à préciser la somme désirable de toutes les populations civilisées de l'Europe, réunies par hypothèse en une vaste confédération. C'est seulement dans cette hypothèse, en effet, que la population pourra sans danger cesser de croître à partir du niveau correspondant jusqu'au plus haut point de valeur morale, intellectuelle et esthétique des individus. Mais, tant que durera le morcellement des États européens, qui les force à rivaliser de fécondité en prévision des guerres possibles, ce niveau devra nécessairement être dépassé un jour, s'il ne l'est pas déjà çà et là, au grand préjudice de la civilisation générale. Supposez ce beau rêve d'Union réalisé, personne ne songera plus à blâmer l'arrêt de la population française, mais tout le monde criera plutôt contre l'exagération prolifique des Russes, des Anglais, des Allemands. Malheureusement, les nationalités rivales ne sont pas près de désarmer, et, avant que la paix s'asseoie sur la solidarité des 
nations reconnues toutes égales, grandes ou petites, comme les familles chinoises, nous avons le temps de fondre bien des canons. 
Gabriel Tarde, Études pénales et sociales (1892)

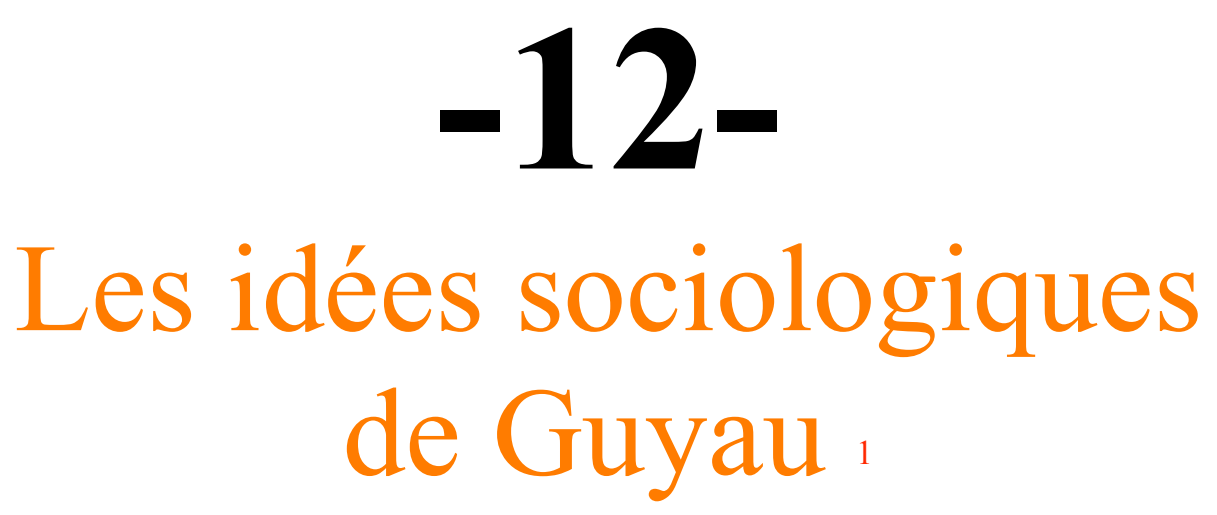

$\underline{\text { Retour à la table des matières }}$

Le livre que M. Alfred Fouillée a consacré à la mémoire de son ami n'est pas seulement un monument funéraire et littéraire d'un style exquis, où sur le buste du philosophe il a tressé en couronne les plus belles fleurs du poète ; c'est avant tout un document philosophique de la plus grande valeur, un résumé magistral de toute l'évolution mentale, harmonieusement continue, à laquelle nous devons la Morale anglaise contemporaine, la Morale d'Épicure, l'Esquisse d'une morale, les Problèmes de l'esthétique, l'Irréligion de l'avenir. L'unité profonde de cet esprit qui s'est répandu beaucoup sans jamais se disperser, éclate sans effort, par cette condensation lumineuse. Non pas éclectique et oscillante, encore moins sceptique, mais synthétique et symphonique au plus haut degré, cette pensée nous charme irrésistiblement par son accord unique et avec elle-même et la réalité, et

\footnotetext{
M. Alfred Fouillée. La morale, L'art et la religion d'après M. Guyau.
} 
avec le coeur et le caractère de l'homme, et avec les plus heureux dons de l'imagination créatrice. De là cette grâce singulière qui n'est point celle du scepticisme et de l'ironie, mais celle de l'harmonie et de l'enthousiasme platonique ou fénélonien. Il y a de l'onction pieuse dans ce prédicateur de ce qu'il appelle l'irréligion; c'est, dans une lampe antique, de l'huile chrétienne qu'il a brûlé toute sa vie. Et quelle vie belle et pure, si courte et si pleine, si heureuse jusque dans la mort ! Si privilégiée après la mort même, par sa survivance en une amitié si rare, où s'est complétée son harmonie !

Il en aura été de Guyau comme de ces jeunes peintres dont l'œuvre, déjà grandement louée de leur vivant, n'attend que leur mort pour faire son assomption glorieuse au ciel de l'art. Le moment est venu pour cette haute pensée, pour cette âme noble entre toutes, de rayonner de tout son éclat et de susciter ses pareilles. A ce rayonnement désirable, et déjà commencé, si je suis bien informé, aura beaucoup servi l'ouvrage de M. Fouillée. - Guyau n'était pas un piétiste ni un quiétiste, il s'en faut; c'était un penseur de ferme raison; mais l'idée maîtresse qui anime et domine toutes ses recherches et qui lui a paru la plus propre, non sans motifs, à embrasser l'art, la morale, la religion, sous un même point de vue, ne lui a-t-elle pas été inspirée par son âme généreuse ? N'est-ce pas une sorte de saint laïque, et des plus parfaits, dont M. Fouillée a été le trop discret hagiographe ? Supposez qu'une nature de cet ordre eût apparu sur les rives du Gange au lieu de se déployer sur les bords de la Méditerranée : nul doute qu'elle n'eût été saluée comme la réincarnation de quelque ancien dieu métaphysicien, et que son tombeau n'eût fait des miracles. Tout d'abord, Guyau a été, on le sait, un vrai prodige de précocité. À dixneuf ans, avec son beau Mémoire couronné, il apparaît au milieu de l'Académie des sciences morales et politiques, comme un adolescent inspiré parmi les «Docteurs de la Loi », non, certes, pour faire la leçon à ses maîtres, il en eût trop coûté à sa modestie, mais pour les émerveiller de son savoir. Et à trente-trois ans, il meurt, après avoir passé toute sa vie à formuler ou à pratiquer un nouvel évangile, fondé en somme, comme l'autre, sur l'omniscience et la toute-puissance de l'amour.

La nécessité interne qui pousse toute sa vie à s'épancher, à se dépenser au dehors et en autrui, ne serait-ce que pour faire le meilleur 
placement d'elle-même, le meilleur ensemencement plutôt : telle est la force universelle à laquelle il demande l'explication du beau, du bon, du vrai, du social en tout et pour tout. Je ne le contredirai pas en ceci ; le fond de tout être est assurément une ambition extraordinaire qui l'oblige à sortir de soi, et rien ne lui est plus essentiel que de viser audelà de son essence même. Tout vient de l'infinitésimal et tend à l'infini, tout ce qui est le plus généralement répandu a commencé par être une petite particularité qui s'est universalisée par degrés et n'a pu y parvenir qu'en bondissant bien des fois par-dessus sa limite. Il en résulte la condamnation la plus absolue de l'égoïsme utilitaire. Guyau a bien raison. Le plus impérieux besoin de la vie, par exemple, est le besoin de vouloir, et d'un vouloir proportionné au savoir et au pouvoir; d'où suit l'impossibilité de s'enfermer dans un petit but égoïste quand l'intelligence s'est ouverte. - Seulement je crois que la formule de Guyau, pour avoir le droit de donner tout ce qu'il attend d'elle, demanderait à être complétée. J'y suis quelque peu intéressé, je l'avoue, car, en la tirant un peu à moi, je ne serais pas fâché de faire participer ma propre manière de voir à la séduction de la sienne.

Parlons d'abord de l'application de son point de vue à la morale. L'expansion de la vie : cela est doublement vague. Il reste à préciser l'idée d'expansion et aussi l'idée de vie. En premier lieu, expansion, est-ce que cela signifie le développement de l'être ou sa reproduction en autrui ? - Les deux, semble-t-on nous répondre. "L'accroissement de la vie et son élargissement au dehors » nous sont présentés comme la seule règle possible dans la doctrine de l'évolution. Le malheur est que cet accroissement est le plus souvent, dans une certaine mesure au moins, opposé à cet élargissement. L'insecte meurt d'avoir engendré ; la paternité copieuse ne s'obtient, en ménage, que moyennant la gêne et les privations des parents. Il faut donc choisir parfois entre les deux buts qui nous sont donnés comme parallèles et qui en réalité peuvent se combattre. Nous croyons nous conformer à la pensée de notre auteur en optant pour le second. Mais sur quoi s'appuyer pour motiver logiquement cette option? Sur une idée qu'on s'est faite ou qu'on vous a faite de la fin générale des choses, et sur un désir qu'on éprouve de s'y orienter. Nous voilà en pleine religion ou en pleine métaphysique. N'importe, allons toujours. Guyau dit très bien, quelque part, pour faire rentrer la notion de fin dans celle de cause, que toute cause est sa propre fin. Autrement dit, produire, c'est se reproduire. Nous dirons 
donc, non pas que l'expansion mais que la répétition extérieure de la vie est la règle de la morale. Entendu en ce sens, mais en ce sens exclusivement, le besoin d'expansion vitale justifie logiquement le sacrifice de la vie quand il est nécessaire à sa fécondité. Encore faut-il expliquer ce qu'on entend par vie. Si par là on veut dire l'accomplissement de toutes les fonctions naturelles ou sociales de l'individu, on passe à côté de la grosse difficulté que soulève le choix à faire entre les fonctions sociales et les fonctions naturelles quand les unes s'opposent aux autres, quand, par exemple, la culture cérébrale d'un certain ordre ne saurait s'acheter chez les descendants auxquels on se sacrifie que moyennant un certain affaiblissement corporel. Jugeons la vie sociale de l'individu supérieure à sa vie physique, aussitôt le problème est résolu. Précisée de la sorte, la formule de Guyau permet d'affirmer avec vérité qu'il n'est nullement contradictoire de poursuivre par sa mort même la reproduction de sa vie la plus haute. C'est ce qu'ont fait tous les inventeurs qui se sont immolés au succès, lisez à la répétition sociale, de leur idée-mère. C'est sans doute ce qu'a fait Guyau lui-même.

Est-ce tout ? Non. L'idée à laquelle nous sentons le besoin de nous dévouer, c'est d'ordinaire le dessein de propager notre foi, notre forme sociale, et, en ce sens, d'épancher notre vie sous sa forme la meilleure. Mais nous pouvons aussi nous consumer à la poursuite d'un but différent, d'un but qui consiste dans des découvertes à faire et non dans la propagation des découvertes déjà faites. L'attrait de l'inconnu, si éloquemment exprimé par Guyau, n'est-il pas éminemment propre à soulever des élans de générosité héroïque? Complétons, par suite, notre formule, et disons que la répétition et la variation de notre vie jugée supérieure constituent tout la moralité humaine. Il était essentiel de faire ces distinctions.

Un cas d'une importance indéniable, mais parfois exagérée, est celui où l'acte vital suprême, le dessein majeur auquel on se sacrifie, consiste à faire plaisir aux autres hommes ou à leur éviter une douleur. $\mathrm{Si}$, au lieu des autres hommes, il s'agissait d'un seul autre homme, pourquoi serait-il rationnel de sacrifier notre bonheur à la réalisation du sien, à moins que nous n'aimions cette personne profondément ? Ici l'amour est la condition indispensable et la seule justification logique $\mathrm{du}$ sacrifice. Mais, s'il s'agit de nous infliger une douleur pour 
épargner une douleur pareille à un groupe considérable de personnes, à notre famille, à notre ville, à notre patrie, ne semble-t-il pas que, indépendamment de toute affection, et par le fait même que nous pensons aux souffrances à détruire, que nous les nombrons, que nous sommes forcés de les juger numériquement supérieures à notre souffrance propre, nous sommes également forcés de juger rationnelle la production de celle-ci en vue de la destruction de celles-là, et, par suite, de vouloir ce but dès que nous l'avons conçu, c'est-à-dire de nous approprier comme notre acte vital suprême la pensée de cette abnégation, de ce dépouillement volontaire! Ainsi naît en nous fatalement, dans la force de l'âge, quand le besoin de volonté est intense et demande au jugement sa voie, un désir supérieur qui, contraire à nos désirs égoïstes, s'accorde avec ceux de nos semblables. Mais cette voie n'est pas la seule qui aboutisse à la conciliation des désirs. Plus expansive encore, sinon aussi généreuse, est une existence vouée à la réussite d'un projet quelconque, utile ou non à grossir la somme du bonheur général, mais répondant au désir général bien ou mal inspiré. Notre but peut être, non de multiplier les plaisirs des gens, mais de multiplier leurs connaissances, même douloureuses et désespérantes, leurs besoins, même irréalisables entièrement; et, si ce désir est aussi le leur ou si nous parvenons, n'importe comment, à le leur faire partager, les historiens ne manqueront jamais de dire plus tard que nous avons travaillé dans le sens du progrès. Quand Napoléon prépare la descente en Angleterre avec le concours enthousiaste de ses sujets, quand Bismark rétablit, aux acclamations des Allemands, l'Empire germanique, est-ce que, dans ces cœurs de despotes, égoïsme et altruisme ne concourent pas aussi puissamment que dans l'âme d'un saint Vincent de Paul prenant plaisir à faire plaisir ? Sera-ce une raison pourtant de juger la moralité des premiers égale à celle du troisième ? Et, si nous devons répondre négativement, n'est-ce pas la preuve que la formule de Guyau, même rectifiée, n'est pas le dernier mot de la morale ? - Il y manque quoi ? L'idée même du devoir. Si Guyau a rejeté cette antique notion, c'est peut-être parce que, en ne faisant pas à la finalité sa place légitime, il a ôté d'avance au devoir la seule source positive d'où il l'aurait vu découler. Le rapport du moyen à la fin est le genre dont le devoir est une espèce tout à fait singulière, qui se montre quand la fin, née en nous sans nous, suggérée autoritairement par l'exemple de notre milieu, inconsciente et souveraine, devient en quelque sorte pratiquement 
absolue, comme les astronomes disent que la distance des étoiles à la terre est pratiquement infinie. La prétention de fonder la morale sur la seule volonté de l'individu, sur un désir librement choisi par l'individu, est donc, je crois, chimérique. Il y aura toujours dans la moralité, même la plus intelligente et la plus civilisée, une part nécessaire d'obéissance passive à décret non motivé, à un commandement à la fois intérieur et supérieur ; - et il n'y a rien là que le positivisme doive proscrire, s'il sait le rôle nécessairement joué en sociologie par ces communications incessantes de personne à personne que la nouvelle psychologie commence à déchiffrer. Personne, ce nous semble, n'était mieux préparé que notre auteur à expliquer les titres positivistes de l'idée d'obligation et à montrer leur force, au lieu de chercher à s'en passer : il lui eût suffi de faire, en morale, un plus large emploi de ce point de vue sociologique qu'il a eu le mérite d'importer en esthétique et en mythologie comparée et qui, sous sa plume, a renouvelé ces deux sciences. - On nous objecte, il est vrai, que le devoir ainsi compris est une sorte d'instinct moral et que le caractère de tous les instincts - c'est un des grands principes secondaires de Guyau - est de se détruire en devenant conscients, lorsque du moins la conscience y découvre une opposition avec quelque instinct plus fondamental. Toutefois cette règle, si ingénieusement développée qu'elle puisse être, est loin d'être sans exception, et, pour n'en citer qu'une seule, je ne m'aperçois guère que les instincts criminels, là où réellement ils existent, tendent, par la culture de l'esprit, à se dissoudre et à disparaître. Au contraire, la perversité des malfaiteurs-nés semble se fortifier, celle d'un Barré et d'un Lebiez notamment, sur les bancs de l'école. Est-il défendu d'espérer, par compensation, qu'il en sera de même des instincts généreux et moraux ? Les plus braves officiers, les plus disciplinés, ceux qui se font tuer le plus aveuglément pour une cause dont ils s'interdisent d'examiner la valeur, pour une entreprise follement décidée par un ministre ou une chambre, ne sont-ils pas précisément les plus instruits ? Où a-t-on vu l'instruction étouffer, et non épurer en l'affermissant, le sentiment, de l'honneur? La force de vivre en autrui, de mourir pour autrui, nous sera toujours donnée tant que nous ne pourrons nous empêcher de sympathiser avec autrui, de nous mirer en autrui, de refléter dans notre amour-propre les jugements que nos semblables portent sur nous. Or, plus l'intensité de 
la vie sociale s'avivera, moins nous pourrons nous en empêcher ${ }^{1}$. Ajoutez que la soumission de notre caprice personnel à l'impérieux écho de la voix des ancêtres traduite en devoirs unanimement reçus, sauf les cas où elle commandera des choses manifestement absurdes ou contradictoires, ne manquera jamais d'une justification trop réelle, à savoir notre ignorance de l'avenir. Le besoin, en effet, de formuler des règles générales de conduite ne se fonde-t-il pas sur l'impossibilité où nous sommes de prévoir les dernières conséquences de nos actes? $\mathrm{Si}$, malgré cette impossibilité, nous voulons que nos décisions aient une raison suffisante, les maximes morales s'offrent nécessairement à nous comme des théorèmes empruntés à une sorte de calcul des probabilités séculaire. Si un colonel, par exemple, pouvait prévoir avec certitude que son obéissance aux ordres de son chef aura pour conséquence finale la défaite de l'armée, il devrait désobéir. Si un jeune larron, hésitant à commettre un vol, voyait clairement qu'en définitive, et de résultat en résultat, ce vol produira une amélioration du sort de ses semblables ou le salut de l'un deux, il devrait voler. Un assassin devrait tuer, s'il était sûr, par son homicide, de rendre finalement service au genre humain. Dans cette hypothèse, le devoir varierait à chaque heure, d'homme à homme, et serait unique pour chaque cas. L'idée du devoir se confondrait avec celle du succès, tandis qu'à présent l'immense avantage d'obéir au devoir c'est d'être dispensé de réussir. La conduite morale serait donc une suite de problèmes résolus chacun à part en vertu de données concrètes et singulières, au lieu de se résoudre par la simple application de quelques formules algébriques. Il n'y aurait plus de maximes possibles, puisque les maximes supposent des prévisions qui se vérifient ou sont supposées se vérifier dans la majorité des cas, non dans tous les cas, et que l'on recommande de la sorte parce qu'on ignore si l'on se trouve ou non dans ce cas exceptionnel.

Guyau a dit lui-même: "Est-il besoin du secours d'idées mythiques et mystiques pour comprendre la société humaine et ses nécessités, parmi lesquelles se trouve la nécessité même du désintéressement? Plus l'être humain deviendra conscient, plus il aura conscience de la nécessité, de la rationalité inhérente à la fonction qu'il accomplit dans la société humaine, plus il se verra et se comprendra lui-même dans son rôle d'être social. » (Irréligion de l'avenir, p. 352). Et plus loin : "La réflexion de la conscience sur elle même ne dissout vraiment que les joies irrationnelles et, par compensation, elle dissout aussi les peines déraisonnables. Le vrai résiste à l'analyse : c'est à nous de chercher dans le vrai, non seulement le beau, mais le bon. Il existe, à tout prendre, autant de vérité solide et résistante dans l'amour éclairé de la famille, dans celui même de la patrie, dans celui de l'humanité, que dans tel fait scientifique le plus positif, dans telle loi physique comme celle de la gravitation et de l'attraction. » (ibid. p. 410) 
En somme, heureuse ignorance! Rarement, très rarement, avouons-le, malgré ce qui vient d'être dit plus haut, le sacrifice de soi, s'il était certain d'avance, serait accepté résolument. Ce qu'on accepte, c'est le risque de ce sacrifice, et ici viennent se placer lumineusement les considérations aussi profondes que délicates de Guyau sur le plaisir de ce beau danger. Alors le problème qui se pose pour la moyenne des hommes est, par exemple, celui-ci : je désire beaucoup voir ma patrie gagner cette bataille, et je suis certain que le seul moyen de la gagner est, pour moi comme pour mes camarades, de risquer ma vie ; cependant, je désire encore plus continuer à vivre ; que faire? Rien de plus simple ; il s'agit d'une certitude en lutte avec une éventualité, redoutable il est vrai, mais intéressante, attrayante même si le danger plaît par lui-même. Un bien certain peut très bien entrer en nous en balance avec un mal jugé supérieur mais simplement possible, et l'emporter sur la perspective de celui-ci ${ }^{1}$.

Ce qui est grave, et ce que Guyau n'ose pas s'avouer, c'est qu'il faut se tromper, s'abuser soi-même pour se résoudre à certains sacrifices, et c'est, au fond, la vérité triste qu'il cherche à se dissimuler sous l'euphémisme du risque métaphysique. "L'action, nous dit-il, se fait à elle-même sa certitude intérieure. » C'est cela même. Nous devons travailler courageusement, sérieusement, comme si nous avions foi dans l'importance souveraine de notre action, dans la durée éternelle de notre vie, dans le succès assuré de notre cause, de notre patrie, de notre humanité, dans la réalité permanente et indiscutable de ce monde. Nous devons nous faire une foi factice et illusoire en tout cela. Que d'illusions nécessaires 2 ! Mais est-ce assez de l'illusion et de l'ignorance ?Si l'on pousse à bout l'analyse, est-ce qu'on est point conduit ici à la justification du mensonge même ? Au lieu de dire à l'individu : "Sacrifie ton intérêt à celui des tiens », conseil excellent, mais inefficace; au lieu de s'adresser ainsi à la victime pour lui demander son propre holocauste, il semble plus pratique de s'adresser

1 «Il est rare que les sacrifices définitifs se présentent dans la vie comme certains; le soldat, par exemple, n'est pas certain, loin de là, de tomber dans la mêlée ; Il n'y a ici qu'une simple possibilité. En d'autres termes, il y a danger. » (Esquisse d'une morale, p. 208). 
franchement au sacrificateur et de dire à la société, ou à la partie dirigeante de la société, comme l'a essayé Platon: "Élève les individus de telle manière qu'il se développe en eux des sentiments propres à les faire se précipiter dans la mort, s'il le faut pour le bien public, » c'est-à-dire : "Mens sciemment aux enfants, persuade-leur que le sort le plus beau, que la gloire la plus enviable et la plus immortelle, que la félicité la plus enivrante, est de mourir pour la patrie, par exemple.» Or, nous savons, par l'expérience des civilisations passées, par l'expérience surtout de la nôtre, par les enseignements de nos nouveaux psychologues, par nos essais mêmes heureux ou malheureux en pédagogie, nous savons que la société, quand elle le veut bien, a parfaitement le pouvoir d'accréditer dans ses familles et dans ses écoles, par l'empire persistant des pères sur les enfants et des professeurs sur les élèves, telle erreur historique, telle calomnie, telle légende, qui lui convient. Elle peut aussi bien, à la condition de le vouloir, refondre ou retremper les sentiments moraux moyennant force impostures. Reste à savoir si elle en a le droit et le devoir, le droit et le devoir de mentir ! Non, non, non, répéterons-nous mille fois, certes, nous autres philosophes, qui nourrissons en nous l'amour pour ainsi dire professionnel de la vérité. Mais je ne suis pas bien sûr que la société dans son ensemble, si jamais elle se rend compte clairement et de sa puissance et de l'utilité pour elle d'en user comme il vient d'être dit, soit suffisamment retenue par ce scrupule, très rare chez les plus tendres mères, de n'oser tromper leurs enfants. On peut se demander au surplus si notre passion du vrai, née de l'illusion de croire à la beauté du réel, à son harmonie et à sa finalité providentielle, ne devient pas une simple survivance à mesure que se montre mieux à nous le caractère incohérent, anarchique, absurde, de la réalité, dont le vrai n'est que l'image. L'amour de la vérité, ne seraitce, par hasard, que l'amour d'une laide, le plus tenace et le plus robuste des amours, parait-il, mais, à coup sûr, le plus rare et le moins aisé à généraliser?

Si la morale de Guyau, malgré sa profondeur et ses clartés, parfois décevantes comme les transparences de la mer, se ressent un peu et fort heureusement de sa poésie et de sa jeunesse, son esthétique et sa théorie de la religion s'en ressentent aussi, mais avec plus de bonheur encore. Partout, il nous apparaît comme une âme jeune, mais infiniment pénétrante, qui, voulant prendre tout au sérieux, cherche le 
sérieux de tout, s'attriste à ne pas le trouver, puis se rassénère à penser qu'il y a espoir de le découvrir un jour et s'endort pour l'éternité dans cette espérance. - Quel charme d'ingéniosité poétique et vraie et quelle fécondité inépuisable d'aperçus dans son explication sociomorphique et non plus anthropomorphique des dieux! Ce n'est pas lui qui donnera aux religions pour origine quelque hallucination contagieuse, ou aux beaux-arts le plaisir du jeu. Ce n'est pas lui non plus qui se posera la question ironique de savoir si, après tout, certaines hallucinations ne sont pas plus solides que toutes les vérités et si certains jeux ne sont pas plus sérieux que toutes les affaires, ou même si la plus sérieuse affaire de la vie n'est pas de s'amuser. Quand vous voyez une jolie femme danser, songez combien elle s'enlaidirait en accouchant, et que peut-être aucun de ses enfants, né de ces enlaidissements répétés, ne l'égalerait en beauté. Cela veut dire que la plus belle femme n'est pas la plus féconde, quoi qu'en ait dit Napoléon ler à Mme de Staël, et que la danse, ou tel autre jeu réputé frivole, a fort bien pu être le premier bel art, sans que l'esthétique ait à en rougir. Le principe de l'expansion exige-t-il, comme il le semble à Guyau, que l'œuvre d'art soit, autant que faire se peut, un être vivant ? Dironsnous avec lui que « la machine qui ressemblera le plus à un être vivant sera la plus belle ${ }^{1}$ », et que « si l'art humain pouvait produire des êtres vivants au lieu de peindre la vie », il aurait produit son chef-d'œuvre véritable, dont tous ses chefs-d'œuvre actuels ne sont que le simulacre et l'avortement? À ce point de vue on s'explique bien l'importance esthétique prêtée par Guyau à l'éducation devenue pour lui «l'art supérieur »; mais on peut s'étonner qu'il n'ait pas donné le premier rang, après l'éducation aux arts industriels, à l'art de la politique, à l'art militaire même, si la guerre et la victoire sont la condition indispensable de l'expansion, non seulement sociale, mais physiologique des peuples. Or, il a sans doute raison de nier qu'esthétique soit synonyme d'inutile, mais il n'en est pas moins certain que les arts esthétiques doivent être distingués plus ou moins nettement des arts simplement utilitaires. Guyau a-t-il réussi à formuler leur caractéristique ? Malgré la délicatesse et la pénétration de ses vues à ce sujet, il ne me le

Il a des considérations aussi justes qu'ingénieuses à cet égard, notamment celle-ci, que « l'idéal de l'industrie, étant l'économie de la force, est bien la vie; car c'est dans la vie que la force est la plus épargnée ; c'est là le foyer qui produit le plus en dépensant le moins ». Mais cela est surtout vrai de la vie supérieure, des fonctions cérébrales, et surtout des plus élevées, des plus spirituelles de ces fonctions. 
semble pas. Me pardonnera-t-on d'indiquer la direction dans laquelle, à mon avis, on aurait le plus de chance de découvrir la différence cherchée ? Je considère l'évolution des sociétés comme une lente et difficile fusion des psychologies individuelles en une même psychologie sociale. Cela suppose trois choses, dont les deux premières sont nécessaires, et la troisième de luxe, mais néanmoins d'un prix infini : l'accord des croyances, - c'est la religion qui s'en charge ; l'accord des désirs, - c'est l'œuvre de la morale ; enfin l'accord des sensations ellesmêmes, - et c'est la tâche des beaux-arts. Il s'agit de superposer, autrement dit, aux sensations grossières et animales qui nous divisent, qui ne sont point communicables d'homme à homme par les voies rapides de la vie sociale, des sensations raffinées et spiritualisées qui, devenues les notes dominantes des sensibilités en contact, en communication sympathique, fassent d'elles un même cerveau résonnant à l'unisson. Ces sensations doivent être agréables, cela va sans dire, sans cela, elles ne parviendraient pas à se propager par imitation; mai cela ne suffit pas. Il faut, pour que le but voulu soit rempli, que leur agrément combinaison géniale d'un homme provoquée par les particularités de sa vie sociale, soit, par suite, de nature à se répandre par la parole ou par les autres procédés artificiels d'expression. Tous les plaisirs d'espèce visuelle et acoustique surtout, mais aussi ceux d'espèce inférieure même, qu'ils se rattachent à la fonction de génération ou à celle de nutrition, de locomotion, de respiration - Guyau n'a pas tort de vanter les qualités esthétiques de ces derniers - peuvent entrer comme ingrédients dans la fabrication mystérieuse de ce charme complexe ; l'essentiel est qu'il soit fabriqué parce que la société existe, et que, si elle n'existait pas, il ne l'eût pas été. Dans ce composé, ce qui a trait aux fonctions de l'amour domine ; il semble que toute chose vraiment digne du nom d'œuvre d'art, poème, peinture, statue, musique, édifice même, se reconnaisse à une sorte de savourement amoureux qu'elle procure à l'œil, à l'oreille, à l'imagination, à l'esprit tout entier; jouer c'est déjà jouir ainsi spirituellement et socialement les uns des autres, et je suis porté à croire que les premiers hommes se sont rassemblés pour s'amuser, avant de songer à se rassembler pour agir. L'inventeur du premier jeu a été peut-être l'introducteur du ferment social dans le monde. Voyez les enfants, cette image atavistique de nos ancêtres, à ce qu'on prétend. 
Le plaisir du jeu n'est cependant devenu le plaisir de l'art qu'en cessant d'être une surprise amoureuse des sens et se transformant en une habitude collective et consacrée, en une coutume rituelle ${ }^{1}$, car, en cet état, la religion s'en est toujours emparée. Et, de fait, rites et jeux sont congénères et synonymes au début des sociétés; les fêtes y font partie du culte ; les danses, les chants, les bas-reliefs sculptés, les drames, les épopées, concourent ensemble à la célébration solennelle du dieu national, invisible ou visible. Ne suffit-il pas, pour restituer à l'art son caractère profondément sérieux, de signaler sa source religieuse ? Envisagées comme moyen d'apaiser la colère ou de capter la faveur du dieu, les solennités mystiques et ne sont qu'une industrie supérieure ; mais, de tout temps, elles ont été aussi appréciées pour elles-mêmes, comme un beau spectacle ou une belle audition, approuvée par le goût comme une joie honorable, intense et collective ; et, sous ce dernier rapport, elles ont été l'esthétique en ébauche. Le culte a été, par suite, la première forme de l'art industriel, et, par son côté artistique, il a peu à peu façonné, discipliné les sensibilités et les imaginations, pendant que les dogmes et les langues disciplinaient les intelligences et que les commandements divins ou royaux disciplinaient les volontés. Il a collaboré activement ainsi avec la religion et la morale aux fins de la civilisation, qui suppose l'assimilation intime et la pénétration réciproque des esprits. En s'émancipant plus tard et en se développant séparément, les beaux-arts n'ont cessé de travailler dans le même sens. Nos peintres et nos architectes, par exemple, ont fait notre oeil européen et, à chaque nouveau charme amoureux qu'un peintre ou un musicien de génie découvre et met en circulation, se creuse la distinction qui nous sépare, par nos sensations mêmes, des Africains ou des Asiatiques. Tous ces charmes subtils ne grossissent pas à jamais le trésor de nos jouissances sociales; beaucoup n'ont qu'une saison, et il faut se hâter de les goûter dans leur fleur, par exemple la rime-calembour de nos poètes, comme il faut se hâter de prendre certains remèdes qui ne guérissent plus quand ils ne sont plus à la mode. Mais la succession de ces beautés d'un jour est inépuisable, et c'est en cela que se montre la fécondité de l'art, l'expansion vraie de sa vie propre. La composition poétique, artistique, est réellement un amour et une génération, mais l'amour et la génération d'un charme spécial, unique, combinaison

Les règles du goût sont purement et simplement la consécration de ces habitudes. 
singulière de charmes antérieurs, variation d'un thème traditionnel. Ce qu'on appelle le mouvement artistique ou littéraire d'une époque est une filiation pareille de charmes originaux tour à tour aimés et féconds. Qu'est-ce qu'engendrer? Si ce n'était que se reproduire, il n'en vaudrait guère la peine ; mais c'est se varier, c'est, moyennant le type de son espèce régulièrement répété, susciter de vraies inventions vivantes, pas toutes belles à la vérité, un vers nouveau sur un mètre consacré. De même, qu'est-ce que composer artistiquement? Ce n'est pas seulement imiter la nature, simple moyen à l'usage de l'artiste, moyen nécessaire d'ailleurs puisqu'il s'adresse à des esprits et que l'esprit est un composé d'images. Ce n'est pas seulement non plus, se peindre, se reproduire soi-même dans ses oeuvres. C'est, avant tout par la synthèse de ces deux reproductions, créer le germe d'un attrait inconnu et l'ensemencer sur les sensibilités environnantes. Ainsi se forme à la longue une sorte de caenesthésie sociale, qui est le fond du plaisir de vivre en société.

Toutefois, quand cette élaboration des sens et de l'imagination, comme il arrive aux époques de crise religieuse et de crise morale, s'opère en désaccord et non plus en harmonie avec l'élaboration des croyances et des volontés, il semble que l'art redevienne un pur jeu, mais cette phase ne peut être que passagère. On en a la preuve à notre époque, par le succès de l'art réaliste, qui, en dépit de sa hideur fréquente, a eu du moins l'avantage, d'ailleurs plus apparent que réel, de s'appuyer aux croyances scientifiques du jour, seule religion en voie de progrès.

Cela nous conduit, ou nous entraîne, à demander avec Guyau si c'est bien la religion ou l'irréligion de l'avenir qu'il faut dire. Il a montré, sans doute, que les sociétés modernes se détachent petit à petit, et même qu'elles pourront se détacher tout à fait, des dogmes et des cultes. Mais, après ce détachement complet, se trouveront-elles fortifiées ou affaiblies? Affaiblies, je le crains, à moins que les illusions religieuses ne soient remplacées par d'autres sortes d'illusions, aussi flatteuses notamment pour notre orgueil et pour nos espérances posthumes. Il en est des religions établies comme des armées permanentes : c'est un mal si l'on veut, mais un mal nécessaire partout tant qu'il existe quelque part chez les voisins. L'illusion dans l'humanité ne pourra désarmer impunément que lorsque la paix 
perpétuelle s'établira. Nous sommes loin de cet idéal. En attendant, nous suffira-t-il, comme nous le propose Guyau, pour remplacer le christianisme, de "courir le risque métaphysique », et de laisser s'essorer nos esprits en une libre diversité de petites religions individuelles appelées des systèmes ? Non. Ce que je retiens, c'est la nécessité reconnue par lui de courir le risque en question. Autrement dit, il faudra toujours, pour rester moral, condition nécessaire de toute société forte, embrasser une hypothèse résolument et y adhérer avec une conviction pleine, très supérieure à son degré réel de probabilité, et cette conviction, on ne l'aura jamais si l'on doit être seul à l'avoir. Notre auteur ne veut pas, il est vrai, qu'on s'abuse ainsi : il croit que, tout en ne me faisant aucune illusion sur les chances d'erreur inhérentes à l'hypothèse choisie par moi, je pourrai, croyant faiblement en elle, être capable de m'immoler héroïquement à cause d'elle, sur la foi de cette étoile filante adoptée pour étoile polaire. Mais cela, n'est-ce pas l'illogique érigé en loi morale ? À telle dose de foi correspond telle dose de dévouement, ni plus ni moins. - Il est inévitable du reste que, si un certain nombre de systèmes métaphysiques se formulent à la fois dans une société, la concurrence de leurs ambitions déchaîne la guerre entre eux et fasse triompher le plus fort, dont le triomphe inaugurera le despotisme. C'est inévitable, puisque, conformément à l'idée-mère de Guyau, le besoin de se propager universellement, d'épancher sa vie sans mesure est l'âme de tout système, comme de tout être. Au moins sera-ce le système le plus vrai qui triomphera ? Ce n'est pas sûr; à vraisemblance égale, ou même inégale, ce sera le plus apte à nourrir l'orgueil du moi et son rêve d'immortalité. Il en sera ainsi, du moins aussi longtemps qu'on sentira le besoin de rester fort pour lutter dans la bataille éternelle des nations. Actuellement les plus libres penseurs d'entre nous se bornent à nier faiblement la vie future ; la majorité des savants doute, voilà tout. Je me demande si, dans cette position même, il n'y a pas un reste d'illusion qui nous empêche de suivre jusqu'au bout l'induction des données scientifiques. Sur la pente logique de la négation, qu'est-ce qui nous retient, si ce n'est le contre-coup des affirmations religieuses, accréditées encore autour de nous ? Après avoir dû aux religions notre ancienne foi, ne leur devons-nous pas notre doute encore? Mais, quand, par hypothèse, toute religion sera morte et toute digue abaissée dans le courant de la logique inductive, le savant, si du moins la science ne se transforme pas à fond, sera forcé de nier 
catégoriquement l'au-delà de la tombe. Cette position sera-t-elle tenable pour tout le monde, pour la majorité même ? Je ne puis croire que, plus la vie humaine se fera douce et charmante, plus la résignation au néant final deviendra aisée. Le système philosophique qui succédera aux religions aura charge d'âmes comme elles; il devra veiller à notre salut 1 .

Je ne vois donc pas en quoi il différera essentiellement d'une religion; surtout si l'on ajoute qu'il aura son art à lui, comme chaque dogme a son rite. Et ainsi sera pleinement restauré le sérieux de l'art, dont les pratiques, malgré leur vanité apparente, seront regardées comme les plus merveilleux des talismans. Déjà, pour un Leconte de Lisle, pour un Banville, le respect de la consonne d'appui ou de tel autre charme conventionnel en train de se ritualiser, est quelque chose de comparable à la récitation de la syllabe om par maint ascète indien. Les habitudes chères à la main de l'artiste ou à l'œil, à l'oreille, à l'imagination du public, ont une tendance à se cristalliser en devoirs rituels, et si cette tendance à notre époque n'apparaît guère c'est pour s'y être généralisée au point de s'y neutraliser elle-même. Il y a des centaines d'écoles différentes qui aspirent concurremment à transformer leurs tics, leurs manies, en règles du goût. Toutes ces poétiques ont beau coexister, elles n'en sont pas plus tolérantes pour cela. Elles se combattent, et l'une d'elles est destinée à rester seule sur le champ de bataille esthétique.

En attendant, le néo-mysticisme contemporain se comptait, chez certains raffinés, aux obscurités ou aux lacunes de la science; et je comprends que cette déification de l'inconnaissable, non sans quelque affectation, soit l'objet de sévères attaques de la part d'un esprit aussi logique et aussi subtil que M. de Roberty. Ses livres sur l'Inconnaissable, sur l'Agnosticisme, ont signalé les contradictions cachées sous ce culte de l'ignorance soi-disant invincible, sous le mépris affiché du savant pour le savoir, sinon pour son savoir. Mais la soif religieuse des peuples a d'autres sources que ce maladif amour du mystère ou ces prétentieuses tristesses d'esprits blasés, tantôt se vantant de tout ignorer, tantôt se plaignant de trop connaître, de ne plus s'abuser sur rien. Avant tout la religion se présente comme une connaissance suprême, comme une vérité offerte à tous et offrait à tous les sécurités qu'ils rêvent. Et, mieux encore, elle est la joie sociale de se sentir unis, unanimes, non seulement dans des croyances et des espérances communes, mais essentiellement, dans une solidarité fraternelle. Elle a été, avant tout, le procédé social par lequel le sentiment de la fraternité a franchi le seuil de la famille antique, puis les remparts de la cité et les frontières des nations pour prétendre embrasser le genre humain tout entier. Voilà pourquoi rien n'est plus près, de nos jours, d'être ou de paraître une nouvelle création religieuse, que le socialisme en ses multiples manifestations. 
Or, si jamais on voit ainsi à une métaphysique régnante s'attacher, s'accorder une poétique triomphante, je ne vois pas trop ce qu'il manquera d'essentiel à ce catholicisme d'un nouveau genre. Par malheur, je ne vois pas trop non plus ce que la pensée indépendante aura gagné à ce changement. - Au surplus, il est bien possible que cette prévision à longue portée ne se réalise pas. Les philosophes ont tant de peine à se mettre d'accord! Même en s'admirant, il faut encore qu'ils se critiquent. Mon article même en témoigne, puisque, très sincère et très sympathique admirateur du talent de Guyau, je parais m'être complu néanmoins à marquer entre nous les divergences au lieu de me féliciter, comme je l'aurais dû, de nos consonances sur tant de points.

Il me reste, et ce sera justice, à louer le poète en lui. Ce n'est pas que la coexistence ou l'alternance à certains degrés de l'aptitude philosophique et du talent poétique soit très rare, surtout dans notre siècle, où elle devient assez fréquente, chose bonne à noter au point de vue de mes conjectures de tout à l'heure sur l'harmonie future de la pensée et de l'art. Baudelaire va même jusqu'à appeler quelque part cette complexité de dons naturels « la forme banale de l'originalité ", oubliant qu'on pourrait tout aussi bien et mieux qualifier « la forme originale de la banalité » sa prétention à la singularité macabre ou telle autre excentricité voulue, plus bruyante que brillante, de ses imitateurs contemporains. Mais, chez notre auteur, les deux facultés dont il s'agit s'élèvent ensemble si haut, et, si fraternellement, se communiquent leur frisson sacré, comme deux cîmes un peu inégales, mais jumelles, de peupliers, que leur lien semble d'une espèce unique, aussi simple qu'intime et profond. Chez d'autres, il arrive que la réflexion et l'inspiration se succèdent sans presque se toucher, et que, par un effet de saturation bien connu des physiciens, comme si elles étaient deux couleurs complémentaires de leur âme, l'excès même de la première rend à la seconde toute sa fraîcheur, puis réciproquement. Dans ce cas, il n'y a presque rien de commun entre les fantaisies, l'humeur, les tristesses ou les gaietés du poète, et les conceptions, l'état moral, les souffrances ou les joies du philosophe. De là, pour ces natures doubles, la nécessité douloureuse de mettre un terme à leur schisme intérieur, et, si elles veulent produire quelque chose, de sacrifier un jour leur poésie comme une branche gourmande. Au contraire, Guyau souffre et pense en vers comme il pense et souffre en prose, à cela 
près qu'il développe et analyse en vers, non sa pensée, mais les douleurs chères et subtiles qu'elle lui cause, flore délicate de ces hauteurs, et qu'il réserve pour la prose le détail de sa pensée. Ainsi ses poésies sont comme la musique dont ses théories sont le libretto. Elles ont une grâce adolescente, à la Musset, mais d'un Musset grave, sans solution de continuité ni caprices, ni envolées non plus, paisible encore en ses plus sublimes et ses plus naturels soulèvements, comme d'une vague méditerranéenne, docile à l'attrait d'un astre, non au souffle du vent. Du Musset profane peut-être, elles ont eu le tort de garder quelquefois le négligé prosodique, l'hexamètre librement croisé, qui sied moins bien à leur gravité, je ne dis pas la fière pauvreté des rimes, qui rehausse leur distinction. Leur insuffisance plastique, çà et là, tient, je crois, aux idées de leur auteur sur l'esthétique. Dans ses vers philosophiques, il subordonne tout à la sincérité et à la transparence de l'expression. Jamais poète de talent, jamais prosodiste initié à tous les secrets du métier, comme il l'a si bien démontré dans son admirable étude sur le vers français moderne, ne s'est moins joué avec les mots et les rythmes, malgré ses dispositions à exceller en ce jeu qui n'est point si frivole... N'importe, je donnerais bien des volumes de nos jongleurs rythmiques pour un de ses beaux vers, si nombreux - si justement mis en lumière par $\mathrm{M}$. Fouillée - où toute sa pensée et toute son âme se condensent. Parmi les plus belles pièces à mon gré, je citerai particulièrement le Luxe, le Rémouleur, surtout l'Analyse spectrale. Mais plutôt faudrait-il choisir parmi ses morceaux de plus mol abandon, d'élégiaque lyrisme, celles où il a mis le fond de son cœur. Les lecteurs de poésies commencent à être tellement las de voyager dans le lourd chariot mal suspendu et sur le dur pavé de l'alexandrin parnassien, où ils sont secoués et assourdis, qu'il leur arrive parfois de chercher le repos dans l'absurde palanquin des décadents, sans rythme ni raison. Les Vers d'un philosophe leur seront une promenade en gondole vénitienne errant flexueuse-ment, amoureusement, mais en cadence, en sa noirceur gracieuse, à travers de riches palais d'idées. Après s'être évertués pendant longtemps jadis à faire difficilement des vers faciles, et, dans ce but, à éviter les rimes en relief, les sonorités à effet, les accouplements hybrides et inféconds de mots ou d'idées, les poètes se sont mis, à la queue-leu-leu, à poursuivre un autre idéal, qu'ils atteignent à merveille par des procédés précisément inverses : faire assez facilement des vers très difficiles. Affaire de mode, voilà tout. 
Je félicite Guyau de ne s'être pas mis à la mode; mais cette remarque me donne occasion de faire à ses théories sur l'esthétique des vers le seul reproche que je leur adresse. Ici encore ce sociologue éminent n'a pas fait à la sociologie sa part suffisante. Je n'ai qu'à l'approuver pleinement quand il demande à la physiologie, à la psychologie, à la logique, la justification des mètres poétiques, quand il signale l'analogie fondamentale à cet égard ente l'hexamètre antique et l'alexandrin moderne, entre la rime et le rythme, et explique par la loi physique de « la contagion sympathique », la puissance d'émotion inhérente à l'harmonie réglée des syllabes. Mais cette explication suffit-elle ? Non. La physiologie, la psychologie et la logique, même coalisées, ne sauraient nous dire pourquoi le point initial de l'évolution prosodique au moyen-âge a été le vers héroïque de 10 syllabes et non le vers de 12, pourquoi le vers de 12 s'est substitué en France, mais non en Espagne ni en Italie, au vers de 10, pourquoi ce dernier, primitivement (comme on le voit par le Cantique de sainte Eulalie, en langue romane) coupé indifféremment par la césure après le sixième ou après le quatrième pied - liberté à mon sens très précieuse - a fini chez nous par se fixer exclusivement à cette seconde coupe, rigueur excessive et arbitraire qui a bien pu contribuer à lui faire préférer l'alexandrin. Il y aurait lieu à une foule d'et cotera. Au risque de scandaliser tous les Théodore de Banville et tous les Becq de Fouquières, je me permets d'avancer - et me fais fort de prouver - que nos plaisirs les plus vifs, les plus sincères, goûtés à la lecture des vers, ont leur source en grande partie dans une tradition et une coutume - ce qui ne veut pas dire dans une convention - quand ce n'est pas dans une mode. Je ne nie pas la joie que causent à $\mathrm{M}$. de Banville ses consonnes d'appui, et je suis sûr de sa sincérité ; mais je suis sûr également que, s'il était né il y a cent ans, il eût éprouvé une félicité non moindre à rimer faiblement, à faire rimer des adjectifs ensemble, à jouer de délicates variations, perceptibles aux oreilles aussi fines qu'elles, sur le thème de l'alexandrin classique. La préoccupation d'ôter aux règles les plus arbitraires de la prosodie toute couleur artificielle, c'est-à-dire toute origine simplement inventive et sociale, va si loin chez Guyau, à son insu, que (p. 234, en note, Problèmes de l'esthétique) il cherche et croit trouver une raison logique et psychologique à cette singularité : nos poètes font rimer très bien, très richement à leur point de vue, court avec cour, coup avec cou, mais il ne peuvent souffrir que le 
pluriel rime avec le singulier, par exemple murmures avec mûre, et, si quelque novateur s'avisait de faire rimer maintiennent ou soutiennent avec chrétienne, il serait conspué par le Parnasse tout entier. Il n'y a qu'un mot à dire : c'est l'usage, un usage dû à l'influence contagieuse sympathiquement contagieuse, soit, mais surtout socialement - d'un maître tel que Victor Hugo, auquel il a plu de s'imposer à lui-même telle ou telle exigence de forme, et non telles autres, en vertu des idiosyncrasies de son goût personnel. Guyau cependant est loin, en général, de s'agenouiller devant le fait et de prendre un usage pour une loi. Il s'est récrié contre l'abus de la rime riche, il à bien vu que la rime, comme l'individu, même en ce siècle ploutocratique, pouvait avoir d'autres mérites que sa richesse, à savoir sa finesse et son cachet, son esprit d'à-propos, sa conformité par son timbre ou sa nuance, par son indigence même en certains cas, au sujet traité. Il a cru, par exemple, que sa richesse constante, sorte d'emphase continue, ne convenait pas à la simplicité de ton exigée par les sujets philosophiques. J'observe que M. Sully-Prudhomme est d'avis tout juste opposé : c'est dans sa dissertation morale en sonnels intitulée la Justice, qu'il a déployé tout le luxe millionnaire de ses rimes, ainsi que dans le Bonheur, cette dissertation métaphysique en l'air. Lequel a raison des deux ? Sully-Prudhomme dira peut-être que plus la tenture des vers est sévère et lourde, plus le clou de la rime doit être apparent et doré, puisqu'elle reste son unique ornement. Mais Guyau pourra répondre avec beaucoup de vérité que ce clou est un instrument de torture, une façon de crucifier la pensée, il décrira les curieux effets de la rime riche et sonore : décousu et zigzag de la pensée, dégoût de l'expression simple et vraie, habitude de se satisfaire à peu de frais d'idée véritablement originale. Or Guyau aura beau parler d'or, le public spécial des versificateurs se détournera de lui, parce qu'il aura eu le tort impardonnable de ne pas servir à leur oreille les accords faux accoutumés. 
Gabriel Tarde, Études pénales et sociales (1892)

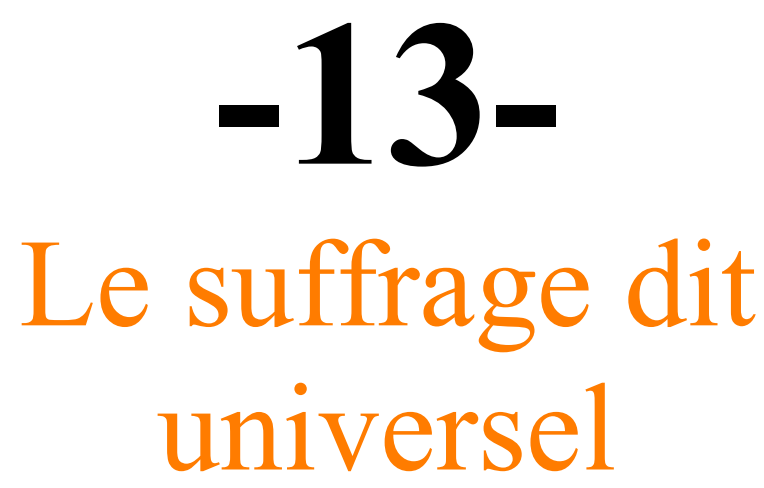

$\underline{\text { Retour à la table des matières }}$

Quand un artiste ou un savant dévoyé, quand un métaphysicien fourvoyé momentanément dans la politique, s'est avisé de concevoir quelque beau projet de réforme sociale, au lieu de fabriquer un système du monde on un plan de comédie, à qui fera-t-il part de son utopie ? Au grand public par la presse quotidienne ? Il tient trop à son rêve pour l'enterrer ainsi. Un seul auditoire peut lui être indulgent c'est celui d'un cercle d'esprits sérieux, habitués à voir dans le paradoxe ou la chimère d'aujourd'hui le germe d'une vérité ou d'une utilité de demain. Voilà pourquoi je me permets de confier au public philosophique une idée dont je ne puis me délivrer a propos du droit de vote. ${ }^{1}$

Je dois dire tout de suite que cette idée ne m'appartient pas et que mon amour pour elle ne se complique d'aucun amour-propre d'auteur. J'en ai lu l'indication il y a longtemps dans un écrit de M. Henri Lasserre, l'historien si universellement connu de Notre-Dame-de-Lourdes, écrivain politique à ses heures. Je sais que cette origine peut la rendre suspecte à plusieurs. Mais il m'a paru anti-philosophique de repousser à priori une proposition, sous prétexte qu'elle émane d'un cerveau clérical. Ce qui serait clérical au premier chef, ce serait précisément d'imiter la congrégation de l'index en excommuniant une brochure in odium auctoris. L'Assemblée Nationale, si j'ai bonne mémoire, s'est occupée en passant d'un projet inspiré par 
En dépit de toutes les objections, le suffrage universel a un grand mérite ; il fonctionne. On peut dire qu'il a cela de commun avec toutes les machines, qui fonctionnent, elles aussi, au profit du premier occupant. Mais il en est de cette machine comme de toutes celles qui, honnies par les ouvriers sans travail, n'ont pas à redouter beaucoup les critiques intéressées de ceux qui ne savent pas s'en servir. Elle a un autre avantage, c'est d'être une méthode statistique de gouvernement, un hommage politique rendu à la vertu des grands nombres, et une réédition originale de l'antique adage pythagoricien : mundum regunt numeri. Ce caractère la recommande en ce temps de grandes masses et de gros chiffres en tout genre, de socialistes et de statisticiens. Mais, par-dessus tout, sa force consiste à être réputée l'expression pure et complète, infaillible et indiscutable, de la souveraineté nationale, ce dogme menteur et nécessaire de l'âge moderne.

Tel est bien son titre supérieur auprès des esprits contemporains. Le vrai et le bien, c'est l'opinion et la volonté du peuple : cette fiction s'impose depuis que la fiction de l'infaillibilité et de la souveraineté monarchique n'a plus cours. Ne discutons pas ce postulat, ce serait peine perdue. Mais demandons-nous si, réellement, le suffrage universel lui est conforme, s'il mérite sa réputation de traduire avec une fidélité suffisante, approximative tout au moins, l'opinion et la volonté du pays. Je réponds non. Combien sommes-nous d'électeurs en France? 10.181.100 (octobre 1885). Combien sommes-nous de français ? 38,050.000 (mai 1886). Ainsi, près de trois quarts de la population ne votent pas, ou plutôt n'ont pas le droit de voter; car si nous ne comptions que ceux qui votent, l'écart des chiffres serait bien plus fort. En octobre 1886,où cependant le scrutin a été particulièrement attractif, il n'y a eu que 7.896.100 votants. Par suite, les quatre cinquièmes des citoyens sont restés étrangers à cette consultation numérique de la nation. D'ordinaire on pourrait dire les cinq sixièmes.

Vous voulez donc faire voter les femmes et les enfants? me dira-ton. Avant de répondre, je me permets de faire remarquer que, de

l'écrit de M. Lasserre, mais l'idée avait été dénaturée par des considérations étrangères à celles que je me permets de présenter. 
toutes parts, à droite, à gauche, on se prosterne devant le mode de suffrage actuel avec un respect semblable à la piété de ces normands qui, tout en baisant les pieds du pape, s'efforçaient de lui lier les mains. C'est lui, tout bas, qu'on accuse de nos maux, et on n'attend leur guérison que de sa réforme. Mais, en général, on ne cherche à le réformer qu'en le réfrénant, et en opposant à son principe essentiel le germe plus ou moins dissimulé d'un principe contradictoire qu'on essaie de greffer sur le sien. Telle était cette fameuse représentation des intérêts qu'on prétendait, propre à compléter la représentation des personnes, et qui était un retour oblique au vote censitaire. Quant à l'élimination de certaines catégories d'électeurs par la rigueur des conditions (de domicile par exemple) imposées à l'exercice du droit de voter, c'est un palliatif sans portée sérieuse. Au lieu d'endiguer le fleuve qui déborde, au lieu de taquiner le taureau lancé, ou bien au lieu d'attacher une importance exagérée à de pures questions de forme, comme celle du scrutin de liste ou du scrutin d'arrondissement, ne vaut-il pas la peine de se demander si le meilleur et le plus sûr moyen de remédier au plus grave des périls qu'entraîne la participation des foules aux affaires publiques ne serait pas de pousser à bout cette grande innovation contemporaine? Si la logique, par hasard, trouvait son compte à la solution la plus rassurante pour la pratique, n'y auraitil pas double avantage?

Et certainement, sans la moindre contestation possible, les femmes doivent être comptées au scrutin, comme les enfants! De quel droit les exclure ? On ne le peut que par une dérogation formelle à la fiction qui sert de base à la statistique électorale comme à toute autre : l'équivalence des unités nombrées. Dans une élection, la tête de Pasteur et la tête d'un gamin de Paris qui vint d'avoir 21 ans, sont et doivent être réputées égales, comme, dans la statistique judiciaire, un vol simple est réputé égal à un autre vol simple, malgré l'intervalle énorme qui peut exister entre la gravité du premier et celle du second. C'est là une fiction nécessaire, et, remarquons-le, d'autant plus près d'être une vérité, par la compensation des erreurs en plus et en moins ainsi produites, qu'elle repose sur de plus grands nombres, c'est-à-dire qu'elle est appliquée plus largement, avec moins d'exceptions et de limitations arbitraires. Arbitrairement on se permet de prendre en considération le sexe et l'âge, qualités toutes physiologiques, après n'avoir tenu compte ni du degré d'instruction, ni du degré de fortune, 
ni de l'état civil, ni de la profession, caractères d'ordre social pourtant, et plus dignes, par suite, que les précédents d'être remarqués dans une statistique essentiellement sociale. Au fond, l'interdiction, vraiment outrageante, des droits politiques aux femmes et aux enfants ne s'explique pas, si ce n'est par cet oubli du faible qui est dans les habitudes du fort. Instinct barbare que le progrès de la civilisation doit refouler. Dira-t-on que l'on refuse aux femmes et aux mineurs les droits politiques parce qu'ils sont incapables de les exercer? Mais sont-ils plus capables d'exercer leurs droits civils, qu'on n'a jamais eu l'idée de leur contester? Or, on comprendrait plutôt le contraire, c'està-dire que le droit de posséder, d'aliéner, d'acquérir, d'hériter, - ce qui s'est vu et se voit encore en beaucoup de coutumes - leur fût refusé, et que l'on reconnût leur droit de participer à l'élection des représentants du pays. En effet, les dépouiller de biens meubles ou immeubles, c'est ne nuire qu'à leur intérêt propre, au profit d'individus plus robustes, plus propres peut-être à jouir de ces biens; il peut y avoir là compensation au point de vue de l'intérêt général. Mais les exproprier de la souveraineté, de la propriété réputée emphatiquement la plus inaliénable de toutes, c'est un préjudice immense pour la Nation en même temps qu'une iniquité injustifiable : car si l'enfant est l'avenir et l'espérance, la femme est avant tout, la mère de l'enfant, et l'intérêt de la Nation est que ses hommes d'État se préoccupent non de la génération présente, où s'arrête trop souvent la pensée de l'homme adulte sans famille, mais de la postérité. De là, sans doute, cette politique à courte vue - à large domaine, c'est possible, mais à courte vue - qui caractérise les Parlements sortis d'un scrutin où les intérêts majeurs des trois-quarts de la nation n'ont pesé pour rien. - Ajoutons que, sans la possession des droits politiques, celle des droits civils devient à la longue plus apparente que réelle, comme le savaient très bien les masses électorales exclues du scrutin, à l'époque des censitaires. De la meilleure foi du monde, et sans même s'en apercevoir, les ministères issus d'un parlement élu sous le régime du cens électoral proposaient et faisaient voter des lois préjudiciables à la bourse des non-électeurs. Pareillement, on pourrait s'expliquer par la privation des droits politiques infligée aux mineurs l'écrasante absurdité des mesures soi-disant protectrices, que nos législateurs font peser sur eux, toujours de la meilleure foi du monde et avec cette inconscience de l'égoïsme humain, principalement masculin, qui est insondable. 
Je dis donc que toutes les têtes seront comptées, grandes ou petites, fortes ou faibles, masculines ou féminines, et qu'il y aura en France 38 millions d'électeurs puisqu'il y a 38 millions de Français. On n'exclura $\mathrm{du}$ vote que les indignes, judiciairement déclarés tels. Plusieurs vont sourire : quelle plaisanterie, qu'une pareille proposition! Ce sont les mêmes assurément qui, en 1847, eussent haussé les épaules si on leur eût prédit que l'année suivante les 200,000 électeurs d'alors allaient pulluler subitement au point de se chiffrer par près de 10 millions. Loin de redouter les gros chiffres ici, il faut les appeler, car c'est leur grosseur qui fait leur poids et même leur prix. A mesure que les nombres s'enflent, les inconvénients de cette statistique politique s'atténuent. Quel est le statisticien qui ne se réjouit de voir s'étendre la base numérique de ses calculs?

Je me hâte d'ajouter que, si la justice et la logique obligent à reconnaître aux femmes et aux mineurs le droit de vote, en vertu du dogme de la souveraineté populaire, elles n'obligent nullement à leur attribuer l'exercice direct de ce droit. L'analogie, qui est une des branches importantes de la logique, veut au contraire que nous appliquions en cette matière un principe en vigueur dans toute l'étendue de notre législation et d'une législation quelconque; le principe de la représentation.

Les enfants, les femmes, ont le droit de propriété sur leurs domaines, le droit d'accepter une donation ou une succession, le droit de plaider; mais ces droits sont exercés en leur nom par leurs représentants naturels ou artificiels, nommés conformément à la loi. C'est le père, la mère, le tuteur qui fait valoir les droits de l'enfant; c'est le mari qui fait valoir les droits de la femme, j'entends les droits civils. Mais, si la femme ou l'enfant avaient aussi bien des droits politiques, pourquoi les personnes qui les représentent pour la mise en mouvement des premiers, n'auraient-elles plus qualité pour les représenter quand il s'agirait d'agir en vertu des seconds? Il serait curieux que le principe de la représentation reçût une exception, en ce qui concerne précisément le droit d'élire les représentants du peuple !

Je suppose que ce système soit appliqué, et je me demande quelles en seront les conséquences. Les célibataires majeurs, filles ou garçons, 
auront un seul billet à déposer dans l'urne. Les hommes mariés sans enfant en déposeront deux, un pour eux-mêmes, l'autre pour leurs femmes. S'ils ont des enfants mineurs, le chiffre des billets de vote dont ils disposeront s'accroîtra d'autant. Les veuves tutrices ou les femmes divorcées, séparées de corps, voteront pour elles-mêmes et pour leurs enfants en minorité dont elles auront la garde. Les tuteurs, même non parents, voteront pour leurs pupilles. En somme, tout le monde, sauf les voleurs et les assassins, votera directement ou par son mandataire légal. Il y aura équation parfaite entre la nation et le corps électoral. Pourtant l'encombrement $d u$ scrutin ne sera pas sensiblement plus grand qu'à présent; ce sont toujours les mêmes électeurs qui s'y rendront, plus les veuves, les femmes séparées de corps ou divorcées, et les filles majeures. Ainsi, il n'y aura pas le moindre inconvénient pratique, à cela près que la tâche des scrutateurs sera un peu plus lourde. ${ }^{1}$ Mais, s'il n'est pas de corvée sociale plus ingrate, il n'en est pas non plus, - par une faveur de la Providence, à coup sûr, - qui trouve plus d'hommes de dévoûment hérö̈quement empressés à la remplir.

Un tel changement n'en aura pas moins une portée immense. Pour en apprécier les effets il ne suffit pas d'un simple coup d'œil jeté sur les chiffres. Regardons-y de près. «Le recensement de 1881, dit M. de Foville, classe comme il suit la population française au point de vue de l'état civil : sur 18.656.500 individus du sexe masculin, on compte 10.110.600 garçons, 7.520.200 mariés et 1.025.700 veufs. Sur 18.748.800 individus du sexe féminin, on a trouvé 9.280.900 filles, 7.503.350 femmes mariées et 1.064.550 veuves. » Ces chiffres combinés avec celui des électeurs français actuellement, nous permettent de dire, à peu de chose près, quelle est la proportion respective des célibataires, des veufs et des gens mariés dans notre corps électoral. Pour plus de simplicité nous ne déduirons pas les indignes, exclus du vote par suite de condamnations. Tous les mariés et tous les veufs votent, sauf l'insignifiante quantité de ceux d'entre eux qui sont mineurs. Additionnons-les, et retranchons leur somme, à

Dans l'état actuel de nos mœurs, malgré le relâchement sensible du lien conjugal, le mari me parait devoir voter pour la femme. Mais, si nos mœurs changeaient au point de transformer en corporation bicéphale l'union des époux, il y aurait lieu d'accorder à la femme mariée, même non séparée ou divorcée, un bulletin de vote individuel. Nous sommes loin encore de ce périlleux idéal. 
savoir 8.545.900, du chiffre des électeurs; le reste, 1.635.200, exprime le nombre des électeurs célibataires. Ajoutons-y, à notre point de vue, les veufs sans enfants mineurs, dont je ne puis préciser le chiffre. En chiffre ronds, le total des célibataires et des veufs sans enfants mineurs peut être évalué à 2 millions, et celui des mariés et des veufs avec enfants mineurs à 8 millions environ. ${ }^{1}$

On me dira sans doute que, s'il en est ainsi, l'importance accordée par notre loi électorale a l'élément célibataire, jeune, aventureux, inexpérimenté, n'a rien d'effrayant, puisqu'elle n'est égale qu'au quart du pouvoir de vote confié à la sagesse relative des chefs de famille. Ce serait pourtant une erreur de le penser. D'abord, ce quart de la masse électorale en est de beaucoup la partie la plus remuante, la plus agitée et la plus agitatrice. Il ne faut pas un quart de ferment pour faire lever la pâte, surtout une aussi bonne pâte que le père de famille Français. Puis, si la discorde se met parmi les 8 millions de maris ou de pères, et que les 2 millions de garçons ou néo-garçons soient relativement d'accord, éblouis par une même utopie, la balance penche fatalement du côté chimérique. On a vu des minorités tout autrement infimes s'imposer aux heures de crise et aiguiller le train politique sur leur voie périlleuse ! - Enfin, cette soi-disant minorité juvénile est la partie du corps électoral la plus fidèle au scrutin, la moins abstentionniste ; et la différence peut aller si loin dans certains cas que les situations numériques soient renversées. - D'ailleurs, alors même que la volonté des pères de famille pèserait en réalité, et non pas seulement en apparence, quatre fois plus que celle des célibataires dans la balance du suffrage, il n'en resterait pas moins certain que cette répartition des voix implique une injustice criante au préjudice des premiers. Où est le fardeau, là doit être l'émolument, dit le vieil adage des légistes. Les garçons ne sont responsables que de leur propre fait, ils n'ont à s'occuper que d'eux-mêmes. Mais les pères et les maris ont charge d'âmes, ils doivent aliment, abri, vêtement, éducation, instruction, protection, aux êtres dont ils répondent devant la loi ; ils partagent leur déshonneur, ils payent leurs sottises et leurs folies, leurs amendes et leurs dommages-intérêts, ils administrent leurs biens, ils ont la

D'après M. Becquart (v. à ce sujet Revue Scientifique, 31 juillet 1886), le type de l'électeur français est âgé de 41 à 44 ans, il est marié et, de plus, il est petit patron. Mais, si l'on tenait compte des abstentions qui portent surtout, comme il va être dit, sur les électeurs mûrs ou âgés et non sur les jeunes, il faudrait modifier beaucoup ces assertions optimistes. 
garde de leurs personnes. Chacun d'eux, aux yeux de la loi, est non pas un individu, mais un groupe ; il ne marche, pour ainsi dire, vrai porte-faix de famille, que le dos courbé sous un poids très cher mais non moins écrasant. Vienne cependant une élection: vite, on le suppose allégé miraculeusement de son fardeau; et la voix de cet homme qui incarne en lui 3, 4, 5, 10 têtes différentes, sera neutralisée par celle du premier étudiant venu, qui vient d'avoir 21 ans. La justice voudrait, la logique exigerait, étant donné le principe de la souveraineté nationale, que le suffrage de chaque votant fût proportionnel au nombre des citoyens français qui composent son groupe familial. Or, les 7.520.200 hommes mariés et les 8, ou 9 cent mille veufs avec enfants mineurs (chiffre approximatif) représentent: 1 • 7.503.350 femmes mariées ; 2 8.475.400 garçons mineurs (à savoir 10.110.600 garçons - 1.635.200 garçons majeurs) ; $3 \bullet$ un chiffre à peu près égal de filles mineures. Le tout s'élève à 24.454.150. Telle est l'immense population qui pèse sur les 8 millions 300 mille pères de famille. Ceux-ci, d'après moi, auraient donc droit à 32.700.000 votes. En d'autres termes, leur importance politique serait, très justement, seize fois plus forte que celle des 2 millions de célibataires mâles ou de veufs sans enfants qui aujourd'hui leur font si souvent échec. Il est vrai que, dans mon système, il faudrait ajouter à ceux-ci les 2 millions de filles ou de veuves sans enfants mineurs qui voteraient aussi ; mais, 8 ou 9 cent mille veuves avec enfants viendraient en revanche grossir les rangs de la majorité ; et la paternité, la maternité, le mariage, ne laisseraient pas de compter encore huit fois plus que le célibat.

Ainsi, la part électorale du célibat masculin devrait être du seizième, et elle est du quart. On voit l'injustice dont il bénéficie. Mais la nation en pâtit, et, je le crains, en pâtira longtemps. Si, nous n'y prenons garde, nous courons à une éphébocratie ou à une célébocratie d'autant plus dangereuse que le mécanisme chaque jour plus compliqué de nos sociétés requiert des esprits plus mûrs et plus exercés pour être compris. Un éphèbe grec ou romain eût été plus capable de comprendre les intérêts de sa cité, et de donner son avis dans les délibérations municipales d'alors, qu'un Français ou un Italien de 30 ans, de 35 ans même, en général, n'est compétent pour décider les graves et solennelles questions aujourd'hui pendantes. - Pourtant, par la plus choquante des antithèses, ce sont les anciens qui ont remis exclusivement aux vieillards, aux patres familias, la puissance 
publique, et c'est nous qui préparons le règne des éphèbes. Je dis que nous le préparons, car si le nombre des abstentions continue à grandir, suivant une progression des plus inquiétantes, il n'y aura bientôt plus que les jeunes qui voteront, parce que le droit de vote a pour eux seuls le charme de la nouveauté et qu'ils n'ont pas eu le temps de connaître la lassitude du scrutin. Mais comment s'étonner que cette fatigue s'appesantisse sur leurs aînés ? Entre autres causes, il en est une qu'on a eu le tort de ne pas signaler. Un fonctionnaire se dégoûte de sa carrière, quand il désespère d'y avancer; on se lasse universellement de ce qui est monotone; voilà pourquoi un droit de vote qui reste toujours égal lui-même, sans aucun espoir de s'amplifier, tout le long de la vie, finit par lasser l'électeur. Ce qui est absurde, en effet, et ce qu'on peut justement reprocher à la fiction fondamentale de notre suffrage, ce n'est pas que la voix d'un homme sol réputée équivalente à celle d'un autre homme, quand l'un et l'autre d'ailleurs ne représentent qu'eux-mêmes, mais c'est que la voix des deux ait un poids immuable et stationnaire, c'est qu'elle n'augmente pas en poids électoral à mesure que grandit la valeur sociale et patriotique de l'électeur, à mesure qu'il progresse en forces, en expériences, en responsabilités.

Or, à cet égard, la réforme que je rêve aurait l'avantage incontestable de proportionner en moyenne, sans nul arbitraire, le plus naturellement et le plus logiquement du monde, la portée numérique du suffrage d'une personne, aux variations de sa force physique ou mentale et de son importance civique pendant le cours de sa vie. L'électeur de 20 à 25 ans, en général, ne compterait que pour un; de 25 à 30 ans, pour deux tout au plus, 30 ans étant l'âge moyen du mariage, en France, pour les hommes; de 30 à 50 ans, il compterait successivement pour 3 , pour 4 , pour 5 , pour 6 , par suite de l'accroissement graduel de sa famille mineure. Plus tard, à l'inverse, ses enfants devenant majeurs ou venant à mourir, son vote retomberait par degrés, à 5 , à 4 , à 3 , à 2 , à 1 , régression correspondante, en moyenne, au déclin de son âge et de son utilité dans la nation. L'apogée électoral, ce serait l'âge de 45 à 50 ans, c'est-à-dire le point culminant, je ne dis pas de l'imagination et de l'amour, mais de l'intelligence et de l'ambition, de l'expérience et de l'aptitude politique, chez la plupart des hommes. Il ne s'agit donc pas, on le voit, dans ce projet, de refaire une gérontocratie ; les vieillards y joueraient 
un très faible rôle. Il ne s'agit pas de retirer à la jeunesse le monopole des initiatives glorieuses et fécondes ; mais il s'agit de lui épargner, ainsi qu'au pays, le fléau des directions fatales. Il s'agit surtout de revendiquer pour ce qui est aussi sacré que la jeunesse, pour l'enfance, qui est presque la moitié numérique de la nation - (17 millions) tandis que la jeunesse ne représente que 3 à 4 millions de Français ou de Françaises, le droit indispensable qui lui est refusé pour des raisons inconcevables; le droit d'intervenir, par l'organe de ses mandataires naturels dans la préparation de cet avenir qui est le sien plus que le nôtre. Il s'agit, ainsi, de favoriser l'avènement d'une démocratie vraie, c'est-à-dire où la puissance se mesure au mérite, les prérogatives aux devoirs, et où l'ascension des honneurs est parallèle à l'aggravation des fardeaux.

Un politicien, si par hasard il lit ceci, ne manquera pas de se demander : Ce système serait-il propre à favoriser les opportunistes ou les radicaux, ou peut-être les monarchistes ? Voilà la grande question, à laquelle je répondrai naïvement : je n'en sais rien. Et je crois que personne n'en peut rien savoir d'assuré, bien qu'il soit infiniment probable que les changements politiques ainsi obtenus n'auraient rien de révolutionnaire. Ce que je sais, par exemple, c'est que la méthode gouvernementale quelconque qui serait consacrée par le suffrage non plus de 6 à 8 millions, mais de 20 à 30 millions d'électeurs imposerait de force aux plus rebelles l'acceptation de son écrasante supériorité, et que son apparition ferait évanouir soudain bien des partis jugés inquiétants, comme l'aurore les fantômes. Ce que je sais encore, c'est que, soutenu par un faisceau de chefs de famille habitués aux préoccupations d'avenir et stables dans leurs résolutions définitives, un gouvernement, quel qu'il soit, un ministère, donnerait le spectacle d'une solidité inouïe de nos jours, et, pouvant se promettre la durée, pourrait se permettre les longs espoirs et les longues prévoyances. Il est permis d'ajouter que, de tous les encouragements au mariage et à la paternité imaginés par les faiseurs de lois, celui que je propose serait peut-être le seul efficace dans une certaine mesure. Qu'on se marie encore à peu près autant que dans le passé malgré le besoin croissant d'indépendance et le poids croissant de la famille, cela a lieu de surprendre, en vérité ; et rien ne montre mieux l'empire persistant de la coutume dans nos sociétés qui se vantent d'être détachées de la tradition. Qu'on ait de moins en moins d'enfants, cela est tout naturel 
au contraire ; car nos sociétés semblent faites par et pour des garçons jeunes ou vieux, et il n'y a pas de meilleure place à y prendre que d'y pratiquer ce célibat à deux qu'on appelle le mariage sans enfants. Mais arrêtons-nous sur la pente du rêve, et bornons-nous en terminant à former le vœu que quelque commis-voyageur en politique, cherchant de l'ouvrage, daigne ramasser notre idée sur son chemin, et, en y mêlant une certaine dose d'inconséquence ou d'extravagance, se l'approprier pour s'en faire un tremplin électoral. On a vu se réaliser, sous l'influence des hypnotiseurs politiques, tant d'autres chimères suggérées, plus audacieuses à coup sûr !

Fin du livre. 